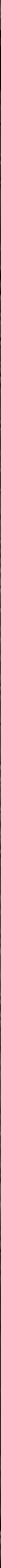



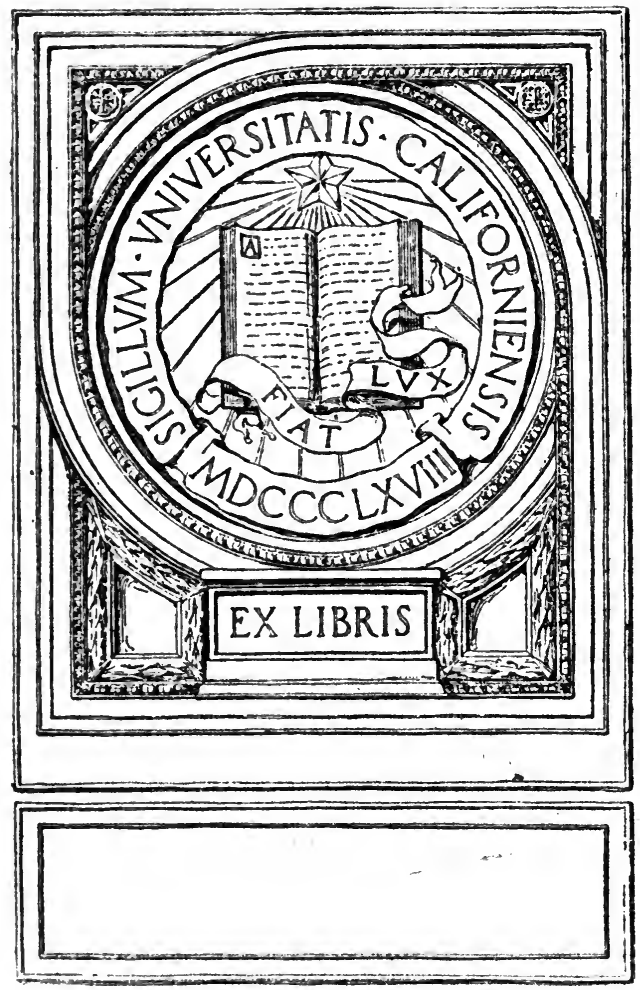
$\gamma: \div$

,

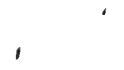

-

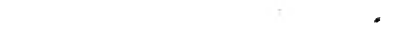





\section{The TRural Text $=\mathbb{J B}$ ook \$eries}

Edited by L. H. BAILEY

\section{THE PRINCIPLES AND PRACTICE OF JUDGING LIVE-STOCK}




\section{The \#ural Text=Bonk Zaries}

Mann, Beginnings in Agriculture. Warren, Elements of Agriculture. Warren, Farm Management.

Lyon and Fippin, Soll Management. J. F. Duggar, Southern Field Crops. B. M. Duggar, Plant Physiology. Harper, Aximal Husbandry for Schools. Montgomery, Corn Crops. Wheeler, Manures and Fertilizers. Livingston, Field Crop Production. Widtsoc, Irrigation Practice.

Piper, Forage Plants and their Culture. Hitchcock, Text-Book of Grasses.

Gay, The Principles and Practice of Judging Live-Stock. 



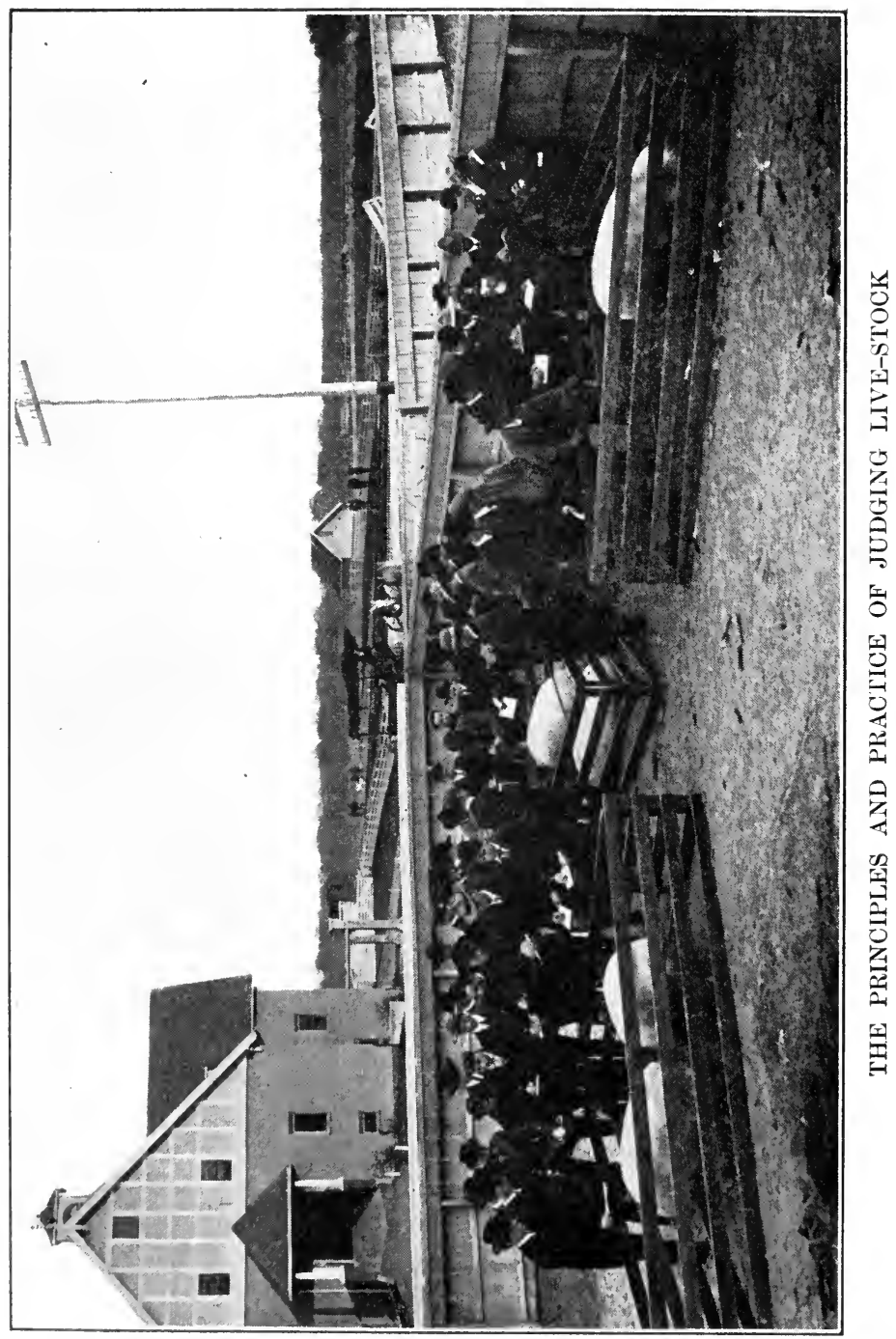




\title{
THE PRINCIPLES AND PRACTICE OF JUDGING LIVE-STOCK
}

\author{
BY \\ CARL WARREN GAY, D.V.M., B.S.A. \\ PROFESSOR OF ANIMAL INDUSTRY, UNIVERSITY OF \\ PENNSYlvaNia, PHILAdelphia \\ PENXYLVANIA
}

\author{
Ňew 19ark \\ THE MACMILLAN COMPANY \\ 1916
}

All rights reserved 


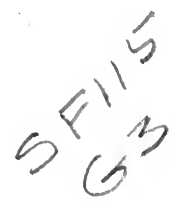

Coprright, 1914,

BY THE MACMILLAN COMPANY.

Set up and electrotyped. Published November, 1914. Reprinted February, 1915; March, August, rgi6.

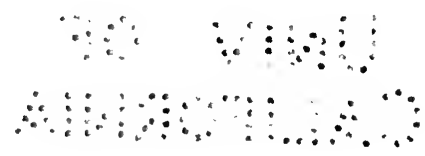

Norwood 斯ess

J. S. Cushing Co. - Berwick \& Smith Co.

Norwood, Mass., U.S.A. 


\section{PREFACE}

WIтн the extension of the live-stock industry and the development of the sciences fundamental thereto, the necessity is felt for striking at the root of things, of getting well under the surface. This necessity is emphasized particularly in the matter of live-stock judging. The study of feeds and feeding, of the principles of breeding, and of systems of live-stock management have progressed further along scientific lines than has the study of live-stock judging.

Doubtless there are many buyers and breeders of animals whose judgment.is more accurate, even, than that of the trained expert, but there is neither science nor system in their reasoning and they cannot tell why they so decide. In order that others may be trained in ways of live-stock improvement it is important that our knowledge of animal excellence be increased, our powers of observation and perception made. more keen, our judgment in making comparisons more logical, and our decisions more accurate. To do this requires a more exhaustive and scientific study of the subject. The best way to understand the exterior of animal form is to study the interior. Nowadays we make soil surveys where we formerly considered only area and topography. It seems reasonable that the best judge of a steer's loin should be a connoisseur of porterhouse; to prognosticate most closely the durability of a horse's foot one should know all of the com- 
plicated structures contained within its horny wall and their related functions, as concerned in locomotion. It is not sufficient simply to require that the texture of a cow's udder shall or shall not be thus and so, but reasons should be given in terms of more or less pounds of milk.

The nomenclature needs revision and a more consistent use of specific terms might be adopted. Sorne names are misleading. It is related how a leading agricultural educator had to see the "milk" vein punctured before he would be convinced that blood and not milk flowed through it. If the name " mammary vein " were employed instead of "milk vein," no such erroneous meaning would be conveyed. Some regions which are specifically designated cannot be definitely described. No one can determine, for instance, just where the shoulder vein of the steer becomes neck on the one side and shoulder on the other. Some terms with a distinct significance are used loosely and interchangeably. It is the fore quarter of the steer but the fore hand of the horse ; the rump of the cow, the croup of the horse. The appearance of the dairy cow is spare or lean, not thin. The draft horse is compact while the heavy harness horse is closely made, and to say that the latter is compact is to suggest draftiness, a feature which he should not possess.

It would be as impracticable to drop the objectionable names in common usage as it is unscientific to retain them ; the intelligent husbandman should command them both in order to converse intelligently with either the stockmen whom he must cultivate and from whom he derives much of his inspiration and knowledge of the work, or those students whose instructor he may be.

The effort has been made, in the preparation of this work, to take the student and stockman a step further 
along this line than he has gone heretofore. Care has been exercised not to sacrifice the popular phase upon which our knowledge of the subject is based but to bridge over onto a more technical consideration of it.

It is hoped that the author's intention of keeping the work thoroughly practical, yet giving it a touch of a somewhat technical nature, will be appreciated by students and stockmen alike.

CARL W. GAY.

Philadelphia,

July 1, 1914. 
. 


\section{CONTENTS}

\section{PART I \\ THE PRINCIPLES OF JUDGING}

CHAPTER

I. General View

PAGE

3

II. The Animal Machine and Its Place in Our Economy 6

\section{PART II}

THE PRACTICE OF JUDGING

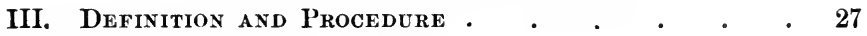

IV. Features of Animal Form to be Considered in JUDGING

V. The Means of Making Observations . . . . 60

VI. Practice Judging • • • • • • • • •

\section{PART III}

\section{JUDGING HORSES}

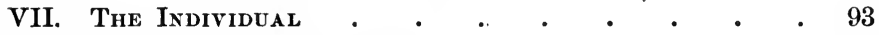

VIII. The Types and Classes $. \quad . \quad . \quad . \quad . \quad .113$

IX. The Breeds . . . . . . . . . 147

X. The Mule • • • • • • • • 168

\section{PART IV \\ JUDGING CATTLE}

XI. The Types

XII. The Breeds • . . . . . . • . 217 


\section{JUDGING SHEEP}

CHAPTER

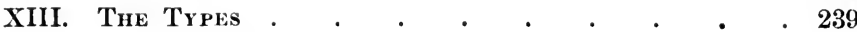

XIV. The Breeds. . . . . . . . . . 252

\section{PAR'T VI \\ JUDGING SWINE}

XV. The Types . . . . . . . . . . . . . 271

XVI. The Breeds . . . . . . . . . . 285

\section{PAR'T VII \\ JUDGING BREEDING ANIMALS}

XVII. Breeding Stock . . . . . . . . . 297

XVIII. Live-Stock Shows. . . . . . . . 307

APPENDIX . . . . . . . . . . . 325 


\section{LIST OF ILLUSTRATIONS}

The Principles and Practice of Live-Stock Judging . Frontispiece FIG.

1. Glandular epithelium. (Piersol, Histology, Lippincott) $\quad 9$

2. Transverse section of dried bone. (Piersol, Histology,

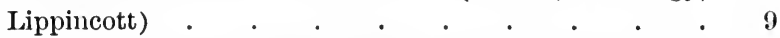

3. Involuntary muscle in longitudinal section. (Piersol, Histology, Lippincott). . . . . . . . 10

4. Involuntary muscle in transverse section. (Piersol, Histology, Lippincott) . . . . . .

5. Section of portion of a nerve trunk. (Piersol, Histology,

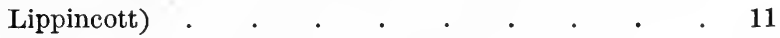

6. Points of the horse. (Bailey, Cyclopedia, Macmillan) $\quad 12$

7. Surface of mucous membrane of the intestine. (Bailey, Cyclopedia, Macmillan) · · $\cdot \dot{C}^{\circ} \cdot{ }^{\circ}$

8. Side view of internal organs of mare. (Bailey, Cyclopedia, Macmillan).

9. Generative organs of the mare. (Bailey, Cyclopedia, Macmillan) . . . . . . . . . .

10. Pelvis of the mare showing the dimensions of the pelvic girdle through which the foetus passes in delivery. (Sisson, Veterinary Anatomy, Saunders) . . .

11. International Students' Judging Contest. Contestants placing a class of Short-horn bulls. (Courtesy Breeders' Gazette, Chicago, Ill.) •. • • •

12. Shod and unshod hoofs in founder. (Bailey, Cyclopedia, Macmillan) . . . . . . . . .

13. Leg showing large spavin. (Bailey, Cyclopedia, Macmillan) 41

14. Leg showing ringbone. (Bailey, Cyclopedia, Macmillan) . 41

15. Leg showing curb. (Bailey, Cyclopedia, Macmillaul) • $\quad 42$

16. Leg showing capped hock. (Bailey, Cyclopedia, Macmillan) 42 
FIG.

PAfR

17. A temporary or milk tooth. (Roberts, The Horse, Macmillan) . . . . . . . . . •

18. Lower jaw of foal from one to two weeks old. (Roberts, The Horse, Macmillan) . . . . . . .

19. Lower jaw of the two-year-old colt. (Roberts, The Horse, Macmillan) . . . . . . . . .

20. Lower jaw of the three-year-old colt. (Roberts, The Horse, Macmillan) . . . . . . . . .

21. Lower jaw of the four-year-old. (Roberts, The Horse, Mac-

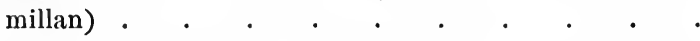

22. Side view of the mouth of a four-year-old. (Roberts, The Horse, Macmillan). . . . . . . . .

23. Lower jaw of a five-year-old. (Roberts, The Horse, Macmillan) . . . . . . . . . .

24. Side view of the mouth of a five-year-old. (Roberts, The Horse, Macmillan)

25. Lower jaw of a six-year-old. (Roberts, The Horse, Mac-

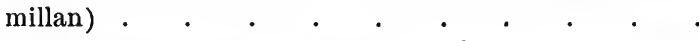

26. Side view of the mouth of a six-year-old: (Roberts, The Horse, Macmillan) ..$\quad$. $\quad . \quad$. .

27. Lower jaw of the seven-year-old. (Roberts, The Horse, Macmillan) . . . . . . . . .

28. Side view of the mouth of a seven-year-old. (Roberts, The Horse, Macmillan). . . . . . . .

29. Lower jaw of an eight-year-old. (Roberts, The Horse, Macmillan) .

30. Side view of the mouth of an eight-year-old. (Roberts, The Horse, Macmillan).

31. Side view of the mouth of an aged horse. (Roberts, The Horse, Macmillan) . . . . . . . .

32. Lower jaw of an aged horse.. (Roberts, The Horse, Macmillan) . . . . . . . . . .

33. Shows the wear of an incisor tooth at the ages of three, four, five, six, nine and twenty years. (Roberts, The Horse, Macmillan). . . . . . . .

34. Cross section of an incisor tooth, showing how the shape changes with advancing years. (Roberts, The Horse, Macmillan)

35. Outline drawing of a horse . . . . . . . . . 
FIG.

PAGE

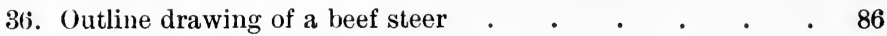

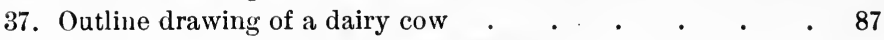

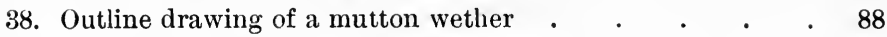

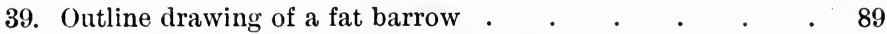

40. Sagittal section of distal part of limb of horse. (After Ellenberger-Baum, Anat. für Künstler) • . $\quad$. 94

41. A trotter at speed showing the reach or extension of the

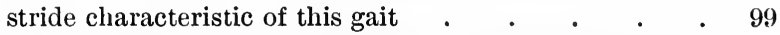

42. The high stepping trot showing the "placing" and the extreme flexion of knees and hocks. (Courtesy Irvington Farm, Sewickley, Pa.) • • • • •

43. The saddle horse trot; going collectedly, well off hocks, moderate knee action and a springy stride. (Courtesy Devon Horse Show Ass'n)

44. A pacer at speed, showing the lateral character of this
gait. (Courtesy The Horseman, Chicago, Ill.)
45. A gaited saddle horse at the rack, although the four-beat

44. A pacer at speed, showing the lateral character of this
gait. (Courtesy The Horseman, Chicago, Ill.)
45. A gaited saddle horse at the rack, although the four-beat phase of this gait is not shown. (Courtesy Longview Farm, Lees Summit, Mo.) · · · · · $\cdot$

46. The canter, the hind foot bearing the weight and beginning a new series of three beats at the phase of contact, after the horse has been projected clear of the ground by the independent forefoot. (Courtesy Devon Horse Show Ass'n) . . . • . . . . . .

47. The jump, in which the forehand lifts, the hindquarters propel. (Courtesy Devon Horse Show Ass'n) • • 106

48. The power horse type . . . . . . . . $\quad$. 114

49. Frontal section of large metatarsal (hind cannon) bone of horse, posterior part.' (Sisson, Veterinary Anatomy, Saunders)

50. Cross section of distal part of left metacarpus (cannon) of horse, just above sesamoids. (Sisson, Veterinary

Anatomy, Saunders) $\cdot$ 51. The speed horse type. (Courtesy The Horseman, Chicago,
.

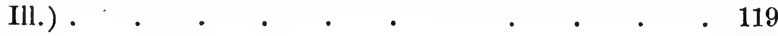

52. The show horse type . $\quad . \quad$. $\quad . \quad$. $\quad . \quad$. 121

53. The saddle horse type. (Courtesy Wm. T. Hunter, Devon, Pa.)

54. A pair of heavy draft geldings 
FI\%.

55. A pair of chunks .

56. A pair of expressers

57. A "four" of coach horses. (Courtesy Devon Horse Show Ass'n) . . . . . . . . . .

58. A park mare to ladies' phaëton. (Courtesy Devon Horse

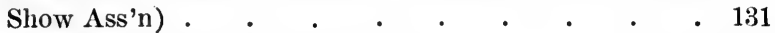

59. A runabout mare correctly turned out . $\quad . \quad$. $\quad . \quad$. 133

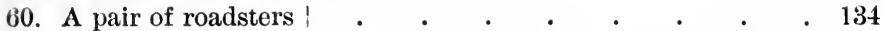

61. A gaited saddle horse. (Courtesy Mrs. R. 'T. Isowndes,

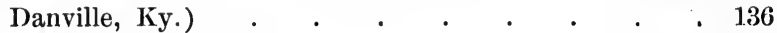

62. A walk-trot-canter mare . . . . . . . . . . 137

63. The thoroughbred type of walk-trot-canter saddle borse.

(Courtesy Devon Horse Show Ass'n) . . . .

64. A light weight hunter. (Courtesy Glen Riddle Farms, Glen

Riddle, Pa.) . . . . . . . . . .

65. A heavy weight hunter. (Courtesy Devon Horse Show Ass'n) . . . . . . . . . .

66. A 42-inch harness pony. (Courtesy Devon Horse Show Ass'n) . . . . . . . . . .

67. An $11 \frac{1}{2}$-hand saddle pony. (Courtesy Devon Horse Show Ass'n) . . . . . . . . . .

68. A $12 \frac{1}{2}$-hand harness pony. (Courtesy Irvington Farm, Sewickley, Pa.) .

69. A 13-hand saddle pony. (Courtesy Devon Horse Show

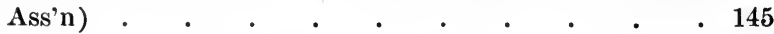

70. A polo pony. (Courtesy Wm. T. Hunter, Devon, Pa.) . 146

71. A Percheron stallion. (Courtesy E. B. White, Leesburg, Va.) 148

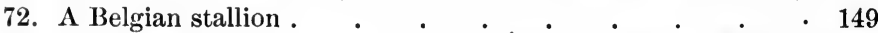

73. A Clydesdale stallion. (Courtesy Conyngham Bros., WilkesBarre, Pa. $)$. $\quad$. . . . . . .

74. A Shire stallion. (Courtesy Truman's Pioneer Stud Farm, Bushnell, Ill.)

75. A Suffolk stallion. (Courtesy Conyngham Bros., WilkesBarre, Pa.) . . . . . . . . .

76. A Hackney stallion. (Courtesy Hon. Henry Fairfax, Aldie, Va.)

77. A French Coach stallion

78. A German Coach stallion

79. A Standardbred stallion 
FIG.

80. A Thoroughbred stallion. (Courtesy Devon Horse Show Ass'n) . . . . . . . . . . . . . 161

81. An American saddle stallion $\quad . \quad$. $\quad . \quad . \quad . \quad \cdot 163$

82. A Shetland stallion. (Courtesy National Stockman and Farmer, Pittsburgh, Pa.) . . . . . . 164

83. A Welsh pony stallion. (Courtesy Geo. A. Heyl, Washington, Ill.) · • • • • • • •

84. A Hackney pony stallion. (Courtesy Irvington Farm, Sewickley, Pa.)

85. A draft mule

86. A plantation mule

87. The block type. This steer dressed the International Grand

Champion carcass. (Courtesy National Stockman and

Farmer, Pittsburgh, Pa.) . . . . . .

88. The fat cells interspersed between the muscle fibers. (Bailey, Cyclopedia, Macmillan) . . . . . 179

89. The "marbling" of meat. (Bailey, Cyclopedia, Macmillan) 180

90. Beef carcass cuts. (Courtesy Illinois Experiment Station, Urbana, Ill.

91. The sirloin cut. (Bailey, Cyclopedia, Macmillan) . $\quad 185$

92. The porterhouse cut. (Bailey, Cyclopedia, Macnillan) . 186

93. The round cut. (Bailey, Cyclopedia, Macmillan) . 186

94. The standing or prime rib cut. (Bailey, Cyclopedia, Mac-

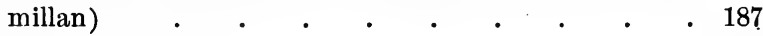

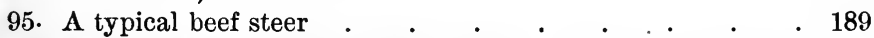

96. A carload of highly finished cattle. (Courtesy National

Stockman and Farmer, Pittsburgh, Pa.) • • 192

97. A carload of blue grays "on feed" . . . . . . . 194

98. A carload of grade Hereford feeders . . . . . . 196

$99 \mathrm{~A}$. Alveoli of the mammary gland of the goat at the time of parturition. Beginning of fat formation. (Grimmer, Chemie und Physiologie der Milch, Paul Parey, Berlin) · · · · · · · · · 200

$99 \mathrm{~B}$. Alveoli of the maminary gland of goat at the time of parturition, showing successive stages of secretion. (Grimmer, Chemie und Physiologie der Milch, Paul Parey, Berlin) . . . . . . . .

100. A typical dairy cow. (Courtesy Penshurst Farm, Narberth, Pa.) . $\quad . \quad$. $\quad$. $\quad$. 202 
FIG.

101. A typical dairy cow, rear view. (Courtesy Penshurst Farm, Narberth, Pa.) . $\quad$. $\quad$. $\quad . \quad$. $\quad . \quad 203$

102. The points of the cow. (Bailey, Cyclopedia, Macmillan). 205

103. Section of the cow's udder, showing the internal structure and arrangement of the gland. (Sisson, Veterinary

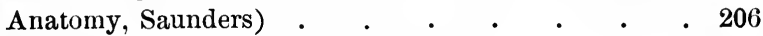

104. Section of cow's udder. (After Moussu) . . . . 208 105. Ayrshire heifer calves, showing the growth, feminine appearance and shape indicative of future dairy development. (Courtesy of Highland Farm, Bryn Mawr, Pa.) . .

106. A typical dual-purpose cow. (Courtesy National Stockman and Farmer, Pittsburgh, Pa.) . $\quad . \quad$. 215

107. A Short-horn bull. (Courtesy Rookwood Farm, Ames, Ia.). 218 108. A Polled Durham bull . 219

109. A Hereford bull. (Courtesy Orchard Lake Farm, Kentland, Ind.) . • • • • • • . • 220

110. An Aberdeen-Angus bull. (Courtesy Chas. Gray, Chicago, Ill.)

111. A Galloway bull .

112. A Jersey cow

113. A Guernsey cow. (Courtesy Pencoyd Farm, Bala, Pa.) . 222 224 226 114. A Holstein-Friesian cow. (Courtesy Lakeside Farm, Syracuse, N. Y.) .

115. An Ayrshire cow. (Courtesy Penshurst Farm, Narberth, Pa.)

116. A Brown Swiss cow

117. A Dutch Belted cow

118. A Red Polled cow

119. A Milking Short-horn cow. (Courtesy National Stockman and Farmer, Pittsburgh, Pa.) . . . . . 227 229 230 232 233 234 235

120. Mutton carcass cuts. (Courtesy Illinois Experiment Station, Urbana, Ill.) . $\quad . \quad$. $\quad . \quad$.

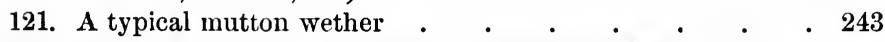

122. Points of the sheep. (Bailey, Cyclopedia, Macmillan) . 244

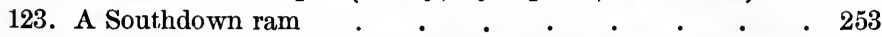

124. A Shropshire ram. (Courtesy Jess C. Andrew, Lafayette, Ind. ) . $\quad . \quad$. $\quad . \quad$. $\quad . \quad$.

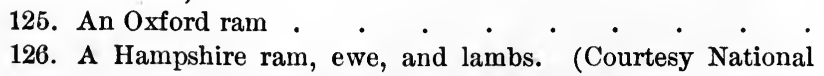
Stockman and Farmer, Pittsburgh, Pa.) . . 
FIG.

127. A Dorset-horn ram

258

128. A Cheviot ram . . . . . . . . . . 259

129. A Leicester ram and ewe . . . . . . . 260

130. A Lincoln ram . . . . . . . . . . . 262

131. A Cotswold ram . . . . . . . . . . . 263

132. An American Merino ram. (Courtesy National Stockman and Farmer, Pittsburgh, Pa.) . . . . . . 264

133. A Delaine Merino ram. (Courtesy National Stockman and Farmer, Pittsburgh, Pa.) . . . . . . 265

134. A Rambouillet ram. (Courtesy National Stockman and Farmer, Pittsburgh, Pa.) . . . . . . . . 266

135. Hog carcass cuts. (Courtesy Illinois Experiment Station,

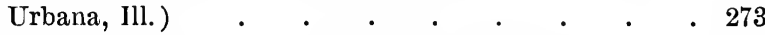

136. A typical fat barrow . . . . . . . . . . . 274

137. Points of the hog. (Bailey, Cyclopedia, Macmillan) . 275

138. A typical bacon barrow . . . . . . . 280

139. A Berkshire boar. (Courtesy Rookwood Farm, Ames, Ia.) 286

140. A Poland China boar . . . . . . . . . $\quad 287$

141. A Duroc Jersey boar . . . . . . . . . . 288

142. A Chester White boar . . $\quad . \quad$. $\quad . \quad$. $\quad . \quad 289$

143. A Hampshire boar . . . . . . . . . 290

144. A Yorkshire sow. (Courtesy Farmers' Advocate, London,

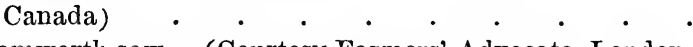

145. A Tamworth sow. (Courtesy Farmers' Advocate, London,

Canada)

291

146. Percheron yearlings whose sire is shown as Figure 71 . (Courtesy E. B. White, Leesburg, Va.)

147. Prepotency of the sire manifested in the production as well as the individuality of his get. (Courtesy Highland Farm, Bryn Mawr, Pa.) . . . . . 299

148. Sex and breed character in the stallion. (Courtesy Conyngham Bros., Wilkes-Barre, Pa.) . . . . . 300

149. Sex and breed character in the bull . . . . . . 301

150. A typical breeding female . . . . . . . 302

151. The characters desired in the breeding stallion and mare, shown in contrast. (Courtesy Fairholme Farms, New Market, N.J.)

152. A typical dairy bull, masculine yet refined, of true dairy type and possessing unusual breed character . . 
FIG.

153. Judging saddle horses - A walk-trot-canter class. (Courtesy Devon Horse Show Ass'n) . . . . . 308

154. Judging saddle horses $-A$ class of hunters. (Courtesy Devon Horse Show Ass'n) . • . . . . 310

155. Judging draft horses - A class of Percheron mares . $\quad .312$

156. Judging beef cattle-A class of Short-horn bulls . . 313

157. Judging dairy cattle - A class of Ayrshire cows . . 315

158. Aged herd of Aberdeen-Angus. (Courtesy Chas. Gray,

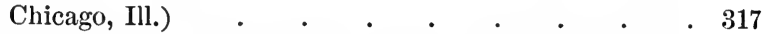

159. Showing in hand. (Courtesy Irvington Farm, Sewickley,

Pa.) . . . . . . . . . . . 318 
PART I

THE PRINCIPLES OF JUDGING 


\section{.}

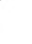




\section{LIVE-STOCK JUDGING}

\section{CHAPTER I}

\section{GENERAL VIEW}

The ultimate object of live-stock husbandry is the production of market animals and their products, an end which is attained by two steps or stages, breeding and feeding. The one furnishes the raw material, the other finishes the product. Thus there are two groups of husbandmen, those concerned with the production of the animal machine and those engaged in the employment of this machine for the manufacture of animal products.

There are, furthermore, two classes of breeders, one whose efforts are devoted to the breeding of foundation stock and the improvement of the race in general, another whose purpose is to supply the feeders from their studs, herds and flocks. The latter are obviously dependent upon the former. The breeder either may finish or work his own stock, as is usually the case with hogs and commonly with horses, dairy cattle and sheep, or may dispose of them while immature or thin to the feeder, as is the rule with beef cattle and range sheep. In some instances, therefore, the breeder is also the feeder, while in others the line between them is rather sharply drawn.

The position of the breeder is fundamental and of primary importance, as he determines the grade of mate- 
rial available to the feeder; with good material insured, however, it is incumbent upon the feeder to make the most of the possibilities which the breeder has afforded him.

1. Breeding for improvement. - Breeding, as we commonly interpret the term, consists in regulating the progeny by controlling the parentage, to attain improvement. The constructive breeder aims at more than the mere multiplication of his foundation stock; he strives for qualitative as well as quantitative improvement with each succeeding generation. Although improvement may be slight in each instance, the cumulative results of a number of generations, the progenitors of which have been carefully selected, may be considerable. This has been the principal factor operating in the evolution of the domestic types and breeds of animals, mutations having been much more useful to plant than to animal breeders. The bases for the qualitative improvement to which selection is made in the breeding of animals are, in most instances, characters which were originally possessed by them in their feral state and useful only for their own subsistence. Under domestication these natural functions have been perverted, readapted and developed so as to amply serve the needs and purposes of man. The motive governing live-stock improvement has been well expressed by Owen: "Whatever the animal kingdom can afford for our food or clothing, tools, weapons, and armament, whatever the lower creation can contribute to our wants, our comforts, our possessions or our pride, that we sternly exact and take at all costs."

2. Selection is judging. - Control of the parents is accomplished by means of selection, and selection is judging. Proficiency in this regard is fundamental, for 
without judicious matings the breeder's facilities, resources and even the merit of his foundation stock count for little in the long run. The master breeders of live-stock history have all been judges of the first order.

It should not be supposed that the activity of the agricultural schools in training students to become expert judges is for the sole purpose of supplying men qualified to tie ribbons in the show ring. Notwithstanding the fact that the placing of show ring awards carries with it great responsibility, since ideals and standards so established serve to lead or mislead the rank and file of livestock breeders, the real benefits of accurate judgment in the show ring are not to be measured by ribbons, plate or cash. They are enjoyed by all consumers of meat or milk, wearers of clothing, and users of horses for either profit or pleasure.

The breeder or feeder buyer constitutes the judge, whether he ever officiates in a show ring or not, and those who benefit by his judgment are the consumers of his product. 


\section{CHAPTER II}

\section{THE ANIMAL MACHINE AND ITS PLACE IN OUR ECONOMY}

The highest type of domesticated animal has been defined as the one which constitutes the most efficient machine for making the greatest return, in its specific product, on the raw material consumed. In this it bears an important economic relation to man as a source of food and clothing, and as an auxiliary in work.

3. Economic purpose of animal machine. - Food with air and water are the three essentials for human existence. Food is that which builds up the body and furnishes energy for its activities; that which brings within reach of the living cells which form the tissues the elements which they need for life and growth. Only such available substances can be called food, no matter what their chemical composition may be. Coal may be fuel for the furnace, but not for cattle; rough forage like hay may form the basis of cattle rations, but it is not available for man's consumption. It is in the conversion of such raw materials as are not available to man in their present form into animal food products or into horse power for his service that the animal machine serves a most important economic purpose. If man were to eliminate the fruits of animal production from his dietary, there would be of necessity an enormous increase in the cost of living, to compensate for the tremendous loss of the crops of the 
field which would be utter waste, or, at best, serve but for fuel if available only in their raw, unconverted state.

4. Intermediate relation of animal to plants and man. There are about fifteen principal chemical elements of nutrition. They are constituents of the human body, likewise the bodies of animals and plants; a few of them compose also the three requisites for the maintenance of life, - air, water and soil, the sources of food. We can, therefore, understand the synthetical relationship between man on the one hand, and the original sources of his subsistence on the other, with the plants and animals as intermediary factors. Some of the hydrogen and oxygen required by man is obtained direct from the water he drinks; more of his oxygen is taken direct from the air he breathes, and in return he gives carbon dioxide, equally essential for plant respiration. The soil, however, contributes to our support only indirectly through the bodies of the plants grown upon it. These plants also make abundant use of the nitrogen of the air, an important function, since nitrogen is a chief constituent of the protoplasm of the human or animal cell, both of which are helpless to draw directly upon the supply in the air. A great wealth of plant products are directly available to man in quantity and variety to meet his nutritive requirements, but the entire body of some plants and the major portion of many others are impossible for human consumption. The corn kernel, after a process of milling, becomes a staple article of food for man, but for every pound of corn there is approximately a pound of stover, which would be absolutely valueless were it not for the ruminant's ability to transform it into digestible, nutritious animal food products, meat and milk. We readily recognize the physical impossibility of a man's consuming sufficient pasture grass or hay to 
sustain life, although the necessary elements are contained therein; yet from these materials are produced, in large part, the meat we eat and the milk we drink, our two most valuable tissue-building foods.

It is with the view of securing the most efficient animal machines for the different kinds of production that the husbandman practices judging.

\section{The Function of the Animal Machine}

5. Efficiency. - Mechanical efficiency is a matter which involves the character of the materials of construction, the perfection of the individual parts, the accuracy with which they are assembled, the power available for their operation, and the effectiveness of its application and control.

Efficiency in the functional capacity of animals is analogous in many respects. Whether in the production of horse power, milk, a carcass, or a fleece, it involves and is directly dependent upon, first, the individual unit of structure, the cell, and its arrangement in the organization of tissue; 'second, the gross structure into which the various individual tissues are incorporated; third, the vital phenomena with which the tissues are engaged for both the maintenance and productiveness of the structure as a whole; fourth, the manner in which they are governed; and, fifth, the significance of abnormal conditions of structure and the extent to which they may impair function.

An elementary consideration of histology, anatomy, physiology and pathology, in their relation to the structures and correlated functions concerned in animal production is, therefore, essential. 


\section{Histology}

6. Tissue. - Any tissue is composed of an essential unit of structure, the cell, and an inter-cellular material by means of which the cells are held together. The character of the cells themselves, their arrangement in the inter-cellular substance, its nature, and the proportion of each are what give to tissues their characteristic features.

The animal body is composed of four kinds of tissue, i.e. epithelial, connective, muscle and nerve. The general nature of each and its place in the

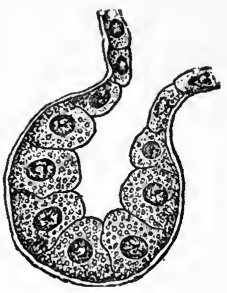

Fig. 1.-Glandular epithelium. organization of the animal economy should be fully understood in order to pass intelligently upon the relative structural and functional merits of two or more individuals.

7. Epithelial tissue. - The epi-

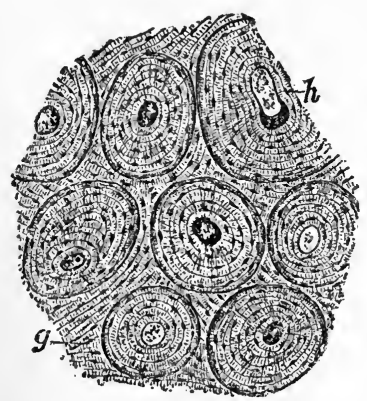

Fig. 2. - Transverse section of dried bone. $h$, one of the Haversian canals, about which the lamellæ are concentrically disposed, constituting the Haversian systems; $g$, the ground or intestinal lamellæ. thelial group is represented by the skin or outer covering of the body; the mucous and serous membranes lining the interior, the former those cavities in communication with the outside as in the respiratory and digestive tracts, the latter the closed cavities of the chest and abdomen. The glands or secreting structures such as the udder, are also composed of epithelial tissue (Fig. 1).

8. Connective tissue. - The connective tissue group com- 
prises all those which enter into the supportive structure or framework of the body, such as bone, cartilage, ligaments and tendons, and the interstitial tissue of all the organs. All of the connective tissues are more or less fibrous in character (Fig. 2).

9. Muscle tissue. - Muscle tissue may be divided into voluntary and involuntary, the former represented by the skeletal muscles with which the judge is most concerned

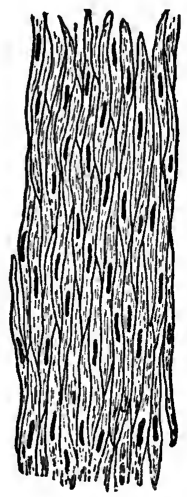

FIG. 3. - Involuntary muscle in longitudinal section; the musclecells are of ten cut obliquely, and hence appear shorter than when isolated.

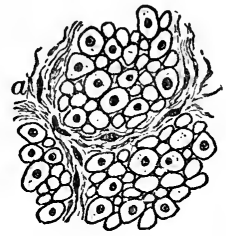

Fig. 4. - Involuntary muscle in transverse section: portions of three bundles are represented separated by areolar tissue $(a)$; the nucleated areas are sections of the musclecells through their nuclei; the smaller figures represent sections of the cells cut nearer the ends.

in the matters of locomotion and meat production, the latter entering into the makeup of the heart, the walls of the blood vessels and the intestines, structures having to do with the vital functions. The characteristic feature of muscle tissue is its contractility, which takes place in response to a nerve stimulus (Figs. 3 and 4).

10. Nerve tissue. - The nervous system is divided into a central, composed of the brain and the spinal cord, and a 
peripheral, made up of the nerve trunks and their nerve endings, which are distributed, in a most general way, to all parts. Nerve tissue has the property of conveying or transmitting impulses to or from the central station or brain, those impulses emanating from the centers and

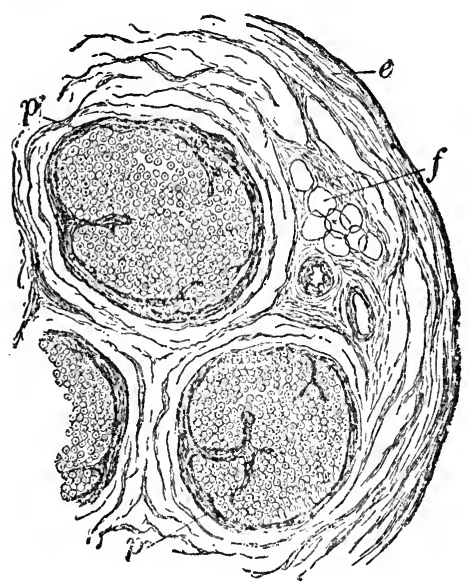

FIG. 5. - Seetion of portion of a nerve trunk, ineluding three bundles of individual nerve fibers surrounded by the perineurium $(p)$; the bundles, together with the blood vessols and adipose tissue, are united by the more general epineurium $(e)$; the seetions of the individual nerve fibers are held in place by the endoneurium; fat cells near which are the seetions of blood vessels $(f)$.

directed to the general muscular system traversing the so-called motor trunks, while those impulses which originate in the peripheral endings and are conveyed to the brain travel along the sensory nerves (Fig. 5).

\section{Anatomy}

11. The skeleton. - The foundation of the structure of the quadruped is the bony skeleton, divided, for con- 
loin, the sacral or coupling, and the coccygeal or tail. The ribs spring from the thoracic vertebræ and are attached, the anterior directly, the posterior indirectly, to the sternum or breast bone, which constitutes the region of the brisket in ruminants. The ribs inclose the thorax or chest cavity and a part of the abdominal cavity. Superiorly upright spines are developed from the thoracic vertebræ, which give form to the withers or chine (Fig. 6).

12. The foreleg. - The legs or extremities consist of columns, too, each divided into regions. The fore leg is composed of a scapula or shoulder blade, humerus or arm, radius and ulna or forearm, carpus or knee, metacarpus or cannon, the first and second phalanges which constitute the pastern, the latter more particularly the coronet, and the pedal, coffin, or foot-bone.

13. The hind leg. - The hind leg includes the pelvis or hip, by means of which the coupling between the spinal column and the hind leg is made and which also forms the pelvic girdle inclosing the pelvic cavity through which the fotus has to pass in the female, the femur or thigh, the patella or knee, the tibia and fibula or lower thigh, the tarsus or hock, the metatarsus or cannon, the rémainder of the leg being a duplication of the anterior extremity.

14. The foot. - The region below the knees and hocks is anatomically considered as the foot proper, the appropriateness of which is shown by a study of the analogous parts in the biped and the intervening stages in the rabbit and the cat.

15. The joints. - The legs constitute supporting columns while at rest, but the extremities of the individual bones, opposed to each other in the columns, are furnished 
with articular or joint surfaces by means of which one bone moves on the other. By the operation of the joints the columns are broken, the legs alternately flexed or extended, and locomotion is thus accomplished. The joint surfaces are maintained in position by the joint capsule and lubricated by the synovia secreted by it.

16. The muscular system. - The skeletal muscular system is composed of the striated, voluntary variety of muscle tissue. Some individual muscles are long and thin, some short and thick, and others broad and flat. They are arranged mostly in groups of those having similar action, and may be in two or more superposed layers. While the primary function of the muscles is to operate the bones, they serve a secondary purpose in furnishing, as it were, the skeleton, giving form to what would otherwise be but a framework. This is much more marked in some parts than in others. The head, for instance, is but little altered in form or proportions from those of the skull, while all but the column of the neck is muscle, giving it a much better outline than it has in the skeleton; the form of the withers of the horse is but slightly altered by the muscles of that region, while the croup is made up of such a mass of muscle as to completely change the skeletal outline of that part.

17. The structure and arrangement of individual muscles. - Each muscle has, in its relation with the bones, an origin where the fibers are attached directly to a considerable area of bone surface, and an insertion which is usually accomplished by means of a tendon into which the muscle fibers are continued. The tendon may have more length than the muscle itself, transmitting the power of the muscle a considerable distance before it is finally inserted. The extensors and flexors of the foot, for 
instance, terminate their muscular portions above the knee, the tendon continuing throughout the entire length of the cannon and the pastern before being inserted. The origin of the muscle serves as the fixed point toward which the bone on which the muscle has its movable insertion is drawn by its contraction. However, other muscles may fix the point of movable insertion when the action of the muscle is reversed. The long muscle concerned with knee action in the horse is an example in point. It has its origin at the side of the head and upper part of the neck and is inserted on the humerus of the arm. With the fixed point above, its contraction elevates and carries forward the arm and with it the leg, but with the leg fixed as in the standing position, its contraction may serve to incline the head and neck to one side.

18. Muscular action. - Each muscle has a definite action, depending upon its position with relation to the joint and the nature of the joint surface itself. Hinge joints have their articular surfaces so arranged as to prevent motion in but one plane, as the elbow or hock joints, while others, as the ball and socket joints of the shoulder and hip, are capable of considerable freedom of motion, even to the extent of rotation. The action of a muscle is to flex or close the angle of a joint, when it is situated in the angle and behind the joint; to extend when in front of the joint or over the summit of the angle; to abduct or adduct when on the side of the joint away from or toward the median plane of the body; to rotate if so arranged as to cross from one side to the other in its course.

All muscles are not equally employed. The class of animals and the particular use to which each is put have much to do in determining which muscles are most fré- 
quently called into requisition. The delicate texture of the so-called tenderloin or fillet of beef is due to its being derived from a group of muscles, the chief use of which is in rearing, and since the unsexed bovine rarely rears, these muscles are so seldom called into play as to leave them practically undeveloped, and therefore very tender.

\section{Physiology}

19. Prehension of food. - The taking of food comes first in an enumeration of the physiological processes by

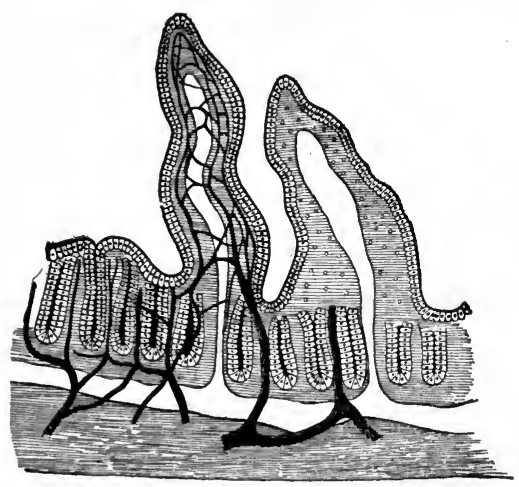

FIG. 7. - Surface of mucous membrane of the intestine. Showing villi with central lacteal duct and blood vessels, and on the surface the absorbing epithelial cells. means of which animals are productive. The chief prehensile organ in the horse is the lip, in cattle and sheep the tongue, and in the hog the snout.

20. Digestion. - In the mouth the food is comminuted by mastication so as to be more completely accessible to the digestive juices, and is acted upon by the saliva which commences the digestion of some of the starches. This is
continued after the food is swallowed into the stomach. Here also the gastric juices, with their enzymes, and the hydrochloric acid, continue the conversion of the raw materials of nutrition presented in the food into forms in which they may be assimilated into the blood stream and become available to the tissues and to such secreting organs as the udder. Digestion is completed in the small 
intestine, where the pancreatic juice and the bile finish the conversion of the starches into soluble sugars and split the fats into fatty acids and glycerin, respectively.

21. Assimilation. - Assimilation takes place chiefly from the small intestine after digestion has been accomplished (Fig. 7), although some of the more indigestible constituents of the ration, as the fiber, undergo a special

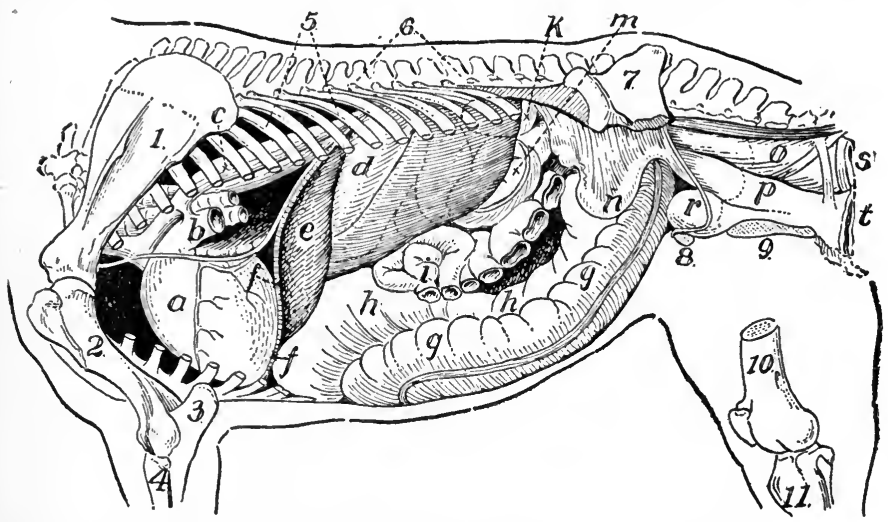

FIG. 8. - Side view of internal organs of mare. 1, scapula; 2, humerus ;

3 , ulna ; 4 , radius; 5 , ribs; 6 , vertebral column; 7 , ilium; 8 , pubis ;

9 , ischium; 10 , femur; 11 , tibia ; $a$, heart; $b$, pulmonary artery; $c$, aorta ; $d$, stomach ; $e$, liver ; $f$, cut edge of diaphragm ; $g g, h h$, large colon; $i$, small intestine; $k$, kidney; $m$, small colon; $n$, uterus; $o$, rectum; $p$, vagina; $r$, urocyst or bladder ; $s$, anus; $t$, vulva.

fermentative disintegration in the large intestine, the digestible portion being assimilated from there. In ruminants the food is bolted and passed immediately to the rumen or paunch, where the fiber undergoes some fermentative changes, but it is later regurgitated to the mouth to be masticated at leisure after the supply has been secured. This is the familiar rumination or chewing of the cud, the cud being simply a mass of food which has. been swallowed 
once then passed back to the mouth from the paunch. It is eventually swallowed to undergo digestion and assimilation in the regular way, and to be replaced in the mouth, repeatedly, by other portions until the entire contents of the paunch have been disposed of in this way. The pig is unlike either the horse (Fig. 8) or the ruminating cattle and sheep, which are strictly herbivorous, it being omnivorous, eating both vegetable and animal matter. It is also monogastric, having but one stomach like the horse, although it has much less capacity of large intestine, and is therefore much less capable of digesting a bulky ration than the horse.

22. Circulation. - The blood stream serves as a transit system, through which the digested nutrient material is conveyed to the tissues and organs to be used for their repair and upbuilding in growth; to be stored up as a reserve fund of energy, as in the case of accumulated fat; to furnish the essentials for glandular secretion, as in the case of the udder ; or to be utilized immediately, as energy, in the maintenance of body temperature or functional activity in the performance of work. Digestion completed, it remains for the circulatory system to accomplish the assimilation and distribution of the digested food constituents.

The circulatory system consists of the heart, which serves as a pump; arteries, which carry the blood, after having been aërated in the lungs and returned to the left side of the heart, to the tissues; and the veins, which return the vitiated blood to the right side of the heart and from thence to the lungs, where the waste products, collected from the tissues, are discharged as carbon dioxide and its red cells are reloaded with a fresh supply of oxygen. In addition to the blood the lymph is circulated through the 
tissues themselves without being confined within definite walls except in the main vessels.

23. Nerve control. - The general function of the nervous system is to exert control over the functions of the other systems, coördinating all movement and regulating all vital processes. The strength and resourcefulness with which this function is exerted is expressed as nerve force, and is usually most marked in the highest bred individuals. Nervousness is no indication of nerve force.

The whole nervous organization is comparable to a telegraph system, in which the central station receives reports and proceeds to act upon them in communicating instructions, for execution, to other parts, usually remote. Nerve impulses may be sensory or motor, and motor impulses may be voluntary or involuntary, depending upon the character of the function involved. For instance, the horse receives a certain pressure from the bit representing an idea in the mind of his rider or driver; the sensory impulse is conveyed to the brain of the horse, from which is sent out the motor impulse which results in the execution of the idea.

\section{REPRODUCTION}

24. Impregnation. - Copulation is the physical act by means of which the male germ cell, or spermatozoön, is conveyed to the genital tract of the female, there to meet the female cell, or ovum, recently discharged from the ovary. Any prospective breeding animal must be capable of it. The female will only submit to the male during the period of œstrum, or heat, at which time a Graffian follicle in the ovary is maturing and a ripe ovum is liberated. Conception takes place in either the body or the horns of the uterus (Fig. 9), depending upon the species, and its 
occurrence, except in rare instances, prohibits the subsequent appearance of œstrum.

25. Gestation. - The duration of gestation is usually correlated with the size and longevity of the species, being three weeks in the case of the mouse and twenty-two

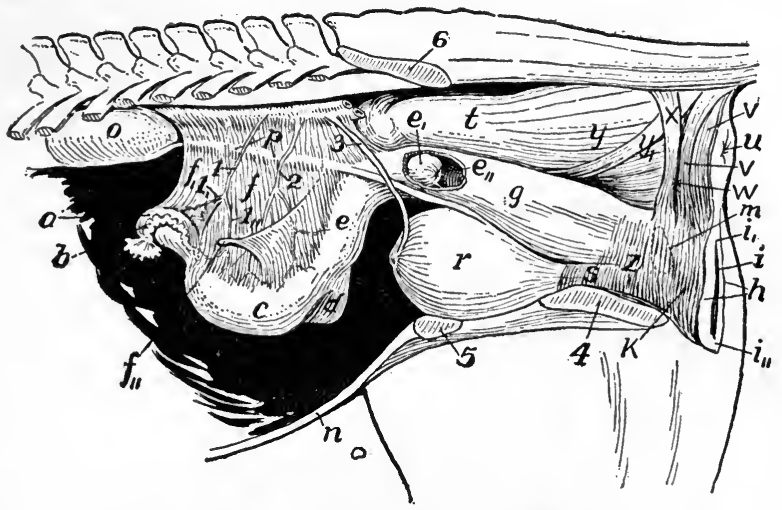

FIG. 9. - Generative organs of the mare. $a$, right ovary; $b$, right oviduct; $c$, right uterine horn; $d$, left uterine horn; $e$, body of the uterus; $e_{1}$, vaginal part of uterus; $e_{2}$, mouth of uterus; $f$, broad ligament; $f_{1}$, suspensory ligament of the ovary; $f_{2}$, round ligament; $g$, vagina; $h$, vulva; $i$, vulvar cavity; $i_{1}$, posteri or commissure : $i_{2}$, anterior commissure; $k$, muscle constrictor cunni; $m$, corpus cavernosum vestibule; $n$, abdominal wall; $o$, left kidney; $p$, left ureter ; $r$, bladder ; $s$, urethra ; $t$, rectum ; $u$, anus ; $v$, external sphincter muscle of anus; $w$, point where the levator ani muscle passes under the external sphincter; $x$, levator ani muscle; $y$, longitudinal fibers of the rectum; $y_{1}$, posterior band of fibers ; $z$, muscle constrictor vestibule; 1 , utero-ovarian artery; $\mathbf{1}_{1}$, branch to the ovary; $1_{2}$, branch to the horn of the uterus; 2 , external uterine artery; 3 , umbilical artery; 4 and 5, sections through pelvic bone.

months in the case of the elephant. There is established following conception, and through the medium of a special development of the walls of the pregnant uterus and of the membranes enveloping the embryo, a temporary circulatory system, by means of which the constituents of the 
blood of the dam are passed by osmosis into the fotal circulation, through the arteries of the umbilical or navel cord and back through the veins of the same structure into the general venous circulation of the dam, to begin another cycle. By this means the fœtus is nourished until after birth, when the establishment of respiration and digestion enables him to aërate his own blood and nourish his own tissues. All connection with.his mother is cut off with the severing of the cord, which takes place soon after birth.

26. Parturition. - Parturition is accomplished by the general relaxation of the ligaments which unite the bones

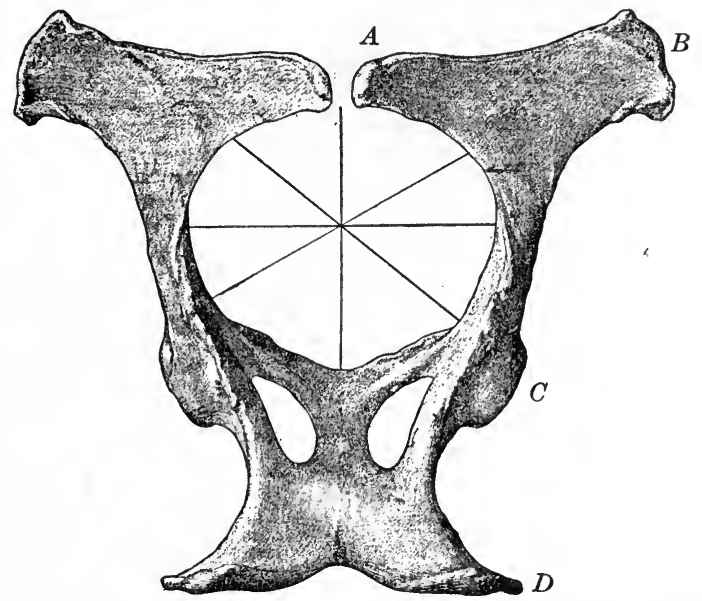

FIG. 10. - Pelvis of the mare, showing the dimensions of the pelvic girdle through which the fœetus passes in delivery. $A$, coupling, $B$, point of the hip; $C$, hip joint; $D$, point of the buttocks.

constituting the pelvic girdle (Fig. 10), through which the fœtus must pass, and the soft structures of the pelvic and perineal regions, followed by labor. Normally the fœtus is presented head first, with the chin resting on the extended 
fore legs in such a way as to form a conical protrusion. This helps in the dilation of the parts involved as the contractions of labor gradually cause the expulsion of the fœtus. Not only do the structures of the dam favor this expulsion by their relaxation, but the suppleness and flexibility of the fœtus itself materially assists. The head, at this age, is capable of considerable compression and alteration in form to accommodate itself to the restricted passage through which it is forced, while the chest may have its vertical dimension flattened by the bending backward of the spinous processes of the thoracic vertebræ, to which this dimension of the chest is largely due. In the case of multiple births, as in the sow, considerable time may elapse, with apparently complete cessation of labor, between the expulsion of each fœtus.

27. Lactation. - There is naturally a distinct correlation between reproduction and lactation. As pregnancy advances lactation diminishes, if the female is milking at the time, accompanied by a corresponding increase in weight due to the deposition of fat, in addition to the growth of the fœtus. Some females cannot become pregnant while suckling young. There is usually a complete cessation of lactation for a period prior to parturition, although some cows will milk persistently for years and can hardly be dried off, though calving regularly. With the approach of parturition the udder manifests a return of functional activity, "springing," as we say, $\mathbf{i}$ 'ddicating the increase in size and fullness of form most marked in females pregnant for the first time. Such udders finally secrete a characteristic waxy material, and finally milk, a few days or hours before parturition. After the birth of the fœtus, the expulsion of the membranes constituting the afterbirth and the ultimate contraction of the uterus, the 
great volume of blood supply furnished the uterus and fœtus is diverted to the mammary apparatus, stimulating it to the maximum of functional capacity, as noted in the fresh cow. The first material secreted by the udder differs both physically and chemically from milk, being thick and yellowish in appearance and possessed of special purgative properties designed to remove the fœcal matter, meconium, that has accumulated during fœtal development, as the first operation of the new-born digestive apparatus.

\section{Pathology}

28. Abnormal structure impairs function. - The relation between structure and function is intimate and reciprocal. Functional limitations are determined by the structure, while the development of the structure itself is, in a measure, responsive to the activity of its function. Carrying one's arm in a sling continuously will cause such complete atrophy or wasting of the part as to seriously impair its usefulness, while the heart of the athlete undergoes hypertrophy, or an over-development, in an effort to meet the excessive demands made upon it. The removal of one kidney may induce a compensatory hypertrophy of the other one. An active secreting mammary gland is "dried off " by arresting its functional stimulus, the milking process, while the rudimentary gland of the male, even, may be rendered capable of some functional activity by persistent stimulation.

It is obvious, therefore, that but a slight structural defect may seriously impair the functional capacity of the part or the individual. It is not sufficient simply to detect the presence of an existing defect or abnormality; its true significance, in interfering with the function of the part, must be foretold. 



\section{PART II}

\section{THE PRACTICE OF JUDGING}




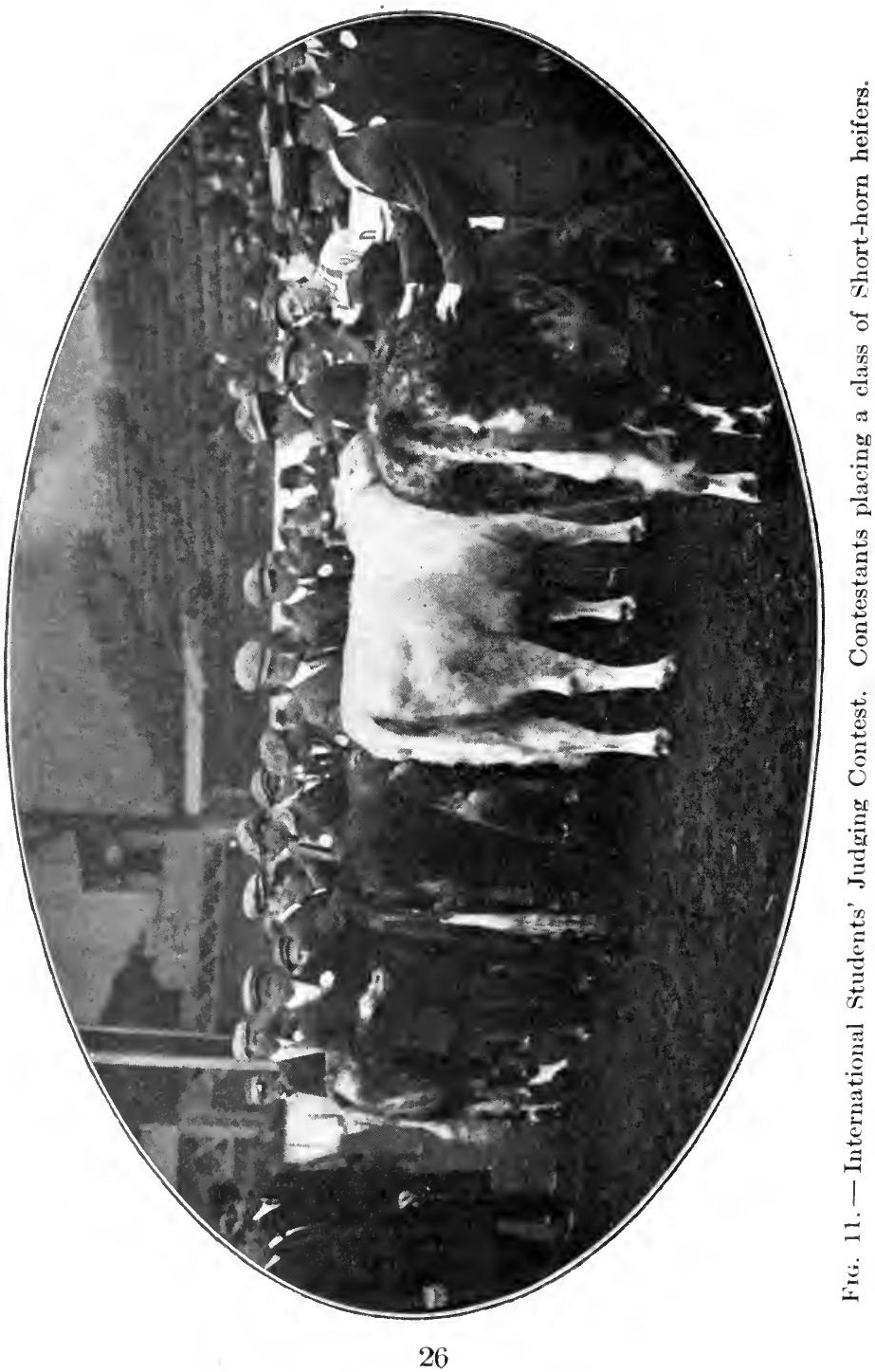




\section{CHAPTER III}

\section{DEFINITION AND PROCEDURE}

JUDGING is not an exact science in which determinations can be made with mathematical precision, but results are more or less approximate, depending upon the accuracy with which observations are made and the correctness of the judgment with which decisions are reached. Discrepancies may be due either to inaccuracy in observation, to error in judgment or to both.

29. Judging. - Judging consists of making a thorough analysis of each individual, then measuring them to a standard - the ideal. Four steps are involved.

30. Information. - First, information. In order to be consistent a judge must have a definite notion of what constitutes merit. Full information, therefore, as to individual excellence, market demand, and breed requirements is essential to insure selection to the correct ideal or measurement to an accepted standard.

31. Observation. - Second, observation. The study of animal form requires the keenest powers of observation to be exercised with greatest accuracy. The possession $\mathrm{o}$ an instrument does not necessarily insure proficiency in its use; one may have acquired a definite mind picture of what he seeks yet fail to recognize it when it is seen. Observation is the application of the standard, the actual measurement of merit by means of which a close estimate or a careful analysis may be made. 
32. Comparison. - Third, comparison. It is one thing to buy a carload of animals that must all conform to specified requirements, but quite another matter to pick out the first, second, third and fourth best from a car lot offering. It may be simple enough to make analyses and give descriptions of any number of individuals, noting carefully all commendable features as well as defects, yet most difficult to balance a superior head and neck, but low back of one, against the good back and deficient hindquarters of another. The first described is observation; the second, comparison. The judge must do this before he can ascertain, in the aggregate, the relative merits of the different individuals under his consideration and before he can arrive at a final conclusion as to their placing in competition.

33. Conclusion. - Fourth, conclusion. The last step consists in weighing the evidence collected by the two preceding steps and returning a verdict thereon.

When a decision is once made it is most gratifying to an exhibitor or seller, as well as most assuring to the judge, if he is able to give full reasons for having made the awards as he has done.

34. System in judging. - The most comprehensive judging is secured by a systematic procedure. It is true many good judges do their work intuitively, but even intuition may be systematized to advantage. Judging must be done with a reasonable degree of dispatch, although time often serves to clear up certain points which at first seem obscure. The judge is, therefore, justified in using some deliberation, although his observations should be so conducted as to enable him to form a most definite and accurate impression in the least time.

35. First impressions are lasting and, if made under 
normal conditions, are most likely to be correct. The judge should see to it, therefore, that the first view he takes will be fair to both the animal and himself. Experienced showmen and salesmen appreciate the importance of this first view in establishing favor for or prejudice against the animal they are exhibiting. If they have an animal possessed of real merit, they endeavor to enter the ring at such a time, usually either first or last, or to take such a position as will insure the judge's having one good, impressive look at the particular individual in which their interest is centered. This accomplished, they feel assured of careful consideration, in turn, with no danger of being smothered in a large class, as sometimes happens. Given an inferior animal, however, the attendant makes his entry as inconspicuous as possible among the others in order to avoid undue exposure of his exhibit's worthlessness, in the hope of being left in a higher position than he truly deserves.

36. Conditions under which shown. - In order not to be misled in his observations the judge should understand and allow for the conditions under which the animals are shown. It seems to be considered legitimate to take advantage of everything that rightfully belongs to an animal so long as there is no real misrepresentation. It is perfectly proper to pose an individual for inspection. That is simply putting his best foot forward, as it were, and it enables the judge to better see him as he really is. Standing a horse uphill, for instance, accentuates his good points, yet there is no deception attempted, and to stand him downhill would be manifestly unfair both to the horse and to the judge.

37. Posing. - The most extreme posing encountered is the so-called camping of horses. Practiced in moderation, 
camping is justifiable on the ground that it serves to keep a horse on all four feet, and is a protection to any one passing about him, since the horse must assume a natural standing position before he is able to kick or strike. Overdone, camping is unsightly and may be resorted to for the purpose of making a low back or bent hocks appear straight.

Cattle and sheep should be stood up on their feet to enable the judge to get a good look at them, but they may be held in such a manner as to materially alter their lines, handling qualities in the former and conformation in the latter. Such trickery can hardly be accepted as proper, neither can the holding up of a hog's back by keeping down his nose in quest of corn in the litter of the show ring, after having taught him by experience to expect it there. 


\section{CHAPTER IV}

\section{FEATURES OF ANIMAL FORM TO BE CON- SIDERED IN JUDGING}

38. General appearance is determined by all those features which may be observed at a casual glance, and usually includes a number of the individual features hereafter enumerated.

39. Height or stature is a consideration in horses only, as a rule, in which it is measured at the highest point of the withers and is expressed in hands, four inches to the hand. Fractions of a hand are given in inches most commonly, as fifteen hands, two inches, or $15-2$, when the height is sixty-two inches.

40. Weight, as registered by the scales, is not stated exactly, a unit of twenty-five pounds being the division usually allowed in the case of horses and cattle on account of possible variations of less amount being due to feeding and watering.

41. Scale. - Height and weight combined constitute scale.

42. Style is especially marked in horses, constituting a most important feature of show, but greatly enhancing the appearance of any class of animals ; it may be manifested by cattle, sheep and hogs as well as horses.

43. Symmetry is the result of the balancing of parts in such proportions as to give an even, uniform, harmonious appearance of the whole. It is as though the assembled 
parts had been constructed the one for the other rather than formed independently.

44. Type is the sum total of those features the possession of which enables an individual to meet the definite requirements of special service or production. It is manifested by that form and contour which mark the distinction between an individual that is blocky from one that is angular, for instance.

45. Conformation. - Type has to do with the general structure resulting from the assembling of all component parts, while conformation involves the individual structure of each of these parts as a unit. The strength of a chain is measured by the strength of its weakest link, therefore defection in one part may offset an otherwise perfect structure. However, some parts, as the hock joint of a horse or the loin of a steer, for instance, have greater relative importance than others; thus a deficiency in them would have more influence on the serviceability of the whole than a corresponding inferiority of structure in some other part. Appreciation of conformation, therefore, consists not alone in the detection of points, both superior and inferior, but in attaching to each due significance as bearing on the general excellence of the animal or interference with its adaptability for the purpose to which it is to be put.

46. Quality is that which pertains to the character of the individual unit of structure, the cell, and the proportion of them to the intercellular substance by which they are united in the organization of tissue. Quality is manifested in the texture of the tissue such as the hide, hair and bone especially, and by the general finish and refinement of the animal structure as a whole. Quality establishes the grade of the animal structure and its products. 
More highly organized tissues are the result of better breeding.

47. Substance refers to the size and number of the individual units of structure and the gross amount of the tissue into which they are organized. It is manifested by the scale of the animal in general and the amount of any one tissue in particular, such as bone. Quality and substance are not correlated, but more or less of each is essential, depending upon the type of the animal.

48. Condition. - An animal is in condition when in that state most favorable to the performance or production peculiar to his class or type. Condition is the result of fitting, a process involving a balance between feed and work during which the animal accumulates or reduces fat until the optimum degree of obesity is attained. In block animals and even in market draft horses the maximum degree of fatness is desired, and its accumulation is favored by most liberal feeding of a wide, fat-forming ration and frequently almost complete prohibition of exercise, while the race horse and dairy cow are capable of their best performance when their normal amount of fat is reduced to the minimum by a course of exercise of their respective functions which is offset only by a carefully guarded narrow ration.

49. Constitution represents such capacity of the vital functions, respiration, circulation and digestion especially, as will insure longevity, fecundity and maximum efficiency in performance or production. It is indicated chiefly by a large, open nostril, the spring and length of the rib, both fore and back, a sleek appearance of coat, an expression of vigor in the eye and countenance and a general appearance of thrift about the animal, although the latter evidences of constitution may all be temporarily impaired 
by ill health. Constitution is of greatest importance in breeding, feeding and working animals.

50. Temperament is the term by which the nature of the nerve control over the functions in general is designated. There are two classes of temperaments, first, the nervous, in which the nervous mechanism operates in such a way as to cause the animal to manifest an active, snappy manner, keenly alive to what is going on about him, possessing unusual nerve force and even nervousness; second, the lymphatic or phlegmatic, in which the nerve factor is apparently less acute, movements being executed more slowly, although preferably not in a dull, sluggish manner, and there is a marked tendency to feed and rest well with little inclination toward much activity or concern. Temperament is a constitutional, not a mental, feature.

51. Disposition is the mental attitude of an animal, independent of intelligence, and reflected by his cheerful, willing, obedient responsiveness, or sour, crabbed rebellion. Disposition is naturally of most importance in the horse and dairy cow, animals in most intimate association with the husbandman.

52. Sex character is the evidence, other than the presence of the sex organs, of the one sex or the other. Masculinity is evidenced by an extraordinary development of the forehand or forequarters, the crest, the strength of the face line, the hardness of feature, burliness, and the bold, domineering manner, suggestive of the impressive sire. Femininity, on the other hand, is expressed by the absence of special development in the fore end, a lightness of shoulder and neck, fineness of feature, and a sweet, matronly expression and appearance. There is a correlation between evidence of masculinity on the one hand and 
both virility and prepotency in the male, on the other; while a female which lacks femininity may not only fail to breed regularly but an absolutely staggy appearance, associated as it is, usually, with more or less continuous œstrum and inability to conceive, has been due in some cases to the existence of hermaphrodism, in which there is a more or less imperfect development of the essential organs of both sexes in the same individual. The importance of sex character is confined, of course, to breeding males and females, although stallions are sometimes favored for show purposes on account of the boldness which characterizes their performance.

53. Breed character or type. - A breed is a group of individuals possessing distinctive characters not common to other members of the same species and so firmly fixed as to be uniformly transmitted. Breed type is the sum total of those distinctive characteristics by which the breed group may be differentiated, as size, form, peculiarities of conformation, color and markings, shape of the head, and horns, if any, with the especial and distinctive features of performance or production. It is with these distinctive characters that the judge is concerned in the judging of breeding classes or the selection of breeding stock. Utility, however, should be the basis of distinction. In order to maintain breed identity, all distinguishing features should receive consideration, but those of a utility character, which relate to performance or production, should be stressed more than such matters as color, markings, or the shape of ear, horn or snout. It has been stated that the best representatives of each of the draft horse breeds, for instance, should approach very closely to the same general type. It is most essential that they all be primarily of draft type, but if the only difference 
between a Percheron and a Belgian is to be color, and not even color can be depended upon to distinguish a Clydesdale from a Shire, what is the use of attempting to establish breed identities?

54. Factors determining breed characters. - As a matter of fact, these distinctive characters of breeds are the result of either or all of those agencies that have been operative during the formative period of the breeds. They are the foundation stock or the origin in blood, the environment by which these hereditary endowments have been molded, or the geographic origin, and the ideal or purpose to which selection has been made. The last is, of course, the final and determining factor in every case, and may be sufficient of itself to account for the differential features of two breeds. The judge is concerned with the origin, history and development of the breeds only in so far as they have been factors in the creation of breed type and character. There is reflected, more or less, in the typical representatives of the different breeds, the three factors which have influenced their development. Since there can be bred on, only such characters as have originally been bred into a breed, there are good economic reasons why these distinctive and useful breed characters should be recognized by the judge and their true significance appreciated.

55. The best breed. - There is scarcely a breed of horses, cattle, sheep or swine that does not possess, by virtue of one or more of these factors, some one character in greater degree than does any other breed, and it is, on this account, better adapted to some particular performance or production. By guarding zealously in our selections these characters, thus retaining the integrity and identity of the breed, we are insuring stock that is much 
better adapted to meet the requirements of a wider range of usefulness.

56. Objectionable breed characters. - Unfortunately not all features by which breeds may be characterized are desirable ones. Some most objectionable characteristics are transmitted with unfailing regularity, and it is as important that they should be recognized and eliminated, so far as is possible, as that the good features should be carefully retained. Fair treatment of all breeds, therefore, requires that these exceptions to the desirable breed character or type shall be noted.

57. Way of going. - The way of going is a definition in itself. It is of principal importance in the horse, although the movements of all classes of animals are taken into account in judging. The particular gait the horse goes, the features of the stride at that gait, the pace or rate at which he moves, the action displayed, and the manner in which he places or sets himself while going are all features of the horse's way of going. In the other classes of live stock it is only necessary to note whether or not the animal goes well upon his toes, with pasterns supported and without cramped hocks as in the case of sheep and swine, or, in such a way as to indicate absence of founder or weakness in hind legs, as well as to exhibit the style and animation desired in breeding and show cattle.

58. Soundness is that condition in which an animal is physically capable of performing the ordinary service of his type or class; anything that renders him incapable, in any degree, constitutes an unsoundness. Soundness is most commonly considered in connection with horses, but its meaning may be extended to include all classes of live stock. For instance, a cow that has lost one quarter of the udder, a hog that is so badly broken down in the 
pasterns that he can only get about the feed lot with difficulty, or a bull with only one testicle in his scrotum or so weak in the hocks that he cannot mount a cow, are almost as much incapacitated as is the horse that is lame.

59. Breeding unsoundness. - Any condition which may prevent a male animal from impregnating the female, or the female from delivering a live, normal young, constitutes breeding unsoundness. Furthermore, the possession by a breeding animal of any condition which, transmitted to its offspring, may partially or completely incapacitate it, is also a breeding unsoundness. However, the transmissibility of many of the so-called hereditary unsoundnesses has not been established; even roaring and moon blindness in horses, the only two things for which stallions are disqualified in France, where the most comprehensive system of inspection is, are now believed to be more frequently the result of preëxisting influenza in the one case, and of an enzoötic infection in the other, than of hereditary influences. Yet, on the other hand, almost any unsoundness of a male or female may manifest itself in the get with more than casual uniformity, thus proving its transmissible nature.

60. Defective conformation. - Unsoundness, or, more particularly, the defective conformation which predisposes to it, is of considerable importance to the judge of any class of stock, but on account of the more complex nature of the horse's function and the greater variety of conditions by which that function may be impaired, discussion of the subject will be directed, chiefly, to the horse.

61. Unsoundness in horses may be of eyes, wind or limb. Mental defects are usually included under vices. So far as show ring judging goes, the matter of unsoundness 
is of no concern to the judge himself, it being settled according to rule by the official veterinarian, but one should not be wholly dependent upon the veterinarian for the detection and disposition of ordinary unsoundnesses. There is no difficulty experienced in diagnosing bad eyes if the lens has become opaque or the cornea clouded, yet serious conditions may exist in the eye without any such manifestations. These require the skilled practitioner to identify them. A diseased condition of any standing will result in atrophy or shrinking of the eyeball, just the same as a lame foot gradually becomes smaller. This reduction in size causes the eyeball to occupy less space in the orbit, with the result that it retracts deeper into the head, and the upper lid, not being distended by the eyeball any longer, looses its even curvature and becomes notched with an angle. A widely dilated pupil or one that does not respond promptly to changes in the amount of light admitted, as when the eye is covered with the hand and then quickly exposed again, is suggestive of imperfect vision.

62. Unsoundness of wind includes the so-called roaring and heaves. While roaring may be understood to be any kind of noise made in breathing, technically roaring is made upon inspiration only and is due to the paralysis of one of the cartilages of the larynx, that cartilaginous sound box with which the trachea or windpipe begins.

Horses with bullish necks that are thick in the throttle and have a narrow angle between the branches of the lower jaw may make a distinct noise when pulled, especially on a curb bit, due to the compression of the larynx. This noise, like that due to pressure from any other cause, is most noticeable upon expiration and is relieved as soon as the horse is stopped and the head released, while true 
roaring may continue till the breathing slows down and may even be induced by threatening to strike the horse.

Heaves are detected by the violent expiration when the horse is exercised, the short, dry cough, the continual dilation of the nostrils and the double lift in the flank on expiration, the ordinary expulsion of the breath being followed by a second additional effort.

63. Unsoundness of limb involves the structure of the foot, the bones, especially at the joints, the ligaments and the tendons. Founder (Fig. 12), the previous existence of
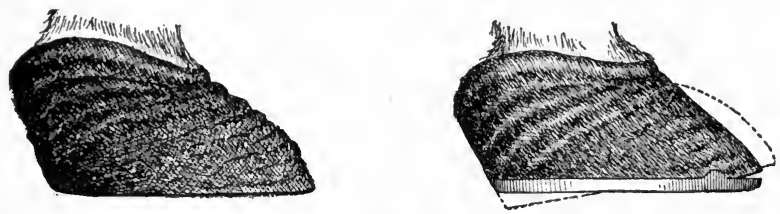

Frg. 12. - Shod and unshod hoofs in founder.

which, unless promptly overcome, is indicated by the dip in the wall of the toe, the dropping of the sole, the uneven ringlike growth of the horn, and, most important of all, the peculiar going on the heels; contraction of heels or soles; cracks and thrush are of the first class. An exostosis is a bony growth, the result of an inflammation in the bone which causes a rapid throwing out of bone cells similar to the formation of "proud flesh" in the soft tissue. Exostoses located at definite points are specifically designated as spavin (Fig. 13), when the hock is involved, ringbone (Fig. 14) high or low, when at the first or second pastern joint, respectively, splint when along the splint bones of the cannon. The seriousness of the exostoses depends upon the extent to which the function of the part is involved. After the acute inflammatory stage has passed the exostosis may merely interfere me- 
chanically, by its presence, with the action of the part, all pain having subsided. In some instances, the process may automatically overcome the primary condition which caused it. If the exostosis constituting a spavin or a ringbone, for instance, becomes sufficiently extensive to obliterate the joint about which it has grown, thereby preventing all movement, the pain of motion in that part and the coincident lameness will be removed. This process is called anchylosis, and accounts for the fact that a great big so-called jack spavin may cause no lameness, while the most acute pain and lameness will attend an occult spavin when there is, as yet,

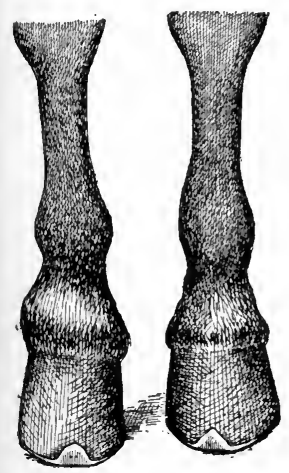

Fig. 14. - Leg showing ringbone at left; at right normal leg in contrast. scarcely any enlargement. The joints in- Fig. 13.- Leg volved in both spavin

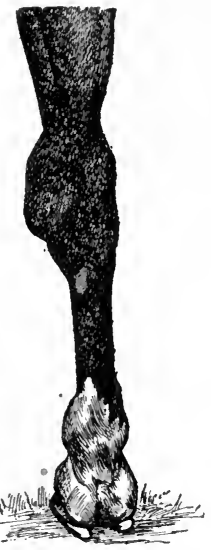
showing large spavin. and ringbone are not the essential joints of those parts, and they can, therefore, be dispensed with and cause no serious interference with function. Exostosis is usually a sequel of or accompanies an inflammation of the joint surface, called arthritis, as in spavin, although it may be independent of the joint, as in sidebone, and, usually, in splint. The lameness due to an arthritis is most marked when the horse is first taken out after a long rest preceded by hard work, and gradually disappears more or less as the horse "warms out of it." The presence of an exostosis is best made out by comparing the 
corresponding joints or regions in the two legs. Many normal but rough joints may be suspected until it is de-

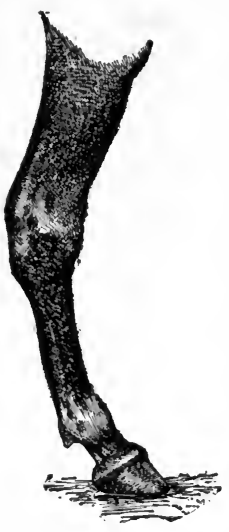

termined that both hocks or all four pastern joints, as the case may be, are symmetrical. Any deviation in the normal outline of the joint or bone that is not duplicated should be carefully investigated. This rule does not always hold, however, as two spavins or more than one ringbone may manifest themselves at the same time. The sidebone may present no enlargement or alteration in form whatever, the lateral cartilage, normally elastic and springing upon pressure, simply becoming Fig. 15. - Leg hard and unyielding as a showing curb.

result of the ossification.

Ligaments are differentiated from tendons by the fact that they unite bone to bone, while the tendon unites muscle to bone. The ligaments most likely to become the seat of an unsoundness are the great suspensory ligament, which sustains the fetlock joint, on the same principle as a truss under a box car, the ligamentous structure at the back of the fetlock joint with which the suspensory ligament is related and the curb ligament at the back of the hock (Fig. 15). Rupture of this suspensory ligament is

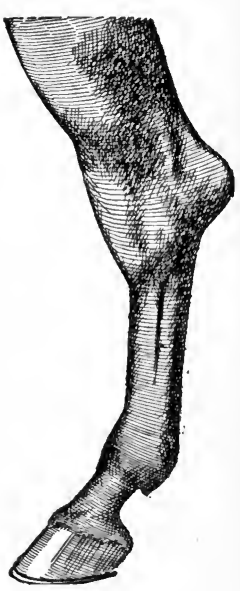

Fig. 16. - Leg showing capped hock. the "breaking down" of the race horse. The tendons most commonly involved are the flexor tendons of the foreleg. If contracted, they cause cocked ankles and 
sprung knees, while if some of their fibers have become ruptured and repaired by low grade connective or scar tissue they are said to be "bowed," a common condition in race horses. Lameness due to sprained ligaments and tendons is usually aggravated by moving the horse instead of being relieved, to some extent, as it is if due to inflammation of the joints.

64. Age. - Its determination in those classes of live stock the majority of whose lives are terminated after a short period of a few years, as beef cattle, hogs and sheep, is a comparatively simple matter, but in the case of the horse, which not only lives to a much greater age, but is valued largely on the age basis, and consequently invites frequent attempts at deception, the indications are more complex and difficult of determination. In the former group the order of eruption of the teeth is the primary consideration, wear being noted only in those breeding animals of advanced age, while eruption in the horse can only be relied upon until he is fairly mature, after which wear is responsible for the changes which mark the ages.

Distinction between the milk or deciduous teeth, which are shed, and the permanent teeth, upon the eruption of which so much depends, involves their size, shape, and color (Fig. 17). In all animals the permanent teeth are larger, less conical in shape, have a much deeper root, a wider base and a thicker coat of enamel, the surface of which is usually ridged per-

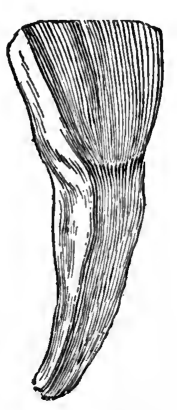

Fig. 17. - A temporary or milk tooth. pendicularly, and yellow instead of white.

The signs of age in the mouth of all animals are subject to considerable variation and correction. Eruption may 
be influenced by early maturity, while the wear will depend upon the nature of the feed. A milk-fed calf will not wear

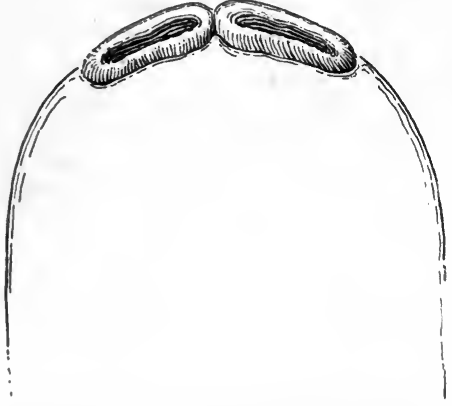

FIg. 18. - Lower jaw of foal from one to two weeks old. out his mouth as rapidly as one that is grazing.

65. The determination of the age of the horse. - As a rule, at birth none of the incisor teeth are through the gums (Fig. 18).

One year. - All the milk incisors are visible, the pinchers and intermediates being well through the gums and in contact, but the corners are not yet level.

Two years. - The pinchers and the intermediates are pushed free from their gums at their base, indicating that the permanent teeth are crowding them (Fig. 19).

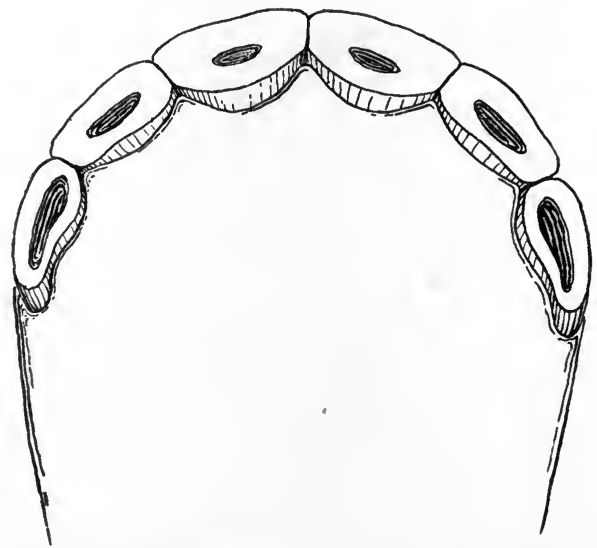

Fig. 19. - Lower jaw of the two-year-old colt. 
Three years. - By two and one half years the middle pinchers are through, and at three they are leveled and in

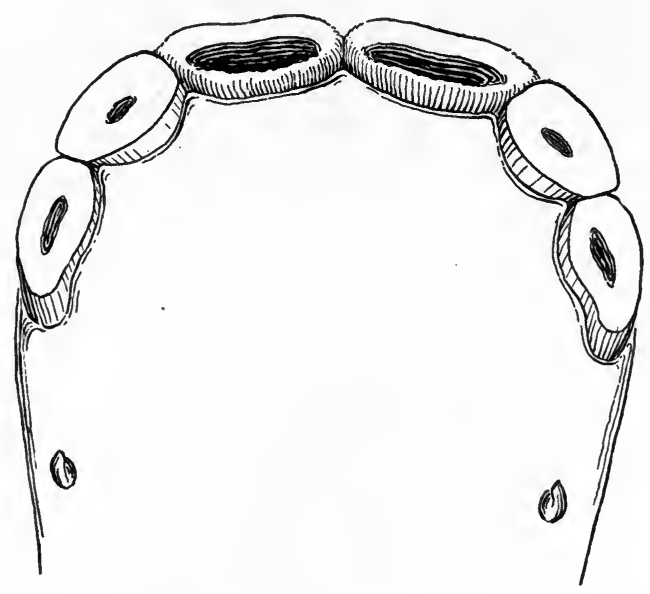

FIG. 20. - Lower jaw of the three-year-old colt.

wear, while the milk intermediates are about to be shed (Fig. 20).

Four years. - At three and one half the permanent intermediates come through and at four they are leveled and wearing. At this age the corner milk teeth manifest the approach of the permanent corners (Figs. 21 and 22).

Five years. - At four and a half the corners are shed, the permanent corners appear and at five there is the socalled full mouth, all permanent incisors being level and in wear (Figs. 23 and 24).

Six years. - The cups of the lower pinchers wear away and the canines in males may appear (Figs. 25 and 26).

Seven years. - The cups of the lower intermediates 


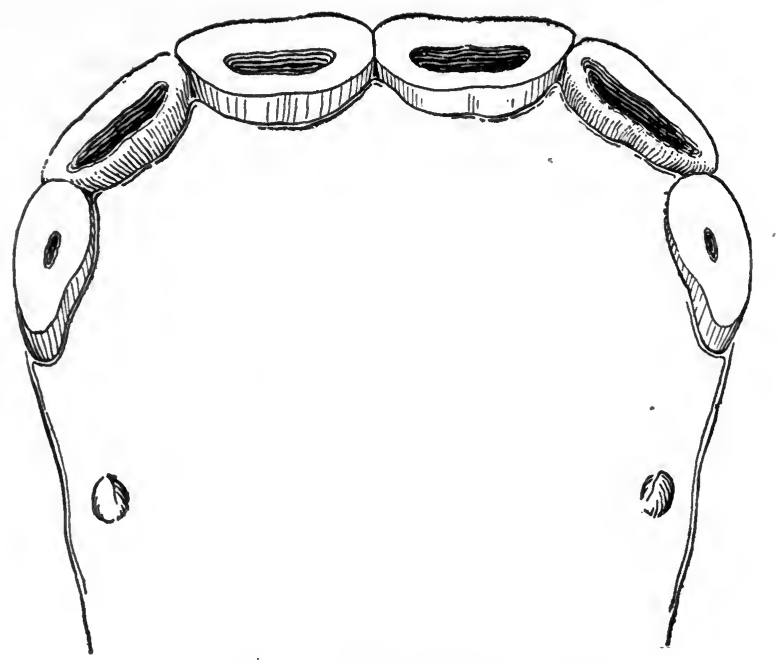

FIG. 21. - Lower jaw of the four-year old.

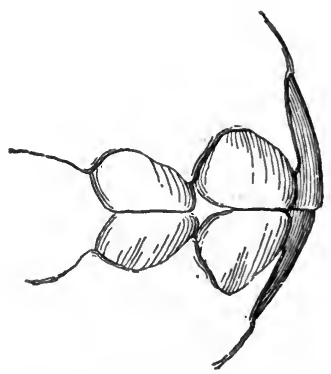

Fig. 22. - Side view of the mouth of a four-year old. 


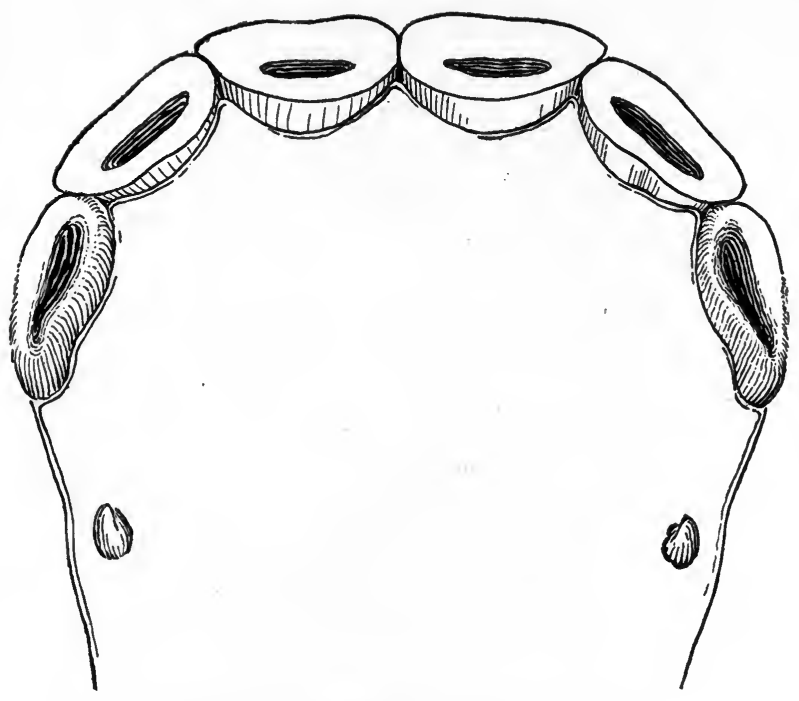

FIG. 23. - Lower jaw of a five-year old.

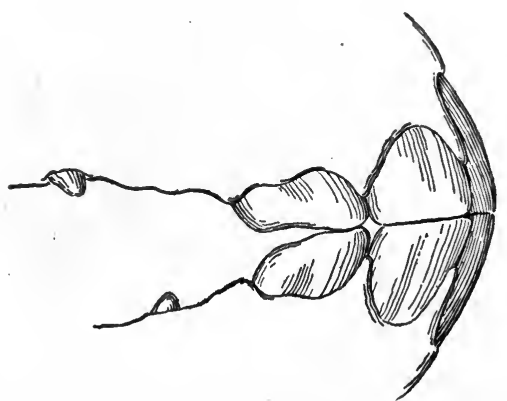

FIG. 24. - Side view of the mouth of a five-year old. 


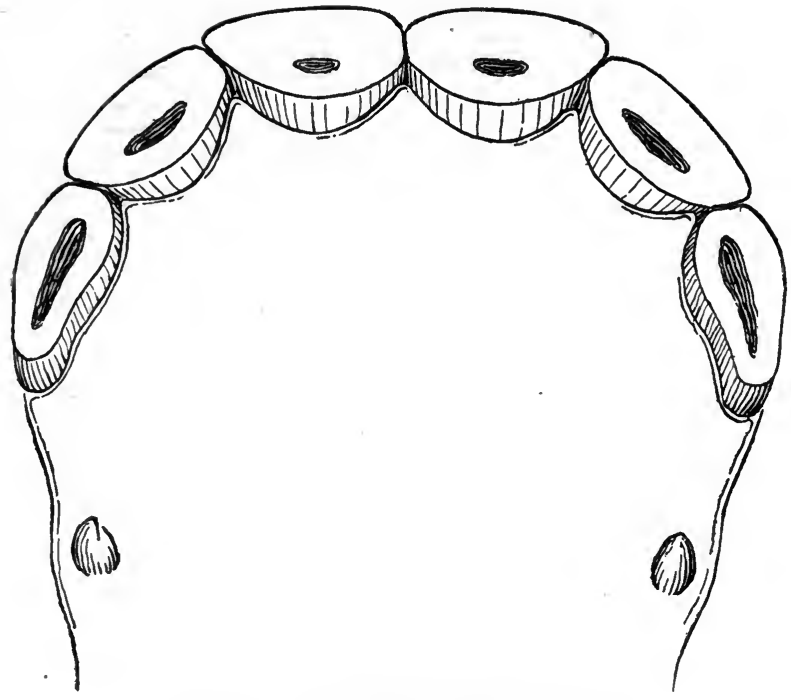

Fig. 25. - Lower jaw of a six-year old.

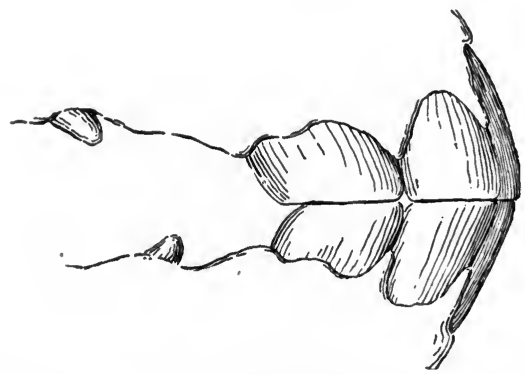

FIG. 26. - Side view of the mouth of a six-year old. 


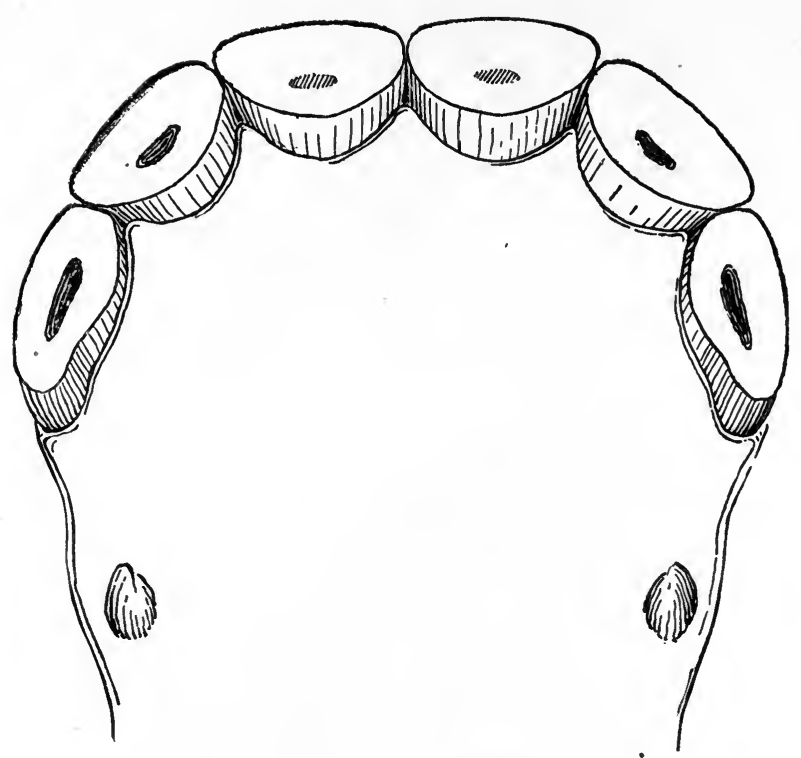

FJg. 27. - Lower jaw of a seven-year old.

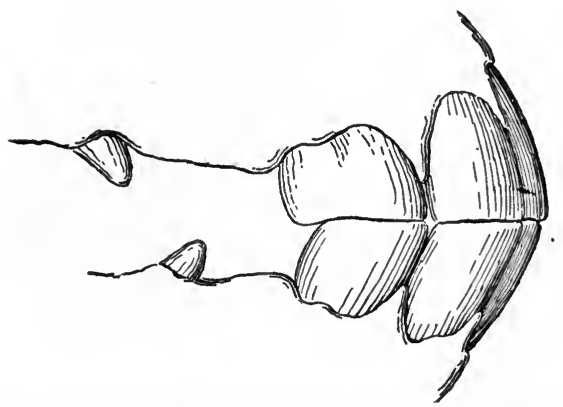

Fig. 28. - Side view of the mouth of a seven-year old. 


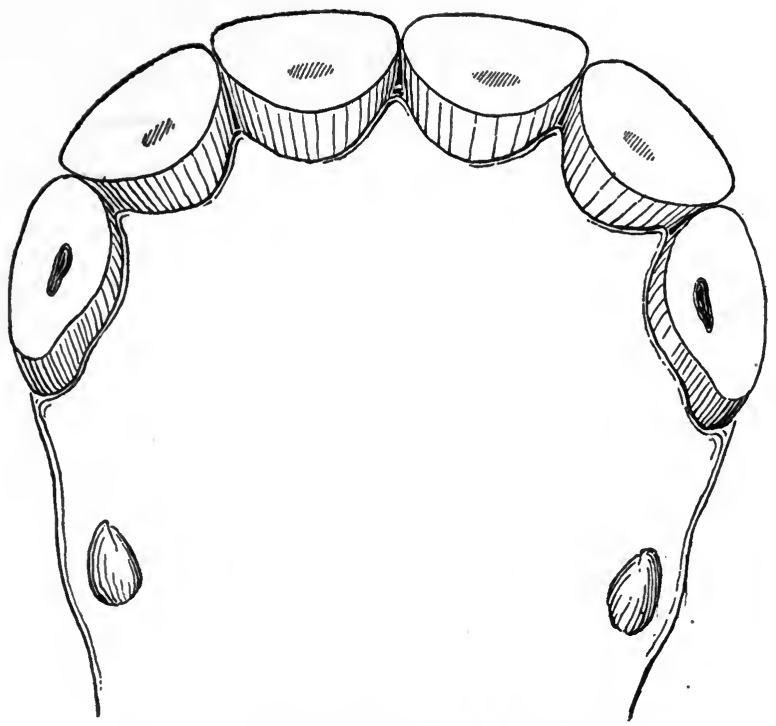

FIG. 29. - Lower jaw of an eight-year old.

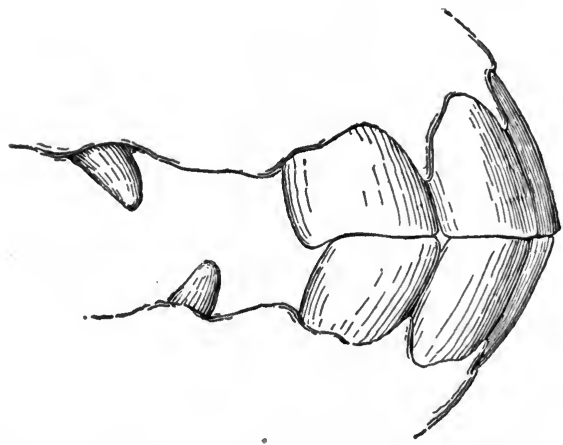

FIG. 30. - Side view of the mouth of an eight-year old. 


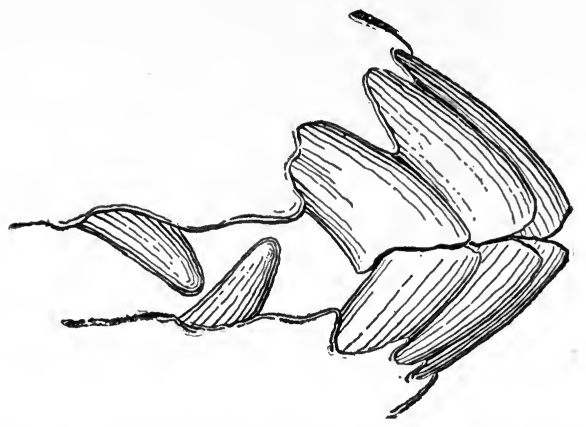

FIG. 31. - Side view of the mouth of an aged horse.

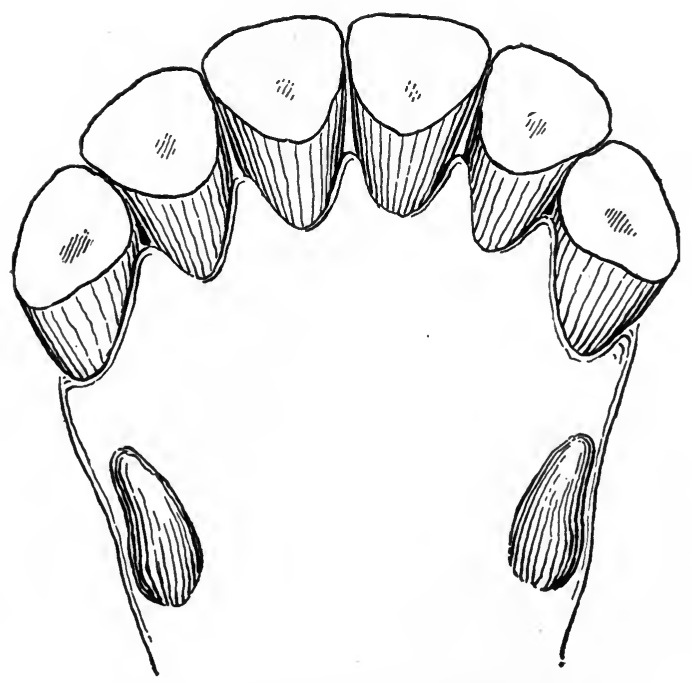

Fig. 32. - Lower jaw of an aged horse. 
wear out, the notch on the upper corner appears and the incisive arch or the angle made by the teeth as they meet becomes more acute (Figs. 27 and 28).

Eight years. - The cups wear out of the corners, the pinchers and intermediate teeth become oval in shape, and show the dental star, upon their table (Figs. 29 and 30).

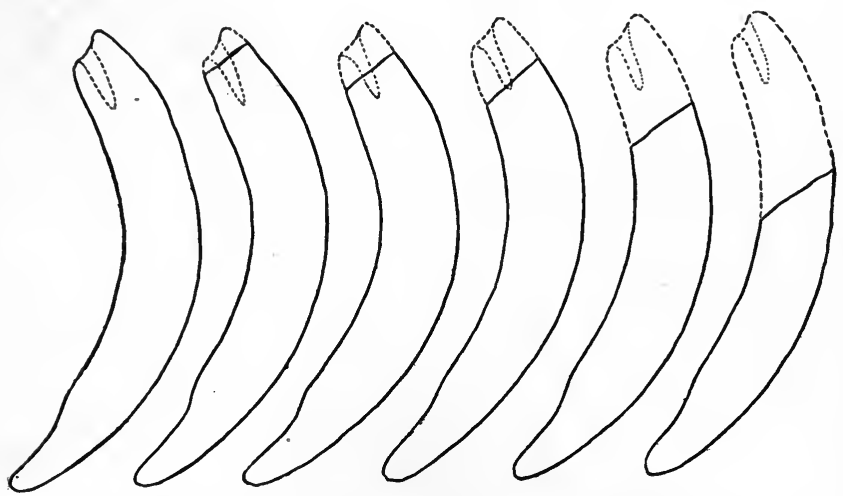

Fig. 33. - Shows the wear of an incisor tooth at the ages of three, four five, six, nine and twenty years, and why the cups, or marks, disappear as age advances. The lower nippers wear away about oneeighth of an inch each year. The upper incisors wear away more slowly.

Nine years. - The notch on the upper corners may have disappeared, the pinchers are round, and the corner teeth oval. The upper pinchers show wear, and the angle of the incisive arch is more acute.

Ten years. - The cups of the upper pinchers are worn out and the angle at which the teeth meet has become so acute as to necessitate raising the horse's head in order to look by the upper teeth to view the lower pinchers. 
Eleven years. - The tables of the intermediate uppers are worn away and the corners show wear. The lower corners have become round and the obliquity of the jaws is still greater.

Twelve years. - The tables of all the upper teeth are worn, those of the lowers are distinctly round and the angle of the jaw is increased.

Beyond this age the indications of the mouth are based upon the increasing obliquity of the jaws (Fig. 31), giving a more acute angle of incidence of the teeth, the increasing changes in the size and shape of all the teeth (Fig. 32), due to their being worn closer to the roots and the narrowing and flattening of the lower and upper jaws, respectively, the result of the tissues closing in and crowding the roots of the teeth down so as to keep the worn tables in contact (Figs. 33 and 34).

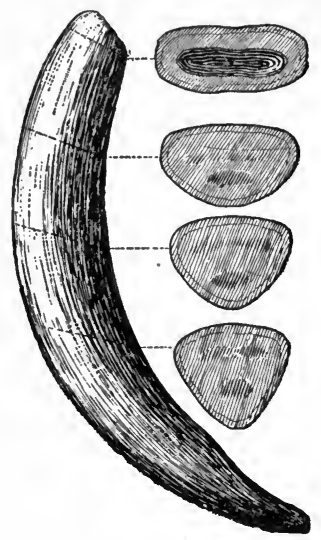

Fig. 34. - Cross section of an incisor tooth, showing how the shape changes with advancing years.

66. Bishoping is quite commonly practiced on the mouths of second-hand horses that are offered for sale. It consists in burning into the table of the tooth a cup to replace the one which has been worn out with age. Mouths are usually bishoped to resemble the appearance of the cups at 6 or 7 years of age. The made-over mouth can be detected by the fact that the appearance of the cups is not in accord with the angle or shape of the teeth. Unless skillfully done the burned cup itself can be recognized, and there will not be the ring of enamel which surrounds the cup of the normal tooth. 
67. Determination of the age of cattle. - The general size, shape and growth of the cattle as well as the appearance of their horns is usually evidence enough to determine their age. It is only in case of disputes, as over the classification of show cattle, that the teeth are called into requisition.

The bovine teeth present some special features. Incisors are not firmly set in the jaw cavity as in the horse, but are imbedded in cartilage in such a way as to permit of considerable movement. This is necessary on account of the fact that the teeth are not opposed by others in the upper jaw, but rather by a peculiar development of the gum to form a cushion against which the feed is crushed by the teeth of the lower jaw. Furthermore, the tissues of the jaw do not close down upon the roots of the teeth crowding them forward as their tables wear away, although this wear begins before the tooth is fully developed.

At birth. - The calf usually has four incisors at birth, although he may have none, and the third pair appears about the tenth day, the last or corner pair anywhere from the seventh to the thirtieth day. These teeth are not leveled, however, until the fifth or sixth month. The pinchers are worn level at ten months.

- One year. - The first intermediate pair of milk teeth are leveled at one year, the second pair at fifteen months and the corners at eighteen to twenty months, at which time the permanent pinchers appear.

Two years. - The first pair of permanent intermediates is in at some time between two and one quarter years and two years and nine months.

Three years. - The second intermediate pair has taken 
its place at from three and a quarter to three and one half years.

Four years. - The corner teeth are in and the mouth is complete at from three years and nine months to four years and six months.

Five years. - The pinchers have commenced to wear level.

Six years. - The pinchers are leveled completely, both pairs of intermediates partly and the corners somewhat.

Seven years. - The first intermediate pair is completely leveled and the second pair is much worn.

Eight years. - The tables of all the teeth are leveled and the pinchers begin to show a hollow which corresponds to the prominence of the cushion of the upper jaw. This concavity appears in the first intermediates at nine and in the second at ten.

There have taken place, meantime, alterations in the appearance of the mouth similar to those described in the horse.

68. Telling the age by the horns. - The growth of the horn is a fairly reliable indication of the age in cattle. The first distinet ring appears at three years, and each succeeding year adds its ring so that two should be added to the count of the rings to determine the age.

69. Determination of the age of sheep. - The eruption of the permanent pinchers takes place in the sheep at from twelve to fifteen months of age and the succeeding two pairs of intermediates and corners follow approximately one year apart. At least this is the basis upon which the age of sheep is usually reckoned, although the exact time of the eruption of the teeth 
involves fractions of years and months. Age is often expressed by two-tooth or four-tooth, as one pair of permanent incisors has appeared in one year, two pairs in two years.

70. Determination of the age of hogs. - Little thought is given to the determination of the hog's age by his teeth. It is difficult, in the first place, to observe his mouth, and in the second place the indications are subject to much irregularity.

71. Early maturity insures attaining full, normal growth and development at the earliest age. Animals may be considered to have a definite period to develop in, rather than a definite degree of development to attain in unlimited time. If one does not make steady growth during this growing period, it will be deficient in development when growth ceases. Early maturity is indicated in any class of stock by weight for age and general evidence of growthiness and proximity to final development.

72. Color has both a market and a breed significance. Certain colors enhance while others detract from the value or usefulness of certain animals. Gray horses withstand heat better than black, white hogs are especially susceptible to skin irritations, to which black hogs are usually immune. The color and color markings are the most striking features of breed type in some instances, as in the Hereford.cattle.

Color is a most convenient aid to an accurate description of an animal, a most important means of establishing identity, as in the case of pedigree registration. For this purpose the various shades of the individual colors, and the exact location, extent and outline of the white markings should be accurately noted. 
73. The classification of the color of horses.

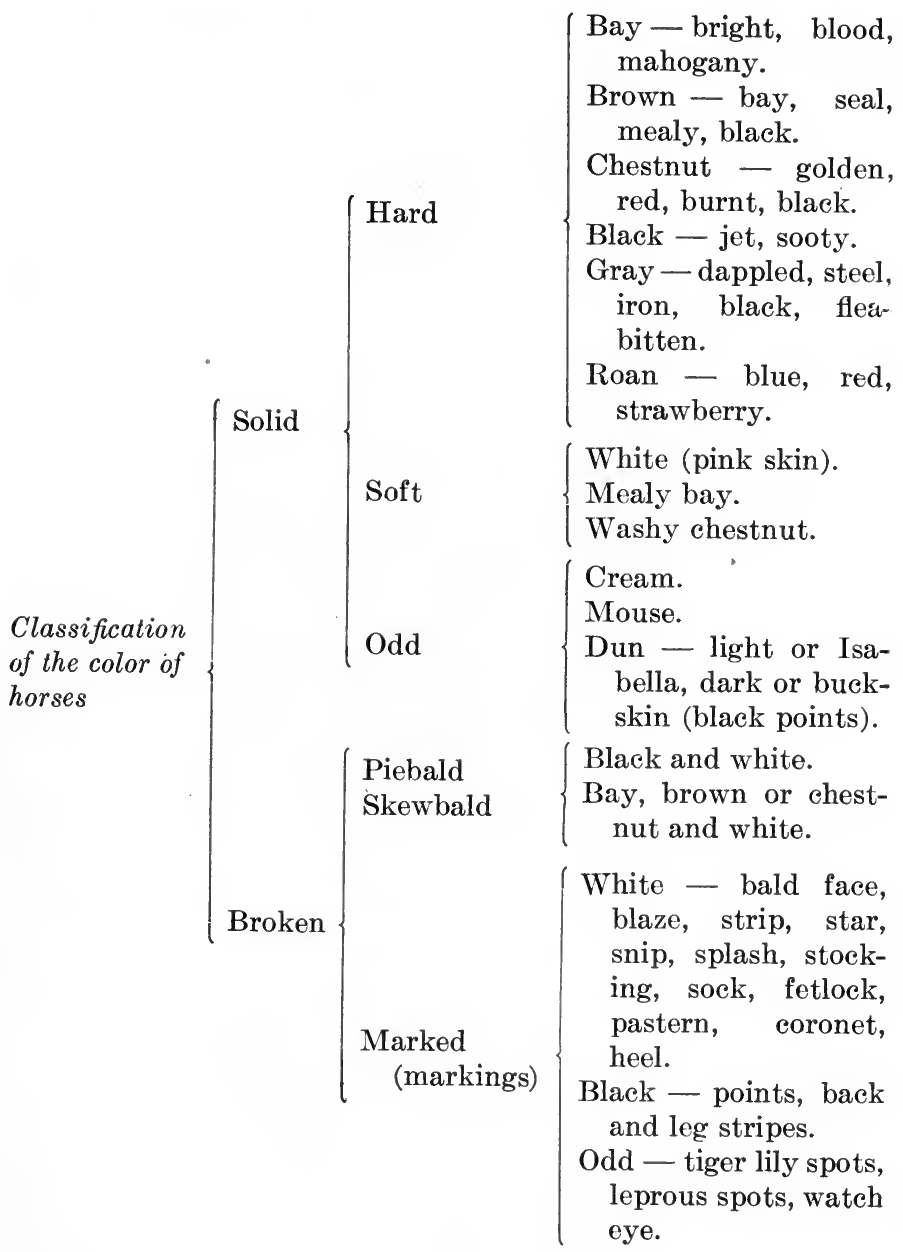




\section{The Law of Correlation}

The law of correlation is one of the principles upon which the practice of judging is based - the correlation of form or structure and function, and the correlation of parts, one to the other.

74. The correlation of form and function. - Actual determination of functional capacity, as in the horse race or pulling contest, the dairy or slaughter test, affords the most accurate and, in some instances, the only means of judging the relative merits of individuals. No one would consider settling a matter of speed supremacy in the show ring, for instance, but would send the contestants away in a race. It even happens that the awarding of the ribbons in dairy and beef cattle rings may be somewhat reversed when the same classes are subjected to the real test in the dairy or the abattoir. However, it is not always practicable to await the results of a try-out of relative merits in performance or production; the judge must estimate functional possibilities from an analysis of structure and, if correct standards of measuring structure are employed, reasonably accurate results may be expected. The more complicated the function, of course, the greater the factor of possible error.

Function is the end, structure the means. Function has its limitations. In the case of the finished block animal, it consists simply of being a carcass of beef, mutton or pork, while in the case of the feeder, function implies doing something, and with the horse and the dairy cow doing may become a still more complicated performance. It is manifestly a simpler proposition to determine how a hog will cut up or a steer hang up by seeing them on foot than to estimate, from an inspection, how many pounds of 
milk or fat a dairy cow will produce in a year or how fast a horse can trot or run. As a matter of fact, the actual test is the only practical means of making the latter determination, although even here an approximate idea of functional capacity can be had from the study of form.

The novice is impressed with the rapidity with which the experienced judge will make his analysis of animal form. The detailed scoring of an animal, even by an expert, will require much more time than may be consumed in forming a very accurate notion of the sum total of the individual's good and bad points. "Practice makes perfect," and the practiced eye can discern more quickly, but, in addition, consideration of the law of correlation enables the expert judge to cut corners, as it were.

75. The correlation of parts. - One part is an index to other parts with which it is correlated. Thus the buyer of feeder cattle seeks out broad, flat backs as he looks down on them from his pony, or short, broad heads if they are faced about to him in the pens. A head of these dimensions will be found only on a low set, broad, deep and usually a thick-fleshed steer, while a long, narrow head indicates the reverse.

As a rule, longitudinal dimensions of all parts are alike long or short and are inversely related to transverse and perpendicular dimensions. Hence a long-legged animal is long all over, head, neck and back, while inversely narrow and short ribbed. It is as essential to know what are not correlated as what are; quality and substance, milk and beef, power and speed are opposed to each other by this same law. 


\section{CHAPTER V}

\section{THE MEANS OF MAKING OBSERVATIONS}

76. The eye and the hand. - The eye and the hand are the means relied upon for making determinations of animal form and features; the latter usually being employed to supplement the eye or verify what has been seen. The relative importance of the eye and the hand for this purpose will depend upon the sort of stock judged. The eye is almost exclusively depended upon in the judging of hogs, even the firmness of the flesh being ascertained by the lay of the hair. Next in order come horses, it being necessary only to run the hand over the tendons and joints to note their texture and detect possible unsoundness and to feel condition on the rib. Cattle are regularly handled: those of the dairy type to get the thickness, pliability, secretions and looseness of the hide, the amount and texture of the hair, the texture of the udder and the openness of the chine; while beef cattle are handled to determine, in addition to the features of the hide and hair already enumerated, the thickness, consistence and evenness of the covering of flesh. Sheep have their form so obscured by the fleece and the fleece is often so cleverly trimmed as to require most careful handling in order to become informed of the details of mutton form and conformation. Handling is also necessary in the examination of the fleece. In fact, in the case of the sheep the hand is 
almost as exclusively depended upon as is the eye in the case of the hog.

77. Method of handling. - In handling it should be remembered that the tips of the fingers are most sensitive to the touch. The hides of cattle are rolled in the flat of the hand or between the fingers and thumb. The hide is most easily picked up over the back rib, the animal's head, meantime being directed forward, as turning to either side loosens the skin very noticeably on that side and causes a corresponding tightness on the other. Depth of covering in cattle and sheep is shown along the spinal column of the back and loin and over the top and side of the shoulder, regions in which the bone is likely to be most conspicuous. Sheep are handled with the flat hand, the fingers kept tight together, care being taken not to muss the fleece by turning down the staple. The fleece is parted for examination at three places, over the heart where it is finest, on the lower outside of the thigh where it is coarsest, and at mid-rib where an average of its quality will be found. A natural seam is selected and opened by the backs of the two hands, which are afterward reversed in such a manner as to press the fleece back with the palms, exposing the staple for its full depth, and the skin.

78. Method of observing. - The study of the horse's way of going is made by having him moved away from, toward, and by, the observer. By lining up the eye with the direction in which the horse is moving the directness of the stride is apparent whether going or coming, as are also the height of the stride, hind and front, and the working of stifles and shoulders. Viewed from the side, as he passes by, the length, height, spring, balance and regularity of the stride can be noted. 


\section{System of Making Observations}

Some definite system of making observations should be followed in order that each look may be made to count, and only one look be necessary; if the views are taken in logical order from head to tail, for instance, there is not only less likelihood of certain points being overlooked, but the impression formed of the animal in toto will be more complete and accurate.

79. Inspection. - Observations must be both general and particular. The first step in the inspection of an animal should be to take a general survey of the tout ensemble from such a distance as to bring the subject entirely within one's field of vision, and thus permitting a consideration of its size, general appearance, lines, proportions and the symmetry of its parts.

The particular observation should follow and include a minute examination, in order, of every detail, from close range. The order of this examination may be: face the animal from in front, noting the bigger things first, i.e. width, height, size and carriage of head, then in detail, the proportions of the head, the expression of the countenance and the features contributing thereto, eyes, ears, forehead, face, nostrils and lips; then the direction of the forelegs, whether normal or showing deviations and what deviations, if any, with the conformation of the forelegs and the feet. Pass to the side position and consider in profile such general features as top and under lines, the carriage of the head, and setting of the body on the legs; then in detail, the head in profile, the setting of the head on the neck, the length, shape and carriage of the neck, the blending of the neck with the shoulders, the direction and conformation of the forelegs viewed from the side, 
the back, rib, heart girth, loin, flank, croup or rump, tail, thighs and finally the direction and conformation of the hind legs and feet. From the rear view first, in general, the width and contour, then, in detail, the hips, stifles, thighs, lower thighs, and the direction and conformation of the hind legs and feet. Finally, inspect the other side, in order to determine whether or not the animal is symmetrical. 


\section{System of Making Observations}

Some definite system of making observations should be followed in order that each look may be made to count, and only one look be necessary; if the views are taken in logical order from head to tail, for instance, there is not only less likelihood of certain points being overlooked, but the impression formed of the animal in toto will be more complete and accurate.

79. Inspection. - Observations must be both general and particular. The first step in the inspection of an animal should be to take a general survey of the tout ensemble from such a distance as to bring the subject entirely within one's field of vision, and thus permitting a consideration of its size, general appearance, lines, proportions and the symmetry of its parts.

The particular observation should follow and include a minute examination, in order, of every detail, from close range. The order of this examination may be: face the animal from in front, noting the bigger things first, i.e. width, height, size and carriage of head, then in detail, the proportions of the head, the expression of the countenance and the features contributing thereto, eyes, ears, forehead, face, nostrils and lips; then the direction of the forelegs, whether normal or showing deviations and what deviations, if any, with the conformation of the forelegs and the feet. Pass to the side position and consider in profile such general features as top and under lines, the carriage of the head, and setting of the body on the legs; then in detail, the head in profile, the setting of the head on the neck, the length, shape and carriage of the neck, the blending of the neck with the shoulders,. the direction and conformation of the forelegs viewed from the side, 
the back, rib, heart girth, loin, flank, croup or rump, tail, thighs and finally the direction and conformation of the hind legs and feet. From the rear view first, in general, the width and contour, then, in detail, the hips, stifles, thighs, lower thighs, and the direction and conformation of the hind legs and feet. Finally, inspect the other side, in order to determine whether or not the animal is symmetrical. 
Head and Neck. - Continued.

9. Eyes - prominent orbit, large, full, bright, clear, lid thin, even curvature

10. Ears - medium size, fine, pointed, set close, carried alert

11. Muzzle - broad, nostrils large but not dilated, lips thin, even, trim

12. Neck - long, muscular but not thick, well crested, throttle well cut out, head well set on

Forehand. -24 .

13. Shoulders - long, sloping, smooth, muscular . . 2

14. Arms - short, muscular, elbow in . . . . . . 2

15. Forearms - wide, muscular . . . . . . . . . 2

16. Knees - straight, wide, deep, strongly supported . 2

17. Cannons - short, broad, flat, tendons sharply defined, set well back . . . . . . . . .

18. Fetlocks - wide, tendons well back, straight, well supported.

19. Pasterns - long, oblique (45 degrees), smooth, strong .. . . . . . . . . . . . . .

20. Feet - large, round, uniform, straight, slope of wall parallel to slope of pastern, sole concave, bars strong, frogs large and elastic ; heels wide, full, one third height of toe; horn dense, smooth, dark color

21. Legs - direction viewed from in front, perpendicular line dropped from the point of the shoulder should divide the leg and foot into two lateral halves. Viewed from the side a perpendicular line dropped from the tuberosity of the scapula should pass through the center of the elbow joint and meet the ground at the center of the foot .

Body. -11 .

22. Withers - well defined but muscular . . . . 2

23. Chest - wide, deep . . . . . . . . . . . 2

24. Ribs - well sprung, long, close . . . . . . . 2

25. Back - short, straight, strong, broad . . . . . 2

26. Loin - short, broad, strongly coupled . . . . . 2

27. Flank - deep: full, long, low under line . . . . 1 
Hindquarters, -32 .

28. Hips - wide, level, muscular . . . . . . . . 2

29. Croup - long, level, muscular . . . . . . . . 2

30. Tail - attached high, well carried . . . . . . 1

31. Thighs - deep, muscular . . . . . . . . . 2

32. Stifles - broad, thick, muscular . . . . . . . 2

33. Gaskins - wide, muscular . . . . . . . . . 2

34. Hocks - straight, wide, point prominent, deep, clean cut, smooth, well supported . . . . . 6

35. Cannons - short, broad, flat, tendons sharply defined, set well back . . . . . . . . . . 2

36. Fetlocks - wide, tendons well set back, straight,

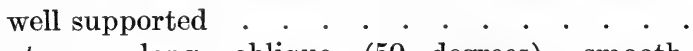

37. Pasterns - long, oblique (50 degrees), smooth, strong . . . . . . . . . . . . . . .

38. Feet - large, round (slightly less than in front), uniform, straight, slope of wall parallel to slope of pastern, sole concave, bars strong, frog large, elastic; heels wide, full, one third height of toe, horn dense, smooth, dark color . . . . . . . .

39. Legs - direction viewed from the rear, a perpendicular line dropped from the point of the buttock should divide the leg and foot into lateral halves; viewed from the side, this same line should touch the point of the hock and meet the ground some little distance back of the heel. A perpendicular line dropped from the hip joint should meet the ground near the center of the foot . . . .

Way of Going. -10.

40. Walk - straight, strong, active . . . . . . 66

41. Trot - powerful, free, moderate action . . . . 4 


\section{SCORE CARD \\ THE HEAVY HARNESS HORSE}

Scale of Points

General Appearance. - 12.

Counts

1. Height

2. Weight

3. Form - close, full made, smooth turned, symmetrical

4. Quality - bone clean, dense, fine, yet indicating substance, tendons and joints sharply defined, hide and hair fine, general refinement, finish . . .

5. Temperament - proud, bold, stylish, disposition good, intelligent

Head and Neck. -7 .

6. Head - size and dimensions in proportion, clear-cut features, straight face line, wide angle in lower jaw

7. Forehead - broad, full

8. Eyes - prominent orbit, large, full, bright, clear, lid thin, even curvature . . . . . . . . . 1

9. Ears - medium size, fine, pointed, set close, carried alert

10. Muzzle - fine, nostrils large, lips thin, trim, even .

11. Neck - long, lofty carriage, high crest, throttle well cut out, head well set on

Forehand. -22 .

12. Shoulders - long, oblique, smooth . . . . . . 2

13. Arms - short, muscular, carried well forward . . 1

14. Forearms - broad, muscular . . . . . . . . 1

15. Knees - straight, wide, deep, strongly supported . 2

16. Cannons - short, broad, flat, tendons sharply de-

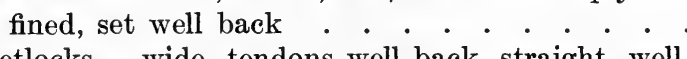

17. Fetlocks - wide, tendons well back, straight, well

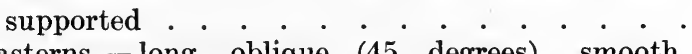

18. Pasterns - long, oblique (45 degrees), smooth, strong 
Forehand.-Continued.

Counts

19. Feet - large, round, uniform, straight, slope of wall parallel to slope of pastern, sole concave, bars strong, frog large, elastic, heels wide, full, one third height of toe, horn dense, smooth, dark color

20. Legs - direction viewed from in front, perpendicular line dropped from the point of the shoulder should divide the leg and foot into two lateral halves; viewed from the side, a perpendicular line dropped from the tuberosity of the scapula should pass through the center of the elbow joint and meet the ground at the center of the foot . . .

Body. -11 .

21. Withers - well set up, narrow, extending well back

22. Chest - wide, deep

23. Ribs - well sprung, long, close . . . . . . . 2

24. Back - short, straight, strong, broad . . . . . 2

25. Loin - short, broad, strongly coupled . . . . . 2

26. Flank - deep, full, long low under line . . . . 1

Hindquarters. -32 .

27. Hips - broad, round, smooth . . . . . . . . 2

28. Croup - long, level, round, smooth . . . . . . 2

29. Tail - set high, well carried . . . . . . . . 2

30. Thighs - full, muscular . . . . . . . . . . 2

31. Stifles - broad, full, muscular . . . . . . . 2

32. Gaskins - broad, muscular . . . . . . . . 2

33. Hocks - straight, wide, point prominent, deep, clean cut, smooth, well supported . . . . . . 6

34. Cannons - short, broad, flat, tendons sharply defined, set well back . . . . . . . . . . 2

35. Fetlocks - wide, tendons well back, straight, well 2 supported . . . . . . . . . . . . . . 2

36. Pasterns - long, oblique (50 degrees), smooth, strong . . . . . . . . . . . . . . . 2

37. Feet - large, round (slightly less than in front), uniform, straight, slope of wall parallel to slope of pastern, sole concave, bars strong, frog large and elastic, heels wide, full one third height of toe, horn dense, smooth, dark color 
Hindquarters. - Continued.

Counts

38. Legs - direction viewed from the rear, a perpendicular line dropped from the point of the buttock should divide the leg and foot into lateral halves; viewed from the side this same line should touch the point of the hock and meet the ground some little distance back of the heel. A perpendicular line dropped from the hip joint should meet the ground near the center of the foot . . . . .

Way of Going. - 16.

39. Walk - straight, snappy, springy, proud, stylish .

40. Trot - in line, bold, flashy, extreme flexion of knees and hocks, balanced, regular . . . . . . .

Total

\section{SCORE CARD}

\section{THE LIGHT HARNESS HORSE}

\section{Scale of Points}

General Appearance. - 12 .

Counts

1. Height

2. Weight

3. Form - rangy, deep, lithe, angular . . . . .

4. Quality - bone clean, dense, fine, yet indicating substance, tendons and joints sharply defined, hide and hair fine, general refinement

5. Temperament - nervous, active, disposition good, intelligent .

Head and Neck. -7 .

6. Head - size and dimensions in proportion, clearcut features, straight face line, wide angle in lower jaw

7. Forehead - broad, full

8. Eyes - prominent orbit, large, full, bright, clear, lid thin, even curvature . . . . . . . . . .

9. Ears-medium size, fine, pointed, set close, carried alert . . . . . . . . . . . . 
Head and Neck. - Continued.

10. Muzzle - fine, nostrils large, lips thin, trim, even

11. Neck - long, lean, crest well defined, extended carriage, well cut out in the throttle, head well set on

Forehand. -23 .

12. Shoulders - long, oblique, smooth . . . . . . 2

13. Arms - short, muscular, carried well forward . . 1

14. Forearms - long, broad, muscular . . . . . . 2

15. Knees - straight, wide, deep, strongly supported . 2

16. Cannons - short, broad, flat, tendons sharply defined, set well back . . . . . . . . . 2

17. Fetlocks - wide, tendons well back, straight, well supported . . . . . . . . . . . . . . 2

18. Pasterns - long, oblique (45 degrees), smooth, strong . . . . . . . . . . . . . .

19. Feet - large, round, uniform, straight, slope of wall parallel to slope of pastern, sole concave, bars strong, frog large, elastic, heels wide, full, one third height of toe, horn dense, smooth, dark color

20. Legs - direction viewed from in front, perpendicular line dropped from the point of the shoulder should divide the leg and foot into two lateral halves. Viewed from the side, a perpendicular line dropped from the tuberosity of the scapula should pass through the center of the elbow joint and meet the ground at the center of the foot .

Body. - 11.

21. Withers - well set up, narrow, extending well back 2

22. Chest - medium width, deep . . . . . . . . 2

23. Ribs - well sprung, long, close . . . . . . . 2

24. Back - short, straight, strong, broad . . . . . 2

25. Loins - short, broad, strongly coupled . . . . . 2

26. Flank - deep, full, long low under line . . . . 1

Hindquarters. -31 .

27. Hips - broad, round, smooth . . . . . . . 2

28. Croup - long, level, smooth . . . . . . . 2 
Hindquarters. - Continued.

Counts

29. Tail - set high, well carried . . . . . . . . 1

30. Thighs - full, muscular . . . . . . . . . . 2

31. Stifles - broad, full, muscular . . . . . . . . 2

32. Gaskins - broad, muscular . . . . . . . . 2

33. Hocks - straight, wide, point prominent, deep, clean cut, smooth, well supported . . . . . 6

34. Cannons - short, broad, flat, tendons sharply defined, set well back . . . . . . . . . . . 2

35. Fetlocks - wide, tendons well back, straight, well supported . . . . . . . . . . . . . . 2

36. Pasterns - long, oblique (50 degrees), smooth, strong 2

37. Feet - large, round (slightly less than in front) uniform, straight, slope of wall parallel to slope of pastern, sole concave, bars strong, frog large and elastic, heels wide, full, one third height of toe, horn dense, smooth, dark color . . . . . .

38. Legs - direction viewed from the rear, a perpendicular line dropped from the point of the buttock should divide the leg and foot into lateral halves; viewed from the side this same line should touch the point of the hock and meet the ground some little distance back of the heel. A perpendicular line dropped from the hip joint should meet the ground near the center of the foot . . . .

Way of Going. - 16.

39. Walk - long, free stride . . . . . . . . . 6

40. Trot - long, rapid, straight, reachy stride . . . 10

Total

100

\section{SCORE CARD}

\section{THE SADDLE HORSE}

Scale of Points

General Appearance. - 12.

Counts

1. Height

2. Weight 
General Appearance. - Continued.

Counts

3. Form - close but not full made, deep but not broad,

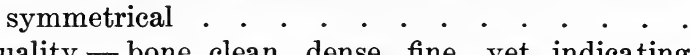

4. Quality - bone clean, dense, fine, yet indicating substance, tendons and joints sharply defined, hide and hair fine, general refinement, finish . .

5. Temperament - active, disposition good, intelligent . . . . . . . . . . . . 4

Head and Neck. -8 .

6. Head - size and dimensions in proportion, clear-cut features, straight face line, wide angle in lower jaw

7. Forehead - broad, full . . . . . . . . . . . 1

8. Eyes - prominent orbit, large, full, bright, clear, lid thin, even curvature . . . . . . . . . . 1

9. Ears - medium size, pointed, set close, carried alert 1

10. Muzzle - fine, nostrils large, lips thin, trim, even . 1

11. Neck - long, supple, well crested, not carried too high, throttle well cut out, head well set on . .

Forehand. -22 .

12. Shoulders - very long, sloping yet muscular . . 3

13. Arms - short, muscular, carried well forward . . 1

14. Forearms - long, broad, muscular . . . . . . 1 .

15. Knees - straight, wide, deep, strongly supported . 2

16. Cannons - short, broad, flat, tendons sharply defined, set well back . . . . . . . . . . . 2

17. Fetlocks - wide, tendons well back, straight, well supported . . . . . . . . . . . . . . 2

18. Pasterns - long, oblique (45 degrees), smooth, strong . . . . . . . . . . . . . . 2

19. Feet - large, round, uniform, straight, slope of wall parallel to slope of pastern, sole concave, bars strong, frog large, elastic, heels wide, full, one third height of toe, horn dense, smooth, dark color

20. Legs - direction viewed from in front, perpendicular line dropped from the point of the shoulder should divide the leg and foot into two lateral halves; viewed from the side, a perpendicular line dropped from the tuberosity of the scapula 
Forehand. - Continued.

should pass through the center of the elbow joint and meet the ground at the center of the foot

Body. -12 .

21. Withers - high, muscular, well finished at top, extending well into back . . . . . . . . . 3

22. Chest - medium width, deep . . . . . . . . 2

23. Ribs - well sprung, long, close . . . . . . . 2

24. Back - short, straight, strong, broad . . . . . 2

25. Loin - short, broad, muscular, strongly coupled $\quad 2$

26. Flank - deep, full, long, low under line . . . . 1

Hindquarters. -31 .

27. Hips - broad, round, smooth . . . . . . . 2

28. Croup - long, level, round, smooth . . . . . 2

29. Tail - set high, well carried . . . . . . . . 2

30. Thighs - full, muscular . . . . . . . . . 2

31. Stifles - broad, full, muscular . . . . . . . . 2

32. Gaskins - broad, muscular . . . . . . . . 2

33. Hocks - straight, wide, point prominent, deep, clean cut, smooth, well supported . . . . . 5

34. Cannons - short, broad, flat, tendons sharply de-

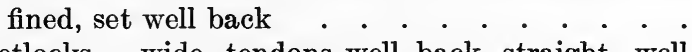

35. Fetlocks - wide, tendons well back, straight, well supported

36. Pasterns - long, oblique (50 degrees), smooth,

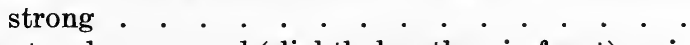

37. Feet - large, round (slightly less than in front), uniform, straight, slope of wall parallel to slope of pastern, sole concave, bars strong, frog large and elastic, heels wide, full, one third height of toe, horn dense, smooth, dark color . . . . . .

38. Legs - direction - viewed from the rear a perpendicular line dropped from the point of the buttock should divide the leg and foot into lateral halves; viewed from the side this same line should touch the point of the hock and meet the ground some little distance back of the heel. A perpendicular line dropped from the hip joint should meet the ground near the center of the foot . . . . . 
Way of Going. - 15.

39. Walk - rapid, flat footed, in line . . . . . . 5

40. Trot - free, springy square, going well off hocks, not extreme knee fold . . . . . . . . . . 5

41. Canter - slow, collected, either lead, no cross canter 5 Total

\section{SCORE CARD}

\section{THE MULE}

\section{Scale of Points}

General Appearance. -16.

1. Height

2. Weight

3. Form - broad, deep, compact, smooth, symmetrical . . . . . . . . . . . . . . 4

4. Quality - refined head and ears, fine hair, ćlean bone, good texture of hoof . . . . . . . . . . . 4

5. Condition — fat, sleek, well furnished . . . . . 4

6. Temperament - active, disposition good . . . . 4

Head and Neck. - 7 .

7. Head - size and dimensions in proportion, clear-cut features, face line straight with a slightly Roman

8. Forehead - broad, full

9. Eyes - prominent orbit, large, full, bright, clear, thin lid, even curvature . . . . . . . . . 1

10. Ears - long, pointed, fine, well set, carried alert . 1

11. Muzzle - broad, nostrils large but not dilated, lips thin, even, trim .

12. Neck - long, muscular, head well set on .

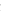


Forehand. - Continued.

Counts

17. Cannon - short, broad, flat, tendons sharply defined, set well back

18. Fetlock - wide, tendons well back, straight, well supported . . . . . . . . . . . . . .

19. Pastern - long, oblique, smooth, strong . . . . 2

20. Foot - large, wide, uniform, straight, slope of wall parallel to slope of pasterns, sole concave, bars strong, frog large, elastic; heels wide, full; horn dense, smooth

21. Leg - viewed from in front, a perpendicular line dropped from the point of the shoulder should divide the leg and foot into two lateral halves; viewed from the side, a perpendicular line dropped from the prominence on the side of the shoulder blade should pass through the center of the elbow joint and meet the ground at the center of the foot

Body. -11 .

22. Withers - well defined, but muscular . . . . 2

23. Chest - deep, wide . . . . . . . . . . . 2

24. Ribs - well sprung, long, close . . . . . . . 2

25. Back - short, straight, strong, broad . . . . . 2

26. Loin - short, broad, strongly coupled . . . . . 2

27. Flank - deep, full, long, low under line . . . . 1

Hindquarters. - 32 .

28. Hips - wide, level, muscular . . . . . . . . 2

29. Croup - long, level, muscular . . . . . . . 2

30. Tail - attached high, well carried . . . . . . 1

31. Thigh - deep, muscular . . . . . . . . . 2

32. Stifle - broad, thick, muscular ${ }^{-}$. . . . . . . 2

33. Gaskin — wide, muscular . . . . . . . . . 2

34. Hock - straight, wide, point prominent, deep, clean cut, smooth, well supported . . . . . . . 6

35. Cannon - Short, broad, flat, tendons sharply defined, set well back · $\cdot \cdot \cdot \cdot \cdot \cdot \cdot \cdot \cdot \cdot$

36. Fetlock - wide, tendons well back, straight, well supported . . . . . . . . . . . . . 
Hindquarters. - Continued.

37. Pastern - long, oblique, smooth, strong . . . .

38. Foot - large, wide, uniform, straight, slope of wall parallel to slope of pastern, sole concave, bars strong, frog large, elastic, heel wide, full, horn dense, smooth

39. Leg - viewed from the rear, a perpendicular line dropped from the point of the buttock should divide the leg and foot into lateral halves; viewed from the side, this same line should touch the point of the hock and meet the ground some little distance back of the heel. A perpendicular line dropped from the hip joint should meet the ground near the center of the foot . . . . . . .

Way of Going. - 10.

40. Walk - straight, strong, active . . . . . . . 5

41. Trot - a long, straight, free, snappy stride . . . 5

\section{SCORE CARD}

\section{THE BEEF STEER}

Scale of Points

General Appearance. -40 .

Counts

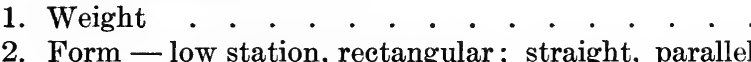
top and under lines; broad, deep, symmetrical

3. Quality - hide medium thickness, loose, pliable, sappy; hair fine; bone dense, smooth; flesh firm, even, smooth . . . . . . . . .

4. Condition - thick even covering of firm flesh, wellfilled purse and flank, indicating ripeness . . . 10

5. Temperament - lymphatic - disposed to fatten . 4

Head and Neck. -8 .

6. Head - short, broad, deep, proportioned . . . . 1

7. Forehead - broad, full . . . . . . . . . . 1

8. Face - short, broad, placid even lazy expression . 1

9. Eyes - large, full, clear . . . . . . . . . . 1 
Head and Neck. - Continued.

10. Ears - medium size, set high, carried alert . . . 1

11. Horns - symmetrical, medium size, fine texture (sharp, well-defined poll) . . . . . . . . 1

12. Muzzle - broad, nostrils large . . . . . . . 1

13. Neck - short, thick, not heavy in throat, full shoulder vein . . . . . . . . . . . . 1

Forequarters. -8 .

14. Shoulder - well laid in, compact on top, thickly covered, especially on side . . . . . . . . 4

15. Brisket - square, broad, and full, dewlap light, not pendant, muscular . . . . . . . . . . 2

16. Leg - short, straight, bone fine . . . . . . . 2

Body. -34 .

17. Back - broad, level, thickly covered . . . . . 10

18. Ribs - well sprung, deep, heart girth large, rib thickly covered, crops full . . . . . . . . 8

19. Chest - deep, full, level on the floor . . . . . 4

20. Loin - broad, thickly covered, smooth, level . . 10

21. Flank - deep, full, straight under line . . . . . 2

Hindquarters. -10 .

22. Hips - broad, level, smooth, not prominent . . . 1

23. Rump - long, broad, level, smooth, straight top line

24. Thighs - broad, thick, deep, full

25. Twist - low, full . . . . . . . . . . . . 2

26. Legs - muscular, short, straight, bone fine . . . 2

\section{SCORE CARD}

\section{THE DAIRY COW}

Scale of Points

General Appearance. -28.

Counts

1. Weight . . . . . . . . . . . . . 4

2. Form - triangular, wedge shaped from side, front, above; symmetrical, straight top line . . . 
General Appearance. - Continued.

Counts

3. Quality - refined head; hide medium thickness, loose, pliable, hair fine, secretions abundant and highly colored; bone clean . . . . . . .

4. Condition - lean, spare, indicating productiveness; no beefiness

5. Temperament - nervous, insuring most economic use of nutrients in milk production; disposition good . . . . . . . . . . . . .

Head and Neck. -8 .

6. Head - long, narrow, feminine ; intelligent expression . . . . . . . . . . . . . . . . 1

7. Forehead - broad, flat . . . . . . . . . . 1

8. Face - face line straight except as altered by breed character . . . . . . . . . . . . . . . 1

9. Eyes - large, clear, mild, yet indicative of nerve force . . . . . . . . . . . . . . .

10. Ears - medium size, fine texture, set high and well carried . . . . . . . . . . . . . . .

11. Horns - Symmetrical size and shape, fine texture, considerable curvature; special features according to breed . . . . . . . . . . . . . . . . . . 1

12. Muzzle - broad, nostrils large . . . . . . . 1

13. Neck - long, lean, light, clean-cut throat . . . 1

Forequarters. -6 .

14. Shoulder - long, light, well laid in, narrow on top 3

15. Brisket - not prominent . . . . . . . . . 2

16. Legs — straight, bone ample . . . . . . . . 1

Body. -26.

17. Chine - narrow, light, spines sharp, wide apart, open 6

18. Ribs - deep, arched below . . . . . . . . 6

19. Chest - deep, full, level on the floor . . . . . . 6

20. Loin - broad, level . . . . . . . . . . . . 6

21. Flank - deep, rather open . . . . . . . . 2

Hindquarters. -8 .

22. Hips - wide apart, prominent as in open frame, symmetrical . . . . . . . . . . . . 
Hindquarters. - Continued.

Counts

23. Rump - long, level, broad, lean, pin bones wide apart, tail head smooth, on line with back, no droop, tail long, fine . . . . . . . . . . . 3

24. Thighs - long, lean, concave from sides and rear, not beefy

25. Legs — straight, strong .

Udder. -24 .

26. Size - large, attached high behind, well forward, well suspended not pendant . . . . . . . . 6

27. Shape - quarters even, square, level . . . . . $\quad 6$

28. Texture - soft, elastic, hair fine, veins prominent . 6

29. Teats - medium size, well placed . . . . . . 4

30. Mammary (milk) veins - large, tortuous, large wells, extensions . . . . . . . . . . .

\section{SCORE CARD}

\section{THE MUTTON SHEEP}

Scale of Points

General Appearance. - 40 .

Counts

1. Weight . . . . . . . . . . . . .

2. Form - low station, rectangular, broad, deep, thickly fleshed, symmetrical, straight top and under line

3. Quality - refined head, fine fleece, hair and skin, clean bone

4. Condition - thick, even covering of firm flesh; thick neck, dock; full purse and flank indicating ripeness

5. Temperament - lymphatic, disposed to fatten . .

Head and Neck. -7 .

6. Head - short, broad, deep . . . . . . . . . 1

7. Forehead - broad, full . . . . . . . . . 1

8. Eyes - large, full, bright . . . . . . . . . 1

9. Ears - fine, well shaped, carried alert . . . . . 1

10. Muzzle - broad, nostril large . . . . . . . 1 
Head and Neck. - Continued.

11. Horns - medium size, fine texture, symmetrical . 1

12. Neck - short, thick, full shoulder vein, throat clean

Forequarters. - 7.

13. Shoulder - broad, smooth, compact on top, thickly fleshed.

14. Brisket - broad, full, square . . . . . . . . 2

15. Legs - short, straight, strong, clean bone . . . 1

Body. -25 .

16. Back - straight, strong, broad, thickly fleshed . 8

17. Ribs - well sprung, deep, crops full . . . . . 4

18. Chest - deep, full, broad on the floor . . . . . 3

19. Loin - broad, thickly fleshed . . . . . . . 8

20. Flank - deep, full . . . . . . . . . . 2

Hindquarters. -12.

21. Rump - long, level, broad, smooth . . . . . 3

22. Leg of mutton - broad, deep, thick; twist full, well let down in the seam . . . . . . . . . 8

23. Legs - short, straight, strong, clean bone . . . 1

Fleece. -9 .

24. Quantity - long, dense, even distribution _. . 3

25. Quality - fine staple, close even crimp, luster . . 3

26. Condition - sound, medium amount of oily yolk, soft, pure, bright . . . . . . . . . . . 3

\section{SCORE CARD}

\section{THE WOOL SHEEP}

Scale of Points

General Appearance. - 26.

1. Weight . . . . . . . . . . . . 4

2. Form - low station, rectangular, broad, deep, thickly fleshed, symmetrical, straight top line and under line. 
General Appearance. - Continued.

3. Quality - refined head, fine fleece, hair and skin, clean bone

4. Condition - thick, even covering of firm flesh; thick neck, dock; full purse and flank indicating ripeness

5. Temperament - active

Head and Neck. -7 .

6. Head — short, broad, deep . . . . . . . . . 1

7. Forehead — broad, full . . . . . . . . . . 1

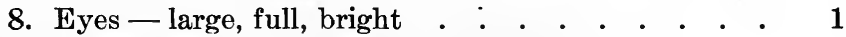

9. Ears - fine, well shaped, carried alert . . . . . 1

10. Muzzle - broad, nostrils large . . . . . . . 1

11. Horns - medium size, fine texture, symmetrical 1

12. Neck - short, thick, full shoulder vein, throat clean 1

Forequarters. -8 .

13. Shoulder - broad, smooth, compact on top, thickly fleshed . . . . . . . . . . . . . 4

14. Brisket - broad, full, square . . . . . . . .2

15. Legs - short, straight, strong, clean bone . . . 2

Body. -26 .

16. Back - straight, strong, broad, thickly fleshed . . 6

17. Ribs - well sprung, deep, crops full . . . . . . 6

18. Chest - deep, full, broad on the floor . . . . . 6

19. Loin - broad, thickly fleshed . . . . . . . 6

20. Flank - deep, full . . . . . . . . . . . 2

Hindquarters. -9.

21. Rump - long, level, broad, smooth . . . . . 3

22. Leg of mutton - broad, deep, thick ; twist full, well let down in the seam . . . . . . . . . . 4

23. Legs - short, straight, strong, clean bone . . . 2

Fleece. -24 .

24. Quantity - long, dense, even distribution . . . 8

25. Quality - fine staple, close even crimp, luster . . 8

26. Condition - sound, medium amount of oily yolk, soft, pure, bright . . . . . . . . . 


\section{SCORE CARD}

\section{THE FAT HOG}

Scale of Points

General Appearance.

Counts

1. Weight .

2. Form - low station, rectangular, broad, deep, long, smooth, symmetrical . . . . . . . .

3. Quality - refined head, smooth, sides free from wrinkles, fine straight hair, clean bone . . . .

4. Condition - thick, even covering of firm flesh, neither too hard nor too soft, no slipping . . . 10

5. Temperament - lymphatic, disposed to fatten . . 4 Head and Neck.

6. Head - short, broad, deep

7. Snout - comparatively short, fine . . . . . . 1

8. Eyes - large, bright, wide apart . . . . . . . 1

9. Face - moderately dished, according to breed, broad between the eyes . . . . . . . . . . 1

10. Ears - medium size, pointed, thin, carried well up 1

11. Jowl - full, deep, trim . . . . . . . . . . 1

12. Neck - thick, deep, short, top line sharply curved upward .

Forequarters.

13. Shoulder - wide, smooth on sides, compact on top 4

14. Breast - prominent, full . . . . . . . . . 2

15. Legs - short, straight, strong, clean bone . . . 2 Body.

16. Chest - deep, wide, full, no constriction . . . . 3

17. Back - broad, thickly covered, well supported, arched . . . . . . . . . . . . . 10

18. Sides - long, deep, smooth, firm, thickly covered . 6

19. Loin - broad, thickly covered . . . . . . . 10

20. Flank - deep, full, under line straight . . . . . 2

Hindquarters.

21. Rump - long, broad, level . . . . . . . . . 2

22. Ham - wide, deep, full, well rounded, firm . . . 10

23. Legs - short, straight, strong, clean bone . . . . 2 


\section{SCORE CARD}

\section{THE BACON HOG}

\section{Scale of Points}

General Appearance. -40 .

Counts

1. Weight (160 to $200 \mathrm{lb}$ ) . . . . . . . . . . 6

2. Form - long, deep, narrow, trim, symmetrical . 10

3. Quality - refined head, smooth, sides free from wrinkles, fine straight hair, clean bone . . . . 10

4. Condition - firm, even covering, ample lean in proportion to fat . . . . . . . . . . . 10

5. Temperament - active . . . . . . . . 4

Head and Neck. -8 .

6. Head - long, medium width, fine . . . . . . 1

7. Snout - medium length, tapering . . . . . . 1

8. Eyes - large, wide apart . . . . . . . . . 1

9. Face - moderately dished according to breed, lean 1

10. Ears - medium size, fine . . . . . . . . . 1

11. Jowl - light, neat . . . . . . . . . : . 2

12. Neck - medium length, full, level on top. . . . 1

Forequarters. -10.

13. Shoulder - light, straight, smooth, compact on top 6

14. Breast - medium width . . . . . . . . 2

15. Legs - straight, strong, clean bone . . . . . 2

Body. -30 .

16. Chest - deep, full . . . . . . . . . . 5

17. Back - long, strong, medium uniform width, thickly covered . . . . . . . . . . . . 6

18. Side - long, deep, firm, smooth, trim . . . . . 12

19. Loin - medium width, strong, thickly covered . . 5

20. Flank - deep, full, trim under line . . . . . . 2

Hindquarters. -12.

21. Rump - long, level, medium width . . . . . . 4

22. Gammon - thick, deep, tapering, trim . . . . 6

23. Legs - straight, strong, clean bone . . . . . . 2 
82. Demonstrations may supplement scoring, the subjects being chosen with the view of showing both desirable and undesirable features. Discussion should not be confined to noting defects and criticizing them but should give equal prominence to the good points and commending them. Neither should the subjects of demon-

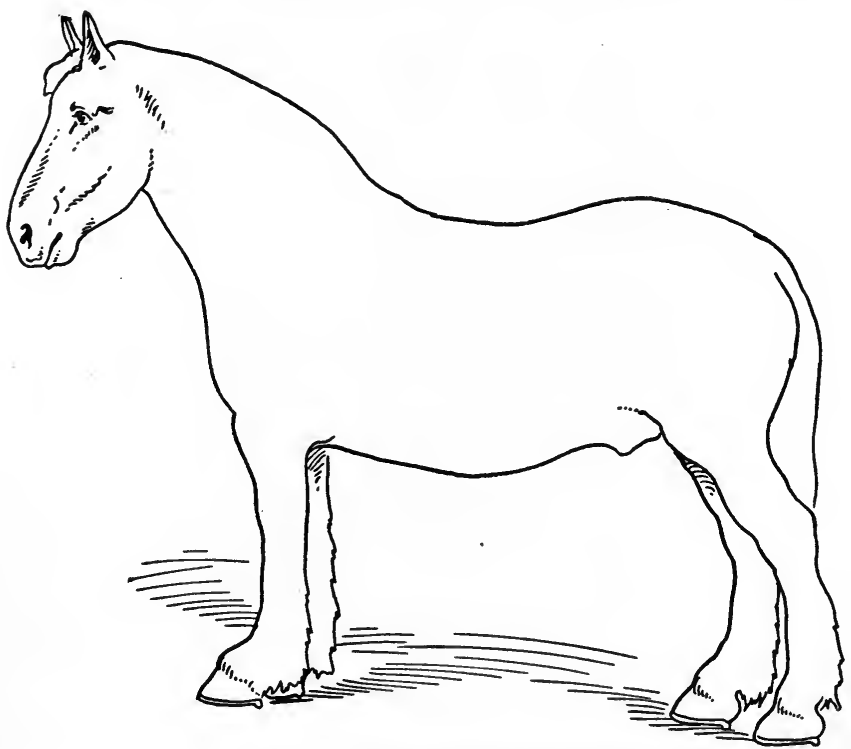

FIG. 35. - Outline drawing of a horse.

stration be chosen for their excellence, altogether, for it is as essential to know those features of form that are opposed to greatest functional capacity as it is those upon which maximum productiveness depends.

Comments and criticisms may be recorded briefly on blank forms having an outline of the animal in question (Figs. 35, 36, 37, 38, 39). This serves the double 
purpose of directing the student's attention to definite points in the animal form and affording a means of making a concise report of his observations. It does away with the monotonous and confusing figures of the score card which often engage much of the student's time that might be more advantageously spent in studying the

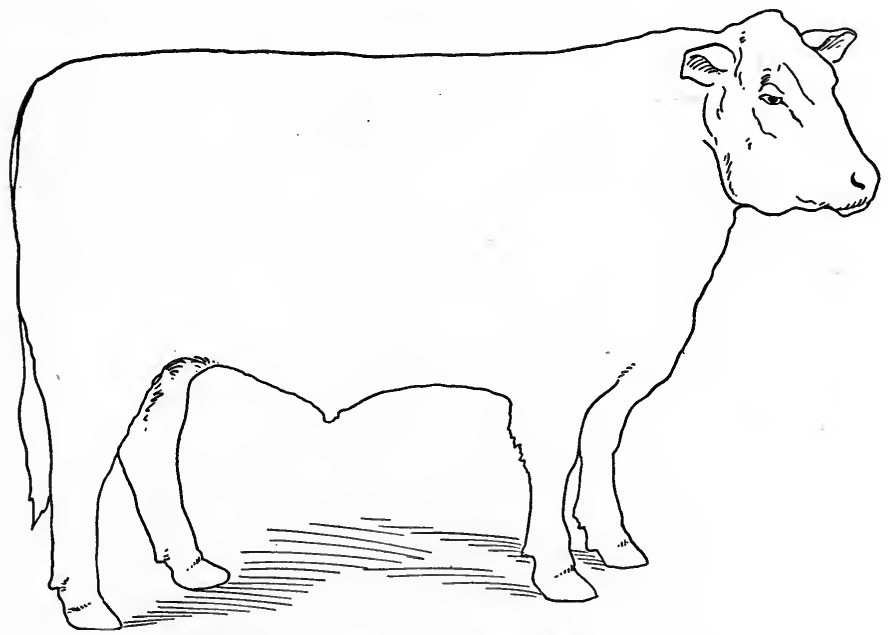

Fig. 36. - Outline drawing of a beef steer.

merits and demerits of the animals before him. The outline blank may be double faced, one side to be used for criticisms, and the other for indicating the points of excellence.

83. Comparisons. - After score card practice, demonstrations and discussions which perfect the student in analysis, exercises in simple comparison should follow by the introduction of more than one subject. Comparison involves not only measuring the character in question to the standard in the mind's eye but carrying, in the eye, 
the image of the character of one individual until there can be placed beside it, in the judge's vision, the analogous character of another individual, so that an opportunity for comparison may be afforded. By repeated comparisons the ideal is gradually crystallized in the student's mind, the good points being rendered more conspicuous by being

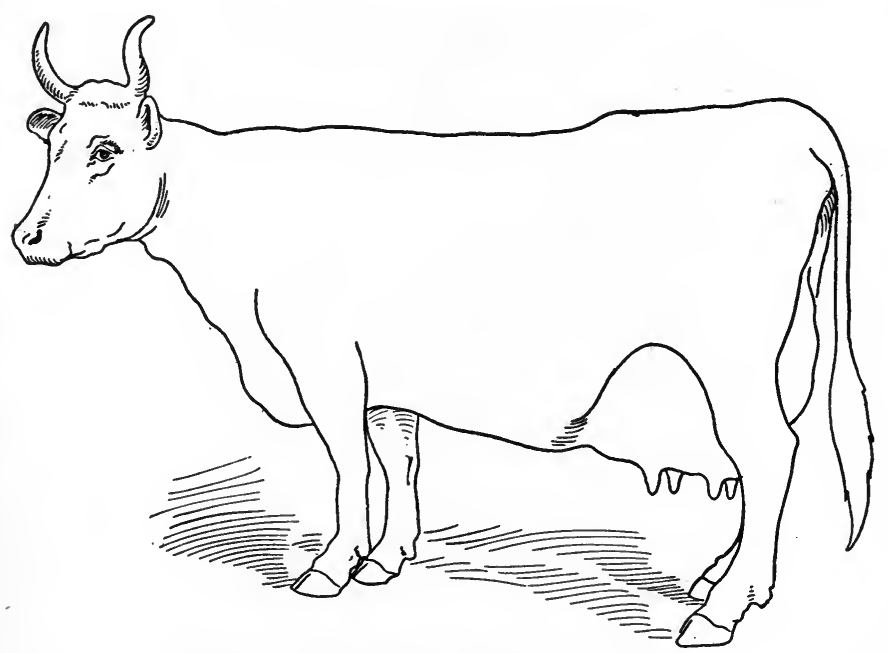

FIG. 37. - Outline drawing of a dairy cow.

set off, as it were, by the bad points and conversely, deficiencies becoming more marked in contrast with merit.

84. Competitive judging. - Finally, but only after having acquired skillful method, keen perception, and a definite notion of the ideal, the student may be permitted to carry his comparisons a step farther and bring the different comparable characters into actual competition, first covering parts or regions only, as heads and necks, 
or hindquarters, then including the individuals as a whole.

This step by step method has been found much more effective than to plunge students immediately into the

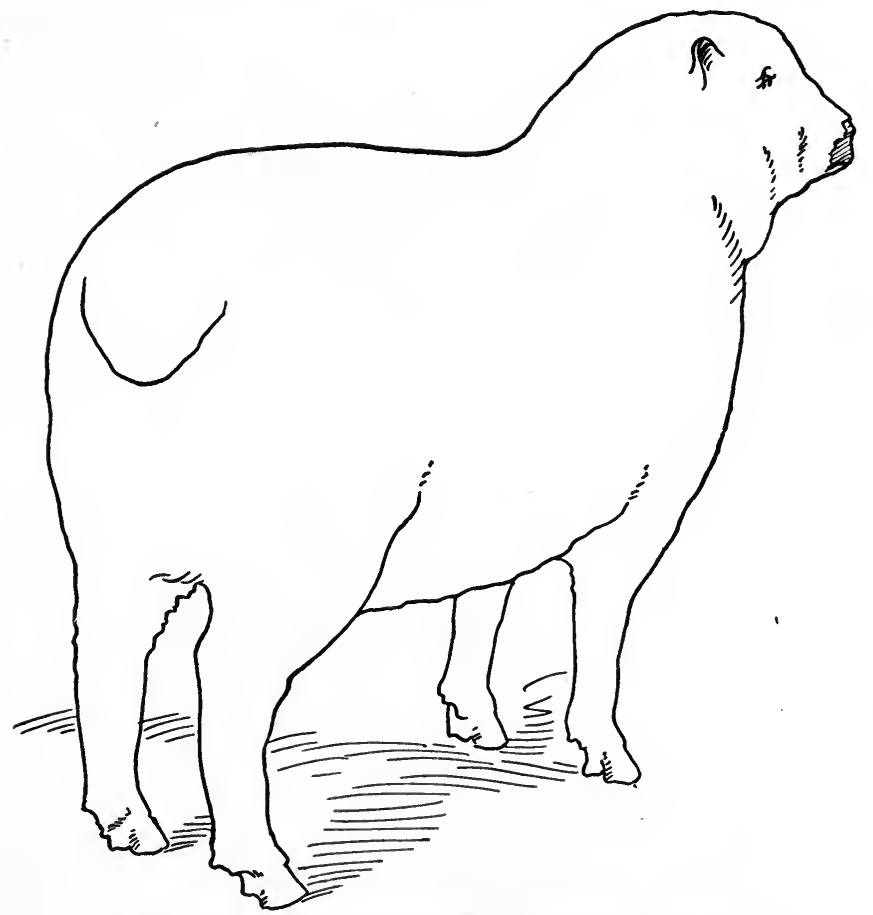

FIg. 38. - Outline drawing of a mutton wether.

perplexities of "placing" a class of animals before they have acquired the standard to which they are to select or mastered the art of applying it. It is interesting to note, in this connection, the different tactics employed in coaching student teams for judging contests. Some 
trainers condition their race horses by repeated trials of as great severity as the race itself; others spend their preliminary seasons in perfecting the gait of their horses, balancing, biting and schooling, at the same time giving them sufficient work to render them physically capable of a more strenuous effort than they are, but rarely, called upon to make in their work outs.

The latter is conceded to be the better method. So it is with the instructors. Some lay most stress on the number

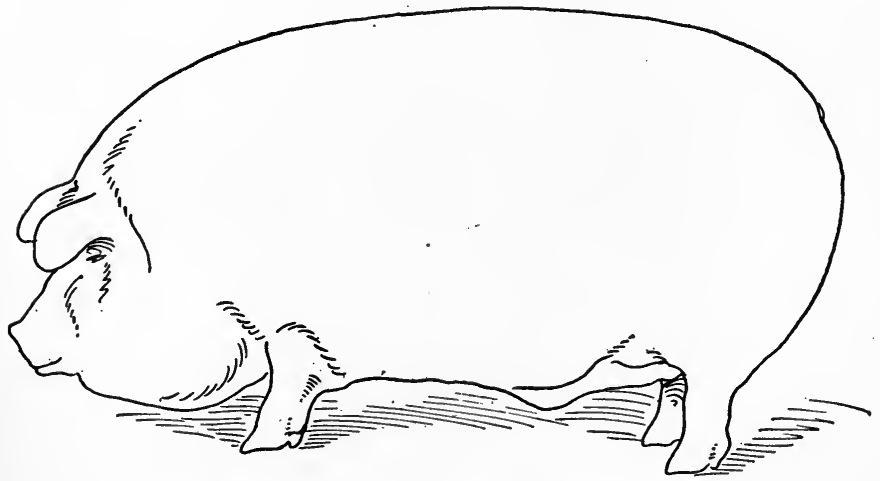

FIG. 39. - Outline drawing of a fat barrow.

of classes which their teams have had an opportunity of placing, notwithstanding that such placing may have been made under wholly unsatisfactory conditions, as when no chance is afforded for subsequent discussion. Such work tends to confuse and render chaotic whatever correct notions the students may have entertained. Others, and usually the more successful ones, spend the time after their team is chosen, which is usually on the basis of competitive judging, in demonstrations and dis- 
cussions of typical and atypical representatives of the types and breeds, creating thereby a clearer conception of the ideals, more accurate powers of observation, and more logical judgment for making competitive decisions when the crucial time for them arrives. 


\section{PART III JUDGING HORSES}




\section{CHAPTER VII}

\section{THE INDIVIDUAL}

IDEALS are the bases upon which animals are judged, and they may concern the individuals, the types and the breeds of horses, cattle, sheep and swine.

85. The horse, Equus caballus. - There is archæological evidence that the horse served primitive man of the stone age together with the reindeer and the dog, although there is no authentic historical reference to his use prior to the time of Joseph in Egypt, 1715 B.c. While the mare's milk and horse meat have been used in a very limited way, the horse's power and speed have been the attributes most commonly made use of by those who have subjugated and domesticated him. He is more than a simple beast of burden, in which field he was preceded and in some ways excelled by the dog, reindeer, camel, elephant, ox, ass and mule; he has taken a most important part in warfare and the conquests of nations, the elaborate ceremonies of church and state, the sports and pastimes of the people and finally in their agricultural and commercial pursuits.

86. Performance. - The entire organization of the horse is designed to enhance his locomotion, and there is no domestic animal whose movements are so characterized by power, agility and grace as those of the horse. He is endowed with such mental limitations as to render his capabilities in locomotion most subservient to his master's demands. The performance required of the horse is 


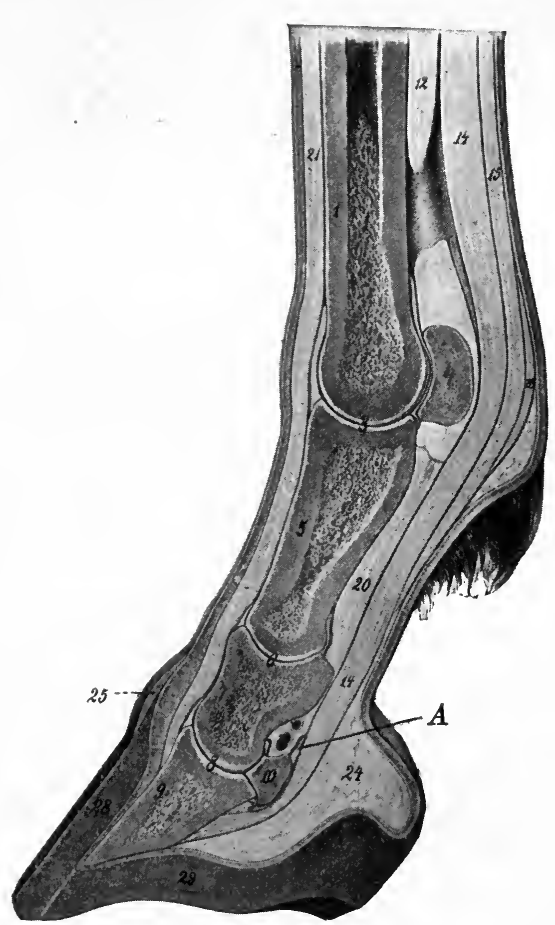

FIG. 40. - Sagittal section of distal part of limb of horse. 1, large metacarpal (fore cannon) bone ; 3 , fetlock joint ; 4 , proximal sesamoid bone; 5 , first phalanx; 6 , pastern joint; 7 , second phalanx; 8 , coffin joint ; 9 , third phalanx ; 10 , distal sesamoid (navicular bone); 12 , suspensory ligament; 14 , deep flexor tendon; 15, superficial flexor tendon; 16 , posterior annular ligament of fetlock ; 20 , inferior sesamoidean ligaments ; 21 , extensor tendon; 24 , plantar cushion; 25 , periople; 28 , wall of hoof; 29 , sole of hoof ; $A$, navicular bursa, proximal part. (After Ellenberger-Baum, Anat. für Künstler.) not simply to be something, as in the case of the meat producing animals; nor yet as in the case of the dairy cow, which yields her body products, day by day, rather than accumulating them in a carcass, but to $d o$ various and oftentimes very complex things. The functional possibilities of the horse, as in the case of any other animal, can best be ascertained by study of the mechanical structure upon which these functions depend.

87. The structure analogous with that of man. - The structure of the horse so far as bones, joints and muscles are concerned is, with a few minor exceptions, very closely analogous to the 
structure of man, provided that man assumes the horizontal and quadrupedal position, and rests on the tips of his fingers and toes. The horse has no collar bone, the union between trunk and anterior extremities being wholly muscular, and the relative length of fore and hind legs is such as to maintain the body in a perfectly horizontal rather than an inclined attitude. He has one digit instead of five and rests only on the last segment of it, so that the wrist corresponds to the horse's knee, the knuckle to his fetlock joint and the three phalanges of the finger to his first and second pastern, and pedal bones (Fig. 40). Likewise the knee of the man is the stifle of the horse, the calf of his leg the gaskin of the horse, his heel the horse's hock, and so on as in the foreleg. As the man raises his weight well up on his toes and feels the tension of the muscles of the thigh and lower leg he can well understand what takes place when the horse "lifts" in the starting or moving of a load or in merely projecting his own body forward, in locomotion.

88. Mechanical structure. - The structure of the horse, mechanically considered, consists of a trunk suspended by an arch, the vertebral column, supported at each end by four vertical columns, the legs, the anatomical features of which have already been described in Chapter II. Greater weight is borne on the forelegs because the appended head and neck bring the center of gravity well forward of the center of the body. The arrangement by which the body is slung between the two forelegs by the great pectoral muscles and the slope of shoulder and pastern provide for the supporting of this weight, especially during locomotion, with least concussion. The center of gravity being displaced further forward when the horse is in motion, still greater weight is thrown on the forelegs, 
the hind legs serving as propellers. The articulation of the thigh directly with the pelvis conveys the propulsive effort throughout the entire length of the spinal column. The supportive action of the forelegs meets the propulsive action of the hind legs in such a way as to restore the equilibrium of the body.

The joints of the leg are hinge joints, capable of motion in two directions only, flexion and extension, while the joints of the hip and shoulder, points at which the legs articulate with the body, are ball and socket joints, which permit of a rotary motion. The legs, generally speaking, are therefore capable of alternate flexion and extension, which take place in the order named, although the flexion of the leg as a whole may involve the extension of some one joint, as in the case of the shoulder at the commencement of flexion of the leg.

89. The stride. - Flexion of the leg, which raises the foot from the ground, plus extension of the leg, which carries the foot forward until it comes in contact with the ground, again constitute a stride, and by the simultaneous or successive strides of the four legs, regularly repeated, the body is advanced. Each leg may engage in a stride independently, as in the case of the walk and the rack or single foot, in which the cadence is distinctly marked by four beats; one fore and the opposite hind leg may operate separately, while the other two act as one, as is done in the gallop, there being three distinct beats but of irregular cadence; a fore and a hind leg may move in unison and mark but two beats, as in the trot, when a diagonal pair are concerned, as the near fore and the off hind, or in the pace, when a lateral pair, as the near fore and the near hind, coöperate.

90. Deviations in the stride. - There is an active and 
a passive period in this form of locomotion which each leg or set of legs experiences in alternate order. One leg, a pair of legs or a set of three legs supports the weight of the horse while the other leg or legs is executing a stride. Hence, we can distinguish a supporting leg and a striding leg, and we find that deviations in the way of going may be accounted for by abnormalities operative during either or both periods. For instance, some lamenesses are manifested only when the leg is supporting, while others are characterized as striding or swinging leg lameness. A horse may interfere because of a base-narrow, toewide position, which places the fetlock of the supporting leg so near the median plane as to insure its being struck, but the likelihood of its being struck is greatly enhanced by the fact that the same defective position of leg which causes the fetlock to approach the median plane is also responsible for the striding leg's being swung in a circle inward. This of itself might be productive of interfering, but to be added to the results of such a position in the supporting leg makes interfering doubly certain. On the other hand, the shortened stride of the spavined horse involves a condition which manifests itself in the striding leg only.

91. The phases of the stride. - The evolution of the stride involves five distinct phases, a preliminary, during which the leg is undergoing flexion, but the foot has not left the ground, - the point at which the real stride begins; next, the breaking over, in which the foot is raised heel first and leaves the ground by being rocked up and over at the toe, although at speed the foot springs directly from the ground, not waiting to break over at the toe; then flight, during which the foot is describing a more or less regular arc of a perpendicular circle; followed by contact, 
at which point the foot is again brought to the ground; and finally recovery, as the weight gradually falls on the foot and the original position of the leg is momentarily established preparatory to a repetition of the stride.

92. The features of the stride which constitute the way of going. - The following features are manifested by the stride as it is executed, some being most marked in one type of horse, while others are more characteristic of another.

Length, as determined by the distance measured from the point at which the horse breaks over to the point at which his foot' comes in contact with the ground again.

Directness, referring to the line of flight of the foot during the stride.

Rapidity, which determines the time consumed in taking the stride.

Power, which the horse is capable of exerting in his stride.

Height, the degree of elevation through which the foot passes in describing the arc of a circle in the stride.

Elasticity, the spring with which the weight is borne by the leg and foot just before the commencement or just after the completion of the stride.

Regularity, the machine-like order in which each stride is taken in turn.

Balance, referring to the comparative display of any or all of the other features in hind as against fore legs.

The sum total of these features as described by the horse in the succession of strides by which he moves constitutes the way of going.

93. Pace. - Length and rapidity of stride contribute to pace; that is, the rate at which the horse moves.

94. Action. - Height and spring of the stride mark action; that is, flexion of knees and hocks. 
95. Gait. - A gait is a particular way of going characterized by definite and distinctive features, regularly executed. The gaits are:

96. The walk, a slow, flat-footed, four-beat gait, which is one of the most useful if properly executed with snap and animation, whether in harness or under saddle. The walk should not be considered useful simply to afford the

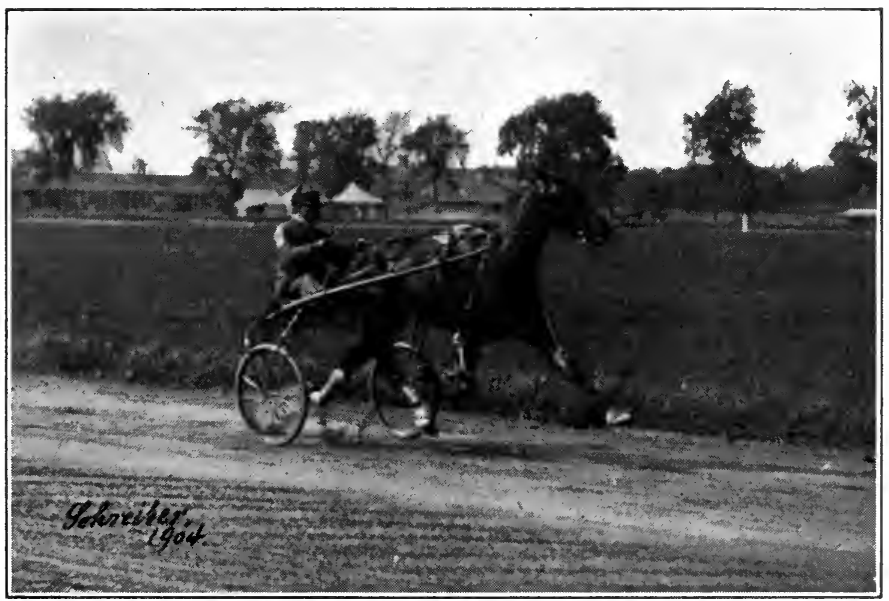

Fig. 41. - A trotter at speed, showing the reach or extension of the stride characteristic of this gait.

horse an opportunity to rest, but should be regarded as a distinct form of locomotion, with as definite a purpose as any other gait which the horse goes.

97. The trot, a rapid, two-beat gait in which the diagonal fore and hind legs act together. There are three varieties of trot, viz. : the fast stepping trot, characterized by the length of stride and rapidity with which the individual strides are taken and constituting the gait of the har- 


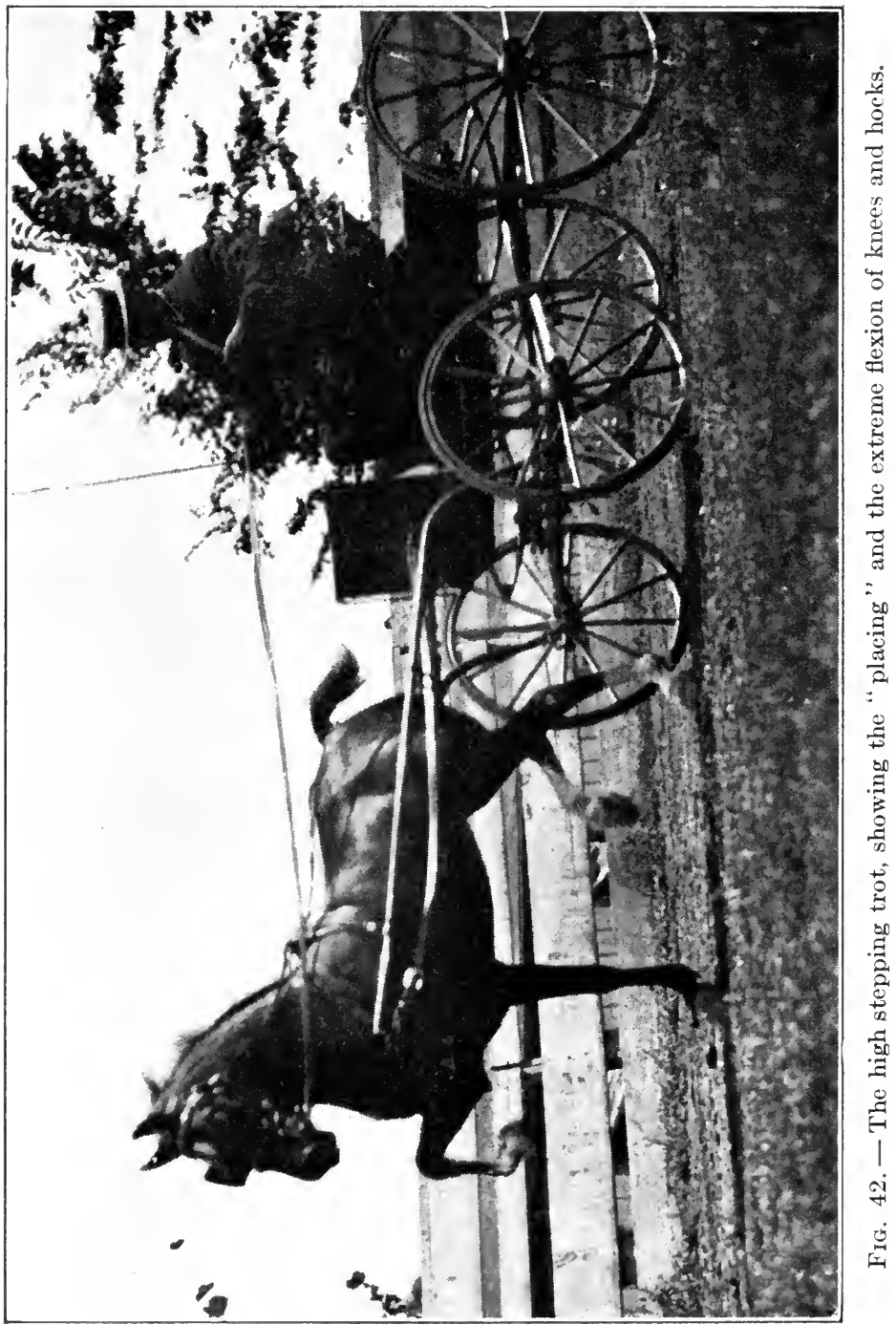


ness race horse (Fig. 41); the high stepping trot, characterized by the height and elasticity of the stride, the horse placing himself, going collectedly and marking each step with extreme flexion as represented in the harness show horse (Fig. 42); and the saddle trot, characterized

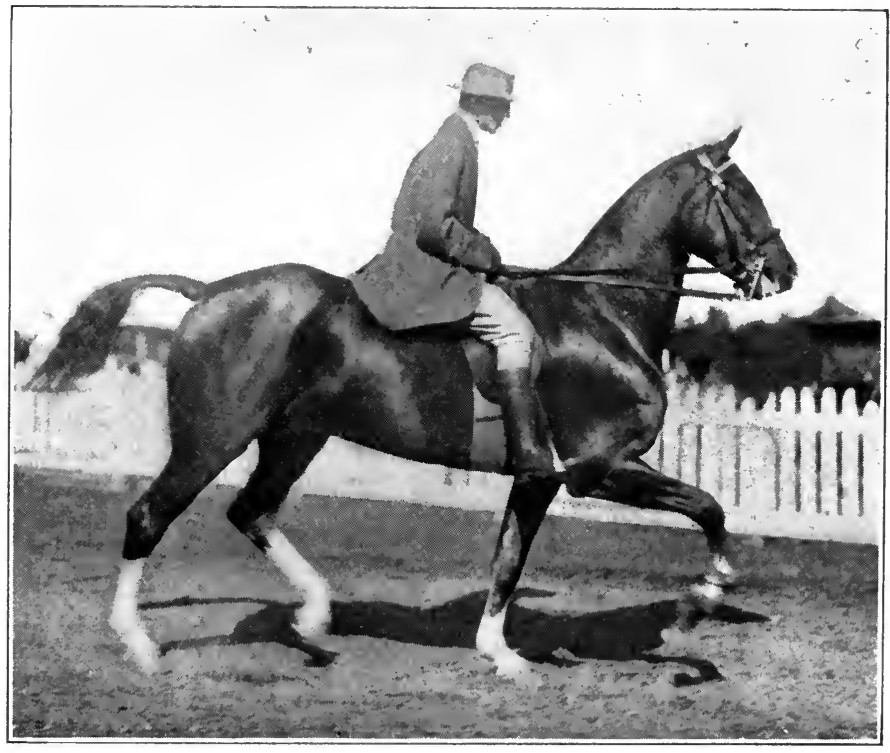

FIG. 43. - The saddle horse trot; going collectedly, well off hocks, moderate knee action, and a springy stride.

by a square, springy, collected and balanced stride, executed in perfect rhythm and with the utmost precision in order to insure the comfort and security of the rider (Fig. 43). The saddle trot is distinct from the long, swinging stride of the trotter, also the high, sometimes pounding step of the actor, and should reveal none of the 


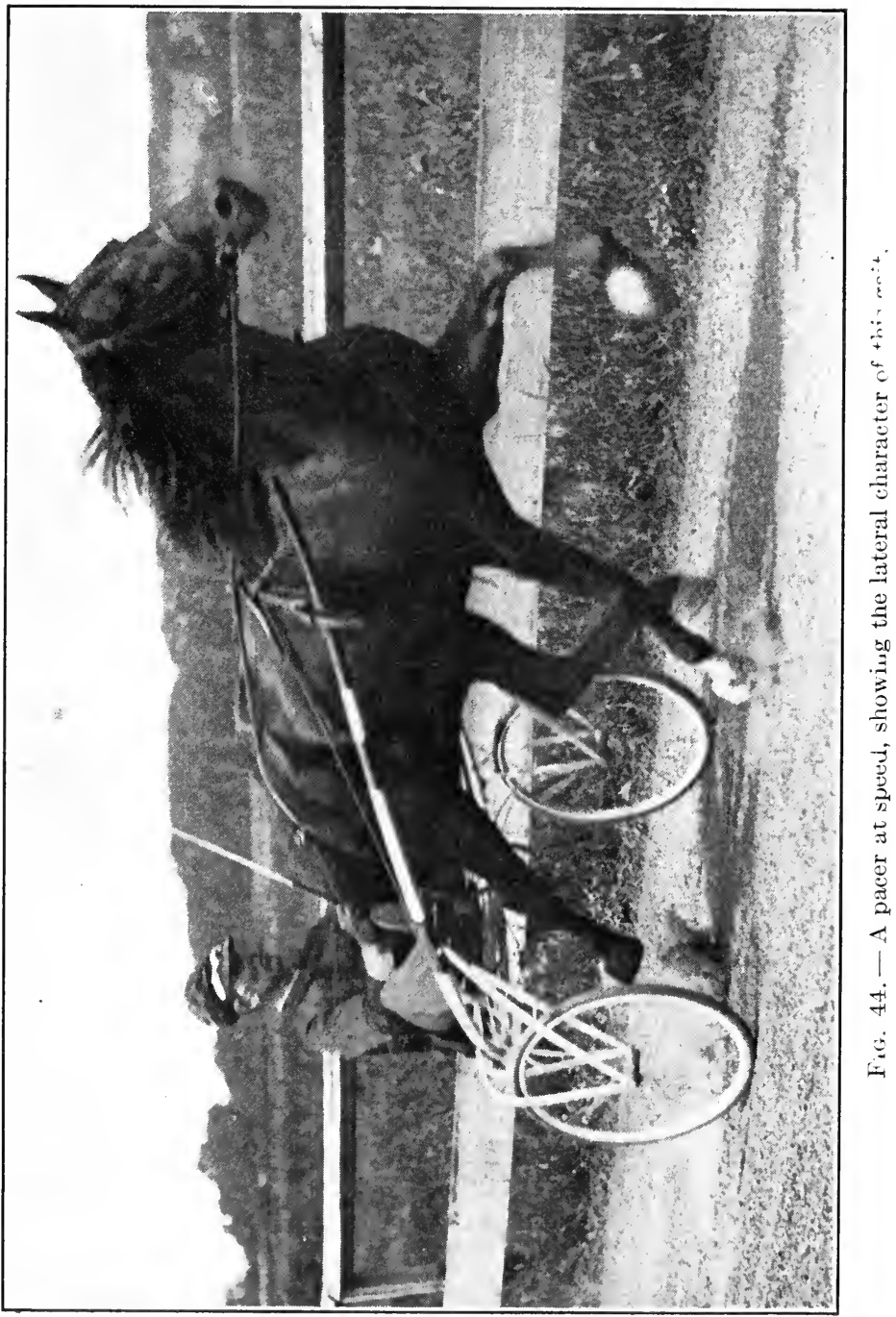


roll or side motion of the lateral gait into which saddle horses degenerate.

98. The pace, a rapid, two-beat gait distinguished from the trot by the fact that the lateral fore and hind legs act together. It is characterized by the readiness with which pacers can get away at speed, more or less side motion (the so-called side wheeler), the absence of much knee fold, and therefore the minimum of concussion, and the necessity for smooth, hard footing and easy draft for its execution (Fig. 44). This, like the trot, is the gait of the harness race horse.

99. The amble, a lateral gait distinguished from the pace by being slower and more broken in cadence. The natural amble is the foundation for the so-called saddle gaits, exclusive of walk, trot and canter.

100. The rack, a fast, flashy, four-beat gait, well described by the discarded term "single foot" (Fig. 45). The rack is the gait which distinguishes the five-gaited saddle horse. While some display greater aptitude than others, few horses will rack of their own accord, or on the halter, but only when called upon to do so with both hand and heel, being ridden well up to the curb. It is preëminently a show gait characterized by considerable action and in many instances quite a bit of speed.

101. The gallop, a fast three-beat gait in which two diagonal legs act together, their one beat falling between the successive beats of the other two legs, the hind one of which makes the first beat of the three. With the third and last beat, the horse is carried clear of the ground and there is a period of silence broken by the contact of the independent hind foot as it begins a new series of strides. The two legs acting independently, the fore, 
with which the horse leads, and its diagonal hind, naturally bear more weight and are subject to more fatigue than are the other pair, which act simultaneously, and therefore share the work. The hind leg receiving the full weight, at the phase of contact at the conclusion of the jump,

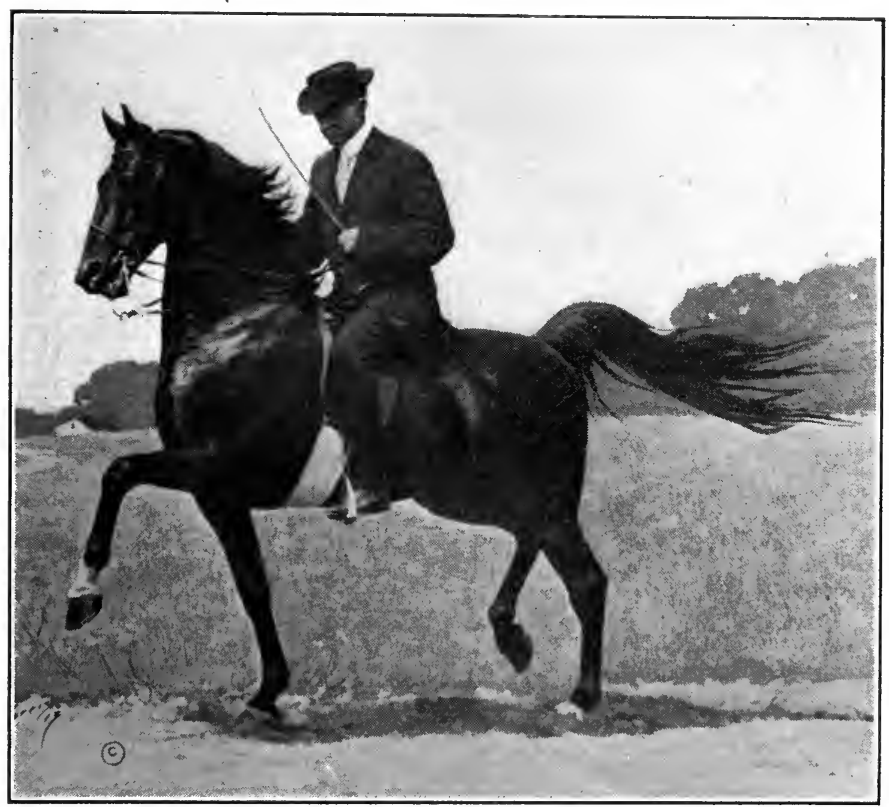

Fig. 45. - A gaited saddle horse at the rack, although the four-beat phase of this gait is not shown.

bears more than the foreleg, which supports the weight alone, just before the projection of the horse at the beginning of the jump. The gallop may become so fast as to break the simultaneous beats of the diagonal pair, the hind foot striking first and causing four beats, although follow- 
ing in such rapid succession as to be distinguished with difficulty.

102. The canter, a slow, collected gallop which the horse is made to do under restraint, the weight being sustained

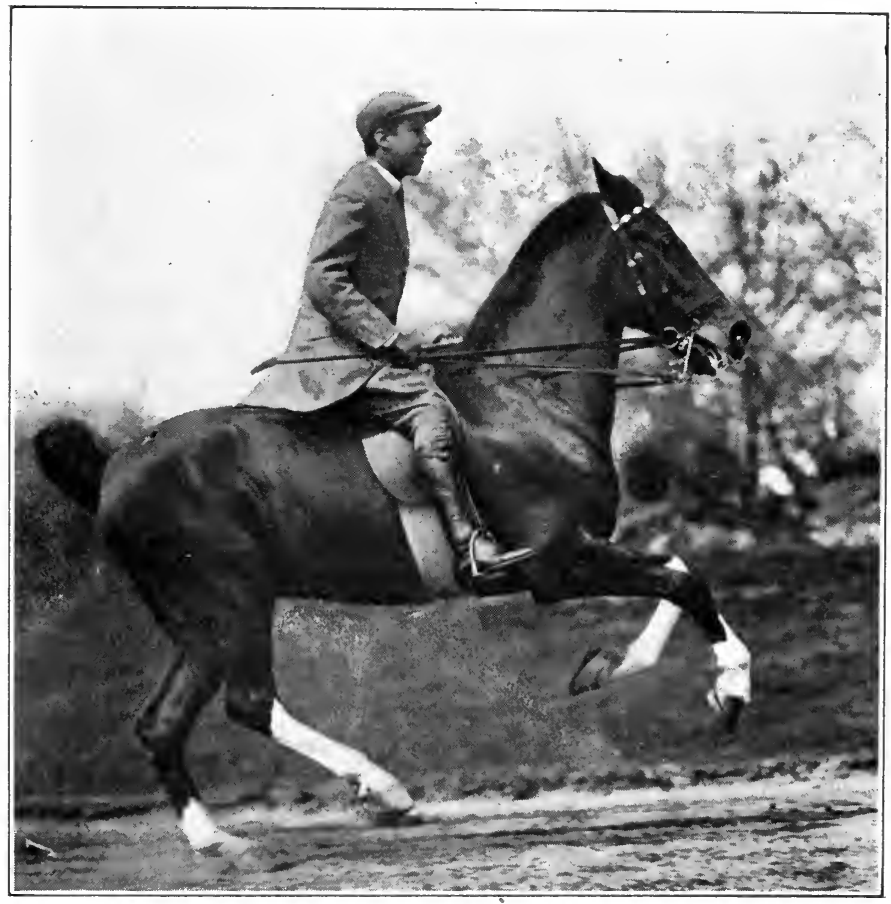

FIG. 46. - The canter, the hind foot bearing the weight and beginning a new series of three beats at the phase of contact, after the horse has been projected clear of the ground by the independent forefoot.

chiefly by the hind quarters, while the lightened forehand rises and falls in a high bounding fashion (Fig. 46). Inasmuch as the canter, like the gallop, causes special wear on the leading forefoot, and its diagonal hind foot, 
the lead should be changed frequently, a well-schooled saddle horse cantering on either lead at command. Cross cantering consists in so confusing the fore and hind leads that the simultaneous beat is of a lateral instead of a diagonal pair of feet, and this beat falls between the suc-

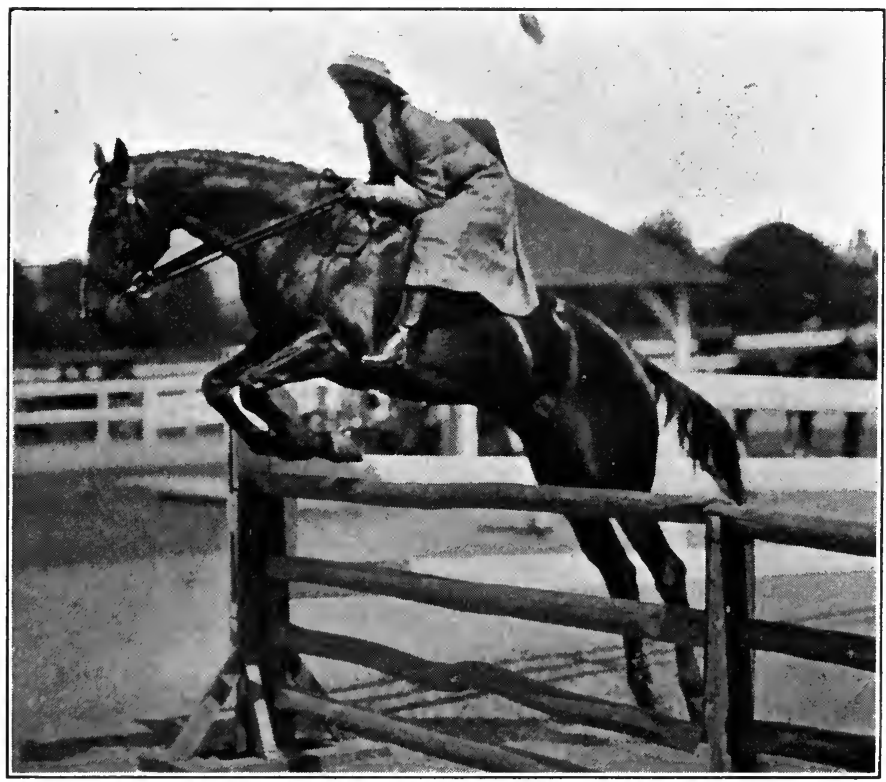

FIG. 47. - The jump, in whieh the forehand lifts, the hindquarters propel.

cessive beats of the other lateral pair, the leading fore and hind on the same side.

103. The jump, either high or broad, is accomplished by the forelegs raising the forehand as the horse takes off in such a manner as to bring his body in line with the direction in which the jump is to be taken, when a strong 
propulsive effort of the hindquarters projects it over in the case of the high jump or across in the case of the broad jump (Fig. 47). Upon alighting the forefeet strike the ground first, the leading foot being a very little in advance, the horse immediately gathering himself and striding out of the way of the hind feet which follow quickly and come in contact with the ground slightly in advance of the prints of the forefeet.

104. The running walk, a slow, single foot or four-beat gait intermediate in both speed and execution between the walk and the rack, and suggestive of a continued breaking out of the walk. Whereas the rack is the show gait of the gaited saddle horse, the running walk is their business gait. At it horses make from six to eight miles an hour and it can be continued all day with no distress to either horse or rider.

105. The fox trot, a short, broken trot in which the hind legs go more or less of a pace, the horse usually marking the beats with his head and ears. It is used in place of the running walk in horses which take to it more kindly.

106. The stepping pace, a distinctly saddle gait, should be differentiated from the ordinary harness pace which is a mark of degeneracy in the saddle horse. The stepping pace is characterized by little if any side motion and a somewhat broken cadence in the action of the lateral pairs of legs.

107. The traverse, a side step, executed by both forehand and hindquarters, in response to rein on the neck and heel in the flank; by it horses may be brought up to a gate to unlatch it or to "dress" in troop maneuvers.

108. Factors influencing the horse's way of going. The particular features or deviations in a horse's way of going may be due to either of two sets of factors, natural 
and acquired. The former class include type, conformation, direction of leg and form of foot, all of which are governed by breeding; the latter embraces educational tactics, mechanical appliances, and the going surface, which are encountered in the horse's schooling and handling.

109. Type as a factor. - Type involves structure and structure is correlated with function, therefore a horse will $d o$ as he $i s$. His capacity for one sort of performance will be limited, for another enhanced, by the plan of his structure; a long, lithe, angular horse will have more speed than power, while the draft horse is short legged, broad, square and compact. The stride of the former horse will be characterized by reach and extension, while the cobby horse, for instance, has a short but trappy stride.

110. Conformation as a factor. - Conformation, involving the details rather than the plan of structure, also influences the horse's way of going. The jumper has a straight hind leg short from the hip to the hock, while the pacer has a bent hind leg, long from the hip to the hock.

Direction of leg and form of foot control the directness of the stride, the former determining the course that will be taken by the foot during its stride, whether it will be advanced in a straight line or describe the are of a circle inward or outward, while the latter fixes the point at which the foot breaks over, whether the center of the toe, the outer or the inner quarter, depending upon whether or not the foot is symmetrical or the inner or outer quarter is higher.

The common deviations in the direction of the leg are classified as follows: 


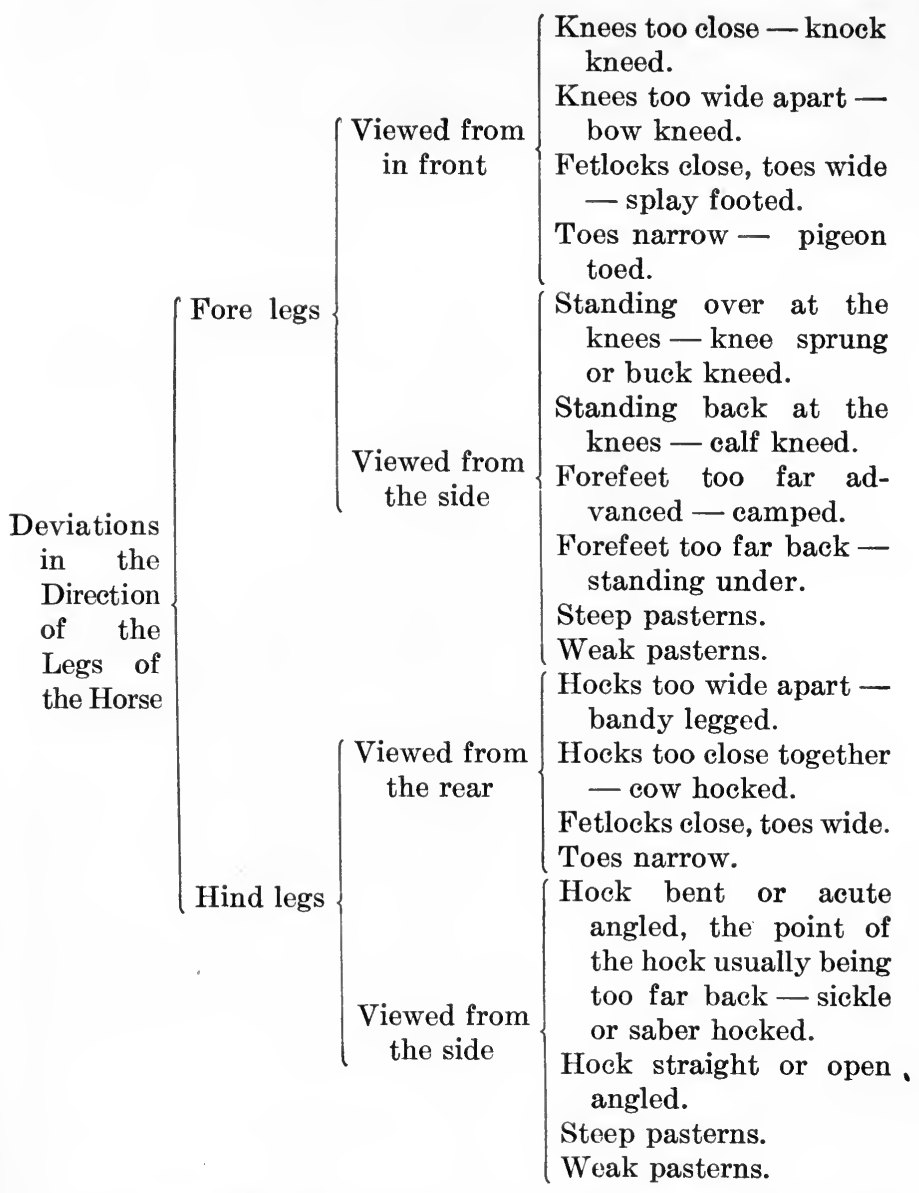

111. Breeding as a factor. - The features of type and conformation which determine the horse's way of going are, in turn, matters of breeding which, in addition, is responsible for the mental factor which governs locomotion 
and is expressed by instinct. Instinct, type and conformation are usually correlated and not antagonistic. Instinct, however, has a broader application in determining the specific gait that a horse shall go, rather than influencing some particular feature of his stride. It is instinctively natural for trotting bred horses to trot, Hackneys to go high and Thoroughbreds to gallop.

112. Education. - Instinct, however, is not sufficient to account for the record attainments in the various gaits of some horses. Education is necessary in order to make the most of hereditary endowments. Given the natural aptitude to trot, step high or gallop, a system of schooling is employed for the perfection of these gaits.

113. Mechanical appliances. - It is in the schooling of horses that the mechanical factors influencing the way of going are resorted to. For instance, the snaffle bit, offering no opposition to the horse extending himself, is conducive to speed, and is therefore regularly used on race horses, while the curb bit, resulting as it does in restraint, is suggestive of a collected and high way of going, and is therefore of great assistance in the schooling of saddle and high-going horses.

Weight influences the stride within limits; increasing the amount of weight in the foot, either by the shoe or by permitting an overgrowth of the foot itself, calls for an extra effort to make the stride, and therefore results in a higher step, although excessive weight will defeat this purpose. The placing of weight in the different parts of the foot, as inside, outside, heel or toe, does not make as much difference as was formerly believed. However, weight at the toe in the position of the usual toe weight attachments will, upon the principle of the pendulum, increase the length of the stride by carrying the foot out, 
even turning up the toe, in extreme cases, while weight at the heel increases the height of the stride by requiring more lift on the part of the flexors. Hopples may be used to keep trotters or pacers in their stride or to convert from one gait to the other.

114. Going surface. - The surface over which the horse steps has a marked influence on the character of his stride which may be taken advantage of in the schooling process. As a general rule, heavy, soft or deep going causes a high stride, while a hard, smooth surface is conducive to speed. Of the speed horses, trotters and pacers take more kindly to the hard track than the runners, which do best on the turf or a deeply scratched dirt track. The difference in the going will frequently account for a horse's trotting or pacing, the heavy or deep going causing double-gaited horses to trot, while a change in footing will shift them to the pace.

The common defects and peculiarities in the horse's way of going for which any of the preceding factors may be responsible or tend to overcome are:

115. Forging - striking the ends of the branches or the under surface of the shoe of a forefoot with the toe of the hind foot.

116. Interfering - striking the supporting leg at the fetlock with the foot of the striding leg. It is a common result of the horse's standing in the base narrow, toe wide or splay footed position.

117. Paddling - an outward deviation in the direction of the stride of the foreleg resulting from the toe narrow or pigeon toed standing position.

118. Winging - exaggerated paddling in horses that go high, and consequently deviate more noticeably.

119. Winding - a twisting of the striding leg, around 
in front of the supporting leg after the manner of a rope walker ; most commonly seen at the walk in wide-fronted draft horses.

120. Scalping - hitting the front of the hind foot above or at the line of the hair against the toe of the forefoot as it breaks over.

121. Speedy cutting - in which the spreading trotter at speed hits the hind leg above the scalping mark against the inside of the breaking over forefoot as he passes.

122. Cross firing - essentially forging in pacers, in which the inside of the near fore and off hind foot, or the reverse, strike in the air, as the stride of the hind leg is about completed and the stride of the foreleg just begun.

123. Pointing - a stride in which extension is more marked than flexion, as is commonly seen in the trot of a Thoroughbred. Pointing also indicates the resting of one forefoot in an advanced position to relieve the back tendons while the horse is standing.

124. Dwelling - a scarcely perceptible pause in the flight of the foot as though the stride had been completed before the foot reaches the ground, and noticeable in actors.

125. Trappy - a quick, high but comparatively short stride.

126. Pounding - hitting the ground hard at the conclusion of a high stride.

127. Rolling - excessive side motion of the shoulders, usually confined to wide-fronted horses. 


\section{CHAPTER VIII}

\section{THE TYPES AND CLASSES}

THERE are four types of horses, the division being made upon the basis of mechanics, each type being subdivided into classes in accordance with market and show ring demands. The four types are power, speed, show and saddle.

128. The power type. - The service of the power or draft horse is to move the maximum load under minimum pace requirements and usually over the paved surfaces of traffic congested city streets.

Stability of equilibrium is the measure of power ; therefore, the essential features of power horse type are those which contribute to or insure stability of equilibrium and muscular development. Factors to the former are weight, low station and breadth of body; to the latter, compactness, massiveness and bone, while depth, which is correlated with breadth and compactness, is a feature of stamina by which continuous service is sustained. The power horse (Fig. 48) should weigh from 1500 to 2400 pounds in order to have sufficient friction between his shoe and the hard surface of the street to give him a secure footing. Furthermore, weight thrown into the collar effectively supplements muscular exertion. Low station, determined by shortness of legs, increases the stability of equilibrium by bringing the center of gravity as near as possibie to the base of support, that 
area of surface upon which the horse stands, included within lines connecting the four points of contact, his feet. Length of leg in turn is largely a matter of length of cannon, and a short cannon is correlated with breadth, depth and compactness, all features of the power type.

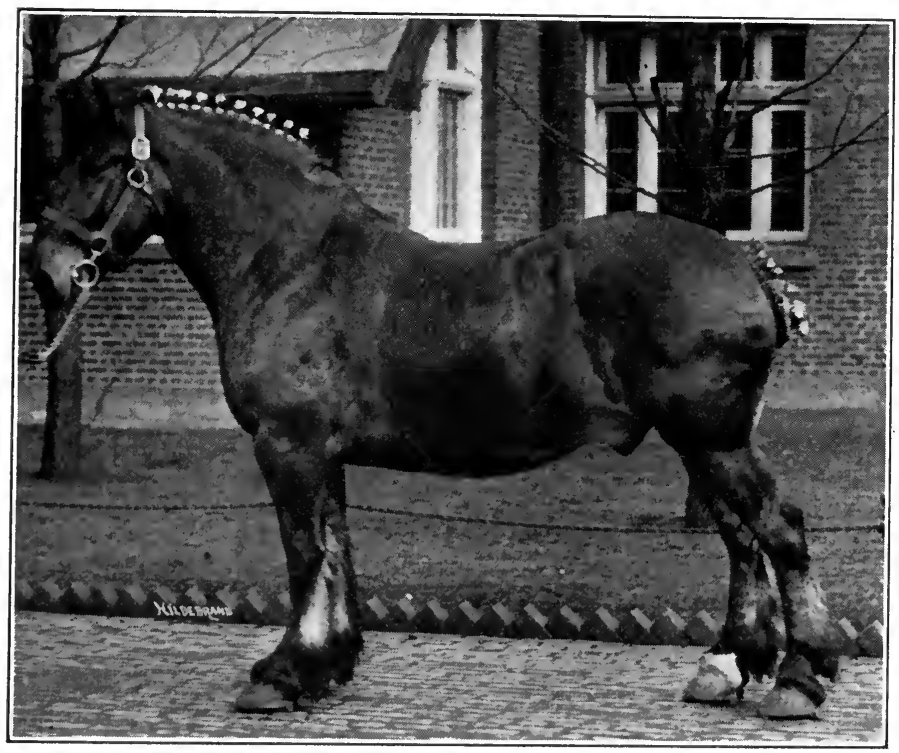

FIG. 48. - The power horse type.

Brcadth, involving primarily the skeleton, increases the base of support laterally, thereby giving greater stability of balance, and it also insures skeletal foundation for the development of a greater muscular system. Depth, directly related to heart, lung and digestive capacity, is essential in order that the horse shall be capable of maintaining a continuous supply of energy throughout his 
long hours of arduous duty. Compactness, the result of a short vertebral column, brings the source of power, the hindquarter, closer to the point at which the power is applied, the shoulder, thereby making for strength and rigidity of the shaft and minimizing loss in transmission. Massive is almost synonymous with muscular, and a massive appearance is suggestive of power, as it indicates extreme development of the short, thick, bulky power variety of muscles. The strength of the bone should correspond to the contracting force of the muscle. The power horse should, therefore, have a framework of heavy but dense, clean bone (Fig. 49). The joint surfaces, also, should be of such area as to withstand the stress of the powerful contraction of the muscles upon the bones whose ends they oppose. Furthermore, the symmetrical appearance of

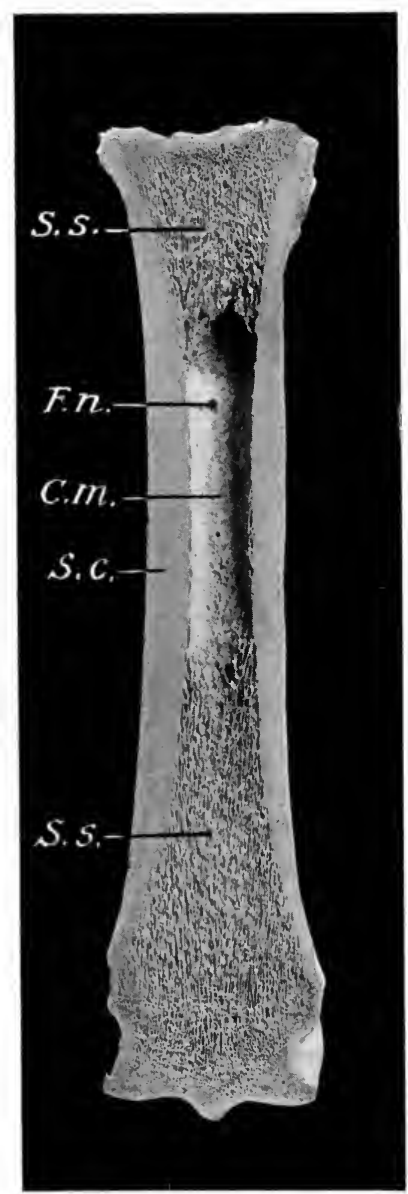

FIG. 49.-Frontal section of large metatarsal (hind cannon) bone of horse, posterior part. S.c., compact substance; S.s., spongy substance; C.m., medullary cavity; F.n., nutrient foramen. Note the greater thickness of the compact substance of the inner and anterior parts of the shaft. 
the power horse requires that his underpinning (Fig. 50) shall balance with the size of his superstructure.

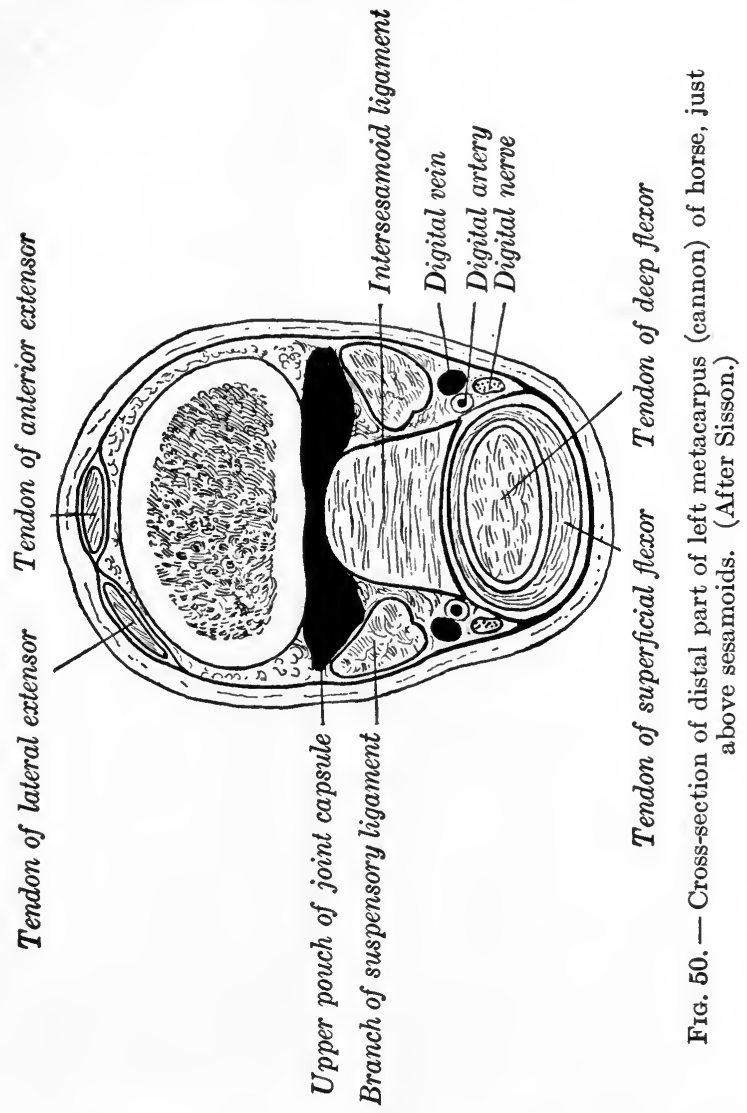

129. Conformation of the draft horse. - The distinctive features of the conformation of the draft horse are: a head of such size as will balance the other features of a 
big horse, yet not manifest coarseness or low breeding; a neck that has sufficient length and shape to fit a collar well, though strong and muscular; broad, muscular withers; a shoulder with as much length and slope as is consistent with a short-legged, heavy-set horse; a broad muscular arm and fore arm; a wide, deep knee affording ample joint surface, the size of the horse considered; a short, broad, flat, clean cannon bone; a pastern of as much length and slope as will support the weight of a draft horse without sagging; a full, round, smooth coronet, elastic cartilages; and a foot that is large in proportion to the size of the horse, of half-flat shape, so as to insure greatest circumference and ground-gripping surface, yet strong in the heels and bars, with an arched sole which shows no tendency to drop or become too flat, as many draft horse feet do, and of such dense, smooth horn as will insure against the shelly, brittle hoofs to which draft horses are heir; a short, broad, straight back; round, deep rib ; short, broad, thick, level loin ; full flank; smooth, short, strong coupling; long, level, broad and muscular croup; thick thigh and stifle; muscular gaskin; broad, deep, smooth, straight, clean-cut hock; with the same sort of hind cannon, pastern and foot as described for the front leg, the hind pasterns of draft horses showing a marked tendency to be steep.

The legs should be set one under each corner, not on each corner, giving the bull dog effect that is noticeable in some very wide-fronted horses. The elbow should be in, not out. The hocks cannot be expected to be very close together in a horse that has much thickness of thigh, but hocks that are wide apart are defective. The four legs should line up straight from either side or end view.

130. Quality in the draft horse. - While not contributing to power, it is essential that the draft horse should 
possess quality, as indicated in texture of bone, hoof and hair, and refinement of head and neck, in order to increase the wearing properties and to improve the general appearance. Quality is not natural to the draft horse, since he is primarily gross, but as much as is consistent with the required substance should be sought.

131. Temperament of the draft horse. - The nature of the work of the draft horse requires that he be steady and easily handled, hence his lymphatic temperament stands him in good stead, unless it makes him absolutely sluggish, which he should not be.

132. Way of going of the draft horse. - Since the most approved systems of draft horse management prescribe that he shall work at the walk, it is important that the walk, in his case, should be developed to its greatest possibilities. He should move at this gait with a powerful, yet snappy, free and true stride. He may be trotted for inspection, because the trot magnifies all features of the walk, and for a draft horse to be able to trot well gives assurance of mechanical excellence which will serve him equally well at the walk.

133. The speed type (Fig. 51). - This type is extremely opposed to the horse that has already been described. Speed performance calls for maximum pace with a minimum impost of weight to be pulled or carried. Instability of equilibr:um is the measure of speed; therefore, the type in general is one in which there is the least opposition to the rapid and repeated displacement of the center of gravity which takes place with each stride and in the direction of the leading foot. In addition to the rapidity with which successive strides can be taken, the length of the individual strides determines thespeed. Muscular contraction, therefore, must be greatest in degree as well as most quickly 
accomplished, and the sort of muscles that are capable of such contraction are long, narrow and bandlike compared to the short, thick muscles of power. Instability of equilibrium as well as length of stride are favored in the horse that is long and rangy in order to have length in his

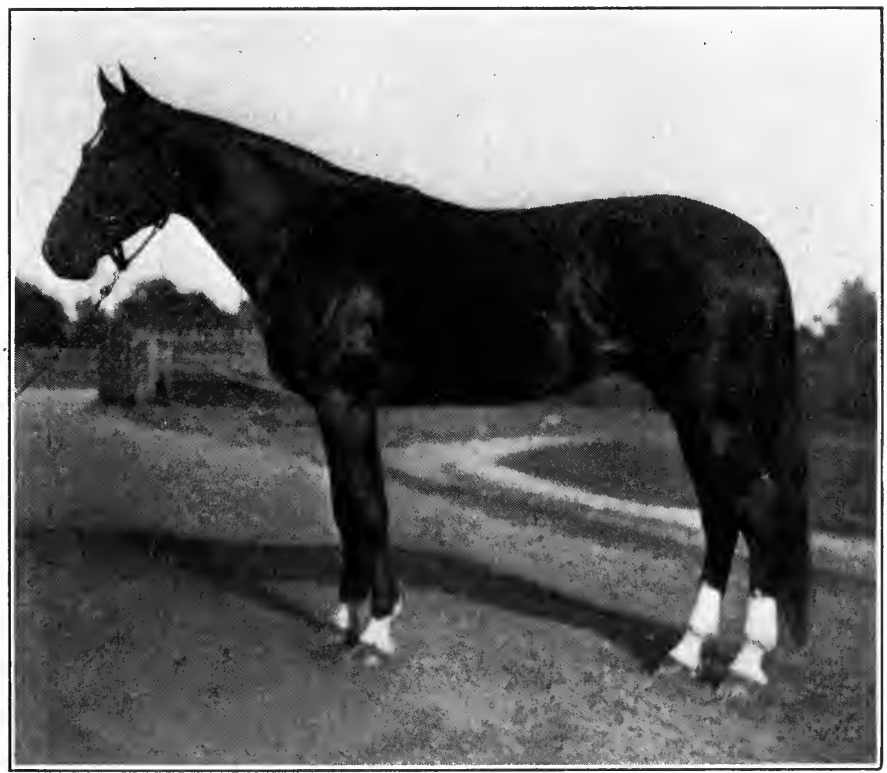

FIG. 51. - The speed horse type.

stride ; lithe as the result of his muscular system consisting of muscles of the speed sort; angular for the same reason, his form not being rounded out by the bulk of his muscles, nor by excess weight in fat; narrow to permit of the greatest directness of shoulder motion, as a narrow base of support is in line with a rapid displacement of the center of 
gravity, and to minimize wind resistance; deep to secure the heart, lung and digestive capacity which his performance necessitates, and yet which cannot be had by width.

134. Conformation of the speed horse. - The special features of speed conformation are enumerated in differentiating trotters, pacers and runners. (Paragraph 137.)

135. Quality in the speed horse.-Quality in the speed type is not only indicative of the structure's capacity to withstand wear and tear, but insures durability with least weight and bulk.

136. Temperament of the speed horse:-A nervous temperament is requisite to speed performance affording the nerve force and courage that is required to control and sustain the performance of which the speed horse is mechanically capable.

137. Way of going of the speed horse.-Horses of the speed type may be either trotters, pacers or runners.

Trotters and pacers, both going two beat gaits in harness, have much in common to distinguish them from runners, which attain speed under saddle at an altogether different gait, yet in some features, trotters and pacers themselves are quite different. As a group they are distinguished from the runner by a greater proportionate length of forearm and lower thigh, a different set to the hind leg, there being a greater tendency to a downward and forward deviation in trotters and pacers and less development of the forehand. Of the two, the pacer has greater length of leg in proportion to the body, a longer, steeper croup and more bent hocks. The runner is characterized by greater development of the forehand, a much straighter hind leg with less proportionate length from the hip joint to the hock, a somewhat thicker stifle and a way of standing easy on his front legs. 
138. The show type (Fig. 52). - So far as speed and power are concerned, show horse requirements are intermediate. It is the manner in which he moves and the

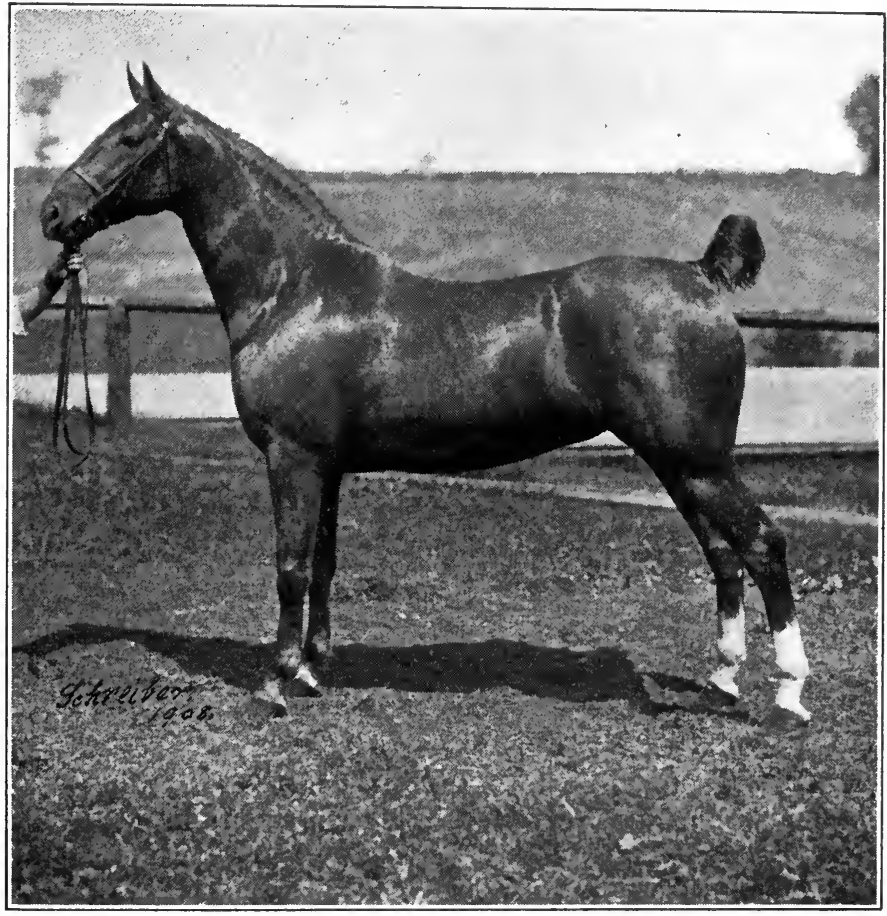

FIG. 52. - The show horse type.

appearance he makes while going rather than the pace or the weight of the load which counts.

These features are best obtained in a horse of a close and full-made form viewed from the side and end, respectively, because such a one possesses the rotundity and smoothness 
that fits heavy harness best and conforms to the lines of the heavy vehicles to which the show horse is put.

139. Conformation of the show horse. - His conformation is distinctive. In no type do good looks count more, and beauty of form involves conformation. Furthermore, certain structural features not only enhance general appearance, but are essential to the kind of performance required of the show horse. The head should be fine, especially about the ears, and so put on such a shapely neck as to permit of extreme flexion at this point, such as takes place when the horse places himself when going. Length, as well as shape of neck is essential to suppleness, the show horse being compelled to bend himself readily in every joint. On account of the full-made form the withers will not be set up to the same extent as in the saddle horse, but a long, sloping shoulder and a comparatively light forehand are requisite to action. In the same way long, sloping pasterns contribute to height and elasticity of stride. A high-set tail is effective in setting off a high stepper's performance, and it can only be had on a long, level, smoothly turned croup.

140. Quality, temperament and way of going of the show type. - Quality in the extreme as an important adjunct to finish and good looks, and a temperament that is proud, bold and stylish in order that his performance may be in line with his physical features and the purpose to which he is put are important.

141. The saddle type. - The saddle horse (Fig. 53) not only has to carry weight of from 135 to 200 pounds or over, but he is required to do it in such a manner as to afford satisfaction to his rider and incur no distress to himself. The various gaits at which the weight is carried serve to differentiate the classes of saddle horses. Ability to support 
weight depends upon a short-span arch, represented in a short, closely coupled back and loin, resting upon strong columns - short, stout legs. To carry the weight, the horse

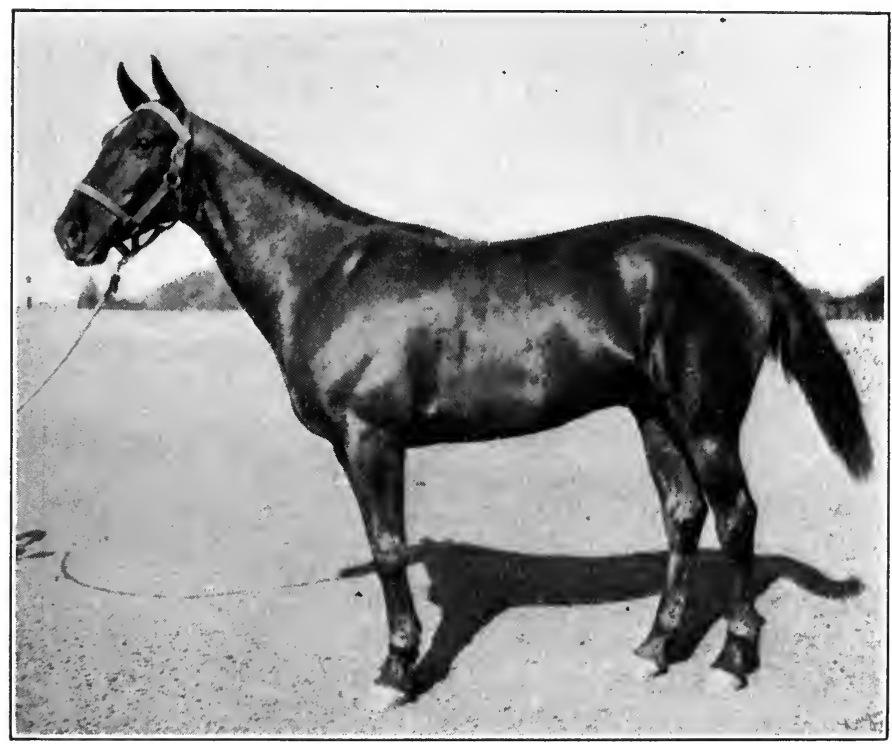

FIG. 53. - The saddle horse type.

is required to move in balance, collecting himself under his load, going well off his hocks and keeping his legs under him as much as possible in order to be supporting the weight at all phases of the stride. The big horse is not necessarily the weight carrier ; unless he is properly set up, his own size may be an encumbrance to him, while. many ponies, by virtue of their distinctly weight-carrying build, are capable of much more than would be expected of them. 
142. Conformation of the saddle horse. - Special conformation requirements of the saddle type are a saddle back, short, straight and strong; a light forehand insuring handiness in carrying weight, a heavily fronted horse not only giving a rough ride but being a blunderer, as a rule; a long, sloping shoulder, longer than in any other type of horse, to give a free, springy stride; and high withers, extending well back, the result of the long, sloping shoulders and serving to keep both saddle and rider from working forward, giving the impression of much horse in front of the rider, forming the narrow front which affords the most secure seat by favoring thigh and knee grip and obviating the difficulty of a wide spread of legs, and preventing the turning of the saddle. Such shoulders and withers are correlated with the long, supple neck so essential in the saddle horse.

143. Quality of the saddle horse. - Quality, combined with substance, is desired in the saddle horse, quality being especially required of the park saddle classes, while substance is necessary for carrying weight. Quality is characteristic of the blood lines in which most saddle horses are bred; substance is therefore most apt to be deficient.

144. Way of going of the saddle horse. - The stride of the saddle horse is distinguished by elasticity, especially, and the safety of the rider demands that he be sure-footed.

145. Intelligence of the saddle horse. - A wellschooled saddle horse should be thoroughly responsive to the hand of the rider on his mouth, the rein on his neck and the heel on his side; he should change gaits, canter on either lead, or in a circle, back and traverse at command, all of which requires a responsive mouth and intelligence of a high order. 
MARKET AND SHOW CLASSES OF HORSES

\begin{tabular}{|c|c|}
\hline I. Work Horse Division & $\begin{array}{ll}\text { A. } & \text { Drafter } \\
\text { B. } & \text { Logger } \\
\text { C. } & \text { Chunk } \\
\text { D. } & \text { Feeder }\end{array}$ \\
\hline II. Heavy Harness Division & $\begin{array}{l}\text { A. Coach Horse } \\
\text { B. Park Horse. } \\
\text { C. Cob }\end{array}$ \\
\hline III. Light Harness Division & $\begin{array}{l}\text { A. Roadster } \\
\text { B. Speed }\left\{\begin{array}{l}\text { Trotter } \\
\text { Pacer }\end{array}\right.\end{array}$ \\
\hline IV. Saddle Division & $\begin{array}{l}\text { A. Race Horse (Runner) } \\
B . \text { Gaited } \\
C . \text { Walk-trot-canter } \\
D . \text { Hunter } \\
\text { E. Combination }\end{array}$ \\
\hline V. Pony Division & $\begin{array}{l}\text { A. Under } 46 \text { inches (Shetland) } \\
B .11-2 \text { to } 14-2 \\
C . \text { Polo Pony }\end{array}$ \\
\hline
\end{tabular}

\section{Work Horse Division}

The work horse division includes drafters, loggers, chunks and expressers.

146. The drafter. - The truest exponent of the power type already described. There is some distinction to be made, however, between the market draft gelding (Fig. 54) and the extreme of the power type. In considering the essential features of power, height is of much less importance than weight and station, but in the selection of draft geldings height is more important. The draft horse market is ruled by buyers who make the appearance of their teams 
on the city streets a feature of their advertising policy, and in establishing the top of the market for draft horses they have more in view than simply horse power. Al-

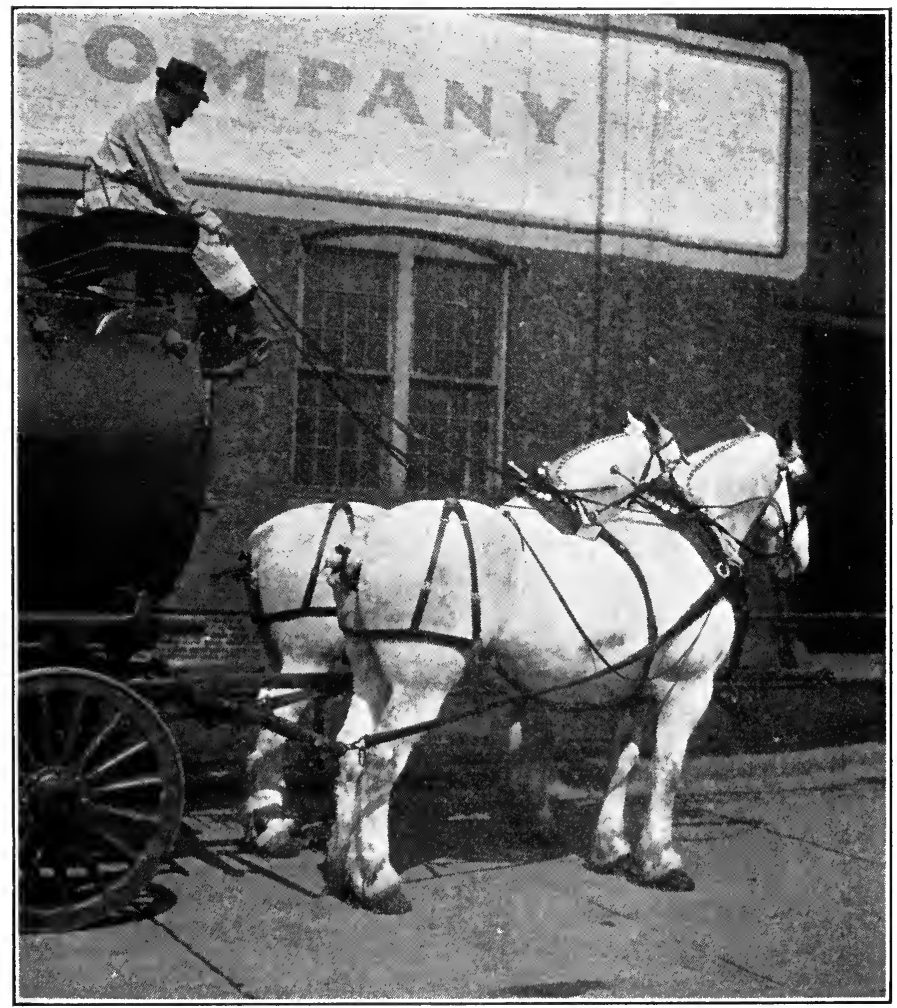

FIG. 54. - A pair of heavy draft geldings.

though somewhat contrary to power, the object of appearance is better served by horses which have more stature than the strict power type permits of. Otherwise, when 


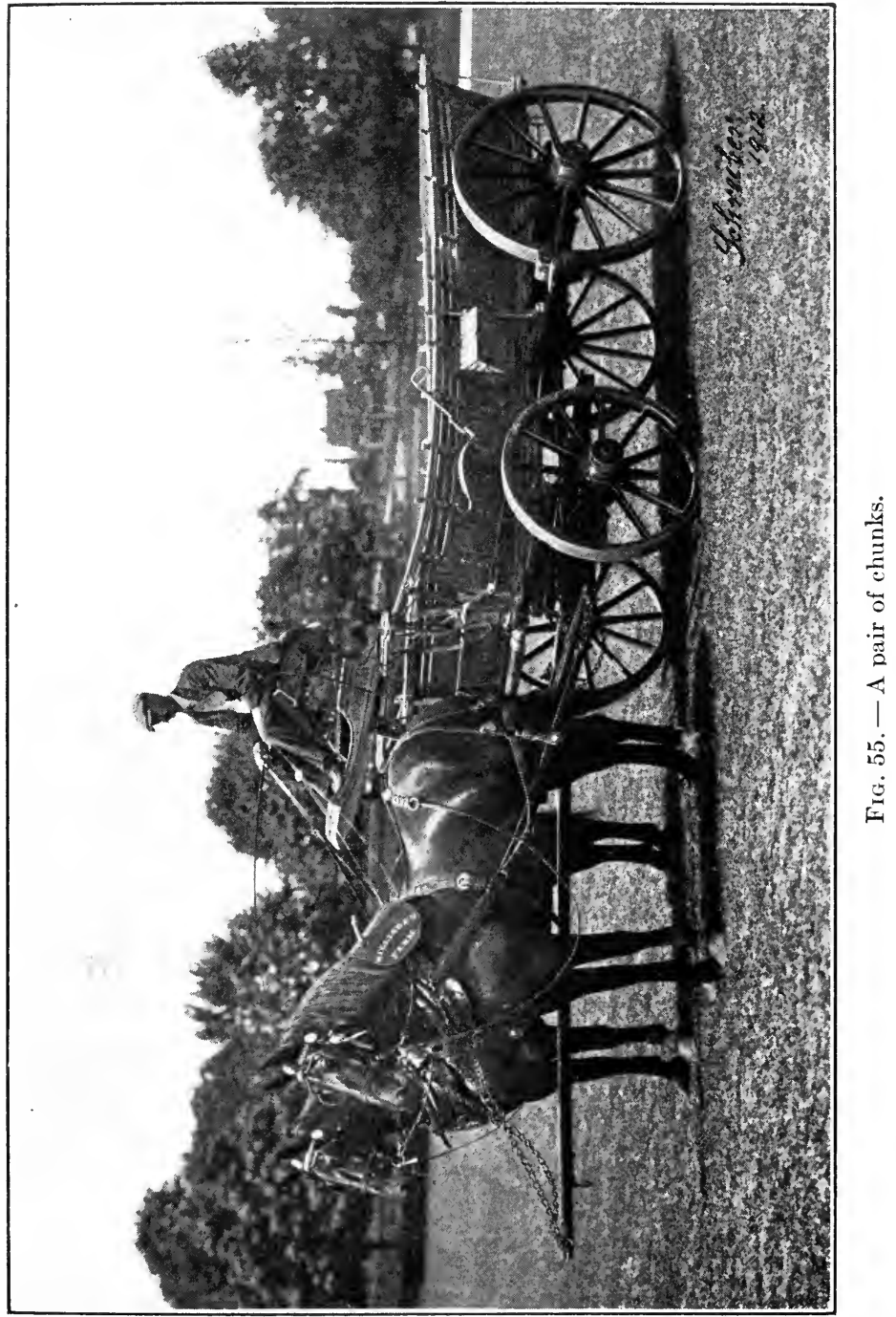


put to the large trucks and vans, the low-down horse will appear squatty, and the effect of the entire equipage will be marred. Drafters are worked singly, in pairs, threes, fours and sixes.

147. The logger. - Briefly, a draft horse minus quality, being coarse, unsymmetrical, low bred or badly enough blemished to be disqualified for the city trade, and taken for service in the woods where power only counts.

148. The chunk. - A drafter minus scale, being the extreme of draft form as indicated by his name, but under weight, usually ranging from 1200 to 1500 pounds (Fig. 55). He is handier for the rough work of farmers and contractors and the more rapid hauling that is required in the delivery service of breweries and such concerns than the typical drafter.

149. The expresser. - A rapid draft horse, capable of

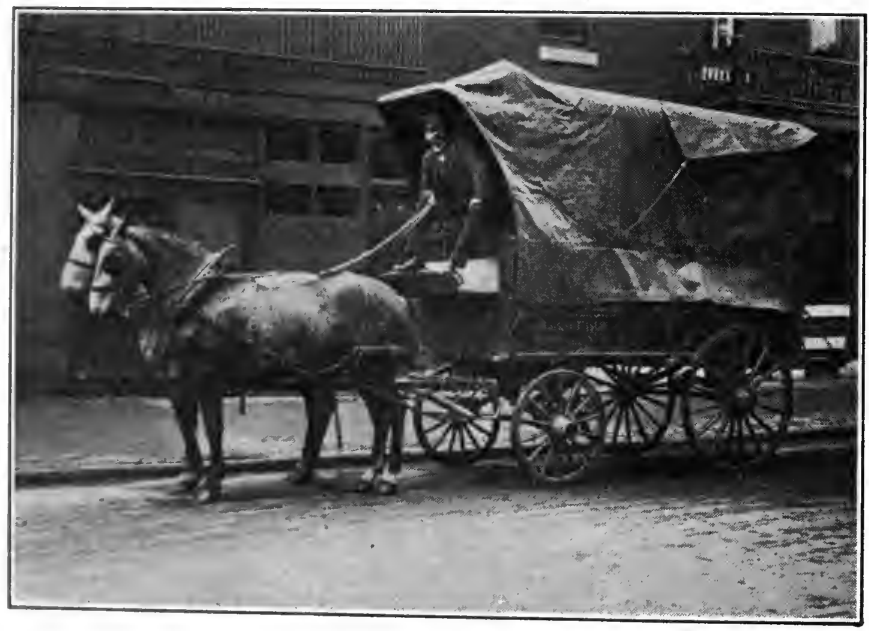

FIG. 56. - A pair of expressers. 
doing his work at the trot. He is on the line between the work horse and the heavy harness horse divisions so far as his makeup is concerned, embracing some of the size and substance of the draft horse with more of the shape and finish of the heavy harness horse (Fig. 56). Expressers vary in weight from 1250 to 1500 pounds and are sometimes subclassified into light and heavy delivery.

150. The feeder. - Any thin horse bought for the purpose of fattening may be properly termed a feeder, but as this practice is limited to horses in the work division, the typical feeder belongs to the draft class or one of its subclasses.

\section{Heavy Harness Division}

These horses conform to the show type and include the coach horse, the park horse, the cob and the runabout horse.

151. The coach horse. - A horse of sufficient size and substance to pull a brougham or road coach (Fig. 57), yet possessing enough quality, style and action to make a good appearance. Twelve hundred pounds weight, sixteen hands height, is standard size. They are required to make a good show while going about an eight-mile pace, and be well enough mannered to go anywhere through city traffic or stand in pose for long waits. Coach horses are put to the brougham, laudau or, as wheelers especially, to the park drag or road coach, singly, in pairs, unicorn (three), four, or five when cock horse is used.

152. The park horse is the most typical representative of the show type. He should be able to go, flashily, a pace of twelve miles an hour with a most extravagant flexion of knees and hocks. Park horses are driven singly, in pairs and fours, put to the gig, the Sayler wagon, demi- 


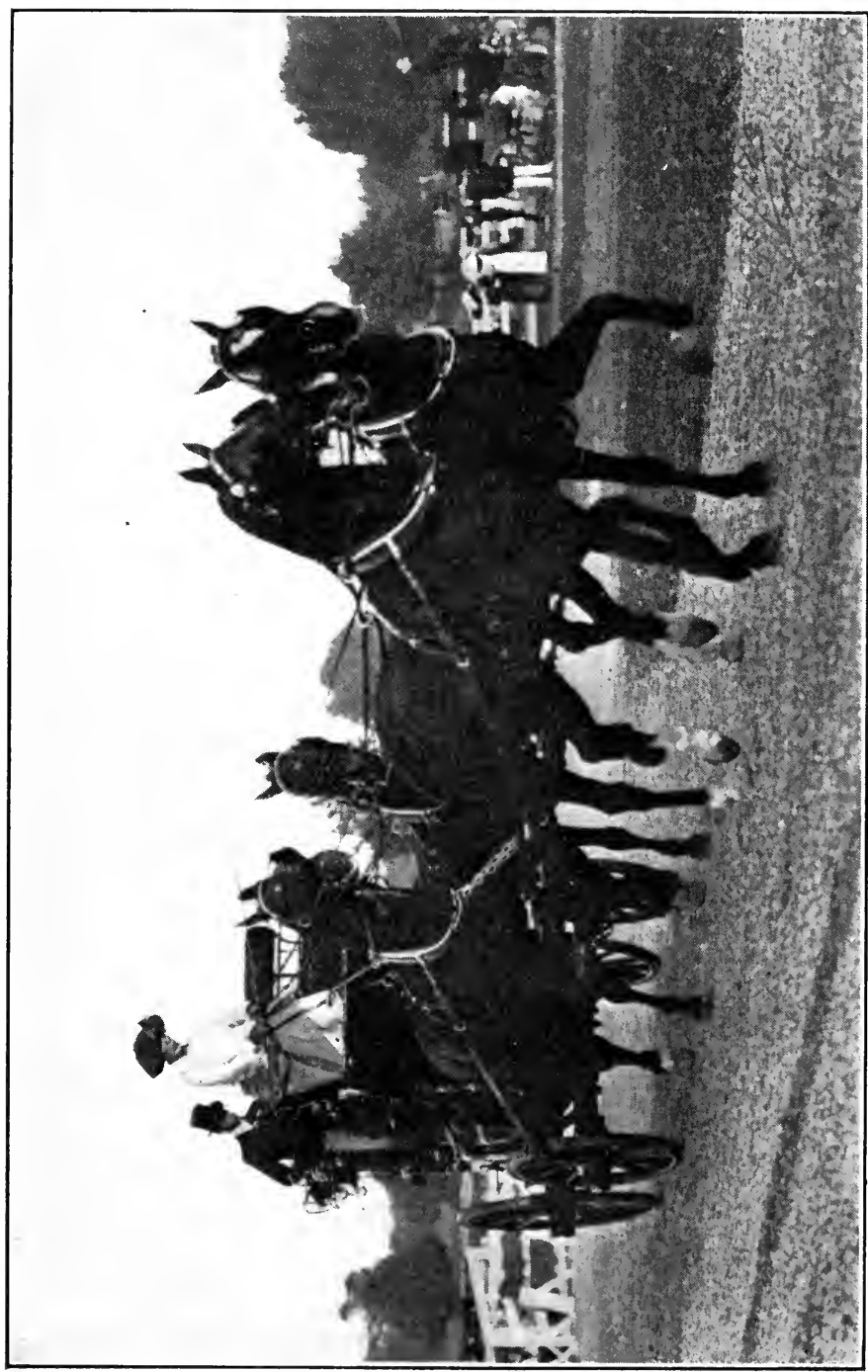

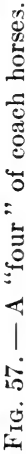




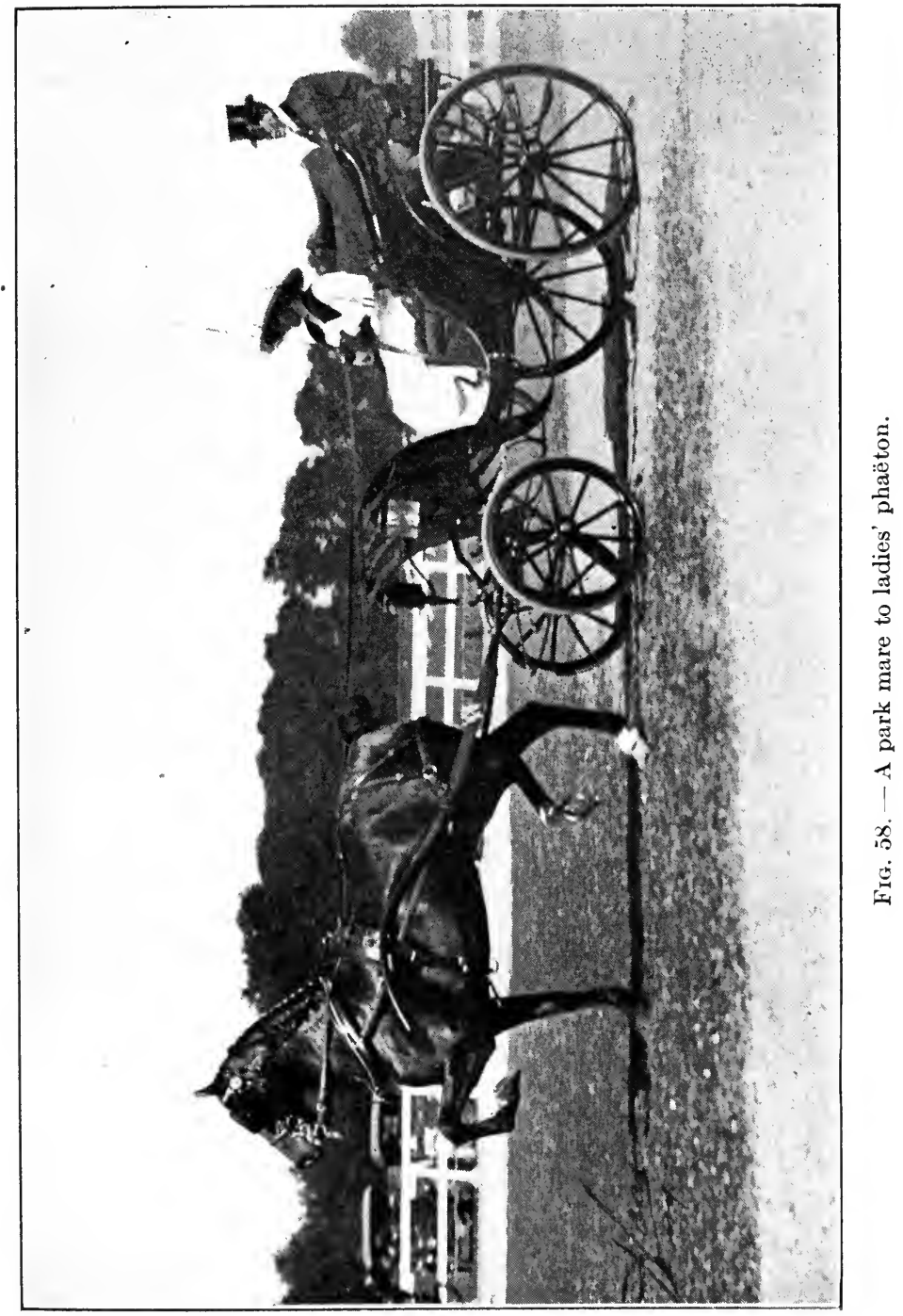


mail, Stanhope, spider or George IV phaëton (Fig. 58), park drag and Victoria, owners to drive, usually, in all but the last instance. They are classified by height.

153. The cob is best described as a big, little, ride or drive, horse. He exemplifies the close, full-made form and high action of the show type, but has unusual bone and muscular development in his comparatively short legs. The typical cob is so extremely close and full made that the term cobby is used to denote such a form. The cob is intermediate between the heavy harness and pony divisions.

154. The runabout horse. - The nature of his service is indicated by the name of the vehicle to which he is put, and handiness is his most essential feature. To this end he should be small, not over 15 hands 1 inch, as a rule, and combine some of the step of the road horse with some of the shape and action of the park horse, although extreme action is not typical of this class. Runabout horses should stand without hitching, back readily, and display the best of manners at all times (Fig. 59). This horse may be considered intermediate between the heavy harness and the light harness divisions.

\section{Light Harness Division}

This division consists of roadsters and speed horses, the latter of which may be either trotters or pacers.

155. The roadster (Fig. 60) typifies the trotter described under the speed type, but is required, in addition, to be of good size and conformation and to have some style, a smooth gait, even though not possessed of extreme speed, and the best of manners. Pacers are not generally recognized in road classes on account of the fact that they pull a wagon unsteadily over any but the best of going, their side motion 


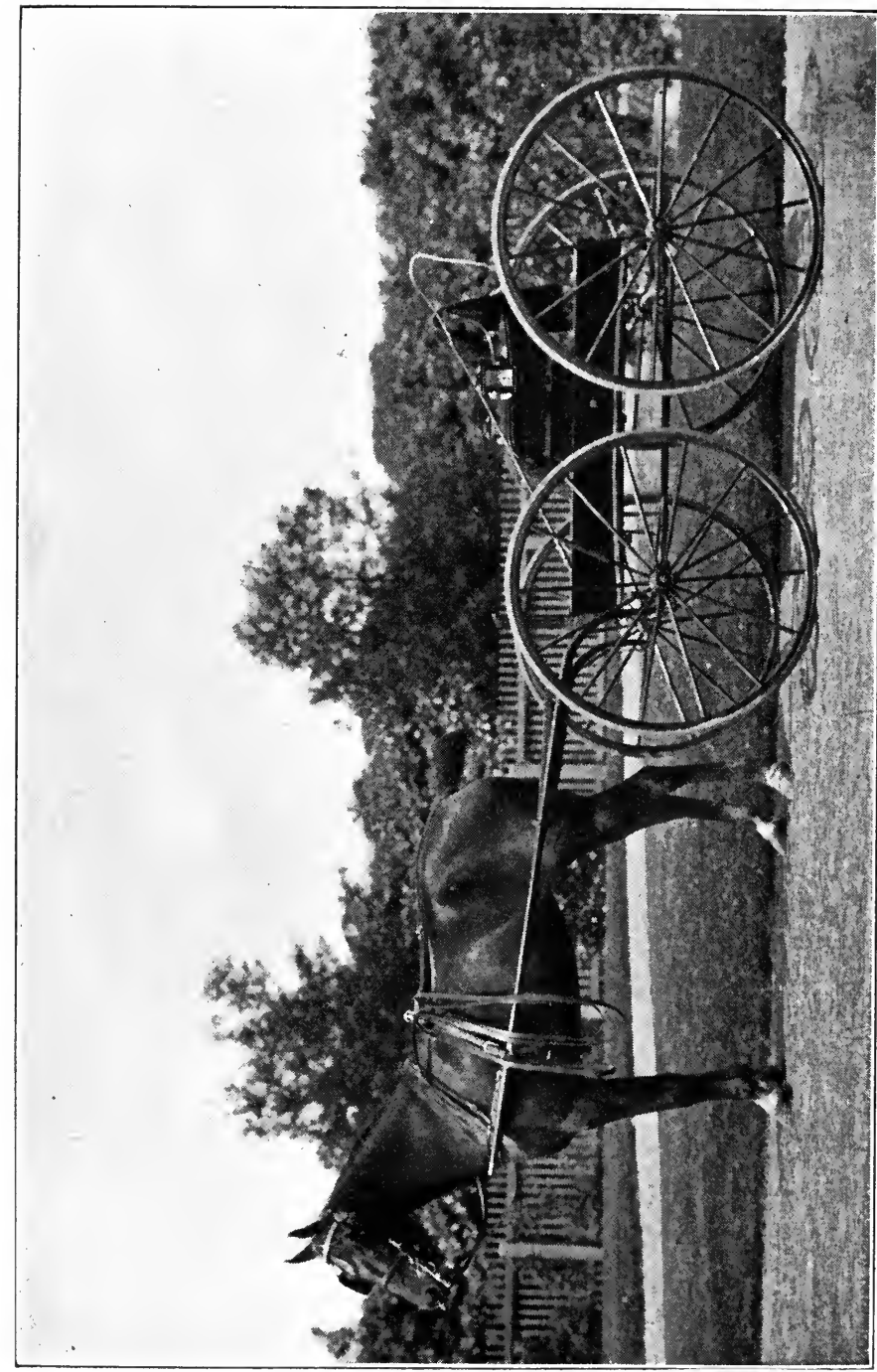

| 


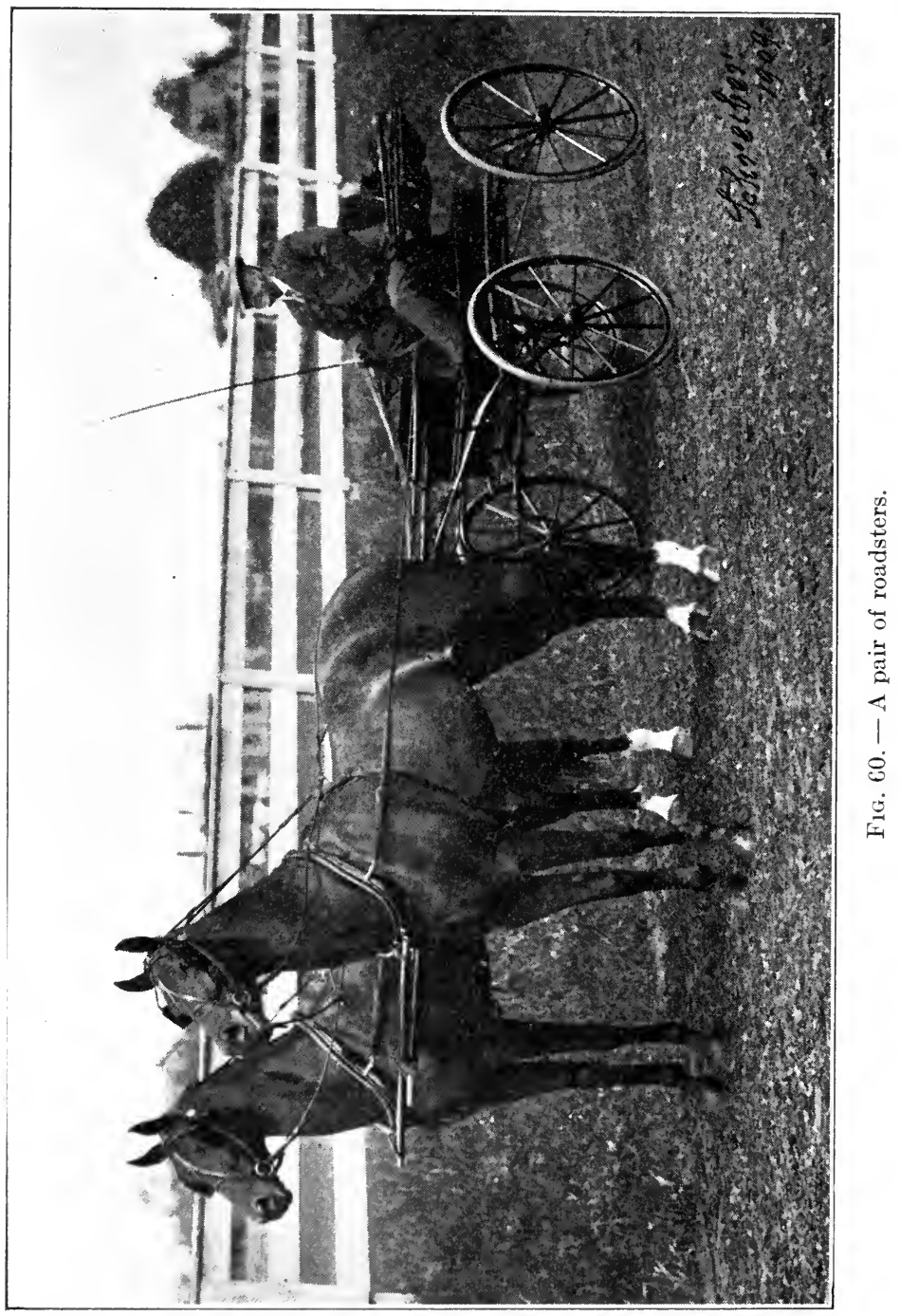


is considered unsightly, and they are too susceptible, in their gait, to the various kinds of footing.

156. The speed horse may be either a trotter or a pacer possessed of sufficient speed, stamina and gameness, to render him a successful race horse. Unfortunately speed performance alone is about all that counts, although the better class of speed horses conform very closely to the road horse just described, possessing extreme speed in addition.

Road horses are hitched singly or in pairs to the American road wagon, while speed horses are hooked to sulkies or speed wagons, depending upon whether or not amateur rules obtain.

\section{Saddle Horse Division}

The saddle horse division embraces the race horse or runner, the gaited saddle horse, the walk-trot-canter saddle horse, the hunter and the combination horse.

157. The race horse is of most extreme speed type, but is used exclusively under saddle. He is a natural galloper, having a wonderful reach and length of jump at the run, but a low, pointing stride at the trot. Running races are conducted on the flat or over the jumps of the steeple-chase course, some horses showing a natural aptitude for the jumps, whereas others cannot even be schooled to take them successfully. Runners are handicapped by the weight which they are required to carry.

158. The gaited saddle horse (Fig. 61). - Since instinct to go certain gaits is hereditary, and only those horses which instinctively go certain gaits can be schooled to a satisfactory performance at them, the majority of gaited saddle horses are Saddle bred, and conform to the description of the Saddle-bred horse given elsewhere. Performance, the 
basis upon which they are classified, requires them to go at least five gaits, i.e. the walk; either the running walk,

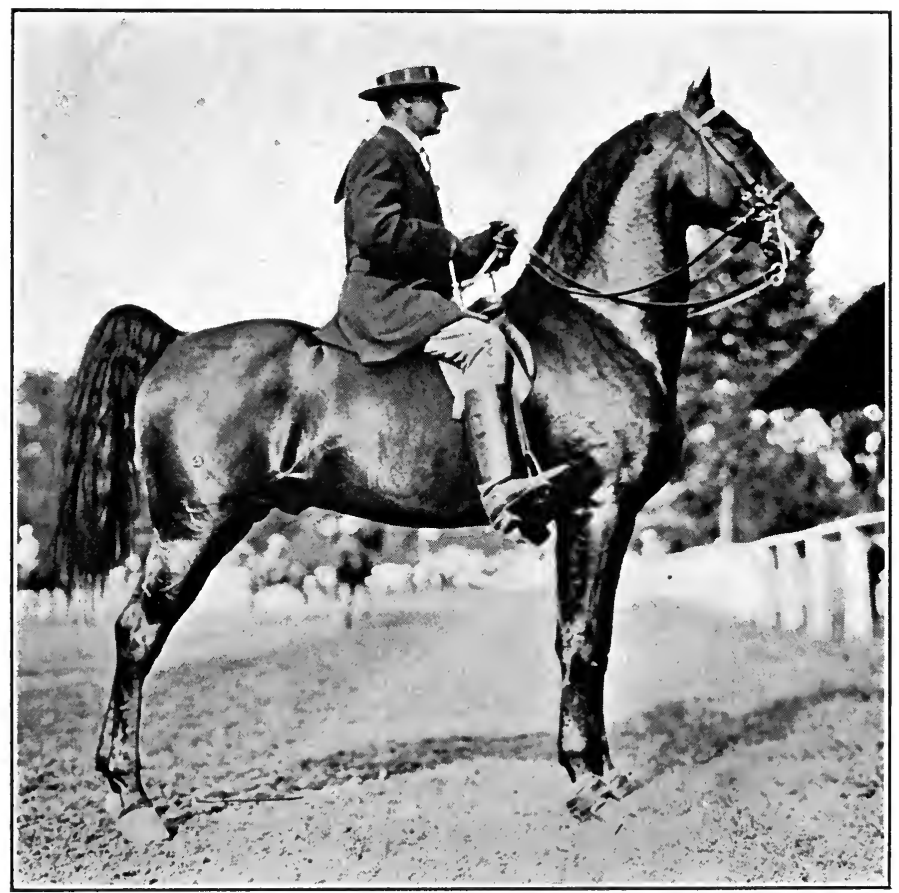

FIG. 61. - A gaited saddle horse.

fox trot or stepping pace; the trot; the rack; and the canter. See pages 99-107. They carry full mane and tail and represent the southern and western idea of a saddle horse.

159. The walk-trot-canter saddle horse. - This class may be subdivided into the American or Saddle bred and the English or Thoroughbred saddle types (Fig. 62). The 
former is distinguished from the gaited saddle horse only by the fact that he either has not been schooled or is not permitted to go more than the three gaits and is usually

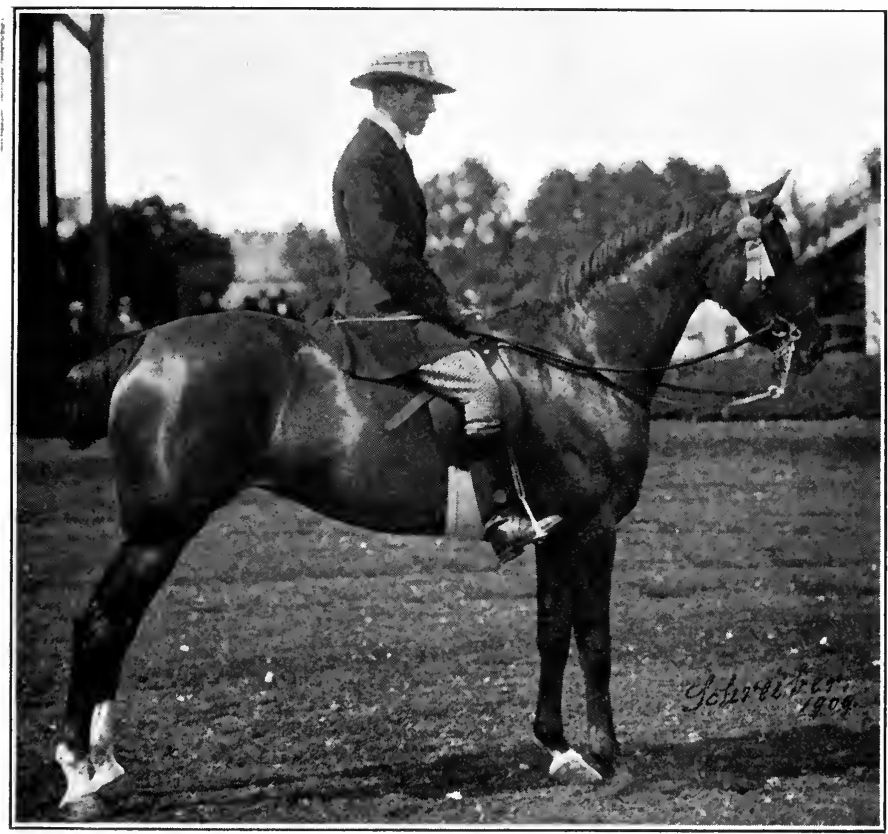

Fig. 62. - A walk-trot-canter mare.

docked and has his mane pulled. The Thoroughbred type (Fig. 63), representing the English idea, is a well-shaped, good-headed Thoroughbred that is not characterized by the usual pointy trot, but can trot in the collected, springy, weight carrying way that is required of the saddle horse. They are usually undocked but have their manes hogged. 


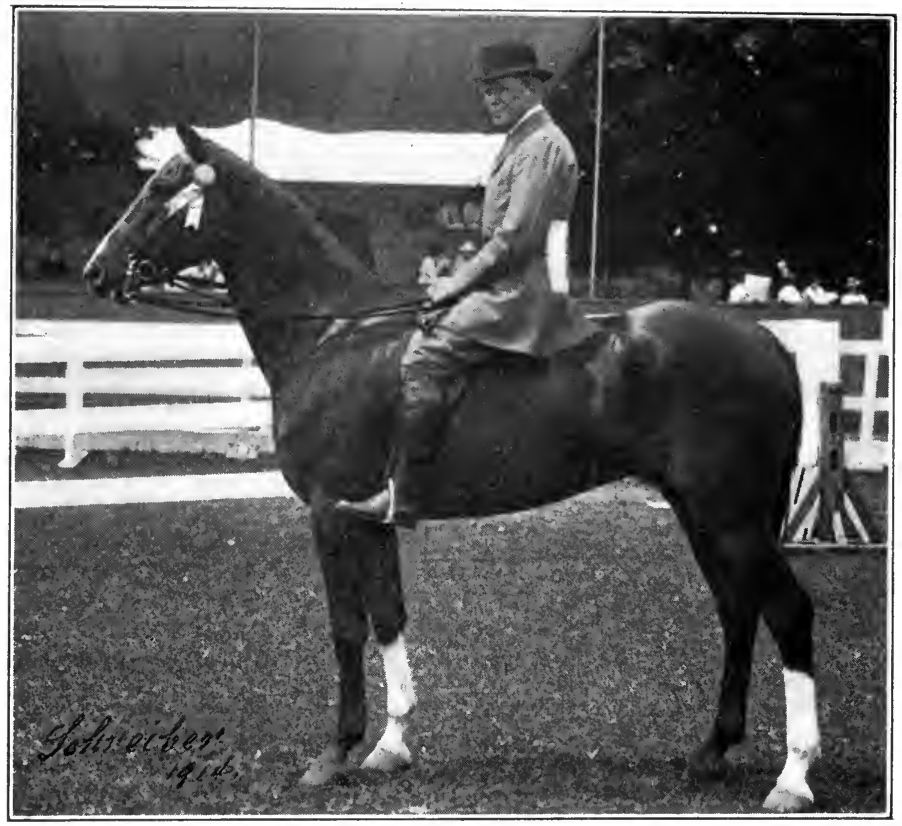

FIG. 63. - The Thoroughbred type of walk-trot-canter saddle horse.

160. The hunter. - This horse is required to carry weight cross country after fox hounds, which necessitates his jumping safely any obstacle likely to be encountered in a cross-country run, having stamina sufficient to stay with the pack as long as they run and to be able to gallop fast enough to follow the hounds. He must have a good head to keep a steady hunting clip and be at all times under the complete control of his rider. The hunter is a weight carrying saddle horse in the extreme sense of the term, having strong, well-developed shoulders and withers, muscular quarters and ample bone. Size 
is sought as being conducive to safety; the regulation fence is lower for a sixteen-hand horse than for one of only fifteen hands' height; furthermore, in case the horse blunders, the momentum of his weight will. allow him to break through the obstacle, whereas the lighter horse

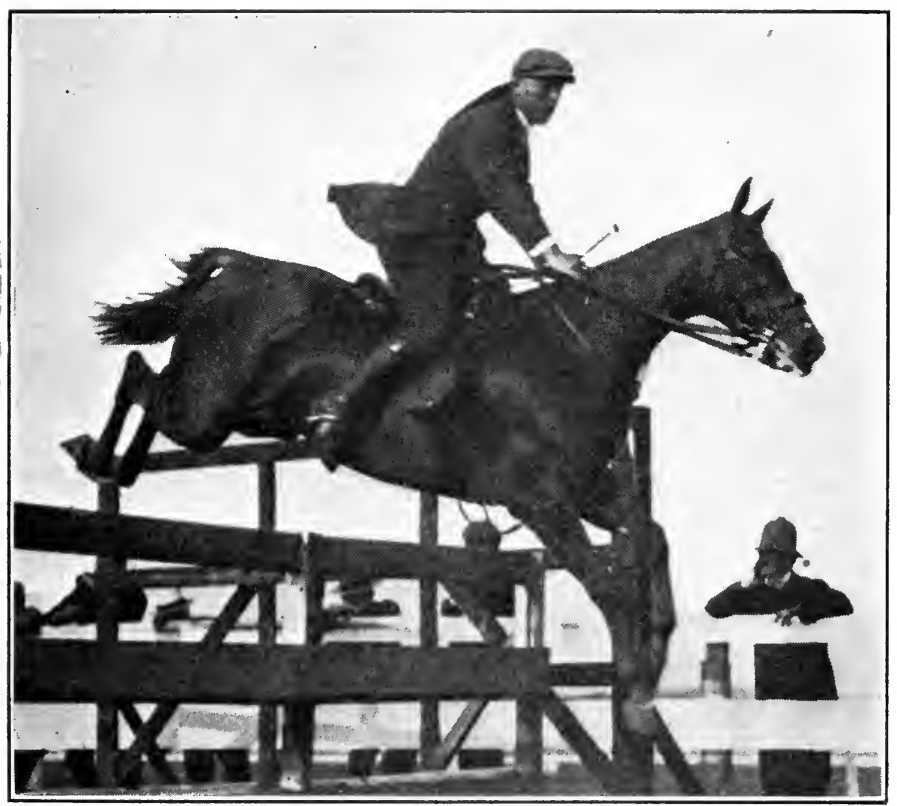

Fig. 64. - A light weight hunter.

would probably trip and come down. Then, other things being equal, the bigger horse is up to more weight, and many people who ride to hounds are following the sport to keep down avoirdupois. Hunters are classified on the basis of weight to which they are up, as light weight (Fig. 64), 135 to 165 pounds, middle weight, 165 pounds to 
190 pounds, and heavy weight (Fig. 65), 190 pounds or over. They are also classified as qualified or green, depending upon whether or not they have hunted one season with a pack recognized by the United Hunts and Steeple Chase Association.

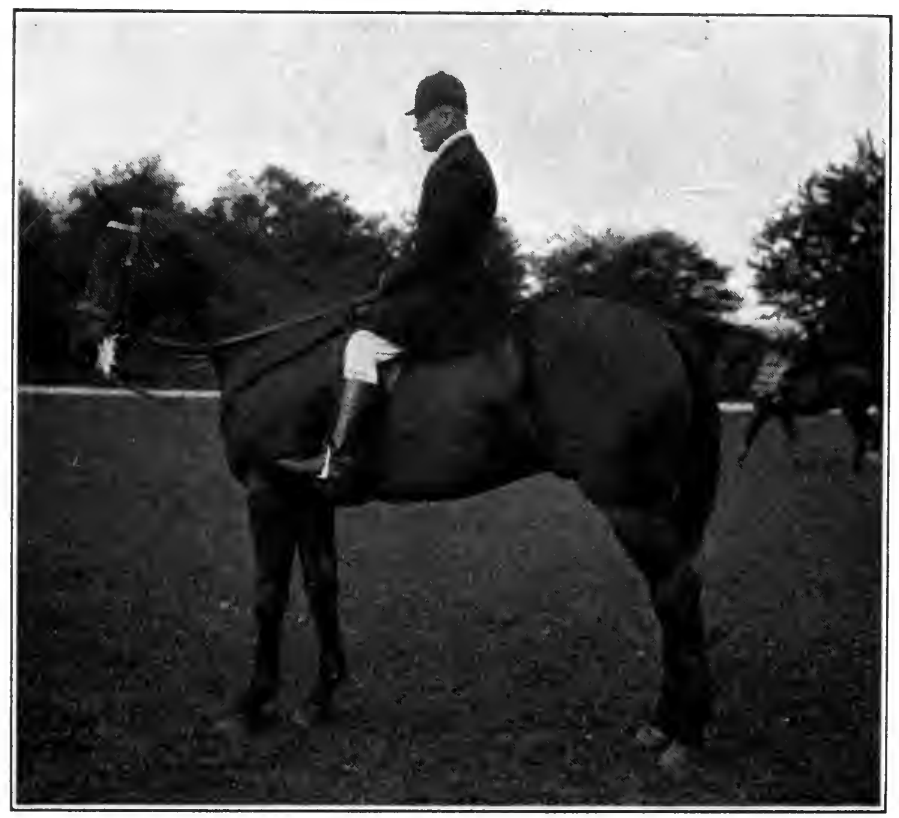

Fig. 65. - A heavy weight hunter.

161. The combination horse. - Nearly all saddle horses are broken to go in harness and many harness horses may be ridden, but in either case they do much better at the one performance or the other. There is, however, a horse of which equally satisfactory performance is expected, whether under saddle or in harness, and 
he is therefore termed a ride-and-drive or combination horse. Although it is customary, for convenience' sake, to show combination horses in harness first, he is more typically a saddle horse going well in harness than a harness horse that is capable of giving a good ride. The combination horse is distinguished from the saddle horse proper by being of a somewhat more harnessy form with more speed at the trot. Under saddle he may go either three or five gaits, the former usually being shown in heavy harness and the latter in light harness.

Classes for "model" horses and for "fine" harness horses are in the catalogs of most southern shows. They both favor the Saddle-bred horse.

162. The model horse. - These horses are judged on conformation and quality only, performance not being considered, and classes for them constitute a most effective means of promoting uniformity of type and individual excellence.

163. The fine harness horses are, in a sense, model horses in harness, the ideal being a horse of extreme refinement and superior conformation, having neither speed nor great action but going, most attractively, a ten or twelve mile pace.

\section{Pony Division}

There is an increasing tendency, so far as the shows are concerned, to disregard any common pony type, but to differentiate between ponies on their conformity to either harness or saddle standards, the same as is done in horse classes. In a general way any equine under fourteen hands two inches is a pony, but it is not so at the shows.

The classifications usually call for ponies under 46 inches, entries being usually, but not necessarily, of Shetland 
breeding and type (Figs. 66 and 67); ponies eleven hands two inches and not exceeding fourteen hands two inches, this class being frequently subdivided at thirteen hands

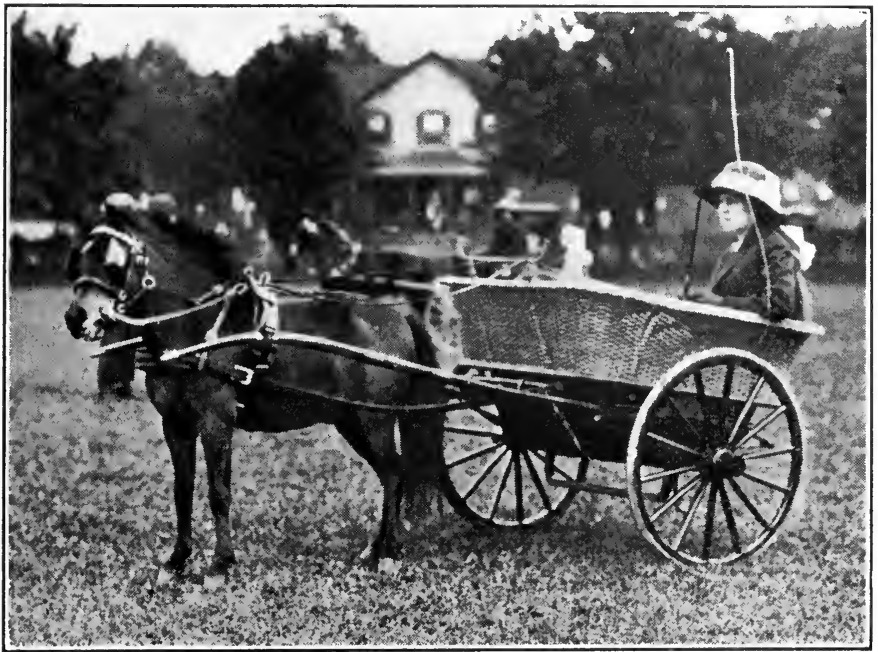

FIG. 66. - A 42 inch harness pony.

(Figs. 68 and 69); and polo ponies (Fig. 70). There are both harness and saddle classes for ponies of each of the first two specifications, and the same ponies may show, and even win, in both, but the line is being more sharply drawn between the harness and the saddle pony types. The heavy harness standard is adhered to in judging harness ponies, while in saddle classes both miniature walk-trot-canter and hunter types are considered.

164. Ponies not exceeding forty-six inches. - These are children's ponies in every sense of the word, dis- 
position and manners being absolutely essential to qualification for this class. That is one reason why Shetlands predominate.

165. Ponies eleven hands two inches, and not exceeding fourteen hands two inches. Ponies of this class are regarded as little horses best adapted to the use of youths

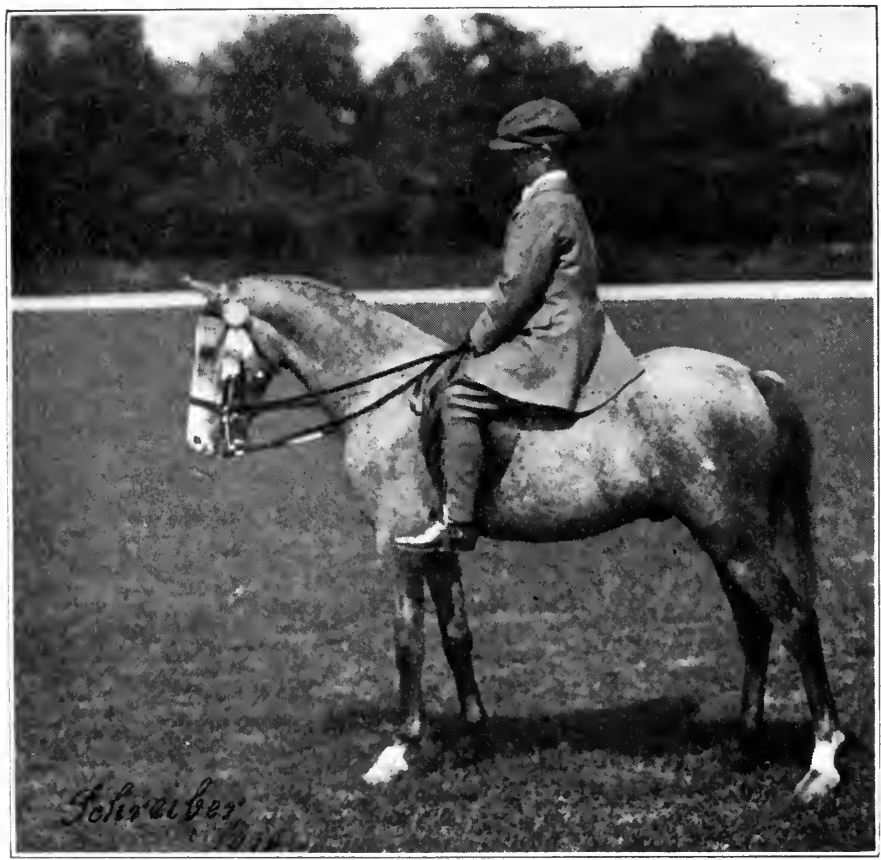

FIG. 67. - An $11 \frac{1}{2}$ hand saddle pony.

and misses who may have graduated from their Shetlands. They are either miniature heavy harness or saddle horses, as noted above. 


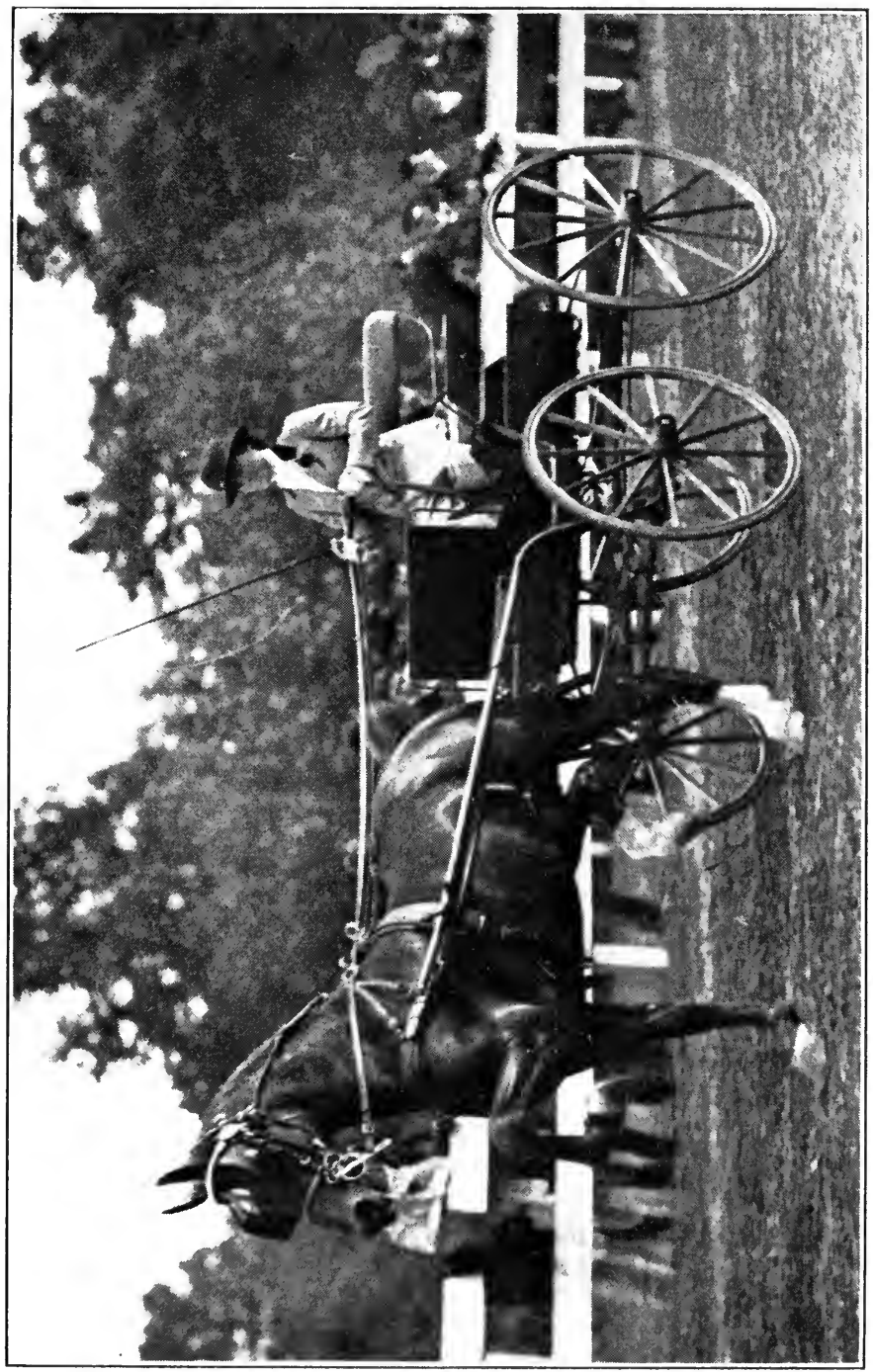

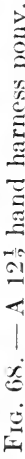


166. Polo ponies. - The polo pony usually stands close to the fourteen hands two inch standard, is of race horse or hunter type, up to weight, handy, fast and clever in order that he may fully qualify for the intricate performance incident to the game.

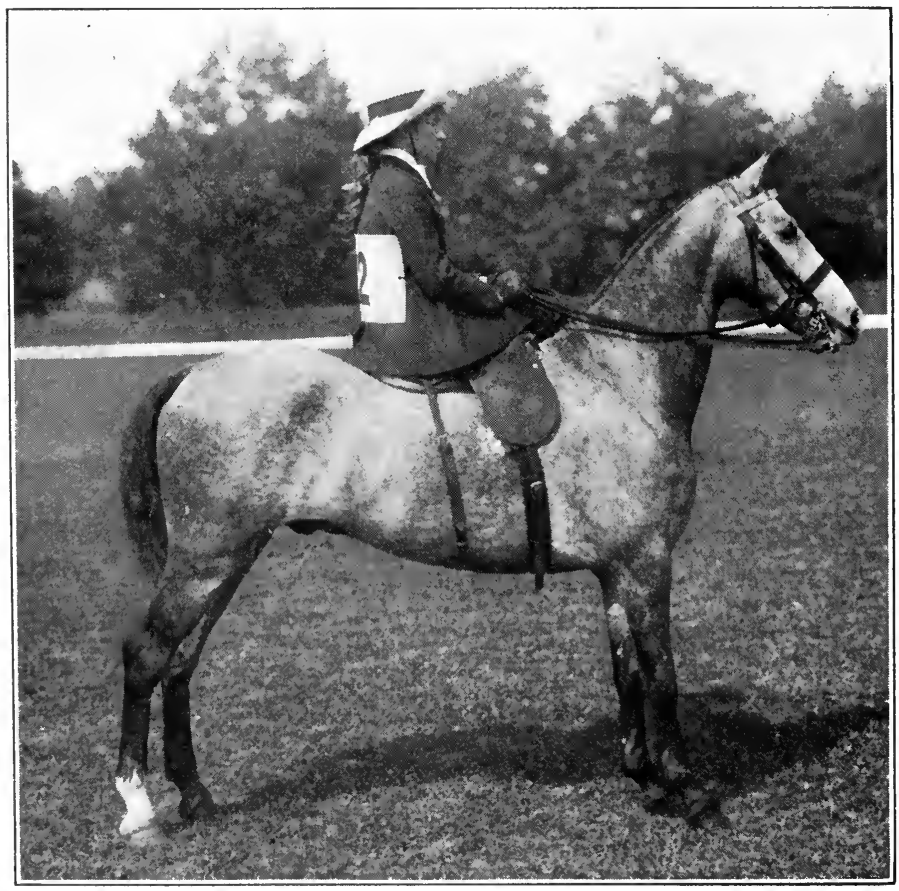

FIG. 69.-A 13 hand saddle pony. 


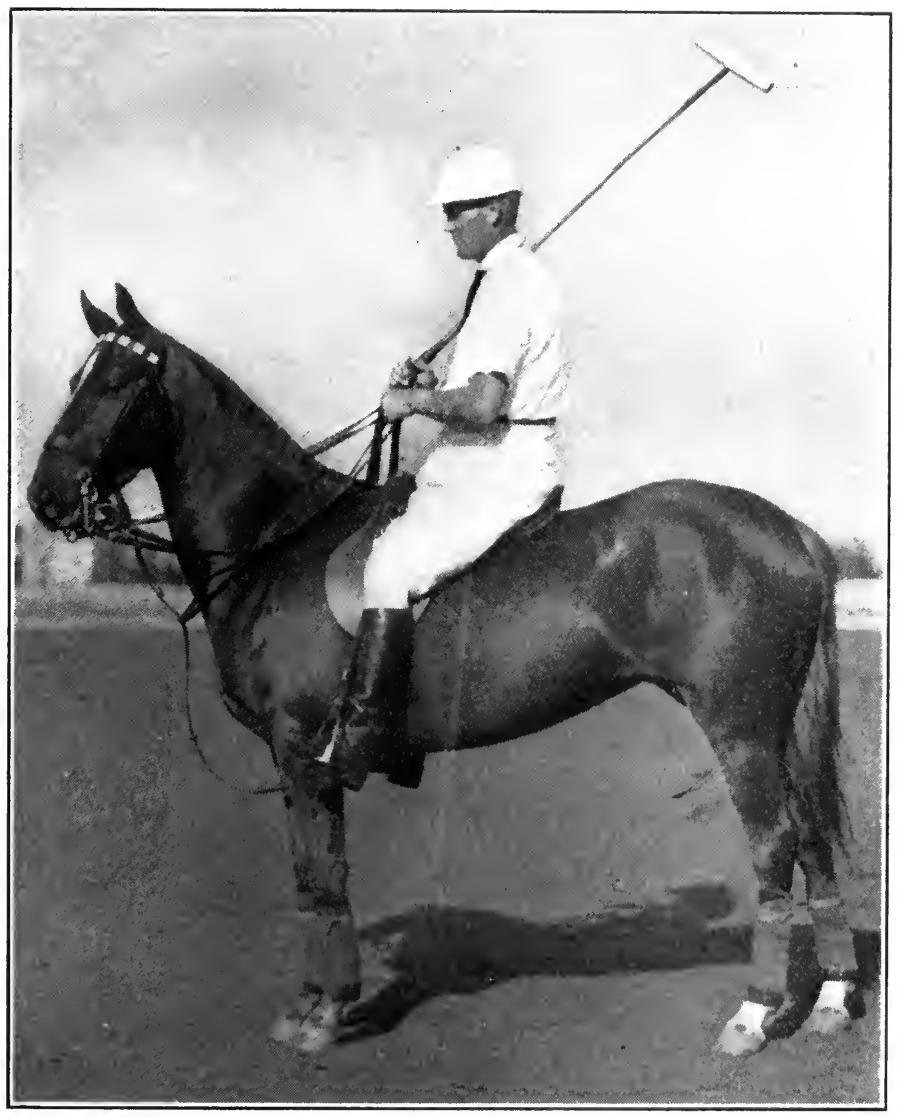

FIg. 70. - A polo pony. 


\section{('HAP'TER IX}

\section{THE BREEDS OF HORSES}

THE breeds of horses may be classified, according to the market classes, to the types of which their representations conform, as follows :

Draft $\left\{\begin{array}{l}\text { Percheron } \\ \text { Belgian } \\ \text { Clydesdale } \\ \text { Shire } \\ \text { Suffolk }\end{array}\right.$ Heavy Harness $\left\{\begin{array}{l}\text { Hackney } \\ \text { French Coach } \\ \text { German Coach }\end{array}\right.$

Light Harness - American Standardbred

Saddle $\left\{\begin{array}{l}\text { Thoroughbred } \\ \text { American Saddle Horse }\end{array}\right.$

Pony $\left\{\begin{array}{l}\text { Shetland } \\ \text { Welsh } \\ \text { Hackney }\end{array}\right.$

167. The Percheron. - The typical Percheron (Fig. 71) is distinguished from the representatives of the other draft breeds by characters which can be attributed, primarily, to the hot blood in the breed's foundation and to the fact that these horses were originally bred for rapid draft service. Percherons do not possess the scale and substance of the Shire, the extremely drafty form of the Belgian, the broad, flat, straight hocks, sloping pasterns and accurate way of going of the Clydesdale, nor the usual good rib and the uniform coloring of the Suffolk. They 
average of medium draft weight, stand over considerable ground for a draft horse, have a somewhat toppy general appearance, and a form that has been most appropriately described as of "a flowing, rounded contour indicative of

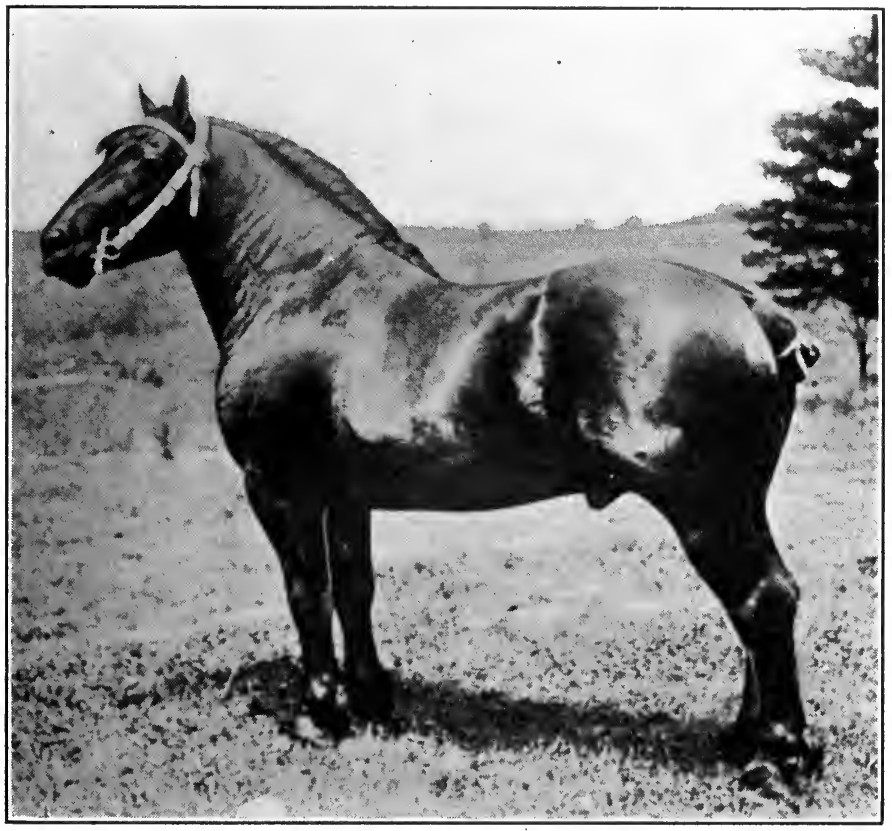

Fig. 71. - A Percheron stallion.

promptitude of movement as well as strength" 1 instead of square and blocky. They possess more general refinement, a better proportioned and more breedy head, and better texture of blue hoof than horses of any other draft breed. They also reflect their Oriental ancestry in an 1 Johnstone's "The Horse Book." 
active, somewhat nervous temperament and go with unusual snap and dash. Gray is the most typical color, though blacks have been most common, and bays, browns and chestnuts occur but are not favored.

In brief the Percheron is a rapid draft horse of a cold and hot blood origin which has had his weight brought up to

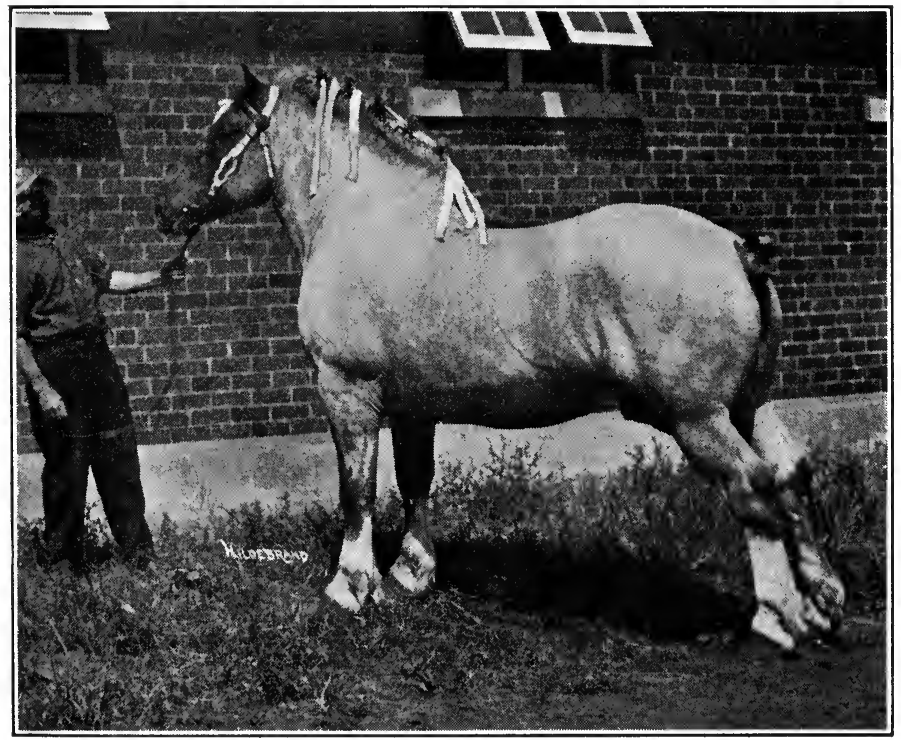

FIG. 72. - A Belgian stallion.

modern draft requirements by his breeders resorting to stronger infusions of cold blood, but selecting to retain the activity and refinement of the original to as great an extent as the law of correlation would permit of.

168. The Belgian. - The Belgian (Fig. 72) is the most uniformly low down and wide out of any of the draft breeds 
and is surpassed in weight only by the Shire. He is extremely compactly put together with square, massive ends and a short, wide and deep middle, characters with which there are too frequently correlated a short, thick, heavycrested neck and short, straight, stubby pasterns. The head is of medium length, broad and deep and strong in

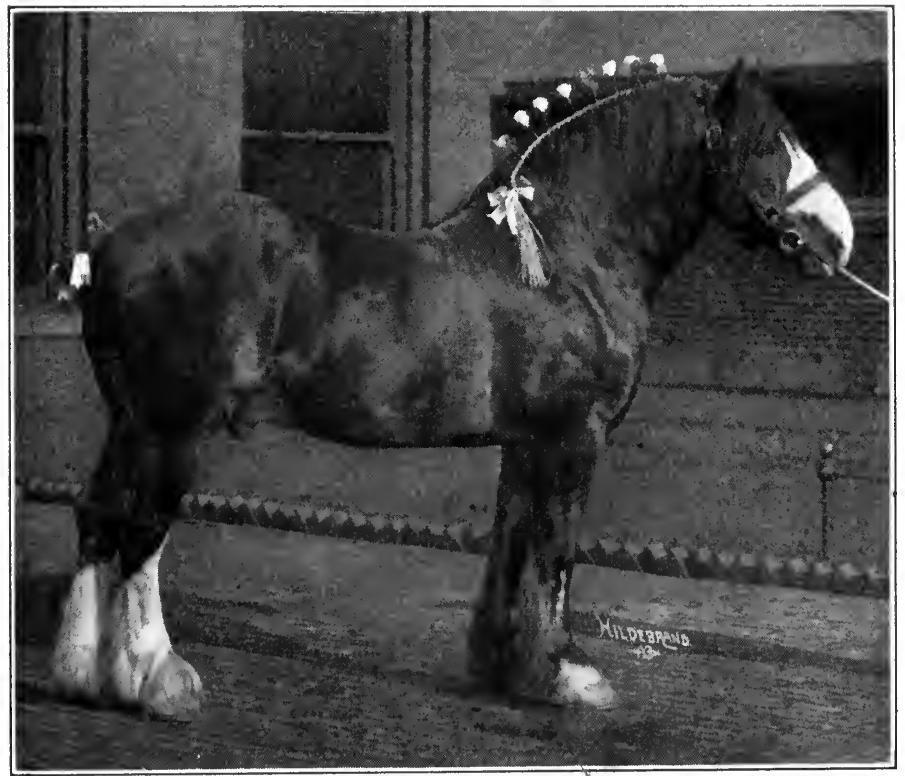

FIG. 73. - A Clydesdale stallion.

the jowl, eyes not sufficiently large or prominent and ears set too low sometimes. His short legs are heavily muscled in the forearm and the gaskin, although the bone is often not of the best quality nor the feet as large and round as the size of the horse requires. Belgians, while essentially cold in their make-up are good movers, es- 
pecially at the trot. Roan, chestnut, bay and brown are the prevailing colors, although black and gray occur.

169. The Clydesdale. - The Clydesdale (Fig. 73) is distinguished by a mechanical perfection in locomotory apparatus which is not generally equaled by representa-

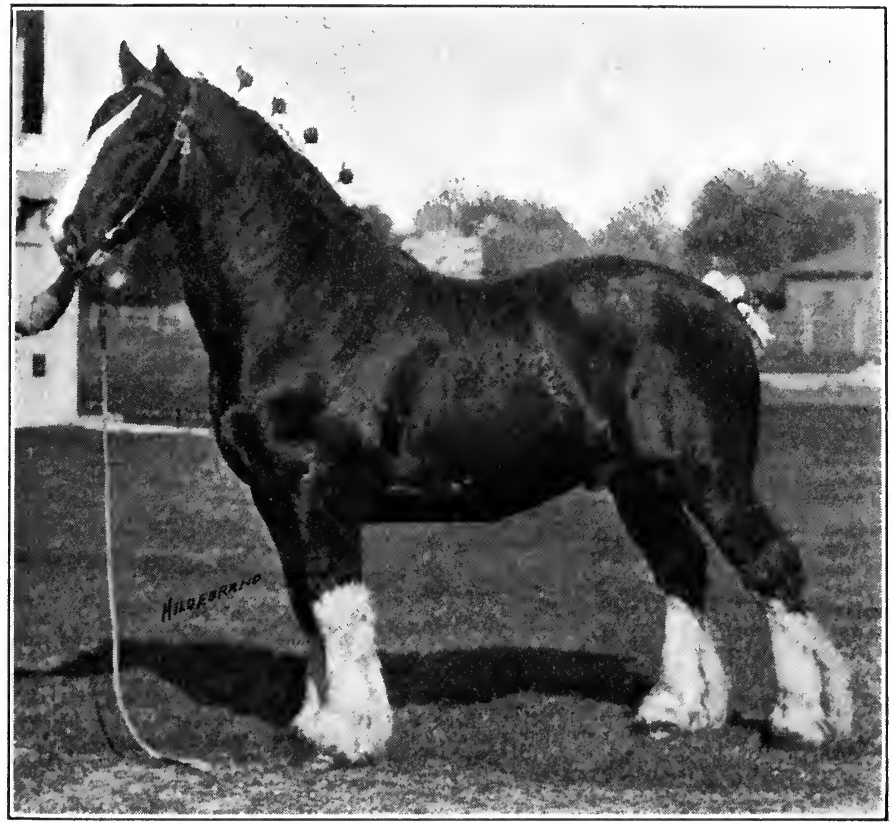

FIg. 74. - A Shire stallion.

tives of other draft breeds. The set of the legs, the slope of the pasterns, the quality of the bone, combined, as it is, with ample substance, and the straight, free, springy, yet powerful stride are most characteristic of this breed. However, such a stride is impossible in a horse of 
extreme draft form, consequently the typical Clydesdale is a more upstanding and correspondingly longer, narrower and shallower bodied individual than the representatives of the other draft breeds. This is comparatively speaking, however, as the Clydesdale is in every respect a draft horse, and his stamp has some things to commend it over the other extreme, which is the only type recognized by some draft horse judges. The Clydesdale has length of neck and slope of shoulders which fit a collar admirably, and which with their long, level croup constitute two ends of a very good top line, provided the back is not too low, as is sometimes the case. Clydesdale colors are bay and brown most commonly with a profusion of white markings; black and gray are not rare.

170. The Shire (Fig. 74). - Bulk and bone are the two features which characterize the Shire most. They are the result of selection to the Englishman's ideal of a draft horse, backed up by an environment in Lincolnshire and Cambridgeshire, England, where they were bred, which is most conducive to just such a structure as the breeders strive to attain. His great scale and substance, with his form, are most impressive of draftiness. Yet with all there is a grossness that is suggestive of a low grade of material in his construction. The head is large, especially long, with the face line inclined to be Roman, and the countenance expressing a sluggish temperament. The hair coat is luxuriant, the mane and tail being especially heavy and feather abundant with oftentimes vestiges of the mustache and tufts at knees and the points of the hocks by which the old Flanders horse was characterized. There is a wide range of colors in the Shire, bay, brown, and black being most common, gray and chestnut not unusual and roans occasional, all considerably marked 
with white. The way of going of a Shire is that of a great horse. He moves slowly, almost ponderously, with a lack of freedom in his stride, but there is power in the movement. Straight shoulders and pasterns, flat, shelly

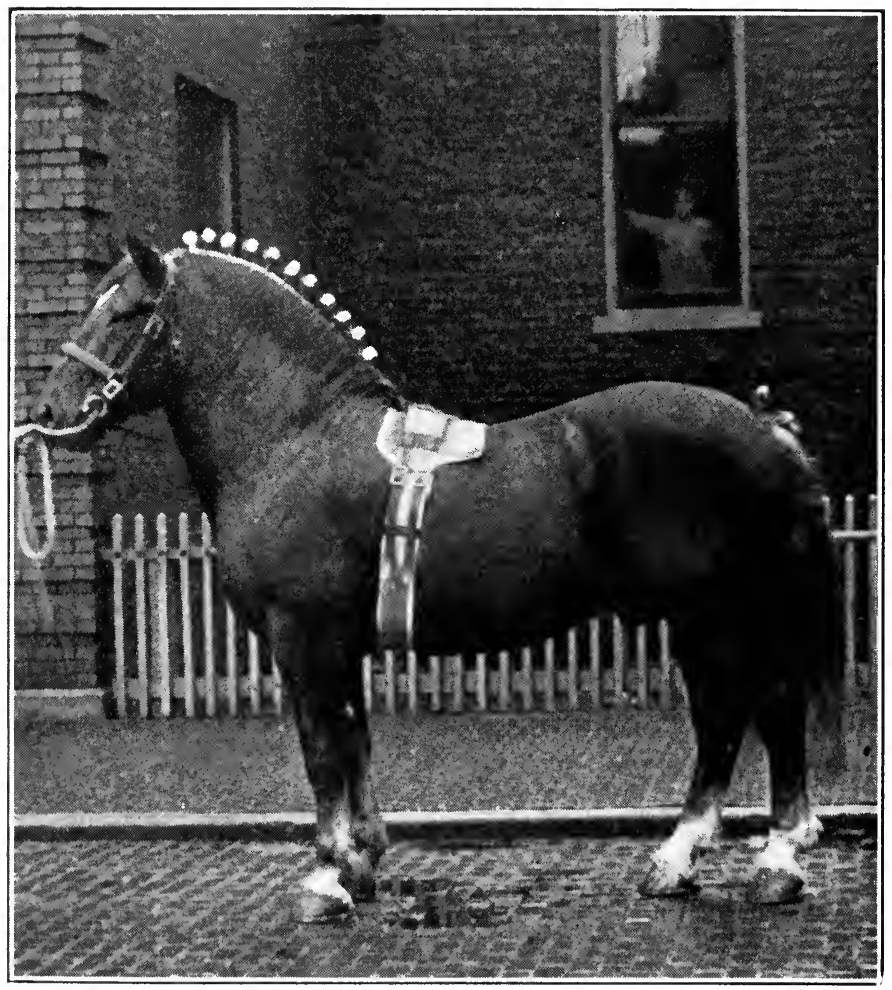

FIG. 75. - A Suffolk stallion.

feet, a sluggish temperament, and a stilty stride are features which Shire breeders seek to improve.

171. The Suffolk. - Having been developed chiefly 
within the confines of one county, descending exclusively from an individual foundation sire, and having been bred primarily for agricultural purposes, this breed is of exceptionally uniform type (Fig. 75). The most striking features are the invariable chestnut color and the "punch" form, i.e. a low set, full, round, compact, massive body. They have fairly fine, intelligent heads, rather full crested necks, corresponding to their ample bodies, and clean legs, devoid of feather. All shades of chestnut are encountered; flaxen manes and tails are not unusual but white markings are.

Suffolks, while they never have been regarded as a heavy draft breed, are quite frequently not up to draft weight. The punch bodies and clean legs are sometimes overdone, giving the effect of too fine bone under a large superstructure.

172. The Hackney. - The antecedents of modern Hackneys were a race of stoutly made trotters possessed of the stamina requisite to the performance of seventeen miles per hour, and they were up to any weight. They represented a Thoroughbred top cross on a common base, the trotting proclivities, in this instance, being alleged to come from the Friesland trotter blood in the dams. This stock was later made the basis of selection to harness requirements, and so faithfully were selections made and requirements met that the Hackney is to-day the heavy harness horse par excellence. The typical representative (Fig. 76) was formerly a low set horse, very close and full made, and therefore weighing more than his height would indicate. Greater favor is now expressed for a more upstanding, finer individual. However, Hackneys rarely exceed $15-3$ in height. The form is harnessy in the extreme, being especially rotund, the head 
well proportioned, with a straight face line, a deep jowl, a neck of fair length and well crested, an especially round rib, smooth level croup, full muscular quarters and ample bone. Chestnut color with white markings all around is the rule, although bays and browns are common. The

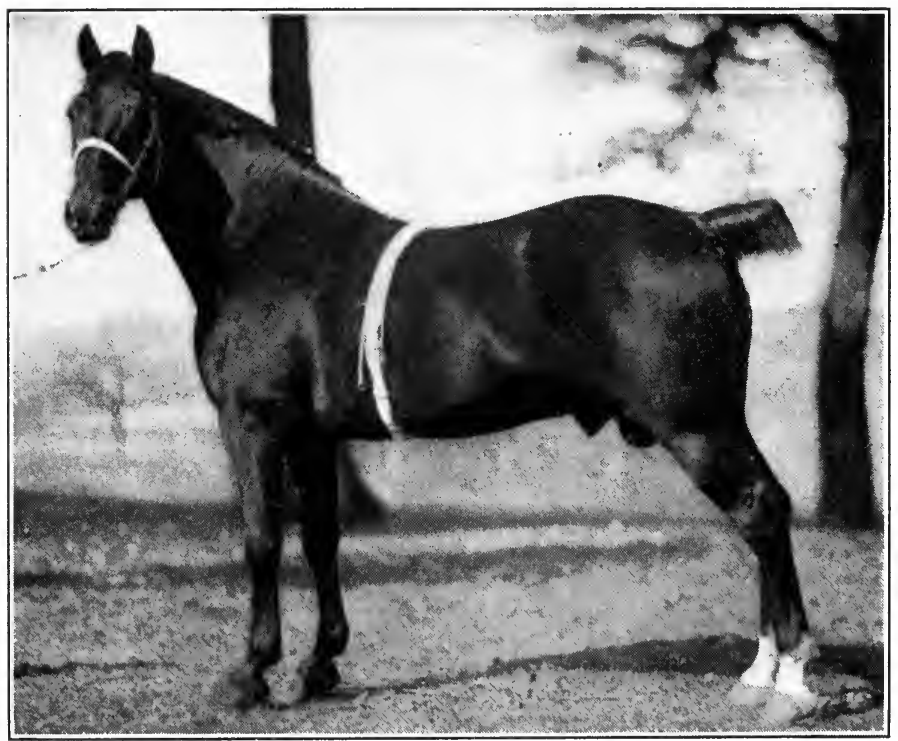

Fig. 76. - A Hackney stallion.

way of going of the Hackney is characteristic. He is naturally disposed to be proud and stylish and goes with a degree of action that is unexcelled, hocks especially being sharply flexed.

There being no discrimination in the studbook between full-sized Hackneys and ponies, the line between them is not sharply drawn. Mares of some size are mated with 
pony stallions and vice versa, with the results that there are many undersized individuals, over the pony limit, yet too small to be acceptable as horses. The naturally full, well-crested neck shows a tendency to be too strong in some cases, the thick throttle compressing the larynx

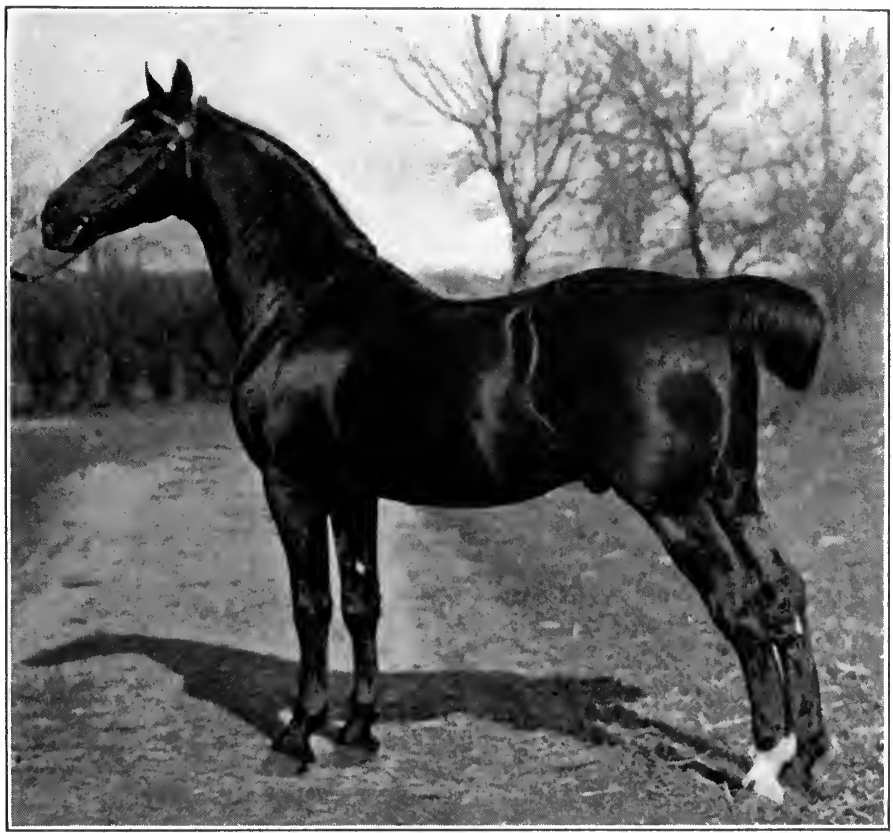

Fig. 77. - A French Coach stallion.

when flexed, as it is when the horse is driven. Hackneys are essentially high steppers and some do not go on in their stride but tramp too much in the same place. Stamina, also, has not been sought nor required in the performance for which the Hackney is best qualified. 
They should not, however, appear soft. Height of stride increases concussion, but that is not sufficient excuse for some Hackneys pounding as they do, nor should their action be labored, but airy.

173. The French Coach (Fig. 77). - Demi-sang or half blooded to begin with and having been bred for cavalry service primarily, the French Coach horse is not as readily distinguishable as the other heavy harness breeds in which the type is more uniform. The most approved individuals of this breed are about sixteen hands high, and weigh from 1200 to 1400 pounds; are rather upstanding, sufficiently close and full made to be of true harness form, yet manifesting no suggestion of draftiness. They should reflect their proximate Thoroughbred ancestry by their refined heads and necks and the texture of bone and hoof in their legs and feet. Hard, solid colors prevail, although one or two white points, though rarely more, are common. They move with a creditable show of both pace and action.

In addition to the rather general lack of uniformity of type there are many individuals of this breed that display too much of the cold character of their original maternal ancestry. Others, which give much promise standing still, are most indifferent actors, and even among those which go well there is a tendency to do it all in front, failing to follow with a balanced action of hocks.

174. The German Coach (Fig.78). - Tap rooted in the region to which the Flemish horse was indigenous and bred primarily for the mounting of the heavy, fully equipped German trooper, size and substance predominate in this breed. They stand full sixteen hands or more and some weigh fifteen hundred pounds, being the largest of the heavy harness breeds. Size and substance, without the introduction of any draft character, and hard, solid colors, more 
uniformly than in any other breed, are the characters by which German Coachers are distinguished from representatives of the other heavy harness breeds.

There is a marked tendency for them to be gross and lymphatic. A drafty form, coarse head and neck, rough

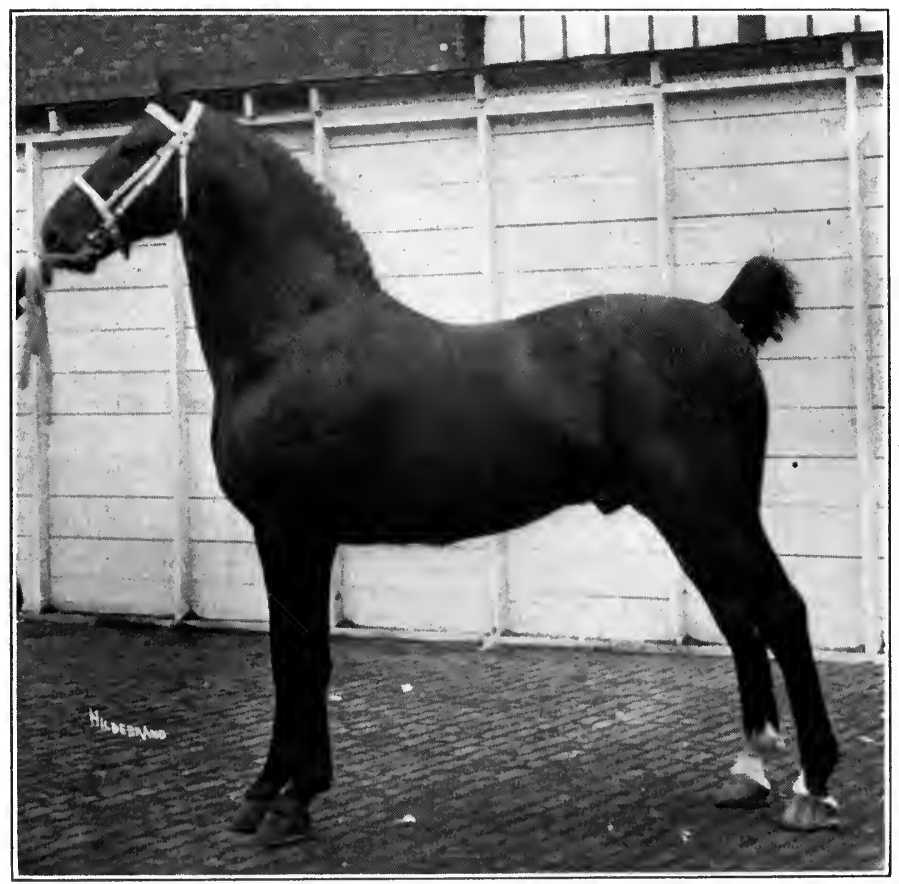

Frg. 78. - A German Coach stallion.

joints, a sluggish disposition and inability to step either high or reasonably fast are features. which judges of this breed of horses should diseriminate against.

175. The Standardbred. - Created at the instance of 
the American road driver who first sought harness speed, bred from a composite foundation, in which the Thoroughbred top cross figured most conspicuously, the base consisting of common bred mares which had shown an aptitude to trot, due, perhaps, to the blood of the Dutch trotter, this horse has been bred to a standard of speed perform-

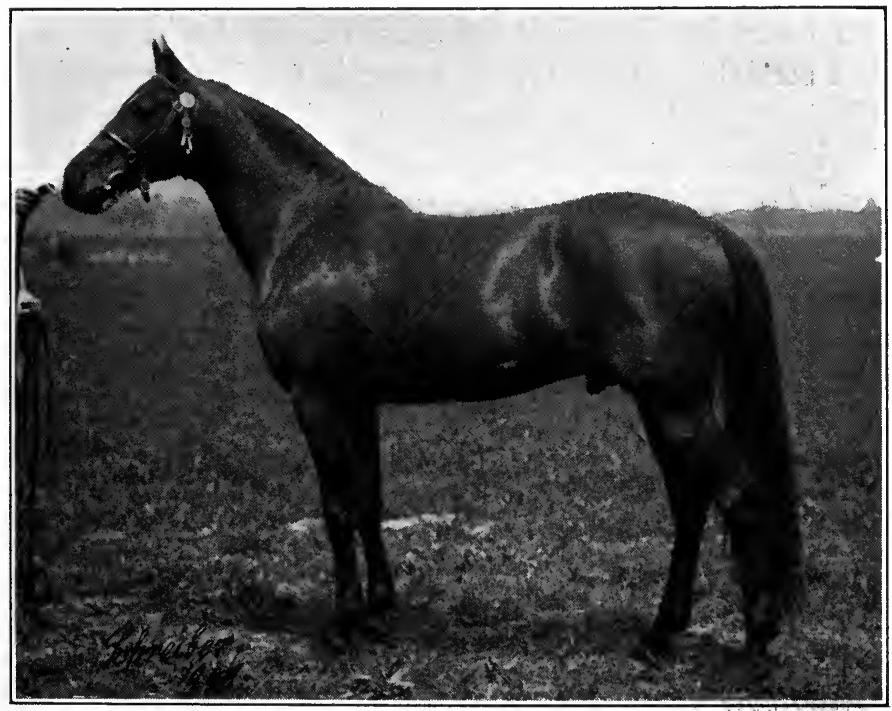

FIG. 79. - A Standardbred stallion.

ance. As a result, the type is not uniform, although the extreme speed performance has been attained in a wonderful degree and with extraordinary regularity. Standardbreds (Fig. 79) range in height from pony stature to sixteen hands and in weight from 800 to 1200 pounds or over, the most approved size being about 15-3 and 1100 pounds. They conform to the general speed type, modified in those 
special features which distinguish trotter and pacer from runner and jumper, i.e. a lower forehand, a longer, more sloping croup, greater relative length from elbow to knee, and from hip to hock, resulting in the hocks being set farther back, and necessitating a more abrupt deviation of the hind legs downward and forward to the ground. The head of the Standardbred is of good size, not especially fine, but clean cut, the neck of medium length, lean and straight. The way of going is most characteristic. Whether at trot or pace the gait is distinguished by the length and rapidity of the individual strides, and the level, true, frictionless manner in which they are executed. Furthermore, the instinct to trot is well marked. Colors are not at all uniform although bays predominate.

Undersized and ill shaped individuals with ewe necks, goose rumps, bent or rounded hocks and tied-in cannons are too common.

176. The Thoroughbred. - As indicated by the name, this is the purest breed of horses, except the Oriental, from which they are derived. They were the first to be improved and the first for which pedigree records were kept and a stud-book established. They also have been bred for about two and one half centuries with running speed as the sole consideration. The typical Thoroughbred is characterized, therefore, by the strongest evidence of breeding and refinement, together with a racy form and temperament. The most representative individuals (Fig. 80) stand near sixteen hands, and weigh 1000 to 1100 pounds. They are rangy, with that length of legs, body and neck which is conducive to a long stride. They conform strictly to the speed form, in fact, are the truest exponents of the speed type, distinguished from the trotter and pacer by greater range, better development of the forehand, more 
level croup, thicker thighs, less proportionate length from hip to hock, and therefore a straighter hind leg, longer, more sloping pasterns, a smaller foot of finer texture, finer bone, and a predisposition to stand over at the knee. The head is the smallest and best proportioned, with features and lineaments most sharply defined; the neck long, slender,

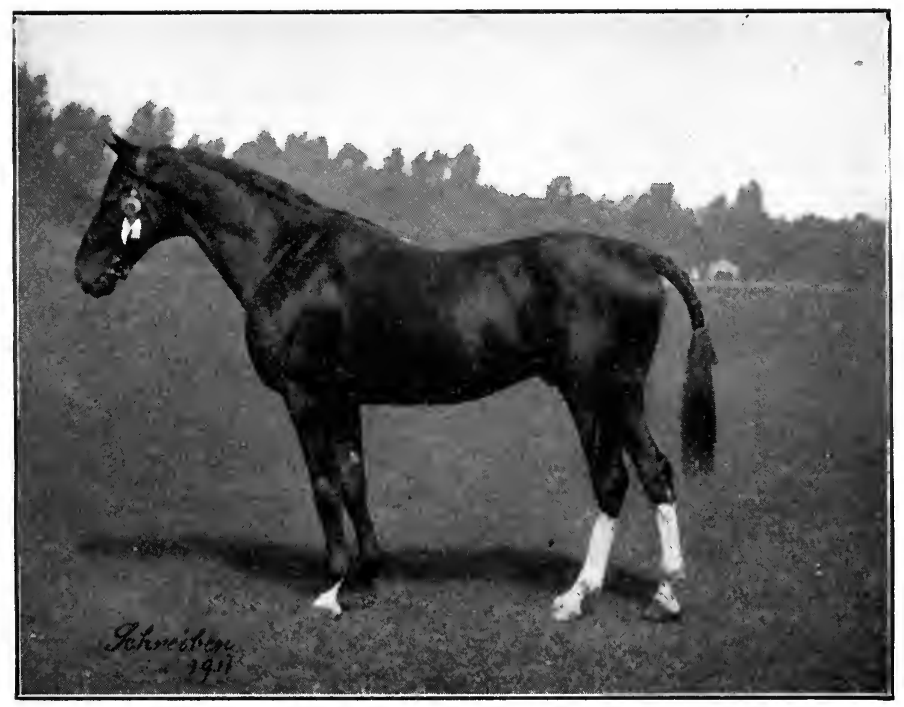

FIG. 80. - A Thoroughbred stallion.

and especially well cut out at the juncture with the head, which it carries well forward rather than up; the shoulder longest and most sloping, the withers highest, leanest and most extended. Bay, chestnut and brown with white markings are the most common colors, although black, gray and white were formerly not infrequent and are yet sometimes seen. The way of going of the Thoroughbred 
is very characteristic ; being essentially a galloper, his walk and trot are not as good as that gait at which he excels. He walks indifferently and trots with a low, pointing stride in front and a dragging of hocks. At the gallop, however, it seems as though his whole makeup were designed with that end in view, each part acting coördinately with the others to make a perfect gallop.

The ranginess of the speed form is sometimes overdone in the Thoroughbred, rendering him weedy (too long-legged and light-bodied). There is also a tendency, in some individuals, to be too fine in bone and too small, especially when measured up to the present standard. Quite commonly they are too "hot" in temperament and erratic in disposition.

Judges of Thoroughbreds usually distinguish between the race horse and the hunter and saddle horse, especially when they are concerned as sires.

177. The American Saddle Horse. - This is a Thoroughbred derivative, rendered especially adaptable to the purpose for which bred by the ambling instinct contributed by the "native" mares with which the foundation Thoroughbreds were mated. Since their foundation, Saddle horses have been selected to a model, as well as a performance, standard. They may be distinguished by the following characters (Fig. 81) ; an upstanding horse of most symmetrical and beautifully molded form, a well-proportioned, blood-like head, the features of which are most clearly defined, an intelligent countenance, and an exceptionally long, shapely and supple neck, on which the head is set in a lofty, graceful manner. The two ends are the most characteristic parts of the Saddle-bred horse, the long, level croup and unusually high set and proudly carried tail balancing the lofty carriage of head, in compliance with 
the Kentuckian's idea of " Head up and tail a-risin'." An extreme degree of quality, finish and style, with a rich bay, brown, chestnut or black color, usually moderately and evenly marked with white, complete a beautiful picture. horse. The way of going was formerly distinguished by

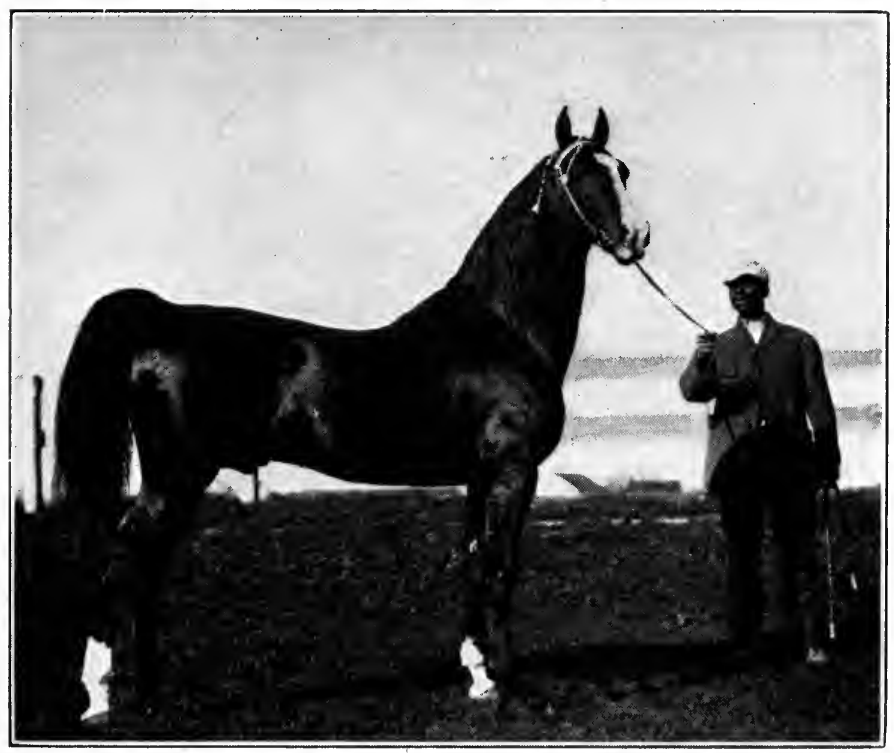

Fig. 81. - An American Saddle stallion.

the rack, but with the increasing favor shown the walktrot-canter horse the rack has been omitted in many representatives of this breed. The trot is quite frequently marked by more action than is usually required of saddle horses, and is, in fact, well suited to harness performance. The highest class Saddle-bred horse is a show horse in every sense of the word, whether under saddle or in harness. 
So much has been made of the two ends of the Saddle horse that they are sometimes deficient in the middle, being both low in the back and short in the rib, while the quality by which they are characterized may be had at such a sacrifice of substance as to render them too fine.

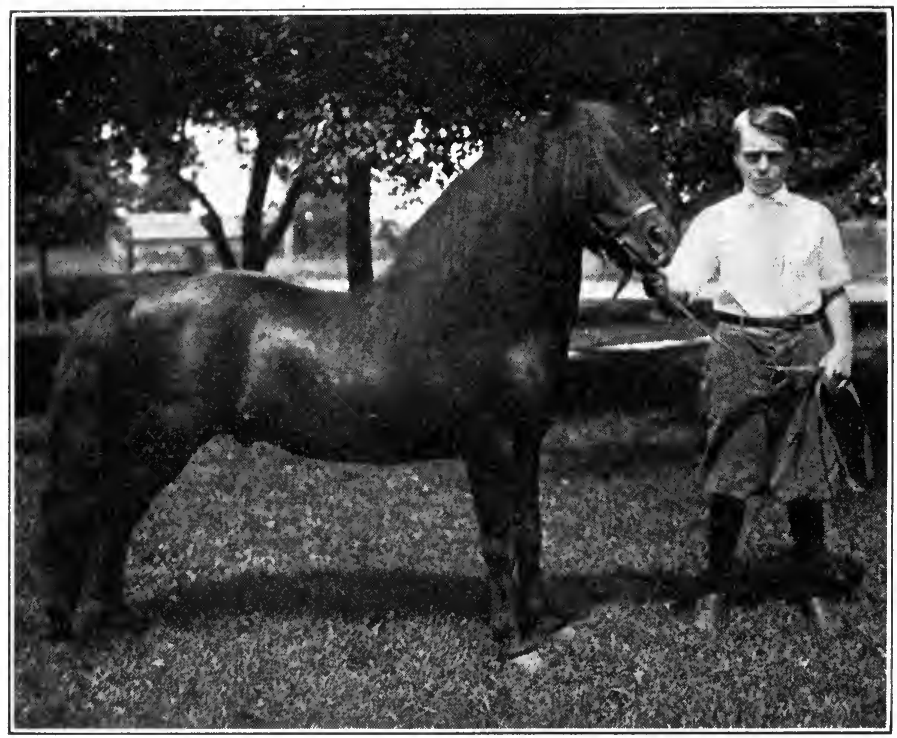

FIG. 82.-A Shetland stallion.

The model and show idea may be allowed to detract from serviceability. Too light, washy colors are sometimes encountered.

178. The Shetland. - This is the smallest of the equine breeds, a standard of 42 inches and a limit of 46 inches, in excess of which they cannot qualify for registration, having been established (Fig. 82). Shetland ponies are used to pack peat, the universal fuel used by the native crofters 
of the Shetland Islands, and they frequently carry loads of 140 pounds. They were first introduced into Great Britain for service in the mines to get the coal out of the

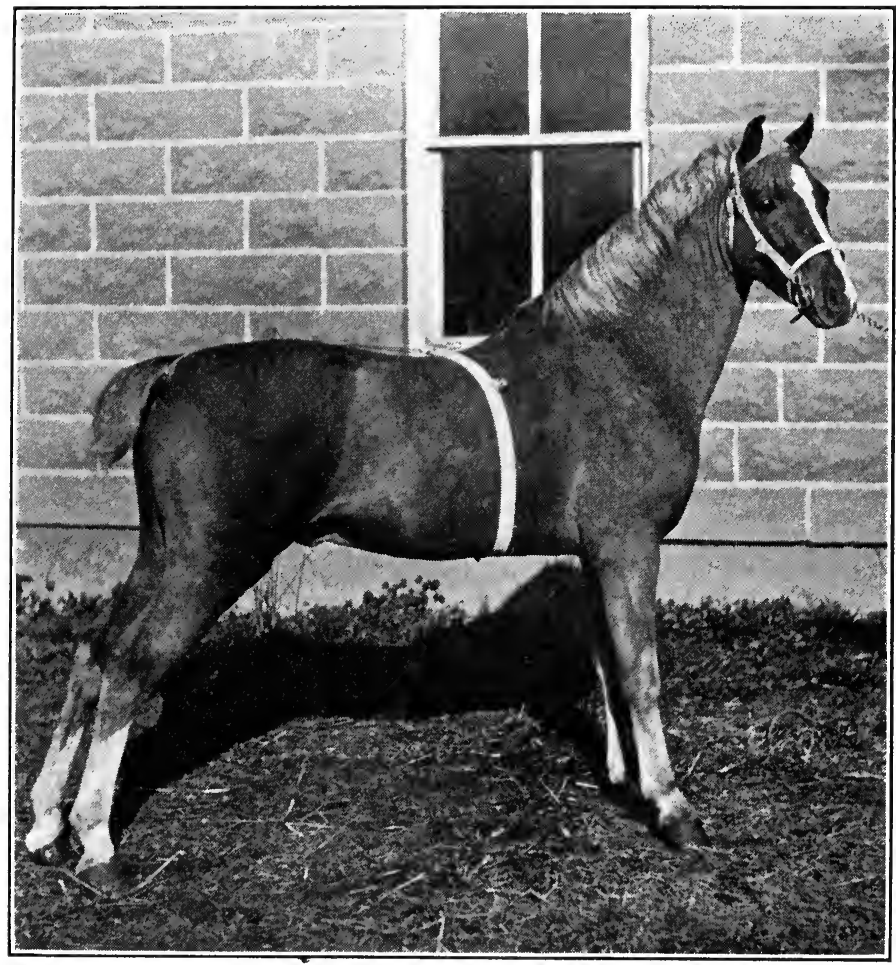

FIG. 83. - A Welsh pony stallion.

shallow veins, where horses and mules could not go. The child's pony idea is claimed to have originated in this country. For these reasons it is not difficult to account for the variance in type from the British and the American 
points of view. The old country type is naturally a pony of power, - a draft horse in miniature - while the American demand is for a pony of less blocky form, with a finer head and neck, a better shape, especially in forehand and hindquarters, and more step. The natural stride is short and pointing, any great display of action usually being due to weighting, which is often excessive. Shetland color is most typically a cinnamon brown or black, although piebalds, skewbalds, bays, chestnuts and even odd colors, as dun and mouse color, are encountered. Breeders generally prefer the hard, solid colors, while the broken colors are most popular with the buyers of ponies for children's use.

Coarse heads, thick necks, round, pudgy middles, steep croups, light thighs and crooked legs are too common. This pony's greatest asset is his docility ; therefore any manifestation of ill temper should be seriously discriminated against.

179. The Welsh. - Derived from a hardy race of ponies native to the Welsh mountains, this breed has been improved in shape and way of going, partly by means of Hackney crosses, till they are very typical heavy harness horses in miniature (Fig. 83). They range in height from the Shetland limit of 11 hands 2 inches to the pony limit of 14 hands 2 inches.

The foreign Welsh Pony and Cob Stud-book extends its classification to include, as cobs, horses of Welsh breeding which stand as high as 15 hands 2 inches. The classification follows:

$A$. Ponies not exceeding 12 hands 2 inches.

$B$. Ponies 12 hands 2 inches to 13 hands 2 inches.

$C$. Ponies 13 hands 2 inches to 14 hands 2 inches.

$D$. Ponies 14 hands 2 inches to 15 hands 2 inches. 
Welsh ponies should be considered more in the nature of little horses than as children's playmates, like the Shetlands. Some go high and others can step quite fast, while all have extraordinary stamina. Bay and brown

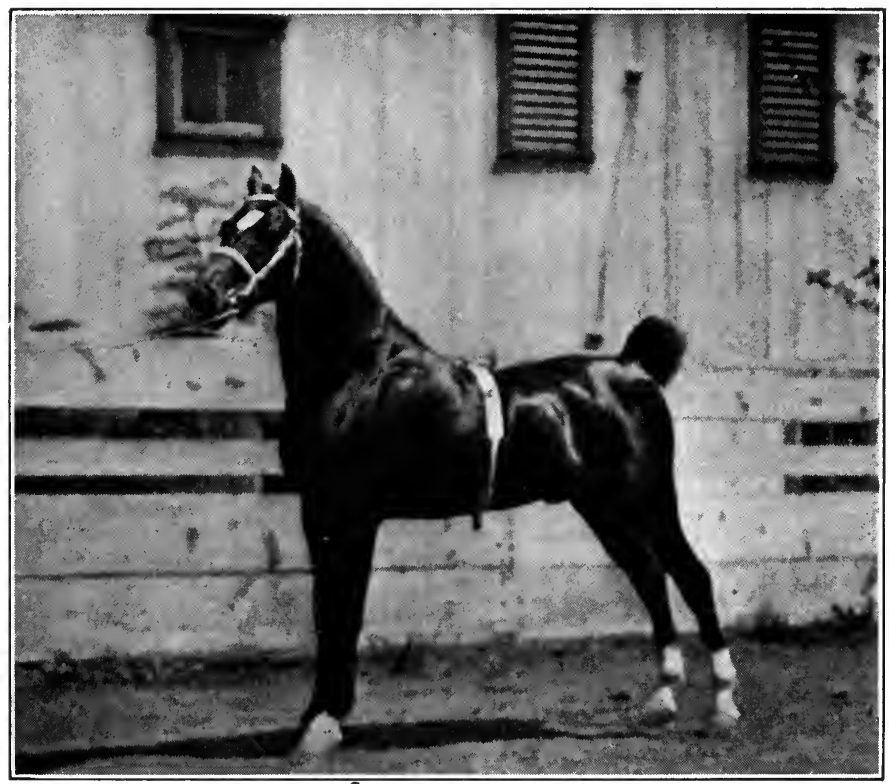

Fig. 84. - A Hackney pony stallion.

are the most common colors, though chestnut, gray and roan are frequently seen.

There is not sufficient attention paid to form in the breeding of most ponies and some Welsh are coarse and ill shaped.

180. The Hackney Pony. - This is simply a Hackney under 14 hands 2 inches, with all of the breed characteristics accentuated (Fig. 84). 


\section{CHAPTER $\mathrm{X}$}

\section{THE MULE}

THE mule is the equine hybrid between the male ass, Equus assinus, and the mare, Equus caballus. Although "with no pride of ancestry, no hope of posterity," as the Missourian has well said, and therefore eliminated from the scope of this work in so far as selection in breeding is concerned, there is ample justification, if little precedent, for including the mule in this discussion.

He rules supreme in the field of the work horse in the South, while in some other agricultural districts he is depended upon for the farm work, and his use in the cities is considerable. It is important for those who use mules, as well as those who purchase them, to know what mule excellence consists of.

Mules have been variously classed, in accordance with the nature of the work to which they are put, but there are essentially but two types, draft and plantation.

181. The draft mule. - These mules are used for power service chiefly outside the cities or at least off the city streets. Mules pull more by their muscular strength and steady, persistent effort than by virtue of their weight, and are especially handy and sure footed in rough and trying places. They "push" rather than "lift" their load. For this reason, as well as on account of the small circumference of their feet and comparatively less weight, they are not as satisfactory on paved city streets as horses. 
The draft mule (Fig. 85) weighs 1200 to 1250 pounds and stands fifteen hands three inches to seventeen hands, a mule being taller in proportion to his weight than a horse.

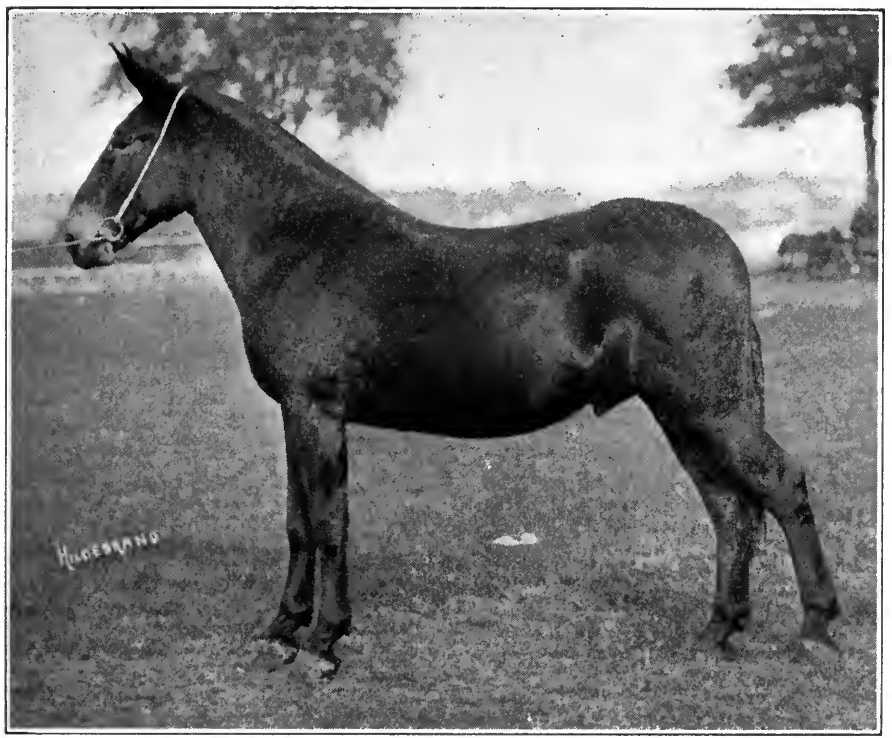

FIG. 85. - A draft mule.

Obrecht ${ }^{1}$ shows one weighing 1900 pounds and standing eighteen hands two inches. This mule conforms to the draft horse type in being low set, broad, deep, compact, massive and big-boned, with quality manifested particularly in smoothness and a straight, strong way of going.

Mules of the draft type are classified as drafters and miners.

Drafter is the largest representative of this type, best

${ }^{1}$ Bulletin No. 122, Illinois Experiment Station. 
adapted to heavy work, as on the streets of Southern cities, city contractors' operations, railroad grades, and in lumber camps.

Miner is characterized by being more blocky and rugged with most power in least stature. They range in height from the twelve hand pitter for working in low chambers to the sixteen hand mule for work at the surface. Their weights vary, accordingly, from 600 to 1300 pounds.

182. The plantation mule. - The requirements of the plantation mule are to walk fast, endure the hard work of

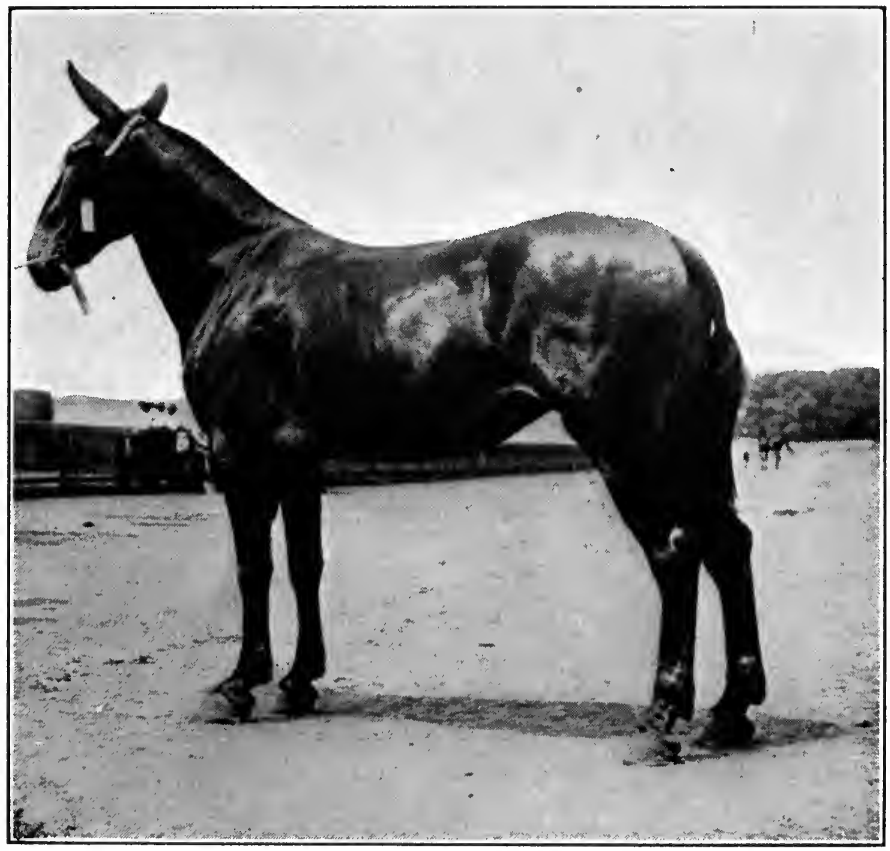

FIG. 86. - A plantation mule. 
the soft ground through the heat of the day and be surefooted, so as not to tramp plants in cultivating. The mule for this service is more rangy and snappy than the draft mule, characters derived from more hot blood in the dams and therefore associated with less size and substance in the mules. Representatives of this type (Fig. 86) weigh from 950 to 1200 pounds and stand fourteen hands two inches to sixteen hands two inches. They are built more on the rapid draft order, conforming somewhat to the shape of an express horse, and should have especially good legs and feet, a high degree of refinement, an active, nervous temperament and be straight, free, snappy movers.

Mules of the plantation type are classified as sugar, cotton and farm.

The sugar mule is for the use of the Southern planter. He is the best representative of this type, rangy, smooth, with great quality and breediness, yet ample bone.

The cotton mule is a smaller, somewhat plainer plantation mule of the same general type as the sugar mule.

The farm mule class comprises the poorer grades of the other two classes, or thin mules that might feed into either of the other classes which are purchased by the farm trade.

Mare mules are usually preferred as being smoother, better shaped and easier keepers. Seal brown is the color most desired, then bay, chestnut and gray. 



\section{PART IV}

\section{JUDGING CATTLE}





\section{CHAPTER XI}

\section{THE TYPES}

183. The block group. - Preliminary to the consideration of beef cattle, those features characteristic of all the block group, namely, beef cattle, mutton sheep and fat hogs, in common, may be disposed of.

All vertebrates are possessed of a muscular system mounted upon a skeleton foundation which serves the purpose of locomotion or any other motion of which the animal is capable. Under feral conditions animals resort to movements of various kinds for their sustenance and their protection. The husbandman has in this instance, as in many others, perverted a natural function into other lines more useful to him, and this muscular system which was furnished the animal as a means of moving, living and having its being becomes the source of one of man's most concentrated, nutritious and digestible foods.

184. Meat, although it may mean any food, is generally understood to be a portion of the animal's body composed chiefly of muscle, the connective tissue by which it is supported, the fatty tissue by which it is enveloped and interspersed, and the section of the skeleton upon which it is mounted. The animal from which the meat is secured gives to it its specific nature, as beef, mutton, or pork. Meat, however, is a carcass term and is not applied to the tissue mentioned in the living animal. The synonymous term, having reference to the animal rather 
than to the carcass, is flesh. Yet there should be discrimination in the use of this term. To speak of eating the flesh of animals implies a meaning identical with meat, but reference to the natural flesh or the thick flesh, of feeder steers, for instance, includes the muscle only, without the fat, and therein lies the distinction. Whereas the muscle that is most efficient for movement is of such firm texture and so devoid of any fat as to render it tough, the chief feature of the muscle which constitutes the desirable lean of meat is just the reverse.

The function of meat-producing animals is the conversion of common foodstuffs, in a form not available to man, into a concentrated, palatable, easily digested form of protein and fat.

The profit returned by them is divided between the breeder who produces them, the feeder who finishes them, the butcher or packer who dresses and wholesales their carcasses, and the retailer who purveys them to the consumers, their ultimate end. It is rare, except in the case of production for limited farm or home use, that one and the same individual is concerned with each step.

185. The breeder's, the feeder's and the butcher's interests in the meat animal. - Success, on the breeder's part, consists in producing an animal that is a satisfactory butcher prospect acceptable to the feeder. The feeder's business is to secure, in the shortest feeding period and with the most economic and productive use of food, the most highly finished and satisfactory butcher beast. The butcher's proposition is to obtain, in the dressed animal, as high a percentage of his gross live weight as possible and to have the maximum amount of the dressed weight carried in those parts of the carcass for which there is greatest demand and the highest price paid. The re- 
tailer, finally, buys ribs and loins of such quality of meat as will secure for him the most generous patronage of those consumers who appreciate and pay for the best meats.

Type is therefore the primary consideration of the breeder ; early maturity, feeding and rapid fattening capacity, of the feeder; dressing percentage and distribution of the weight in the carcass, of the butcher ; and quality, of the man who cuts the carcass on the block.

Economy in production is a matter of type, early maturity, rapid fattening and dressing percentage. Quality of the product depends upon the breeding, feeding, age and dressing of the animal and the cutting of the carcass, and consists of texture, color, consistence, distribution and proportion of the fat and lean and the percentage of meat to bone.

186. The block type. - Prime carcasses of meat are produced by immature, unsexed animals, more commonly males, of the block type fed to their optimum degree of ripeness. The block type is characterized by a blocky or rectangular form set on short legs and furnished with thick flesh (Fig. 87).

187. Early maturity. - There is a marked difference in the extent to which individuals will develop in the same period of time. Interest on investment, labor and feed must all be charged against gross receipts to determine the net profit returned by any block animal, and these three important profit factors are all reduced in the case of the early maturing animal.

188. Rapid fattening is usually correlated with early maturity but should be distinguished from it. One animal matures rapidly, fattening readily at the same time; another may mature slowly, then fatten quickly, after once mature; still another may reach maturity promptly, 
but never develop any capacity to fatten. Rapid fattening, like early maturity, means prompt returns and generous margins.

189. Dressing percentage expresses that proportion of the live animal which is hung up after being killed and

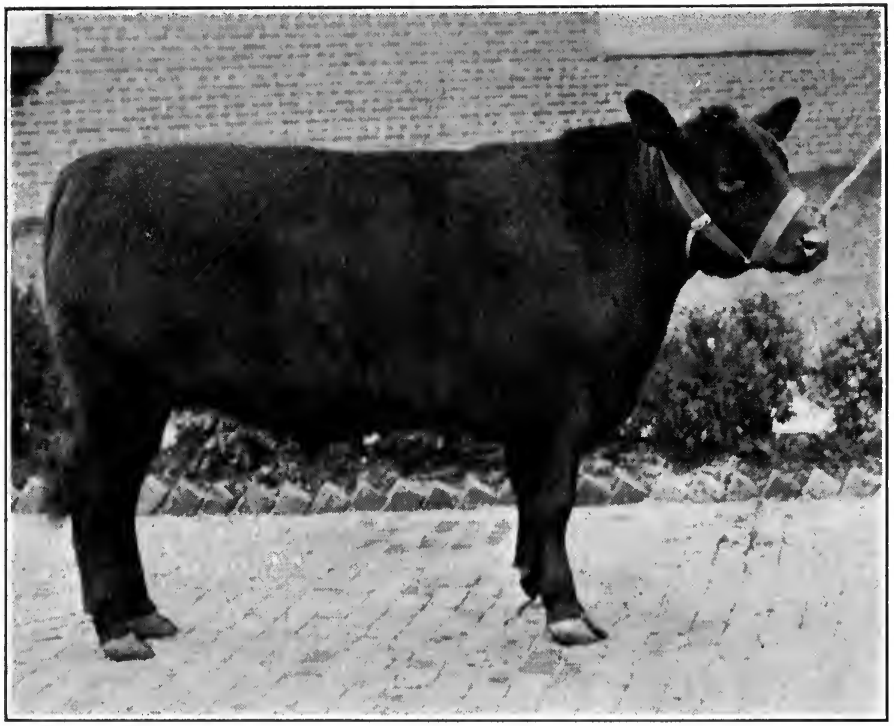

Frg. 87. - The block type. This steer dressed the International Grand Champion carcass.

dressed. The difference between the live weight and the dressed weight represents the offal and a slight shrinkage in chilling.

190. Quality in meat. - So far as the consumer is concerned quality consists of such a fine, delicate texture of the meat as will insure easy mastication, toughness being most suggestive of low quality to the majority of 
meat eaters; also such flavor as will make the meat most palatable, this being of secondary importance to texture as a rule, because flavor may be altered to such an extent in the cooking process. The relative nutritive values of meat figure less in the consumer's demand and are, therefore, of less concern to the judge. Both texture and flavor are contributed to or indicated by the grain of the lean, the proportion of fat to lean, the distribution of the fat, the color and consistence of both lean and fat and the moisture and odor of the meat.

191. The grain of the meat involves especially the part of the carcass from which the cut is taken, improving toward the center of the carcass away from the extremities, the coarser cuts being taken from the neck, shoulders, shanks, the small part of the leg and the rump, the loin and rib cuts being finest grained. Old animals, as a rule, have coarsergrained muscle tissue with more connective tissue in it than do younger ones.

192. Marbling. - A generous proportion of fat to lean is desirable, since it is impossible to secure, age, or prepare prime meat without fat. The better class of meat animals are all fed to a high finish. Unless there is a fairly thick layer of fat surrounding the cuts they rapidly deteriorate and dry out before

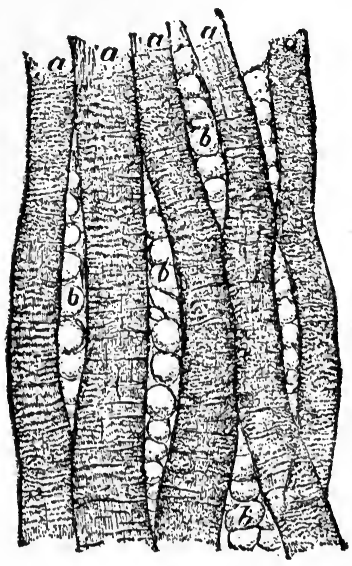

FIG. 88. - The fat cells interspersed between the muscle fibers. they can be properly aged; while in the roasting pan or broiler the envelope of fat retains the juice of the meat. 
As a matter of fact, the so-called juices are not altogether blood and cell protoplasm, but fat. A lean piece of meat will be dry when served. In order to impart, as well as preserve, juiciness in the meat the fat should be distributed though the lean as well as accumulated on the surface of the cuts. Interspersed within and about the bundles of individual muscle fibers (Fig. 88), it constitutes the marbling that is most noticeable in the rib (Fig. 89) and loin cuts of beef, which in addition to furnishing

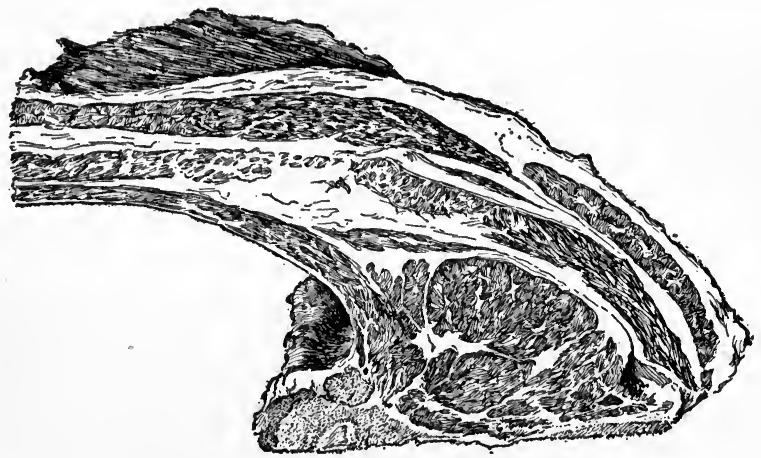

Fig. 89. - The " marbling" of meat.

juice improves the cooking quality of the meat by conducting the heat of the fire uniformly throughout the mass.

193. Color and consistence of fat and lean. - It has been demonstrated that the fat that is most disposed to thus distribute itself instead of accummulating either externally or internally is of a white, not yellow, color, and of a crisp, brittle, not greasy, consistency. Also that the lean most likely to be well marbled is of a clear, deep, red color when cut, neither light red nor bluish, and it has a firm, elastic consistency, neither flabby nor doughy. 
194. Moisture. - Prime meat should just moisten the finger when touched, and should not be slimy. Either immaturity or old age may be responsible for a slimy condition, as may also emaciation from any cause.

195. Odor. - Properly dressed meat in a good state of preservation has scarcely any odor.

196. Taste not only depends upon the prime nature of the meat and the manner of preparing and serving it, but upon the care exercised in dressing. A sheep butcher, for instance, will 'use the utmost care in turning back the pelt so that the wool may not touch the carcass and give it a woolly taste.

197. Proportion of lean to bone. - The amount of the bone in proportion to the weight of the carcass concerns the consumer most of all, bone being waste to him, and on this account rough, coarse-boned steers, hogs and sheep are discriminated against all along the line. Refinement of bone is a feature of the general refinement which results from improved breeding and is correlated with quality of the carcass in general and little waste.

198. Influence of breeding. - Feed is prerequisite to fat, but the amount, distribution, color and consistence of the fat as well as the color and consistence of the lean and the shape of the carcass are matters of breeding. For instance, representatives of leading beef and dairy breeds have been fed the same rations under identical conditions for equal periods with extremely different results between the individuals of the beef and dairy groups. ${ }^{1}$ This test carried through to the actual cutting of the carcasses demonstrated what has usually been found to be the rule, i.e. that the beef-bred animal increases his weight by the formation of fat, while the dairy-bred steer grows

${ }^{1}$ Iowa Experiment Station, Bulletin No. 81. 
an excess of bone; that the former deposits his fat in, as well as upon, the lean, thus enhancing the actual value of the carcass as well as increasing the dressing percentage, while the latter accumulates an excess of fat about the viscera, organs which, with the exception of the kidney, are removed in dressing, the carcass showing no marbling whatever; that the fat of the beef carcass is of the sort described above, while that of the dairy animal is high colored and buttery, the lean of the former fine grained and of good color, while that of the latter is cross grained and dark colored.

Cattle (Bos taurus) are the largest of the domesticated ruminants. They were early domesticated and have served the triple purpose of work, milk and meat in the order named. They are especially adapted to the consumption of large amounts of roughage and are thus conservators of much that would otherwise be wasted.

The types of cattle are beef, dairy and dual purpose.

\section{Beef Catthe}

The unsexed male or female, of immature age and in prime condition yields the most desirable carcass of beef, - bulls, stags and old females, especially worn-out dairy cows, being utilized chiefly as cured beef or cut up for the lower class trade.

199. Production. - Since the best beef animal is the one which hangs up the most superior carcass, the slaughter test must be kept in view by the beef cattle judge, and the most exacting demands of the consumer patron of the retail butcher should be given due consideration. It seems reasonable that the judge of beef cattle should be a connoisseur of sirloin. Since quality of beef is one 
of the ends sought in the fat steer it is well for the judge to know just what that quality consists of (paragraph 190).

The beef steer is, however, required to do more than to satisfy the demands of the beef-eating public; he must return a profit to his butcher, his feeder and his breeder. The factors of quality already considered determine whether or not the carcass will grade as prime and bring the highest price, but there are other factors which fix the other limit of the butcher's margin of profit that are of equal importance. The butcher pays 8 cents a pound for the live steer which weighs 1200 pounds on foot. He immediately subjects the steer to slaughter and dressing which converts him into two sides of beef and the dressing offal, consisting of hide, head, shins and feet, blood, chest and abdominal viscera and their contents. This, with the shrinkage incident to the loss of moisture in chilling, may amount to from $50 \%$ to $25 \%$ of the live weight of the steer originally purchased. While with modern packing methods every particle of the offal has some value, the aggregate will not amount to as much as its original purchase price. Furthermore, there are many pounds of the dressed carcass that must be sold at from $25 \%$ to $50 \%$ less than they cost. Therefore the burden of responsibility for the profit to be yielded by the carcass must rest upon those parts for which a price much in excess of cost can be secured. Quality being equal, the steer that will hang, in dressed sides, the greatest amount of his live weight and that carries the major part of his dressed weight in those regions of the carcass which command the best price, is most profitable.

200. The beef carcass cuts. - The division of the carcass as it is cut up by the butcher should be anticipated by the judge. These divisions are indicated by the following diagram (Fig. 90). 

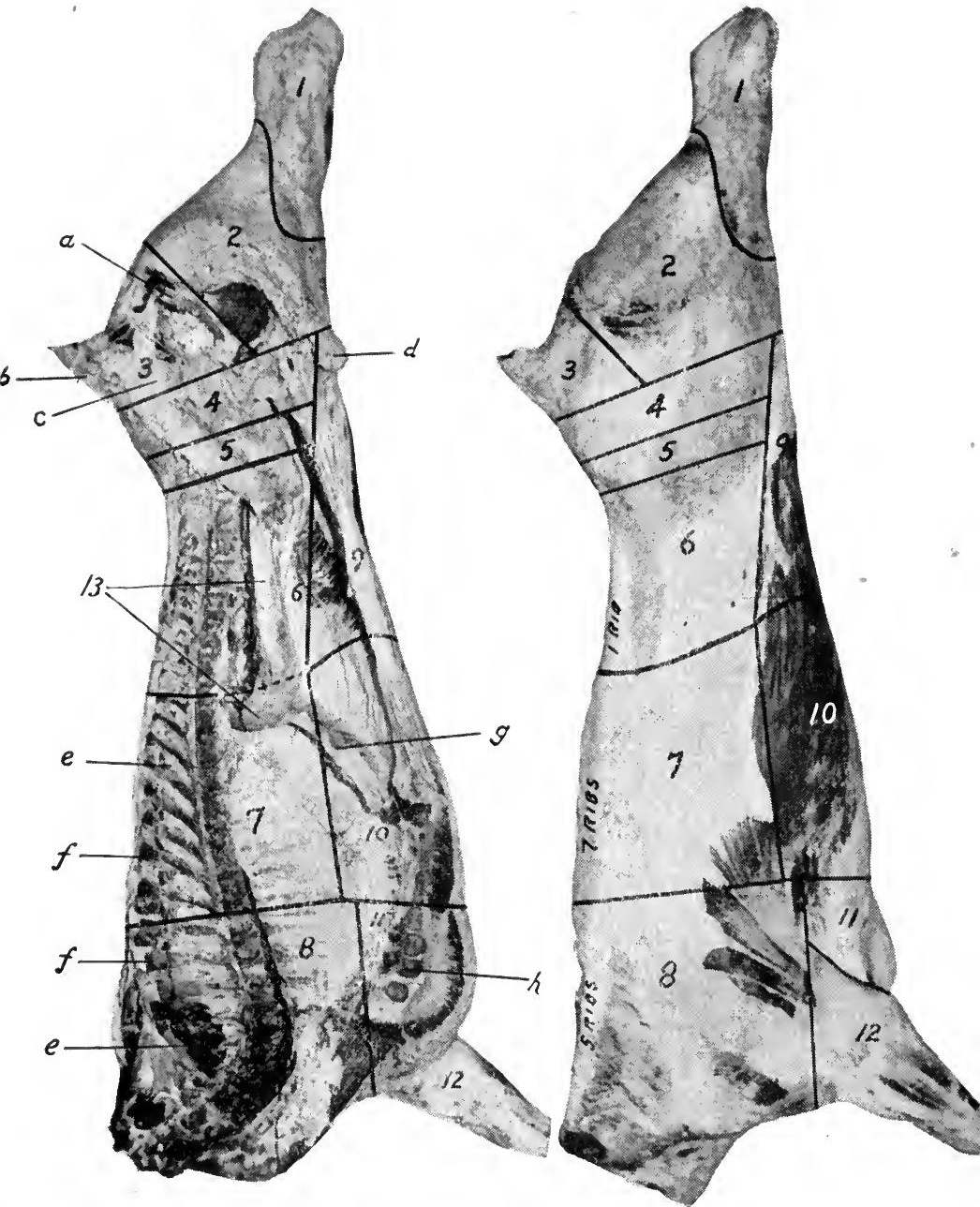

Fig. 90. - Beef carcass cuts. 1, 2, 3, round ; 4, 5, 6, loin; 7, rib; 8, chuck; 9, flan 10 , 11 , plate ; 12 , shank; 13 , suet. 1 , hind shank; 2 , round, R. \& S. off ; 3 , rum 4,5 , loin end ; 6 , pinbone loin ; 5,6 , flatbone loin; 10 , navel ; 11 , brisket. 1,2 , $4,5,6,9$, hindquarter $; 7,8,10,11,12$, forequarter; 7,8 , back ; 7,10 , piece ; 8 , 12 , Kosher chuck; $8,10,11,12$, triangle. $a$, aitch bone ; $b$, rump bone ; $c$, crotc $d$, cod; $e$, chine bones; $f$, "buttons ;" $g$, skirt; $h$, breast bone. Illinois Bulletin 1 . 184 
After being bled out, the head, hide, extremities and viscera removed, the carcass is split into halves. When chilled until set, each side, herefter a unit in the trade, losing all idenity with its fellow, is cut into fore and hind quarters, division being made between the twelfth and thirteenth ribs. One rib is left on the loin to act as a stay and hold its form in order that it may be better cut. The hindquarter, the more valuable, is divided into loin, rump and round, after having the kidney, with its accumulation of suet, and the flank removed.

201. The loin is separated from the rest of the hindquarter by cutting from the stifle, through the hip joint to the rump. The loin includes both sirloin and porterhouse. The sirloin (Fig. 91) is cut forward as far as the

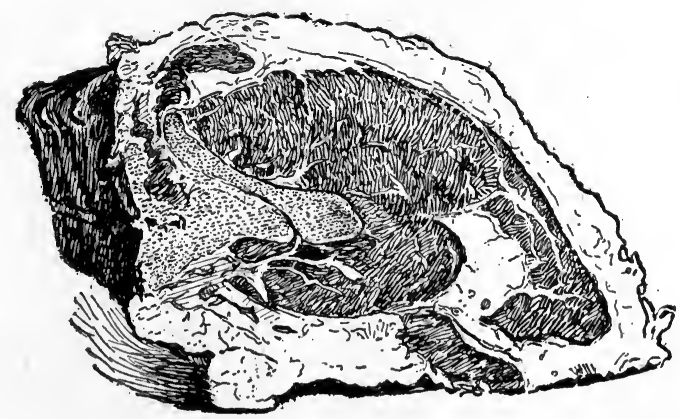

Fig. 91. - The sirloin cut.

point of the hip or hook bone and is identified, when cut, by the cross section of pelvic bone which it contains, the round section of the shaft in the first few cuts and the crescent shaped section of the wing as the margin of the porterhouse is approached. The porterhouse (Fig. 92) is cut forward from the point of the hip 
or rather backward from the last rib to this point, in the region of the loin proper, and this cut is identified by the " $\mathrm{T}$ " bone. This consists of a lumbar vertebra split in

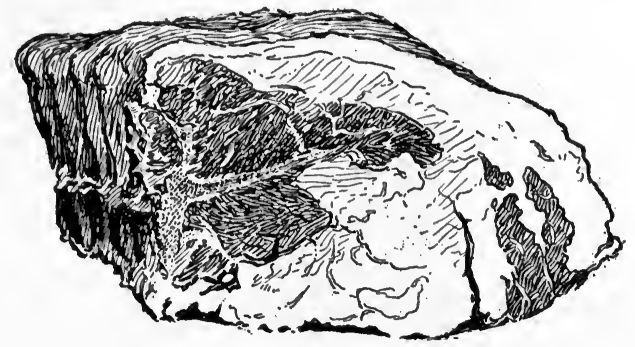

FIG. 92. - The porterhouse cut.

two, which forms the cross, while the lateral process of the one side constitutes the stem; the tenderloin is contained in the lower angle thus formed.

202. The round (Fig. 93) is defined by the cut already made from stifle to hip joint and another from the hip

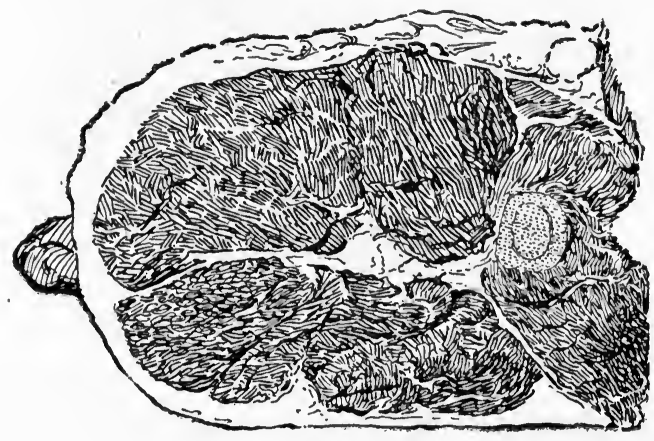

Fig. 93. - The round cut.

joint to the point of the buttock or pin bone. There is then left the rump piece, irregular in shape and marked 
by the tail head. The round cuts contain only the transverse section of the femur or thigh bone. The best quality of meat is on the inside or the top of the round as it lies on the block.

The forequarter is cut into the prime ribs, chuck, neck and plate.

203. The ribs. - The prime ribs (Fig. 94) include the seven ribs counting forward from the loin end of the forequarter, which brings the division of the rib and chuck between the fifth and sixth rib. The distance down on the rib at which the limit between prime ribs and plate is fixed depends upon the thickness of flesh on the rib and the size of the carcass. Since rib cuts are high priced

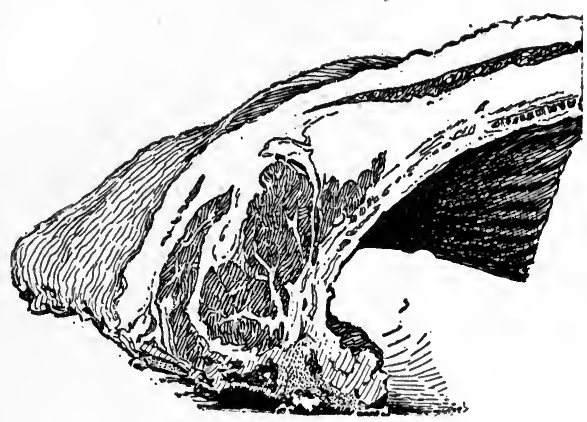

FIG. 94. - The standing or prime rib cut. and plate cuts are low, the butcher will usually keep as much weight in the ribs as their covering will permit of. Carcasses of steers that were bare on the rib will cut proportionately more plate than those from steers that were thickly fleshed on the rib. The division is usually made ten to thirteen inches from the back bone.

204. The chuck includes the balance of the ribs and the shoulder blade, limited below by continuing through the shoulder joint the cut that divides the prime ribs from the plate. The cross cut ribs and the clod are taken from the chuck at the arm, the remainder of the leg being the shank. The fore part of the plate may be separately designated 
as the brisket. What is left in front of the first rib constitutes the neck of the carcass.

\section{SCORE CARD}

205.

\section{BEEF CARCASS}

Scale of Points

General Appearance.

Perfect Score

1. Form - compact, well filled out . . . . . . . . 10

2. Covering - thick, even, smooth, firm, white fat . 5

3. Kidney fat - in proportion to covering, firm, white, brittle

4. Quality - grain straight, fine texture, firm but yielding to pressure ; color, red ; fat to lean well proportioned, marbled; bone, dense, fine

Forequarters.

5. Neck-short, neat . . . . . . . . . . . . 1

6. Chuck-shoulder compact, well covered; ribs, thickly fleshed . . . . . . . . . . . . . . 8

7. Prime ribs - thickly fleshed, carried well down, firm, evenly covered with medium thickness of fat; marbled . . . . . . . . . . . . . . . 12

8. Plate-light, not coarse . . . . . . . . . . 3

9. Shank - arm, full; bone, fine . . . . . . . . . 1

Hindquarters.

10. Loin - flesh thick, firm, even ; marbled; spine fat of medium thickness . . . . . . . . . . . . 18

11. Rump - full ; evenly fleshed to tail head . . . . 4

12. Round - full, thick, carried well down; well interspersed with fat . . . . . . . . . . . . . 10

13. Flank - thick, well filled . . . . . . . . . . 2

14. Shank - bone, dense, fine . . . . . . . . . . 1

Total . . . . . . . . . . 100

206. Relative values of the carcass cuts. - Since the beef steer is a straight business proposition, the most important thing for the judge to know regarding the carcass cuts 
is their relative values. They rank as follows: the highest priced cut of the carcass is the loin; the rib cut is valued at from 10 to $20 \%$ less, per pound, than the loin of the same grade; the round at 40 to $50 \%$ less than the rib; the rump is worth a little less than the round; the best grade of chucks sell at about the same price as the rounds; while the plate, the flank, the shank and the neck

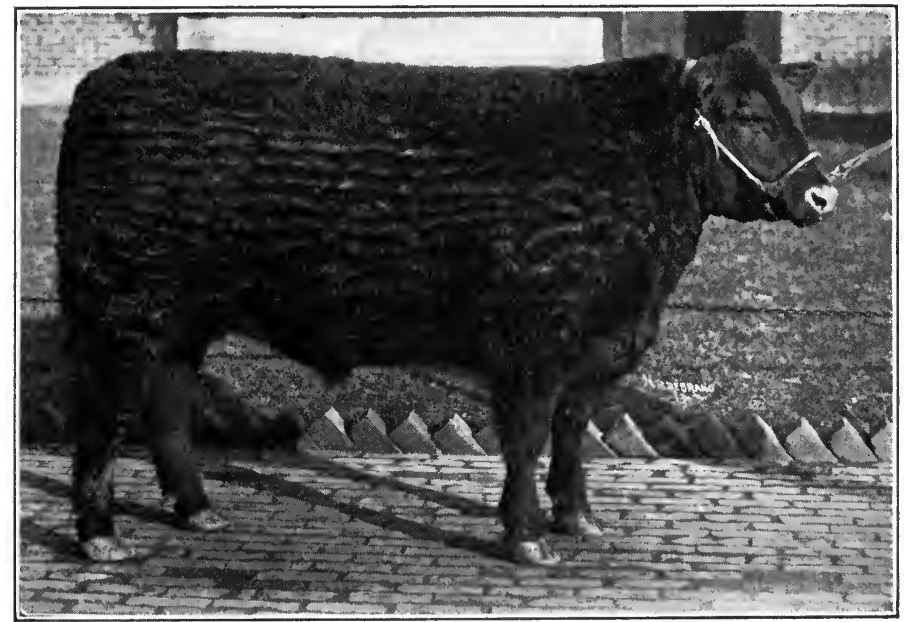

Fig. 95. - A typical beef steer.

sell for less, per pound, than the live weight cost of the steer. Steers dress $50 \%$ to $70 \%$ of their live weight.

207. Dressing percentage. - The dressing percentage of the steer involves type, quality and condition, while the relative weights and values of the different parts of the carcass are determined by type and conformation.

208. Type is fundamental even to conformation in that it is impossible to have a broad, thick loin on a steer 
of any but beef type. The type of steer that favors greatest weight in the carcass, least waste and the greatest proportion of weight in the most valuable cuts is that which conforms to a block or rectangle, being low set on short legs, with top and under lines parallel, the square brisket and hindquarters outlining a parallelogram in profile, while the broad, flat back and loin and wide ends complete the rectangle (Fig. 95).

209. Conformation of the beef steer. - The head of the beef steer serves as an index to the rest of his make-up and should therefore be the opposite of that of the dairy cow, i.e. short, broad and deep, with a more placid, even lazy expression of countenance; the eyes large, full and clear; the muzzle broad, the nostrils large; the ears of medium size, set high and carried alert; the horns symmetrical but not coarse, or a sharp, well-defined pole; the neck as short as possible, thick, yet not heavy in the throat, especially full in that region where the neck blends with the shoulder, termed the shoulder vein; the shoulders well laid in, thickly covered, the side of the shoulder being one place that is especially liable to be bare, broad across the top, without being rough or open but so well covered as to be compact and smooth at this point; chine broad and level with a thick covering of mellow flesh, also straight, showing no sag toward its juncture with the loin; ribs well sprung, deep and thickly covered, especially on the fore rib, that region designated as the crops, a round, deep rib also contributing to the heart girth and abdominal capacity; chest deep, full, level on the floor and square at the brisket; loin broad, thick, smooth, no rolls, level, with no sag or tie where it joins the back; flank deep and full, making a straight under line; hips broad, level, smooth and not prominent; 
rump long, broad, level and smooth, showing no coarseness of bone about the tail head and no unevenness of covering, in the nature of patches, about the tail head or pin bones; thighs broad, thick, and deep, well rounded in appearance from any angle and especially full and low in the region of the inner, lower thigh, known as the twist on account of the rotation of those muscles which takes place when the carcass is hung up by the hamstring, the juncture of the two thighs being referred to as the seam of the twist; the legs short, straight, strong and fine boned.

210. Quality in the steer influences the dressing percentage by controlling the amount of waste or offal. It also makes a higher grade carcass, quality of hide and hair, for instance, being correlated with quality of lean and fat. Quality is of hide and hair, indicated in a loose, medium thin, pliable, unctucus hide covered with a medium coat of fine, soft, straight hair and determined by handling; of bone, as evidenced in a comparatively small, fine head and horn, smooth shoulders, hooks and pins, small cannons, and clearly defined joints ; of flesh, as shown by an even, smooth covering over the back, loin and rib with no rolls or patches of fat and neither too soft nor too hard a feel. Quality is also concerned with general trimness and refinement of the animal throughout, indicative of breeding.

211. Condition has most to do with the weight that is left in the carcass after dressing away the offal. Of course, internal fat increases the amount of waste, but every pound of fat fed into the carcass itself increases the dressed weight and therefore the percentage of live weight, that much. Show animals regularly dress more than ordinary market toppers, chiefly because they are fatter. Condition is ripeness and until the steer has 


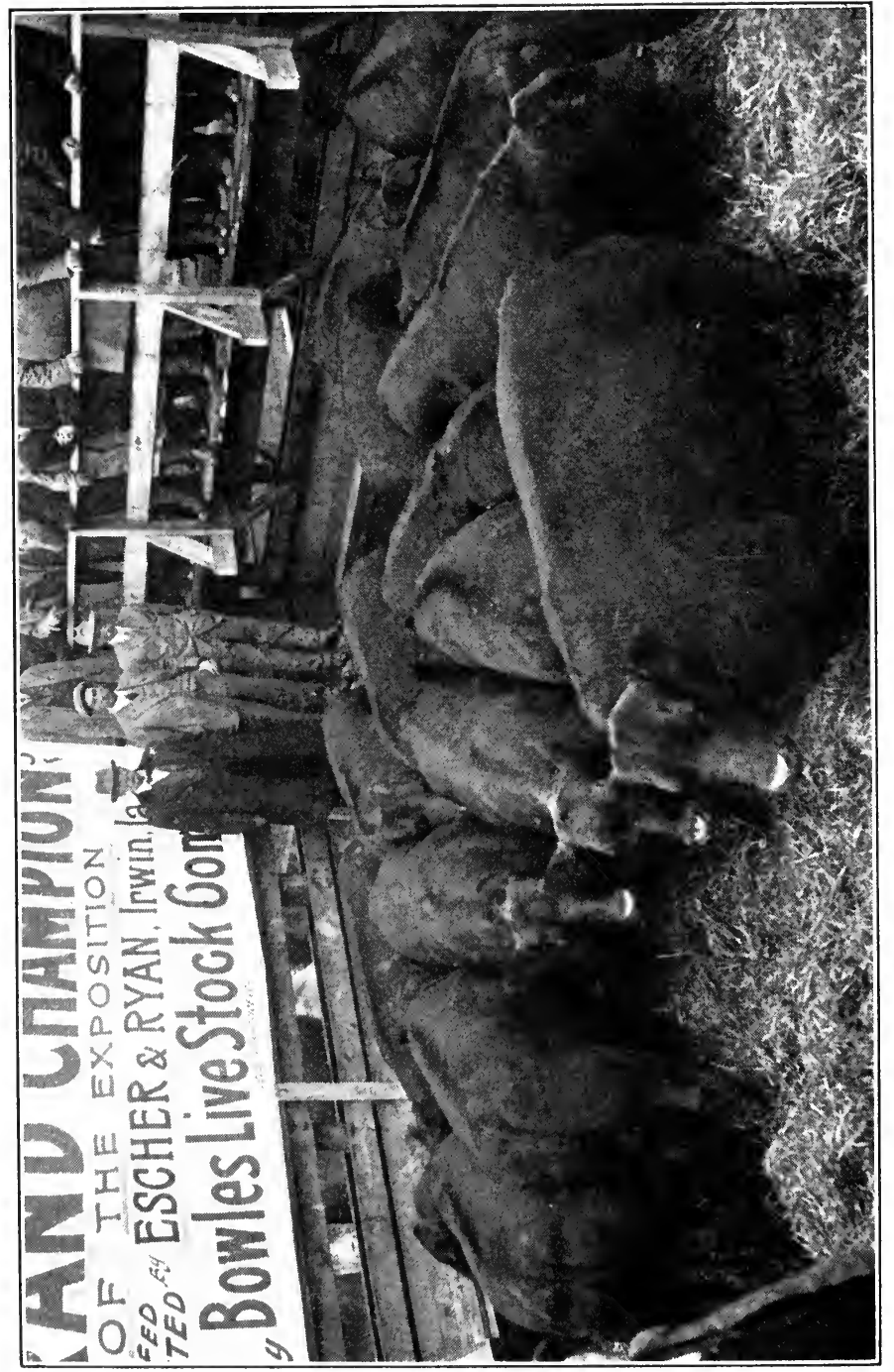

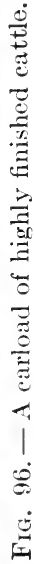


reached this state he has not attained maximum production. Condition or ripeness is indicated by a full purse, flank and tongue root, these being the last places at which fat accumulates in the ripening process.

212. Feeder cattle. - The butcher deals with an actuality, the feeder with a prospect, but in order to be successful in his operations the feeder must keep the butcher requirements constantly in view (Fig. 96). The feeder's profits depend, first of all, upon the production of an acceptable butcher's beast, but secondarily upon the economy with which this can be accomplished. There is a vast difference in the relative efficiency of individual steers so far as economy in production is concerned. Not all show steers are popular with the packers, but even some which are market toppers are money losers when the cost of production is charged against even the premium price which they bring.

213. Feed lot production. - So far as becoming a bullock acceptable to the butcher goes, the feeder steer is the butcher steer minus condition, but in economic production the feeder introduces a feature that is of no account to the butcher, namely, constitution. Profit in the feed lot requires that the cattle shall be good " doers," disposed to consume a full ration, regularly, with no skips or misses due to off-feed periods, and then capable of making full return in gains for each pound of feed consumed (Fig. 97). In addition, therefore, to being bred right feeders must show evidence of thrift, vigor and growth, with early maturity and capacity to fatten rapidly, yet evenly. Just what the fattening process consists of, as well as what it accomplishes, is also of vital concern to the judge of feeder cattle. It should be understood that the gains in weight shown by cattle on feed represent either an increase in the 


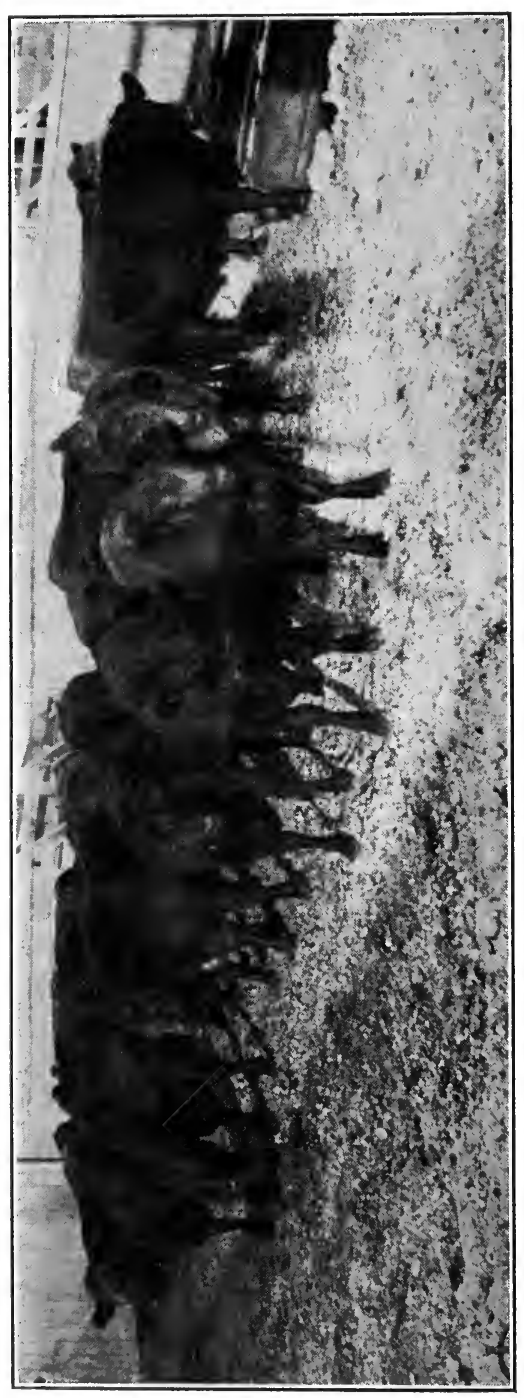

fat content of the body alone, as in the case of the thin but mature steer, or a growth of bone and muscle tissue in addition to the deposition of fat, as takes place in the immaturefeeder. Natural ". flesh is something . with which calves are : endowed at birth and no amount or character of feeding $\cong$ will result in excess of that endowment. Natural flesh is therefore a most important possession of the feeder steer. It $\stackrel{\circ}{\circ}$ is as impossible to coed muscle into a i beef steer as to feed butter fat into the milk of a dairy cow. Furnished an ample and proper ration, they will grow to the limit of their natural endowment, but that is all. Fat, on the other hand, 
will be formed directly in accordance with the amount of a fattening ration fed.

214. The type of the feeder steer (Fig. 98). - Short, broad heads, wide, flat backs, muscular necks and thighs even though thin, sappy hides, full heart girths and lymphatic dispositions which render the cattle only sufficiently aggressive to get all the ration due them, then disposed to lie down and grunt and grow are the features upon which the selection of feeders is based. It is essential to know the fat steer which is the feeder's outcome before passing judgment upon the thin prospect.

215. Method of inspection. - Beef cattle are first viewed from in front, noting their scale, width and low station, then the size, dimensions, proportions, contour and features of the head. Passing to the side the lines are observed, noting especially any sag in the back, droop of the rump or prominence at the tail head, lack of fullness in either crops or fore flank, trimness of under line, and depth of hind flank; then the head in profile, the shortness of the neck, fullness of the shoulder vein, thickness and character of the covering over the back and loin, on the outside of the shoulder, in the crops, on the mid rib, and at the juncture of the back and the loin, as determined by handling, and the length, levelness and smoothness of the rump, setting on of the tail and depth and fullness of the hindquarters. From the side the hide is handled just over the back rib and midway down. The rear view covers the width of the animal throughout and especially of the shoulders, back, loin, rump, thighs and twist, and the fullness, depth and closeness in the seam of the latter. The opposite side is observed in the same order as the first. The legs of a fat steer, ready for the slaughter, are of little account. 


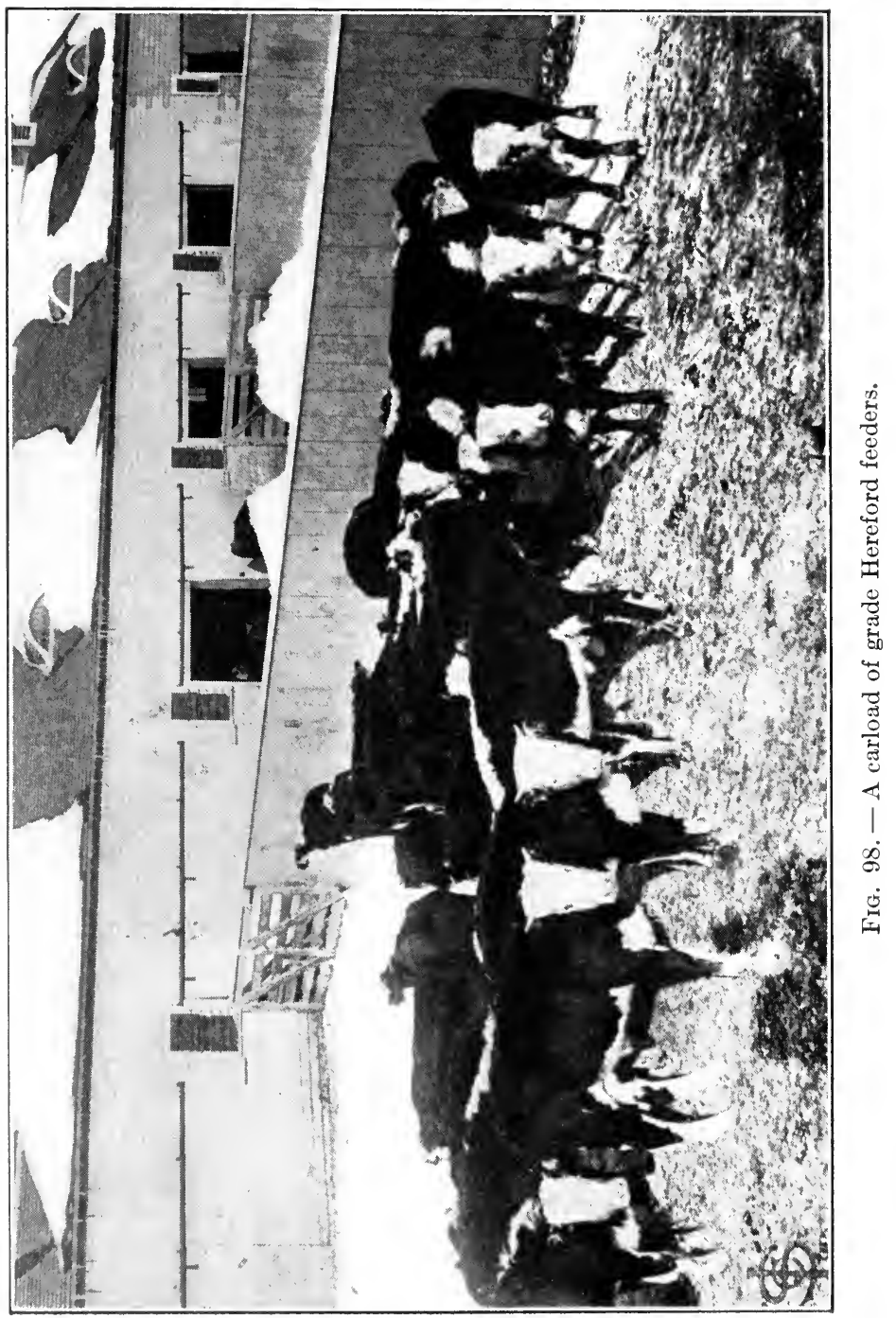


Feeders are usually picked under-conditions that permit of only a very general inspection. They are often sorted as they are run through the alleys, past the mounted buyer who indicates which of the two pens, accepted or rejected, they are to be allotted to.

\section{Dairy Cattle}

The primitive bovine female possessed, in common with all mammals, the capacity to produce milk with which to nurture her young to a self-sustaining age. For this purpose she was required to give but a small amount, of ordinary quality, the scant flow of which was maintained by the succulent spring grasses whose growth was incident to the season at which she invariably calved.

The modern domesticated dairy cow, on the other hand, has given annually, in record instances, milk equivalent in amount to from 25 to 30 times her own weight, and so rich in fat as to yield more than the equivalent of her weight in butter. Furthermore, she may be made to freshen any month in the year and to maintain the milk flow continuously for a period of years in some instances. Live-stock husbandry offers no more striking example of the development of a natural function by means of generations of selective breeding.

216. Production. - The function of the dairy cow is to furnish, for any ten months in the year, milk in such quantity and of such quality as to return a fair margin of profit over the cost of maintenance of the cow herself and the additional expense of her production.

217. Dairy form and function. - The province of the dairy cow can be best understood by considering her as a factory, of which the udder is the essential machine, and in this she stands intermediate between the grain bins 
and hay mows, as the sources of the raw materials, and the finished product in the pail.

There is a most distinct correlation between form and function in the dairy cow; therefore a detailed consideration of each is essential to the intelligent judging of her.

Milk is composed of $87.1 \%$ water, and $12.9 \%$ solids, of which .7\% is mineral matter, $3.2 \%$ casein, $5.1 \%$ sugar and $3.9 \%$ fat, the last three constituents being products of the udder, exclusively. Hence the udder is the final and determining factor in milk production, but its function is wholly dependent upon allied and prerequisite systems and organs. These will be taken up in order.

218. Dairy temperament. - Since the production of beef and milk are in no way correlated but are extreme opposites, the primary factor in milk production is the absence of any tendency to beefiness. All the allied functions, as well as the secretory function of the udder itself, are so governed by the nervous system as to insure the most complete utilization of food nutrients exclusively for milk production, after maintenance requirements have been met.

219. Reproduction. - Given the capacity to divert surplus nutrients from the body to the pail there must be furnished a motive for so doing. Although the undeveloped udder of the virgin heifer and even the rudimentary gland of the bull may be stimulated to the actual production of milk, yet the calf is the only means of bringing cows into a state of profitable production. Under modern methods of dairy husbandry the calf is commonly deprived of that for the production of which he has furnished the incentive. Once fresh, a cow may be kept milking continuously for years, sometimes, without the necessity 
of refreshening, although she is usually rebred so as to come in annually.

220. Feeding capacity. - After being furnished with a reason for becoming functionally active it is necessary that the udder be supplied with the materials from which to produce milk. This function devolves upon the digestive system as a source of the nutrients and the circulatory system as a means of conveyance to the udder.

221. Constitution. - In view of the record performances of some cows it is apparent that high production involves the expenditure of an enormous amount of energy and nerve force to sustain it. A race horse is hardly required to have more stamina and constitution than a cow on test, while resistance to disease is of even greater importance in her case on account of the artificial conditions under which she is kept producing.

222. Udder. - The udder has been referred to as the essential machine of the milk factory, - the cow. It is not a mere reservoir in which the milk accumulates and from which it is simply withdrawn, but the udder is a gland with secretion as its function. While the glandular arrangement does provide a receptacle for the milk as it is produced, secretion goes on most actively during the milking process, and is even controlled, within limits, by the cow at will. The active factors in milk production are the gland tissue cells which intervene between the terminal capillary ramifications of the blood vessels and the ultimate divisions of the interior of the udder (Fig. 99). The water, salt and some free albumen pass directly from the blood into the interior of the gland, but the greater part of the albumen undergoes transformation in its passage through the cell and reappears as casein. Fat and lactose 
may also be considered the products of the cell, since they do not appear in the blood. Fat is produced by a special secretory activity of the cell itself during which its proto-

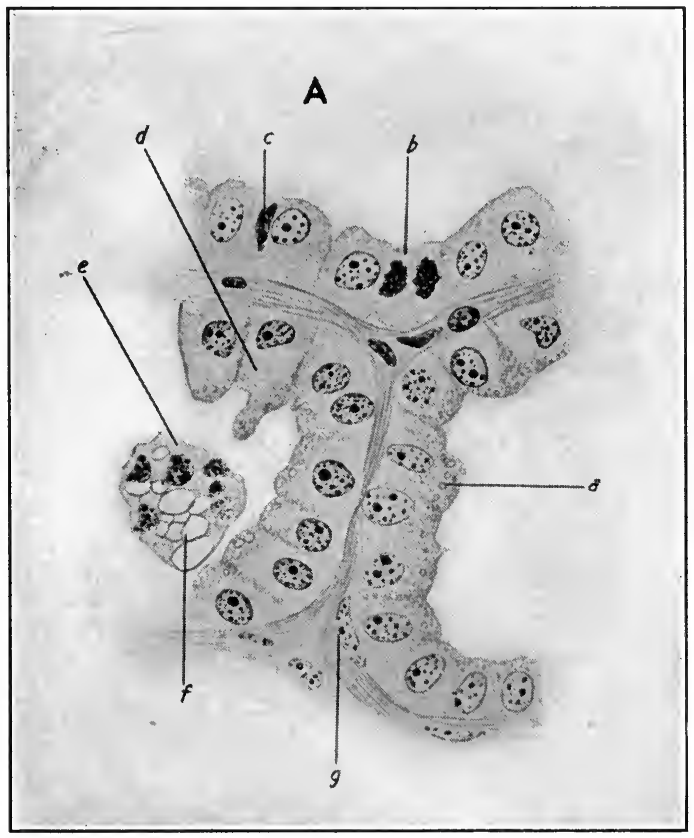

Fig. $99 A .-$ Alveoli of the mammary gland of the goat at the time of parturition. Beginning of fat formation. a, fat droplets in the epithelium; $b$, division of the nucleus (daughter nuclei) ; $c$, leucocyte in epithelium; $d$, epithelial cell with protoplasmic prolongation; $e$, alveolar contents with cells ; $f$, free fat; $g$, interalveolar connective tissue. (After Martin.)

plasm undergoes marked changes and the characteristic globules of fat appear (Fig. 99A). This important function of the epithelial cells which line the finer sections into which the lumen of the udder is divided can be demon- 
strated, microscopically, by comparing the appearance of the active cells in the secreting udder with those that are inactive, in the dry cow or the virgin heifer (Fig. 99B).

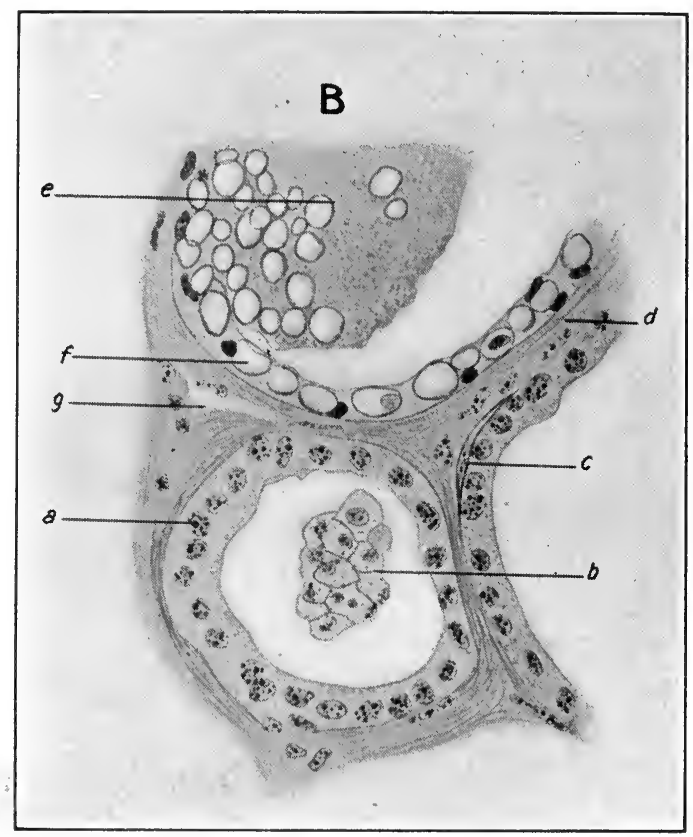

FIG. $99 \mathrm{B.}-$ Alveoli of the mammary gland of goat at the time of parturition, showing successive stages of secretion. $a$, epithelium at rest; $b$, alveolar content consisting of cells; $c$, smooth muscle cell ; $d$, connective tissue; $e$, alveolar content consisting of coagulated casein and free fat; $f$, fat droplets in the epithelial cells; $g$, blood capillaries. (After Martin.)

223. Dairy type (Figs. 100 and 101). - Since the production of milk and beef are not correlated, the dairy form is characterized by an extreme absence of all that pertains to beefiness. The form in general is triangular instead of rec- 
tangular, outlining the so-called wedges, the appearance of which is contributed to by the features of structure already enumerated, the functions of which are prerequisite to milk production. Both reproduction and milk production are distinctly feminine functions, hence femininity should dominate the make-up of a dairy cow. The feminine form is

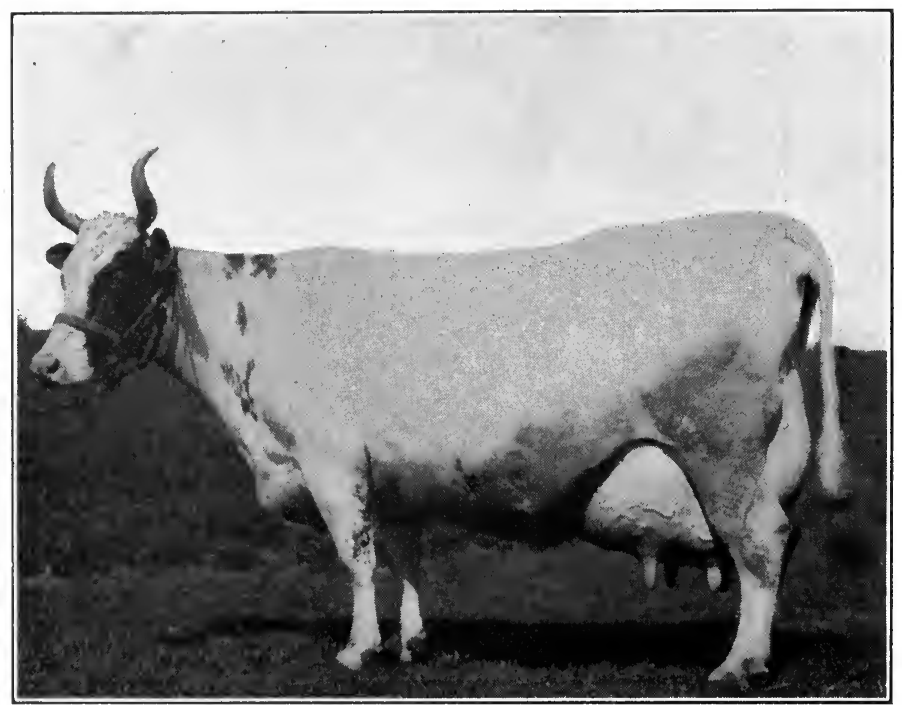

Fig. 100. - A typical dairy cow.

characterized by a light, shallow, narrow forequarter and correspondingly greater width and depth of the hindquarter. This, of itself, is suggestive of both a horizontal and a perpendicular wedge, the apex directed forward whether seen from the side or the front. The wedge or triangle suggestion is made more pronounced in the profile view by the base of the triangle being extended to the 
lowest point of the udder at which the under line begins. This line is kept low at the rear by a deep back rib and full flank, features of digestive capacity, but inclines gradually upward on account of the absence of the square brisket that is characteristic of the beef type and the male

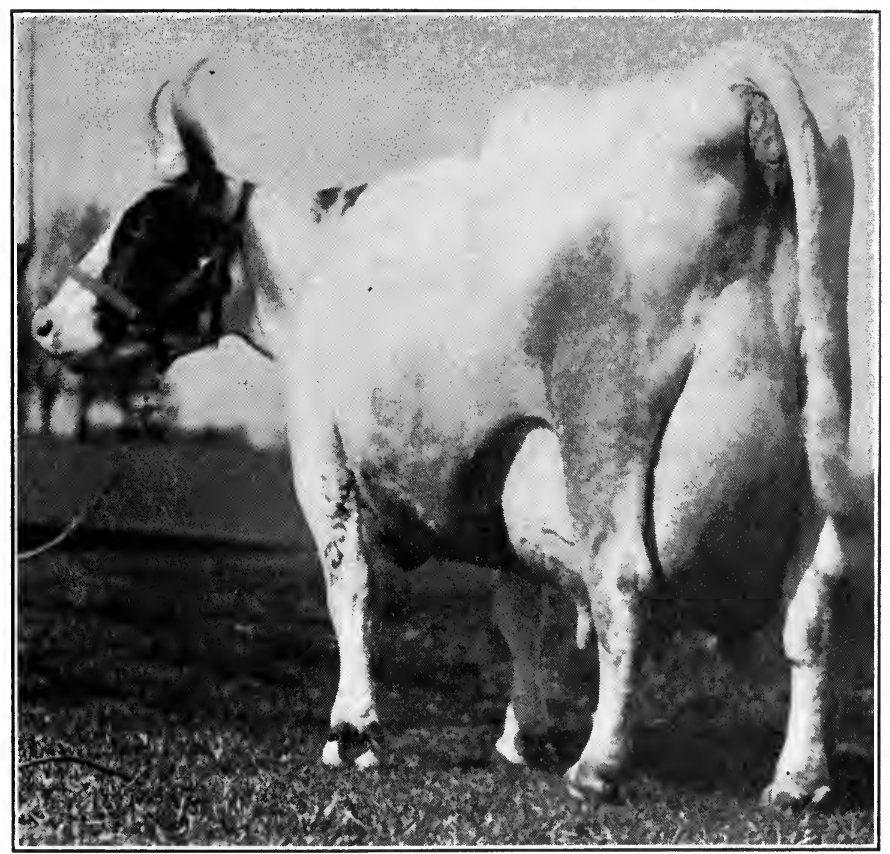

Fig. 101. - A typical dairy cow, rear view.

and is, therefore, foreign to the dairy female. The very lean neck and fine throttle complete this under line, the head being eliminated from consideration. The light, narrow shoulder and chine that is correlated with femininity and the absence of beefiness, with the width on the floor 
of the chest that a cow must have in order to insure ample heart and lung capacity, are responsible for a third triangle, the apex of which is directed upward and is most easily made out when the chine is looked down upon. A fourth, an inverted triangle, may be demonstrated in the hindquarters. The long, broad, level rump forms the base, while the light thighs, concave from both side and rear view, form lines which, inclining downward and inward, approximate an apex. These triangles or wedges, it should be understood, are the effect rather than the cause of a cow's being productive, and mean little except that they represent capacity of the reproductive, digestive, respiratory, circulatory and nervous systems in a female whose proclivities are most extremely opposed to beef production.

224. Conformation. - A long, narrow feminine head with a straight face line, except as altered by breed character; a large, clear eye, with mild expression, yet indicative of nerve force; forehead broad and flat; ears of medium size, fine texture, set high and well carried; horns that are symmetrical in size and shape, of fine texture, with considerable curvature to distinguish them from the long, spreading, straight horn of the steer and the short, heavy horn of the bull, the size, shape and color of the horn being features of breed character and varying accordingly; the neck long and lean in the extreme, showing concavity of both top and sides and a light, clean-cut throat; the shoulders long, light, well laid in and narrow on top; the forelegs straight with ample bone; the chine narrow and light, its spines sharp and wide apart or open, the foreribs deep and arched below; the back long and straight, with no sag, the back ribs well sprung and deep; the loin broad and level, the flank deep but rather open; the hips 
wide apart, prominent, as in an open frame, and symmetrical ; the rump long, level, broad and lean, the pin bones wide apart, the tail head smooth and on a line with the back, showing no droop, the tail long and fine with ample switch; the thighs long and lean, concave from both side and rear view, any natural tendency to beefiness

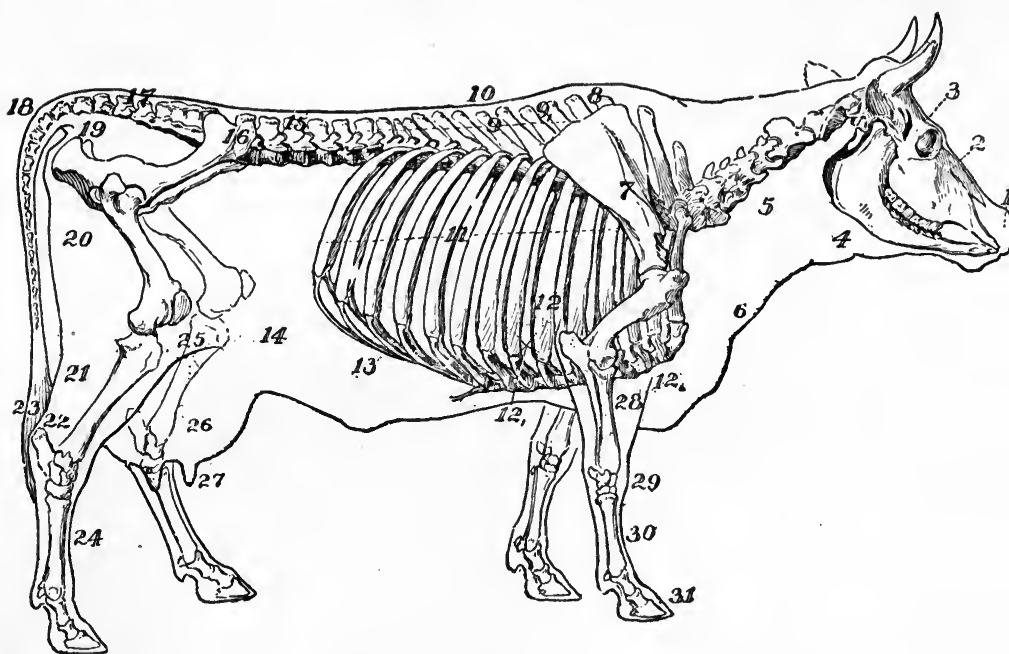

Fig. 102. - The points of the cow. 1, muzzle; 2 , face; 3 , forehead; 4 , throat; 5 , neck; 6 , dewlap; 7 , shoulders; 8 , wethers; 9 , back; $9_{1}$, crops ; 10 , chine ; 11 , ribs ; 12 , foreribs; $12_{1}$, foreflank; $12,12_{1}$, chest; 13 , belly; 14 , flank; 15 , loin ; 16 , hips ; 17 , rump ; 18 , setting of tail; 19, thurl or pin bone; 20 , quarter; 21 , thigh; 22 , hock; 23 , switch; 24 , leg; 25 , stifle; 26 , udder ; 27 , teat; 28 , forearm; 29 , knee ; 30 , shank; 31 , hoof.

manifesting itself here; the hind legs straight and strong; these are the points of the productive dairy cow.

Udder. The udder is considered last because its efficiency is not independent but is contingent upon all other structural and functional features of the cow. The three 
essential features of the udder are its size, shape and texture (Fig. 103). Size is determined by its attachments, which should be high up between the thighs behind and well forward along the abdominal wall below. These attach-

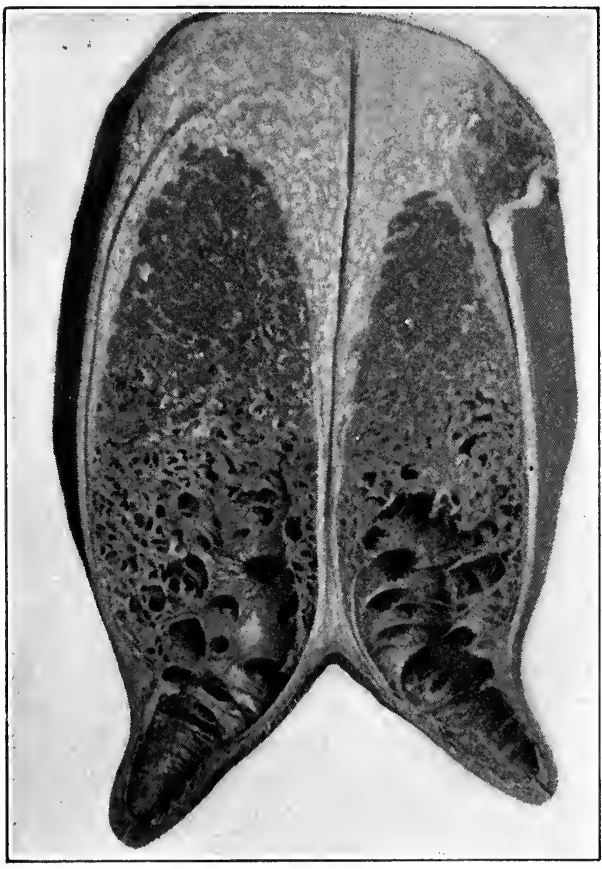

FIG. 103. - Section of the cow's udder showing the internal structure and arrangement of the gland.

ments may be considered as the basis of the udder, and are a reliable indication of its real size even in the dry cow or the one just milked out. It should not be necessary to "stretch" udders in order to ascertain their size: The suspension from these attachmentsshouldalso be considered. A pendant udder may have the appearance of being large, while in reality there is less gland present than in a much smaller but wellsupported udder. With these points fixed, the shape of the udder is next concerned in establishing its capacity. The mammary gland is divisible, longitudinally, into two lateral halves, also transversely, into an anterior and a 
posterior or a fore and hind half. Therefore either half may be subdivided into quarters. The most capacious udder, size as fixed by attachments being equal, is the one in which all four quarters are equally well developed, producing a square and level shape. Finally, even though size and shape of udder are both good, there is one more factor that may still determine great variation in productiveness, and that is texture. The udder, like any other gland of the body, is composed of two kinds of tissue, the gland tissue proper which does the actual secreting of the milk, and an interstitial connective tissue of a fibrous nature which serves as a framework for the gland. It is obvious that the latter tissue has no part in the function of the udder, although a certain amount is necessary for the construction of the gland. The udder that is most productive, therefore, is the one that contains the most of the active glandular tissue and only as much connective tissue as is required to support the gland. The relative proportions of these two kinds of tissue in the udder structure are indicated by the feel of the gland; if firm and beefy the connective tissue is in excess, while if soft, elastic and glovelike, being covered with a thin, pliable skin upon which is a light growth of fine hair and the blood vessels are distinctly marked, the udder is composed of the maximum amount of gland tissue proper and is capable of maximum production. Such an udder almost completely milks away, leaving only a few soft folds where, previous to milking, the udder had completely filled the space between the thighs. The former kind, on the other hand, appears of about the same size and shape after the milk has all been withdrawn.

Udders may be so badly stretched by prolonging the periods between milkings, or cows may be judged in such varying stages of lactation that the udder alone cannot 
always be considered to gauge a cow's productive capacity. The mammary (milk) veins and wells are accessories which may be valuable aids in determining the capacity of an udder, especially if the cow is not in full milk. The mammary (milk) veins are the blood vessels which carry the blood away from the udder and the wells are the orifices in the abdominal wall through which the veins

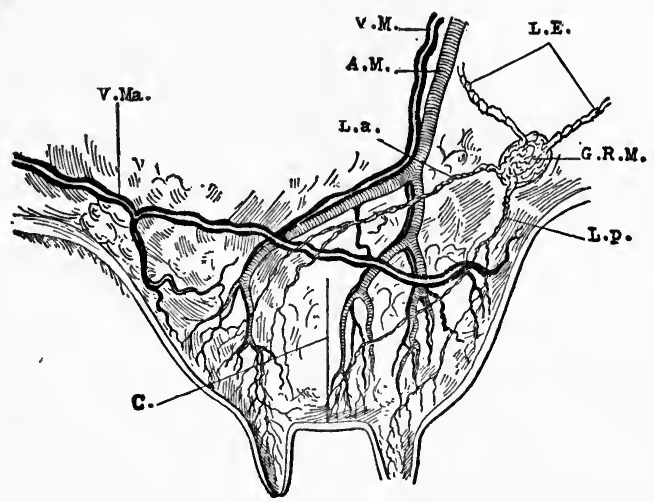

FIG. 104. - Section of cow's udder. G.R.M., lymph gland of udder; L.p., lymphatics of hindquarter; L.a., lymphatics of forequarter; L.E., lymphatics leaving the udder; A.M., mammary artery; V.M., mammary vein; V.Ma., anterior mammary vein; $C$, transverse inter-mammary septum. (After Moussu.)

enter to unite with the general venous system. Their significance lies in the fact that their capacity is proportioned to the amount of blood which is supplied to the udder, the arteries being so deep seated as not to be visible (Fig. 104).1 A vein of large caliber and tortuous course indicates a large flow of blood to the udder, while a small vein passing directly from the udder to its well indicates

1 The so-called milk veins are designated, anatomically, as the anterior mammary veins to distinguish them from the middle and posterior mammary veins which together drain the venous ring at the base of the udder. 
the opposite. Since the raw materials from which milk is produced are conveyed to the udder in the blood stream, the relation between blood supply and production is very intimate. The size of the wells corresponds to the size of the veins and the larger, more tortuous veins usually branch and send small ramifications through smaller wells, the so-called extensions, of which there may be two or three.

The escutcheon, that area on the inner, posterior face of the thigh where the hair is directed the reverse way, was formerly believed to indicate the blood supply and through it the capacity of the udder. This theory was first advanced by Guenon, a Frenchman, but little importance is attached to it now.

Teats should be placed in the center of the quarters and if the latter are of the proper size and shape the teats will all be equidistant and directed straight downward, in parallel lines. They should be of sufficient size to insure a good grasp with a man's hand, short teats being an abomination in this country. where men milkers are most common. The teats should not, however, be so long as to render them liable to be tramped upon by neighbors when the cow is lying down and the udder, with its teats, is protruded sideways. They should be regular in form and tapering. Supernumerary teats, while they may indicate extra development of the mammary system, are usually objectionable.

225. Quality.-Quality of cow and quality of milk are not correlated, exactly, yet the refinement of structure manifested by the cow may have a direct bearing on productiveness. The udder being composed of a framework of nonsecreting tissue and the essential secreting gland tissue which it supports, the more there is of the latter, the greater the capacity of the udder and the finer its 
texture. Quality implies a fine texture of udder just as much as of hide, hair and bone.

Quality in the dairy cow is indicated by a hide of medium thickness, loose, pliable and unctuous, covered with a medium coat of fine, straight, lustrous hair; a high grade of bone, noted in a fine head, smooth shoulders, hooks, pins and tail head and sharply defined joints; horn of medium size, and dense, smooth texture. Coarseness is especially indicated in the parts enumerated and in a general absence of refinement.

226. Substance, as indicated by size rather than by bone, is important, it having been demonstrated that the larger cow produces more economically than the smaller one.

227. Constitution. - The consumption and utilization of the nutrients required for the production of 25,000 pounds of milk or 1000 pounds of butter annually, involves the activity of the functions of digestion, respiration, circulation and lactation to their utmost capacity, and none but cows of the strongest constitutional vigor are capable of such performance. Constitution is indicated by a full chest, a deep flank, a large nostril, a bright eye, a sleek coat and general evidence of thrift and vigor.

228. Condition of the dairy cow in milk is best expressed by the term "spare." Thin is suggestive of emaciation while a working dairy cow is in the best of health and thrift. Spare means without surplus, and that is most descriptive of ideal dairy cow condition when she is retaining from the ration sufficient nutrients for her maintenance only, utilizing all the balance for production. Lean is also expressive of the dairy condition, as it implies the absence of fat or beef. 
229. Temperament. - The dairy cow is of a nervous temperament compared to the lymphatic temperament of the beef steer. Resourceful in nerve force, yet not restive, is the ideal. Dairy temperament is indicated by evidence of nerve force as expressed by the eye, the absence of any beefy tendency, the spare condition associated with dairy capacity and an open, loose-made frame, especially in evidence in the chine.

230. Dry cows. - One is often called upon to buy or place cows after the conclusion of one lactation period, and before they have freshened again. It is obviously a more difficult task to rate them aright under such conditions than when in full milk. The higher condition which they naturally acquire when not producing must be distinguished from actual beefiness, and the inactive udder from one of normally limited capacity. The fat cow will show it most over the back, while the beefy cow is thick in the neck and thighs as well. The attachments of the udder high up behind and well forward, also its texture and balance may still be made out, although the form is much altered and the size reduced. The placing of the teats is a valuable guide in the case of the dry cow as well as in the heifer.

231. Heifer calves. - The judging of young heifers involves some features not enumerated in the judging of milking cows. It cannot be expected that the calf will be a "perfect little cow." Like the feeder steer, she is the dairy cow in prospect, and must have embraced in her make-up the essential features of dairy form and function, such as a refined, feminine head and neck, a loose, soft, sappy hide, ample chest and abdominal capacity and a suggestion of milkiness in both fore and hind quarters (Fig. 105). Special importance is attached to 


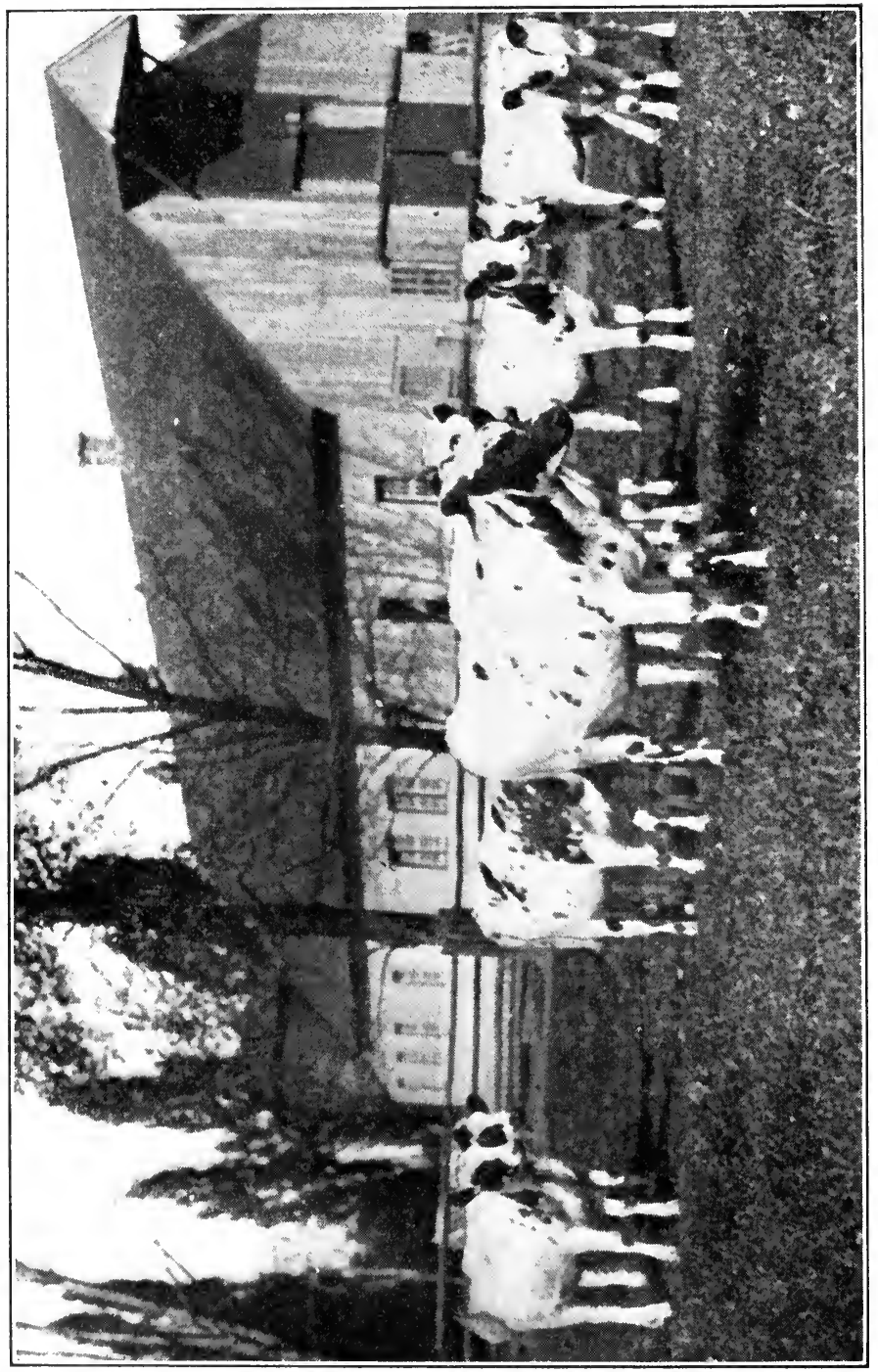

量 
the size and placing of the teats, they being about all of the mammary apparatus that is apparent at this age. Teats of uniform size, placed equidistant and well apart, are indicative of a large, well-formed udder at maturity. Heifers, like dry cows, are usually in higher condition than after calving, when their fat " milks away," as it is commonly described.

232. Method of inspection. - The cow should be viewed first from in front, noting her feminine appearance, her triangular wedge shape and size, then, more in detail, the size, dimensions, proportions, contour and features of her head; passing to the side, observe again the wedge form, outlined by her top and under line, also her head in profile, her throat, the length and leanness of her neck, the lightness and the sharpness of her shoulder and chine, the depth of her forerib, the thickness through the lower part of her chest, the great depth of back rib, the width of loin and hips, the length, levelness, leanness and smoothness of her rump and the extreme leanness of her thighs; from the side the hide over the back rib is handled to determine its thickness, looseness, pliability, the amount and fineness of the hair and the abundance and the color of the skin secretions, these secretions being also examined in the ears, under the tail and at the depth of the switch. Also, from this position, the size, form and texture of the udder, the size and placing of the teats, ogether with the size and course of the mammary veins and wells may be determined. This examination should be continued from the rear position, in which may also be made out the inverted, perpendicular wedge of the hindquarters, the width of loin, hips and hindquarters, the relative width of hook bones and pin bones, the leanness of thighs, the width between them and finally the es- 
cutcheon, its extent and form. The inspection is concluded by a look at the other side, noting again, as has already been done, the openness of the form as indicated in the chine especially, and the general spare appearance indicative of the dairy temperament. It is well to move the cows about in order to verify or extend one's estimate of them.

\section{Dual-purpose Cattle}

233. Production. - Cows of this type are to serve the twofold purpose of milk and beef. In principle and theory the dual-purpose idea is subject to some logical opposition, but the dual-purpose cow is a matter of fact, $90 \%$ of the milk supply of London being derived from milking Shorthorns, the breed that also furnishes a large part of the beef consumed in Great Britain. The principle is opposed on the ground that milk and beef are extreme opposites under the law of correlation, and therefore their joint production, in the same animal, is contrary to the laws of nature. And so it is if extreme production in both lines is attempted, but between any two extremes is a mean, represented by an intermediate or halfway position. It is, therefore, perfectly reasonable to expect from one individual the production of milk to the extent of one half the normal in dairy cows, and the production of a carcass of beef at least $50 \%$ as valuable and one half as economically produced as in the case of a typical beef steer. This is all that should be attempted and apparently all that can be accomplished in the perfection of the dual-purpose cow. The great difficulty seems to be that breeders are not satisfied to maintain this middle ground, but are ambitious to make either dairy or slaughter records with their so-called dual-purpose cattle. Even the judging of the leading dual-purpose breeds has been 


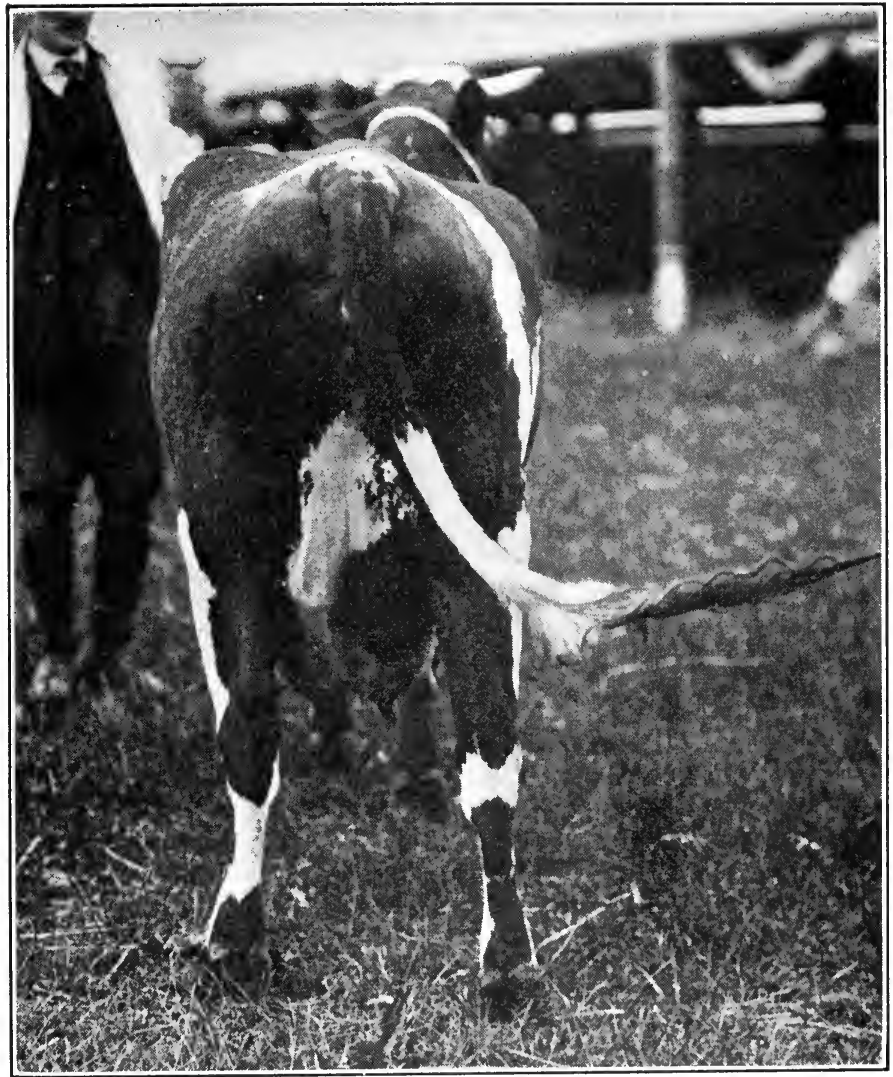

FIG. 106. - A typical dual-purpose cow.

most inconsistent on this account. One judge, presumably from the Middle West, will lay special stress on the beef form, with an utter disregard for udders, while an Eastern judge is just as liable to place the cows in the order of dairy merit only. 
The half-and-half principle is fundamental, and whenaver it is deviated from, the dual purpose is defeated. The ideal dual-purpose cow is one which will produce milk of such quantity and quality as to return a profit over and above her cost of keep, and at the same time possess a sufficiently beefy form to insure her male calves feeding satisfactorily into acceptable butcher cattle, while she herself and her daughters will yield a profitable carcass when their usefulness in the dairy is over.

Another difficulty in the way of dual-purpose attainment on the part of the breeder is the fact that the proposition is self-limiting. Many of the best dual-purpose cows are bought up by dairymen who follow the practice of milking a cow only through one milking period, then turning her to beef and the butcher. Thus the breeding value of the best cows is lost, and what calves there are produced are likely to have second-rate cows for their dams.

234. The dual-purpose type. - The half-and-half idea also prevails in the make-up of the dual-purpose cow (Fig. 106). She has considerable scale, more than is common in dairy cows, her form is less beefy than is typical of the steer, but more beefy than the typical dairy cow, while she is less milky in form than the representative dairy cow, but more milky than the fat steer. Her udder will probably be as large as that of a dairy cow, but inferior to it in both form and texture. Heifer calves should develop into the likeness of their dams, and the bull calves follow the same general type, but, being males, they will incline more naturally to beefiness. In practice it seems to be less difficult to get a cow that will give 10,000 pounds of milk annually and still retain her beef form, and make a profitable and acceptable carcass, than to secure from her a male calf that will make a steer altogether satisfactory to either feeder or butcher. 


\section{CHAPTER XII}

\section{THE BREEDS OF CATTLE}

Cattle breeds may also be classified according to type, viz. : =

$$
\text { Beef }\left\{\begin{array}{l}
\text { Short-horn } \\
\text { Hereford } \\
\text { Aberdeen-Angus } \\
\text { Galloway } \\
\text { Polled Durham }
\end{array}\right.
$$

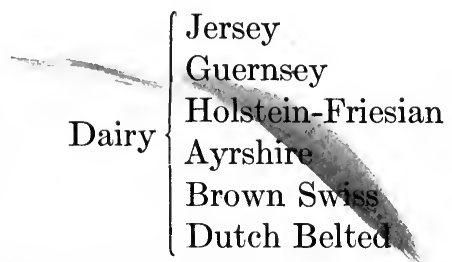

The chief features by which typical representatives of each of the breeds may be differentiated are size, form, character of head, hide and color.

235. The Short-horn. - This, the first of the beef breeds to be improved, and the one to which were devoted the efforts of that select group of eighteenth century stock men, who proved out the theories of Bakewell, and established the principles upon which modern live-stock husbandry is practiced, is of extraordinary importance because of the improvement wrought by it on the common stock the world over. The representative Short-horn (Fig. 107) is essentially a beef animal, and unless specially qualified should be so considered. (Milking Short-horns are discussed in the dual-purpose group.) Short-horns may be differentiated from the other beef breeds by greater size, 
the cows weighing 1400 to 1600 pounds, and the bulls 1800 to 2400 pounds; a more distinctly rectangular form, especially marked at the ends, on account of the square brisket and very long, broad and deep thighs, and a proportionately broader and flatter back, particularly toward the hindquarters; a head full of character and refinement, horns that are short, medium fine, white and waxy in appearance with black tips and well curved; and a hide

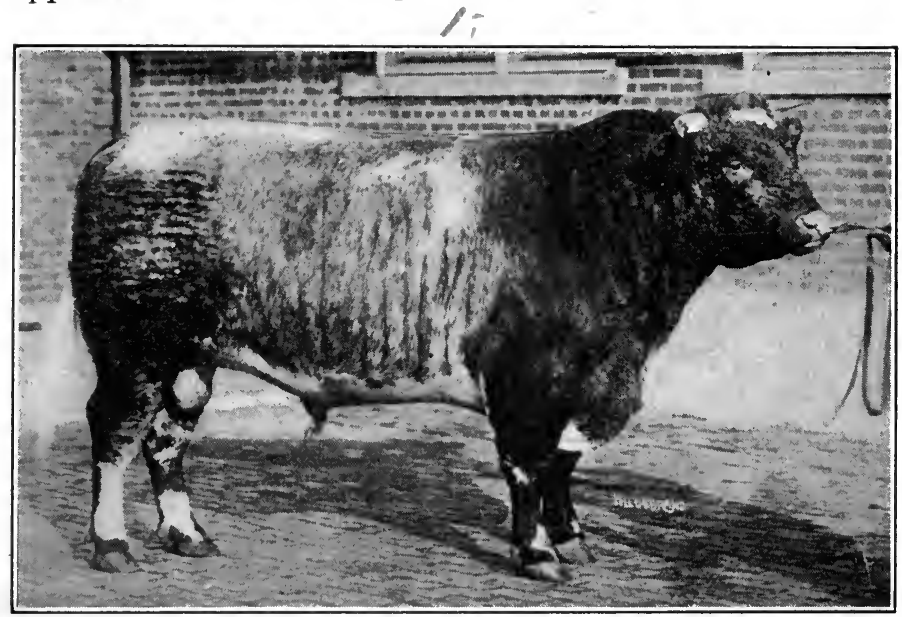

FIG. 107. - A Short-horn bull.

of medium thickness, loose, pliable and sappy, covered with a heavy but mossy coat of hair. The Short-horn colors are red and white, either one exclusively or both in any possible combination, as red, white, spotted or roan. The whites are no longer discriminated against, nor are the reds especially preferred, while roan is regarded as the most representative color.

Typical Short-horns should give evidence of early 
maturity and rapid fattening, and promise of dressing out most profitably a high-class carcass of beef. A lack of general conformity to the most approved beef type is sometimes noticeable in this breed, some leggy individuals . appearing in the ranks. Also rough hips, a drooping rump and a tendency to accumulate fat unevenly in patches about the tail head and the pin bones are un-

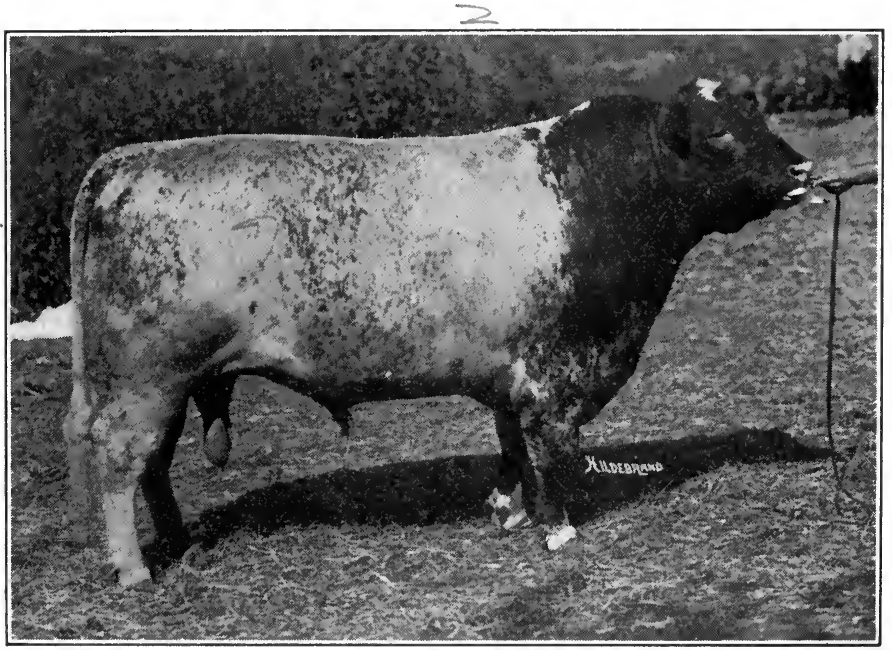

FIg. 108. - A Polled Durham bull.

desirable features, which breeders have endeavored to eliminate.

236. Polled Durham (Fig. 108). - This breed is an American derivation from a straight Short-horn foundation, chiefly, the majority of Polled Durhams being doublestandard, and therefore entitled to full registration in the Short-horn herd book. The aim of the Polled Durham breeders is to duplicate the Short-horn in all respects 
except the horns, and they are, therefore, judged on the same basis.

237. The Hereford. - This breed, developed from a race of cattle native to Herefordshire, England, a district noted for its grassland, received mention as early as 1627 for being unusually economic and rapid producers of beef, characters for which the breed is still most noted. They have the reputation, in this, country, of meeting, excep-

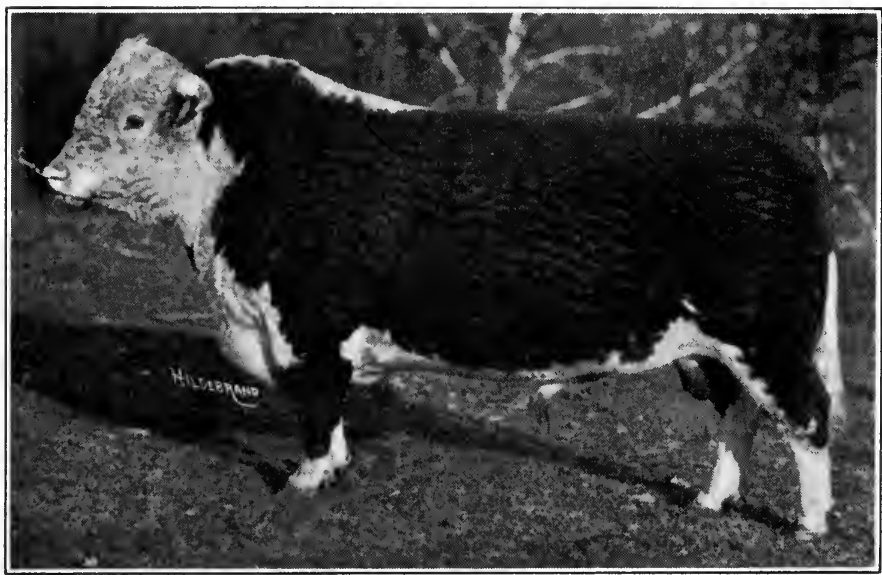

Fig. 109. - A Hereford bull.

tionally well, the conditions of our southwestern range country where beef is made from grass and frequently under most adverse climatic conditions, such as drought. Herefords are also conspicuous in the feed lots of the Middle West.

There is a striking uniformity among the best representatives of the Hereford breed (Fig. 109), especially in the matter of color. They are among the heaviest of beef 
cattle, although, being unusually low and blocky, they do not appear to possess as much actual scale as Short-horns do. The form is less square and more cylindrical than that of the Short-horns, their thighs being full and rounded, rather than straight. The head is short and broad, eyes prominent, the skin about the eyes and the muzzle being flesh-colored; the horns are rather strong, creamcolored, with no black at the tips, spreading, and in bulls directed forward with a characteristic droop. The hide is somewhat heavy, but loose and pliable, and covered with an abundant coat of long, curly but soft and fine hair, which covers the forehead in heavy curls and hangs in locks from the ears. The color, while originally the cause of much dissension among Hereford breeders, has become a most distinct and characteristic feature. Other breeds are red and white, but the distribution of the white in the Hereford is most regular. The face, usually including the ears, jaws and throat, is white, evidence of the old mottled faces being noticeable sometimes in red spots about the eyes; the under side of the neck, the dew lap, the brisket, more or less of the under line, the legs and the switch are also white, and, most curious of all, there is a clear-cut white stripe on top of the neck from about its middle to the top of the shoulders. The balance of the neck, body and legs are red, either of light, medium or dark shade, the medium being preferred. On account of the regularity with which these white markings occur, the Herefords are popularly known as "White Faces."

238. The Aberdeen-Angus. - Two distinct races of polled cattle have existed in Scotland since the earliest times of which we have record, one in northeastern Scotland, which was later evolved into our modern AberdeenAngus, and the other in southwestern Scotland, the ante- 
cedents of the Galloways. The hornless cattle of northeastern Scotland, the best of which were black, first attracted attention on account of the superior carcasses of beef which they dressed out. Their pioneer breeder was a cattle buyer, who early appreciated their butcher value and bred for improvement along that line. Partisans of the breed to-day assign to them first rank among butcher

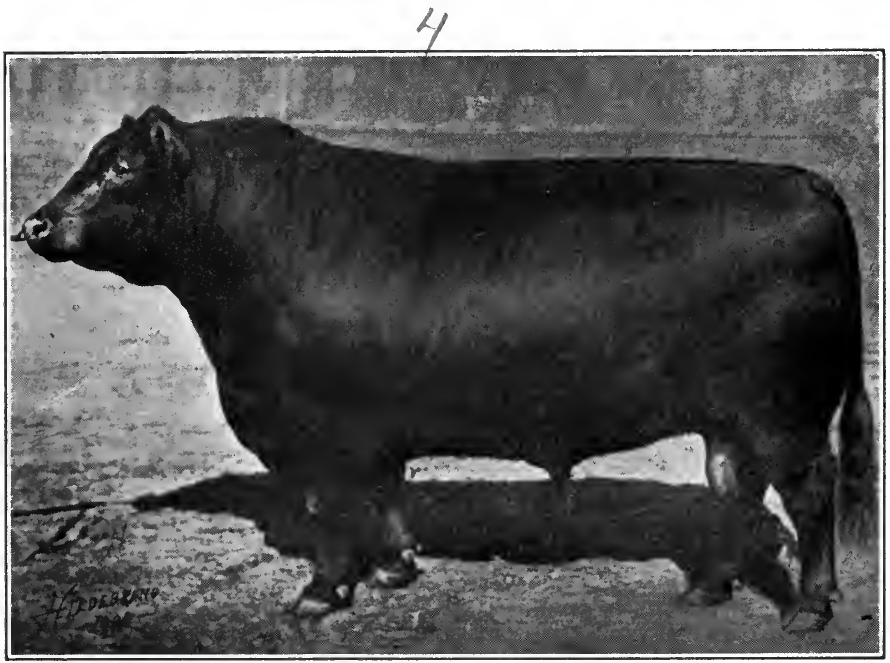

FIG. 110. - An Aberdeen-Angus bull.

beasts as attested by actual competition in slaughter tests to which they refer. Aberdeen-Angus cattle do possess a fineness of bone, a wealth of natural flesh, a capacity to finish evenly and smoothly with a resultant splendid marbling of the lean, which is distinctive of them.

Angus cattle (Fig. 110) are heavy on account of their compact build, but they are not, as a rule, as large as either Short-horns or Herefords. Their form is most 
characteristic; they are extremely short-legged and have a distinctly cylindrical contour, being compact, rotund and smooth. Their naturally fine frame is amplified by an unusual muscular system, which leaves no angles or points in their outline. The head is also readily distinguished from the head of other polled cattle. The forehead is especially broad between the eyes, tapering distinctly from that point to the muzzle below, and upward to the pole, which is prominent, and sharply defined. The hide is of medium thickness, very mellow and covered with a good coat of thick, but soft and short hair. Compared with the rough coats of the other beef breeds, the Angus coat is smooth. The color should be black with no reddish or brindle cast, as was common among some of the foundation animals of the breed. White on the under line back of the navel is permissible, but undesirable.

Heavy open shoulders, scurs, the occurrence of red or brindle color, or too much white are characters which Angus breeders guard against.

239. The Galloway. - Although the oldest and purest of the beef breeds, the Galloway cattle are the last to be bred for systematic improvement, and results have been most marked during the past decade. They have done best in this country on the northwestern ranges, where their protective coats, hardihood and rustling ability have enabled them to do well under most rigorous conditions.

While both are black and polled, the breed characters of the Galloway and Angus are not difficult to distinguish. Galloways (Fig. 111) average lighter in weight than the representatives of the other beef breeds described. Their form is less cylindrical than the Angus or Hereford, having more of the square outline of the Short-horn, but 
with less breadth and thickness. The head is somewhat longer than that of the Angus, but is of more uniform width, not tapering to the muzzle nor to the poll, but broad at the crown with an oval-shaped, rather than a high-pointed, poll. The ears are carried in a peculiar fashion characteristic of this breed. They are set well forward and high, and may be pointed upward and for-

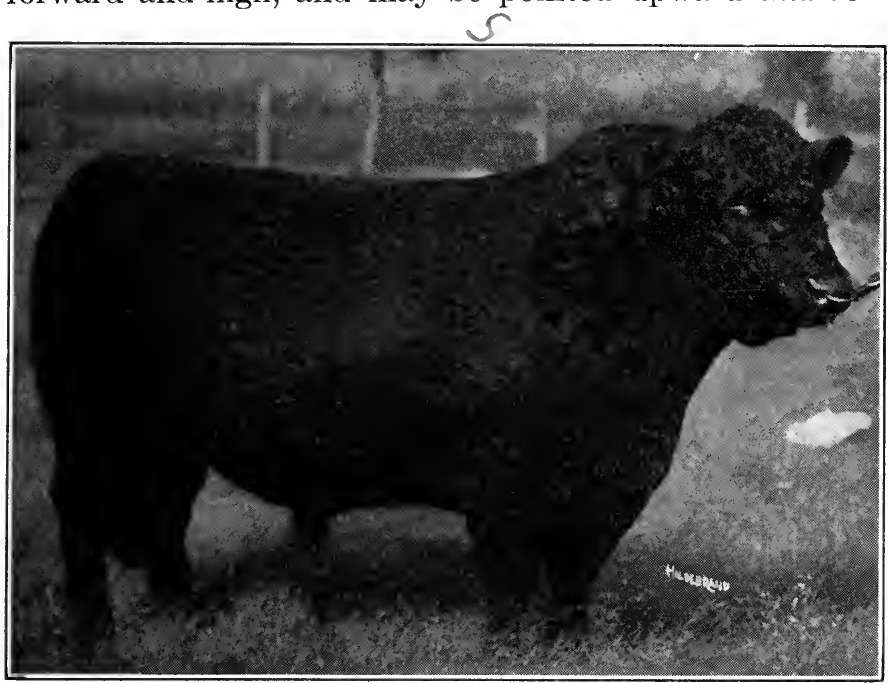

Frg. 111. - A Galloway bull.

ward. The hide is of medium thickness, loose and pliable, and covered with a coat of hair which furnishes one of the most distinctive characters of the breed. The coat is really double, a soft, fine, mossy or furry under coat being overlaid with a long, curly, heavy hair coat, which gives them an extremely shaggy appearance with a heavy mat of curls on the forehead and locks in the ears. Hides taken when the cattle are in full coat sell at a premium on 
account of their value for coats, robes, rugs, etc. The color of the Galloway is black with a peculiar cinnamon tinge, especially noticeable in the under coat and the coat of new-born calves in which it predominates. Any white on the extremities or above the under line is objectionable.

The first Galloways brought forward in this country were very rough, unsymmetrical individuals, especially deficient in spread of rib, and slow to mature and ripen. Some individuals of the breed still show deficiencies in these respects in spite of the great improvement that has been wrought. Prominent tail heads, heavy shoulders, with a disproportionate height between fore and hind quarters, forequarters being low, flat ribs and an absence of condition are respects in which the breed is still subject to some correction. Too much white and the presence of scurs will also count against Galloways.

240. The Jersey. - A definite scale of points having been formulated and agreed upon by the Island breeders as early as 1835 , since which time great care has been taken to keep the blood lines pure, Jerseys are very uniform in breed type and character (Fig. 112). Cows weigh 800 to 1000 pounds, bulls 1200 to 1500 pounds. Their form is especially symmetrical, although distinctly dairy, and shows great refinement. The head is short, broad and deep, the face lean and distinctly dished between the eyes, the eyes wide apart and unusually prominent, ears small, fine and showing rich yellow secretion within, the muzzle black or dark blue surrounded by a light, mealy colored strip of hair and skin, the horns small, fine, white, sharply incurving, waxy in appearance and usually black tipped. The skin is thin, loose, mellow, yellow in color, showing an abundance of rich secretion 
and covered with a very fine, smooth coat of hair. Fawn is the typical Jersey color, ranging from the lightest lemon to the very dark or mulberry fawn. The darker colors are preferred on bulls. The presence of much white is generally considered objectionable in this country, although it is not mentioned in the scale of points, and some of the most meritorious animals of the breed have been spotted.

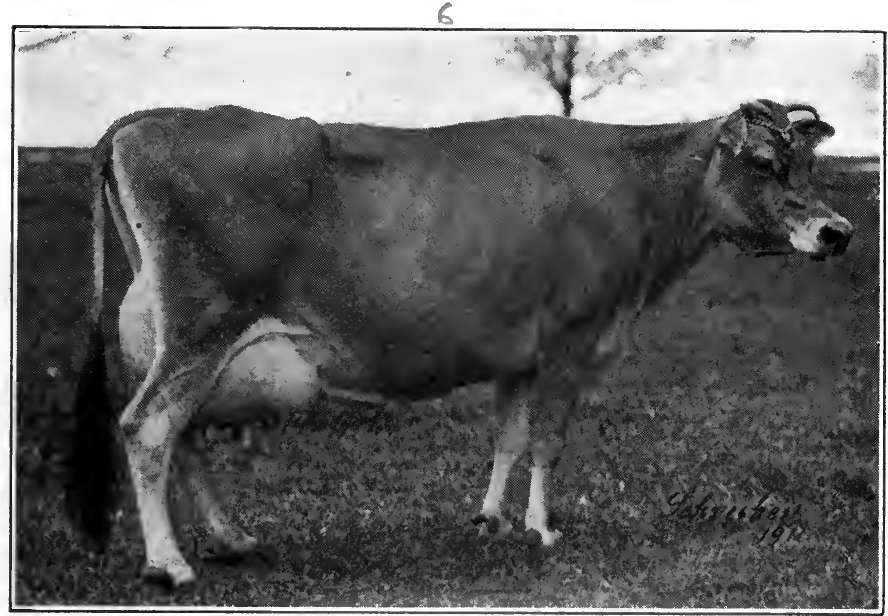

FIg. 112. - A Jersey cow.

Registry rules require that account be taken of the color of the tongue and the switch, whether light or dark.

The typical udder is characterized especially by its good texture and shape, size being commendable also when the size of the cow is considered. The teats are not large, but are well placed, and the veins are especially well developed, being very tortuous in their course, knotted in appearance and entering the abdominal cavity through large and usually several openings. 
Some Jerseys manifest a tendency to be undersized, too fine in bone and deficient in constitutional vigor. Their udders are also sometimes too small, not well balanced in front and with teats that are too short.

Distinction is usually made in this country between the Island and the American bred types of Jerseys. The former is characterized by much more symmetry and

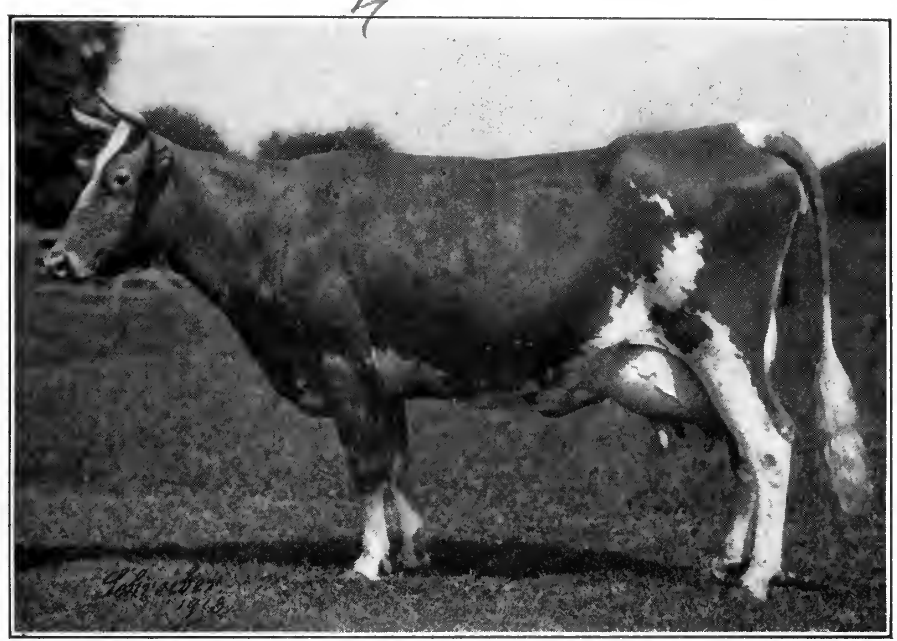

Fig. 113.-A Guernsey cow.

refinement, while the latter are cattle of greater size, more rugged appearance but of less uniform type.

241. The Guernsey. - While also native to one of the Channel Islands and derived practically from the same foundation, the Guernsey differs in many essentials from the Jersey (Fig. 113). They were not bred for points nor were such early efforts put forth to render them especially productive. They are, therefore, larger and plainer, of 
more substantial appearance, the cows weighing about 1000 and the bulls 1500 pounds; their form is indicative of dairy capacity, but is less symmetrical and refined and shows greater variation than that of the Jersey. The head is longer, with a comparatively straight face line, no dish, although the orbits are raised with unusual prominence; the muzzle is flesh or cream colored, a smutty appearance not being permitted, and the horns are medium sized, amber colored and symmetrically shaped. The skin affords one of the most striking features of Guernsey breed type in its rich, yellow color and the abundance of its highly colored secretions. This color is manifested wherever the skin is denuded of hair, as about the eyes, under the tail, on the udder and teats and even in the appendages of the skin, as the horns and the hoof, which are also of the deep amber hue. Guernseys are most commonly of a reddish fawn shade, broken by a considerable amount of white, although solid colors of other shades of fawn are not rare. The udder of the Guernsey cow is of good size, shape and texture with large teats, and veins to correspond. The lack of uniformity in shape already referred to in the description of the cows is even more noticeable in their udders, fore udders especially being deficient, with all four quarters cut up in many individuals.

242. The Holstein-Friesian. - This lowland race of dairy cattle reflect in their great size, their open frame and their enormous capacity both to consume and to produce, the environment under which they have been developed.

They are much the largest of any of the dairy breeds

- (Fig. 114), the cows weighing from 1200 to 1500 pounds and the bulls 2000 pounds or over. They have a most ca- 
very large and voluminous in accordance with its productive capacity; which in quantity surpasses any. The veins are also large and tortuous and the teats match the udder in size.

Some Holstein-Friesians are deficient in dairy temperament, showing a disposition to be beefy. Also heavy hides, drooping rumps, too pendant udders, which in

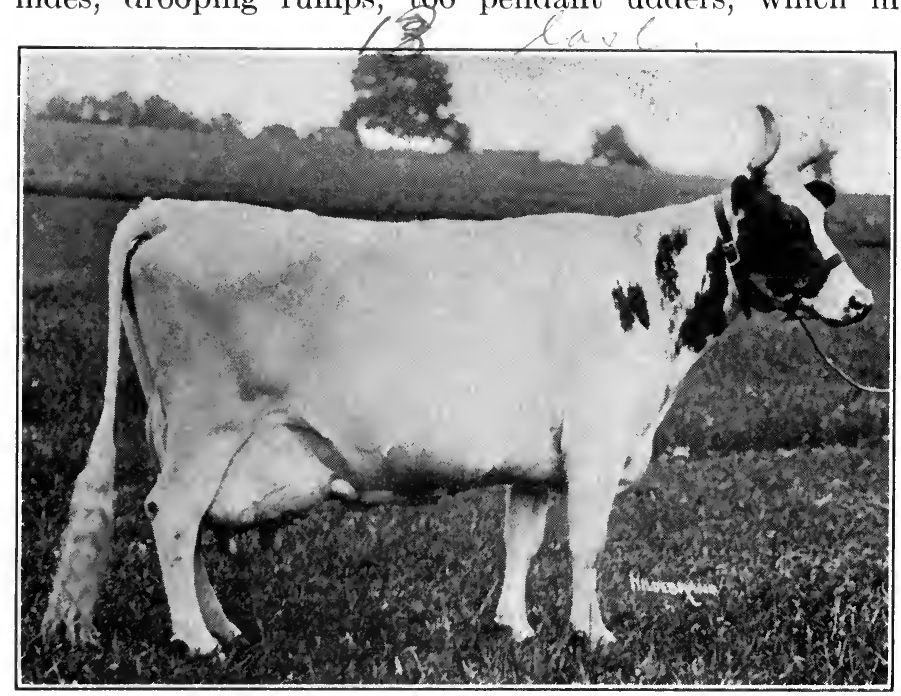

FIG. 115. - An Ayrshire cow.

addition may be beefy or badly cut up between the quarters, and unsymmetrical teats should be discriminated against.

243. The Ayrshire. - Representatives of this breed, created by the Scottish tenant farmer under conditions that called for thrift and hardihood, are of medium size, cows weighing 1000 pounds, bulls 1500 or more. Their form is the most symmetrical of any of the dairy breeds 
(Fig. 115), although it shows much less refinement than the Jersey, and Ayrshire cattle are of very uniform type. They lack some of the angularity which characterizes the dairy breeds, although the most typical individuals give no suggestion of beefiness. They are more short legged and compact in body than is usual in dairy cows. The Ayrshire head is very characteristic; it is of medium length and width, not especially fine, but surmounted with long, strong, symmetrical, white horns inclining generally upward, forward and outward with considerable spread, and a peculiar backward turn at the tips. The hide is of medium thickness, mellow and pliable, the secretions of a rich yellow or brownish color and the hair coat fairly heavy but fine. The most typical Ayrshire color is white and a peculiar red with a brownish cast (wine colored). The old-fashioned Ayrshire was more often red with white spots, while the more approved type now is white with red spots. The red is sometimes brindled, but this is undesirable.

The udder of the Ayrshire is one of its most distinctive features. In shape, especially in fore udder development, and in texture it is unsurpassed, while its size is greater than at first apparent, on account of the snug manner in which it is suspended against the abdominal wall. The teats are rather short but well placed, the floor of the udder being remarkably level, on account of the even development of all four quarters. Short teats are the charge most frequently brought against this breed, although some udders do not have sufficient capacity and some cows are undersized.

244. The Brown Swiss. - This breed is descendant from a very old race of cattle in the mountains of Switzerland. They have been generally considered a dual- 
purpose breed, but in order to encourage dairy production the Brown Swiss Cattle Breeders' Association have declared them a dairy breed.

They are of medium size, bulls averaging about 1800 pounds in weight, cows 1200 pounds (Fig. 116). Their form is characterized by a prominence of frame, as shown

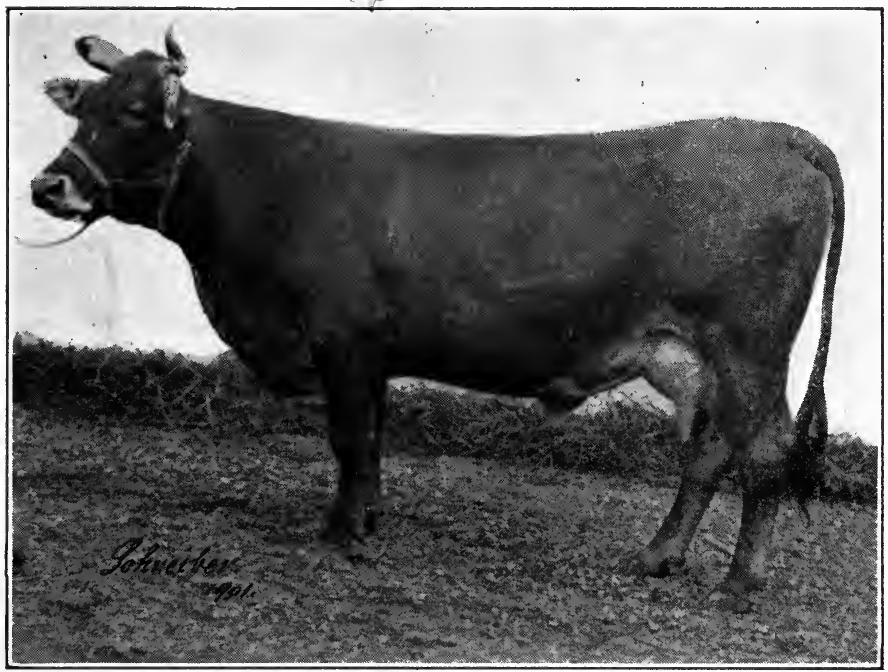

Fig. 116. - A Brown Swiss cow.

in the bone of the head, shoulders and cannons. They are lower set and less angular than the other dairy breeds. The head is long, broad and dished between the eyes, the horns rather short and flat, directed outward and upward with black tips. The hide is of more than usual thickness, but soft and pliable. Color is a peculiar shade of brown or brownish fawn, varying from light to dark, with a light tuft at the poll, inside the ears and along the 
back, a mealy colored muzzle, black nose, tongue and switch. The udder is of good size, with large, well-placed teats.

Coarseness of bone in head and shoulders, and an inclination to be beefy are rather uniformly noted in this breed.

245. The Dutch Belted (Fig. 117). - Of Dutch origin, but selected for the distinctive color markings, the Dutch

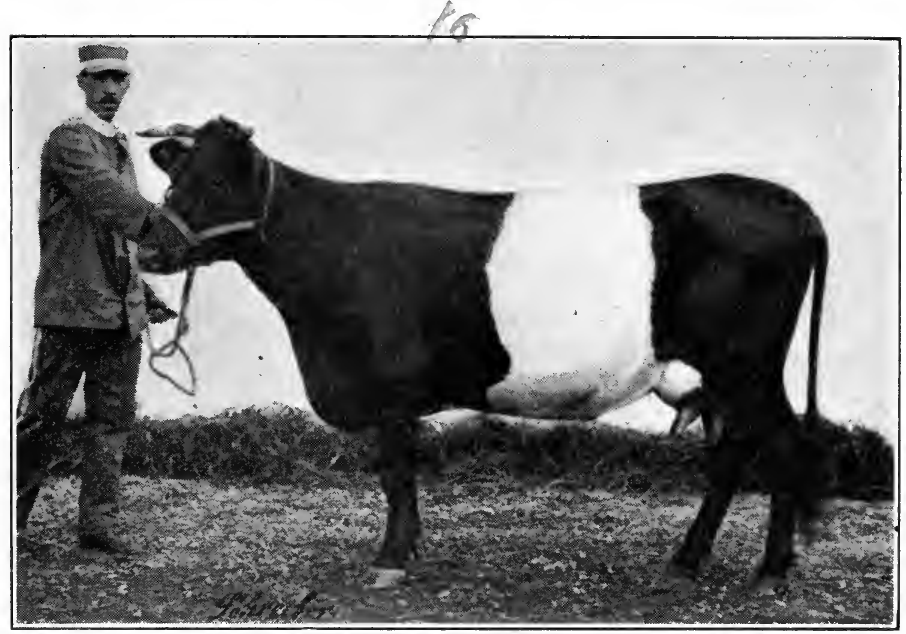

FIG. 117. - A Dutsh Belted cow.

Belted cattle are smaller than the Holsteins, cows weighing from 900 to 1300 pounds, and bulls up to 2000 pounds. They are of well-marked dairy form; heads are long and slightly dished, with long, fine, spreading horns, and dark tongues. Color is most distinctive, being black with a clearly defined white belt passing completely around the body, wide enough to just miss the shoulders in front and the hips behind, and showing no irregularities in outline. The udders are of good size and well developed. 
Having been selected especially for the characteristic belt, there is not the same improvement shown in this as in the other dairy breeds.

\section{Dual Purpose}

246. The Red Polled (Fig. 118). - This breed, founded in a combination of the dairy qualities of the old Suffolk

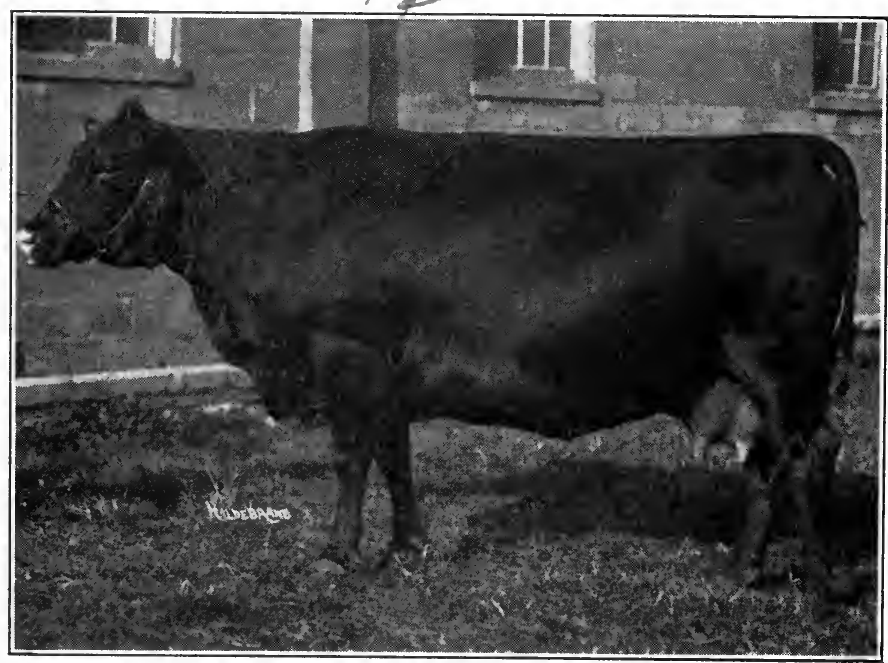

Fig. 118. - A Red Polled cow.

and the beef propensities of the Norfolk stock, is characterized by a uniformly red color, polled head and the capacity to produce milk in large quantity and yet retain the beef form in fair degree. They weigh 1200 to 1500 pounds for cows, 1800 to 2000 pounds for bulls. The form is that of the dual-purpose type. The head is of medium width, dished between the eyes and well finished with a 
prominent poll. The hide is loose, mellow and pliable even though of medium thickness, and the hair coat is fine, though abundant. The color is some shade of red; the cherry red being preferable to either the lighter or the darker shades. White is permissible in the switch, on the udder or along the under line as far as the navel only.

The udder is usually well developed for so beefy a cow, but it lacks balance, the forequarters frequently being

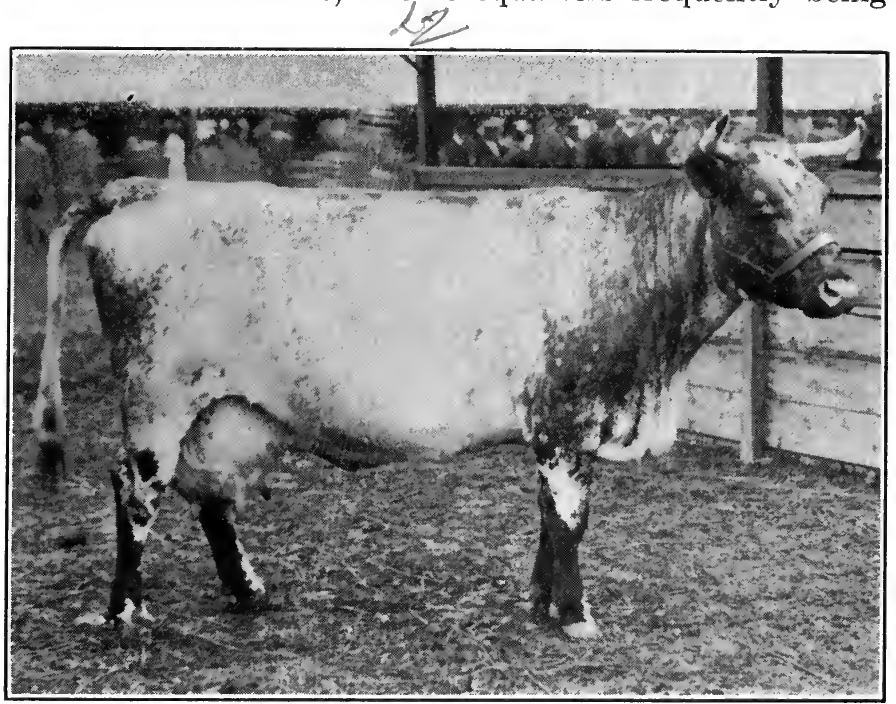

FIG. 119. - A Milking Short-horn cow.

deficient, and it is often of the pendant sort with large teats. The veins and wells are proportionately well developed.

The tendency, already noted, for dual-purpose cattle to deviate to one or the other extremes is responsible for a lack of uniformity in the type of the Red Polled. They 
are also subject to the occasional occurrence of scurs, as are all other polled breeds.

247. The Milking Short-horn (Fig. 119). - This is a family within the breed, there being a rather sharp distinction between the blood lines of Milking Short-horns and the regular or beef Short-horns. The former are largely descendant from a Bates foundation. They have the general Short-horn character but more of a dualpurpose form. 
PART V

\section{JUDGING SHEEP}





\section{CHAPTER XIII}

\section{THE TYPES OF SHEEP}

Flocks of domesticated sheep, Ovis, species musimon, or ammon, are referred to in the very earliest records of husbandry. They were kept, however, for their fleeces, the evolution of the mutton sheep having been accomplished at a comparatively recent date by the English husbandmen contemporary with or subsequent to Bakewell.

Sheep, being ruminants, have an economic importance similar to that of cattle but they fit into a niche which cattle do not fill. Sheep are much better rustlers, consume many weeds and grasses which cattle refuse, graze closer, and therefore do fairly well on rough, unproductive lands, where cattle could not subsist. They are also natural gleaners and much that would otherwise be waste, in stubble fields, may be saved by turning in sheep. Then they have the advantage of maturing and reproducing at an earlier age than cattle.

The prevailing high price of beef has materially increased the consumption of mutton. This and the low price of wool have resulted in a much better grade of mutton being offered to the consumer. Sheep are now much more generally mutton bred, fed to a higher degree of ripeness and sold as lambs or yearlings.

248. Types of sheep. - While every sheep may yield both a mutton carcass and a fleece the two products are not correlated, and both are, therefore, seldom secured, in 
equally high degrees of excellence, from the same individual. As a rule, the sheep with the best mutton carcass shears a comparatively poor fleece, while the sheep that grows the greatest amount of finest wool is not wholly acceptable to the butcher, dressing out, with excessive waste, a light, ill-shaped carcass of low quality mutton. Hence, there are two distinct types of sheep, one grown for its carcass, in whose case the wool constitutes a by-product, and the other, kept primarily for its fleece and having a butcher value analogous to that of the dairy cow. Sheep of the former type are in the majority, however, even their fleeces supplying the bulk of the wool that is marketed. It is not profitable under present conditions to maintain flocks for their fleeces only, as used to be extensively practiced.

\section{Mutton Sheep}

The mutton wether is as close an analogy for the beef steer, already described, as it is possible for a sheep to be. Mutton and beef may be regarded as contemporaneous before the meat eaters of the world.

249. Production. - Nearly all of the mutton dressed is consumed fresh, therefore primeness in the carcass is especially desirable. On account of their lesser size, mutton carcasses are most commonly handled entire by the wholesaler, neither split into sides nor quartered, as in the case of beef. Preference for lamb is shown in this country almost to the exclusion of a sheep carcass of any other age. From two thirds to three fourths of all the sheep slaughtered here are lambs, while the Briton appreciates, as well, the flesh of a prime yearling wether. Lamb can be distinguished from mutton by the relative sizes of the carcasses, by the softer consistence of both 


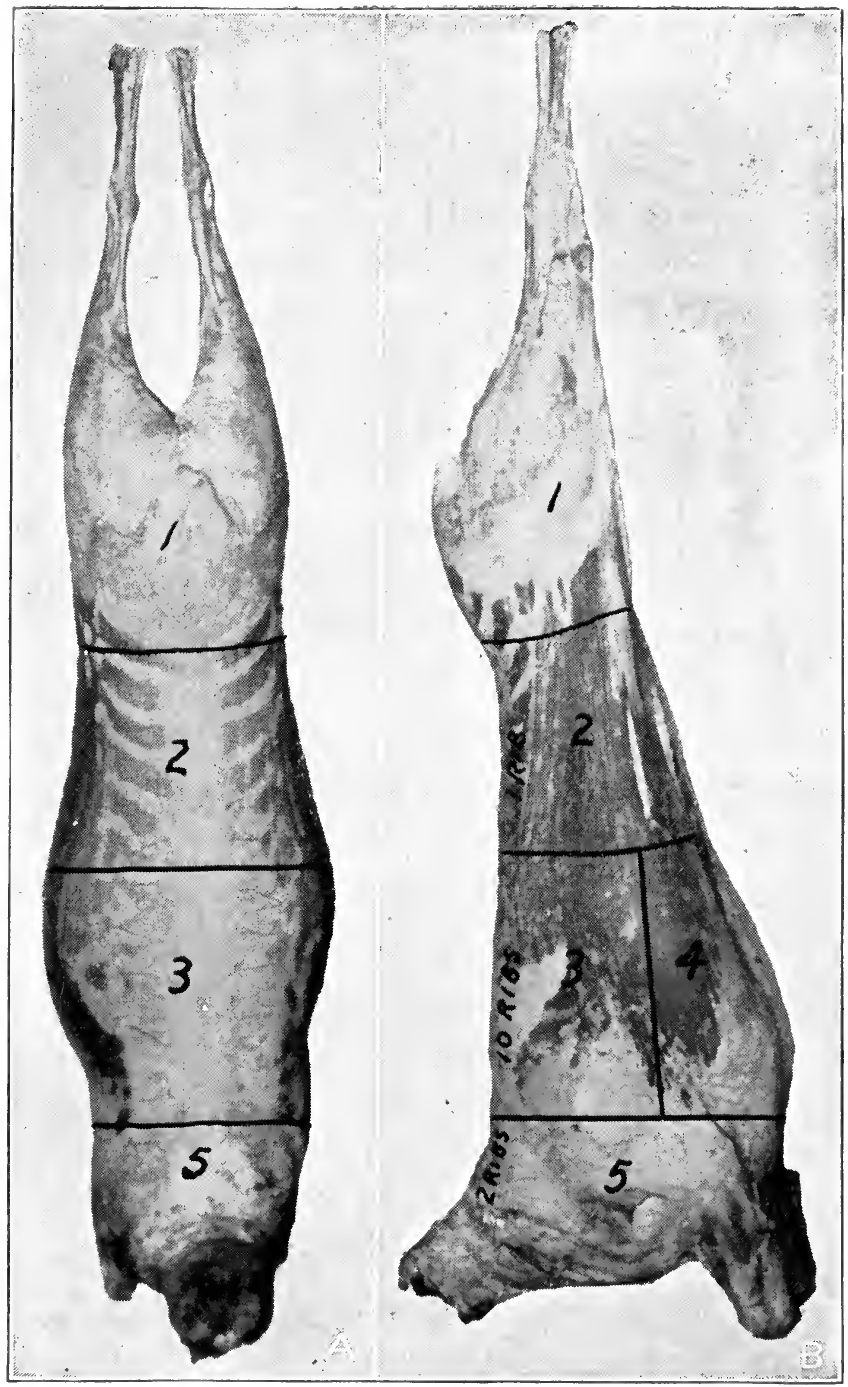

FIg. 120. - Mutton carcass cuts. 1, 2, saddle; $3,4,5$, rack; $1,2,3$, long saddle; $2,3,4,5$, body. 1 , leg; 2 , loin; 3 , short rack; 2,3 , back; 4 , breast; 5 , chuck; 4, 5, stew. (Illinois Bulletin 147.) 
lean and fat, a somewhat lighter color and the incomplete ossification of the so-called "break" joints of the knees and hocks, viz., the union between the centers of ossification in the end and the shaft of the forearm and lower thigh bones, respectively. The division of the carcass is shown in the accompanying diagram (Fig. 120).

250. The mutton carcass cuts (Fig. 120). - The mutton carcass is not usually split at first but instead is divided into two transverse halves, a saddle and a rack, the cut being made between the twelfth and thirteenth ribs. The posterior or back half, the saddle, is subsequently divided into the leg of mutton and the loin, the forward half or rack into the short rack, chuck and breast.

251. The saddle, which weighs slightly less than the rack, is cut at the point of the hip or margin of the loin into the legs of mutton, which are afterward separated and trimmed, and the loin, the former being about twice as heavy as the latter.

252. The rack, counting forward ten ribs from the saddle end, is cut between the second and third ribs. The upper part of this section of the rack constitutes the short rack, the lower part the breast, the line of division being more or less arbitrarily determined, as in the steer. The short rack represents from two thirds to three fourths the value of the rack, although but about two fifths its weight. The balance of the carcass, including and in front of the second rib, is the chuck, or shoulder and, with the breast, is designated the stew.

The highest priced cuts are taken from the short rack (rib chops), the leg of mutton, the loin (loin chops) and the stew, in the order named. Sheep dress $45-63 \%$ of their live weight, yearlings averaging a higher percentage than lambs. 
253. The mutton type is simply the block standard applied to sheep (Fig. 121). The low-set, wide, deep, symmetrical individual is the one that does best for both butcher and feeder, furnishing the highest percentage of

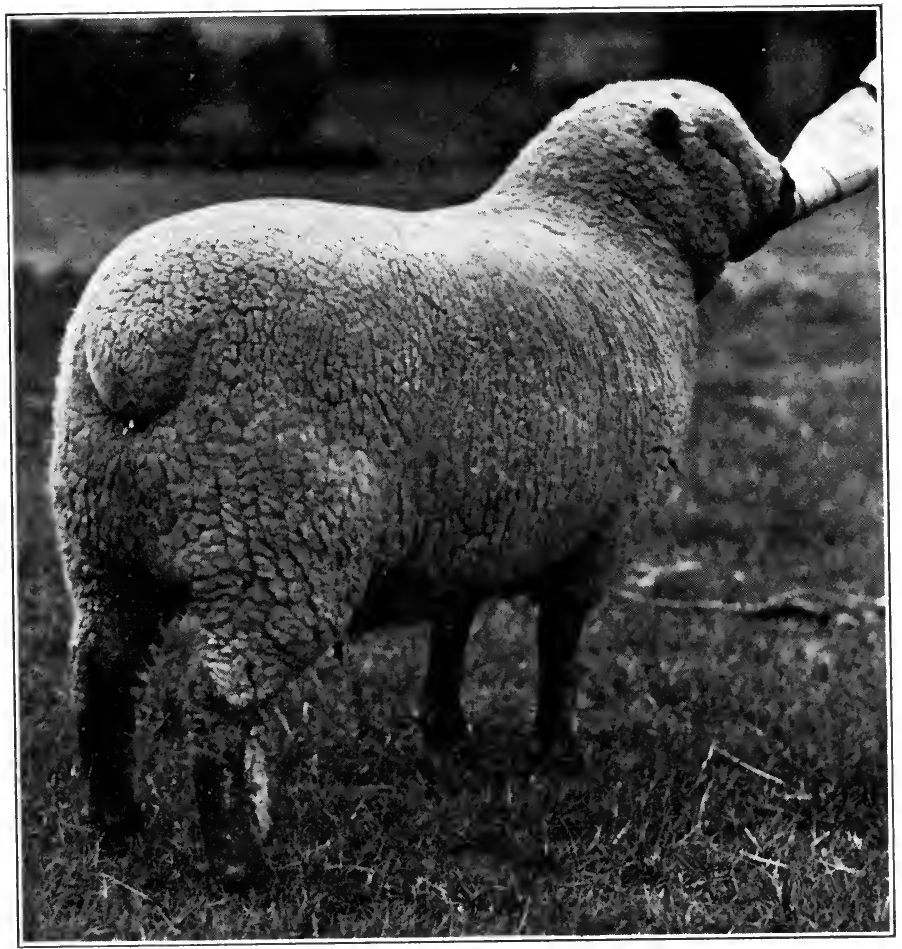

Fig. 121. - A typical mutton wether.

the most desirable parts of the carcass with least waste in killing to the former, and insuring, to the latter, most economic production of such an acceptable butcher carcass. 
254. Conformation (Fig. 122). - Head short, broad and deep, a large, full, clear eye, broad muzzle, large nostril, fine, well-shaped ears, nicely poised and carried. 'The size and shape of the head also whether covered with wool or hair, and the carriage of the ears is a matter which involves the breed as does also the presence or absence of horns. The horns of the horned breeds should be strong, or fine, depending upon sex, of good texture and symmetrical in

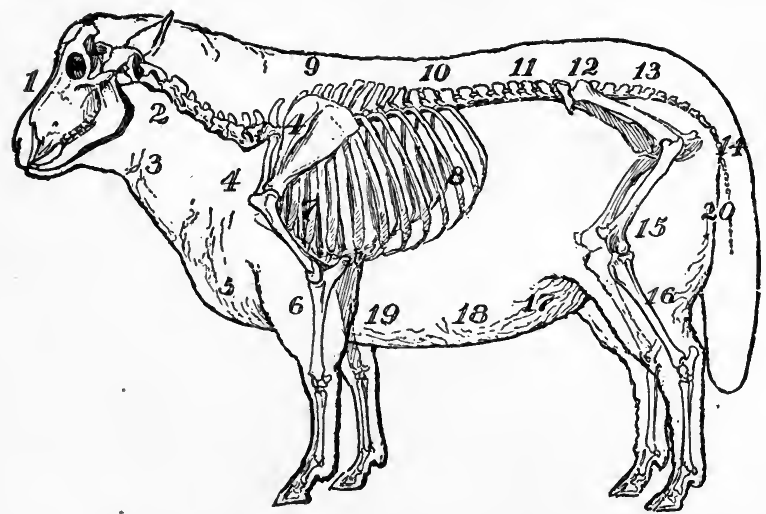

FIG. 122. - Points of the sheep. 1, head; 2, neck; 3 , shoulder vein ; 4 , shoulder; 5 , brisket; 6 , foreleg; 7 , chest; 8 , ribs; 9 , top of shoulder ; 10 , back; 11 , loin ; 12 , hip ; 13 , rump ; 14, tail ; 15 , giggot or leg of mutton; 16 , hind leg; 17 , flank; 18 , belly ; 19 , foreflank ; 20 , twist.

size and shape. The neck desired is short, thick just back of the poll and begins there to swell into the width of the shoulders, being especially full in the neck vein. Typical shoulders are broad, not prominent, but closely laid in, and well covered with flesh, both at the side, where they are apt to be bare, and over the top, where they are often too open, that is, having too much space between the tips of the shoulder blades and the spine; the back 
straight, strong, broad and especially thickly covered with flesh; the ribs well arched and deep, especially the forerib, the crops so well filled as to be even with the sides of the shoulders; the chest deep, full, broad on the floor, and square at the brisket; the loin broad, and thickly fleshed, this region being most frequently bare; the hips broad, level, smooth and not too prominent; the rump long, level, broad and smooth, especially at the dock, where there may be an accumulation of blubbery tallow; the leg of mutton broad, deep and thick, the twist full and well let down in the seam; the legs short, straight, pasterns and hocks strong, the sheep standing well up on its toes, and having straight hind legs.

255. Quality in the sheep not only determines the quality of the meat, as in the case of cattle and hogs, but of the fleece as well. It is also an important factor in dressing percentage, as it controls the waste to a considerable extent. Quality is indicated by a refined head and ears, smooth shoulders and hips, clean-boned joints and cannons, fine hair on the face, ears and legs, fine fleece and a trim under line.

256. Condition. - Fat contributes to the primeness of a cut of mutton or lamb about as much as it does to beef, although the mutton carcass, while somewhat fatter, does not naturally marble quite so nicely as the beef carcass does, and tallow is less nutritious, digestible and palatable than suet. The most acceptable butcher condition is indicated by a uniform covering of firm, but not hard, flesh, showing especially at the dock, the neck and along the back, with no bareness of loin or rib, nor any accumulation of soft fat in the foreflank, which has "slipped" from the ribs above, nor at the tail head, on the back rib, or the margin of the loin, where rolls appear. 


\section{Wool SheeP}

The fleece was the first animal product to be improved by selection and breeding, and its improvement antedates the era of modern husbandry by centuries. The royal robes of the ancient nobility were woven from wool that would compare favorably with that from our modern flocks. The development of the mutton breeds, on the other hand, was begun less than 200 years ago. Prior to 1893 wool growing was one of the most important livestock industries in this country, and American Merinos were exported in large numbers to Australia, South America and South Africa. Subsequent reduction in the price of wool and an advance in the demand and the price paid for mutton resulted in a reversal of patronage and a great diminution in the fine wool flocks in this country.

257. Production. - The fleece, originally furnished to the sheep in amount and character sufficient only for its protection, has been increased in quantity and improved in texture until it may actually be a serious burden both to bear on account of its weight and to endure on account of its warmth.

The annual fleece may constitute as much as one fifth of the sheep's weight, and the total amount of wool produced in the sheep's life may far exceed the weight of its body.

Sheep are classified, on the basis of fleece, as long wool, middle wool and fine wool. Fleeces of the first two classes are shorn from sheep of mutton form, while the fine wool sheep are devoted to wool production, primarily.

258. The classification of wool. - Market wool is classified according to the length and strength of its staple and consequently the material into which it can 
be manufactured, as clothing, delaine and combing, in each of which there are different commercial grades.

259. Clothing. - Clothing wool is of fine, short staple, about two inches in length and goes into the highest grade of woolen cloth. Clothing wools are graded on their quality into Picklock, XXX, XX, X, No. 1, or one half blood; No. 2, or three eighths blood and No. 3, or one fourth blood.

260. Delaine wool is fine, but longer than clothing, two to three inches, of sound staple and is used in the manufacture of delaine cloths. Delaine wools are graded as fine, medium and low.

261. Combing wool is characterized by the length and strength of its staple, being at least three inches in length and strong enough to withstand the combing process. It is made up into worsted goods. Such a long wool is naturally coarse, the finest grading only No. 2 or three eighths.

262. The type of the wool sheep grown to-day is much less extreme in form than the more distinctly wool, and wool only, type of a quarter of a century ago. The relative reduction and increase in the price of wool and mutton, respectively, has led to a demand for better mutton, even in wool sheep, so that the common source of the finest fleeces now is, in reality, a dual purpose sheep. As a result of the inevitable law of correlation, under which mutton and wool are almost as much opposed to one another as beef and milk or lard and bacon, the old-fashioned, fine wool sheep were the extreme opposite of the mutton sheep in form. They were small, with long legs, heads, necks and bodies, of an angular, rather than a blocky, form, having light quarters, peeked ends and flat ribs. Sheep of this type not only grew wool of the finest staple, but also in great amounts. They were 
covered from tip to toe, well wooled under the belly and in the arm pits and groin, where most sheep are comparatively bare. In addition, they presented the maximum skin area from which to grow the fleece by virtue of the elaborate system of folds into which their skin was thrown. In response to modern demand this form has been increased in size, and its angularity has been amplified into rotundness, at least, insuring not only more of a carcass but greater constitutional vigor. The folds and wrinkles have been almost completely bred out, fine wool sheep being classified at the present time as to the presence or absence of wrinkles.

263. Conformation. - Attention has already been directed to the fact that the market demands an acceptable mutton carcass from every sheep, even though they may be primarily wool producers. The conformation of the wool sheep, therefore, follows that already described. for the mutton sheep as far as is consistent with fine wool production, and does not depart therefrom in the same extreme degree as does the dairy cow from the beef steer. It is generally characterized, however, by being more sparely furnished with natural flesh and by having less breadth and fullness of parts than is characteristic of the mutton sheep.

264. Quality. - There is naturally associated with the fine fleece by which this sheep is distinguished an unusual degree of refinement. They are not large, and while somewhat unsymmetrical in shape they have fine heads, clean bone, delicate, pink skins, and what hair there is on the tip of their noses and legs matches, in fineness, the fleece with which they are covered.

265. The fleece. - Quantity, quality and condition are the essentials of a good fleece. Quantity is determined by 
length and density which, however, are not correlated but opposed, thus making the longest fleece the most open, as a rule. There should be sought, therefore, such a balance between the length of staple and the density with which they grow, as will insure neither being sacrificed to the other, the maximum of both being secured.

266. Quality involves primarily the texture of the individual staple, which, in turn, is in proportion to the amount of crimp. The finest, shortest, densest fleeces have the closest crimp, while the coarsest, longest, most open fleeces have the crimp enlarged to kinks or ringlets. The finer wools, of more delicate texture, are usually possessed of a distinct luster, a feature of the fiber itself and independent of either yolk or discoloration.

267. Condition of the fleece depends upon soundness, i.e. whether or not the fiber has made a regular uninterrupted growth, as shown by continuous crimp of uniform degree, and no break in the staple itself; yolk, the secretion of the skin, through the wool, which should be sufficiently abundant to indicate normal activity of all vital functions of the sheep, yet not excessive to be scoured out prior to manufacture, nor dry and flaky, which indicates some constitutional disturbance, usually resulting from improper feeding; softness, the resistance offered by the fleece to pressure of the hand, as opposed to harshness, in which case the fibers do not yield, but grate against each other; purity, which refers to the absence of such foreign matter as sand, cockle burrs and hay seed, also kemp, a vestige of the old hair coat which sometimes makes its appearance in coarse fleeces and renders them of less value for manufacture, because the kempy fibers do not take the dye ; and brightness, as opposed to discoloration, the natural fleece being white, or cream tinted if there is 
much yolk in it, while any discoloration tends to darken it. The brightest fleeces are taken from sheep that are kept under the best systems of care and management, while the sheep that are grown on the open range, for instance, have their fleeces badly soiled.

268. Method of inspection:- Sheep present difficulties, on account of their fleeces, which require special means of making accurate observations and determinations of their conformation. Their form is so effectively obscured by the fleece, which may be further complicated by the shepherd's clever trimming, as to make most careful handling necessary. The hands should not be depended upon altogether, however. The lines, general contour, length and strength of the legs, the width between them and the style and carriage of the sheep can best be made out by viewing them from a little distance. Then thorough handling must be resorted to in order to verify conclusions arrived at by looking the sheep over. It is especially important that the handling should be systematically done, in order that omissions and repetitions may be avoided, and a definite and accurate idea of the sheep formed. The usual system is to approach the held sheep from the left side, and with the right hand over the back of the head, part the lips with the first and second fingers to determine the age; then look it full in the face, noting the proportions, dimensions and features of the head, after which span the neck with the thumb and forefinger of each hand to find out its fullness and from this its length and the manner in which it blends into the shoulders. The breadth and compactness of the shoulder is felt by the right hand, crossways over the top of the shoulder, when, without changing this position, the depth of both chest and foreflank can be made out by the left hand, 
first at the point of the brisket, noting, at the same time, whether it is full or sharp, then back of the elbow, fullness as well as depth at this point being made out. The right hand next feels along the spine from the shoulder to the dock, to get the straightness and the thickness of covering of the back and loin, with the levelness and fullness of the rump. Passing back to the shoulder with both hands, measure and feel the width, covering and smoothness of the shoulders; slipping the hands backward to find the spring of forerib, then again the width and covering at midrib, the width, as measured between the hands, and the thickness, as detected by the thumbs, of the loin, the length of the rump, the left hand remaining at the margin of the loin, just in front of the hip, while the right is carried back to the point of the buttocks. After this the width and fullness of the rump and finally. the depth and fullness of the leg of mutton are measured by inclosing it between the thumb and first finger of one or both hands.

269. Examination of the fleece. - The fleece is examined by parting it at one of the natural openings to ascertain the length and fineness of staple and the condition of the fleece and skin. Texture and softness are best detected by pressing down upon the fleece with the flat hand. The fleece should be opened at at least three points; namely, over the heart, at midrib, and on the outside of the thigh where it is finest, medium and coarsest, respectively. The wooling over the face, legs, and belly should be given due consideration, especially in breeding classes.

In judging fine wool sheep, it is customary to set them up on their hind ends, thus exposing the fleece of the belly, arm pits and groin to a better view. 


\section{CHAPTER XIV}

\section{THE BREEDS OF SHEEP}

Classification of the Breeds of Sheep

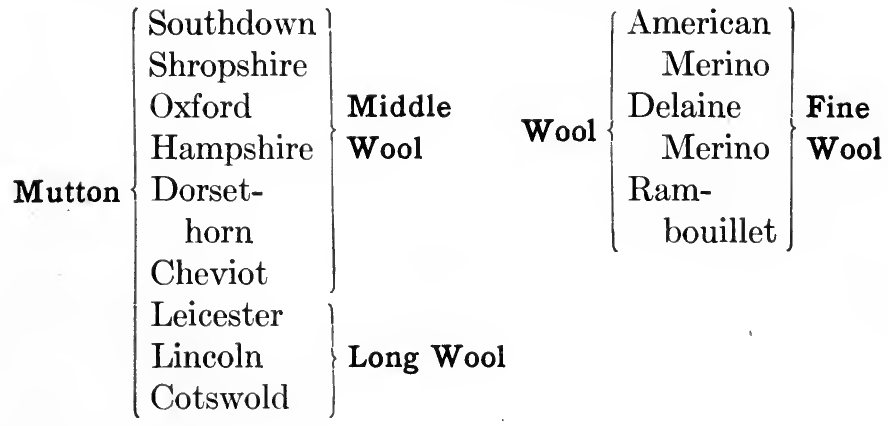

270. The Southdown. - This is the oldest, purest and smallest of the Down breeds and has the distinction of representing the ideal of mutton form and quality (Fig. 123). It is one of the smallest breeds, rams weighing 175 pounds and ewes 135 pounds. The form is the lowest down, most compact, broadest, deepest and most thickly fleshed of any sheep. All the features of block type and conformation, i.e. the short, broad head, short, full neck, blending with broad, but compact and smooth shoulders, broad, thickly covered back and loin, and a wide, full, and deep leg of mutton, are especially well marked in the Southdown. The head is extraordinarily short, wide between the eyes, and rather fine, the ears short, small, pointed, 
and covered on the outside with little tufts of wool; the face below the eyes is bare of wool, and covered with brownish gray hair, while the cheeks and forehead are wooled over. The fleece of the Southdown is very dense, but, being short and comparatively free from yolk, the clip is light, six to eight pounds, and grades as one half and three eighths. It is very evenly distributed, however, except on the legs, which are covered with hair similar to that on the face.

A lack of size, a light fleece and occasionally a dark

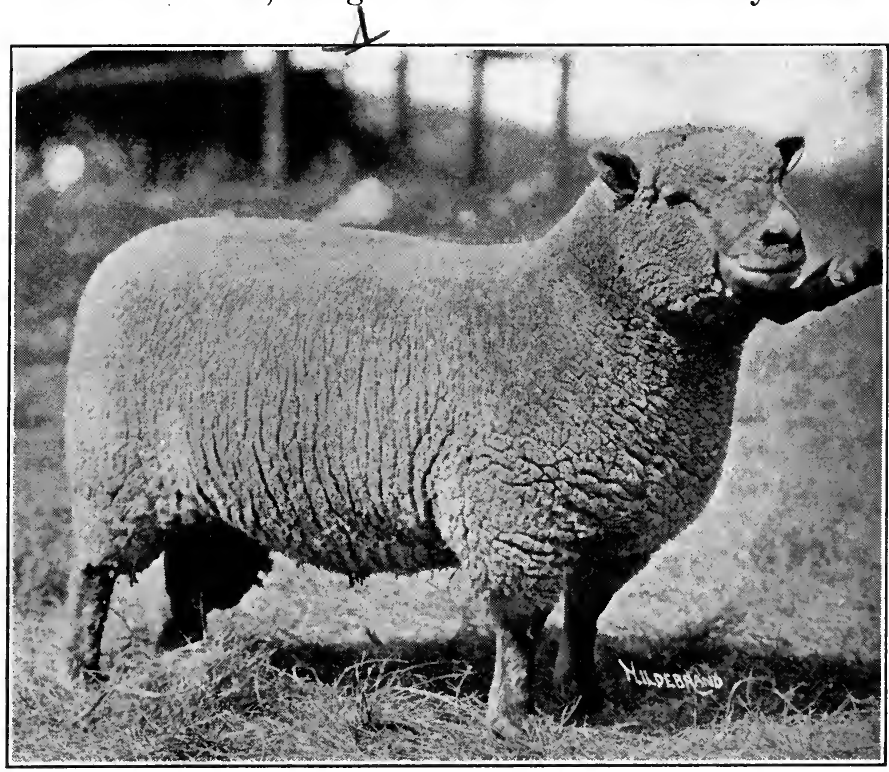

Fig. 123. - A Southdown ram.

skin are the points in which a Southdown can sometimes be criticized.

271. The Shropshire. - This is the most generally 
adaptable and popular breed of sheep in this country. It is chiefly characterized by the wooling of the head and legs and by its stylish carriage (Fig. 124). The Shropshire is intermediate in size; being larger than the Southdown but smaller than the Oxford and Hampshire, the rams weighing

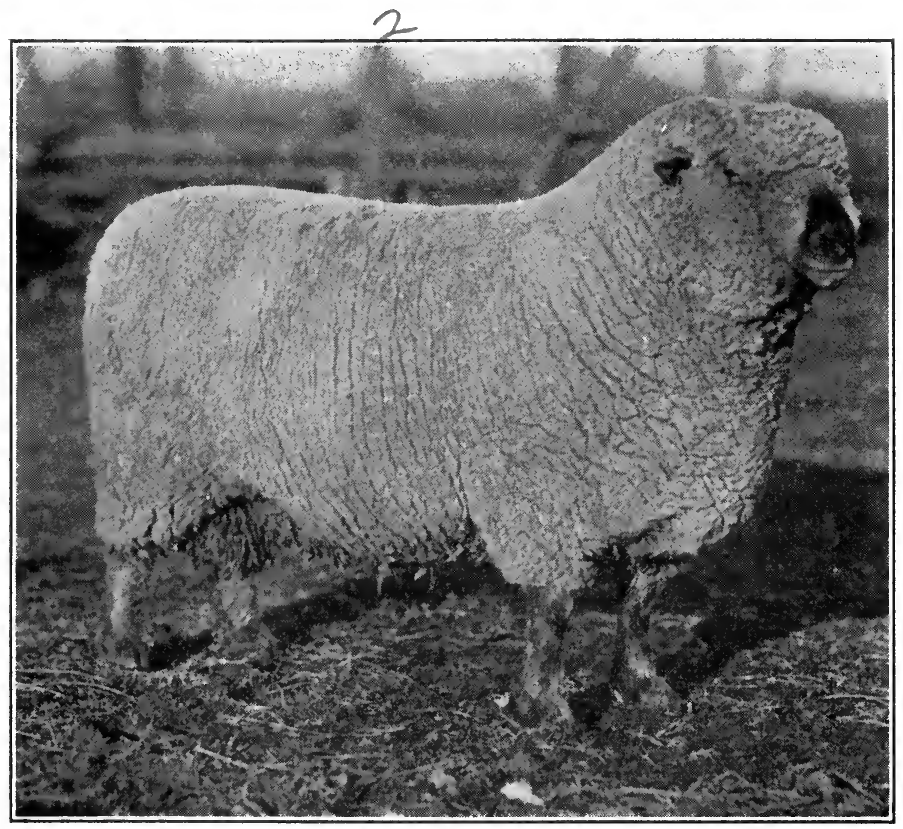

FIG. 124. - A Shropshire ram.

225 pounds and the ewes 150 to 160 pounds. The form is distinctly mutton, yet less extreme than in the case of the Southdown. The head is completely wooled over with a hood, only the tip of the nose being exposed, which is covered with very heavy, dark brown hair; the ears are rather stubby, but pointed, and covered on the back 
with fine tufts of wool. The head is carried higher and more alert than in most other breeds. The fleece is most typical of the middle wool class, combining quality with quantity, and it is evenly distributed over the body, even down to the hoofs. Shropshire fleeces weigh eight

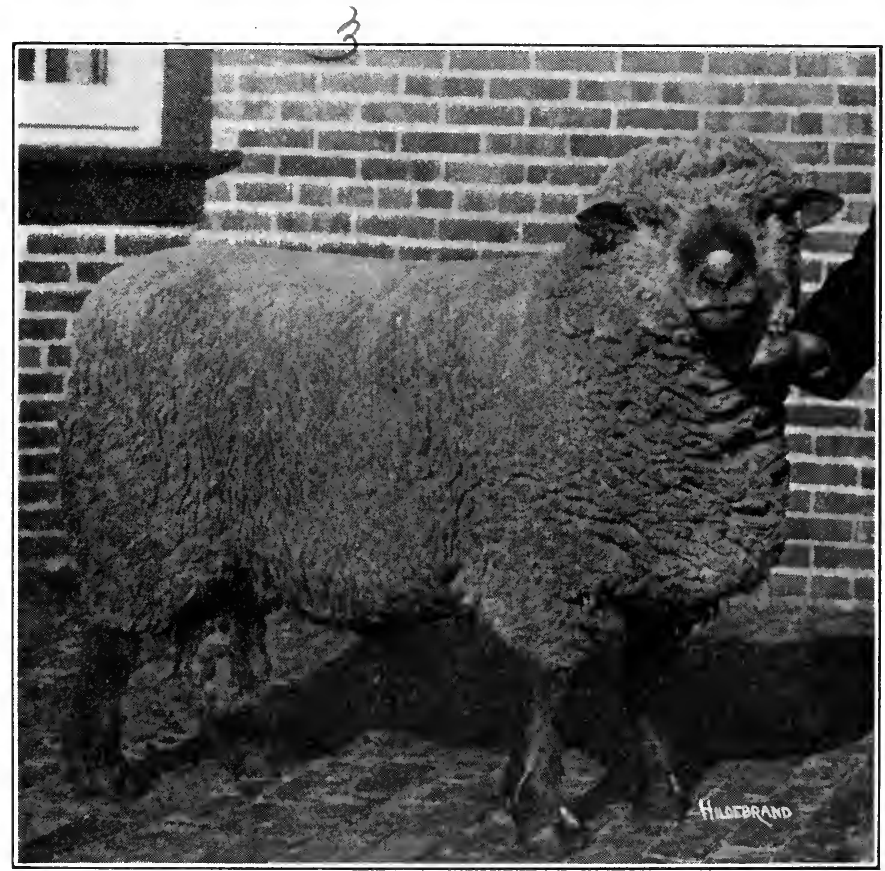

FIG. 125. - An Oxford ram.

to twelve pounds. Patches of black or brown fleece, especially about the head, dark skins and scurs are the most common causes of criticism of the Shropshire.

272. The Oxford (Fig. 125). - This breed was derived, comparatively recently, from a Hampshire-Cotswold cross. 
It is the largest of the Down breeds, the rams weighing from 250 pounds to 350 pounds and the ewes 180 pounds to 275 pounds. The Oxford is not only heavy, but is large in frame and stature. The form is of the most approved mutton type, the development of back, loin and hindquarters being especially heavy. The head is longer than that of the Shropshire, which the Oxford resembles most,

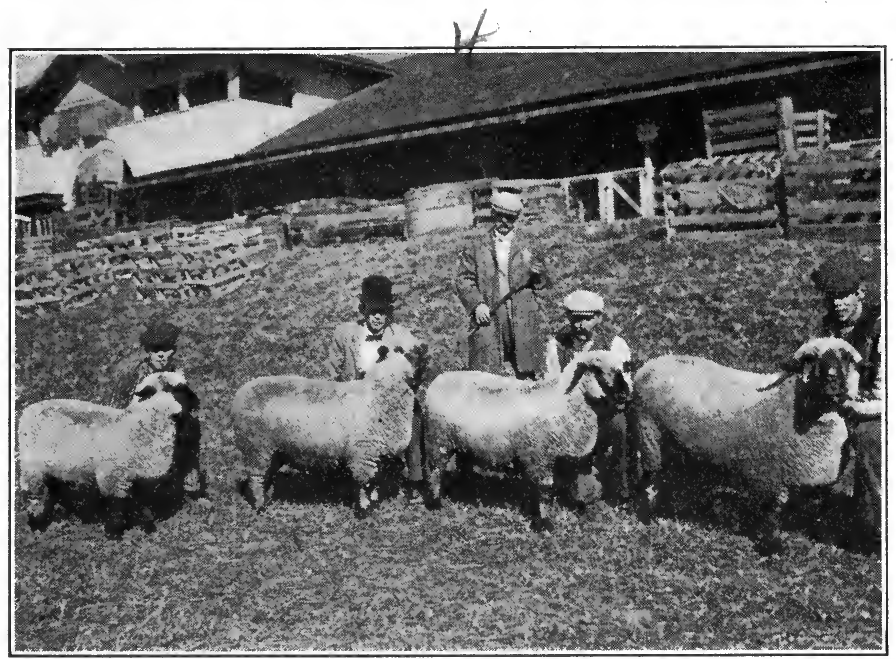

FIG. 126. - A Hampshire ram, ewe and lambs.

and there is no hood, the head being wooled only down to the line between the eyes, the balance of the face being covered with grayish brown hair; the ears are longer and finer than those of the Shropshire, and are covered with brown hair instead of wool, as are also the legs. The fleece is the longest and coarsest of the Down breeds, averaging about $10 \%$ heavier than that of the Shropshire. It is sometimes too coarse and open, and may show dark 
patches of either wool or skin, which are seriously objected to.

273. The Hampshire. - This old breed is characterized by its size, 250 pounds for rams, and 185 to 195 pounds for ewes, and rugged appearance, indicative of the rapid and early growth in the lambs, for which the breed is most noted. Hampshires (Fig. 126) are of superior mutton form but are big boned, as shown in the head and legs, and they are, therefore, prone to coarseness. The head is very typical, being wooled only on the forehead and cheeks, while the face and ears are covered with very dark brown or black hair ; the head itself is large and marked by a distinctly Roman nose ; the ears are also large, carried straight out from the head and inclined to lop, if at all coarse. The fleece is inferior to that of most of the other Down breeds, being short, not dense and fine, nor well distributed, and yielding lightly.

Coarseness in head and ears, especially, and a light fleece are just criticisms of some Hampshires.

274. The Dorset-horn. - This is another one of the old, pure English breeds (Fig. 127). The size is medium, rams weighing 200 pounds and ewes 160 pounds. The form is similar to that of the Shropshire but is less symmetrical. The head is characterized by the presence of horns which curve forward, closely, in spiral shape; the face and ears are covered with fine white hair, although there is a foretop of wool. The fleece is medium both as to quantity and quality, being short, lacking somewhat in density, unusually free from oil, and not evenly distributed, showing a tendency to be bare on the belly. Average fleeces weigh six to seven pounds. Dorset ewes make exceptional mothers, being deep milkers and prolific. 
The most common defects noticed among representatives of this breed are a lack of mutton development in fore-

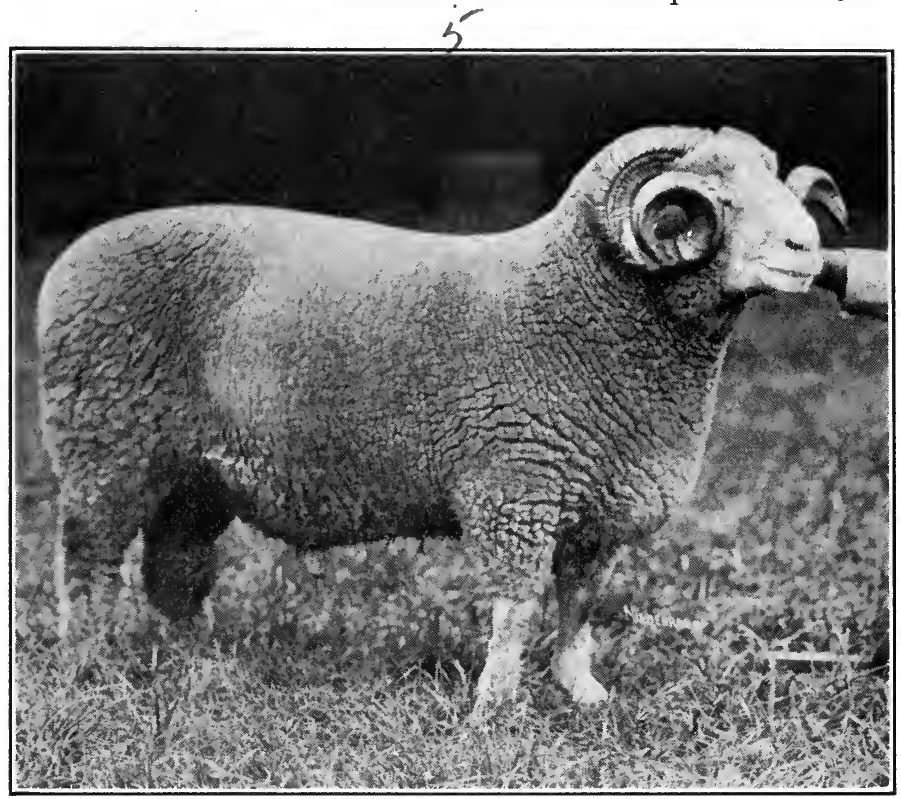

FrG. 127. - A Dorset-horn ram.

quarters and spring of rib, and a light fleece that is not evenly distributed.

275. The Cheviot. - Cheviots have been bred for centuries in the Cheviot Hills of the Scotch border, although outside this district to which they are native they have received less consideration than some of the other breeds. The Cheviot (Fig. 128) is of medium size, rams weighing 200 pounds, ewes 150 pounds; it has a good mutton form, although hardly equal to that of the Down breeds, and yields an excellent fleece of pure white wool. 
The head is broad between the eyes, which are very bright and alert, the ears are carried erect, and both head and ears, as well as legs, are covered with fine white hair, no wool, the fleece ending abruptly with a "ruff" just back of the ears and about the throat. The Cheviot fleece is somewhat longer and consequently more open than that of the Down breeds, classing as half combing, and is snowy white

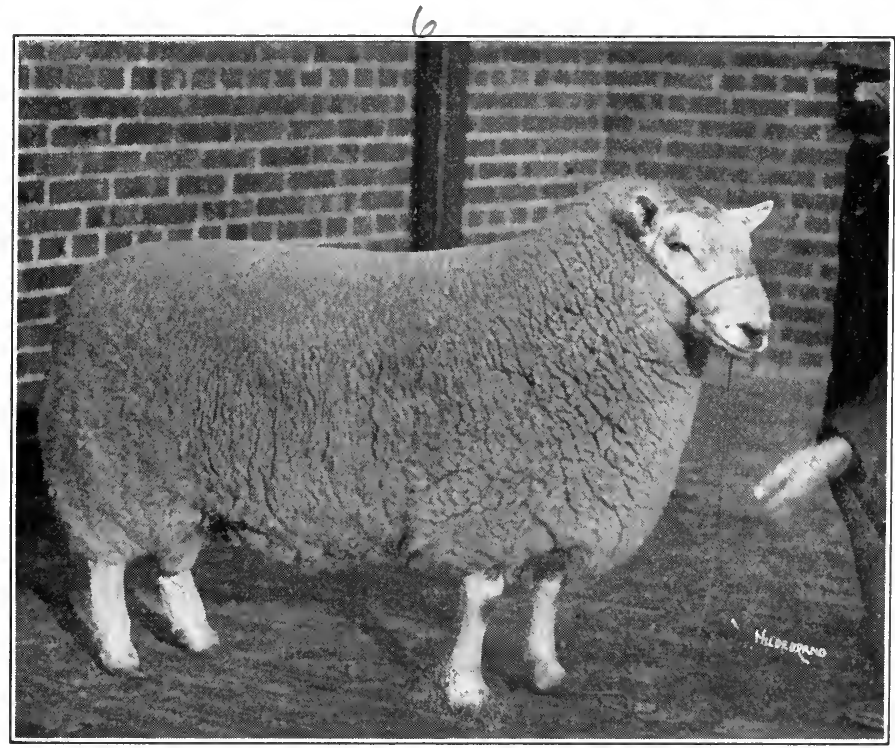

FIG. 128. - A Cheviot ram.

instead of the heavy gray tinge noticeable in most Down fleeces. The clip is light - four and one half to five pounds of washed wool. Cheviots dress well and cut a very good grade of mutton. They have a very alert carriage.

Too light a fleece, a form deficient in compactness and a timid disposition are sometimes encountered in this breed. 


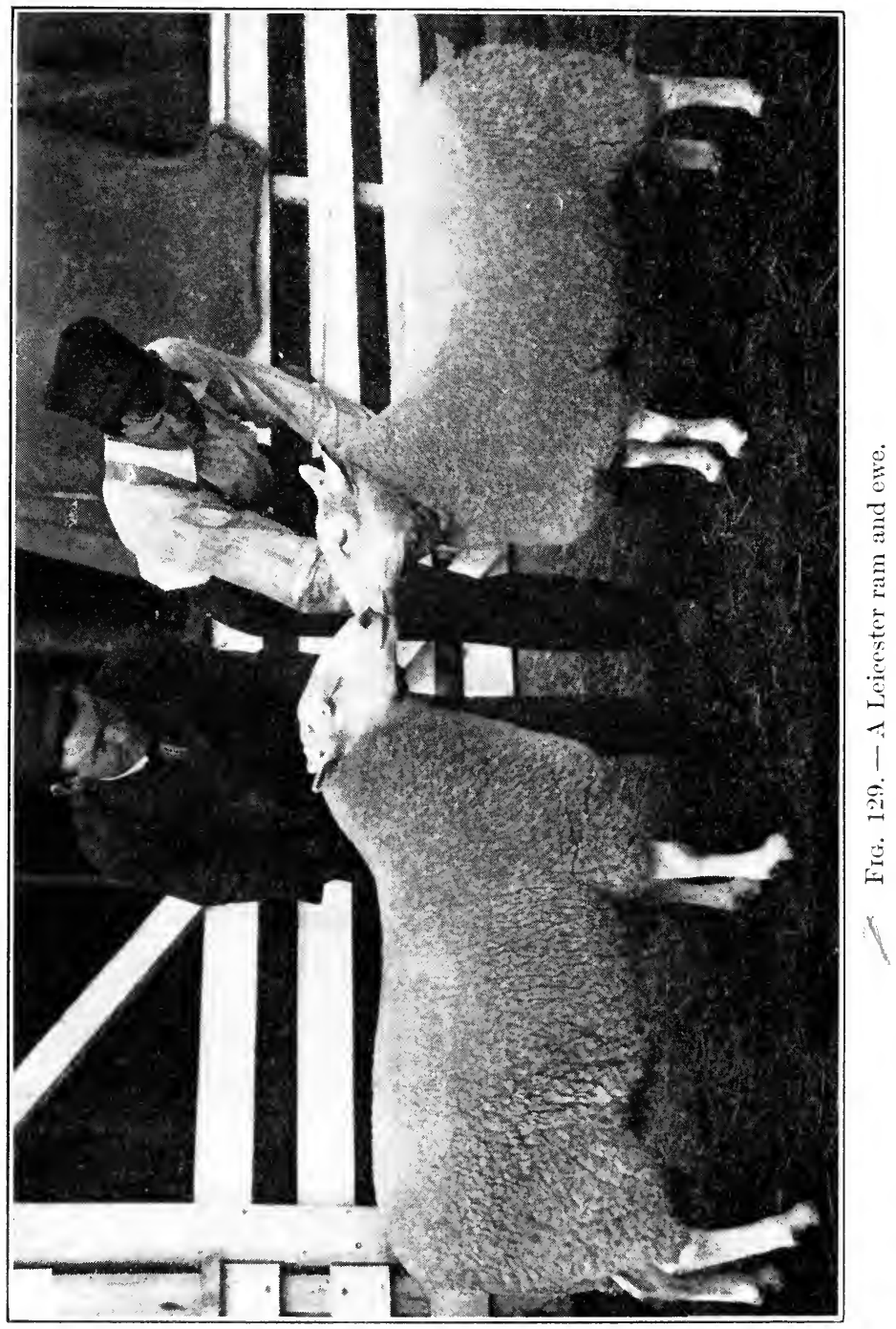


276. The Leicester. - This breed is of greatest historic importance on account of its having been the object of Bakewell's efforts, and having been the first breed improved it was most extensively used in the improvement of other breeds. Its early development is reflected in the refinement and uniformity of individuals of this breed. Leicesters (Fig.129) are the smallest of the three long wool breeds, rams weighing 225 to 250 pounds, and ewes 175 pounds to 200 pounds. Their form is square in outline, although of rather high station, and is characterized by a peculiar roundness and prominence of the rump, suggestive of a torpedo stern. The head is broad and prominent between the eyes, tapering toward the muzzle with a slightly Roman nose, in spite of the refinement of bone; the ears are fine, well poised and, like the face, are covered with short, white hair, with an occasional black spot. The expression of the Leicester countenance has been described as especially "sheepy." The fleece is long, having a five to six inch staple, very fine, white, falls in ringlets and weighs nine to eleven pounds. The hoofs and lips are black.

Uneven and excessive fattening and bodies bare of fleece on the under side are the common deficiencies of this breed. Classifications make no distinction between Bakewell or English and Border Leicesters, although the latter are in the majority. They may be differentiated by the white face, free from wool, of the Border Leicester and the bluish face and tuft on the head of the English Leicester. The Border type is also more rugged looking.

277. The Lincoln. - Bred originally in the fen country of Lincolnshire, where the environment was conducive to size, this breed is still, even after the refining influence of Leicester crosses, the largest of the sheep breeds (Fig. 130). Rams weigh 200 to 250 pounds, and shear an exceptionally 
heavy fleece, weighing fourteen to eighteen pounds, on an average. In addition to their scale they have a square, massive, mutton form. The head is characterized by a tuft of wool on the forehead which is readily distinguishable from the bare forehead of the Leicester and the forelock of the Cotswold. The face and ears, as well as the

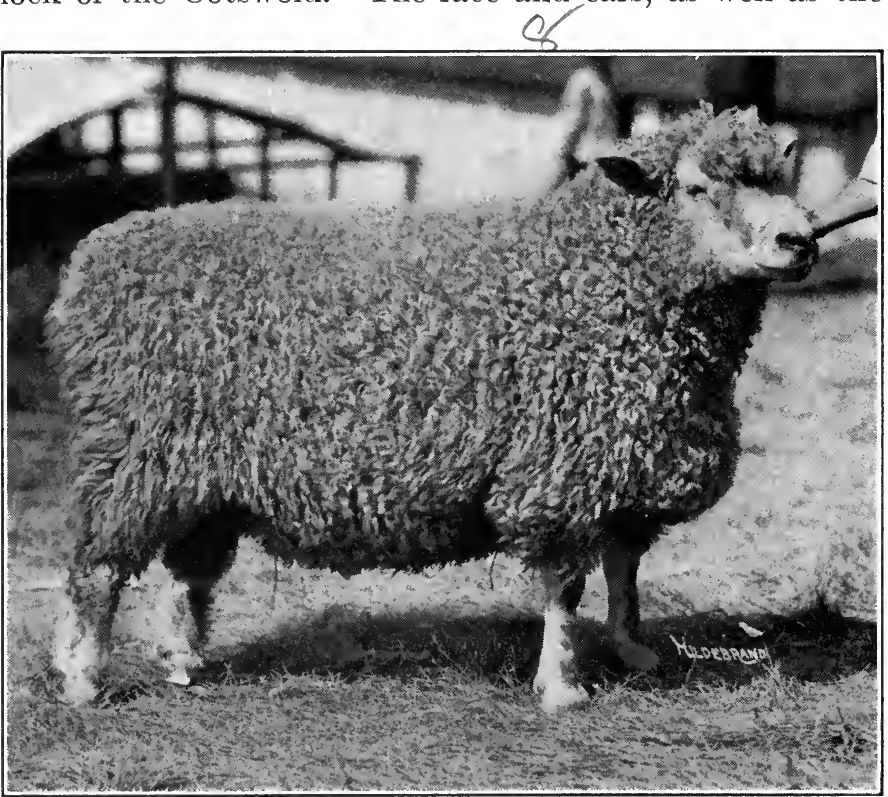

FIG. 130. - A Lincoln ram.

legs below the knees and hocks, are covered with white hair. The fleece is the longest of any, not less than eight inches in staple, is moderately fine, white, lustrous, and unusually sound. A tendency to coarseness of both mutton and wool is noticeable in this large breed of sheep.

278. The Cotswold. - This is a very old breed, native 
to the Cotswold hills in Gloucestershire, England. The original Cotswolds have been much improved in the way of a more compact form, greater symmetry, weight, early maturity, style and fleece (Fig. 131). Cotswolds are among the largest of the breeds of sheep, weighing 200 to 250 pounds. They are upstanding, but of good mutton form, showing special strength of back and loin. The head is very

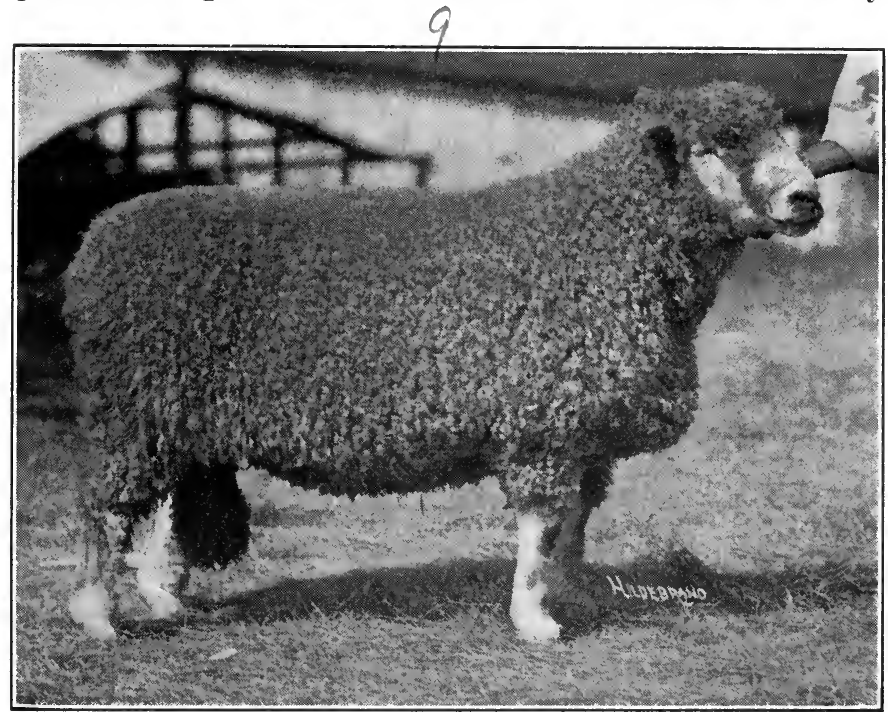

Fig. 131. - A Cotswold ram.

stylishly carried and is characterized by a heavy forelock, which falls over the face and eyes; the face and ears are covered with white or grayish white hairs. The fleece of the Cotswold is in the combing class, being ten inches or more in length of staple, open, arranging itself in locks, but yields heavily, sixteen to eighteen pounds. It should be evenly distributed all over the body except the face. 
A coarse texture of mutton and an excess of external fat are the objections most commonly raised against representatives of this breed.

279. The Merino. - This group embraces all the fine wool breeds and their subclasses, the name, like the original stock, being derived from Spain. Merinos are most

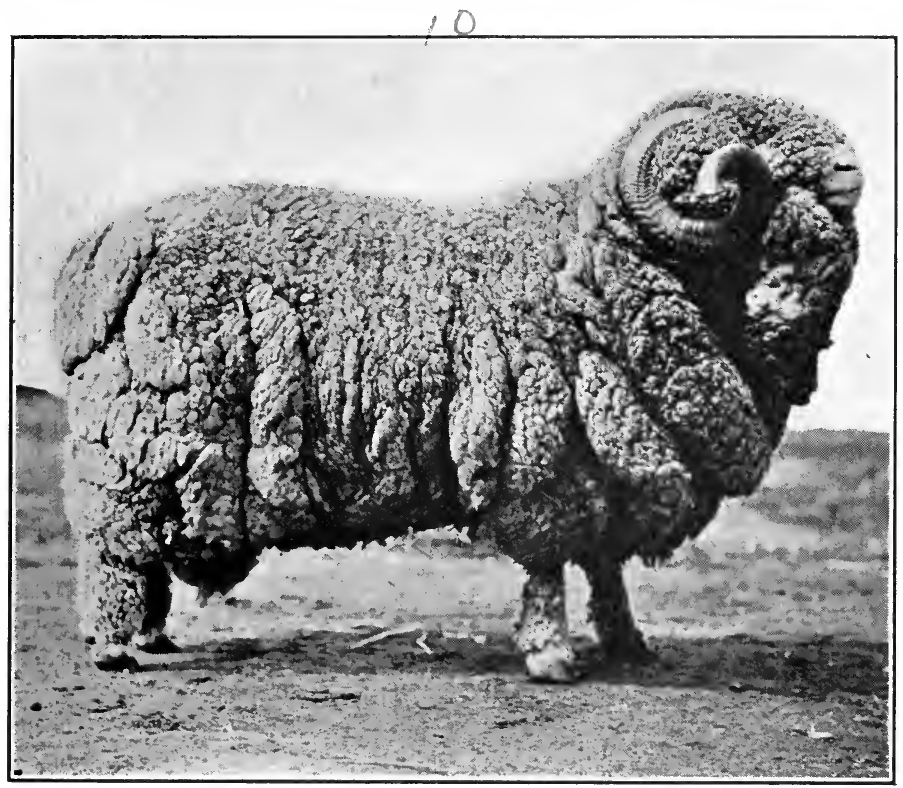

FIG. 132. - An American Merino ram.

comprehensively classed as American, Delaine and Rambouillet. Being essentially wool rather than mutton sheep, the Merinos are, as a class, quite different in size and form from the breeds already described.

American (Fig. 132). These are the smallest of the Merinos, or of any other breed for that matter, the rams 
weighing from 100 to 175 pounds, the ewes 80 to 100 pounds. Their form is light, angular and lacks symmetry when compared with that of the mutton breeds. The head is small, completely wooled over except at the tip of the nose, and surmounted by heavy, sharply incurving, spiral horns in the male, while the ewes have none. The fleece is short,

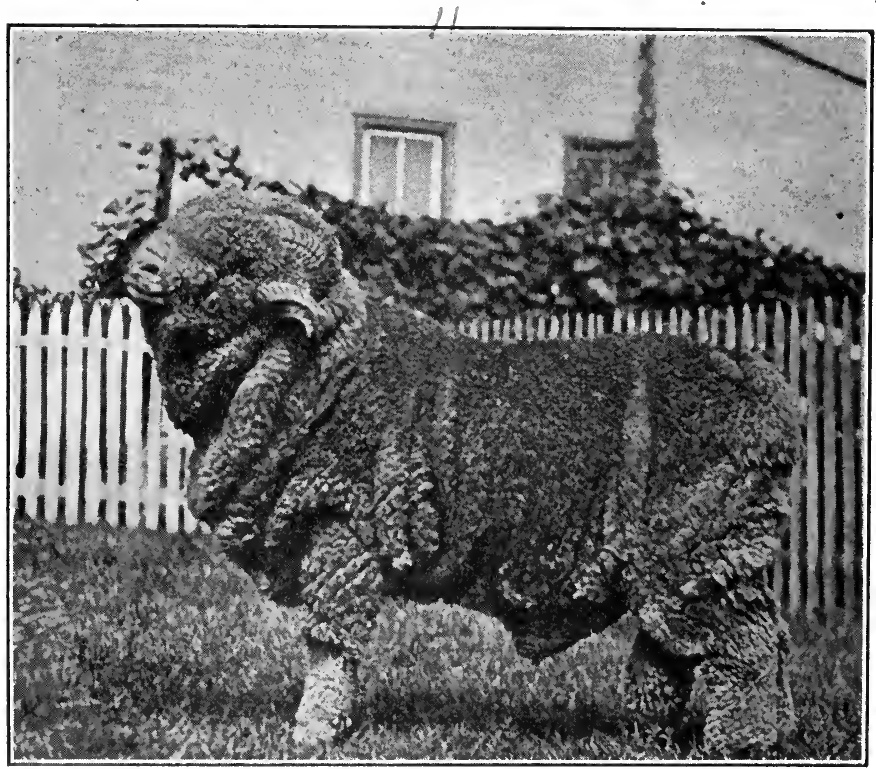

FIG. 133. - A Delaine Merino ram.

but very dense and fine, being two and one half inches in length and shearing from twelve to twenty pounds. The amount of yolk which it contains causes the fleece to soil on the surface, giving the "Black Topped" effect. The Merino's skin is a most delicate pink. The fleece completely covers the sheep from tip to toe, and the normal surface area is increased by the skin being thrown into 
folds and wrinkles, there being from three to five folds on the neck, showing most on the lower side, two to three at the elbow, with wrinkles on the side, and across the hips, and folds around the tail and across the thighs. Merinos

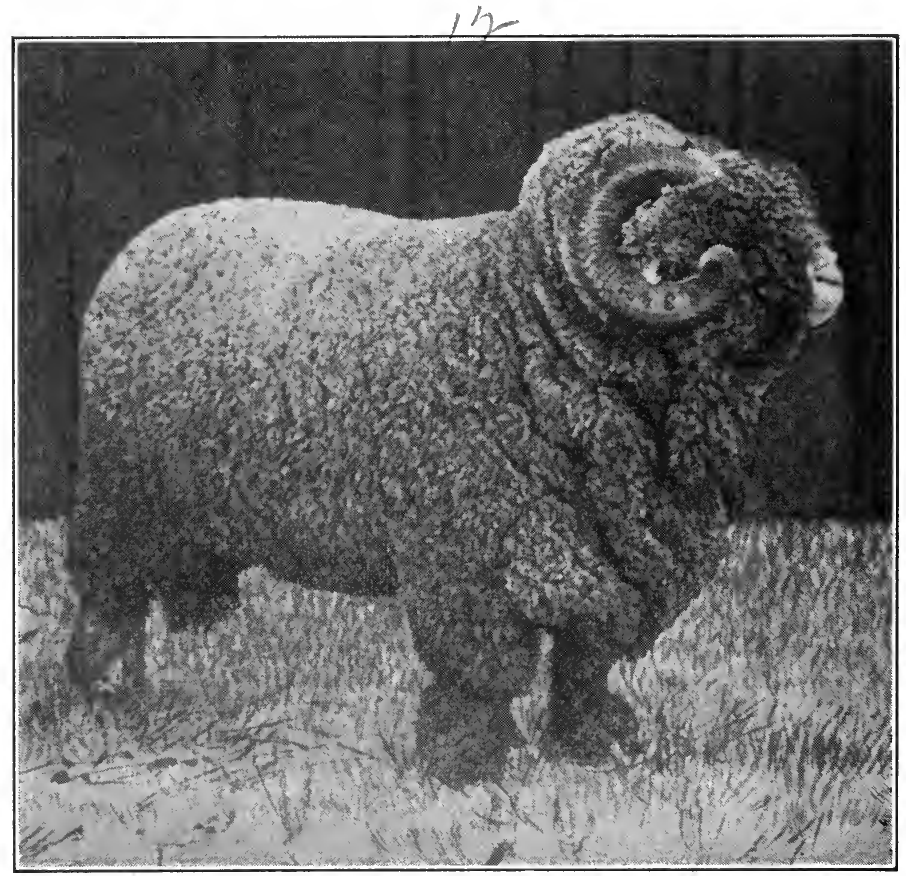

FIG. 134. - A Rambouillet ram.

are classed on the basis of the presence or absence of wrinkles as

Class $A$. Have heavy wrinkles and folds, as in the most extreme American type.

Class $B$. Have only a few folds about the neck and brisket, and possibly the thighs. 
Class $C$. Are smooth with the exception of a slight suggestion of wrinkles about the neck.

Delaine (Fig. 133). These are distinguished from the American Merinos by greater size, rams weighing 140 to 200 pounds, and ewes 100 to 150 pounds, and a better mutton form, the smoothness of which is enhanced by the almost complete absence of wrinkles (Class $C$ ). The head may be either horned or polled, depending upon the numerous subfamilies within the breed. The fleece is not so fine and crimpy, nor so rich in yolk as that of the American, but the staple is longer and stronger, and the fleece weighs from nine to eighteen pounds.

Rambouillet. This is the largest of the Merinos, and combines so much of the fine wool character with size and mutton form as to constitute a dual-purpose sheep (Fig. 134). Rams weigh 175 to 180 pounds and ewes 140 to 160 pounds. This sheep is rather upstanding, but has a well-formed mutton body. The head is of good size, with a strong nose, and usually, though not always, large spiral horns in the male, though none in the female. The fleece completely covers the sheep as in the case of the other Merinos and is fine, dense and white, comparatively free from an excess of yolk, has a three-inch staple, and shears from ten to fifteen pounds. Evidence of constitution and hardiness should be a feature of this breed. 



\section{PART VI \\ JUDGING SWINE}





\section{CHAPTER XV}

\section{THE TYPES OF SWINE}

The hog (Sus scrofa) is a monogastric, omnivorous animal with an especial predisposition to obesity and a propensity for making extremely rapid gains in weight. Unlike the ruminant, the hog is ill adapted to the consumption of rough foodstuffs but requires his ration in concentrated form. His scavenger habits render him an indispensable party to the great industry of marketing corn through cattle, as it is practiced throughout the middle western United States, and he furnishes a most profitable outlet for the dairy by-products of the eastern United States and southeastern Canada.

Types. There are two distinct types of swine, fat and bacon, each directly opposed to the other in the character of their products, their ration requirements and, consequently, in their forms.

\section{The Fat Hog}

There is. no more efficient means of transforming corn, the staple crop of the American farmer, into lard and a fat, energizing meat upon which the great masses of laboring people depend, than the fat hog.

280. Production. - The fat or lard hog supplies fresh pork for roasts and chops from his ribs and loin, cured pork products, as hams, shoulders, and bacon sides, lard, 
and such odd products as sausage, scrapple, head cheese, and pickled feet. On account of the lard rendered, and the fact that so much of the carcass is demanded in the cured state, there is greater uniformity in the relative values of the different parts of the carcasses of hogs than of cattle or sheep. The carcass is also more completely utilized for higher priced products, and dressing about $80 \%$ of the live weight, the butcher is enabled to pay a higher proportionate price to the producer than he pays for beef and mutton and still sell, at a profit, for a lower price to the consumer. There is also less discrimination in the matter of quality in hog carcasses. Weight really has more to do with the grading of hog carcasses than have texture or color. The weights most desired range from 200-400 pounds according to the class of carcass the hog will dress out.

The divisions of the carcass are essential for the hog judge to know (Fig. 135).

281. The hog carcass cuts. - The simplest division of the hog carcass makes four general sections of it first, the hams, the middle piece, the shoulders and the head. Then each is further subdivided after being split in half.

282. The hams are separated from the rest of the carcass a short distance in front of the point of the hips and are afterward trimmed more or less.

283. The middle piece, extending from the hams to the shoulders, includes the pork loin, with tenderloin, from which chops and roasts of fresh pork are taken, the side, from which the bacon strip and sparerib comes, and the fat back.

284. The shoulder, separated from the middle between fourth and fifth ribs, embraces the picnic or California ham, consisting, more in detail, of the picnic butt and 


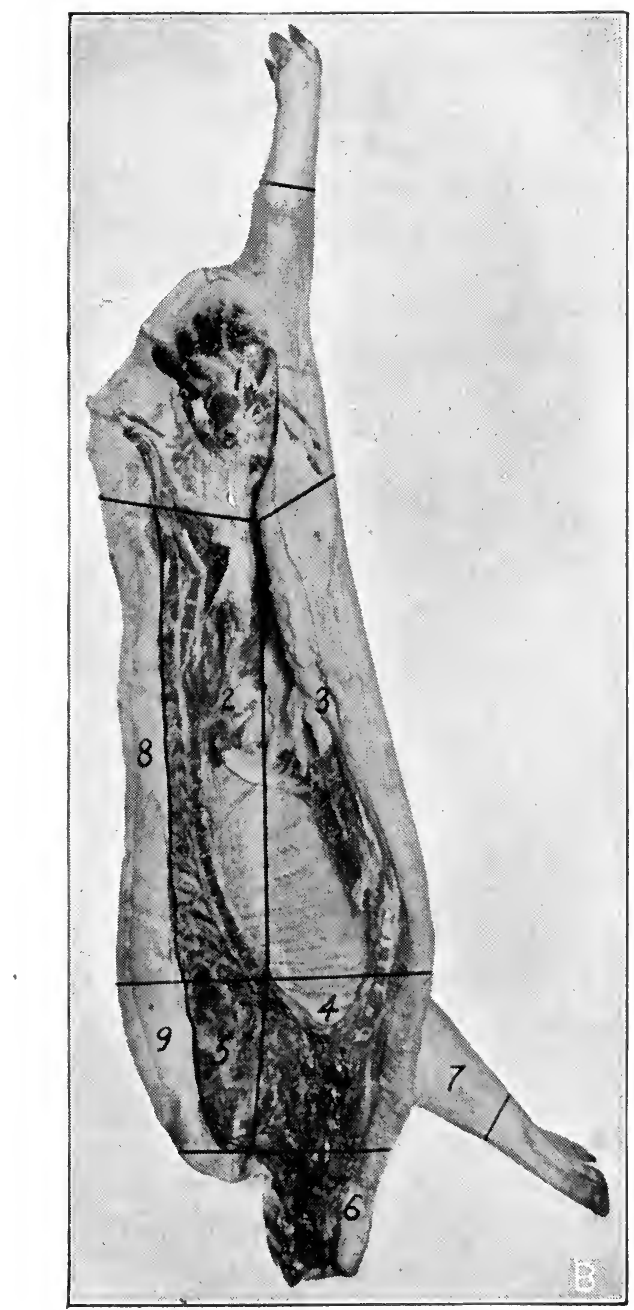

FIG. 135. - Hog carcass cuts. 1, short-cut ham; 2 , loin; 3 , belly ; 4 , picnic butt ; 5 , Boston butt ; 6 , jowl ; 7 , hock ; 8 , fat back ; 9 , clear plate ; 2,8 , back; $2,3,8$, side; 4,7 , picnic shoulder; 5,9 , shoulder butt; 8,9 , long fat back; $4,5,7,9$, rough shoulder. (Illinois Bulletin 147.) 
hock, and the shoulder butt, composed of the Boston butt and the clear plate.

The head piece furnishes the meat for sausage, head cheese and scrapple.

285. Lard is yielded by the fat back, the clear plate, the leaf lard or internal fat and the trimmings, amounting in all to from one tenth to one third of the weight of the carcass.

Hogs dress from 73 to $89 \%$.

286. Type. - The type of the fat hog is the same block type that is also characteristic of the beef steer and the

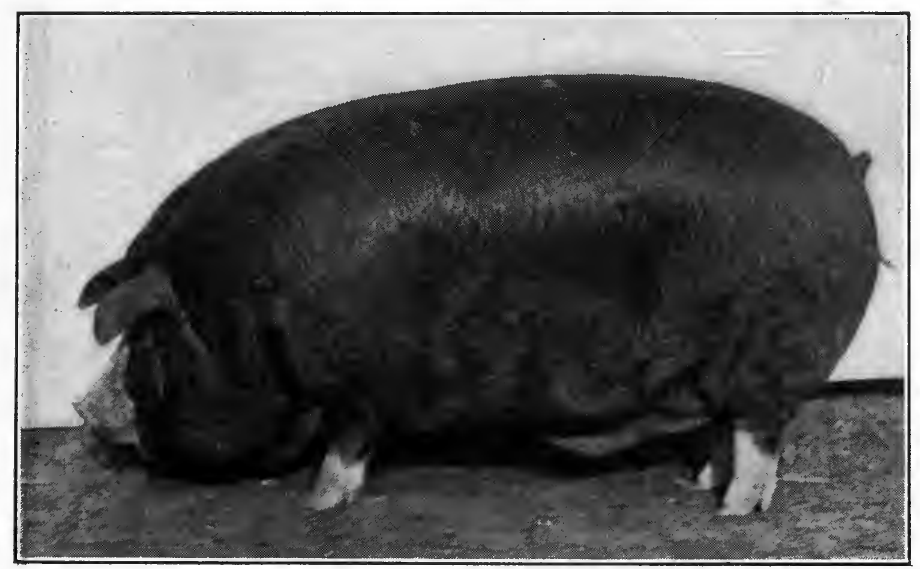

Fig. 136. - A typical fat barrow.

mutton wether (Fig. 136). It is a low, broad, deep form, that is productive of greatest weight in a given compass, earliest maturity, the most rapid fattening in the feeder, the highest dressing percentage, and the best yielding carcass.

287. Conformation (Fig. 137). - The head of the lard hog, like that of all other block animals, is short, broad and deep, 
the snout being comparatively short, with breadth marked particularly between the eyes and depth through the jowl; the eyes large, the eye of the hog being naturally small and deep set; the ears of medium size, pointed and thin, carried well up, not lopped, although these features involve to a large extent the breed of the hog, and close set at the poll; the jowl, the region of the lower jaw, full and deep, blending well with the lower part of the neck, but trim, giving no evidence of being pendant or flabby; the neck hardly definable, it really constituting only the

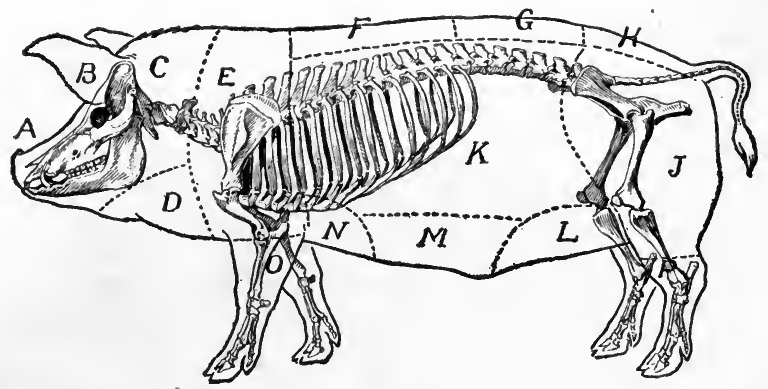

FIG. 137. - Points of the hog. $a$ snout; $b$, ear; $c$, neck; $d$, jowl; $e$, shoulder; $f$, back; $g$, loin; $h$, rump; $j$, ham; $k$, side or ribs; $l$, flank; $m$, belly ; $n$, fore flank; $o$, foreleg; $p$, hind leg.

union of the head with the body, and consisting of but two dimensions, width and depth, without appreciable length, as far as such a thing is possible in an animal structure; the top line making a sharp curve upward from the poll to the top of the shoulders, while the jowl is continued into the point of the shoulder and the brisket; the socalled shoulder vein, the thickest part where the neck blends into the shoulder, especially full; the shoulders not having greater width than is carried throughout the rest of the hog, but broad and compact on top, well laid in 
and smooth on the sides, indicating fine bone, thickly covered; the chest deep, wide, full on the floor and at the breast, with no constriction just back of the shoulders nor between and behind the forelegs; the back broad, flat and thickly covered, carrying a maximum of lard and meat and well supported with a slight arch; sides as long and deep as is consistent with width, the primary essential in the lard hog. Since side meat makes bacon, and the better grade is from the upper part of the side, length is more important than depth, although as much depth of side as possible, so long as it comes from length of rib and not from the weight of the contents of the abdomen, is desirable. Another indication of side meat of the right sort is the smoothness, the absence of wrinkles and creases, and the firm, rather than flabby, appearance. If the back is broad and the rib is well arched the side will be more or less at right angles with the back and will carry well out to the line established by the shoulder in front and the ham behind. If the back is narrow and the rib flat, there will be no sharp demarcation between the back and the side; the side will be deep but pendant and the hog will fall away directly behind the shoulders and continue narrow to the hindquarters. The loin should conform to the back, already described, in being broad and thickly covered, the flank deep and full enough to make the side carry out evenly and the under line straight; the rump broad, long and as level as possible, there always being some droop of the rump corresponding to the sharp curve at the top of the neck which is followed more or less by the whole top line. The maximum weight in the hams, the most valuable part of the hog carcass, is secured by the breadth of rump being continued down into the thighs as deeply as possible toward the hocks and ampli- 
fied by a fullness which makes them rounded out behind and to both inside and outside. They should, however, be firm and show development of muscle, rather than composed largely of fat, which makes them soft and flabby and requires extensive trimming before they can be cured. The essential thing, so far as the legs of the fat hog are concerned, is that they shall be sufficiently straight and strong to carry its weight through the feeding period and finally to the shambles. This latter formerly meant much more than now, as hogs were at one time driven over land considerable distances, while the trip from the farm to the car and from the car to the slaughter is comparatively short now. This matter of legs is of much greater importance in breeding animals, but it is nevertheless essential that market hogs should stand well up on their toes. Broken down pasterns, knock or buck knees and crooked hocks are the common defects in the conformation of the legs.

288. Quality in hogs influences both the texture of the carcass and the dressing percentage. It is indicated by the size and shape of the head and ears, the smoothness of the shoulders, the character of the bone in the cannons and joints, the amount, texture and course of the hair, the trimness of the jowl and the under line, and the general refinement of the hog throughout.

289. Condition. - Most hogs are marketed at weights which make them less mature at slaughter time than the majority of cattle are. They are, therefore, fattening as they grow, which is equally true of cattle only in the case of baby beeves. Condition, comparatively speaking, is of less degree, so far as actual ripeness is concerned, although a thin hog is, in reality, fatter than a finished steer because it is more his nature to be so. Furthermore, for the same 
reason, the butcher hog is less apt to be overdone than the butcher steer. Show hogs do manifest an overripe condition sometimes by " slipping " just back of the shoulders, having their sides break in folds, wrinkles or creases, or their flesh become too hard or too soft.

290. Feeding hogs. - On account of the prolificacy of the sow, the rapid growth and early marketing age of the pigs, and the danger of cholera involved in shipping hogs about, there is no such thing on the market as a feeding hog. The feeders of hogs either breed their own or secure them in their immediate vicinity. Since hogs, as a class, make so much greater proportionate gains on a unit of feed consumed than cattle or sheep do, less consideration is given to the type fed. There is, however, a great difference in the economy with which gains are made in the different individuals, as well as in the character of the carcass when finished. The type that feeds best is of the same general form that is required by the butcher, namely, low, wide and deep, early, rapid and economic production being as closely correlated with this form as are desirable killing qualities. The feeding hog should also possess quality to insure against growing a wasteful carcass, although he should not appear trim, but should show his feeding capacity by being habitually full; constitution, as evidenced by a deep and full forerib; and a feeding temperament. A leggy, long-headed, narrow, flat-sided, light-hammed and wild-eyed hog will be unprofitable both to his feeder in the making and to the butcher when he is finally finished.

\section{The Bacon Hog}

The entire dressed carcass of this hog is cured into bacon which, therefore, is the sole product of hogs of this type. 
In this they differ materially from the fat or lard hogs whose carcasses yield fresh pork, lard and cured meat, one portion of the latter being bacon. This lard hog bacon, however, must be considered as a by-product of pork and lard production. It consists only of the lower two thirds of the side, between the shoulders and hams and below the limit of the fresh cuts from the back and loin; and being cut from a hog that has been bred and fed for lard the side is too soft and coarse grained to rank with true bacon.

291. Production. - The carcass of the bacon hog is split into two Wiltshire sides which are cured entire and are then all cut up for bacon. There is, however, a difference in the grade of bacon derived from the different regions of the side, that cut from the upper part and center of the strip being superior to that at the lower part and ends.

Merit in a Wiltshire side is determined by weight, 160-200 pounds ; shape, - long and trim with maximum development along the back from shoulders to gammons, where the highest priced cuts of bacon are taken; consistence, which should be firm, not soft or flabby ; texture of lean, which is finer than in any other pork product; and fat, only enough to show a uniform margin one to one and a half inches wide along the back bone. Such a side can be produced only in a hog of the correct type.

292. Type. - The bacon type is characterized by length, and all that is correlated with it, i.e. length of side primarily, with a long snout, long legs, a narrow, trim body and especially light fore and hind quarters (Fig. 138).

293. Conformation. - Being a longer, narrower hog all over, the head of the bacon hog is characterized by greater length, less width and depth, making it more 
tapering to the snout, lighter and neater in the jowl, with a fine and usually upright ear. The neck is much better defined than in the lard hog, being level on top, showing none of the arch from the pole to the top of the shoulders, characteristic of the lard hog, and no marked fullness of shoulder vein, but just an even thickness of medium length. The shoulders are light, comparatively straight, lengthening the back, and shortening the distance from

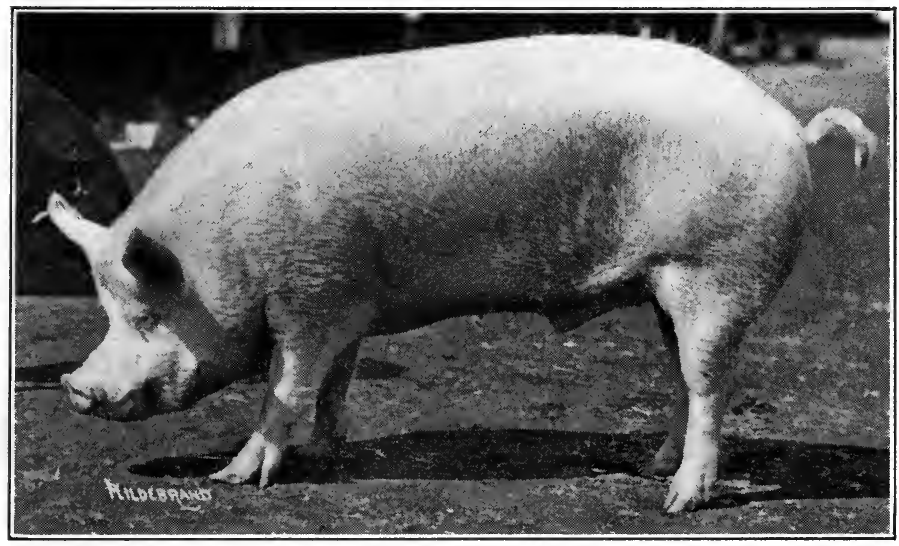

FIG. 138. - A typical bacon barrow.

the shoulder forward, neither sharp nor open but compact on top and especially smooth on account of their being of equal width and well blended with the back. The back may be considered the foundation of the sides, therefore its most desirable features are those which are conducive to a most acceptable side, i.e. as great length as can be had and still be carried up well with just a suggestion of an arch, width sufficient to insure ample abdominal capacity and a meaty side, yet not wide enough to predispose to a 
short or fat side as in the case of the lard hog, where width is a primary essential. The law of correlation is in no place more manifest than in the distinctions between a lard and a bacon hog. The rib has a peculiar turn which is responsible for the shape of back and side by which the bacon hog is characterized. It arches abruptly a short distance from the vertebral column, which it leaves at a right angle, and then continues straight in its course throughout the depth of the side, the lower end incurving again to the sternum or breast bone in such a way as to insure the greatest capacity of chest for the width of the hog. The result is a relatively flat back except as it is rounded by the depth of flesh, and a straight, deep side. The loin should have breadth proportionate to that of the back forward and the rump in the rear, there being a tendency in some bacon hogs to lose width at the loin; strength sufficient to make the loin the crown of the arch of the top line, and a flank only so deep and full as to carry out the straightness of the side. The rump desired is long, comparatively level, carrying throughout the hindquarters the uniform width of the shoulders, back and loin having a rounded contour from side to side, and continued into deep, comparatively thick but smooth and tapering gammons. The shoulders, back, sides, loin and hindquarters should be covered with uniformly thick, smooth, firm flesh. There is naturally a well-marked correlation between bone and muscle, and since bacon consists more essentially of muscle than of lard, the bacon hog is naturally heavier boned than the lard hog. Quality of hair and flesh also being characteristic of the bacon hog, the bone should be smooth and clean, though ample. The extra length of legs which goes with the long body makes it especially important that they be straight, but 
the broken-down pasterns and cramped hocks are not as common as in the much heavier bodied and lighter boned lard hog.

294. Quality. - General refinement is usually more marked in hogs of bacon type, although their bone is naturally heavier. Trimness of jowl and under line, fine ears, light, smooth shoulders, tapering hindquarters and gammons, with a fine, smooth coat of hair, are indicative of the best texture of lean and even deposition of fat so essential in high class bacon.

295. Condition. - The determination or description of condition in the bacon hog, as in the dairy cow, is a fine point. He should not be fat as the lard hog, yet simply being half fat does not constitute bacon condition. There is in bacon hogs, as in all other fat stock, an optimum state which constitutes ripeness, but it is quite different in degree of fatness from what constitutes ripeness in lard hogs, cattle and sheep. The condition sought in the bacon hog is that in which there has been sufficient fat deposited to show the narrow margin along the back when the carcass is split, and this fat is of the sort which gives firmness to the side, being composed largely of the solid palmatin and stearin fats rather than the olein which melts at ordinary temperatures. It should be interspersed evenly with the lean. There is difficulty in holding this condition after the hogs have attained 200 pounds weight.

296. Feeding hogs. - Hogs grown for the production of bacon are marketed at such an early age that the feeder type concerns the breeder more than any one else. Pigs for this purpose should not only conform to the correct type but they should have constitutional vigor as indicated by a full, though not wide, chest, a bright eye 
and a general appearance of thrift. They are of a sort that is slower in maturing and fattening than are lard hogs, but should give promise of having no difficulty in making the required weight of 160 to 200 pounds in six to eight months.

297. The method of inspection. - Hogs of either type are rarely handled at all, the eye being depended upon almost altogether. Some judges touch the side to determine the consistence of the flesh, but even this can usually be made out by noting the lay of the hair and the presence of wrinkles.

From in front, the general width, symmetry and smoothness, also the character and features of the head, and the length, the bone and the direction of the legs can be noted; then from the side and above, the length in general, the top and under lines, the station, the length and the strength of the forelegs, the head in profile, the width and smoothness of the shoulders, the breadth and covering of the back and the loin, the fullness of the forerib and flank, the length and levelness of the rump, the depth and fullness, or taper, of the hams, or gammons, as the case may be, and the straightness and strength of the legs are ascertained; from the rear, the uniformity with which the width is carried throughout, more particularly, the width and smoothness of shoulders, the breadth of back, loin and rump, the depth of hindquarters and the fullness or taper of the ham or gammon, with the length and straightness of the hind legs, receive consideration. The opinions formed from the one side inspection should then be verified by a final look from the other side.

Throughout this inspection quality, as indicated by the amount, the character and the lay of the hair, the fineness of the head, the ears, the shoulders, the cannons and the 
joints, the smoothness and evenness of the covering, with an absence of wrinkles, creases and folds, and a trim under line should be borne in mind. Condition also, as manifested by the general degree of fatness, the consistence and smoothness of the covering, and the trimness of jowl and under line, can be determined incident to the general inspection. 


\section{CHAPTER XVI}

\section{THE BREEDS OF SWINE}

\section{Classification of the Breeds of Swine}

\section{Fat $\left\{\begin{array}{l}\text { Berkshire } \\ \text { Poland China } \\ \text { Duroc Jersey } \\ \text { Chester White } \\ \text { Hamp }\end{array} \quad\right.$ Bacon $\left\{\begin{array}{l}\text { Large Improved } \\ \text { shire } \\ \text { Tamworth }\end{array}\right.$}

Hampshire

298. The Berkshire. - The original stock of the Berkshire breed was very old, but it has been modified in both color and form to such an extent, by engrafting other stocks, as to bring the real origin of the breed within the era of general live-stock improvement, which began in Great Britain in Bakewell's time. At that, it was the first breed improved, and has been most potent in the improvement of others.

The typical Berkshire (Fig. 139) represents the early improvement wrought in the breed by an exceptional degree of style, character and refinement, as well as in the uniformity with which he possesses merit, as measured by feeders' and packers' standards. The Berkshire averages a little larger than any of the other fat hog breeds, but does not attain as great size as the two leading bacon breeds, boars weighing 500 pounds and sows 400 pounds at maturity. Its form is characterized by more length and trimness of body than is usual in breeds of this type, the 
latter character being especially noticeable in the hams. The head is distinctive, the snout being of medium length with only a moderate dish in the face, the ear very neat, well shaped, carried erect, and the jowl full but not flabby. The color is black with six white points, but the absence of a white point is less objectionable than the presence of an irregular white patch on the body.

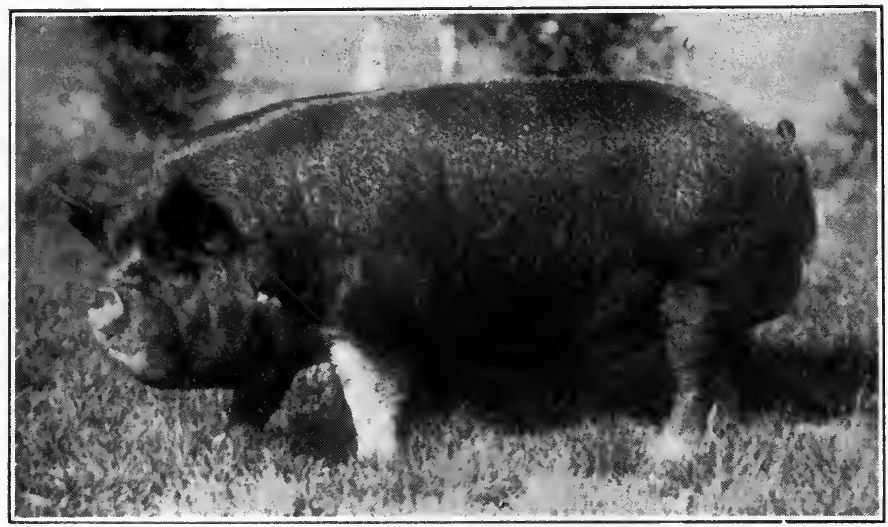

Frg. 139. - A Berkshire boar.

The Berkshire has ample bone of superior quality, straight, strong legs, stands well up on his toes, and moves with a stylish carriage. He is a show hog from tip to tip.

The old-fashioned, short, extremely dished face, a tendency to be leggy and to show an occasional splash of white or a sandy tint on the body are not favored by Berkshire breeders.

299. The Poland China. - This is an American breed of most composite origin, but selected and bred for pork and lard production exclusively. Poland Chinas (Fig. 140) 
are but little smaller than Berkshires and of the same color and markings, although readily distinguishable from them by their form and head. The shape of the Poland China conforms to that of the fat hog in the extreme width of body and fullness of shoulders and hams, being most characteristic, although often secured at a sacrifice of length. The head is distinguished by more length of snout; although it is very fine and tapering, with little, if any,

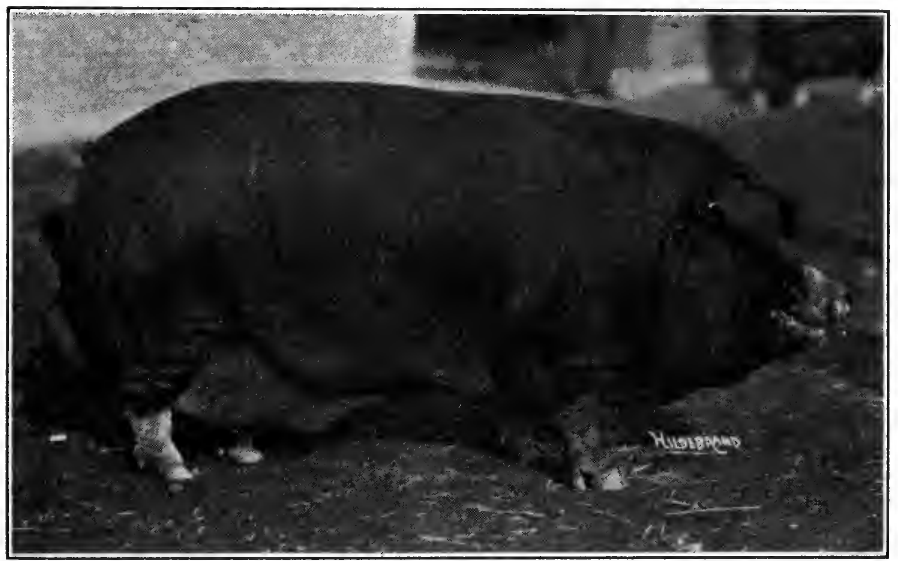

FIG. 140. - A Poland China boar.

dish in the face, and an ear that is erect two thirds of the way from the knuckle, breaking forward for the last one third of its length. The jowl is heavy in accordance with that fullness which prevails throughout the make-up of the fat hog. Color is black with white points, but there is less regularity in the white on the face than in the Berkshire. Poland Chinas show a marked inclination to mature early and fatten rapidly.

A lack of size, and especially of length, too fine bone, 
and a short, droopy rump, are the criticisms which the Poland China breeders are endeavoring to meet.

300. The Duroc Jersey. - This breed, evolved from two parent stocks, the Duroc and the Jersey Red, having a local reputation in New York and New Jersey respectively, has, like most of the other breeds, been molded to a uniform type by breeding for a definite purpose, which, in this instance, was to meet the requirements of

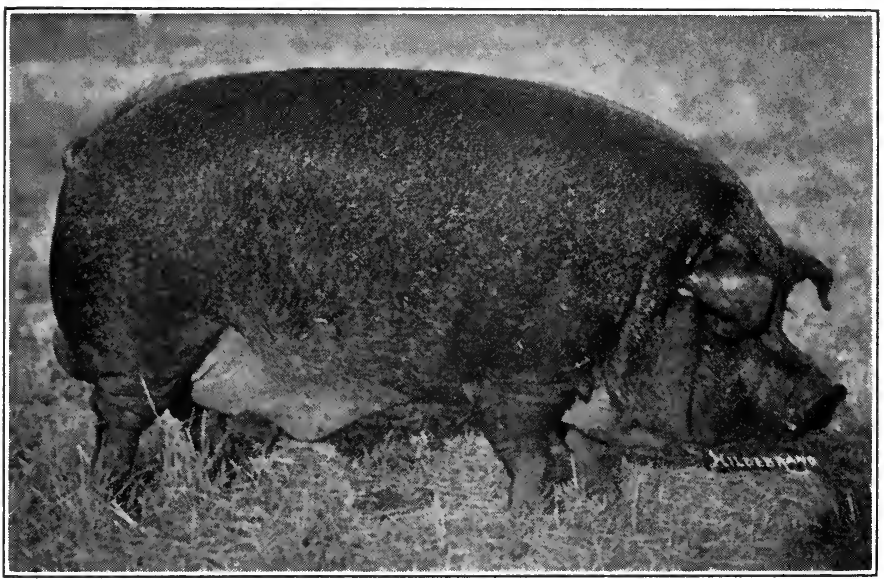

Fig. 141. - A Duroc Jersey boar.

the corn belt farmer. In size the Duroc Jerseys do not differ materially from the Poland Chinas and Chester Whites, but they usually possess greater substance than the former (Fig. 141). They conform closely to the fat hog type in shape, being low, broad and deep, with very full, yet smooth, hams and shoulders: The head is of medium size, the snout of medium length, the face very slightly dished, the ears of medium size and arching 
gradually forward, the jowl heavy and full, like the hams, shoulders and body all through. Color is red, the cherry shade preferred, although the best shades grow lighter with age. Dark spots are sometimes seen under the belly and on the.legs and too many are objected to. As a rule the bone is especially heavy.

A general lack of refinement, shown especially in creases and wrinkles along the sides, has been charged against some individuals of this breed.

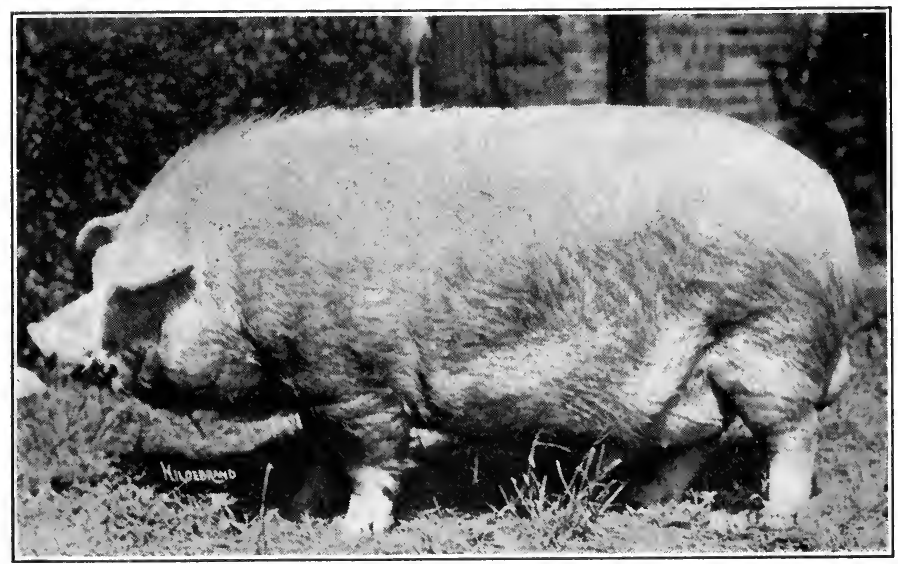

FIG. 142. - A Chester White boar.

301. The Chester White. - This breed, largely of Yorkshire extraction in the beginning, was formerly considered one of the three largest breeds, but it ranks now with the Poland China and Duroc Jersey in size (Fig. 142). Its form is characterized by more length than in either of the two breeds mentioned and it is not, therefore, as uniformly wide, nor as well filled in the hams as they are. The head is of medium size, the face long but straight, 
the ears large, falling gradually forward, sometimes in a careless fashion. Color is white, although bluish black skin spots are not unusual. The pigment must be confined to the skin, however, the hair growing from them being white, and, even then, too many spots are objectionable.

On account of their length many Chester Whites manifest a tendency to be wide in front and gradually narrow

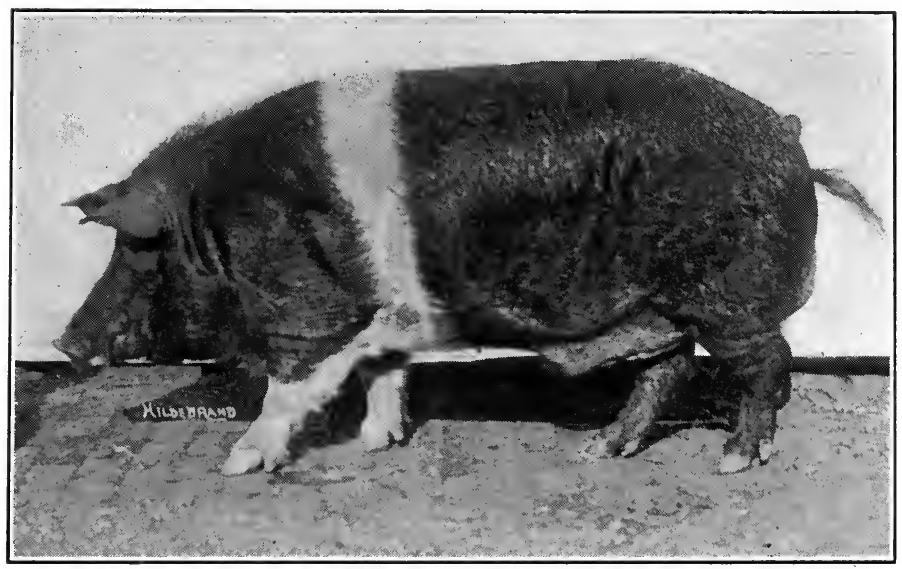

FIG. 143. - A Hampshire boar.

toward the hindquarters. Coarseness, noticeable especially in heavy, lop ears, prominent shoulders, and a rough, curly coat of hair, is a fair objection to some individuals.

302. The Hampshire. - This breed, formerly called Thin Rind, has been classed as of both fat and bacon type, but barrows of this breed have been shown most often in fat classes. Typical representatives (Fig. 143) weigh somewhat less than those of the other fat breeds 
and their form is less extreme. In fact, in length and width of body and fullness of hams and shoulders they are intermediate as to type. The head is somewhat elongated, the face straight and tapering, the ears erect but directed forward. Color is the most striking feature of Hampshire hogs, although it is not fixed by any means. That desired is a white belt clearly defined on an otherwise black body. The belt is sometimes missing, however, solid

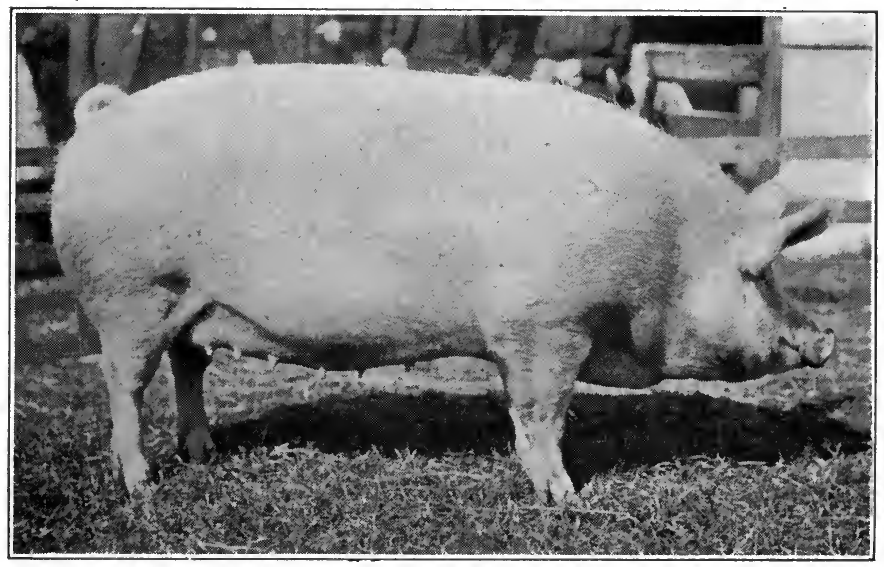

FIG. 144. - A Yorkshire sow.

black colors occurring in litters where some of the pigs, like the parents, are belted. Quality is usually conspicuous in Hampshires, they being smooth and fine.

303. The Yorkshire. - The Large Improved Yorkshire is the only representative of this breed with which American hog growers are much concerned. This is one of the oldest breeds of swine, and earliest references to it indicate that it was then, as now, notable for size, boars and even sows weighing 1000 pounds (Fig. 144). Yorkshire form 
is strictly bacon, being characterized by length and depth of side, balanced by an absence of width and fullness throughout, the neck, shoulders and hindquarters being thin, light and tapering. The head is of medium length, the snout only slightly dished, not turned up, the ears large but fine, shapely, well set and carried erect, the jowl muscular but firm. Color is white, bluish spots in the skin only being permissible but rather objectionable as in

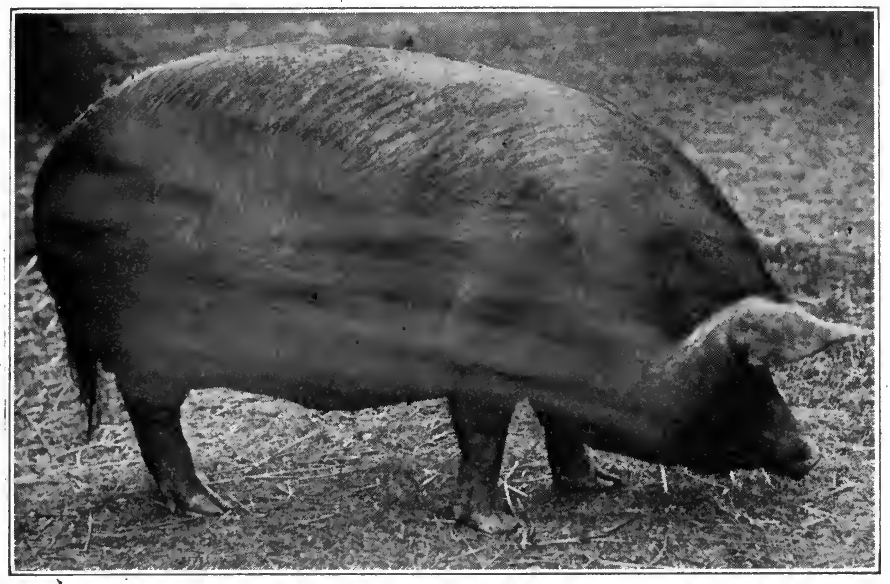

FIg. 145. - A Tamworth sow.

the case of the Chester White. Quality in bone, hair and general refinement is characteristic of this breed.

A short, under-shot snout, heavy, lop ears, a narrow, weak loin, and too much length of leg are the defects most commonly noted in this breed.

304. The Tamworth. - This is also a very old and probably pure breed, the original characters of which have been perpetuated and modified along the line of bacon 
production. After the Yorkshire, this is the largest of the breeds. Its form is even more extremely rangy, long and narrow than the Yorkshire, with a very light neck, jowl and hindquarters (Fig. 145). The head is long and tapering, the longest of any breed, the snout straight, there being little or no dish in the face, the ears very large, but well pointed and thin. Color is cherry red, with no spots, but it is inclined to darken rather than grow lighter with age. This breed is especially active and strong on its legs.

Extremes of type, too long legs, light hindquarters, especially, and too much weight in front, due to excessive length of head, prominent shoulders and a coarse coat are the exceptions taken to this breed. 



\section{PART VII \\ JUDGING BREEDING ANIMALS}





\section{CHAPTER XVII}

\section{BREEDING STOCK}

Sales and show classifications both distinguish between market and breeding animals. The former are quite generally unsexed and command consideration only for what they themselves are. Breeding animals, on the other hand, have more than an intrinsic worth, they are the progenitors of future generations to whom are to be transmitted the characters of a numerous ancestry. Therefore, breeding animals should not be judged merely as individuals, but as representatives of an ancestry whose influence will dominate the succeeding generations of which they are the progenitors.

305. In the selection of breeding animals it must be borne in mind that they do not represent, in their physical make-up, all the characters which they have inherited, nor yet all the characters which they are capable of transmitting. Thus, the failure in the stud of some showring champions can be accounted for, likewise the superior value, as sires, of some individuals, themselves incapable of winning most humble honors in the show ring.

306. The successful sire or dam is the one which will produce, regularly, progeny of uniform excellence, true to type and possessing constitutional vigor sufficient to insure their living productive and reproductive lives (Figs. 146 and 147).

Reproduction has been termed a superabundant de297 
velopment, by which we infer that an animal may be fully developed, as an individual, yet incapable of reproduction, the latter being over and above normal individual development. Therefore, stock animals should have size,

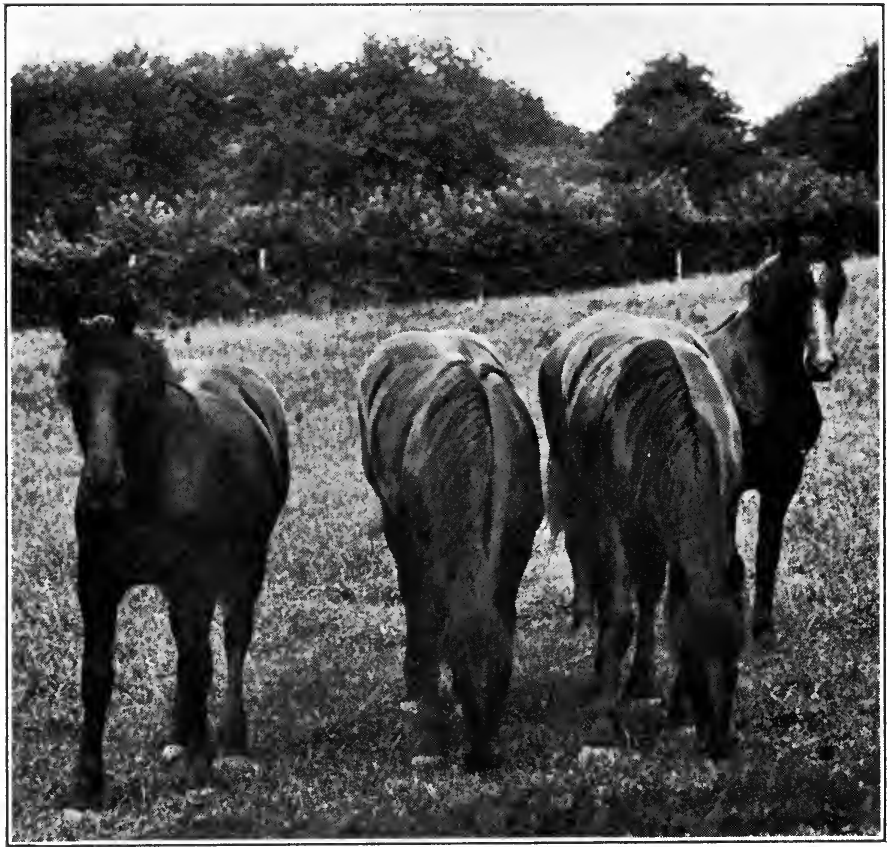

FIG. 146. - Percheron yearlings whose sire is shown as Figure 71. They manifest uniform excellence transmitted by the superior sire of marked prepotency, as well as the characters desired in colts of this age.

and be well-developed individuals in order that the "super" function may be most manifest.

307. Prepotency. - In the selection of breeding stock the pedigree is of greatest importance, yet the individual 


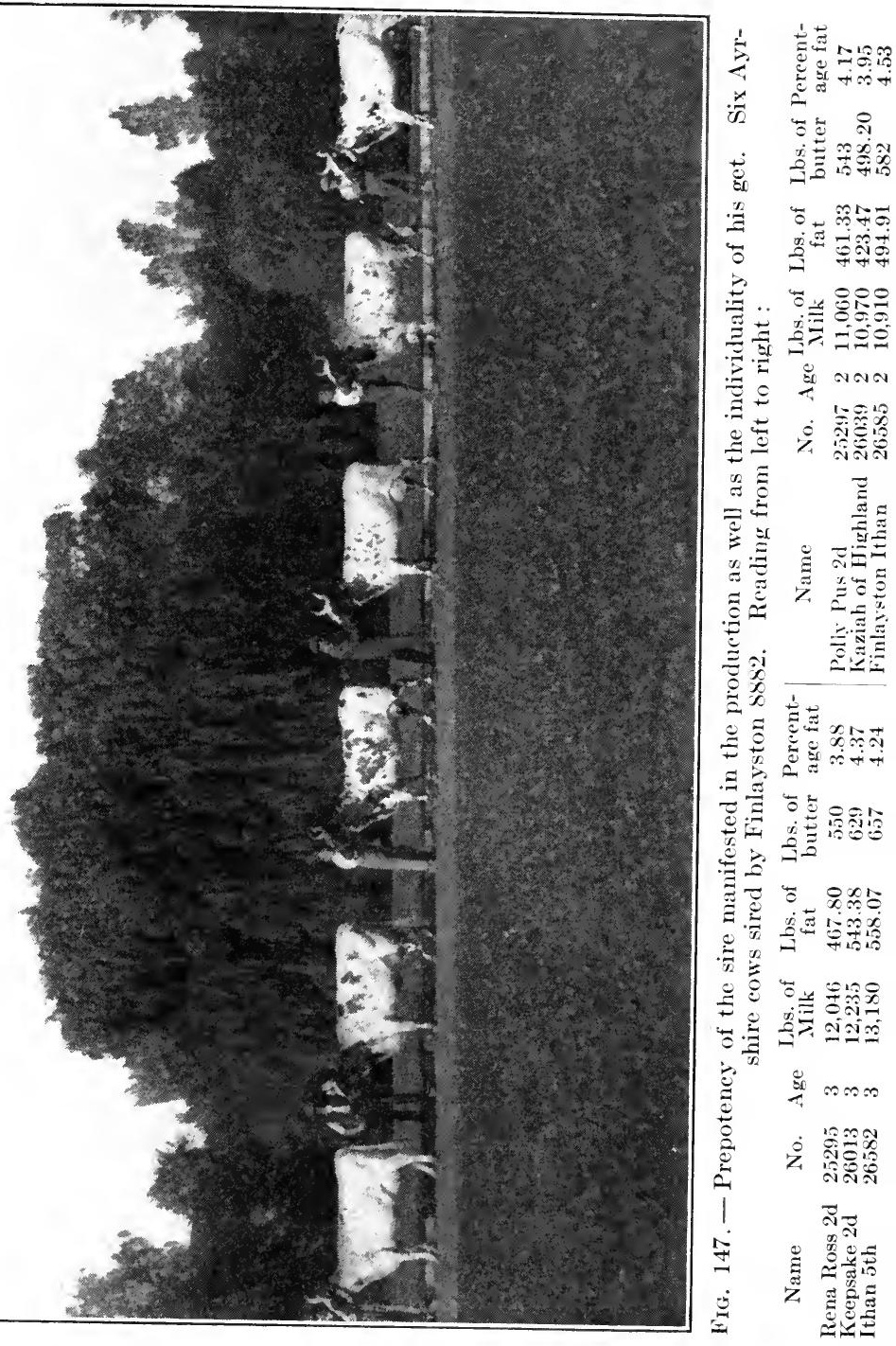


only is to be considered in show-ring judging. However, a superior ancestry may be evidenced by character and breediness, manifested in the head and neck especially.

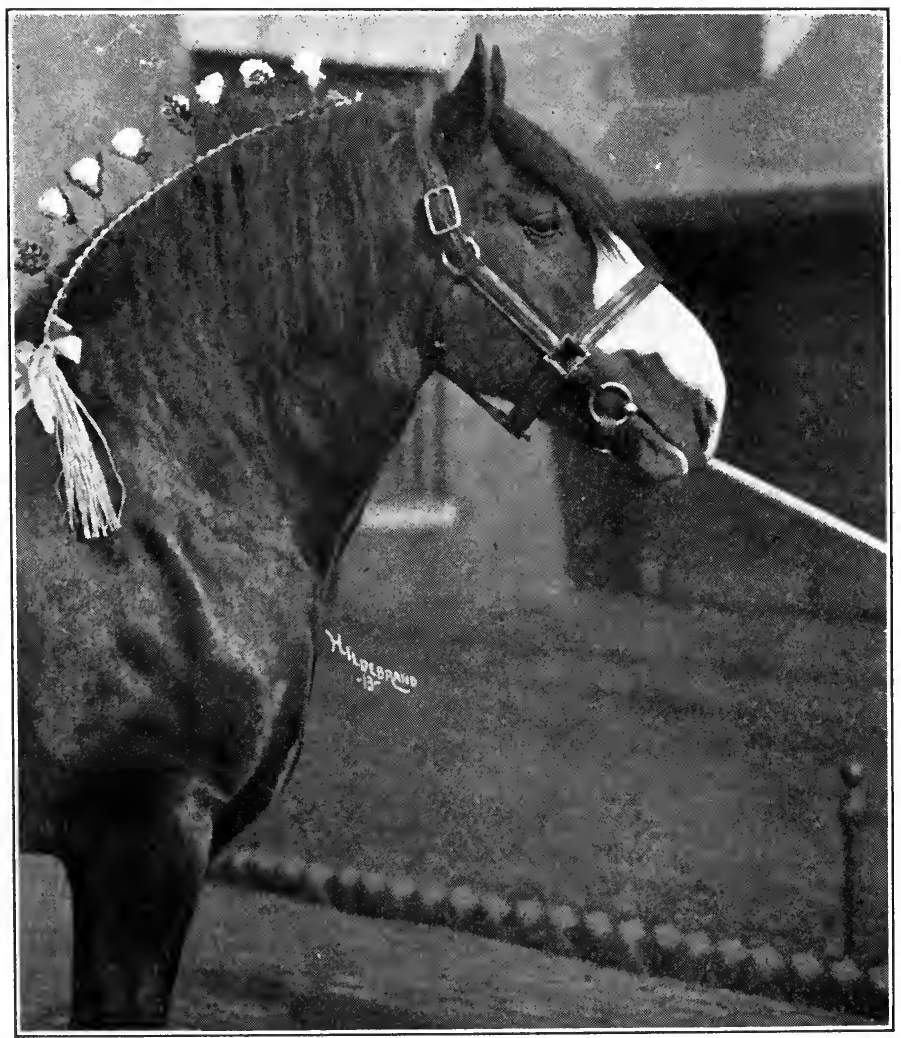

FIG. 148. - Sex and breed character in the stallion.

While it is true that an individual may transmit characters which he himself does not manifest and he may fail to 
transmit characters which are incorporated in his make-up, there is greater likelihood of certain characters, good or bad, appearing or not appearing in the offspring, if they are or are not present in the parents. Therefore, the type

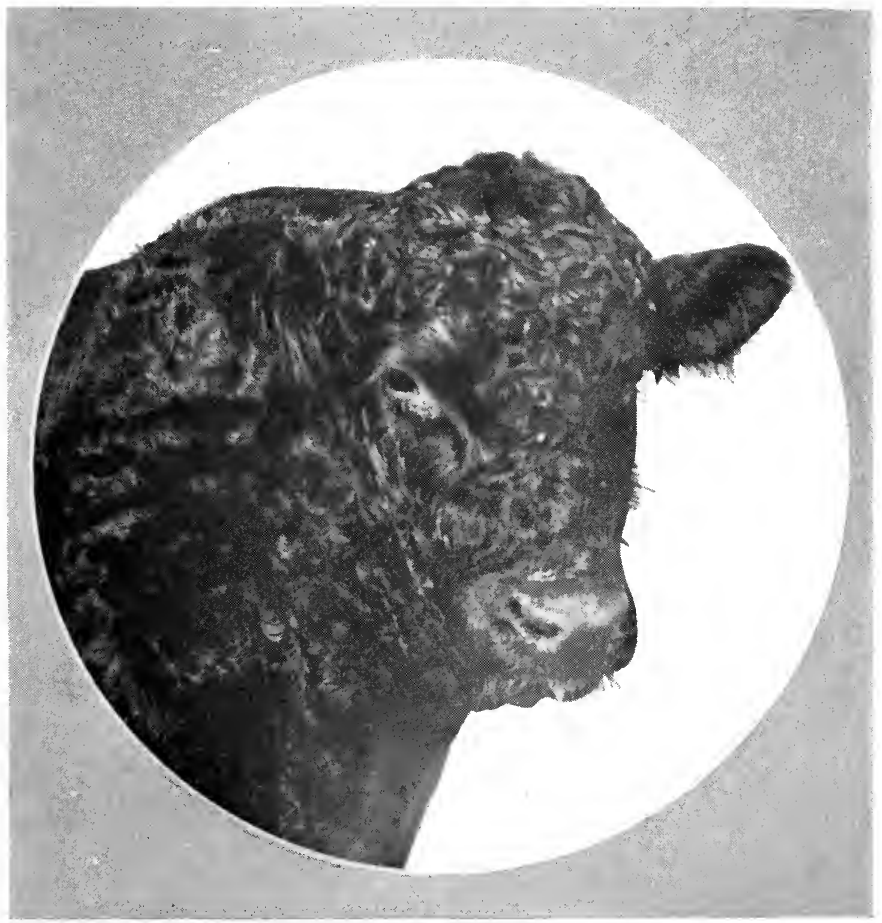

FIG. 149. - Sex and breed character in the bull.

and individuality desired in the progeny should be well marked in the parents. It is one thing to possess merit, quite another to transmit it. The force with which the characters of one or the other of the parents are impressed 
upon their offspring constitutes prepotency, and prepotency, as well as virility, is indicated by strong sex character-masculinity in the male and femininity in the female.

308. Masculinity (Figs. 148 and 149).- The evidence of masculinity is noted in the forehand or quarter, which

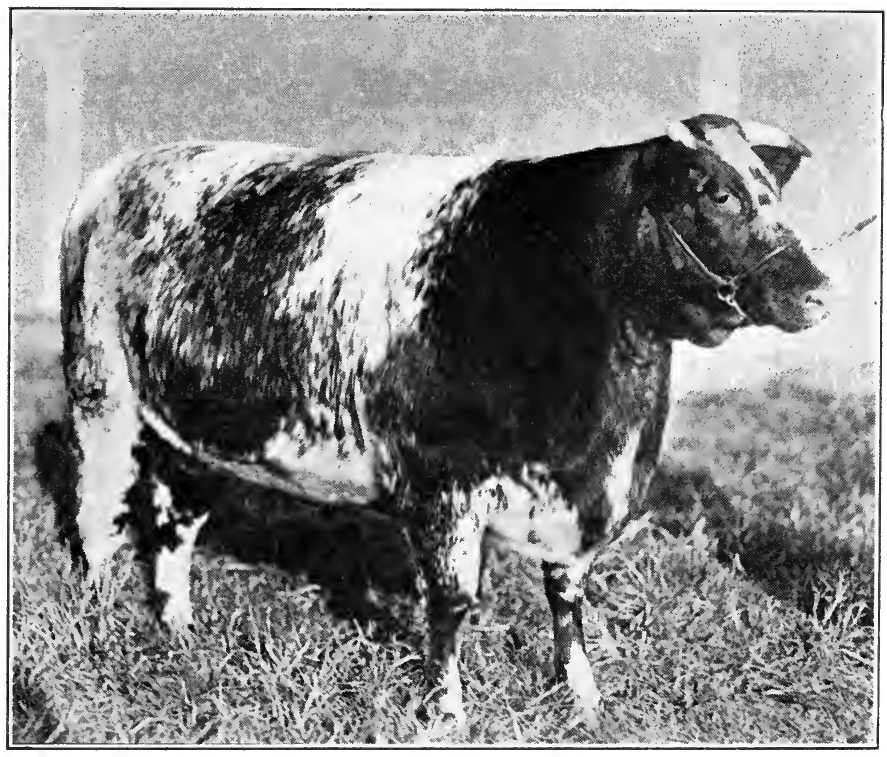

FIG. 150. - A typical breeding female.

is especially well developed, the heavy-crested neck, the strong-featured countenance, the bold demeanor, and even the voice all betokening the sire. It has been amply demonstrated, in practice, that the male which is wanting in these features, whose head and neck are not markedly different from those of the female, is no stock getter at all, 
or else he is a very indifferent breeder, in so far as any prepotency is concerned.

309. Femininity (Fig. 150) is naturally characterized in the opposite manner. It implies, primarily, a total absence of any masculine character. Hence, the forequarters of the female are light, fine and undeveloped ; the hindquarters, on the contrary, are broad, the head is proportionately smaller, the expression of the countenance sweeter, and the manner more demure. "Staggy" females are not regular nor satisfactory breeders, as a rule, and an extreme manifestation of masculine character in the female may be associated with hermaphrodism.

310. Form in breeding animals. - There are special features of form in addition to the sex characters which may distinguish the male from the female (Fig. 151). It is generally conceded that the male animal should be larger than the female, although there are many instances in nature to contradict this theory. The form of the male is more compact, the female, since she is to be host to the developing fœtus as well as contributing her share of the hereditary material, being more roomy, and capacious of middle, longer in back, more open in the flank, and broader across the hips and buttock, the latter features insuring safe and comparatively easy delivery of the young.

311. Constitution in breeding animals. - Constitution is the last word in either production or reproduction. It limits the extent to which inherent possibilities may be realized. No matter how much speed or power, milkiness or beefiness, horses or cattle are endowed with, they cannot perform or produce to the full capacity of their endowment unless they have the stamina and constitutional vigor upon which to base such performance or pro- 


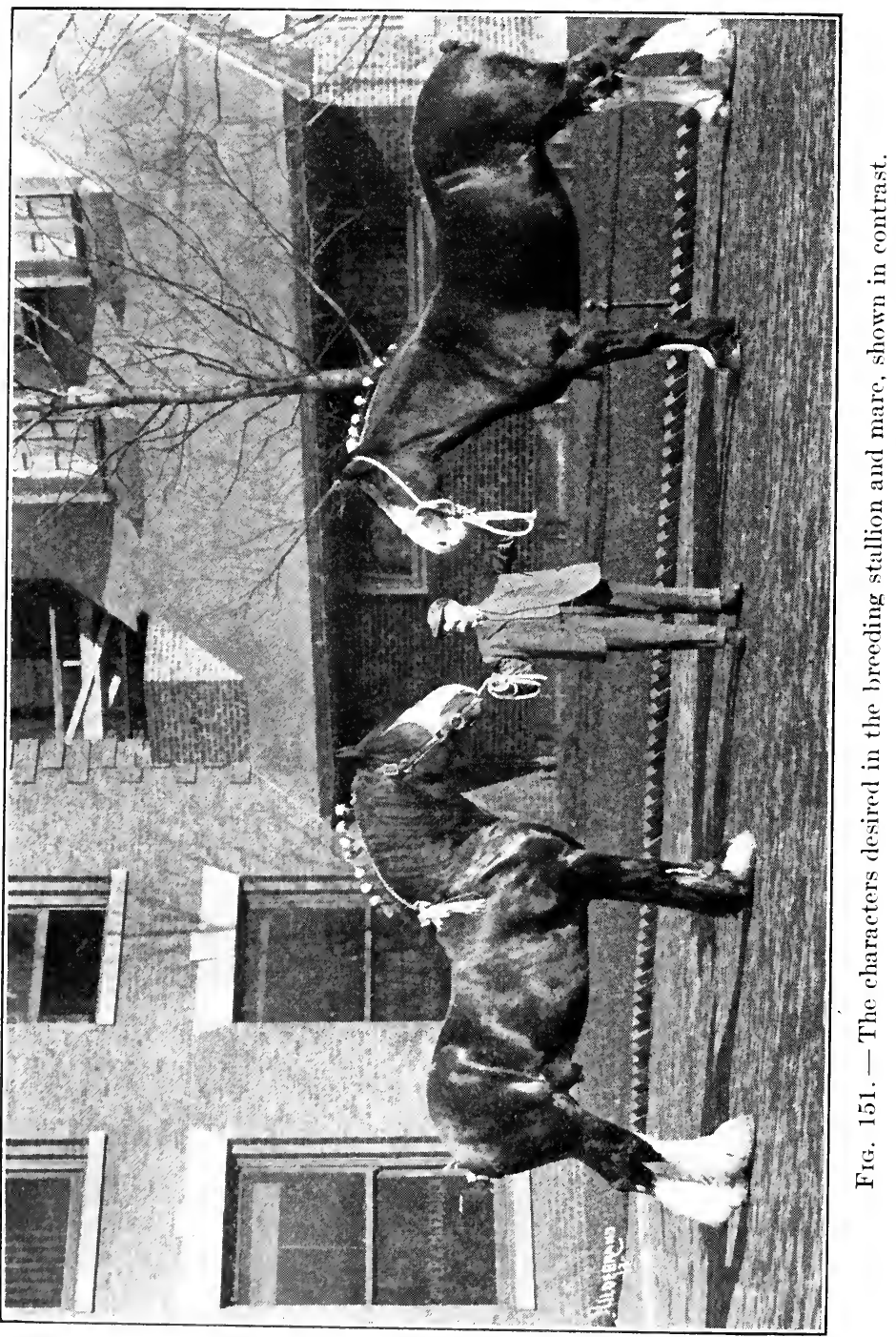


duction. It is essential that there should be transmitted, in addition to the characters desired, all the constitutional vigor that will be required to insure maximum attainment along the line of that character. Nothing will impair production nor prohibit reproduction of successive generations and the perpetuation of the stock without deterioration more than weak constitution. Hence, all other

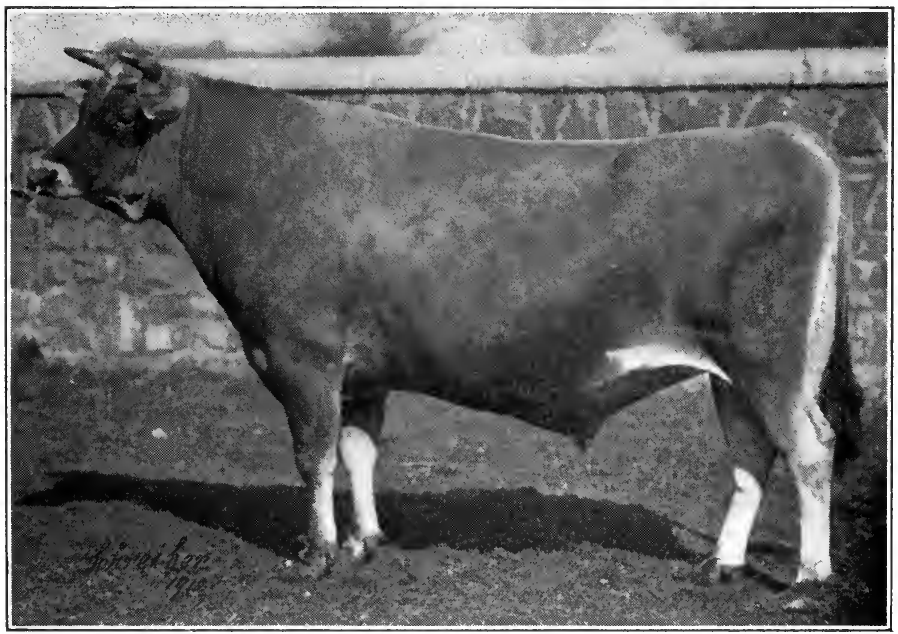

FIG. 152. - A typical dairy bull, masculine yet refined, of true dairy type and possessing unusual breed character. (3 yr. old form.)

attributes essential in breeding animals may count for naught unless associated, in the sire or dam, with a strong constitution.

312. Substance in breeding animals. - Substance is more essential than quality in most breeding animals, especially the males. It is a serious fault for any stud animal to be undersized, or too fine in bone. Ruggedness in males is more desirable than extreme finish. 
With these exceptions, the judging of breeding classes is conducted along the same general lines as described for the market and breed types. The beef bull should be the masculine personification of the butcher steer, while the dairy bull (Fig. 152) should conform, as closely as it is possible for a male to do, to the milky form of the dairy cow. Most judges even attach importance to the size and placing of the rudimentary teats of the dairy bull. What is analogous to the crest of the stallion and bull is designated the scrag in the ram and the shield in the boar. 


\section{CHAPTER XVIII}

\section{LIVE-STOCK SHOWS}

StREss has already been laid on the fact that the selection of breeding stock is a more important phase of the judging of animals than that which is done in the show ring. The great, even though lesser, importance of the latter should not be underestimated, however. The show ring has been a most influential agency in promoting the live-stock interests and in improving the class of stock bred.

313. The benefits of the stock show concern two classes of people, those who show and those who go. To the former, it constitutes the best advertising medium available. There is no better means of getting one's stock before those people to whom it is of greatest interest. It furnishes, to the exhibitors, also, an excellent opportunity to indulge in a most wholesome competition, and finally, although of least importance after a full accounting is taken, it may be a source of revenue in cash prizes.

Those who go to the shows in the capacity of spectators only, derive merely entertainment in return for their admission fee, but there are usually in attendance at the shows a great many stock men whose singleness of purpose is to learn of live stock. To these the show is a great exposition of market and breed types; of most approved systems of breeding and methods of feeding. It affords inspiration to the ambitious stock man, then demonstrates the best means of attaining success. This 


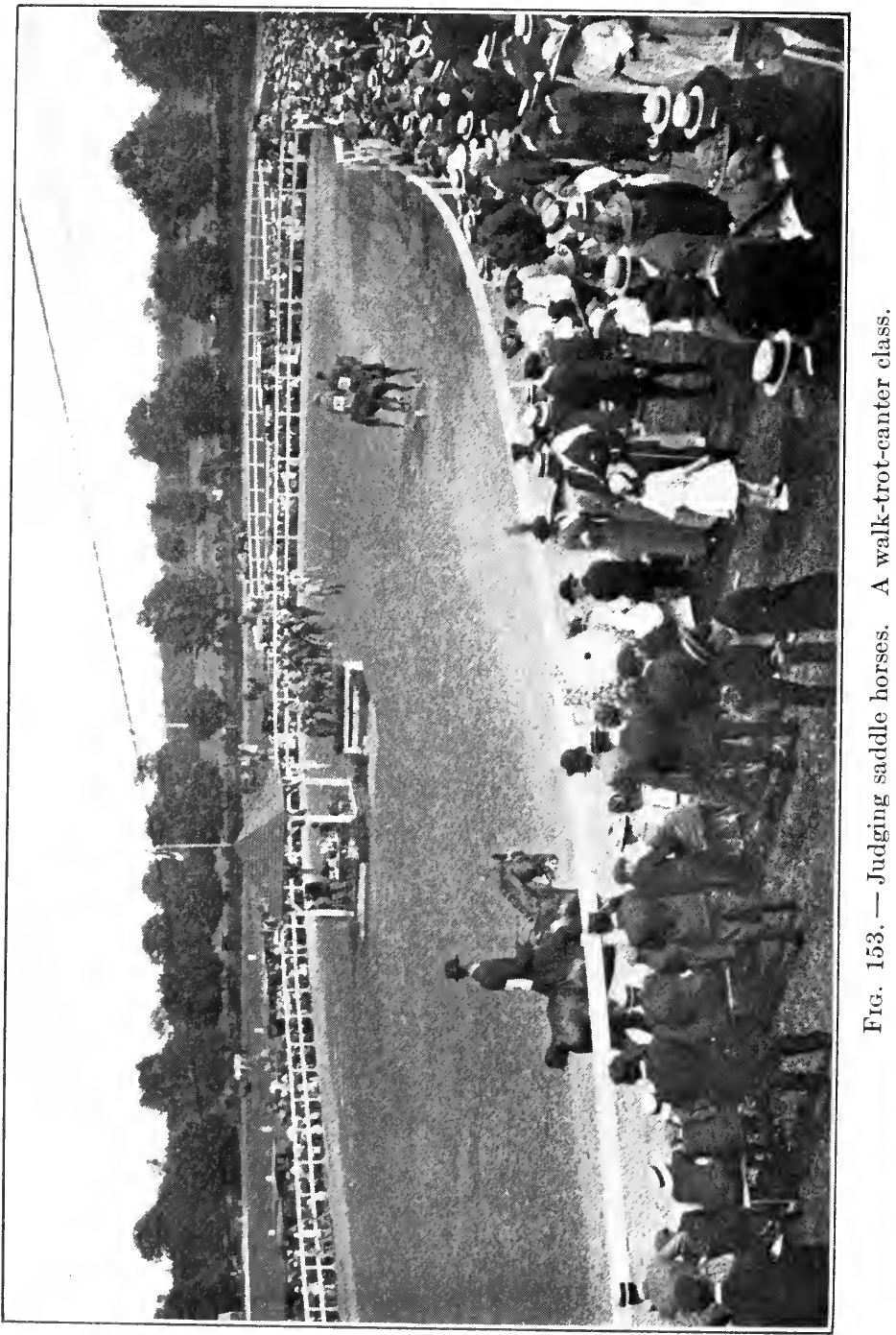


educational feature is being appreciated more and more and is given greater prominence at the leading shows each year. In general the show stimulates interest in live stock.

314. Show classification. - There are two great divisions of all show classes: Market and Breeding.

Classification within the market division is made on the basis of type, and all entries of a type may be further classified as to age, weight, height or sex.

Breeding classes are provided for each of the recognized breeds, each breed group being subclassified as to sex and finally on the basis of age for each of the sexes.

There are usually offered, in addition, special classes for get of sire, produce of dam, groups, herds and pens, both owned or bred by the exhibitor. Then there are championships decided among the first, and usually the second, prize winners in class, and finally a grand championship for the winner among champions.

315. Market division, Horses. - The bases upon which market horses are classified and shown have been given in connection with the market classes of horses - such a variety of classes within specified weights, heights and "Performance only to count" or "Performance 60\%, conformation, quality, and manners $40 \%$," as to make a detailed list unnecessary here (Figs. 153 and 154).

316. Market division, Fat classes. - The fat classes of the market division for the breeds and their grades and cross-breeds are as follows:

Cattle.

Steer, spayed or martin heifer, calved since January 1 of the second year preceding the year of the show.

Steer, spayed or martin heifer, one year and under two. Steer, spayed or martin heifer, under one year.

A lot consists of three head, representing each age. 


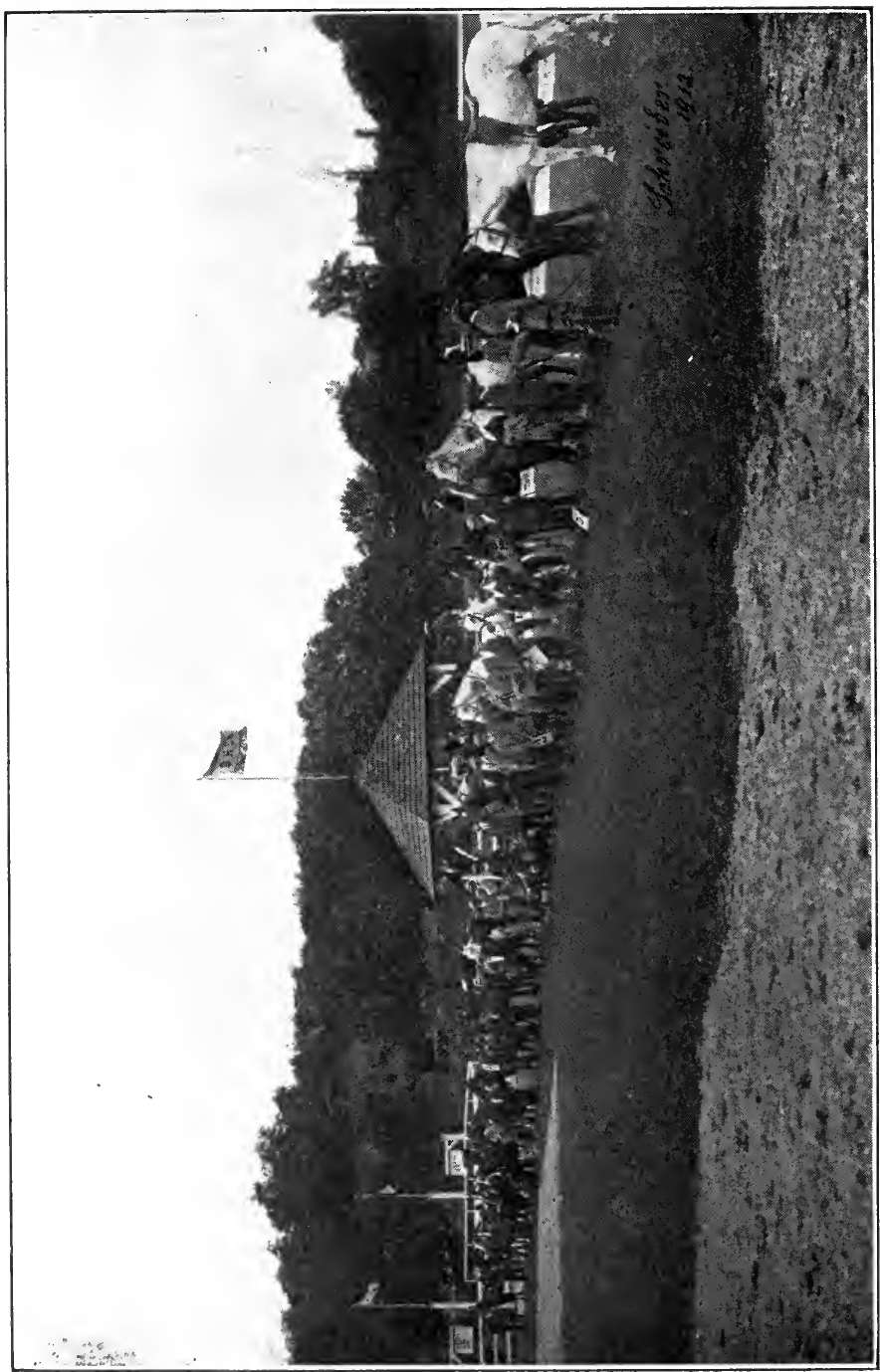

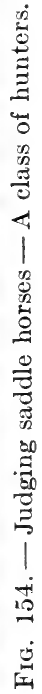


Sheep.

Wether, one year and under two.

Wether lamb.

Pen of five wether lambs.

Swine.

Barrow, under six months.

Barrow, over six months and under twelve.

Barrow, over twelve months and under eighteen.

A pen consists of three barrows.

317. Breeding classes, Horses (Fig. 155). - The following classes are offered for each of the representative breeds :

Stallion, four years old or over.

Stallion, three and under four.

Stallion, two and under three.

Stallion, one and under two.

Stallion foal.

Brood mare, four years old or over. ${ }^{1}$

Brood mare, three and under four.

Brood mare, two and under three.

Brood mare, one and under two.

Filly foal.

318. Breeding classes, Beef cattle (Fig. 156). - The following classes are offered for each of the representative breeds :

Bull, three years old or over.

Bull, two and under three.

Senior yearling bull, calved between September 1 and January 1 of the year preceding the year of the show.

Junior yearling bull, calved between January 1 and

1 The International Clydesdale Classification provides for yeld mares, i.e. neither in foal nor suckling. 


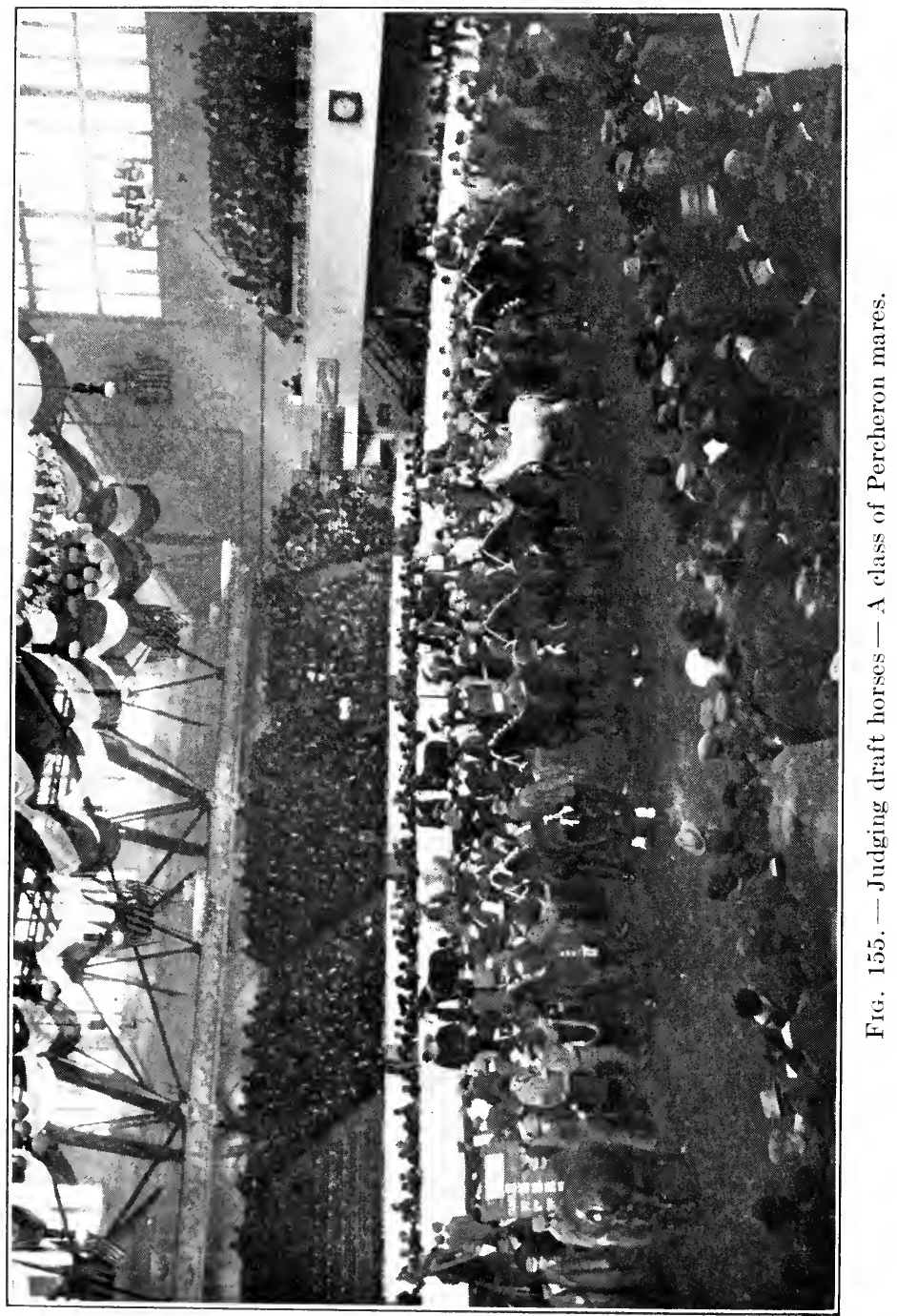




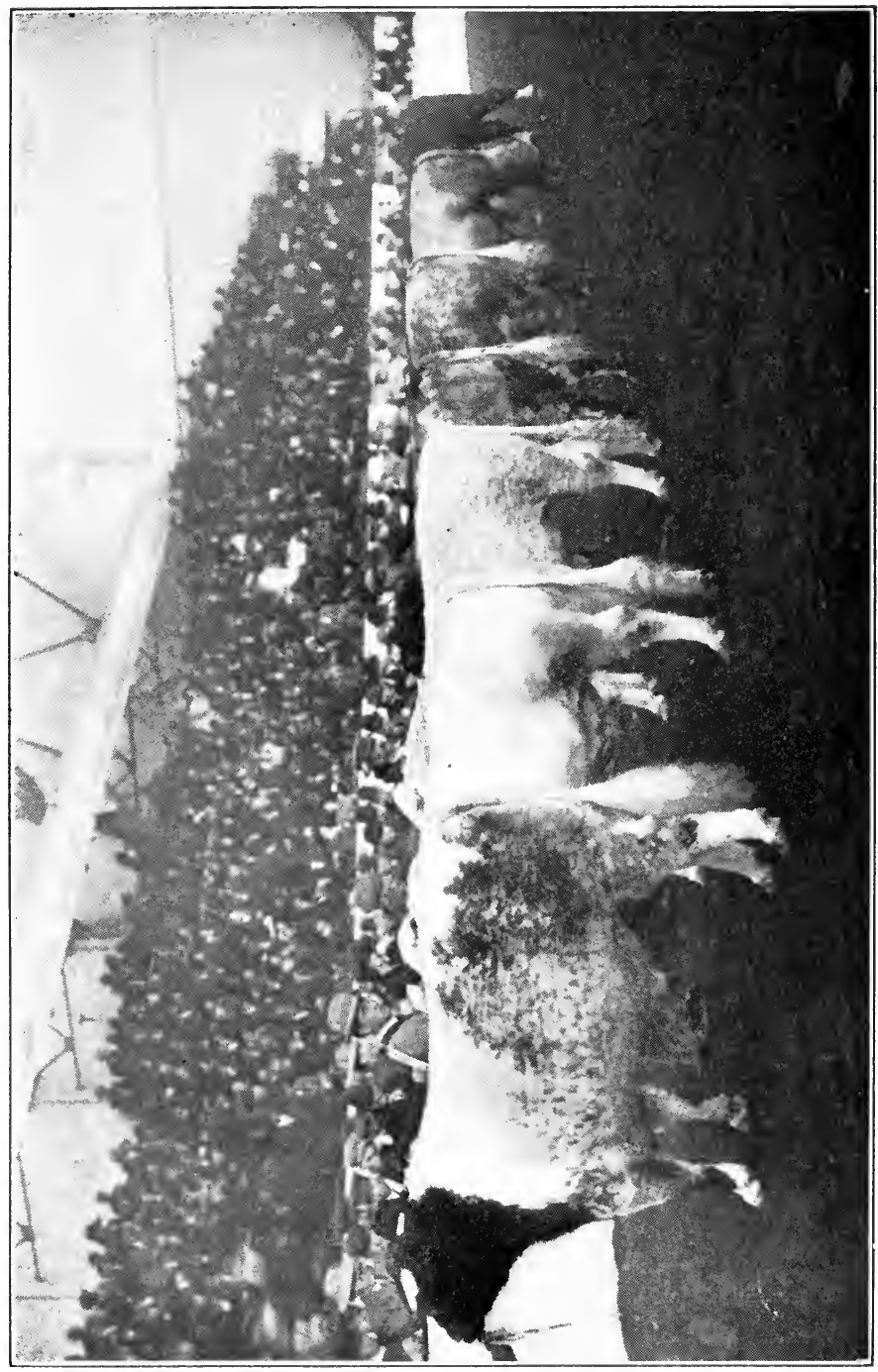

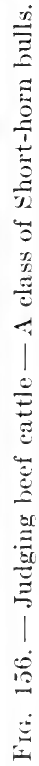


September 1 of the year preceding the year of the show.

Senior bull calf, calved between September 1 and January 1 of the year of the show.

Junior bull calf, calved since January 1 of the year of the show.

Cow, three years old or over.

Cow or heifer, two and under three.

Senior yearling heifer, calved between September 1 and January 1 of the year preceding the year of the show.

Junior yearling heifer, calved between January 1 and September 1 of the year preceding the year of the show.

Senior heifer calf, calved between September 1 and January 1 of the year of the show.

Junior heifer calf, calved since January 1 of the year of the show.

319. Breeding classes, Dairy cattle (Fig. 157). - The following classes are offered for each of the representative breeds :

Bull, three years old or over.

Bull, two and under three.

Bull, one and under two.

Bull calf, six months old and under twelve months.

Bull calf, under six months.

Cow, five years old or over.

Cow, four and under five.

Cow, three and under four.

Heifer, two and under three.

Heifer not in milk, eighteen months old and under two years.

Heifer not in milk, one year old and under eighteen months. Heifer calf, six months old and under twelve months. Heifer calf, under six months. 


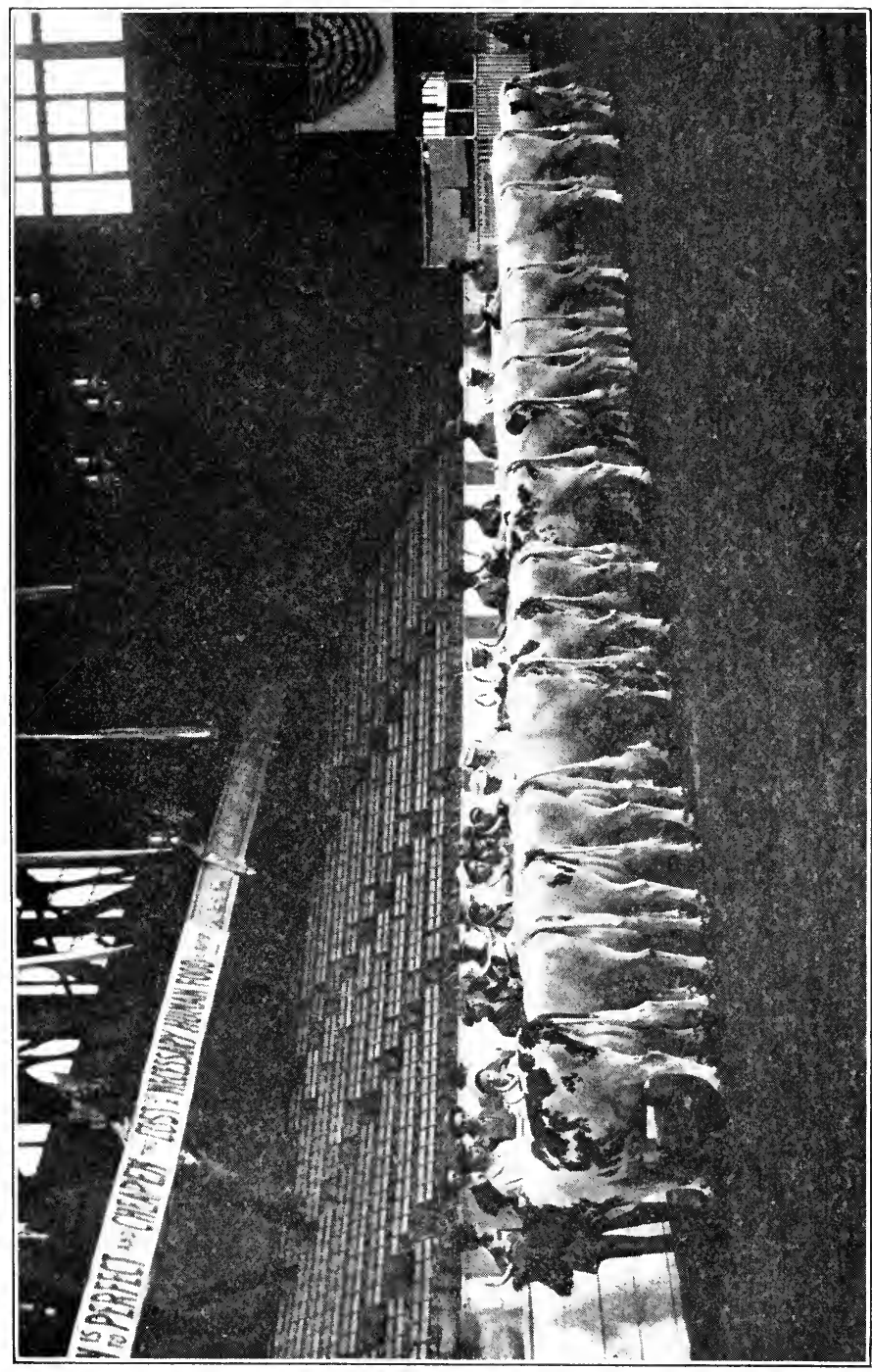

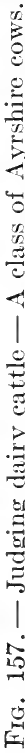


Aged herd consists of one bull, two or over, one cow or heifer, two and under three, one heifer, one and under two, and one heifer under one year (Fig. 158).

Young herd consists of one bull under two, two heifers, one and under two, and two heifers under one year.

Calf herd consists of one bull and two heifers all under one year and bred by exhibitor.

320. Breeding classes, Sheep. - The following classes are offered for each of the representative breeds:

Ram, two years or over.

Ram, one and under two.

Ram lamb, under one year.

Ewe, one year and under two.

Ewe lamb, under one year.

A flock consists of one ram, one year old or over, two yearling ewes and two ewe lambs.

321. Breeding classes, Swine. - The following classes are offered for each of the representative breeds:

Boar, two years old or over.

Boar, eighteen months and under twenty-four.

Boar, twelve months and under eighteen.

Boar, six months and under twelve.

Boar, under six months.

Sow, two years or over.

Sow, eighteen months and under twenty-four.

Sow, twelve months and under eighteen.

Sow, six months and under twelve.

Sow, under six months.

There are also shown pens of one boar and three sows.

322. Age basis. - All ages are reckoned from January first except in the senior yearling and calf classes. Their ages date from September first, preceding. 


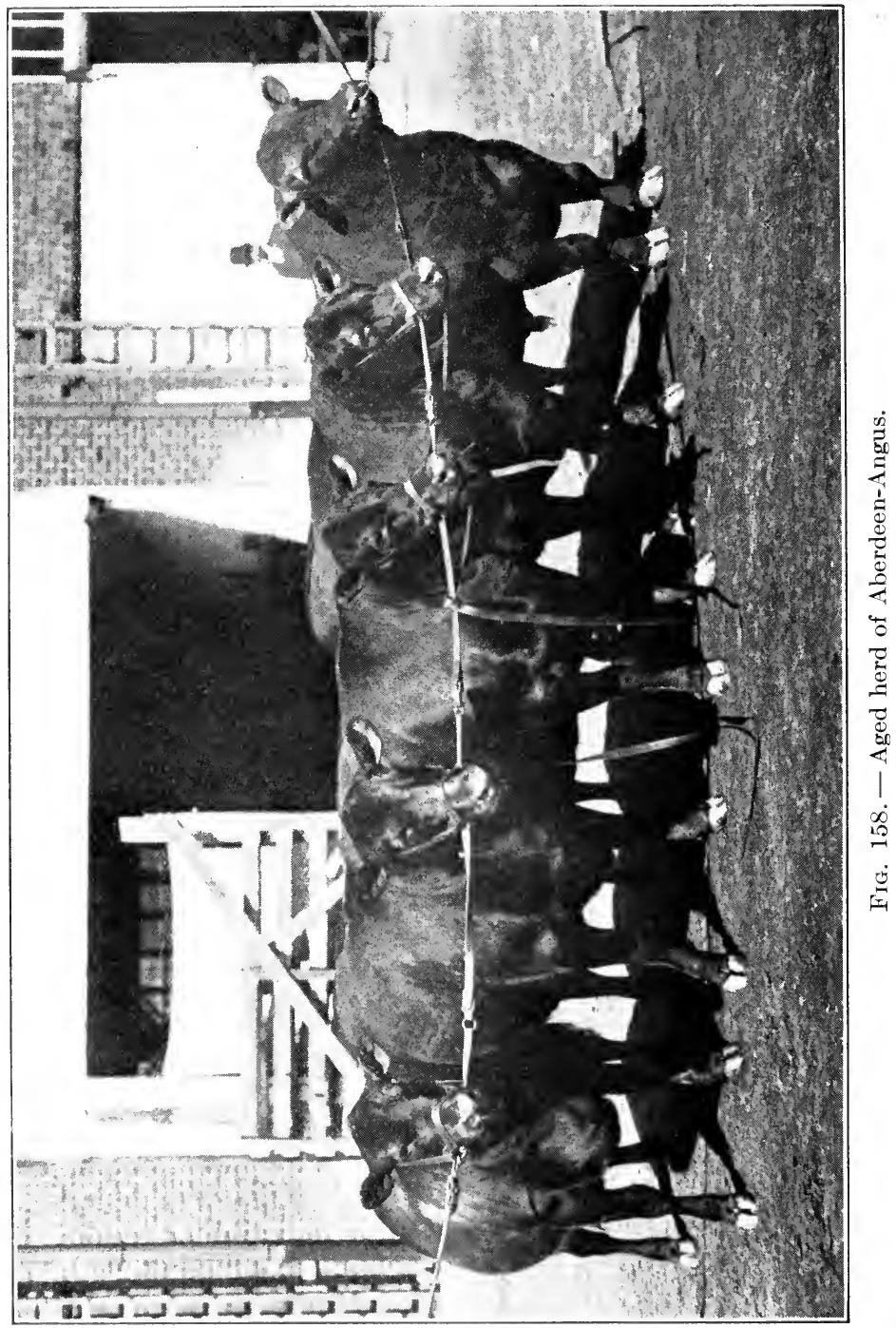




\section{Manner of Showing}

The judge should have a thorough understanding of the customary manner of showing the various classes of animals.

323. Horses. - The market classes of horses are shown in harness or under saddle, in accordance with their

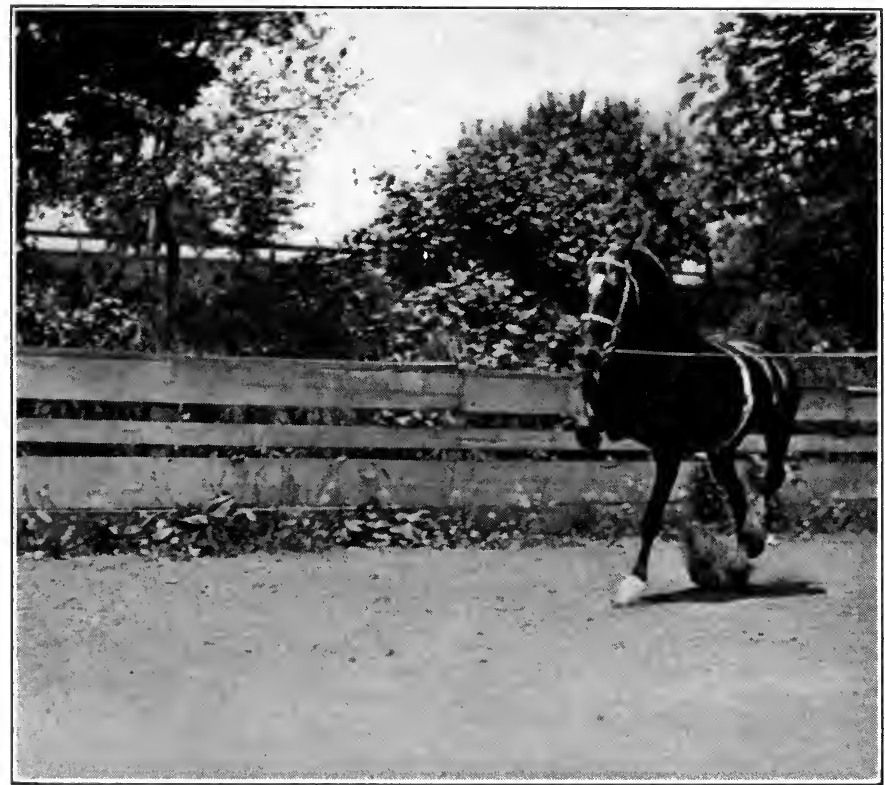

FIG. 159. - Showing in hand.

specific class requirements. Exception is made in the case of drafters, which, in addition to being shown in single, pair, three, four and six horse hitches, are also shown to halter.

Horses in the breeding division are, without exception, 
shown "in hand" (Fig. 159), either to halter or lead bridle in the case of draft and saddle horses, beside or in front of a saddle pony if trotters or pacers, and usually on a long lounge rein in the hand of a foot runner in the instance of Hackneys and Coach horses. It is preferable that horses so shown should not be prompted, but the Clydesdale show men are about the only ones to evince any regard for this preference. Prompting is frequently grossly overdone in the showing of draft horses and Hackneys, the voice, whip and all sorts of noisy contrivances being resorted to.

Horses are led from the near side except when shown on the long rein, as Hackneys are. Then the horse is run up to the rail of the ring with the runner on his left, reversed and brought back with the rein over his back and the runner on his right and a little behind him.

Harness and saddle horses are driven or ridden well into the corners of the show ring, in order to make as much of the straight-away as possible, and are usually called upon to work both ways of the ring for the purpose of obviating any deviation in the stride which may be due to taking the turns; also to enable the judge to see both horses of a pair, or the saddle horse cantering on both leads.

The special requirements of the service under which the horse is classed should be borne in mind by the judge. Work and station wagon horses should be handy in backing up to a platform, real or imaginary; runabout horses should stand without hitching; and saddle horses should stand to be mounted.

Drafters and saddle horses are shown at the walk, as well as at the trot, and the other saddle gaits in the case of the latter, while harness horses are rarely, if ever, walked. Entries in roadster classes are expected to show 
as much speed as is possible in a small ring, while high steppers show at a park gait of eight to twelve miles, unless "pace and action" are specified. All horses are required to stand in pose either squarely on their feet or camped.

Performance alone may count, or, in addition, conformation, quality, manners and appointments, proportionately, as specified in the catalogue.

324. "Vetting." - Veterinary examination may be required before the horses are shown, a report of which is to be furnished to the judge when the class is called, or they may be shown subject to disqualification, in case they manifest unsoundness in the ring. Unsoundness detected or suspected in the show ring by the judge is usually referred to the official veterinarian, whose rulings are final. Also, measurements and determination of age, as in the breeding classes, are settled by the veterinarian and the entries qualified or disqualified upon this basis.

Cattle. Methods and practices differ sufficiently in the showing of beef and dairy cattle to warrant separate consideration of them.

325. Beef cattle, in the steer and cow classes, are shown in halters, unless a particularly unruly one requires a ring in his nose, while bulls are regularly led by a ring in which a strap is snapped.

The coats of beef cattle receive special preparation. Both sexes of those breeds which have a sufficiently long and heavy coat, as the Short-horn, Hereford and Galloway, together with their pure bred and grade steers, are shown rough, i.e. with the hair washed out and then brushed or combed the wrong way or arranged in some fantastic design. Showing rough enables a clever show man to overcome the appearance of many defects, roughing the 
coat especially where there may be a slack spot, as in the crops, while smoothing it down upon or roughing round about any undue coarseness or prominence. Angus breeding cattle, as a rule, are shown smooth while their grade steers are usually shown rough if they have enough hair.

Some beef cattle, especially the smoother coated ones, are trimmed about the ears and poll, while the horns are generally rubbed and polished to a fine finish. Their coats are thoroughly groomed, usually blanketed, their switches washed and picked out, egg shampoos and everything possible being resorted to that might enhance the handling quality of the hide and hair.

Cattle are taught to stand squarely on their feet, a careless position often giving the appearance of a low back or some other physical defect, while a special pose may improve the appearance of certain lines very materially. Also, carrying the head to one side or the other may alter the handling. They are taught to lead promptly so as to make the best appearance when asked to move about.

Even breeding beef cattle are shown in high condition, about as fat as they can be made without being overdone.

326. Dairy cattle. - Cows are shown in halters, while bulls are led with rings in their noses and almost invariably by means of staffs. The coats of dairy cattle of both sexes are shown as sleek as they can be made without removing the secretions. Their heads, ears and tails are clipped, horns polished and switches carefully hair dressed.

The too common practice of "stretching" udders by deferred milking is a practice not to be countenanced. Dairy cattle are taught to pose in that position which shows their lines and features to best advantage.

Regular trimming of the feet of all cattle is necessary in 
order to enable them to stand well. Too long a toe, for instance, will throw an animal down on his dew claws, putting every joint on a tension and the leg in an unnatural position.

327. Sheep are led by placing the left hand under or partly around the neck, with the right tickling the tail just enough to induce them to step forward, standing, of course, on the left side, the same as in handling any other animal. They are held by one hand under the jaw, the other free to be passed to the back of the head or to the dock, in case it becomes necessary to steady the sheep, or to assist, in any other way, keeping him in pose.

Trimming is the universal practice among shepherds and is defended on the ground that there is no deception practiced, since none but a most incompetent judge would be influenced by the appearance of the clipped fleece, while it does have the advantage of greatly improving the looks of the sheep while on exhibition. It has been suggested by one of our leading authorities ${ }^{1}$ that it is as becoming for sheep to be trimmed as for "Men and women to wear their best clothes when going to a party." Some shepherds display great cleverness in the trimming of their sheep, overcoming the appearance of a low back or a light hindquarter, for instance, in a most ingenious way.

The fleece is washed before trimming, then dried out to render it fluffy and bright. Cotted portions may be combed out after having been softened with olive oil. After the fleece of the sheep has been carefully prepared for the show ring by washing and trimming it is usually protected by a duck blanket, hood and all, in the case of those breeds which are wooled on the face.

${ }^{1}$ Kleinheinz, "Sheep Management." 
Coloring the fleece, while common, is not so generally practiced as trimming, and for less satisfactory reasons. Ochre is used, and the color is usually yellow, although red and even brown are sometimes employed. 'If the skin and fleece of the sheep are in proper condition, their appearance is not improved by the addition of any coloring.

Much time is spent by shepherds in training their. sheep to stand well while being shown, not only to remain quiet and permit of handling by the judge but so as to display their good points to greatest advantage. In order to stand well their feet must be trimmed and their pasterns strong to keep them up on their toes.

328. Swine. - Since hogs are not taken in hand, but merely kept within bounds by means of hurdles or paddles, the manner of showing is practiced by the hog himself, rather than by the man who has him on exhibition. A hog with style will show himself and such a one, of the right sort, well fitted, has had about all done for him that can be done when he enters the ring. It is customary to wash them thoroughly and brush them smooth, oil, and even lamp black, in the case of black hogs, being added to enhance their sleek appearance. 



\title{
APPENDIX
}

\section{RECORD PERFORMANCES AND PRODUCTION}

\section{WORLD'S TROTTING AND PACING RECORDS ${ }^{1}$}

\author{
Trotting \\ Trotting - Distance Records
}

$\frac{1}{4}$ mile (mare to wagon, straightaway) - Lou Dillon (1903) . . . . . . .

$\frac{1}{4}$ mile (gelding to wagon, straightaway) - Uhlan (1913) ..........

$\frac{1}{4}$ mile (to sulky) - Uhlan, blk. g., by Bingen (1913) . . . . . . . . . . .

$\frac{1}{2}$ mile (to wagon) - Uhlan, blk. g., 7, by Bingen (1911)............

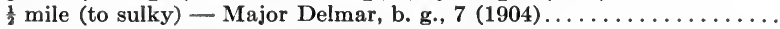

1 mile - Uhlan, blk. g., 8 , by Bingen $(1912) \ldots \ldots \ldots \ldots \ldots \ldots \ldots$

$1 \frac{1}{16}$ miles - Masetto, blk. g., by Constantine $(1904) \ldots \ldots \ldots \ldots \ldots$

$1 \frac{1}{8}$ miles - Major Delmar, b. g., 5, by Delmar (1902)................

$1 \frac{1}{4}$ - Lily Young, ch. m., 11, by Young Fullerton (1902)...........

$-1 \frac{1}{2}$ miles - Dr. Strong, gr. g., 6, by Strong Boy (1903)............

2 miles - The Harvester, br. h., 6, by Walnut Hall (1910) (1st mile

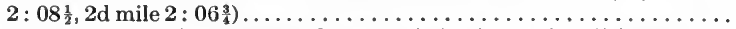

(The fastest 2 -mile race record was made in Europe by Kirkwood, Jr., br. h., 10 , by Silverthorne, 1897 , in $4: 26 \frac{7}{10}$.)

3 miles - Nightingale, ch. m., 8, by Mambrino King (1893) (1st mile

$2: 22,2 \mathrm{~d}$ mile $2: 19,3 \mathrm{~d}$ mile $\left.2: 14 \frac{1}{2}\right) \ldots \ldots \ldots \ldots \ldots \ldots \ldots \ldots$

4 miles — Senator L., b. h., 6, by Dexter Prince (1894) . . . . . . . . . . .

(The above record was excelled in England in 1899 by Polly G.,

American name Bertie R., $2: 12 \frac{1}{4}$, time $9: 58$.)

5 miles - Zombro, b. s., 5, by McKinney (1902) (in race)..........

6 miles — Longtime, b. g., untraced (1893) . . . . . . . . . . . . . . . .

10 miles — Pascal, blk. g., by Pascarel $(1893) \ldots \ldots \ldots \ldots \ldots \ldots \ldots \ldots \ldots \ldots$

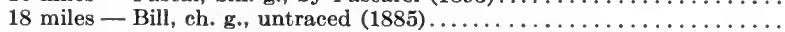

20 miles - Capt. MeGowan, ro. h., untraced $(1865) \ldots \ldots \ldots \ldots \ldots \ldots$

$*: 25 \frac{3}{4}$

$*: 26 \frac{1}{4}$

$*: 27$

$*: 561$

$*: 59 \frac{1}{2}$

$* 1: 58$

$2: 17 \frac{1}{2}$

$2: 22 \frac{1}{2}$

$2: 44 \frac{1}{4}$

$3: 17 \frac{1}{2}$

$* 4: 15 \frac{1}{4}$

30 miles — Gen. Taylor, gr. h., 10, by Morse Horse (1857).......... 1: 47: 59

50 miles - Ariel, br. m., untraced $(1846) \ldots \ldots \ldots \ldots \ldots \ldots \ldots \ldots \ldots$ : $55: 40 \frac{1}{2}$

100 - Conqueror, b. g., 11, by Latourette's Bellfounder (1853)....... 8 : 55: 33

\section{Fastest Trotters for Sex and Age}

Stallion - The Harvester, br., 5, by Walnut Hall (1910)........ *2: 01

Mare - Lou Dillon, ch., 5, by Sidney Dillon (1903)............ ** $1: 58 \frac{1}{2}$

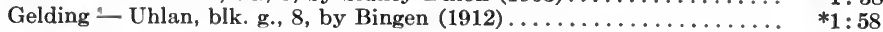

1 A novel feature of this table is that it is truly a table of "world's" records. When a foreign record excells an American record, notice is made of the fact. The lines in black-faced type are the new world's records made in 1913. A star* indicates a performance against time. A double star $* *$ indicates a performance against time behind a wind shield. - Compiled by The Horseman, Chicago, Ill. 


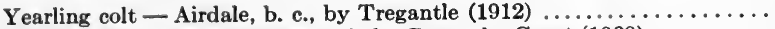

Yearling filly - Miss Stokes, b. f., by Peter the Great (1909) ..........

Two-year-old colt - Peter Volo, br., by Peter the Great (rgr3) .......

Two-year-old filly - Native Belle, b. f., by Moko (1909)............. Two-year-old gelding - Judge Jones, by Prodigal (1913), and Bon

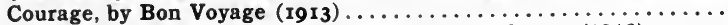

Three-year-old colt - Colorado E., b., by The Bondsman (1910)......

Three-year-old filly - Native Belle, b., by Moko (1910) .............

Three-year-old gelding - Peter Thompson, b., by Peter the Great (1911)

Four-year-old colt — Directum, blk., by Director (1893)............

Four-year-old filly — Joan, br., by Directum Spier (1910) . . . . . . . .

Four-year-old gelding — Uhlan, blk., by Bingen (1908)............

Five-year-old mare - Lou Dillon, ch., by Sidney Dillon (1903).........

Five-year-old stallion - The Harvester, br., by Walnut Hall (1910) ....

Five-year-old gelding — Uhlan, blk., by Bingen (1909)............

Green mare - Lou Dillon, ch. m., 5, by Sidney Dillon (1903) . . . . . . .

Green stallion - Colorado E., b., 3, by The Bondsman (1910) ........

Green geldings - Highball, b., 7, by Dr. Hooker (1907), and Lewis

Forrest, blk., 6, by Gen. Forrest $(1911) \ldots \ldots \ldots \ldots \ldots \ldots \ldots \ldots$

$* 2: 15$ ?

$* 2: 19 \frac{1}{4}$

2: $04 \frac{1}{2}$

2: $07 \frac{3}{4}$

2: $12 \frac{3}{4}$

2: $04 \frac{3}{4}$

*2: $06 \frac{1}{2}$

2: $07 \frac{1}{2}$

2: $05 \frac{1}{4}$

2: 04

2: $07 \frac{1}{4}$

*1: $58 \frac{1}{2}$

*2: 01

*2: $02 \frac{1}{4}$

$* 1: 58 \frac{1}{2}$

2: $04 \frac{3}{6}$

2: $06 \frac{1}{4}$

1: 00

2: $02 \frac{1}{3}$

2:01

2: $03 \frac{1}{2}$

$2: 23 \frac{3}{4}$

2: $04 \frac{1}{2}$

2: 04 ?

2: 04

2: 02 ?

2:01\}

2: $01 \frac{3}{4}$

2: 02

2: $05 \frac{1}{4}$

2: $06 \frac{1}{4}$

2: $06 \frac{1}{4}$

2: 061

2:07!

2: $07 \frac{1}{4}$

$2: 11 \frac{1}{4}$

2: 09 3

$2: 25 \frac{3}{4}$

$2: 08 \frac{1}{4}$

\section{Fastest Trotting Races}

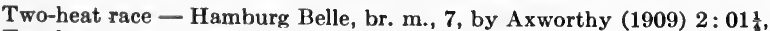
Two-heat race by stallion - The Harvester, br., 5, by Walnut Hall

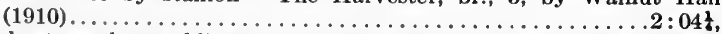
Two-heat race by a gelding - Uhlan, blk. g., 5, by Bingen (1909) $2: 04 \frac{3}{4}$, Three-heat race by stallion - The Harvester, br. h., 5 , by Walnut Hall

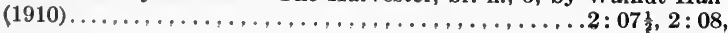


Three-heat race by mare - Hamburg Belle, b., by Axworthy (1908) ............................

Three-heat race by gelding - Paderewski, ch. g., by Constenaro (1909)

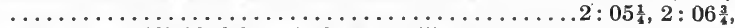

Three-heat race (divided heats), by a stallion - Billy Burk, b., 5, by Silent Brook (1911) (First heat won by Spanish Queen). . . . . . .

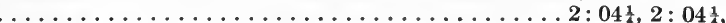

Same for mare - Dudie Archdale, blk. m., by Archdale (1913) (Anvil

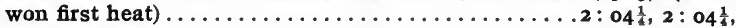

Same for gelding - Country Jay, ch., 14, by Jay Hawker (1910) (Sonoma Girl won first heat)............. $2: 04 \frac{1}{2}, 2: 05 \frac{1}{4}$,

Four-heat race by a mare - Dudie Archdale, blk. m., by Archdale (1912) (Billy Burk won first heat) ..........

Same by a gelding - Norman B., blk., by Phallas (1905) (Dr. Strong won

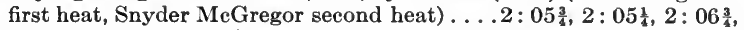

Five-heat race - Brace Girdle, b. m., 11, by Tregantle (1911) (Billy Burk won first, Hailworthy second) $2: 03 \frac{3}{4}, 2: 05 \frac{1}{4}, 2: 05 \frac{1}{4}, 2: 08 \frac{1}{2}$,

Six-heat race - Spanish Queen, b. m., 7, by Onward Silver (1910) (Major Strong won first, General $H$. second and third heats) .............

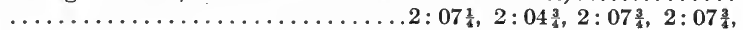

Six-heat race by a stallion - Manrico, blk., 3, by Moko (Baldy McGregor

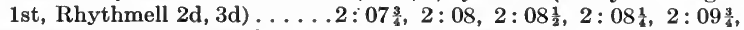

Seven-heat race - Monte Carlo, b. g., 7, by Mendocino (1903) (Hawthorne won third and fourth and Dr. Strong fifth and sixth heats) $\ldots \ldots \ldots \ldots \ldots \ldots 2: 07 \frac{1}{4}, 2: 07 \frac{1}{4}, 2: 06 \frac{1}{4}, 2: 10,2: 09 \frac{1}{2}, 2: 13$,

Eight-heat race - Nutbearer, b. g., 8, by Nutbreaker (1902) (Alice Carr won first, Rythmic second, Wentworth third and Dulce Cor fourth and sixth heats) $2: 09 \frac{1}{4}, 2: 08 \frac{3}{4}, 2: 09 \frac{1}{4}, 2: 08 \frac{1}{2}, 2: 10 \frac{3}{4}, 2: 12 \frac{3}{4}, 2: 10 \frac{3}{4}$,

Nine-heat race - Alix, b. m., 5, by Patronage (1893) (Pixley won sixth and eighth, Nightingale seventh, Lord Clinton fifth and Hulda

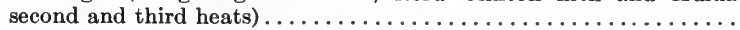
$\ldots \ldots \ldots 2: 07 \frac{3}{4}, 2: 10 \frac{1}{4}, 2: 10 \frac{1}{2}, 2: 11 \frac{3}{4}, 2: 11 \frac{1}{2}, 2: 09 \frac{3}{4}, 2: 12 \frac{3}{4}, 2: 15 \frac{1}{4}$

Ten-heat race - Pedlar, b. h., by Electioneer (1895) (Don C. won first and second heats, Soudan third, Prince Lavalard fourth and seventh,

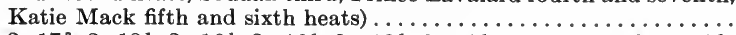
$2: 17 \frac{3}{4}, 2: 18 \frac{1}{4}, 2: 16 \frac{1}{4}, 2: 16 \frac{1}{4}, 2: 18 \frac{1}{4}, 2: 18 \frac{1}{4}, 2: 21,2: 22 \frac{3}{4}, 2: 23 \frac{1}{4}$,

\section{Trotting to Wagon-Distance Records}

$\frac{1}{2}$ mile - Uhlan, blk, g., 7 , by Bingen (1911) ...............

1 mile - Lou Dillon, ch. m., 5, by Sidney Dillon (1903) (amateur driver)

1 mile by a stallion - John A. McKerron, b., by Nutwood Wilkes (1900)

1 mile by a gelding - Uhlan, blk., 7, by Bingen (1911) (am.)........

1 mile in a race - Lou Dillon, ch. m., 5, by Sidney Dillon (1903).......

1 mile in a race, by a gelding - Lord Derby, b., 7, by Mambrino King

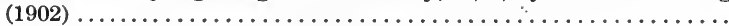

2 miles — Pelagon, b. g., 12, by Milroi 20585 (1909)... . . . . . . . .

3 miles — Ed Bryan, b. g., 10, by Little Corporal (1905) . . . . . . . . . .

5 miles - Ed Bryan, h. g., 12, by Little Corporal $(1907) \ldots \ldots \ldots \ldots \ldots$

10 miles - Julia Aldrich, ch. m., untraced $(1858) \ldots \ldots \ldots \ldots \ldots \ldots$

20 miles — Controller, h. g., by Mayboy $(1878) \ldots \ldots \ldots \ldots \ldots \ldots$

\section{Trotting to Wagon-Fastest Races}

Fastest two-heat race - Lou Dillon, ch. m., 5, by Sidney Dillon (1903) ............................. 2:04,

Fastest two-heat race by a stallion - John A. McKerron, b., 5, by Nutwood Wilkes (1900)........................ 2 10, 
Fastest two-heat race by a gelding - Lord Derby, b., 7, by Mambrino King (1902) ........................ $05 \frac{3}{4}$,

Fastest three-heat race - American Boy, b. g., by Potential (1907)...

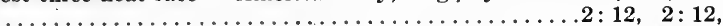

Fastest three-heat race (divided heats) - Lord Derby, b. g., 7, by Mambrino King (1902) (The Monk won first heat).....2:06 $\frac{1}{2}, 2: 06$,

Fastest four-heat race - Invader, b., 9, by Jay Bird (1908) (Alexander won the second heat, Lady Jones the third) $\ldots 2: 11 \frac{1}{4}, 2: 10 \frac{1}{2}, 2: 11$,

Four-heat race by a mare - Aerolite, b., 7, by Acolyte (1904) (Dartmore won first heat, Hugh Wynne second) $\ldots \ldots \ldots \ldots 2: 14,2: 13 \frac{1}{2}, 2: 12$,

\section{Trotting under Saddle}

1 mile - Country Jay, ch. g., by Jay Hawker (1909).............

2 miles - Geo. M. Patchen, b. h., 14, by Cassius M. Clay (1863)....... (Note. - The above record has been excelled in New Zealand by Redchild, $4: 40$, in 1910.)

3 miles - Dutchman, b. g., 11, by Tippoo Saib, Jr. (1839)... . . . . .

4 miles - Dutchman, b. g., 8, by Tippo Saib, Jr. (1836) . . . . . . . . .

\section{Trotting with Running Mate}

I mile, against time - Uhlan, blk. g., by Bingen (19r3) $\ldots \ldots \ldots \ldots$

1 mile, in a race — Frank, b. g., 7, by Abraham (1883) ............

\section{Trotting Teams}

1 mile - Uhlan, blk. g., 8, by Bingen, and Lewis Forrest, blk. g., by Gen.

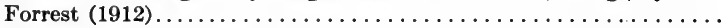

1 mile, in a race - Roseleaf, blk. f., 4 , by Gold Leaf, and Sallie Simmons,

b. f., 4, by Simmons $(1894) \ldots \ldots \ldots \ldots \ldots \ldots \ldots \ldots \ldots$

Two-heat race - Maxy Cobb, b. h., by Happy Medium, and Neta

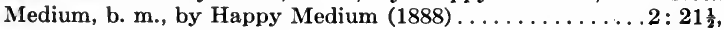

Three-heat race - Arab, by Arthurton, and Cone, ch. g., by Arthurton (1887) ........................ $2: 29 \frac{1}{4}, 2: 23$,

\section{Trotting Teams - Tandem}

1 mile - Mambrino Sparkle, ch. m., 8, by Mambrino Chief, Jr., and William H., b. g., 11, by Young Wilkes (1886)..............

\section{Trotting Teams - Three Abreast}

1 mile - Belle Hamlin, br. m., 12, Globe, br. m., 10, and Justina, b. m.,

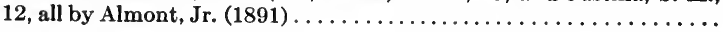

\section{Trotting Teams - Four-in-Hand}

1 mile - Damiana, ch. m., 9 ; Bellnut, ch. g., 8; Maud V., ch. m., 9, and Nutspra, ch. f., 4, all by Nutmeg (1896)...............

\section{Pacing \\ Pacing - Distance Records}

$\frac{1}{2}$ mile - Dan Patch, br. h., 8, by Joe Patchen (1904).............

1 mile - Dan Patch, br. h., 9, by Joe Patchen $(1905) \ldots \ldots \ldots \ldots \ldots \ldots$

1 mile (in open) - Minor Heir, br. h., by Heir at Law $(1910) \ldots \ldots \ldots$

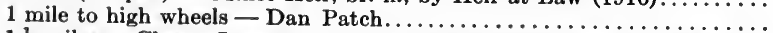


$1 \frac{1}{8}$ miles — Carl Wilkes, ch. g., by Wilkes Nutwood (1902) . . . . . . . .

$1 \frac{1}{1}$ miles - Nervolo, b. h., 7, by Colbert (1903) ..................

$1 \frac{1}{2}$ miles - Locanda, br. h., 6, by Allerton (1903)...............

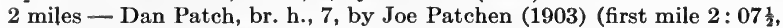

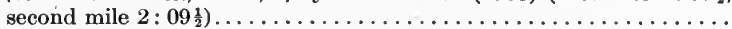

3 miles — Elastic Pointer, br. h., 15, by Brown Hal (1909)............ (The above record has been excelled in New Zealand by Almont, $6: 50$, in 1908.)

4 miles - Joe Jefferson, b. h., 12, by Thomas Jefferson (1891).........

5 miles — Lady St. Clair, b. m., 12, by St. Clair (1874) . . . . . . . . . . (The above record has been excelled in England by Professor, American name Roy B., $2: 09 \frac{1}{4}$, in 1907, time $12: 25 \frac{3}{5}$.)

\section{Fastest Pacers for Sex and Age}

Stallion - Dan Patch, br., 9, by Joe Patchen (1905) . . . . . . . . . . . Gelding — Prince Alert, b., 11, by Crown Prince (1903) . . . . . . . . .

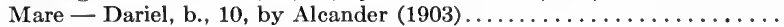

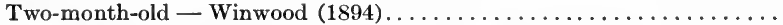
Yearling colt — Frank Perry, b., by Toddington (1911)............ Yearling filly — Present Queen, b., by Searchlight (1911) . . . . . . . . . Yearling gelding - Rollo, gr., by Jerome Eddy $(1891) \ldots \ldots \ldots \ldots \ldots$ Two-year-old colt — Directly, blk., by Direct (1894) . . . . . . . . . . Two-year-old filly - Fleeta Dillon, b., by Sidney Dillon (1909)........ Two-year-old gelding - John Malcom, b. g., by Dan Logan (1913).... . Three-year-old — William, b. c., by Abe J. (rgr3) ............... Three-year-old filly - Miss De Forest, b., by The De Forest (1911) . . . Three-year-old gelding - Hemet, br., by Geo. W. McKinney (1912) . . . Four-year-old - Braden Direct, blk. h., by Baron Direct (1912) . . . . . . Four-year-old filly — The Maid, b., by Hal Index (1899)............ Four-year-old gelding - W. Wood, b., by Steinway $(1892) . \ldots \ldots \ldots \ldots$ Five-year-old gelding - Coney, blk., by McKinney (1900).......... Five-year-old stallion - Braden Direct, blk. h., by Baron Direct (1913).

Five-year-old mare - Leata J., blk. m., by Royal McKinney (1913).... Green - Minor Heir, br. h., 6, by Heir-at-Law (1908) . . . . . . . . . . . . Green gelding - My Star, ch., 8, by Wilstar (1906).............. Green mare - Leata J., blk. m., by Royal McKinney (1913).........

$* 1: 55 \frac{1}{4}$

*1: 59

*2: $00 \frac{1}{4}$

*2: 58

*2 : 15

*2: $21 \frac{1}{4}$

*2: $28 \frac{1}{4}$

*2: $07 \frac{3}{4}$

*2: $08 \frac{3}{4}$

2: $11 \frac{1}{4}$

2: 05

2: $05 \frac{1}{4}$

2: $08 \frac{1}{4}$

2: $02 \frac{3}{4}$

2: $05 \frac{3}{4}$

2:07

2:02

2: 013

2: $03^{\frac{1}{2}}$

*1: 59

2: $03 \frac{1}{3}$

2: $03^{\frac{3}{4}}$

\section{Fastest Pacing - In Races}

$\frac{1}{2}$ mile by a gelding - Prince Alert, b. g., 10, by Crown Prince (1902)... $\frac{1}{2}$ mile by a stallion - Hal Chaffin, br. h., 13, by Brown Hal (1911)....

Stallion - Minor Heir, br., 8, by Heir-at-Law $(1910) \ldots \ldots \ldots \ldots \ldots$ (The above record was made in a dash.)

Mare - Evelyn W., b. m., by The Spy (1912).................

Geldings - Prince Alert, b., 9, by Crown Prince (1910), and Bolivar, b.,

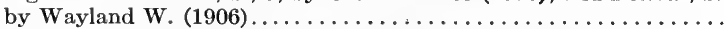

Yearling — Belle Acton, b, f., by Shadeland Onward (1892) . . . . . . . .

Two-year-old mare - Extasy, b. f., by Baron Wilkes (1898). . . . . . . . .

Two-year-old gelding - John Malcolm, b. g., by Dan Logan (I913).....

Three-year-old filly - Miss De Forest, b., by The De Forest (1911) . . . . . .

Three-year-old colt - William, b. c., by Abe J. (1913) .................

Four-year-old — Braden Direct, blk. h., by Baron Direct (1912)........

Five-year-old stallion - Braden Direct, blk. h., by Baron Direct (1913)

Five-year-old gelding - Coney, blk., by McKinney (1900)...........

Five-year-old mare - Leata J., blk., m., by Royal McKinney (1913)....

Green mare - Leata J., blk. m., by Royal McKinney (1913)..........
$: 57 \frac{3}{4}$

$1: 00 \frac{1}{2}$

$1: 59$

$2: 00 \frac{1}{2}$

$2: 00 \frac{3}{4}$

$2: 30$

$2: 10 \frac{1}{2}$

2: $11 \frac{1}{4}$

$2: 05 \frac{1}{4}$

2: 05

2:02 $\frac{3}{4}$

2: $01 \frac{1}{2}$

2: 02 룬

2: 03

2: 03 


\section{Fastest Pacing Heat Records}

First heat - Minor Heir, br. h., 8, by Heir-at-Law (1910).......... (The above record was made in a dash. He also holds the first heat record in a race of $2: 00 \frac{1}{2}$ made in 1908.)

Second heat - Evelyn W., b. m., by The Spy $(1912) \ldots \ldots \ldots \ldots \ldots$ Second heat, gelding - Prince Alert, b., 9, by Crown Prince (1901).... . Third heat - Star Pointer, b. h., 8, by Brown Hal (1897) ............. Fourth heat, stallion - Directum I, ch. h., by Directum Kelly (1913) ... Fourth heat by a mare - Evelyn W., b., 8, by The Spy (1911)........ Fourth heat by a gelding - Robert J., b. g., 8, by Hartford (1896).... Fifth heat - Frank Bogash, Jr., b. g., 8, by Frank Bogash (1913)...... Fifth heat (mare) - Aileen Wilson, 8, by Arrowwood (1908) . . . . . . . Sixth heat - Babe, br. g., by Atlantic King (1912)................. Seventh heat - Walter Cochato, 4 , blk. h., by Cochato (1912)........ Seventh heat, gelding - Jerry B., ch., 8, by Argot Wilkes (1908)...... Eighth heat - King Direct, blk. h., by Direct (1904).............. Ninth heat - Dombey, Jr., br. h., by Dombey $(1899) \ldots \ldots \ldots \ldots \ldots$. . . . Tenth heat - Kitty R., b. m., by Kermiss $(1898) \ldots \ldots \ldots \ldots \ldots \ldots$. . . . . Eleventh heat - Clipcetta, blk. m., by Elk Nutwood (1898) . . . . . . . Twelfth heat - Dandy O., b. h., 3, by Dall Brino (1891)........... Dead heat - Robert J., b. g., 8, by Hartford, and John R. Gentry,

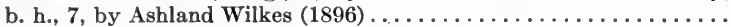

\section{Fastest Pacing Races}

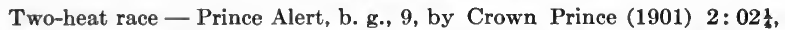
Two-heat race by stallion - Earl J., gr. h., by The Earl (1913) 2:02 $\frac{3}{4}$,

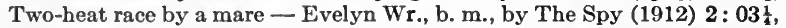
Three-heat race, divided heats - Gratt, blk. h., 9, by Grattan (1906) (Boliver won first heat) ............... 2:00 $\frac{3}{4}, 2: 02 \frac{1}{2}$,

Three-heat race by a stallion - Vernon McKinney, b., 6, by Guy McKinney (1911)..................... $2: 03 \frac{1}{4}, 2: 02$,

Three-heat race by a mare - The Broncho, b., 8, by Stormcliffe (1906)

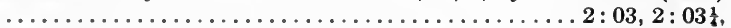

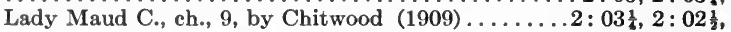
Three-heat race by a gelding - Independence Boy, ch., 6, by Thistle (1911) ........................ $02 \frac{3}{4}, 2: 01 \frac{3}{4}$,

Four-heat race by a gelding - John M., blk. g., 6, by Paris (1904) (Dan R. won first heat, Gallagher second heat) ......2:02, 2:06, $2: 03 \frac{1}{2}$,

Four-heat race by a mare - Evelyn W., b., 8, by The Spy (1911) (Second heat won by Earl, Jr.) ................ $2: 03,2: 03,2: 03 \frac{1}{2}$,

Five-heat race - Evelyn W., b. m., by The Spy (1912) (Earl, Jr., won $2 d, 3 d) \ldots \ldots \ldots \ldots \ldots \ldots \ldots \ldots 2: 01 \frac{1}{2}, 2: 03 \frac{1}{2}, 2: 01 \frac{1}{2}, 2: 03 \frac{1}{2}$,

Five-heat race, by a stallion - Minor Heir, br. h., by Heir-at-Law (1908) (The Eel won the third and fourth heats) $2: 01 \frac{1}{3}, 2: 01,2: 05 \frac{1}{2}, 2: 08$,

Six-heat race - Babe, br. g., by Atlantic King (1912) (Ty Cobb won 1st,

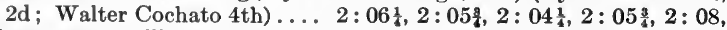

Six-heat race, stallion - Planet, b. h., 6, by Bonnie McGregor (1897) (Aileen won first heat and Frank Bogash second and third heats) $\ldots \ldots \ldots \ldots \ldots \ldots \ldots \ldots \ldots 2: 07 \frac{1}{4}, 2: 05 \frac{3}{4}, 2: 04 \frac{1}{4}, 2: 05 \frac{1}{4}, 2: 07 \frac{1}{4}$,

Seven-heat race - Jerry B., ch. g., by Argot Wilkes (1908) (Minor Heir won the first and second, The Eel third, and Copa de Oro fourth heats) ..........

Eight-heat race - Directum, blk. h., 8, by Director (1895) (Coleridge won first and second, Paul third, and Ben D. fourth and fifth heats) $\ldots \ldots \ldots \ldots \ldots 2: 05 \frac{1}{4}, 2: 06 \frac{3}{4}, 2: 07 \frac{1}{6}, 2: 07 \frac{1}{2}, 2: 07 \frac{1}{2}, 2: 08 \frac{3}{4}, 2: 10$, 
Nine-heat race - Dombey, .Jr., br. h., by Dombey (1899) (Belle Colley won first and sixth, Marion G. second and fifth, Maxine fourth and seventh heats) $2: 09 \frac{1}{4}, 2: 10,2: 11 \frac{3}{4}, 2: 11 \frac{1}{2}, 2: 13 \frac{1}{4}, 2: 15,2: 12 \frac{3}{4}, 2: 15$,

Ten-heat race - Kitty R., b. f., 4, by Kermiss (1898) (Miss Maymo won first, The Bishop second and third, Tom. Webster fourth, Harry C.

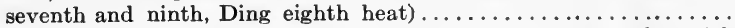
$\ldots \ldots 2: 11 \frac{1}{2}, 2: 12,2: 13 \frac{1}{2}, 2: 11 \frac{1}{4}, 2: 10 \frac{1}{4}, 2: 13 \frac{3}{4}, 2: 14 \frac{3}{4}, 2: 16 \frac{1}{4}, 2: 17 \frac{3}{4}$,

Eleven-heat race - Clipcetta, blk. m., by Elk Nutwood (1898) (Kentucky Joe'won first and fifth, Bonnie second, Donatus third and eighth,

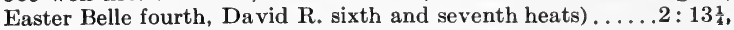
$2: 13 \frac{1}{4}, 2: 14 \frac{1}{4}, 2: 16 \frac{1}{4}, 2: 13 \frac{1}{4}, 2: 15 \frac{1}{4}, 2: 15 \frac{1}{4}, 2: 19 \frac{1}{4}, 2: 19 \frac{1}{4}, 2: 25 \frac{1}{2}$,

Twelve-heat race - Dandy O., b. h., 3, by Dall Brino (1891) (to high wheels) (Birchwood won first and second, Jessie L. third and fourth, Maud M. fifth and sixth, Rahletta seventh, Ialene eighth, Fred K.

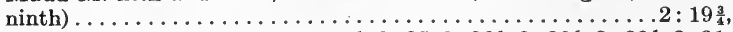
$2: 18 \frac{1}{2}, 2: 17 \frac{3}{4}, 2: 19 \frac{3}{4}, 2: 22,2: 25 \frac{1}{4}, 2: 25,2: 26 \frac{1}{4}, 2: 30 \frac{1}{2}, 2: 29 \frac{1}{2}, 2: 31$,

\section{Pacing to Wagon}

$\frac{1}{2}$ mile - Morning Star, b. g., by Star Pointer (1906)..............

1 mile - Dan Patch, br. h., 7, by Joe Patchen (1903)..............

1 mile by a mare - Aileen Wilson, blk., 10, by Arrowwood (1910). . . . .

1 mile by a gelding — Little Boy, b., 8, by Kenton (1901)...........

1 mile in a race by a stallion - Hontas Crooke, ch., by Budd Crooke

(1901), and Fred S. Wedgewood, ro., by Fred S. Wilkes (1902)...

1 mile in a race by a mare - Edith W., b., 9, by Ben Lomond, Jr. (1902)

1 mile in a race by a gelding - Angus Pointer, b., by Sidney Pointer

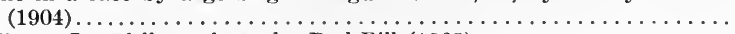

3 miles — Longfellow, ch. g., by Red Bill (1868)...............

5 miles — Lady St. Clair, b. m., 12, by St. Clair (1874) . . . . . . . .

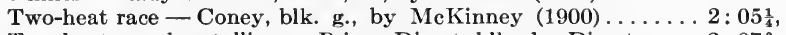

Two-heat race by stallion — Prince Direct, blk., by Direct. . . 2: 07 $\frac{3}{4}$,

Two-heat race by a mare - Edith W., b., 9, by Ben Lomond, Jr. 2: 05,

Three-heat race - Angus Pointer, b. g., by Sidney Pointer (1904) (Baron Grattan won first heat) $\ldots \ldots \ldots \ldots \ldots \ldots \ldots \ldots 2: 06 \frac{1}{4}, 2: 04 \frac{1}{2}$,

\section{Pacing under Saddle}

1 mile - Kruger, ch. g., by Mercury (1907) (amateur rider). . . . . . . . . 1 mile in a race - Billy Boyce, b. g., by Corbeau $(1868) \ldots \ldots \ldots \ldots$. . . 2 miles - Bowery Boy, br. g., pedigree untraced (1839)........... 3 miles - Oneida Chief, ch. g., by Kentucky Hunter (1843) . . . . . . .

\section{Pacing with Running Mate}

1 mile - Flying Jib, b. g., 8, by Algona $(1894) \ldots \ldots \ldots \ldots \ldots \ldots$

\section{Pacing Teams}

$\frac{1}{2}$ mile - Prince Direct, blk. h., 9, by Direct, and Morning Star, b. g., 7,

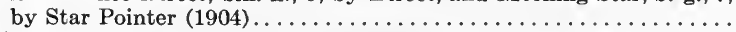

1 mile - Minor Heir, br. h., 10 , by Heir at Law, and George Gano, by

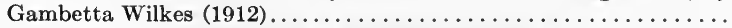

1 mile in a race - Charley B., blk. g., and Bobby Hal, b. g., $\varepsilon$, by Octoroon (1909). 


\section{Fastest Half-Mile Track Records}

\section{Trotting}

Gelding - Uhlan, blk. g., 7, by Eingen (1911) ..............

Stallion - Willy, br. h., 7, by Wilburn M. (1911)...............

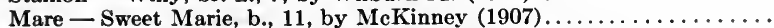
Yearling filly - Edna the Great, b. f., by Caduceus the Great (1912). . .

Yearling colt - U. Forbes, blk. c., by J. Malcolm Forbes (1913).......

Two-year-old - Nowaday Girl, b. f., by MacDougall, $2: 10 \frac{1}{4}(1912)$....

Two-year-old colt - Royal Hall, b. c., by Royal Reaper (1913)........

Three-year-old colt - Al. Stanley, ro. c., by Todd $(1909) \ldots \ldots \ldots \ldots \ldots$.

Three-year-old filly - Muda Guy, b. f., by Guy Axworthy (1909) . . . . .

Four-year-old - Pat L., b. c., by Republican $(1896) \ldots \ldots \ldots \ldots \ldots \ldots$

Mare in race - Sweet Marie, b. m., 11, by McKinney (1907)... . . . .

First heat - Joe Bowers, b. h., 7, by Symboleer (1911)............

First heat by a mare - Sweet Marie, b. m., 11, by McKinney (1907)...

Second heat - Sweet Marie, b. m., 11, by McKinney (1907)..........

Third heat - Early Alice, br. m., 7, by Early Reaper (1908) . . . . . . . .

Fourth heat - Charley H., br. g., 8, by Cicerone $(1910) \ldots \ldots \ldots \ldots \ldots$

Fourth heat by a stallion - Kenyon W., blk., 9, by Marcos Bozarris

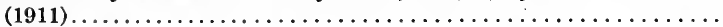

Two-heat race - George G., b. g., 8, by Homeward (1906) . . . . . 2: $08 \frac{3}{4}$,

Three-heat race - Locust Jack, g. g , 7, by Kellar Thomas (1908) ... . .

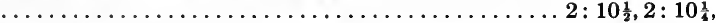

Four-heat race - Norman B., blk. g., by Phallas (1904) (Tonso won first heat) $\ldots \ldots \ldots \ldots \ldots \ldots \ldots \ldots \ldots \ldots \ldots \ldots 2: 14 \frac{1}{2}, 2: 12 \frac{1}{2}, 2: 13$, Eleanor B., b. m., by Allerio (1906) (Leavette won third heat) ..... $\ldots \ldots \ldots \ldots \ldots \ldots \ldots \ldots \ldots \ldots \ldots \ldots 2: 14 \frac{1}{4}, 2: 13 \frac{1}{4}, 2: 13 \frac{1}{4}$,

Five-heat race - Kenyon W., blk. h., 9, by Marcos Bozzaris (1911) (Joe

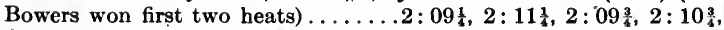

Five-heat race by a mare - Marigold, b., 8, by Delham (1911) (Baron

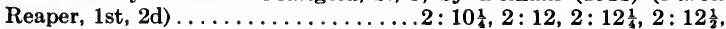

Five-heat race by a gelding - Charley H., br. g., 8, by Cicerone (1910) (Early Alice won $2 \mathrm{~d}$ and $3 \mathrm{~d}$ heats) ...2 $2: 11 \frac{1}{2}, 2: 11 \frac{1}{4}, 2: 10 \frac{3}{4}, 2: 09 \frac{1}{4}$,

1 mile to wagon - Sweet Marie, b. m., 11, by McKinney (1907)........

1 mile, by a team - York Boy, b. g., by Wilkes Boy, and Bemay, blk.

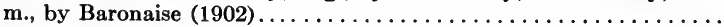

Saddle - Country Jay, ch. g., 15, by Jayhawker $(1911) \ldots \ldots \ldots \ldots \ldots$

Two miles — Prince C., br. h., 10, by Martyr (1911).............

2:09

$2: 14 \frac{1}{2}$

$2: 13 \frac{3}{4}$

$2: 14$

$2: 12 \frac{1}{6}$

$2: 15 \frac{1}{4}$

$2: 08 \frac{1}{2}$

$2: 12 \frac{1}{4}$

$2: 17 \frac{1}{4}$

$4: 42$

\section{Pacing}

Stallion - Dan Patch, br. h., 9, by Joe Patchen (1905) . ............

Mare - Alcyfras, ro., 8 , by. Alcryon $(1911) \ldots \ldots \ldots \ldots \ldots \ldots \ldots \ldots \ldots$

$* 2: 01$

Gelding - Prince Alert, b., 11, by Crown Prince $(1903) \ldots \ldots \ldots \ldots \ldots$

$* 2: 04 \frac{1}{2}$

$* 2: 03 \frac{1}{2}$

Stallion (race) - Directum I., ch. h., by Directum Kelly (rgr3) . . . . . .

Mare in race - Lady Maud C.; ch., 10, by Chitwood (1911)...........

Gelding (race) - Prince Alert, b. g., 9, by Crown Prince $(1901) \ldots \ldots \ldots$

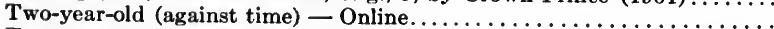

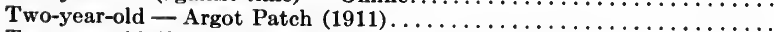

Two-year-old filly — Tillie Tipton, b., by Ozono $(1912) \ldots \ldots \ldots \ldots \ldots$

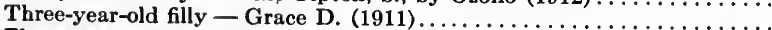

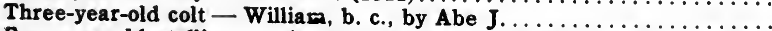

Four-year-old stallion - Director Jay., ro. h., by The Director General

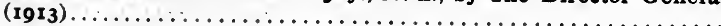


Two-heat race - Lady Maud C. (1911)................. $04^{\frac{3}{4}}$,

Two-heat race, by a gelding - Prince Alert, b. g., 10, by Crown Prince (1902) ........................

Three-heat race - Prince Alert, b. g., 7, by Crown Prince (1899) .....

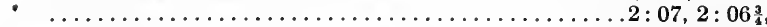

Three-heat race, by a stallion - Bedworth, Jr., b., by Bedworth (1903)

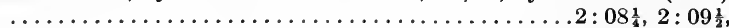

Three-heat race, by a mare - The Broncho, b., by Stormcliffe (1905)..

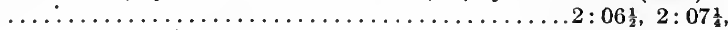

Four-heat race - Prince Alert, b. g., 7, by Crown Prince (1899) (Democracy won second heat) $\ldots \ldots \ldots \ldots \ldots \ldots \ldots \ldots 2: 10,2: 07 \frac{3}{4}, 2: 07$,

Five-heat race - Prince Alert, b. g., 7, by Crown Prince (1899) (Roan Wilkes won first and second heats) $2: 09,2: 08 \frac{1}{2}, 2: 10 \frac{1}{2}, 2: 07 \frac{1}{4}$,

Six-heat race — Hal B., Jr., br. h., by Hal B. (1912).............. $\ldots \ldots \ldots \ldots \ldots \ldots \ldots \ldots \ldots 2: 07 \frac{1}{4}, 2: 07 \frac{\frac{3}{4}}{4}, 2: 07 \frac{1}{4}, 2: 08,2: 11$,

Six-heat race (gelding) - Harry L., b. g., by Coleridge (1906) (Index won

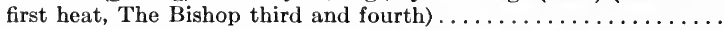
$\ldots \ldots \ldots \ldots \ldots \ldots \ldots \ldots 2: 08 \frac{1}{4}, 2: 07 \frac{1}{4}, 2: 09 \frac{1}{4}, 2: 12 \frac{1}{4}, 2: 08 \frac{1}{4}$,

Mile in race, by team - Charley B., blk. g., by Octoroon, and Bobby Hal,

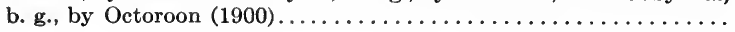

\section{To Wagon - Half-Mile Track}

1 mile - Dan Patch, br. h., by Joe Patchen (1905)...............

1 mile in a race - Joe Patchen, blk. h., by Patchen Wilkes (1906)......

1 mile, mare - Nerva Patchen, ch., by Bourbon Patchen (1901).......

\section{WORLD'S RUNNING RECORDS}

$\frac{1}{4}$ mile - Bob Wade, Butte, Mont., Aug. 20, 1890.............

$\frac{3}{8}$ mile - Atoka, Butte, Mont., Aug. 23, $1906 \ldots \ldots \ldots \ldots \ldots \ldots \ldots \ldots$ Pinkerton, Belmont Park, N. Y., Oct. 15, 1906 (made in first $\frac{3}{8}$ of 6

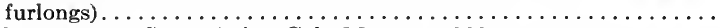

$\frac{1}{2}$ mile - Donan, Santa Anita, Cal., Mar. 13, 1909. . . . . . . . . . . . Amon (2), Juarez, Mex., Feb. 9, 1911 ; Geraldine (straight course),

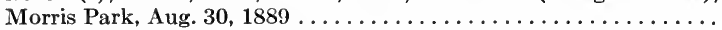

$3 \frac{1}{2}$ furlongs - Calisse (2), Juarez, Mex., Jan. 27, $1911 \ldots \ldots \ldots \ldots \ldots$ $4 \frac{1}{2}$ furlongs - Perceptor, 2 years, Belmont Park, New York, May 19, 1908.

5 furlongs - Great Surprise, Epsom, England, April 23, 1912 (straight

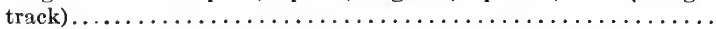
2-year-old Eastern Rose, Epsom, England, April 23, 1912 . . . . .

$5 \frac{1}{2}$ furlongs - Queen Marguerite, Belmont Park, N. Y., May 19, 1908. Straightaway, Plater, New York, Oct. 21, 1902............

6 furlongs, straightaway - Artful, New York, Oct. 15, 1904....... Master Willie, Epsom, England, June 6, $1901 \ldots \ldots \ldots \ldots \ldots \ldots$. Canonite, Epsom, England, April 23, 1912 (circular track)..... Iron Mask (127 lb.), Louisville, Ky., Sept. 23, 1913........... $6 \frac{1}{2}$ furlongs - Lady Vera, Belmont Park, New York, Oct. 19, 1906 . . . . 7 furlongs - Rosenben, 126 lb. up, Belmont Park (circular track), New

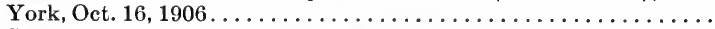

Sunspot, 120 lb. up, Epsom, England, May 30, 1911.......... $7 \frac{1}{2}$ furlongs - Restigouche, Belmont track, New York, May 22, 1908... $\frac{5}{8}$ miles - Tern's Trick, Oakland, Cal., Dec. 29, 1910 ............ 
1 mile - Center Shot (circular course), Los Angeles, Dec. 22, 1908...

Dick Welles, 3-year-old, Chicago, $1903 \ldots \ldots \ldots \ldots \ldots \ldots \ldots$

Kiamesha, Belmont track, New York, Oct. 9, 1905 ; Fern L., Seattle,

Wash., Aug. 15, 1908; Bourbon Beau, Juarez, Mex., Feb. 14, 1912 1 mile - Salvator (straight course, against time), Monmouth Park,

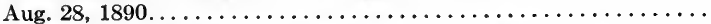

Caiman (American bred), Lingfield Park, straight course, Surrey,

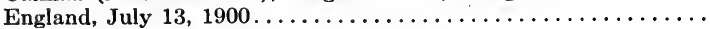

Circular course, Kildeer, New York, Aug. 13, 1902 ..........

1 mile 20 yards — Froglegs, Louisville, Ky., May 13, $1913 \ldots \ldots \ldots \ldots$

1 mile 44 yards - Prevoyant (110 lb.), Epsom, Eng., June 6, 1913....

1 mile 50 yards - Grand Opera, 4-year-old, Chicago, 1903.........

1 mile 70 yards - Princess Callaway (3), Latonia, Ky., Oct. 27, 1911 ...

Levetie, Fort Erie, Can., July 4, 1912

1 mile 100 yards - Rapid Water, Oakland, Cal., Nov. 30, 1907 . . . . .

$1 \frac{1}{1} 6$ miles - Gretna Green, Fort Erie, Ont., Aug. 28, 1909 . . . . . . . .

$1^{3}{ }^{3}$ miles - Milton B., Latonia, Cincinnati, O.. July 4, 1913 . ........

Il miles - Vox Populi, $110 \mathrm{lb}$. up, Los Angeles, Dec. 19, 1908.......

Charles Edward, 126 lb., New York, July 16, 1907...........

1 조 miles - Whisk Broom II (139 lb.), Belmont Park, New York, June

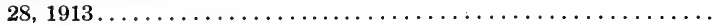

$1 \frac{5}{16}$ miles - Ballot, Sheepshead, N. Y., July 1, $1908 \ldots \ldots \ldots \ldots \ldots \ldots$

$1 \frac{3}{8}$ miles - Long Set (130 lb.), Liverpool, England, July 25, $1913 \ldots \ldots$. .

$1 \frac{1}{2}$ miles - Marajax, 4 years, 109 lb. up, Manchester, Eng., June 9, 1911

$1 \frac{5}{8}$ miles - War Mint (3), Hurst Park, London, Eng., Sept. 26, 1912 . .

$1 \frac{3}{6}$ miles - Major Daingerfield, 4-year-old, New York, 1903 . . . . . . . .

2 miles - Everett, Pimlico track, Baltimore, Md., Oct. 31, 1910......

Pradella, Ascot, England, June 19, 1906. . . . . . . . . . . . .

2 miles 1 furlong - Balscadden (5), Newbury, Eng., Sept. 27, 1912 . . .

$2 \frac{1}{4}$ miles — Ethelbert, Brighton Beach, Aüg. 4, 1900............

$2 \frac{1}{2}$ miles - Prince Palatine (130 lb.), Ascot, England, June 20, 1913 . . . .

3 miles - Carrie Roy, Ascot, Eng., June 13, 1884 . . . . . . . . . . . .

4 miles, against time - Lucretia Borgia, Oakland, Cal., May 20, 1897 .. .

(In a race), Soternia, Louisville, Ky., Oct. $7,1912 \ldots \ldots \ldots \ldots \ldots$

10 miles — Mr. Brown, Rancocas, N. J., March $2,1880 \ldots \ldots \ldots \ldots \ldots$

$1: 37 \frac{1}{4}$

$1: 39 \frac{3}{5}$

$1: 35 \frac{3}{5}$

$1: 41 \frac{1}{5}$

$1: 42$

$1: 44 \frac{1}{5}$

$1: 43 \frac{1}{5}$

$1: 56 \frac{3}{5}$

$1: 50$

$1: 50 \frac{3}{5}$

2:00

$2: 09 \frac{3}{5}$

$2: 16 \frac{4}{5}$

$2: 27 \frac{2}{5}$

$2: 42 \frac{2}{5}$

$2: 57$

$3: 25 \frac{3}{5}$

$3: 19 \frac{2}{5}$

$3: 37 \frac{1}{5}$

$3: 49 \frac{1}{5}$

$4: 22 \frac{3}{5}$

5: 09

$7: 11$

$7: 10 \frac{4}{5}$

$26: 18$

\section{Records for I9r3}

6 furlongs, circular track - Iron Mask (127 lb.), Louisville, Ky., Sept. 23 1 mile 20 yards — Froglegs, Louisville, Ky., May $13 \ldots \ldots \ldots \ldots \ldots \ldots$ $11^{\frac{3}{6}}$ miles - Milton B., Latonia, Cincinnati, O., July $4 \ldots \ldots \ldots \ldots \ldots$ $1 \frac{2}{4}$ miles - Whisk Broom II (139 lb.), Belmont Park, N. Y., June 28... $1 \frac{3}{8}$ miles - Long Set (130 lb.), Liverpool, Eng., July 25 . . . . . . . . . . . 2 miles 1 furlong - Baldscaddeb (126), Newberry, Eng., Sept. 29 . . . . . $2 \frac{1}{2}$ miles — Prince Palatine (130), June $20 \ldots \ldots \ldots \ldots \ldots \ldots \ldots \ldots$

$1: 07 \frac{4}{5}$

$1: 39$

$1: 56 \frac{3}{5}$

2:00

$2: 16 \frac{4}{5}$

$3: 35^{\frac{2}{5}}$

$4: 22 \frac{3}{5}$

\section{Running Races - Hurdle}

1 mile, 4 hurdles — Bob Thomas, Aug. 13, $1890 \ldots \ldots \ldots \ldots \ldots \ldots$

2 miles - Charawind, Oct. 6, 1903, Morris Park, N. Y................

3 miles - Alert Dream, Melbourne, Australia, March $3,1909 \ldots \ldots \ldots$ 2 miles (steeplechase) - Findowrie, Ca ufield, Australia, Dec. 27, 1909. 3 miles (steeplechase) - Fincastle, Toronto, Can., Sept. 30, 1911 . . . . . 


\section{DAIRY RECORDS}

\section{Highest Yields of Jerseys}

Best Five Records in Year's Tests at Various Ages, June 1, 1914

\section{Class 1 - Cows Under Two Years}

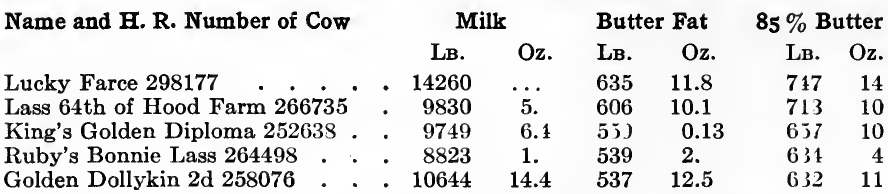

Class 2 - Cows Two Years and Under Two and One Half Years . Name and H. R. Number of Cow Milk Butter Fat $85 \%$ Butter LB. Oz. LB. Oz. LB. Oz. $\begin{array}{lllllll}\text { Pearly Exile of St. Lambert } 205101 & 123 \dot{4} & 8 . & 816 & 1.27 & 960 & 1\end{array}$ $\begin{array}{lllllll}\text { Lass 66th of Hood Farm } 271896 & \text {. } 14513 & 2 . & 720 & 8 . & 817 & 10\end{array}$

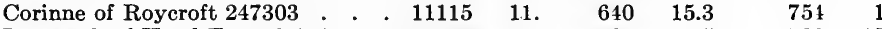

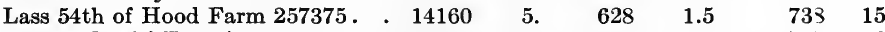
$\begin{array}{lllllllr}\text { Tonona Pogis' Fontaine 280417 } & \text {. } & 10755 & \ldots & 609 & 12.8 & 717 & 6\end{array}$

Class 3 - Cows Two and One Half Years and Under Three Years Name and H. R. Number of Cow Milk Butter Fat $\quad \mathbf{8 5} \%$ Butter $\mathrm{Oz} . \mathrm{LB} . \quad \mathrm{Oz}, \mathrm{LB}, \mathrm{Oz}$

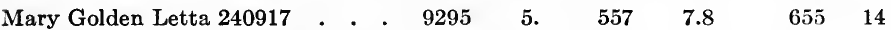

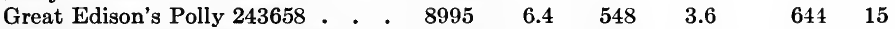

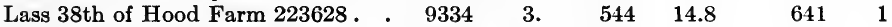
$\begin{array}{llllllll}\text { Lass 51st of Hood Farm 247084 . } & \text {. } & 8968 & 10 . & 539 & 5.1 & 634 & 8\end{array}$

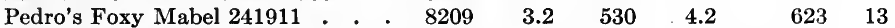

Class 4-Cows Three Years and Under Three and One Half Years Name and H. R. Number of Cow

\begin{tabular}{rrlrrr}
\multicolumn{2}{c}{ Milk } & \multicolumn{2}{c}{ Butter Fat } & \multicolumn{2}{c}{ 85 $\%$ Butter } \\
LB. & Oz. & LB. & Oz. & LB. & Oz. \\
3339 & 11.2 & 702 & 3.1 & 826 & 1 \\
2694 & 15. & 690 & 6.9 & 812 & 2 \\
9045 & 15. & 659 & 6.6 & 775 & 12 \\
3198 & 1.6 & 632 & 9.7 & 744 & 4 \\
0292 & 6.2 & 625 & 11.7 & 736 & 2
\end{tabular}

Class 5 - Cows Three and One Half Years and Under Four Years

Name and H. R. Number of Cow

Lass 40th of Hood Farm 223642 - 15362

Lass 47th of Hood Farm 240327 . 11410

Lass 30th of Hood Farm 214511 . 11990

Lass 42d of Hood Farm 223636 . . 10391

Great Edison's Polly 243658 . . . 9696
Milk

LB. Oz.

Oz.

LB. Oz.

$85 \%$ Butter

1
9
5
8
11

1. $\quad 747$

9. 685

5. 684

8. $\quad 636$

$11.2 \quad 624$
5.2

12.6

13.9

10.1

1.7
LB. Oz.

$879 \quad 3$

$806 \quad 13$

$805 \quad 12$

$748 \quad 15$

$738 \quad 3$ 
Class 6-Cows Four Years and Under Four and One Half Years

Name and H. R. Number of Cow

Spermfield Owl's Temisia 215982

Spermfield Owl's Dawson 193935

Lass 45th of Hood Farm 233488.

Goldmont's Kathletta 225977. . . 12065
Milk

LB. Oz.

9994

...

$$
\text { ii. }
$$

4.

$\cdots$

9.6
Butter Fat

LB. $\mathrm{Oz}$.

$640 \quad 14.4$

$629 \quad 2.3$

$615 \quad 5.6$

613

607
6.

8.1
$85 \%$ Butter

LB. Oz.

$754 \ldots$

$740 \quad 3$

$723 \quad 15$

$721 \quad 10$

$714 \quad 11$

Class 7 - Cows Four and One Half Years and Under Five Years

Name and H. R. Number of Cow

Olympia's Fern 252060

Sophie 19th of Hood Farm 189748 . 14373

Rosaire's Olga 4th's Pride 179509 • 14104

Lass 30th of Hood Farm 214511 . . 11413

Pogis Oneida 209479 . . . . . 11438
Milk is. Oz.

13.6

3.

13.6

13. 4.8
Butter Fat

LB. Oz.

$937 \quad 13.3$

$854 \quad 13.7$

$836 \quad 15.8$

664

631
...

11.8
$85 \%$ Butter

LB. Oz.

11035

$1005 \quad 11$

$984 \quad 11$

781

$743 \quad 3$

Class 8-Cows Five Years and Over

Name and H. R. Number of Cow

Milk LB. Oz.

Sophie 19th of Hood Farm $189748 \quad 17557$

Spermfield Owl's Eva 193934 . . 16457

Eminent's Bess 209719 . . . . . 18782

Jacoba Irene $146443 \quad$. . . . . . 17253

Sophie 19th of Hood Farm 189748 . 15099
Butter Fat

LB. Oz.

$999 \quad 2.2$

12. 999

$6.4 \quad 993$

15.6

3.2

962

952

6. 931
4.06

13.2

15.4

15.5
$85 \%$ Butter

LB. Oz.

$\begin{array}{ll}1175 & 7\end{array}$

$1168 \quad 8$

$1132 \quad 12$

1121

1096

\section{Highest Yields of Guernseys}

Highest record in milk for Guernseys :

1 yr. May Rilma 22761

30 days Murne Cowan 19597

7 days Murne Cowan 19597

24 hours Murne Cowan 19597
$19673.00 \mathrm{lb}$. $2361.50 \mathrm{lb}$. $564.80 \mathrm{lb}$. $82.10 \mathrm{lb}$.

$1073.41 \mathrm{lb}$. $103.03 \mathrm{lb}$. $24.40 \mathrm{lb}$. $24.40 \mathrm{lb}$. $3.70 \mathrm{lb}$.

May Rilma 2276r, Reëntry, I 726

Sire Mars of Wooderest (9290) A. R.

Sire Mr. Dooley of Mapleton (6834)

Dam Charity of Mapleton (13769) 
Dam Rilma of Paxtang (10331)

Sire Sheet Anchor 2d (4119) A. R.

Dam Princess Bonnie of Paxtang (8777.

Breeder - A. J. Cassatt, Berwyn, Penn.

Owner - E. B. Cassatt, Berwyn, Penn.

Born - Dec. 15, $1906 . \quad$ Calved - April 4, 1913.

Requirement for admission : $360.00 \mathrm{lb}$. butter fat. fat.

Official year's record : $19673.00 \mathrm{lb}$. milk; $1073.41 \mathrm{lb}$. butter

Supervised by Pennsylvania Agricultural Experiment Station.

Milk

\begin{tabular}{|c|c|c|c|c|c|}
\hline May, 1913 & & & $1761.20 \mathrm{lb}$. & $4.49 \%$ & $79.08 \mathrm{lb}$. \\
\hline June, 1913 & . & & $1839.90 \mathrm{lb}$. & $5.60 \%$ & $103.03 \mathrm{lb}$. \\
\hline July, 1913 & . & & $1690.60 \mathrm{lb}$. & $5.04 \%$ & $97.20 \mathrm{lb}$. \\
\hline Aug., 1913 & . & . & $1773.80 \mathrm{lb}$. & $5.48 \%$ & $85.21 \mathrm{lb}$. \\
\hline Sept., 1913 & . & . & $1687.50 \mathrm{lb}$. & $5.59 \%$ & $94.33 \mathrm{lb}$. \\
\hline Oct., 1913 & . & . & $1702.60 \mathrm{lb}$. & $5.28 \%$ & $89.90 \mathrm{lb}$. \\
\hline Nov., 1913 & . & . & $1656.20 \mathrm{lb}$. & $5.29 \%$ & $87.61 \mathrm{lb}$. \\
\hline Dec., 1913 & . & . & $1563.00 \mathrm{lb}$. & $5.57 \%$ & $87.06 \mathrm{lb}$. \\
\hline Jan., 1914 & . & . & $1570.80 \mathrm{lb}$. & $5.72 \%$ & $89.85 \mathrm{lb}$. \\
\hline Feb., 1914 & - & . & $1431.20 \mathrm{lb}$. & $5.97 \%$ & $85.44 \mathrm{lb}$. \\
\hline Mar., 1913 & . & . & $1538.80 \mathrm{lb}$. & $6.04 \%$ & $92.94 \mathrm{lb}$. \\
\hline April, 1914 & . & . & $1457.40 \mathrm{lb}$. & $5.61 \%$ & $81.76 \mathrm{lb}$. \\
\hline Total & . & . & . $19673.00 \mathrm{lb}$. & 5.46 Av.\% & $1073.41 \mathrm{lb}$. \\
\hline
\end{tabular}

Entry of Additional Record. Previous year's record: $12125.60 \mathrm{lb}$. milk; $589.07 \mathrm{lb}$. butter fat. Published in Vol. XXVI.

\section{Feed Record}

MAY, 1913. $10 \mathrm{lb}$. grain daily of the following mixture: 250 lb. bran, $50 \mathrm{lb}$. each hominy, cottonseed meal and oil meal, $100 \mathrm{lb}$. gluten; $3 \mathrm{lb}$. beet pulp, $2 \mathrm{lb}$. molasses, hay, with pasture.

June, $1913.18 \mathrm{lb}$. grain daily of the following mixture : $250 \mathrm{lb}$. bran, $50 \mathrm{lb}$. each hominy, ground oats, cottonseed meal and oil meal ; $3 \mathrm{lb}$. beet pulp, $2 \mathrm{lb}$. molasses, green feed.

JULY, 1913. $18 \mathrm{lb}$. grain daily of the following mixture on 1st, and from 11 th to $31 \mathrm{st}, 15 \mathrm{lb}$. daily from $2 \mathrm{~d}$ to 11 th : $250 \mathrm{lb}$. bran, $50 \mathrm{lb}$. each hominy, cottonseed meal, ground oats and oil meal, $100 \mathrm{lb}$. gluten; $3 \mathrm{lb}$. each molasses and beet pulp, corn fodder from 1 st to 15 th, clover from 17 th to 31 st. 
AUG., 1913. $18 \mathrm{lb}$. grain daily of the following mixture: $250 \mathrm{lb}$. bran, $50 \mathrm{lb}$. each hominy, cottonseed meal and oil meal, $100 \mathrm{lb}$. gluten; $3 \mathrm{lb}$. each beet pulp and molasses, corn fodder, alfalfa, clover with pasture.

SEPT., 1913. Same grain ration as given in August from 1st to $3 \mathrm{~d}$ and 9 th to 30 th ; from $3 \mathrm{~d}$ to 9 th $12 \mathrm{lb}$. daily of same mixture; $3 \mathrm{lb}$. each pulp and molasses, corn fodder and clover pasture.

Oct., 1913. Same grain ration as given in August; 3 lb. each beet pulp and molasses, green clover and pasture.

Nov., 1913. Same grain ration as given in August; $3 \mathrm{lb}$. each beet pulp and molasses, $25 \mathrm{lb}$. ensilage with pasture.

Dec., 1913. Same grain ration as given in August; $3 \mathrm{lb}$. each beet pulp and molasses, ensilage, alfalfa from 8th to 31 st, clover hay.

$\mathrm{J}_{\mathrm{AN} . \text {, }}$ 1914. Same grain ration as given in August; $3 \mathrm{lb}$. each beet pulp and molasses, $16 \mathrm{lb}$. carrots, ensilage, alfalfa, clover, hay.

FEB., 1914. Same grain ration as given in August; 6 lb. each beet pulp and molasses, carrots, ensilage and clover hay.

Mar., 1914. Same ration as given in February.

ApriL, 1914. Same ration as given in February; no ensilage 12 th.

Five Leading Cows in the Several Classes in the A. R. as they Appeared June 15,1914

Class $\mathbf{A}-5$ years and over

\begin{tabular}{|c|c|c|c|c|}
\hline $\mathrm{Agr}$ & & $\begin{array}{c}\text { LB. } \\
\text { MILK }\end{array}$ & $\begin{array}{l}\text { LB. } \\
\text { B. F. }\end{array}$ & B. F. \\
\hline $6 y$. & $4 \mathrm{~m}$. & 19673.00 & 1073.41 & 5.46 \\
\hline & 5 & 18602.80 & 957.38 & \\
\hline & 6 & 16630.70 & 927.16 & \\
\hline & 2 & 14686.80 & 898.82 & \\
\hline & 3 & 18808.50 & 876.34 & \\
\hline
\end{tabular}

Class B $-4 \frac{1}{2}$ to 5 years

May Rilma 22761, A. R. 1726, Reëntry

Spotswood Daisy Pearl 17696, A. R. 790, Reëntry ......... .

Miranda of Mapletion 19606, A. R. 914 ,

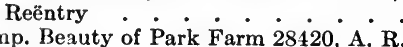
1850

Dolly Dimple $1914 \dot{4}, \dot{A}, \dot{R}, 628, \dot{0} \dot{n}$

$3 \quad 18808.50$

876.34

4.66

Dairymaid of Pinehurst 24656, A. R. 843, Reëntry

Lady Lesbia $25142{ }^{\circ}$ A. R. $1348^{\circ}$, Reëntry

Glenanaar of the Glen 23619, A. R. 1907

Imp. Dinah II of the Fountain 28482,

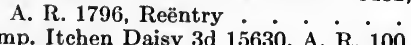

Reëntry

$\begin{array}{rrrrr}4 & 8 & 17285.30 & 910.67 & 5.27 \\ 4 & 10 & 13582.75 & 787.03 & 5.79 \\ 4 & 7 & 16813.10 & 780.66 & 4.64 \\ & & & & \\ 4 & 11 & 14877.00 & 726.77 & 4.89 \\ 4 & 7 & 13636.80 & 714.10 & 5.24\end{array}$




\section{Class $\mathrm{C}-4$ to $4 \frac{1}{2}$ years}

AGE

LB.

LB.
B. F.

Azucena's Pride 2d 24957, A. R. 1469,

Reëntry

A. R. 2081. Anton's Frances 27291, A. R. 1497,
A. $4 \mathrm{y} \cdot{ }^{\circ} 1 \mathrm{~m}$.

Mins

855.70

5.28

Reëntry . . . . . . . . . 4

Honor Bright F 17524, A. R. 875 . . 4

Golden Elsie 23744, A. R. 1968 . . . 4

$$
5
$$

13513.90

748.81

5.54

$6 \quad 12555.60$

696.05

5.54

12674.00

694.64

692.87

5.48

4.59

\section{Class D $-3 \frac{1}{2}$ to 4 years}

Dolly Dimple 19144, A. R. 628, Reëntry $3 \quad 9$

Langwater Dorothy 27944, A. R. 1822,

Reëntry
Imp. Princess of the Blicqs 28485, A. R. 1908

Rose of Langwater 24204, A. R. $1445_{\text {, }}^{\circ}$

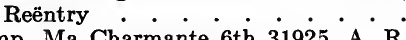

Imp. Ma Charmante 6th 31925, A. R. 1995

39

$18458.80 \quad 906.89$

4.91

4.86

$3 \quad 8$

$3 \quad 11$

11

$16099.70 \quad 781.65$

6.14

$12608.80 \quad 774.16$

5.01

3

$15008.20 \quad 751.62$

5.01

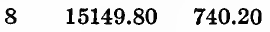

4.89

\section{Class $\mathrm{E}-3$ to $3 \frac{1}{2}$ years}

Jehanna Chene 30889, A. R. 2588 . . $3 \quad 5$

Dairymaid of Pinehurst 24656, A. R.

843, Reëntry $\cdot{ }^{\circ} \cdot 0^{\circ} \cdot{ }^{\circ} 3$

Masher's Elsie 24986, A. R. $1967 \quad$. . 3

Miranda of Edgewater 30970, A. R. 23633

Sweet Maria 25151, A. R. 1803 . . . 3

$5 \quad 16186.70 \quad 863.36$

5.33

$14562.40 \quad 860.26$

$14458.70 \quad 745.75$

$14617.30 \quad 730.49$

$\begin{array}{llll}0 & 12542.50 & 682.86 & 5.44\end{array}$

5.91

5.16

5.00

\section{Class $\mathrm{F}-2 \frac{1}{2}$ to 3 years}

Langwater Hope 27946, A. R. 1978 . 2

Azucena's Pride 2d 24957, A. R. 1469 .

Rose of Langwater 24204, A. R. 1445 .

Imp. Buttercup II of the Beauregard

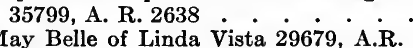

27

15078.80

773.59

706.46

669.89

5.13

5.59

12633.30

5.17

2

$11 \quad 10623.30$

659.71

6.21

2134

- 2

7

11981.76

653.02

5.43

\section{Class $\mathbf{G}-2$ to $2 \frac{1}{2}$ years}

Dolly Dimple 19144, A. R. 628 . . . 2

Golden Elsie 2d 33422, A. R. 2274 • : 2

2

14009.13

13409.00

703.36

672.94

5.02

Princess Deasie 36703, A. R. 2275 . . 2

$3 \quad 11943.10$

666.22

5.02

5.58

Nellie Tostevin of Mapleton 3d 30318,

A. R. 2121 . . . . . . . . . 2

Langwater Princess 22138, A. R. 1044 . 2

$4 \quad 11675.90$

664.01

5.69

$4 \quad 12280.50$

651.19

5.30

The average of these 35 leading Guernsey cows is $14597.73 \mathrm{lb}$. milk; $771.37 \mathrm{lb}$. butter fat. Average per cent of butter fat, 5.28. 


\section{Summary of 3047 Advanced Regiser Records}

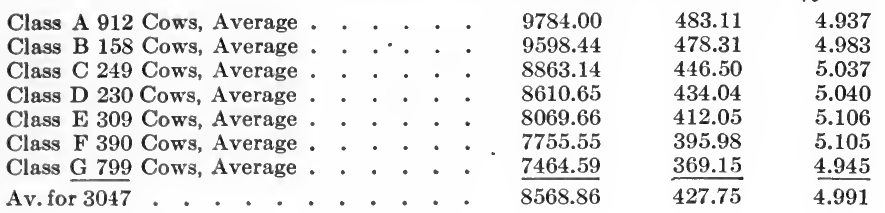

Some Results Attained in Official Testing of HolsteinFriesian Cows for Milk and Fat, October 1st, 1913

Leading Holstein-Friesian Cows and Heifers, by Classes, in the 7-Day Division

\section{Full-aged Cows (Class 5)}

\begin{abstract}
Name and A. R. Number of Cow
\end{abstract}
K. P. Pontiac Lass . . . . 11168

$$
\begin{gathered}
\text { H.B. } \\
\text { ber- }
\end{gathered}
$$

De Kol Queen La Polka 2d . 7765 $\begin{array}{clc}\begin{array}{c}\text { Pounds } \\ \text { of }\end{array} & \begin{array}{c}\text { Av. } \\ \text { Per }\end{array} & \begin{array}{c}\text { Lb. of } \\ \text { Butter }\end{array} \\ \text { Milk } & \text { Cent } & \text { Fat }\end{array}$

$\begin{array}{lll}585.9 & 6.03 & 35.343\end{array}$

$\begin{array}{lll}841.8 & 3.36 & 28.305\end{array}$

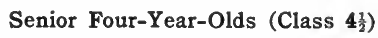
Agatha Pontiac . . . . . $11167 \quad 99818 \quad 4 \quad 9 \quad 15$ Belle Pietertje De Kol Parana $8554 \quad 79149 \quad 4.1019$ $\begin{array}{llr}575.8 & 5.13 & 29.520\end{array}$ $\begin{array}{lll}684.6 & 3.52 & 24.094\end{array}$

Junior Four-Year-Olds (Class 4)

Fairmont Zerma Segis Pietje . $11560 \quad 107672 \quad 4 \quad 111$ Lieuwkje Korṇdyke . . . . $14877 \quad 120296 \quad 4 \quad 111$

$\begin{array}{lll}608.4 & 4.68 & 28.484\end{array}$ $690.4 \quad 3.71 \quad 25.633$

Senior Three-Year-Olds (Class $3 \frac{1}{2}$ ) Johanna Korndyke Aaggie . . $22782 \quad 139481 \quad 3 \quad 6 \quad 24$ Friend Echo Elnora . . . . 18037 $114198 \quad 31123$

$588.4 \quad 4.67$

27.451

$678.5 \quad 3.59$

24.336

Junior Three-Year-Olds (Class 3)

Finderne Pietertje Johanna $\quad$. $19022 \quad 121082 \quad 3 \quad 213$

$637.9 \quad 4.42$

28.164

Senior Two-Year-Olds (Class 2 $\frac{1}{2}$ )

Lockhart De Kol . . . . . $9240 \quad 101544 \quad 2 \quad 1121$

$\begin{array}{ll}566.9 & 4.13\end{array}$

23.418

$610.5 \quad 3.39$

20.668

Junior Two-Year-Olds (Class 2)

Finderne Pontiac Netherland . $\begin{array}{lllll}18183 & 133504 & 2 & 2 & 24\end{array}$

Dutchland Colantha Vale . . $18976 \quad 132794 \quad 2 \quad 5 \quad 14$

$567.5 \quad 3.98$

22.610

$599.3 \quad 3.05$

18.294 
Leading Holstein-Friesian Cows and Heifers, by Classes, in the 30-Day Division

\section{Full-aged Cows (Class 5)}

Name and A.R. Number of Cow

\begin{tabular}{|c|c|c|c|c|c|}
\hline$\underset{\text { ber }}{\text { Num.B. }}$ & & & $\begin{array}{l}\text { Pounds } \\
\text { of } \\
\text { Milk }\end{array}$ & $\begin{array}{l}\text { Av. } \\
\text { Per } \\
\text { Cent }\end{array}$ & $\begin{array}{l}\text { Lb. of } \\
\text { Butter } \\
\text { Fat }\end{array}$ \\
\hline 06812 & 5 & 520 & 2316.4 & 5.92 & 137.198 \\
\hline 72325 & 6 & 529 & 3376.5 & 3.44 & 116.085 \\
\hline
\end{tabular}

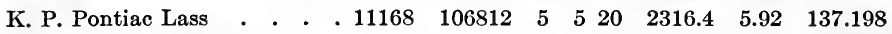

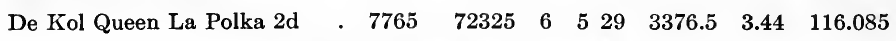

Senior Four-Year-Olds (Class $4 \frac{1}{2}$ )

Agatha Pontiac . . . . . $11167 \quad 99818 \quad 4 \quad 9 \quad 15$

$2365.5 \quad 4.74 \quad 112.081$

$\begin{array}{llllllllll}\text { Chimacum Wayne Boon } & \text { • } & \text {. } 13094 & 111306 & 4 & 7 & 4 & 2944.0 & 3.73 & 109.773\end{array}$

Junior Four-Year-Olds (Class 4)

$\begin{array}{lllllllll}\text { Fairview Rag Apple De Kol } & \text {. } 17094 & 166790 & 4 & 4 & 13 & 2215.8 & 4.25 & 117.587\end{array}$

$\begin{array}{lllllllll}\text { Jessie Fobes Bessie Homestead } & 9555 & 100742 & 4 & 1 & 18 & 2886.0 & 3.94 & 113.727\end{array}$

Senior Three-Year-Olds (Class $3 \frac{1}{2}$ )

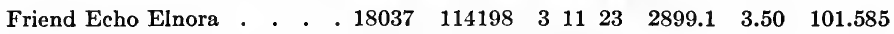

Junior Three-Year-Olds (Class 3)

$\begin{array}{lllllllll}\text { Findarne Pietertje Johanna } & \text {. } 19022 & 121082 & 3 & 2 & 13 & 2701.7 & 4.19 & 113.260\end{array}$

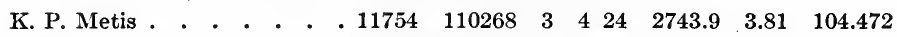

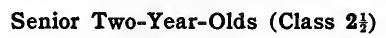

$\begin{array}{lllllllllll}\text { Lockhart De Kol . . . . } \quad 9240 & 101544 & 2 & 11 & 21 & 2415.9 & 3.86 & 93.226\end{array}$

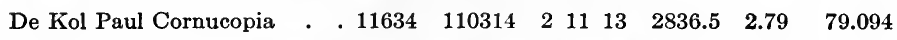

Junior Two-Year-Olds (Class 2)

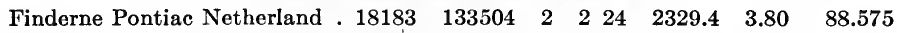

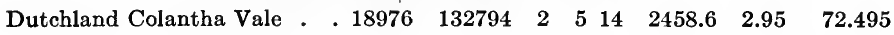

Leading Holstein-Friesian Cows and Heifers, by Classes, in the Semi-Official Yearly Division

Semi-Official Yearly or Lactation Records

Full-aged Ccws (Class 5)

$\begin{array}{llllllllll}\text { Banostine Belle De Kol } & \text {. } 10126 & 90441 & j & 2 & 22 & 365 & 27404.4 & 3.86 & 1058.34\end{array}$

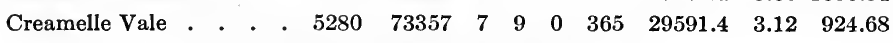

Senior Four-Year-Olds (Class $4 \frac{1}{2}$ )

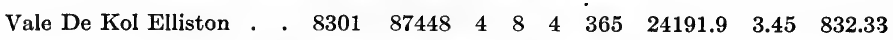

Junior Four-Year-Olds (Class 4)

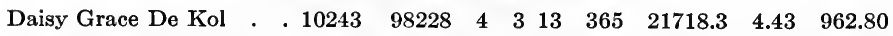

Maple Crest Pontiac Girl. $\begin{array}{lllllllll}13603 & 143952 & 4 & 5 & 27 & 365 & 22730.2 & 3.90 & 887.53\end{array}$

\section{Senior Three-Year-Olds (Class $3 \frac{1}{2}$ )}

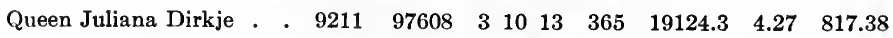

$\begin{array}{lllllllllll}\text { Friend Echo Elnora. . } & 18037 & 114198 & 3 & 11 & 23 & 365 & 23148.6 & 3.17 & 732.70\end{array}$ 


\section{Junior Three-Year-Olds (Class 3)}

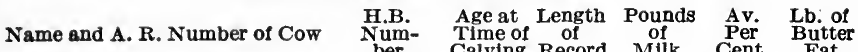
Dutchland Changeling Co-

$\begin{array}{lllllllllll}\text { lantha Lad . . . . . } 14928 & 120762 & 3 & 1 & 16 & 365 & 21239.8 & 3.57 & 757.37\end{array}$

$\begin{array}{llllllllll}\text { Dutchland Colantha Mona } & 15329 & 120767 & 3 & 2 & 3 & 365 & 22645.0 & 2.65 & 600.39\end{array}$

\section{Senior Two-Year-Olds (Class 21)}

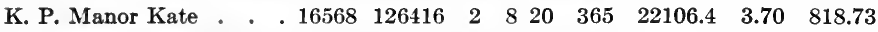

Junior Two-Year-Olds (Class 2)

$\begin{array}{llllllllll}\text { Woodcrest Rifton Lassie } & .13380 & 116441 & 2 & 1 & 23 & 365 & 19560.9 & 3.71 & 726.66\end{array}$

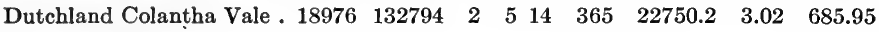

Leading Ayrshire Cows and Heifers thit have Qualified for Advanced Registry

Mature Form (Five Years Old or Over)

Pounds Pounds Pounds Per

of $\begin{array}{lll}\text { of } & \text { of Cent } \\ \text { Filk } & \text { Butter Fat }\end{array}$

27943 Auchenbrain Brown Kate 4th $\quad$ • $\quad \begin{array}{llllll} & 547 & 23022 & 917.60 & 1080 & 3.99\end{array}$

\section{Four Year Old Form}

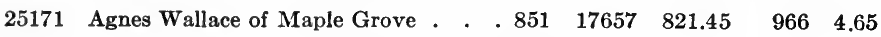

Three Year Old Form

26292 Elizabeth of Juneau $\quad$. . . . . . . $523 \quad 15122 \quad 536.15 \quad 631 \quad 3.55$

Two Year Old Form

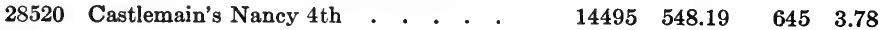

\section{Ayrshire Cumulative Records}

Six Years' Record

$\begin{array}{cccc}\text { Name } & \begin{array}{c}\text { Pounds } \\ \text { of } \\ \text { Milk }\end{array} & \begin{array}{c}\text { Pounds } \\ \text { of } \\ \text { Fat }\end{array} & \begin{array}{c}\text { Pounds } \\ \text { of }\end{array} \\ \text { Autter } & \begin{array}{c}\text { Average } \\ \text { Fat }\end{array}\end{array}$

Crimson Rambler . . . . . . . . . . $59446 \quad 2124.03 \quad 2499 \quad 3.60$

Five Years' Record

Lady Wonder 4th . . . . . . . . . . . $54765 \quad 2104.29 \quad 2475 \quad 3.81$

Four Years' Record

Bessie of Rosemont $\quad$. . . . . . . . . 48475 $4999.80 \quad 2352 \quad 4.14$

Three Years' Record

$\begin{array}{lllllllllllll}\text { Lilly of Willowmoor } & \text {. } & \text {. } & \text {. } & \text {. } & \text {. } & \text {. } & \text {. } & \text {. } & 4047 & 1717.28 & 2021 & 3.86\end{array}$

Two Years' Record

Imported Auchenbrain Brown Kate 4th $\quad$. $\begin{array}{llll}34206 & 1377.24 & 1621 & 4.05\end{array}$ 


\section{KILLING RECORDS}

Dressing Percentages of First Prize and Champion Carcasses at the International Live Stock Exposition, 1900-1913

\begin{tabular}{|c|c|c|c|c|c|c|c|}
\hline \multirow[b]{2}{*}{ Year } & \multicolumn{2}{|c|}{ Catthe Carcasses } & \multicolumn{3}{|c|}{ Hog Carcasses } & \multicolumn{2}{|c|}{ Wether Carcasses } \\
\hline & $2 \underset{\%}{\mathrm{yr} .}$ old & $\underset{\%}{\text { Yearling }}$ & $\begin{array}{c}\text { Wt. } 300 \mathrm{lb} . \\
\text { or more } \\
\%\end{array}$ & $\begin{array}{c}\text { Wt. 200 } \\
\text { and under } \\
300 \text { lb. } \\
\%\end{array}$ & $\begin{array}{c}\text { Wt. } 100 \\
\text { and under } \\
200 \mathrm{lb} . \\
\%\end{array}$ & $\underset{\%}{\text { Yearling }}$ & $\underset{\%}{\operatorname{Lamb}}$ \\
\hline 1900 & 65.07 & 66.2 & * & $*$ & * & * & * \\
\hline 1901 & 63.15 & 66.44 & * & $*$ & * & * & * \\
\hline 1902 & .6508 & .6496 & * & $*$ & * & * & * \\
\hline 1903 & 68.88 & 67.16 & * & $*$ & * & * & $*$ \\
\hline 1904 & 66.7 & 66.6 & * & $*$ & * & * & $*$ \\
\hline 1905 & .667 & .6488 & $*$ & $*$ & $*$ & $*$ & $*$ \\
\hline 1906 & 69.5 & 67.1 & 87.60 & 86.52 & 83.41 & 61.94 & 54.24 \\
\hline 1907 & 66.64 & 63. & 87.09 & 89.25 & 85.22 & 57.86 & 50.52 \\
\hline 1908 & 65.55 & 67.47 & 89.6 & 88.9 & 88.6 & 59.88 & 57.25 \\
\hline 1909 & 66.8 & 65.8 & $t$ & $t$ & $t$ & 63.48 & 60.64 \\
\hline 1910 & 66.91 & 66.43 & 84.9 & 86. & 81.8 & 58.8 & 56.4 \\
\hline 1911 & .662 & .678 & 86.3 & 86.9 & 83.5 & 60.45 & 55.24 \\
\hline 1912 & 67.13 & 65.09 & 85.77 & 79.33 & 81.30 & 60. & 55.13 \\
\hline 1913 & 66.97 & 65.80 & 87.96 & 92. & 88.31 & 62.68 & 54.76 \\
\hline
\end{tabular}

* No killing tabulations for swine and sheep were available during the years 1900 to 1905 , inclusive.

† No tabulation printed, but the persentages range from 73.48 to 87.42 on 22 swine carcasses exhibited. - Compiled by Dewitt C. Wing, Breeders' Gazette, Chicago, Ill.

\section{SHEARING RECORDS}

Fleece Records of Ewes from Illinois University Flock Shropshire

\begin{tabular}{|c|c|c|c|c|c|}
\hline $\begin{array}{c}\text { Association } \\
\text { Number }\end{array}$ & $\begin{array}{c}\text { No. } \\
\text { SEASONS } \\
\text { SHEARED }\end{array}$ & $\begin{array}{c}\text { AvERAGE } \\
\text { LB. OF WOOL } \\
\text { PER YEAR }\end{array}$ & $\begin{array}{c}\text { Assoctation } \\
\text { NUMBER }\end{array}$ & $\begin{array}{c}\text { No. } \\
\text { SEASONs } \\
\text { SHEaRED }\end{array}$ & $\begin{array}{c}\text { AvERAGE } \\
\text { LB. OF WOOL } \\
\text { PER YEAR }\end{array}$ \\
\hline 287038 & 3 & 7.3 & 375446 & 1 & 7. \\
\hline 351061 & 3 & 7.48 & 385052 & 1 & 5.4 \\
\hline 369856 & 1 & $9.25^{\circ}$ & 385035 & 1 & 8.25 \\
\hline 369869 & 1 & 6.33 & 385036 & 1 & 9.75 \\
\hline 341212 & 4 & 11.4 & 385038 & 1 & 7.8 \\
\hline 341219 & 4 & 8.56 & 385039 & 1 & 8.75 \\
\hline 371033 & 2 & 10. & 385040 & 1 & 7.8 \\
\hline 371027 & 1 & 9.5 & 385041 & 1 & 7.5 \\
\hline 375445 & 1 & 7.9 & 385042 & 1 & 7.5 \\
\hline
\end{tabular}




\begin{tabular}{|c|c|c|c|c|c|}
\hline $\begin{array}{c}\text { Association } \\
\text { Number }\end{array}$ & $\begin{array}{c}\text { No. } \\
\text { SEASONs } \\
\text { SHEARED }\end{array}$ & $\begin{array}{c}\text { AVERAGE } \\
\text { LB. OF WOOL } \\
\text { PER YEAR }\end{array}$ & $\begin{array}{l}\text { Association } \\
\text { NUMBer }\end{array}$ & $\begin{array}{c}\text { No. } \\
\text { SEASONS } \\
\text { SHEARED }\end{array}$ & $\begin{array}{c}\text { Average } \\
\text { LB. OF WoOL } \\
\text { PER YeAR }\end{array}$ \\
\hline 385020 & 1 & 7.8 & 295406 & 1 & 8.3 \\
\hline 385050 & 1 & 6.75 & 306662 & 1 & 8.7 \\
\hline 385028 & 1 & 5.4 & 344989 & 1 & 9.3 \\
\hline 385029 & 1 & 5.4 & 344982 & 1 & 8.5 \\
\hline 385030 & 1 & 6.5 & 325910 & 2 & 9.85 \\
\hline 385047 & 1 & 4.8 & 325912 & 2 & 8.8 \\
\hline 385051 & 1 & 7.5 & 325913 & 2 & 9.4 \\
\hline 385049 & 1 & 10.75 & 325914 & 2 & 11.95 \\
\hline 385032 & 1 & 6.4 & 372654 & 2 & 9.25 \\
\hline 268052 & 2 & 9. & 321329 & 1 & 7.7 \\
\hline 287032 & 2 & 8.6 & 226302 & 2 & 6.65 \\
\hline 287009 & 2 & 8. & 345311 & 2 & 9.15 \\
\hline 351060 & 1 & 5.6 & 341211 & 1 & 9.7 \\
\hline 341214 & 2 & 10.5 & 341213 & 2 & 11.55 \\
\hline 341215 & 2 & 9.75 & 341218 & 1 & 9.2 \\
\hline 341216 & 2 & 9.75 & 344974 & 1 & 7.4 \\
\hline 292589 & 1 & 9.7 & & & \\
\hline \multicolumn{6}{|c|}{ Hampshires } \\
\hline 24776 & 3 & 7.77 & 34484 & 1 & 9.75 \\
\hline 22359 & 4 & 9.22 & 34937 & 1 & 9. \\
\hline 25110 & 4 & 9.45 & 34936 & 1 & 7.2 \\
\hline 22280 & 4 & 9.1 & 34935 & 1 & 8.5 \\
\hline 22339 & 4 & 8.97 & 14364 & 1 & 7.15 \\
\hline 24701 & 4 & 9.36 & 22196 & 2 & 9.4 \\
\hline 24706 & 4 & 7.06 & 22171 & 1 & 8.2 \\
\hline 34485 & 1 & 9.5 & 22198 & 1 & 6.2 \\
\hline 34482 & 1 & 8.5 & 11550 & 5 & 7.4 \\
\hline 34483 & 1 & 8. & 22198 & 2 & 9.1 \\
\hline \multicolumn{6}{|c|}{ Southdown } \\
\hline 30561 & 5 & 7.28 & 29521 & 1 & 5.7 \\
\hline 30563 & 4 & 6.55 & 30574 & 1 & 4.5 \\
\hline 29519 & 5 & 5. & 30575 & 1 & 5.5 \\
\hline \multirow[t]{2}{*}{30565} & 5 & 7.7 & 26193 & 1 & 7.7 \\
\hline & 1 & 6.2 & 30567 & 3 & 7.87 \\
\hline 29363 & 5 & 6.65 & $\cdot 16220$ & 4 & 3.92 \\
\hline 30566 & 4 & 7.32 & 18883 & 3 & 6.66 \\
\hline 29521 & 2 & 5.15 & 16072 & 2 & 6.12 \\
\hline 30568 & 3 & 6.17 & 16072 & 6 & 5.93 \\
\hline 30570 & 1 & 7.7 & 20182 & 5 & 5.6 \\
\hline 30571 & 1 & 5.25 & 16072 & 1 & 5.4 \\
\hline 30572 & 1 & 5. & $\longrightarrow$ & 2 & 5.5 \\
\hline
\end{tabular}




\begin{tabular}{|c|c|c|c|c|c|}
\hline $\begin{array}{l}\text { Association } \\
\text { NUMBER }\end{array}$ & $\begin{array}{c}\text { No. } \\
\text { SEASONS } \\
\text { SHEARED }\end{array}$ & $\begin{array}{c}\text { AVERAGE } \\
\text { LB. OF WOOL } \\
\text { PER YEAR }\end{array}$ & $\begin{array}{l}\text { Association } \\
\text { NUMBER }\end{array}$ & $\begin{array}{c}\text { No. } \\
\text { SEASONS } \\
\text { SHEARED }\end{array}$ & $\begin{array}{c}\text { AvERAGE } \\
\text { LB. OF WOOL } \\
\text { PER YEAR }\end{array}$ \\
\hline 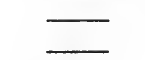 & $\begin{array}{l}4 \\
3\end{array}$ & $\begin{array}{l}5.57 \\
5.1\end{array}$ & $\begin{array}{l}30562 \\
30564\end{array}$ & $\begin{array}{l}4 \\
3\end{array}$ & $\begin{array}{l}7 . \\
5.2\end{array}$ \\
\hline 24115 & 2 & 6.1 & - & 1 & 7.1 \\
\hline & $\begin{array}{l}2 \\
2\end{array}$ & $\begin{array}{l}6 . \\
4.45\end{array}$ & 29520 & 3 & 7.1 \\
\hline \multicolumn{6}{|c|}{ Rambouillet } \\
\hline 71541 & 3 & 19.3 & 67403 & 3 & 14.7 \\
\hline 71542 & 3 & 15.5 & 67404 & 3 & 14.9 \\
\hline 71543 & 3 & 17.75 & 20170 & 5 & 11.23 \\
\hline 71544 & 3 & 21.65 & 20171 & 4 & 10.7 \\
\hline 71545 & 3 & 17.9 & 34037 & 8 & 13.9 \\
\hline 51068 & 6 & 14.9 & 34038 & 7 & 12.16 \\
\hline 51070 & 6 & 14.5 & 34040 & 1 & 13.7 \\
\hline 51073 & 6 & 13.14 & 34041 & 6 & 11.6 \\
\hline 54300 & 5 & 13.73 & 34042 & 3 & 11.9 \\
\hline 67398 & 3 & 16.5 & 34043 & 7 & 13.5 \\
\hline 67408 & 3 & 16.95 & 43217 & 5 & 10.6 \\
\hline 67411 & 3 & 15.68 & 43213 & 5 & 10. \\
\hline 73338 & 1 & 14.75 & 48450 & 3 & 10. \\
\hline 73339 & 2 & 14.75 & 48451 & 4 & 9.6 \\
\hline 73340 & 2 & 13.1 & 48452 & 4 & 11.05 \\
\hline 73342 & 2 & 12. & 51067 & 1 & 12. \\
\hline 73344 & 1 & 12.8 & 51071 & 4 & 12. \\
\hline 71546 & 2 & 14.8 & 51072 & 4 & 10.8 \\
\hline 34039 & 5 & 13.4 & 54298 & 4 & 15.2 \\
\hline 34042 & 5 & 13.2 & 54301 & 2 & 11.6 \\
\hline 54297 & 4 & 15.2 & 67400 & 1 & 21.4 \\
\hline 54299 & 4 & 13.9 & 67402 & 2 & 11.3 \\
\hline 67399 & 1 & 15.8 & & & \\
\hline
\end{tabular}

\section{Oxford Down}

62777
65700

$\begin{array}{rrrr}9.1 & 65551 & 1 & 9.5 \\ 10.5 & 65552 & 1 & 11.4\end{array}$

\section{Dorset Ewes}

$\begin{array}{rr}7271 & 1 \\ 11432 & 1\end{array}$

$\begin{array}{llll}5.6 & 13795 & 1 & 7.8 \\ 4.1 & 13798 & 1 & 5.6\end{array}$

$\begin{array}{ll}1385 & 1 \\ 1989 & 1 \\ 1024 & 1\end{array}$

\section{Tunis Sheep}

$\begin{array}{llll}6 . & 1991 & 1 & 8.5 \\ 6.5 & - & 1 & 5 . \\ 4.8 & - & 1 & 7.5\end{array}$

- Compiled by Prof. W. C. Coffey, Urbana, Ill. 


\section{THE SCALE OF POINTS}

The following scales of points have been furnished by the secretaries of those breed associations which have adopted them.

\section{American Saddle Horse}

Show Ring Classification Adopted by the Stockholders of the American Saddle Horse Breeders' Association, Anndal Meeting, April, 1910

The Saddle horse must be sound, of good conformation, substance, finish, style, and shown without artificial appliances, and up to carrying at least one hundred and sixty (160) pounds.

The three-gaited horse should go plain walk; briskly and with speed equal to four (4) miles an hour; canter reasonably high and gentle; trot, steady, straight and true; action enough to be attractive; well balanced and with speed equal to twelve (12) miles an hour.

Added to the foregoing the five-gaited horse should go running walk, fox trot or slow pace, smoothly and equal to six (6) miles an hour; rack easily without being forced, with speed equal to twelve (12) miles an hour. Must stand quietly, back readily and lead with either foot in a canter from a halt.

High rate of speed and racing is forbidden.

High School Gaits are not Saddle Gaits. It is understood that an animal which has been educated in high school may inadvertently show a step or two in this school when changing suit. Such evidence is not to disqualify a horse, though it is objectionable, but any intentional exhibition of high school is prohibited and shall disqualify an entry.

\section{Shetland Pony \\ Scale of Points}

Constitution. - Constitution indicated by general healthy appearance, perfect respiration, brightness of eye . . . Size. - Ponies over four years old 42 inches and under in height, two points to be deducted for every inch over 42 inches up to 46 inches, fractional portions to count as full inches

Head. - Head symmetrical, rather small and fine, wide between eyes, ears short and erect . . . . . . .

Body. - Barrel well rounded, back short and level, deep chest, good breast, compact "pony build". . . . . . 10 
Legs. - Legs muscular, flat-boned, hind legs not cow-hocked or too crooked... . . . . . . . . . . . 25

Mane and tail. - Foretop, mane and tail heavy . . . . 10

Feet. - Good . . . . . . . . . . . . . . . $\frac{10}{100}$

\section{Aberdeen-Angus Cattle - Scale of Points}

1. Color. - Black; white is objectionable, except on

Perfect

SCORE

the under line behind the navel, and there only to moderate extent; a white scrotum is most undesirable

2. Head. - Forehead broad; face slightly prominent, and tapering toward the nose, muzzle fine; nostrils wide and open; distance from eyes to nostrils of moderate length; eyes mild, full and expressive, indicative of good disposition; ears of good medium size, well set and well covered with hair; poll well defined, and without any appearance of horns or scurs ; jaws clean . . .

3. Throat. - Clean, without any development of loose flesh underneath

4. Neck. - Of medium length, muscular, with moderate crest (which increases with age), spreading out to meet the shoulders, with full neck vein . .

5. Shoulders. - Moderately oblique, well covered on the blades and top; with vertebra or backbone slightly above the scapula or shoulder blades, which should be moderately broad . . . . .

6. Chest. - Wide and deep; also round and full just back of elbows . . . . . . . . . . . .

7. Brisket. - Deep and moderately projecting from between thelegs, and proportionately covered with flesh and fat .

8. Ribs. - Well sprung from the backbone, arched and deep, neatly jointed to the crops and loins

9. Back. - Broad and straight from crops to hooks; loins strong; hook bones moderate in width, not prominent, and well covered; rumps long, full, level and rounded neatly into hindquarters

10. Hindquarters. - Deep and full; thighs thick and muscular, and in proportion to hindquarters; twist filled out well in its "seam," so as to form an even, wide plain between the thighs . . . . 
11. Tail. - Fine, coming neatly out of the body on a line with the back and hanging at right angles to it

12. Under line. - Straight as nearly as possible; flank deep and full

13. Legs. - Short, straight and squarely placed, hind legs slightly inclined forward below the hocks; forearm muscular; bones fine and clean . . .

14. Flesh. - Even and without patchiness $\cdot \dot{\text { 15. }} \cdot \dot{\text { Skin. }}$ - Of moderate thickness and mellow touch, abundantly covered with thick, soft hair (much of the thriftiness, feeling properties and value of the animal depends on this quality, which is of great weight in the grazier's and butcher's judgment. A good "touch" will compensate for some deficiencies of form. Nothing can compensate for. a skin hard and stiff. In raising the skin from the body it should have a substantial, soft, flexible feeling, and when beneath the outspread hand it should move easily as though resting on a soft, cellular substance, which, however, becomes firmer as the animal ripens. A thin, papery shin is objectionable, especially in cold climate) . .

16. General appearance. - Elegant, well bred and masculine. The walk square, the step quick and the head up

Perfection .

When bulls are exhibited with their progeny in a separate class, add 25 points for progeny.

\section{Hereford Cattle - Score Card}

Color, 5 points -

Medium, deep, rich red, with white head, breast, belly, crest, switch and ankles.

Objections. White back of crop high on flank or too high on legs.

Head, 8 points -

Forehead broad and prominent, face short, slightly tapering towards nose; muzzle full; nostrils wide and open; eyes large and expressive; ears of medium size, well set and well 
covered with hair; horns of medium size, even color, coming from head at right angles, set on level with crops, back and tail head, curving forward and downward.

Throat, 2 points -

Clean, without any excessive development of loose flesh or fat underneath.

Neck, 2 points -

Short, neat, spreading out to meet shoulders, with full neck vein, free from loose skin. (Males: neck muscular, with full crest according to age.)

Shoulders, 6 points -

Straight, round, full, smooth and well covered; top of shoulder blades slightly below vertebra, good width on top.

Chest, 6 points -

Wide, deep, round and full just back of shoulders. Brisket, 2 points -

Deep and wide, moderately projecting, free from flabbiness.

Ribs, 8 points -

Well sprung from backbone, close together, long and arched, carrying the full width of shoulders and deeply and smoothly covered.

Back and loin, 10 points -

Broad, straight and heavily covered from crops to hooks; hooks moderately wide and well covered.

Rump, 5 points -

Long, wide, smooth and well covered, carrying width in proportion to width of back and hooks, joining smoothly into quarters.

Quarters, 4 points -

Long, straight, muscular, full, deep and thick.

Thigh and twist, 3 points -

Full and thick, earried well down to hocks.

Tail, 1 point -

Tail level with line of back, tail dropping at right angles to back line.

Under line, 3 points -

Straight, flanks deep and full.

Legs, 6 points -

Short, straight and squarely placed, perpendicular both from side and end view, forearm muscular, bones strong and clean.

Flesh, 8 points -

Deep, firm, smooth, uniform covering of all parts and free from patchiness. 
Skin, 6 points -

Of moderate thickness, mellow, pliable and loose, abundantly covered with long, thick, silky hair.

General appearance, 10 points -

Vigorous, compact and symmetrical. Bulls masculine and possessing an abundance of quality and predominant breeding characteristics. Females matronly, roomy, smooth, showing quality and feminine appearance throughout.

Weight, 5 points -

Age and condition to be considered.

The following are the average weights of all Herefords exhibited at the American Royal Show for five years:

Aged bulls . . . . . . . 2238 Aged cows . . . . . 1689 Two-year-old bulls . . 1911 Two-year-old heifers . 1517

Senior yearling bulls . 1439 Senior yearling heifers . 1269 Junior yearling bulls . 1318 Junior yearling heifers . 1128 Senior bull calves . . 979 Senior heifer calves . . 828 Junior bull calves . . 748 Junior heifer calves . . 634

\section{Galloway Catthe - Score Card}

Color - Black, with a brownish tinge.

Head - Short and wide, with broad forehead and wide nostrils ; without the slightest symptoms of horns or.scurs.

Eyes - Large and prominent.

Ear - Moderate in length and broad, pointing forwards and upwards with fringe of long hairs.

Neck-Moderate in length, clean and filling well into the shoulders; the top in a line with the back in a female, and in a male naturally rising with age.

Body - Deep, rounded and symmetrical.

Shoulders - Fine and straight, moderately wide above; coarse shoulder points and sharp or high shoulders are objectionable.

Breast - Full and deep.

Back and rump - Straight.

Ribs - Deep and well sprung.

Loin and sirloin - Well filled.

Hook bones - Not prominent.

Hindquarters - Long, moderately wide and well filled.

Flank - Deep and full.

Thighs - Broad, straight and well let down to hock; rounded buttocks are very objectionable. 
Legs - Short and clean, with fine bone.

Tail - Well set on, and moderately thick.

Skin - Mellow and moderately thick.

Hair - Soft and wavy, with mossy undercoat; wiry or curly hair is very objectionable.

The last point is a very important one. Some animals are without this thick mossy covering, which should, in the very best hides, have a feeling akin to a sealskin jacket. The great advantage of such a covering is obvious. In cold or windy weather it has warmth and on wet days will throw off a great amount of rain. For the making of fine robes it is a necessity ; coarse hair will not wear nearly so well. The defects specially to be guarded against as objectionable are the following :

Galloways should not have

1. Narrow, tapering muzzle.

2. Long, lean, narrow head.

3. Small, dull, deep-set eyes.

4. Long, drooping ears.

5. Small, scraggy neck.

6. Contracted brisket or narrow, sunken ehest.

7. Bare shoulders, narrow on top.

8. Flatness behind the shoulders.

9. Light fore or back ribs.

10. Prominent hook bones.

11. High or drooping rumps.

12. Weak or slack loins.

13. Bare or rough back, lacking flesh.

14. Rounded buttocks.

15. Double thighs.

16. Coarse, big bones.

17. Thick, stiff skin.

18. Hard, wiry or too curly hair.

19. Hair without soft undercoat.

20. Rough, angular form.

These defects should be avoided by the careful breeder. It is hard to get a herd without some of these faults, but a knowledge of what should be shunned will assist in bringing a herd up to a good standard of excellence. 


\section{Jersey Cattle - Score Card}

\section{Cow}

Name

By Scale of Points Adopted by the American Jergey Cattle Clob, MAY 7, 1913

\section{Dairy Temperament and Constitution}

Head, 7.

$A$ - Medium size, lean; face dished; broad between eyes; horns medium size, incurving

$B$ - Eyes full and placid; ears medium size,

Counts fine, carried alert; muzzle broad, with wide-open nostrils and muscular lips; jaw strong . . . . . . . . . .

Neck, 4. -

Thin, rather long, with clean throat, neatly joined to head and shoulders . . . . . . Body, 37.

$A$ - Shoulders light, good distance through from point to point, but thin at withers ; chest deep and full between and just back of forelegs

$B$ - Ribs amply sprung and wide apart, giving wedge shape, with deep, large abdomen, firmly held up, with strong, muscular development

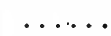

ack straight and strong, with prominent spinal processes; loins broad and strong

$D$ - Rump long to tail-setting, and level from hip bones to rump bones

$E$ - Hip bones high and wide apart

$F$ - Thighs flat and wide apart, giving ample room for udder

$G$ - Legs proportionate to size and of fine quality, well apart, with good feet, and not to weave or cross in walking . . . .

$H$ - Hide loose and mellow

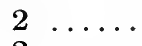

2

$I$ - Tail thin, long, with good switch, not coarse at setting-on . . . . . . . 


\section{Mammary Development}

Udder, 26. -

$A$ - Large size, flexible and not fleshy

$B$ - Broad, level or spherical, not deeply cut between teats

$C$ - Fore udder full and well rounded, running well forward of front teats

$D$ - Rear udder well rounded, and well out Teats, 8. and up behind

Of good and uniform length and size, regularly and squarely placed

Milk Veins, 4. -

Large, long, tortuous and elastic, entering large and numerous orifices . . . . . . . .

Size, 4. -

Mature cows, 800 to 1000 pounds .

General Appearance, 10.-

A symmetrical balancing of all the parts, and a proportion of parts to each other, depending on size of animal, with the general appearance of a high-class animal, with capacity for food and productiveness at pail

$\frac{10}{100} \cdots \cdots$

Date..............191 .

Scorer

Bull

Name

By Scale of Points Adopted by the American Jergey Cattle Club, Head, 10. MAY 7, 1913

$A$ - Broad, medium length ; face dished ; narrow between horns; horns medium in size and incurving

$B$ - Muzzle broad, nostrils open, eyes full and bold; entire expression one of vigor, Neck, 7. resolution and masculinity . . . .

Counts

6

4

10

6

8

4

4

$6 \ldots$.

.

0

.....

.....

$\ldots .$.

..... 
Body, 57. -

Counts

$A$ - Shoulders full and strong, good distance through from point to point, with welldefined withers; chest deep and full between and just back of forelegs . .

$B-$ Barrel long, of good depth and breadth, with strong, rounded, well-sprung ribs

$C$ - Back straight and strong

$D$ - Rump of good length and proportion to size of body, and level from hip bones to rump bones

$E$ - Loins broad and strong ; hips rounded, and of medium width compared with female

$F$ - Thighs rather flat, well cut up behind, high arched flank

$G$ - Legs proportionate to size and of fine quality, well apart, with good feet, and not to weave or cross in walking . ' .

Rudimentary Teats, 2. - Well placed . . . .

Hide, 2. - Loose and mellow . . . . . .

Tail, 2. -

Thin, long, reaching the hock, with good switch, not coarse or high at setting-on . . . . Size, 5. -

Mature bulls, 1200 to 1500 pounds . . .

General Appearance, 15. -

Thoroughly masculine in character, with a harmonious blending of the parts to each other; thoroughly robust, and such an animal as in a herd of wild cattle would likely become master of the herd by the law of natural selection and survival of the fittest

Date............. .

\section{Guernsey Cattle - Scale of Points}

\section{Cow}

Dairy Clean-cut, lean face; strong sinewy

Temperament,

Constitution, 38 jaw; wide muzzle with wide open nostrils ; full, bright eye with quiet and gentle expression; forehead long and broad 
Long, thin neck with strong juncture

Counts

to head; clean throat. Backbone rising well between shoulder blades ; large rugged spinal processes, indicating good development of the spinal cord

Pelvis arching and wide; rump long; wide, strong structure of spine at setting on of tail. Long, thin tail with good switch. Thin incurving thighs

Ribs amply and fully sprung and wide apart, giving an open, relaxed conformation; thin arching flanks.

Abdomen large and deep, with strong muscular and navel development, indicative of capacity and vitality

Hide firm yet loose, with an oily feeling and texture, but not thick.

Milking Marks Escutcheon wide on thighs; high and

denoting

Quantity of

Flow

10

Udder

Formation

26

Indicating

Color of Milk,

15

Milking Marks Udder showing plenty of substance denoting Qual- but not too meaty . . . . . ity of Flow

6

Symmetry and Color of hair a shade of fawn, with Size,

5

broad, with thigh ovals . . . .

Milk veins long, crooked, branching and prominent, with large or deep wells

Udder full in front

Udder full and well up behind . .

Udder of large size and capacity .

Teats well apart, squarely placed, and of good and even size

Skin deep yellow in ear, on end of bone of tail, at base of horns, on udder, teats, and body generally. Hoofs amber-colored . . . . . . 15

white markings. Cream-colored nose. Horns amber-colored, small, curved, and not coarse - . .

four years old or over, about $1050 \mathrm{lb}$. 


\section{Bull}

Counts

Dairy Clean-cut, lean face; strong sinewy Temperament, jaws; wide muzzle with wide-open Constitution, nostrils; full bright eye with quiet 38

Dairy

Prepotency,

15

Rudimen-

taries and

Milk Veins,

10

Indicating

Color of Milk in Offspring, 15

Symmetry and Size, 22 and gentle expression; forehead long and broad . . . . . . .

Long masculine neck with strong juncture to head; clean throat. Backbone rising well between shoulder blades; large rugged spinal processes, indicating good development of the spinal cord.

Pelvis arching and wide; rump long; wide, strong structure of spine at setting of tail. Long, thin tail with good switch. Thin incurving thighs

Ribs amply and fully sprung and wide apart, giving an open relaxed conformation; thin, arching flank . .

Abdomen large and deep, with strong muscular and navel development, indicative of capacity and vitality

Hide firm yet loose, with an oily feeling and texture, but not thick . . 3

As shown by having a great deal of vigor, style, alertness, and resolute appearance . . . . . . . .

Rudimentaries of good size, squarely and broadly placed in front of and free from scrotum. Milk veins prominent . . . . . . . .

Skin deep yellow in ear, on end of bone of tail, at base of horns and bodygenerally; hoofs a mber-colored

Color of hair, a shade of fawn with white markings. Cream-colored nose. Horns amber-colored, curving and not coarse . . . . . . 8

Size for the breed : - Mature bulls four years old or over, about $1500 \mathrm{lb}$. General appearance as indicative of the power to beget animals of strong dairy qualities 


\section{Holstein-Friesian Cattle - Score Card}

Cow

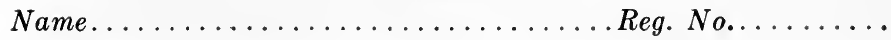

Dropped

Weight

The interlines in smaller type relate entirely to the method of application agreed upon by the Inspectors, in order to secure uniformity of work. The abbreviations are as follows: vs, very slight; $s$, slight; $m$, marked ; vm, very marked; e, extreme.

\begin{tabular}{|c|c|c|c|}
\hline Parts & DÉSCRIPTION & $\underset{\text { PossIBLE }}{\text { ScORE }}$ & $\begin{array}{c}\text { DIS- } \\
\text { CREDITS }\end{array}$ \\
\hline Head & 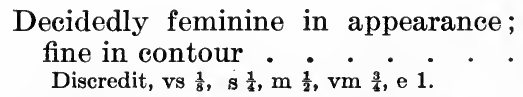 & 2 & \\
\hline Forehead & $\begin{array}{l}\text { Broad between the eyes; dishing } \\
\text { Discredit, vs } \frac{1}{8}, \mathrm{~s} \frac{1}{4}, \mathrm{~m} \frac{1}{2}, \mathrm{vm} \frac{3}{4}, \mathrm{e} 1 \text {. }\end{array}$ & 2 & \\
\hline Face & $\begin{array}{l}\text { Of medium length; clean and trim, } \\
\text { especially under the eyes; showing } \\
\text { facial veins; the bridge of the nose } \\
\text { straight } . . \\
\text { Discredit, s } \frac{1}{8}, \mathrm{~m}_{\frac{1}{4}}, \mathrm{e}_{\frac{1}{2}}^{\frac{1}{2}} .\end{array}$ & 2 & \\
\hline Muzzle & $\begin{array}{l}\text { Broad, with strong lips } \\
\text { Discredit, } \mathrm{s} \frac{1}{8}, \mathrm{~m} \frac{1}{4}, \mathrm{e} \frac{1}{2} .\end{array}$ & 1 & \\
\hline Ears & $\begin{array}{l}\text { Of medium size; of fine texture; the } \\
\text { hair plentiful and soft; the secre- } \\
\text { tions oily and abundant } \\
\text { Discredit, } m \frac{1}{8}, \mathrm{e}^{\frac{1}{4}} \text {. }\end{array}$ & 1 & \\
\hline Eyes & $\begin{array}{l}\text { Large; full ; mild ; bright } \quad \cdot \quad \cdot \\
\text { Discredit, } s \frac{1}{3}, \mathrm{~m} \frac{\frac{1}{4}}{4}, \mathrm{e} \frac{1}{2} .\end{array}$ & 2 & \\
\hline Horns & $\begin{array}{l}\text { Small ; tapering finely towards the } \\
\text { tips; set moderately narrow at } \\
\text { base; oval; inclining forward; well } \\
\text { bent inward; of fine texture; in } \\
\text { appearance waxy..... } \\
\text { Discredit, } m \frac{1}{8}, e^{\frac{1}{4} .}\end{array}$ & 1 & \\
\hline$N e c k$ & $\begin{array}{l}\text { Long ; fine and clean at juncture with } \\
\text { the head; free from dewlap; evenly } \\
\text { and smoothly joined to shoulders } \\
\text { Discredit, vs } \frac{1}{8}, \mathrm{~s} \frac{1}{4}, \mathrm{~m} \frac{1}{2}, \mathrm{vm} \frac{3}{4}, \mathrm{e} 1 \text {. }\end{array}$ & 4 & \\
\hline Shoulders & $\begin{array}{l}\text { Slightly lower than the hips; fine and } \\
\text { even over tops; moderately broad } \\
\text { and full at sides } \\
\text { Discredit, vs } \frac{1}{8}, \mathrm{~s} \frac{1}{4}, \mathrm{~m} \frac{1}{2}, \text { vm } \frac{3}{4}, \mathrm{e} \text {. }\end{array}$ & 3 & \\
\hline
\end{tabular}




\begin{tabular}{|c|c|c|c|}
\hline PARTS & DEscription & $\mid \begin{array}{c}\text { Possible } \\
\text { Score }\end{array}$ & \begin{tabular}{|c|c|c|} 
DIS- \\
CREDITS
\end{tabular} \\
\hline Chest & $\begin{array}{l}\text { Of moderate depth and lowness; } \\
\text { smooth and moderately full in the } \\
\text { brisket; full in the foreflanks (or } \\
\text { through at the heart) } \\
\text { Discredit, vs } \frac{1}{3}, \mathrm{~s} \frac{1}{2}, \mathrm{~m} 1, \mathrm{vm} 1 \frac{1}{2}, \mathrm{e} 2 .\end{array}$ & 6 & \\
\hline Crops & $\begin{array}{l}\text { Moderately full } \\
\text { Discredit, vs } \frac{1}{2}, \mathrm{~s} \frac{1}{2}, \mathrm{~m} \frac{3}{4}, \text { vm } 1 \frac{1}{2}, e_{2} .\end{array}$ & 2 & \\
\hline Chine & $\begin{array}{l}\text { Straight; strong; broadly developed, } \\
\text { with open vertebræ } \cdot . \cdot{ }^{-} \cdot \\
\text { Discredit, vs } \frac{1}{8}, \mathrm{~s} \frac{1}{4}, \mathrm{~m} \frac{1}{2}, \text { vm } \frac{3}{4}, \text { e } 1 .\end{array}$ & 6 & \\
\hline Barrel & $\begin{array}{l}\text { Long; of wedge shape; well rounded; } \\
\text { with a large abdomen, trimly held } \\
\text { up. (In judging the last item age } \\
\text { must be considered.) . } \\
\text { Discredit, vs } \frac{1}{3}, \mathrm{~s} \frac{1}{4}, \mathrm{~m} \frac{1}{2}, \text { vm } \frac{3}{3}, \text { e i. }\end{array}$ & 7 & \\
\hline $\begin{array}{l}\text { Loin and } \\
\text { Hips }\end{array}$ & $\begin{array}{l}\text { Broad ; level or nearly level between } \\
\text { the hook bones; level and strong } \\
\text { laterally; spreading from chine } \\
\text { broadly and nearly level; hook } \\
\text { bones fairly prominent } \\
\text { Discredit, vs } \frac{1}{8}, \mathrm{~s} \frac{1}{3}, \mathrm{~m} \frac{1}{2}, \text { vm } \frac{3}{4}, \mathrm{e} 1 .\end{array}$ & 6 & \\
\hline Rump & 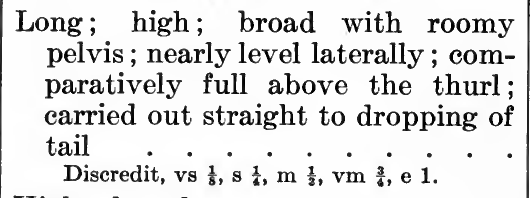 & 6 & \\
\hline Thurl & 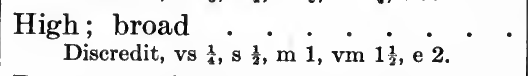 & 3 & \\
\hline Quarters & $\begin{array}{l}\text { Deep; straight behind ; twist filled } \\
\text { with development of udder; wide } \\
\text { and moderately full at the sides } \\
\text { Discredit, vs } \frac{1}{8}, \mathrm{~s} \frac{1}{3}, \mathrm{~m} \frac{1}{2}, \text { vm } \frac{3}{3}, \mathrm{e} 1 \text {. }\end{array}$ & 4 & \\
\hline Flanks & $\begin{array}{l}\text { Deep; comparatively full } . . . \\
\quad \text { Discredit, vs } \frac{1}{3}, s \frac{1}{4}, m \frac{1}{2}, v m \frac{\frac{3}{4}}{4}, \text { e }\end{array}$ & 2 & \\
\hline Legs & $\begin{array}{l}\text { Comparatively short; clean and } \\
\text { nearly straight; wide apart; firmly } \\
\text { and squarely set under the body; } \\
\text { feet of medium size, round, solid } \\
\text { and deep } \\
\text { Discredit, vs } \frac{1}{3}, \text { s } \frac{1}{4}, \mathrm{~m} \frac{1}{2}, \text { vm } \frac{3}{3}, \mathrm{i} \text {. }\end{array}$ & 4 & \\
\hline
\end{tabular}


\begin{tabular}{l|l}
\hline \multicolumn{1}{c|}{ Parts } & Description \\
\hline Tail & Large at base, the setting well back;
\end{tabular} tapering finely to switch; the end of the bone reaching to hocks or below; the switch full .... Discredit, $\mathrm{s} \frac{1}{8}, \mathrm{~m} \frac{1}{4}, \mathrm{e} \frac{1}{2}$.

Hair and Handling

Mammary Veins

Udder

Teats

Escutcheon

*General Vigor

\section{*General}

Symmetry and Fineness

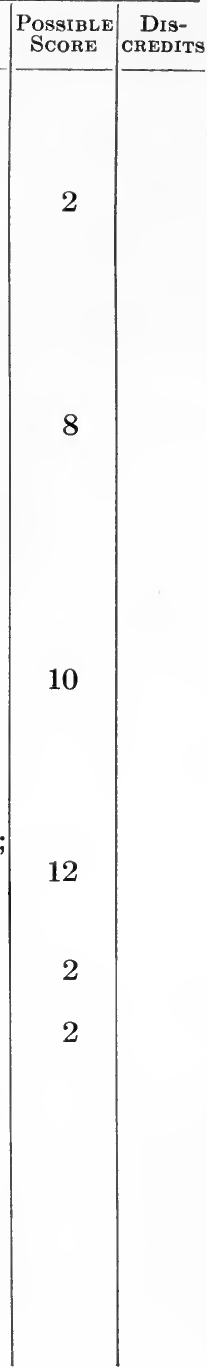




\begin{tabular}{c|c}
\hline Parts & Description \\
\hline
\end{tabular}

*General Style and Bearing

For deficiency Inspectors shall discredit from the total received not to exceed eight points
Discredit, vs $1, \mathrm{~s} \frac{1}{2}, \mathrm{~m} 3, \mathrm{vm} 5$, e 8 .

*Credits for Excess of Requirement in Production. A cow shall be credited one point in excess of what she is otherwise entitled to, for each and every eight per cent that her milk or butter record exceeds the minimum requirement

*In scaling for the Advanced Register, defects caused solely by age, or by accident, or by disease not hereditary, shall not be considered. But in scaling for the show ring, such defects shall be considered and duly discredited

*A cow that in the judgment of the Inspector will not reach at full age, in milking condition and ordinary flesh, $1000 \mathrm{lb}$., live weight, shall be disqualified for entry in the Advanced. Register

*No cow shall be received to the Advanced Register that, with all credits due her, will not scale, in the judgment of the Inspector, at least 75 points. (See in last paragraph of Rule VI an exception to these requirements.)

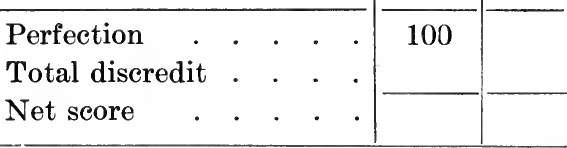

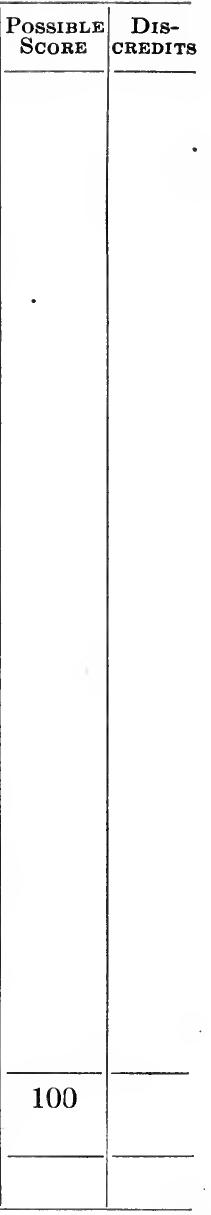

* Not now in use by Advanced Register, but of great value as an aid in judging cattle. 


\section{Bull}

Name.....................Reg. No.......

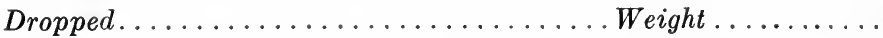

The interlines in smaller type relate entirely to the method of application agreed upon by the Inspectors, in order to secure uniformity of work. The abbreviations are as follows: vs, very slight; s, slight; $m$, marked; vm, very marked; e, extreme.

\begin{tabular}{|c|c|c|c|}
\hline Parts & Description & $\left|\begin{array}{c}\text { Possible } \\
\text {.Score }\end{array}\right|$ & $\begin{array}{c}\text { DIS- } \\
\text { CREDITS }\end{array}$ \\
\hline Head & $\begin{array}{l}\text { Showing full vigor; elegant in contour } \\
\text { Discredit, vs } \frac{1}{8}, \frac{1}{4}, \mathrm{~m} \frac{1}{2}, \mathrm{vm} \frac{3}{4}, \mathrm{e} 1 \text {. }\end{array}$ & 2 & \\
\hline Forehead & $\begin{array}{l}\text { Broad between the eyes; dishing } \\
\text { Discredit, vs } \frac{1}{8}, \mathrm{~s} \frac{1}{4}, \mathrm{~m} \frac{1}{2}, \mathrm{vm} \frac{3}{6}, \mathrm{e} 1 \text {. }\end{array}$ & 2 & \\
\hline Face & $\begin{array}{l}\text { Of medium length; clean and trim, } \\
\text { especially under the eyes; the } \\
\text { bridge of the nose straight. . } \\
\text { Discredit, } s \frac{1}{8}, \mathrm{~m}_{\frac{1}{2}, \mathrm{e}} \frac{\frac{1}{2}}{2} \text {. }\end{array}$ & 2 & \\
\hline Muzzle & $\begin{array}{c}\text { Broad, with strong lips } \cdot \cdot \cdot \cdot \cdot \cdot \cdot \\
\text { Discredit, } 8 \frac{1}{8}, m_{\frac{1}{4}}, \mathrm{e} \frac{1}{2} .\end{array}$ & 1 & \\
\hline Ears & $\begin{array}{l}\text { Of medium size; of fine texture; the } \\
\text { hair plentiful and soft; the secre- } \\
\text { tions oily and abundant } \\
\text { Discredit, } m \frac{1}{8}, \mathrm{e}^{\frac{1}{2}} \text {. }\end{array}$ & 1 & \\
\hline Eyes & $\begin{array}{l}\text { Large ; full ; mild ; bright } \\
\text { Discredit, s } \frac{1}{8}, \mathrm{~m} \frac{1}{4}, \mathrm{e} \frac{1}{2} .\end{array}$ & 2 & \\
\hline Horns & $\begin{array}{l}\text { Short; of medium size at base ; grad- } \\
\text { ually diminishing toward tips; } \\
\text { oval; inclining forward; moder- } \\
\text { ately curved inward; of fine tex- } \\
\text { ture; in appearance waxy.. } \\
\text { Discredit, } \mathrm{m} \frac{1}{8}, \mathrm{e} \frac{1}{\frac{1}{3} .}\end{array}$ & 1 & \\
\hline Neck & $\begin{array}{l}\text { Long; finely crested (if the animal is } \\
\text { mature); fine and clean at junc- } \\
\text { ture with the head; nearly free } \\
\text { from dewlap; strongly and } \\
\text { smoothly joined to shoulders . } \\
\text { Discredit, vs } \frac{1}{8}, \mathrm{~s}_{\frac{1}{4}}, \mathrm{~m} \frac{1}{2}, \mathrm{vm} \frac{3}{4}, \mathrm{e} 1 .\end{array}$ & 5 & \\
\hline Shoulders & $\begin{array}{l}\text { Of medium height; of medium thick- } \\
\text { ness, and smoothly rounded at tops; } \\
\text { broad and full at sides; smooth } \\
\text { over front } \\
\text { Discredit, vs } \frac{1}{8}, \text { s } \frac{1}{4}, \mathrm{~m} \frac{\mathrm{i}}{2}, \mathrm{vm} \frac{\mathrm{s}}{4}, \mathrm{e} 1 .\end{array}$ & 4 & \\
\hline
\end{tabular}




\begin{tabular}{|c|c|}
\hline Parts & Description \\
\hline Chest & $\begin{array}{l}\text { Deep and low; well filled and smooth } \\
\text { in the brisket; broad between the } \\
\text { forearms; full in the foreflanks (or } \\
\text { through at the heart) }\end{array}$ \\
\hline
\end{tabular}

Crops

Discredit, vs $\frac{1}{3}, \mathrm{~s} \frac{1}{2}, \mathrm{~m} 1$, vm $1 \frac{1}{2}$, e 2 .

Comparatively full; nearly level with the shoulders

Discredit, vs $\frac{1}{3}, \mathrm{~s} \frac{1}{2}, \mathrm{~m}, 1, \mathrm{vm} 1 \frac{1}{2}, \mathrm{e} 2$.

Chine

Strong ; straight; broadly developed, with open vertebræ . . . .

Discredit, vs $\frac{1}{8}, \mathrm{~s} \frac{1}{2}, \mathrm{~m} \frac{1}{2}, \mathrm{vm} \frac{3}{6}, \mathrm{e} 1$.

Barrel

Loin and Hips

Long; well rounded; with large abdomen, strongly and trimly held up

Discredit, vs $\frac{1}{3}, \mathrm{~s} \frac{\mathrm{x}}{2}, \mathrm{~m}$ 1, vm $1 \frac{1}{2}, \mathrm{e}$.

Broad; level or nearly level between hook bones; level and strong laterally; spreading out from the chine broadly and nearly level ; the hook bones fairly prominent . . .

Discredit, vs $\frac{1}{3}, \mathrm{~s} \frac{1}{2}, \mathrm{~m} \frac{1}{2}, \mathrm{vm} \frac{3}{4}, \mathrm{e} 1$.

Rump

Thurl

Quarters

Long; broad; high; nearly level laterally; comparatively full above the thurl; carried out straight to dropping of tail

Discredit, vs $\frac{1}{8}, \mathrm{~s} \frac{1}{3}, \mathrm{~m} \frac{1}{2}, \mathrm{vm} \frac{3}{6}, \mathrm{e} 1$.

High ; broad

Discredit, vs $\frac{1}{3}, \mathrm{~s} \frac{1}{2}, \mathrm{~m} \dot{1}, \mathrm{vm} 1 \frac{1}{2}, \mathrm{e} 2$.

Deep; broad ; straight behind ; wide and full at sides; open in the twist

Discredit, vs $\frac{1}{8}, \mathrm{~s} \frac{1}{3}, \mathrm{~m} \frac{1}{2}, \mathrm{vm} \frac{3}{4}, \mathrm{e} 1$.

Flanks

Legs

Deep ; full

Discredit, vs $\frac{1}{8}, \mathrm{~s} \frac{1}{3}, \mathrm{~m} \frac{\dot{1}}{2}$, vm $\frac{3}{4}$, e $1_{\text {. }}$

Comparatively short; clean and nearly straight ; wide apart ; firmly and squarely set under the body; arms wide, strong and tapering; feet of medium size, round, solid and deep

Discredit, vs $\frac{1}{8}, \mathrm{~s} \frac{1}{3}, \mathrm{~m} \frac{1}{2}, \mathrm{vm} \frac{a_{4}}{4}$, e $1^{\circ}$.

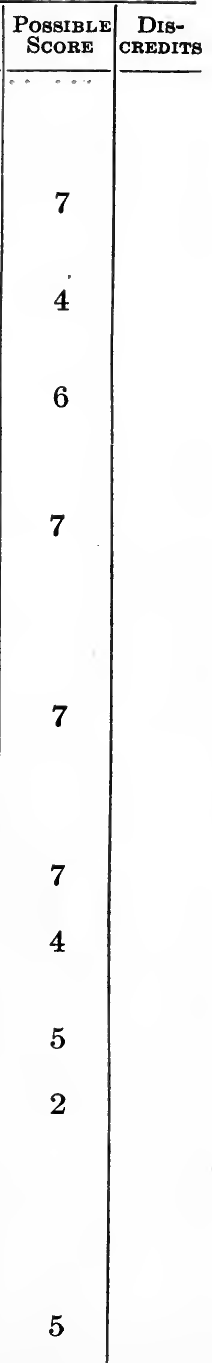




\begin{tabular}{|c|c|c|c|}
\hline Parts & Description & $\begin{array}{l}\text { Possible } \\
\text { Score }\end{array}$ & $\begin{array}{c}\text { Dis- } \\
\text { Cratedrs }\end{array}$ \\
\hline Tail & $\begin{array}{l}\text { Large at base, the setting well back; } \\
\text { tapering finely to switch; the end } \\
\text { of bone reaching to hocks or below; } \\
\text { the switch full } \\
\text { Discredit, } \mathrm{s} \frac{1}{8}, \mathrm{~m} \frac{1}{\frac{1}{2}}, \mathrm{e} \frac{1}{2} .\end{array}$ & 2 & \\
\hline $\begin{array}{l}\text { Hair and } \\
\text { Handling }\end{array}$ & $\begin{array}{l}\text { Hair healthful in appearance; fine, } \\
\text { soft, and furry; skin of medium } \\
\text { thickness and loose; mellow under } \\
\text { the hand; the secretions oily, } \\
\text { abundant, and of a rich brown or } \\
\text { yellow color } \\
\text { Discredit, vs } \frac{1}{4}, 8 \frac{1}{2}, \dot{m} 1 \text {, vm } 1 \frac{1}{2}, \text { e } 2 .\end{array}$ & 10 & \\
\hline $\begin{array}{l}\text { Mammary } \\
\text { Veins. . }\end{array}$ & $\begin{array}{l}\text { Large; full ; entering large orifices; } \\
\text { double extension; with special } \\
\text { development, such as forks, } \\
\text { branches, connections, etc. } \\
\text { Discredit, vs } \mathrm{s} \frac{1}{2}, \mathrm{~m} 1 \text {, vm } 1 \frac{1}{2}, \mathrm{e} 2 .\end{array}$ & 10 & \\
\hline $\begin{array}{l}\text { Rudimen- } \\
\text { tary Teats }\end{array}$ & $\underset{\text { Discredit, vs } \frac{1}{3}, \mathrm{~s} \frac{1}{4}, \mathrm{~m} \frac{1}{2}, \mathrm{vm} \frac{3}{4}, \mathrm{e} 1 .}{\text { Large; well }}$ & 2 & \\
\hline Escutcheon & $\underset{\text { Discredit, vs } \frac{1}{2}, \text { s } 1, \mathrm{~m} 2 \text {, vm } 3, \text { e } 4 .}{\text { Largest }}$ & 2 & \\
\hline $\begin{array}{l}\text { *General } \\
\text { Vigor }\end{array}$ & $\begin{array}{l}\text { For deficiency Inspectors shall dis- } \\
\text { credit from the total received not } \\
\text { to exceed eight points } \cdot \text {. } \\
\text { Discredit, vs } 1, \mathrm{~s} 1, \mathrm{~m} 3, \mathrm{vm} 5 \text {, } 8 .\end{array}$ & & \\
\hline $\begin{array}{l}\text { *General } \\
\text { Symmetry } \\
\text { and Fine- } \\
\text { ness }\end{array}$ & $\begin{array}{l}\text { For deficiency Inspectors shall dis- } \\
\text { credit from the total received not } \\
\text { to exceed eight points } \\
\text { Discredit, vs } 1, \mathrm{~s} 2, \mathrm{~m} 3, \mathrm{vm} 5, \mathrm{e} 8 .\end{array}$ & & \\
\hline $\begin{array}{l}\text { *General } \\
\text { Style and } \\
\text { Bearing }\end{array}$ & $\begin{array}{l}\text { For deficiency Inspectors shall dis- } \\
\text { credit from the total received not } \\
\text { to exceed eight points } \\
\text { Discredit, vs } 1, \mathrm{~s} 2, \mathrm{~m} 3, \mathrm{vm} \text {, e } 8 .\end{array}$ & & \\
\hline $\begin{array}{l}{ }^{*} \text { Credits for } \\
\text { Offspring }\end{array}$ & $\begin{array}{l}\text { A bull shall be credited one point in } \\
\text { excess of what he is otherwise en- } \\
\text { titled to, for each and every animal } \\
\text { of which he is sire actually entered } \\
\text { in the Advanced Register, not to } \\
\text { exceed ten in number }\end{array}$ & & \\
\hline
\end{tabular}




\begin{tabular}{|c|c|c|c|}
\hline Parts & DEscription & $\underset{\text { Score }}{\text { Possible }}$ & $\underset{\text { Dis- }}{\text { DrEDITS }}$ \\
\hline & $\begin{array}{l}\text { * In scaling for the Advanced Reg- } \\
\text { ister, defects caused solely by age, } \\
\text { or by accident, or by disease not } \\
\text { hereditary, shall not be considered. } \\
\text { But in scaling for the show-ring, } \\
\text { such defects shall be considered and } \\
\text { duly discredited } \\
\text { *A bull that in the judgment of the } \\
\text { Inspector will not reach, at full age } \\
\text { and in good flesh, } 1800 \text { lb., live } \\
\text { weight, shall be disqualified for } \\
\text { entry in the Advanced Register . } \\
\text { * No bull shall be received to the } \\
\text { Advanced Register that, with all } \\
\text { credits due him, will not scale, in the } \\
\text { judgment of the Inspector, at least } \\
80 \text { points. (See amendment to Rule } \\
\text { IV, an exception to these require- } \\
\text { ments.) }\end{array}$ & . & \\
\hline & \multirow[b]{2}{*}{ Net score $\cdot$ : $\cdot$. } & 100 & \\
\hline & & & \\
\hline
\end{tabular}

* Not now in use by Advanced Register, but of great value as an aid in judging cattle.

$J U D G E$

Ayrshire Cattle - Scale of Points, Adopted 1906

Head Cow

Forehead - broad and clearly defined . . 1

Horns - wide set on and inclining upward . 1

Face - of medium length, slightly dished;

clean cut, showing veins . . . . . . 2

Muzzle - broad and strong without coarse-

ness, nostrils large . . . . . . . . . 1 
Jaws - wide at the base and strong . . . 1

Eyes - full and bright with placid expression 3

Ears - of medium size and fine, carried alert 1 Neck - fine throughout, throat clean, neatly joined to head and shoulders, of good length, moderately thin, nearly free from loose skin, elegant in bearing . . . . . Forequarters

Shoulders - light, good distance through from point to point but sharp at withers, smoothly blending into body . . . . . 2

Chest - low, deep and full between back and forelegs

Brisket - light

Legs and feet - legs straight and short, well apart, shanks fine and smooth, joints firm ; feet medium size, round, solid and deep . . 1 Body

Back - strong and straight, chine lean, sharp and open-jointed . . . . . . . . . . . 4

Loin - broad, strong and level . . . . . 2

Ribs - long, broad, wide apart and well sprung

Abdomen - capacious, deep, firmly held up with strong muscular development . . . 3

Flank - thin and arching . . . . . . 1 Hindquarters

Rump - wide, level, long from hooks to pin bones, a reasonable pelvic arch allowed . . 3 Hooks - wide apart and not projecting above back nor unduly overlaid with fat . . . 2

Pin bones - high, wide apart . . . . . 1

Thighs - thin, long and wide apart . . . 2

Tail - fine, long and set on level with back . 1

Legs and feet - legs strong, short, straight, when viewed from behind, and set well apart; shanks fine and smooth, joints firm, feet medium size, round, solid and deep 2 Udder - Long, wide, deep but not pendulous nor fleshy; firmly attached to the body, extending well up behind and far forward; quarters even; sole nearly level and not indented between teats, udder veins well developed and plainly visible . . . . 
Teats - evenly placed, distance apart from side to side equal to half the breadth of udder, from back to front equal to one third the length; length $2 \frac{1}{2}$ to $3 \frac{1}{2}$ inches, thickness in keeping with length, hanging perpendicular and not tapering

Mammary Veins - large, long, tortuous, branching and entering large orifices . . . . .

Escutcheon - distinctly defined, spreading over thighs and extending well upward

Color - red of any shade, brown, or these with white; mahogany and white, or white; each color distinctly defined. [Brindle markings allowed but not desirable] . .

\section{Covering}

Skin - medium thickness, mellow and elastic 3

Hair - soft and fine

Secretions - Oily, of rich brown or yellow color

Style - alert, vigorous, showing strong character; temperament inclined to nervousness but still docile

Weight - at maturity not less than one thousand pounds

Total

\section{Bull}

Head

Forehead - broad and clearly defined . . . 2

Horn - strong at base, set wide apart, inclining upward

Face - of medium length, clean cut, showing facial veins . . . . . . . . . . . 2

Muzzle - broad and strong without coarseness

Nostrils - large and open . . . . . . . 2

Jaws - wide at the base and strong . . . 1

Eyes - moderately large, full and bright . 3 Ears - of medium size and fine, carried alert 1 Expression - full of vigor, resolute and masculine 1 
Neck

Of medium length, somewhat arched, large and strong in the muscles on top, inclined to flatness on sides, enlarging symmetrically toward the shoulders, throat clean and free from loose skin

Forequarters

Shoulders - strong, smoothly blending into body with good distance through from point to point and fine on top

Chest - low, deep and full between back and forelegs

Brisket - deep, not too prominent and with very little dewlap

Legs and feet - legs well apart, straight and short, shanks fine and smooth, joints firm, Body feet of medium size, round, solid and deep 2

Back - short and straight, chine strongly developed and open jointed . . . . . 5

Loin — broad, strong and level . . . . 4

Ribs - long, broad, strong, well sprung and wide apart

Abdomen - large and deep, trimly held up, with muscular development

Flank - thin and arching . . . . . . 1

Hindquarters

Rump - level, long from hooks to pin bones 5

Hooks - medium distance apart, proportionately narrower than in female, not rising above the level of the back

Pin bones - high, wide apart

Thighs - thin, long and wide apart . . . 4

Tail - fine, long and set on level with back 1

Legs and feet - legs straight, set well apart, shanks fine and smooth, feet medium size, round, solid and deep, not to cross in walking

Scrotum - well developed and strongly carried Rudimentaries, Veins, etc.-Teats of uniform size, squarely placed, wide apart and free from scrotum ; veins long, large, tortuous, with extensions entering large orifices; escutcheon pronounced and covering a surface. 
Color - red of any shade, brown, or these with white; mahogany and white, or white; each color distinctly defined . . . .

Covering

Skin - medium thickness, mellow and elastic 3

Hair - soft and fine . . . . . . . . . 2

Secretions - oily, of rich brown or yellow color 1

Style - active, vigorous, showing strong mas-

culine character, temperament inclined to

nervousness but not irritable or vicious

Weight - at maturity not less than 1500 pounds

Total .

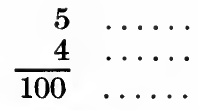

\section{Brown Swiss Cattle - Scale of Points}

\section{Cow and Heifer}

No.

No. of

1 Head, medium size and rather long

2 Face, dished, narrow between horns and wide between eyes

3 Ears, large, fringed inside with light-colored hair, skin inside of ear a deep orange color

4 Nose, black, large and square with mouth surrounded by mealy-colored band, tongue black . . . . . 2

5 Eyes, moderately large, full and bright . . . . . 2

6 Horns, short, regularly set with black tips . . . .

7 Neck, straight, throat clean, neatly joined to head, shoulders, of good length, moderately thin at the withers

8 Chest, low, deep and full between and back of forelegs

9 Back, level to setting of tail and broad across the loin

10 Ribs, long and broad, wide apart and well sprung, with thin, arching flanks

Abdomen, large and deep

Hips, wide apart, rump long and broad

Thighs, wide, quarters not thin . . . . . . .

Legs, short and straight with good hoofs . . .

Tail, slender, well set on, with good switch . . .

17 Color - shades from dark to light brown, at some seasons of the year gray; white splashes near udder not objectionable, light stripe along back. White splashes on body or sides objectionable. Hair between horns usually lighter shade than body . . 
No.

No. of

Points

18 Fore udder, wide, deep, well rounded but not pendulous, nor fleshy, extending far forward on the abdomen

19 Rear udder, wide, deep, but not pendulous, nor fleshy, extending well up behind . . . . . . . . . . 12

20 Teats, rather large, set well apart and hanging straight

21 Milk, veins large, long, tortuous, elastic and entering good wells

22 Disposition quiet

23 Size, evidence of constitution, and stamina . . .

\section{Bull}

1 Head, same as cow . . . . . . . . . . . . 2

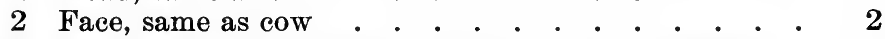

3 Expression, full of vigor, resolution and masculinity . 3

4 Ears, same as cow . . . . . . . . . . . . 2

5 Nose, same as cow . . . . . . . . . . . . . . 2

6 Eyes, same as cow . . . . . . . . . . . . 2

7 Horns, same as cow

8 Neck, of medium length, somewhat arched, large and strong in muscles on top, sloping symmetrically to shoulders. Shoulders large and strong, smoothly blending into body

9 Chest, same as cow

10 Back, same as cow

11 Ribs and abdomen, same as cow

12 Hips, same as cow

13 Thighs, same as cow

14 Legs, same as cow

15 Tail, same as cow

16 Hide, same as cow

17 Color, same as cow

18 Scrotum, well developed and strongly carried $\cdot \dot{*} \cdot$

19 Rudimentary teats, squarely placed, wide apart and free from the scrotum

20 Milk veins, same as cow

21 Disposition quiet

22 Size, evidence of constitution and stamina 


\section{Dotch Belted Cattle - Scale of Points \\ Cow}

1. Body. - Color black, with a clearly defined conPerfect tinuous white belt, the belt to be of medium width, beginning behind the shoulders and extending nearly to the hips . . . . . . . . . . .

2. Head. - Comparatively long and somewhat dishing; broad between the eyes; poll, prominent; muzzle, fine; tongue, dark . . . . . . . .

3. Eyes. - Black, full and mild. Horns. - Long compared with their diameter . . . . . . .

4. Neck. - Fine, and moderately thin, and should harmonize in symmetry with the head and shoulders

5. Shoulders. - Fine at the top, becoming deep and broad as they extend backward and downward, with a low chest

6. Barrel. - Large and deep with well-developed abdomen; ribs well rounded and free from fat . .

7. Hips. - Broad; chine level, with full loin . . .

8. Rump. - High, long and broad . . . . . .

9. Hindquarters. - Long and deep, rear line incurving. Tail. - Long, slim, tapering to a full switch . . .

10. Legs. - Short, clean, standing well apart . . . .

11. Udder. - Large, well developed front and rear, teats of convenient size and wide apart; mammary veins large, long and crooked, entering large orifices .

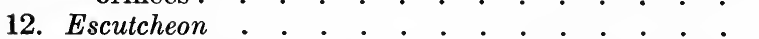

13. Hair. - Fine and soft ; skin of moderate thickness, of a rich dark or yellow color . . . . . . . 3

14. Quiet disposition and free from excessive fat $\cdot{ }^{\cdot} \quad 4$

15. General condition and apparent constitution . . 6

Perfection . . . . . . . . . . . . $\overline{100}$

\section{Bull}

The scale of points for males shall be the same as that given for females, except that No. 11 shall be omitted and the bull shall be credited 10 points for size and widespread placing of rudimentary teats, and 10 additional points for perfection of belt. 


\section{Kerry Cattle - Scale of Points}

\section{Cow}

General formation and character, head, horns and hair

Udder, size, shape, situation of teats, milk veins and escutcheon, etc.

Quality and touch

Color

Perfect

30 points

40 points

20 points

20 points

100 points

\section{Bull}

General formation and character

Head, horns and hair .

Quality and touch

Color

Perfect

25 points

25 points

20 points

30 points

100 points

\section{Dexter Cow}

Head, neck and horns

Body, top line, under line, ribs, setting on of tail, Bag shortness of leg, etc.

Quality and touch

Color

Perfect

15 points

25 points

40 points

10 points

10 points

100 points

\section{Dexter Bull}

General formation and character

25 points

Head, horns and hair

Quality and touch

Color

25 points

20 points

30 points

Perfect

100 points 


\section{Devon Cattle - Scale of Points}

Cow

Head, moderately long, with a broad indented forehead, tapering considerably towards the nostrils; the nose of a flesh color, nostrils high and open, the jaws clean, the eye bright, lively and prominent, and surrounded by a flesh-colored ring, throat clean, ears thin, the expression gentle and intelligent; horns matching; spreading and gracefully turned up, of a waxy color, tipped with a darker shade

Neck, upper line short, fine at head, widening and deep at withers and strongly set to the shoulders . . . . .

Shoulders, fine, flat and sloping, with strong arms and firm joints

Chest, deep, broad, and somewhat circular in character . Ribs, well sprung from the backbone, nicely arched, deep, with flanks fully developed

$B a c k$, straight and level from the withers to the setting on of the tail, loin broad and full, hips and rump of medium width, and on a level with the back . . . . . . .

Hindquarters, deep, thick and square $\dot{0} \cdot \dot{\cdot} \cdot \dot{ } \cdot$ belly and well up behind; teats moderately large, and. squarely placed

Tail, well set on at a right angle with the back, tapering, with a switch of white or roan hair and reaching the hocks

Legs, straight, squarely placed when viewed from behind, not to cross or sweep in walking, hoof well formed . .

Skin, moderately thick and mellow, covered with an abundant coat of rich hair of a red color; no white spot admissible, except the udder

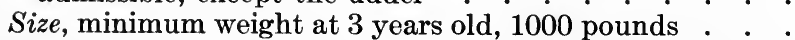

General Appearance, as indicated by stylish and quick movement, form, constitution and vigor, and the under line as nearly as possible parallel with the line of the back

Perfection is 
Bull

Head, masculine, full and broad, tapering toward the nose, which should be flesh-colored; nostrils high and open, muzzle broad, eyes full and placid and surrounded with flesh-colored ring, ears of medium size and thickness, horns medium size, growing at right angles from the head, or slightly elevated, waxy at the base, tipped with a darker shade

Cheek, full and broad at root of tongue. Throat clean . $N e c k$, of medium length and muscular, widening from the head to the shoulders, and strongly set on . . . . .

Shoulders, fine, flat, sloping and well fleshed, arms strong with firm joints

Chest, deep, broad and somewhat circular

Ribs, well sprung from the backbone, nicely arched, deep with flanks fully developed

Back, straight and level from the withers to the setting on of the tail, loin broad and full, hips and rump of medium width and on a level with the back . . .

Hindquarters, deep, thick and square . . . . . .

Tail, well set on at a right angle with the back, tapering, with a switch of white or roan hair and reaching the hocks

Legs, short, straight and squarely placed when viewed from behind, not to cross or sweep in walking, hoof well formed . . . . . . . . . . . . . . . .

Skin, moderately thick and mellow, covered with an abundant coat of rich hair of a red color; no white spot admissible unless around the purse . . . . . . .

Size, minimum weight at 3 years old 1400 pounds . . . General Appearance, as indicated by stylish and quick movement, form, constitution, and vigor, and the under line as nearly as possible parallel with the line of the back

Perfection is 


\section{Red-polled Cattle - Scale of Points}

\section{Cow}

Disqualifications. - Scurs, or any evidence whatever of a horny growth on the head. Any white spots on body above lower line or brush of tail.

1. Color. - Any shade of red. The switch of tail and Perfect udder may be white, with some white running forward to the navel. Nose of a clear flesh color. Interior of ears should be of a yellowish, waxy color.

Objections : An extreme dark or an extreme light red is not desirable. A cloudy nose or one with dark spots.

2. Head. - Of medium length, wide between the eyes, sloping gradually from above eyes to poll. The poll well defined and prominent, with a sharp dip behind it in center of head. Ears of medium size and well carried. Eyes prominent; face well dished between the eyes. Muzzle wide, with large nostrils

Objections : A rounding or flat appearance of the poll. Head too long and narrow.

3. Neck. - Of medium length, clean cut, and straight from head to top of shoulder with inclination to arch when fattened, and may show folds of loose skin underneath when in milking form

4. Shoulder. - Of medium thickness and smoothly laid, coming up level with line of back

Objections: Shoulder too prominent, giving the appearance of weakness in heart girth; shoulder protruding above line of back.

5. Chest. - Broad and deep, insuring constitution. Brisket prominent and coming well forward

ack and ribs. - Back medium long, straight and level from withers to setting on of tail, moderately wide, with spring of ribs starting from the backbone, giving a rounding appearance, with ribs flat and fairly wide apart

Objections : Front ribs too straight, causing depression back of shoulders. Drop in back or loin below the top line.

7. Hips. - Wide, rounding over the hooks, and well covered

8. Quarters. - Of good length, full, rounding and level ; thighs wide, roomy and not too meaty 
Objections: Prominent hooks and sunken quarters.

9. Tail. - Tail head strong and setting well forward, long and tapering to a full switch . . . . . . 2

10." Legs. - Short, straight, squarely placed, medium bone

Objections: Hocks crooked; legs placed too close together.

11. Fore udder. - Full and flexible, reaching well forward, extending down level with hind udder . .

12. Hind udder. - Full and well up behind . . . . .

13. Teats. - Well placed, wide apart and of reasonably good size

Objections: Lack of development, especially in forward udder. Udder too deep, "bottle shaped" and teats too close together. Teats unevenly placed and either too large or too small.

14. Milk veins. - Of medium size, full, flexible, extending well forward, well retained within the body; milk wells of medium size

15. Hide. - Loose, mellow, flexible, inclined to thickness, with a good full coat of soft hair . . . . . .

Objections : Thin, papery skin or wiry hair.

16. Condition. - Healthy; moderate to liberal flesh evenly laid on; glossy coat; animal presented in good bloom

Perfection

\section{Bull}

Disqualifications. - Scurs, or any evidence whatever of a horny growth on the head. Any white spots on body above lower line or brush of tail.

1. Color. - Any shade of red. The switch of tail may be white, with some white running forward to the navel. Nose of a clear flesh color. Interior of ears should be of a yellowish, waxy color . . . .

Objections : An extreme dark or an extreme light red is not desirable. A cloudy nose or one with dark spots.

2. Head. - Wide, strong and masculine, relatively short. Poll stronger and less prominent than in cow. Ears of medium size and well carried; eyes prominent; muzzle wide with large nostrils . . . 
Objections: Long, narrow, or lacking in masculine character

3. Neck. - Of medium length, full erest, of good thickness, strong, of masculine appearance

4. Shoulder. - Of medium thickness and smoothly laid, coming up level with line of back . . . . . .

Objections: Shoulder too prominent, giving the appearance of weakness in heart girth; shoulder protruding above line of back.

5. Chest. - Broad and deep, insuring constitution. Brisket prominent and coming well forward

6. Back and ribs. - Back medium long, straight and level from withers to setting on of tail, moderately wide, with spring of ribs starting from the backbone, giving a rounding appearance, with ribs flat and fairly wide apart . . . . . . . . .

Objection: Front ribs too straight, causing depression back of shoulders. Drop in back or loin below the top line.

7. Hips. - Wide, rounding over the hooks, and well covered

8. Quarters. - Of good length, full, rounding and level; thighs wide and moderately full, deep . . . . .

Objections: Prominent hooks, sunken quarters.

9. Tail. - Tail head strong and setting well forward, long and tapering to a full switch . . . . . .

10. Legs. - Short, straight, squarely placed, medium bone

Objection : Hocks crooked; legs placed too close together.

11. Rudimentaries. - Large, wide apart, and placed well forward

Position of rudimentaries . . . . . . . . .

Objections: Rudimentaries placed back on scrotum, or placed too close together, indicating tendency to transmit badly formed udders.

12. Hide. - Loose, mellow, flexible, inclined to thickness, with good full coat of soft hair

Objections: Thin, papery skin or wiry hair.

13. Condition. - Healthy; moderate to liberal flesh evenly laid on; glossy coat; animal presented in good bloom

Perfection 
Sotthdown Sheep - Standard of Excellence

Head. - Medium in size and hornless, fine, carried well up, the forehead or face well covered with wool, especially between the ears and on the cheeks, and in the ewe slightly dished.

Lips and Under Jaw. - Fine and thin -

Ears. - Rather small, tolerably wide apart, covered with fine hair, and carried with a lively back and forth movement

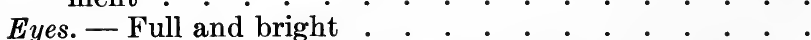
Face. - A uniform tint of brown, or gray, or mouse color . Neck. - Short, fine at the head, but nicely tapering, and broad and straight on top at the shoulders . . . . Shoulders. - Broad and full, smoothly joining the neck with the back . . . . . . . . . . . . .

ast. - Wide, deep and projecting well forward, the forelegs standing wide apart . . . . . . . . . .

Back and Loin. - Broad and straight from shoulders to rump Ribs. - Well arched, extending far backward, the last projecting more than the others

Rump. - Broad, square and full, with tail well set up . . Hips. - Wide, with little space between them and last ribs Thighs. - Full and well let down in twist, the legs standing well apart

Limbs. - Short and fine in bone, and in color to agree with the face... . . . . . . . . . . . . .

Forelegs. - Well wooled and carrying mutton to the knees,

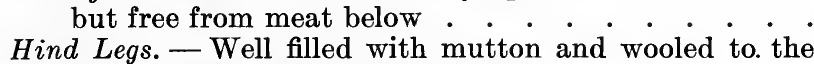
hocks, neat and clean below . . . . . . . . . Belly. - Straight and covered with wool, the flank extending so as to form a line parallel with the back or top line

Fleece. - Compact, the whole body well covered with moderately long and close wool white in color, carrying some yolk

Form. - Throughout smooth and symmetrical, with no coarseness in any part . . . . . . . . . . .

General Appearance. - Spirited and attractive, with a determined look, a proud and firm step, indicating constitutional vigor and thorough breeding 


\section{Shropshire Sheep - Scale of Points}

\section{Type and General Appearance}

An alert, attractive, and stylish appearance, showing at a glance the true characteristies of the Shropshire. $\quad 30$ Points.

\section{Form and Constitution}

Head. - To impress at once the Shropshire characteristics. Heads of Rams. - To be masculine as indicated by a broad nostril, short, broad between ears and eyes.

Neck. - Short and muscular, fitting into shoulders in graceful outlines.

Heads of Ewes. - To be feminine in appearance, medium in length, but not delicate.

Neck. - Not so strong as in the ram.

In all cases head and face nicely covered with wool ; ears, short and erect; eyes, bright; color of face, brown to a clear dark (not sooty) black.

Body. - Well proportioned, with shoulders so placed as to fit in evenly to a deep wide brisket. A full heart-girth ; broad, level back; ribs well sprung, with straight under line; loins thick-fleshed; fore and hind flank deep; a low coupled twist, and full leg of mutton.

Legs. - Brown to clear dark color (not sooty black), well set apart, short and straight with strong upright pasterns.

Size. - When fully matured and in proper breeding condition, rams should weigh not less than 175 to 250 pounds and ewes not less than 140 to 180 pounds.

35 Points.

\section{Fleshing}

While the body should be well formed, with the full outline pleasing to the eye, yet it is the quality and quantity of flesh, not fat, which gives value to the carcass. Therefore the parts furnishing the high-priced cuts should be fully developed.

The back, loins and legs should be so fleshed as to show a large percentage of flesh compared with the other parts of the body; at the same time symmetry must prevail throughout. Strong bone in legs conformable with size of body usually goes with a large proportion of lean meat to fat in the finished carcass. 


\section{Fleece and Skin}

Fleece of good length, elastic to the touch, medium fine and slightly crimped, free from black fiber and hairiness. Ram's scrotum to be well covered with wool.

Rams should shear 8 to 15 pounds of wool and ewes 7 to 11 .

Skin to be a bright cherry or clear color and comparatively free from dark spots.

10 Points.

\section{Objections}

Long narrow head with long ears and neck; long legs; black wool on head to any noticeable extent; failure of wool to meet closely at the junction of face-wool and on cheeks; white spots on face and legs; crooked spine; light flanks, with long, weak pasterns; spotted skin; narrow chest showing lack of constitution.

\section{Disqualification for Registry}

Such lack of type as to render it doubtful to a breeder what the breed is; Horns or Stubs, not Scurs. Heads quite bare of wool.

\section{Oxford Down Sheep - Scale of Points}

1. Form. - Of good general appearance, made by a wellbalanced conformation, free from coarseness in any part and showing good style at. rest and in motion . . . . . . . . . . . . .

2. Head. - Of moderate length and width between the
ears and between the eyes, and well covered with wool over the poll and down to the eyes. Color of face an even dark gray or brown, with or without gray spots on the nose

3. Weight. - When fully matured and in good condition, rams should weigh 250 to 350 pounds ; ewes 180 to 275

4. Ears. - Medium size, not too thick and of an even brown or dark gray color . . . . . . . .

5. Legs. - Short, strong in bone, flat and even, brown or dark gray color, placed squarely under the body and well apart. 
6. Girth. - Large around the heart and wide and full in the chest . . . . . . . . . . . . . . 10

7. The Movement must be bold and vigorous . . . . 5

8. Eyes. - Bold, prominent and bright . . . . . . 4

9. Skin. - Bright pink in color . . . . . . . . 3

10. Neck. - Strong and muscular in rams, and well set on in both sexes . . . . . . . . . . . . . 3

11. Back. - Wide and straight on top of shoulders and back, loin and rump, from base of neck to tail . .

12. Full Shoulders and Thighs. - Well meated inside and out . . . . . . . . . . . . . . 5

13. Flanks. - Well filled and strong, so as to make the lower line of the body as straight as possible and

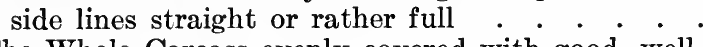

14. The Whole Carcass evenly covered with good, wellmarbled meat . . . . . . . . . . . .

15. Fleece. - Of moderate length, close and of even quality, covering the whole carcass well, and free from black patches on the body, neck or head . . 15

Perfection . . . . . . . . . . . . . 100

\section{Hampshire Sheep - Standard of Excellence}

\section{Head and Legs}

Head. - Moderately large, but not coarse; well covered with wool on forehead and cheeks.

Nostrils. - Wide.

Color (head and legs). - Dark brown or black.

Eyes. - Prominent and lustrous.

Ears. - Moderately long and thin, and dark brown or black color.

Legs - Well under outside of body, straight, with good size of bone, black.

\section{Neck, Shoulders and Chest}

Neck. - A regular taper from shoulders to head, without any hollow in front of shoulders, set high up on body.

Shoulders. - Sloping, full, and not higher than the line of back and neck.

Chest. - Deep and full in the heart place, with breast prominent and full. 


\section{Body}

Back. - Straight, with full spring of rib.

Loin. - Wide and straight, without depression in front of hips. Quarters. - Long from hips to rump, without sloping, and deep in thigh. Broad in hips and rump, with full hams. Inside of thigh full.

Scale of Points

Head. - Size and shape, 5; ears and eyes, 3 ; color, 5; legs and feet, 2

Neck, Shoulders and Breast. - Neck; 5; shoulders, 10; chest and breast, 15 .

Body. - Back and loins, 15; rib, 5 . . . . . . . . 20

Quarters. - Length, 10 ; width, 10 ; twist, 5 . . . . . . 25

Wool. - Forehead and cheeks, 2; belly, well covered, 3;

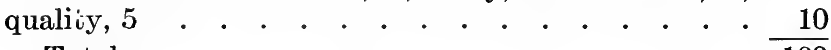

Total . . . . . . . . . . . . . . . 100

\section{Dorset Sheep - Scale of Points}

Head. - Neat, face white, nostrils large, well covered on crown and under jaws with wool . . . . . .

Horns. - Small and gracefully curving forward rather close to jaw

Eyes. - Prominent and bright

Ears. - Medium size covered with short white hair . . . 2

Neck. - Short, symmetrical, strongly set on shoulders, gradually tapering to junction of head . . . . . .

Shoulders. - Broad and full, joining neck forward and chine backward with no depression at either point (important). . . . . . . . . . . . . . . 15

Brisket. - Wide and full, forward, chest full and deep . . Foreflank. - Quite full, showing little depression behind shoulder

Back and Loin. - Wide and straight, from which ribs should spring with a fine, circular arch . . . . .

Quarters. - Wide and full, mutton extending down to hocks

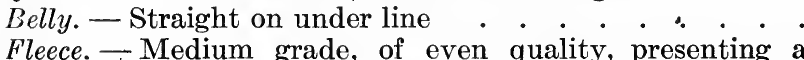
smooth surface and extending over belly and well down on $\operatorname{legs}$. . . . . . . . . . . . .

General Conformation. - Of the mutton type, body moderately long; short, stout legs, placed squarely under body, skin pink, appearance attractive 


\section{Cheviot Sheep - Standard for Judging}

General Conformation and Quality. - Deep and full breast and large through chest. Back, wide and straight with wellsprung, deep ribs, legs well placed and leg of mutton full and thick. Body well fleshed, skin pink with no blue or dark coloring, fleece compact and medium fine, bone strong and fine, general appearance graceful, symmetrical, active 20 points.

Size. - In good flesh when fully matured a twenty months' old ram should weigh not less than 200 pounds, and a ewe not less than 130 pounds -10 points.

Head. - Should be free from horns or scurs of any length. It should be medium length and broad, with ample breadth between the eyes. Ears should be of medium length and usually erect when at repose. Head covered with clean white hairs, extending from nostrils to back of poll. Ridge of head from between eyes to nostrils straight or slightly arched in female and more strongly arched or Roman in rams. Color of tip of nose black. -15 points.

Body. - Well proportioned, having notable depth, with thickness on top and at flanks. Loins should be very broad and thick, shoulders should set well back and be smoothly covered, and crops be full and well arched. The rump should be long, broad and level. -20 points.

Legs. - Should be short, well set apart and be covered with clean white hair, with no wool below hocks and knees. The hind legs should be flat and deep below hocks. Pasterns should be strong and not show weakness, supporting the body well. -10 points.

Feet. - Symmetrical, squarely placed when in repose and hoofs black in color. -5 points.

Fleece. - Should cover the body completely to behind the poll and ears and down to knees and hocks. Under part of the body should be well covered. In mature animals should be not less than three inches long for annual growth and be compact and of medium wool class. Rams should shear at least 12 pounds and ewes 8 when in mature form, to be desirable representatives of the breed. -20 points.

\section{Objections}

Scurs on the head, flesh-colored skin about the nostrils, hair about the thighs or kemp on the body, reddish or sandy hair on head or legs, lack of wool on under part of body. 


\section{Disqualifications}

All male lambs shall be ineligible to registration, if having scurs or horns exceeding one inch in length.

\section{Leicester Sheep - Scale of Points}

1. Head. - Long, moderately small, tapering towards the muzzle; white and well covered with hair;

lips and nostrils black .
2. Nose. - Somewhat narrow, almost straight in ewes, and slightly Roman in rams . . . . . .

3. Face. - Having a wedge-shaped appearance, well covered with fine white hairs

4. Ears. - Thin, rather long, mobile and directed backward ; a black speck on face and ears not uncommon

5. Eyes. - Large and prominent

6. Neck. - Strong and moderately short, level with the

back and broad at the base where it leaves the chest, gradually tapering toward the head, being fine where head and neck join; neck straight from chest, showing a straight line from rump to poll .

7. Breast. - Deep, broad and full

8. Shoulders. - Upright, wide across the top, giving good thickness through the heart . . . . . . .

9: Chest. - Well filled behind the shoulder, with large girth

10. Back. - Broad and well fleshed, ribs well sprung, loins wide, hips level, quarters straight and long . . .

11. Barrel. - Round, well-ribbed home, straight lines above and below . . . . . . . . . . . .

12. Legs. - Of moderate length, fairly large and wide apart, with strong flat bone, covered with white hair; brown hair or spots objectionable . . . .

13. Flesh. - Firm, springy pelt; pink skin . . . . .

14. Fleece. - Fine, uniform and sound in staple, curly, with good, bright luster and no dark hairs or kemp, belly well covered

15. Carcass. - Rectangular, legs well set on, hocks straight, pasterns good, with neat feet, good general appearance

Perfection 
1. Constitution. - Body deep, back wide and straight, wide and full in the thigh; bright large eyes ; skin soft and pink

2. Size. - Matured rams not less than 250 pounds, when in good condition; ewes 200 pounds or over .

3. Appearance. - Good carriage and symmetry of form

4. Body. - Well proportioned, good bone, good length; broad hindquarters, legs standing wide apart;

5. Head. - Covered with wool to the ears, tuft on the forehead; eyes expressive, ears fair length, dotted or mottled in color

6. Neck. - Medium length, good muscle, good shape, well set on body

7. Legs. - Broad and set well apart, good shape; color white, but some black spots do not disqualify, wooled to the knees

8. Fleece. - Of even length and quality over the body, not less than eight inches for one year's growth .

9. Quality of Wool. - Rather fine long wool, strong, lustrous fiber; no tendency to cot .

Perfection

Cotswold Sheep - Standard of Excellence and Scale of PoInts

For Cotswold Ram - Head not too fine, moderately small and broad between the eyes and nostrils, but without a short, thick appearance, and in young animals well covered on the crown with long, lustrous wool . . .

Face. - Either white or slightly mixed with gray, or white dappled with brown

Nostrils. - Wide and expanded; nose dark . . . . .

Eyes. - Prominent but mild looking . . . . . . . .

Ears. - Broad, long, moderately thin and covered with short hair

Collar. - Full from breast and shoulders, tapering gradually all the way to where the neck and head join. The neck should be short, thick and strong, indicating constitutional vigor, and free from coarse and loose skin '. Shoulders. - Broad and full, and at the same time join so gradually to the collar forward and chine backward as not to leave the least hollow in either place 
Forelegs. - The mutton on the arm or forethigh should

come quite to the knee. Leg upright with heavy bone,

being clear from superfluous skin, with wool to fetlock, and may be mixed with gray

Breast. - Broad and well forward, keeping the legs wide apart; girth or chest, full and deep . . . . . . Foreflank. - Quite full, not showing hollow behind the shoulders

Back and Loin. - Broad, flat and straight, from which the ribs must spring with a fine circular arch . . . . . 12 Belly. - Straight on under line.

Quarters. - Long and full, with mutton quite down to the hock . . . . . . . . . . . . . . Hock. - Should stand neither in nor out . . . . . . Twist or Junction inside the Thighs. - Deep, wide and full, which, with a broad breast, will keep the legs open and upright . . . . . . . . . . . . . . . .

Fleece. - The whole body should be covered with long, lustrous wool . . . . . . . . . . . . . . . . 18 Total . . . . . . . . . . . . . $\overline{100}$

For Cotswold Ewe. - Head moderately fine, broad between the eyes and nostrils, but without a short, thick appearance, and well covered on crown with long, lustrous wool

Face. - Either white or slightly mixed with gray, or white dappled with brown . . . . . . . . . . . 4 Nostrils. - Wide and expanded; nose dark . . . . . 1 Eyes. — Prominent but mild looking . . . . . . . . 2

Ears. - Broad, long, moderately thin, and covered with short hair

Collar. - Full from breast and shoulders, tapering gradually all the way to where the neck and head join; the neck should be fine and graceful, and free from coarse and loose skin

Shoulders. - Broad and full, and at the same time join so gradually to the collar forward and chine backward as not to leave the least hollow in either place. . . . .

Forelegs. - The mutton on the arm or forethigh should come quite to the knee; leg upright with heavy bone, being clear from superfluous skin, with wool to fetlock, and may be mixed with gray . . . . . . . 
Breast. - Broad and well forward, keeping the legs wide apart; girth or chest, full and deep

Foreflank. - Quite full, not showing hollow behind the shoulder.

Back and Loin. - Broad, flat and straight, from which the ribs must spring with a fine circular arch . . . . .

Belly. - Straight on under line

Quarters. - Long and full, with mutton quite down to the hock

Hock. - Should stand neither in nor out

Twist or Junction inside the Thighs. - Deep, wide and full,

which, with a broad breast, will keep the legs open and upright

Fleece. - The whole body should be covered with long, lustrous wool

Total

\section{Berkshire Swine - Standard of Excellence}

Color. - Black, white feet, face and tip of tail, but skin and hair occasionally showing tinge of bronze or copper color. An occasional splash of white not objectionable; lack of either of white points admissible . . . .

Face and Snout. - Face well dished and broad between eyes.

Snout short and broad

Eyes. - Prominent, clean, clear, large, dark hazel or gray

Ears. - Medium size, setting well apart, carried fairly erect, inclining forward, especially with age . . . . . . Jowl. - Full, firm, not flabby or hanging too low, running back well on neck

Neck. - Full, short and slightly arched; broad on top;

well connected with shoulder .

Hair. - Fine, straight, smooth, lying close to and covering the body well. Free from bristles

Skin. - Smooth and mellow

Chest. - Deep, full and wide, with good heart girth . .

Shoulder. - Smooth and even on top and in line with side .

Side. - Deep, smooth, well let down; straight side and bottom lines

Back. - Broad, full, strong, level or slightly arched; ribs

well sprung . 
Perfect SCORE

Flank. - Extending well back and low down on leg, making nearly a straight line with lower part of side . . . . 5

Loin. - Full, wide and well covered with flesh . . . . 6

Ham. - Deep, wide, thick and firm, extending well up on back and holding thickness well down to hock . .

Tail. - Well up on line with back; neither too fine, short, nor tapering . . . . . . . . . . . .

Legs and Feet. - Straight and strong, set wide apart, short in pastern, with hoofs nearly erect, capable of carrying great weight

Size. - Size all that is possible without loss of quality or symmetry, with good length. Weight in good condition : boars at 12 months, 350 to $450 \mathrm{lb}$; ; at 24 months, 500 to $700 \mathrm{lb}$.; sows at 12 months, 350 to $400 \mathrm{lb}$.; at 24 months, 500 to $700 \mathrm{lb}$. . . . . . . . . . . . 6

Appearance and character. - Vigorous, attractive, of good disposition, firm and easy movement . . . . . .

\section{Poland China Swine-Description and Score Card}

Head and face. - 3 .

Head should be broad, even and smooth between and above the eyes. Slightly dished, tapering evenly and gradually to near the end of the nose. Broad lower jaw, head inclined to shortness but not enough to give appearance of stubby nose. And in male a masculine appearance and expression.

Objections: Head long, narrow between the eyes ; nose uneven and coarse; too large at the muzzle or the head too short; not full or high above the eyes; or too much wrinkled around or above the eyes.

Eyes. - 2 .

Full, clear, prominent and expressive.

Objections : Dull expression, deep set or obscure. Sight impaired by wrinkles, fat, or other cause.

Ears. - 2 .

Ears attached to the head by a short, firm knuckle, giving free and easy action. Standing up slightly at the base to within two thirds of the tip, where a gentle break or drop should occur; in size neither too large nor too small, but even, fine, thin, leaf shape; slightly inclined outward. 
Objections : Large, floppy, straight, upright or coarse; knuckle long, letting the ear drop too close to the head and face, hindering of free use of the ears.

Neck. -2.

Short, wide, even, smooth, well arched. Rounding and full from poll to shoulder, with due regard to the characteristics of the sex.

Objections: Long, narrow, thin and drooping from the shoulder to the poll with unevenness caused by wrinkles or creases.

Jowl. - 2 .

Full, broad, deep, smooth and firm, carrying fullness back near to point of shoulders, and below line of lower jaw so that lower line will be as low as breast bone when head is carried up level.

Objections: Light, flabby, thin and wedge shaped, deeply wrinkled, not drooping below line of lower jaw, and not carrying fullness back to shoulder and brisket.

Shoulder. - 6 .

Broad and oval at top, showing evenness with the back and neck, with good width from the top to the bottom, and even smoothness extending well forward.

Objections : Narrow at top or bottom; not as deep as the body, uneven width. Shields on pigs under eight months of age, or showing too much shield at any age.

Chest. - 12 .

Large, wide, deep and full; even under line to the shoulder and sides with no creases; giving plenty of room for the heart and other organs, making a large girth indicating much vitality. Brisket smooth, even and broad; wide between the legs and extending well forward, showing in front.

Objections : Pinched appearance at the top or bottom, or tucked in back of the forelegs; showing too narrow between the legs; not depth enough back of the shoulder. Brisket uneven, narrow, not prominent:

Back and loin. - 14.

Broad, straight or slightly arched, carrying same width from shoulder to ham, surface even, smooth, free from lumps, creases, or projections; not too long but broad on top, indicating well-sprung ribs; should not be higher at hip than at shoulder and should fill out at junction with side, so that a straightedge placed along at top of side will touch all the way from point of shoulder to point of ham. Should be shorter than lower belly line. 
Objections : Narrow, creased back of shoulders, swayed or hollow, dropping below a straight line; humped or wrinkled; too long or sunfish shaped; loin high, narrow, depressed or humped up; surface lumpy, creased, ridgy or uneven; width at side not as much as shoulder and ham.

Sides and ribs. - 8 .

Sides full, firm and deep, free from wrinkles; carrying size down to belly; even from ham to shoulder; ribs of good length, well sprung at top and bottom.

Objections: Flat, thin, flabby, pinched, not as full at bottom as at top; drawn in at shoulder so as to produce a crease, or pinched and tucked up and in as it approaches the ham; uneven surface; ribs flat or too short.

Belly and flank. - 4 .

Belly broad, straight and full, indicating capacity and room, being about the same or on a level at the flank with the under line of the chest. Under line straight, or nearly so, and free from flabby appearance.

Objections : Belly uneven and flabby, or apparent looseness in the make-up. Pinched up in the flank or flanked too high. Ham and rump. - 10.

Hams broad, full, deep and long from rump to hock. Fully developed above and below, being wide at the point of the hip, carrying width well down to the lower part of the hams. Fleshy, plump, rounding fullness perceptible everywhere. Rump rounding and gradually sloping from the loin to the root of the tail. Broad and well developed all along from loin and gradually rounding to the buttock; lower front part of ham should be full and stifle well covered with flesh. Even width of ham and rump with the back, loin, and body. Even a greater width as to females not objectionable.

Objections: Ham short, narrow, too round or slim. Not filled out above or below, or unshapely for deep meat; not as wide as the body; back or loin too tapering or small. Rump narrow or pointed, not plump or well filled or too steep from loin to the tail.

Legs and feet. - 10.

Legs medium length, straight, heavy bone, set well apart and squarely under body, tapering, well muscled and wide above knee and hock; below hock and knee round and tapering, capable of sustaining weight of animal in full flesh without breaking down; bone firm and of fine texture; pasterns short and nearly upright. Feet firm, short, tough and free from defects. 
Objections : Legs long, slim, coarse, crooked ; muscles small above hock and knee; as large at foot as above knee; pasterns long, slim, crooked or weak; the hocks turned in or out of straight line; legs too close together; hoofs long, slim and weak; toes spreading out or crooked or unable to bear up weight of animal without breaking down.

Tail. -1 .

Tail of medium length and size, smooth and tapering well and carried in a curve.

Objections : Coarse and long, without a curl; or short, crooked or stubby; or too small, fine, uneven, not tapering. Coat. -3 .

Fine, straight, smooth, lying close to and covering the body well; not clipped; evenly distributed over the body.

Objections: Bristles, hair coarse, harsh, thin, wavy or curly; swirls ; standing up; ends of hair split and brown, not evenly distributed over all of the body, except the belly. Clipped coats should be cut 1.5 points.

Color. -2 .

Black with six (6) white points ; tip of tail, four white feet and white in face, or on the nose or on the point of the lower jaw. All to be perceptible without close examination. Splashes of white on the jaw, legs, or flank or a few spots of white on the body not objectionable.

Objections: Solid black, white mixed or sandy spots. Speckled with white hairs over the body; mottled face or white and black; hair mixed, making a grizzly appearance. Size. -10 .

Large for age. Condition, vigor and vitality to be considered. There should be a difference between breeding animals and those kept or fitted for the show of at least 25 per cent in size. In show condition or when fat, weights for the different ages should be about as follows: Boars over two years old, seven hundred (700) pounds. Sows over two years old, six hundred (600) pounds. Boars eighteen months old, six hundred (600) pounds. Sows eighteen months old, five hundred (500) pounds. Boars one year old, four hundred and fifty (450) pounds. Sows one year old, four hundred and fifty (450) pounds. Boars and sows six months old, one hundred and eighty (180) pounds. All hogs in just fair breeding condition, one fourth less for size. The keeping and chance that a young boar has cuts quite a figure in his size and should be considered, other points being equal. Fine quality and size, combined, are desirable. 
Objections : Overgrown, coarse, flabby, loose appearance, gangling, hard to fatten ; too fine, undersize ; short, stubby, inclined to chubby fatness. Not a hardy, robust animal. Action and style. - 3 .

Action vigorous, easy and graceful. Style attractive; high carriage; and in males testicles should be prominent and of about the same size, and yet not too large or pouchy.

Objections: Clumsy, slow, awkward movement; low carriage, waddling or twisting walk. A seeming tired or lazy appearance; not standing erect and firm.

Condition. - 2 .

Healthy, skin clear of scurf, scales and sores; soft and mellow to the touch; flesh fine; evenly laid on and free from lumps and wrinkles. Hair soft and lying close to the body; good feeding qualities.

Objections: Unhealthy, skin scaly, wrinkled, scabby or harsh, flabbiness or lumpy'flesh; too much fat for breeding. Hair harsh, dry and standing up from the body; poor feeders; deafness, partial or total.

Disposition. - 2 .

Lively, easily handled and seemingly kind and responsive to good treatment. turn.

Objections : Cross, sluggish, restless, wild or of a vicious Symmetry of points. -2 .

The adaptation of all the points, size and style combined, to make the desired type or model.

\section{Chester White Swine-Scale of Points}

\begin{tabular}{|c|c|c|c|c|c|c|c|c|}
\hline Head and & d Face & & & & 4 & Feet and $\mathrm{L}$ & Legs & \\
\hline Eyes & -200 & - & • & • & 2 & Tail . . & . & \\
\hline Ears & - & & . & - & 2 & Coat & . & \\
\hline Neck & & - & & - & 2 & Color . & & \\
\hline Jowl - & - & - & . & - & 2 & Size . . & & \\
\hline Shoulders & s & . & . & • & 6 & Action and & Styl & \\
\hline Chest . & & . & . & - & 12 & Condition & . & \\
\hline Back and & d Loin & • & & - & 14 & Disposition & . & \\
\hline Sides and & d Ribs & • & . & - & 9 & Symmetry & . & \\
\hline Belly and & d Flan & & & & 4 & & & \\
\hline Ham and & d Rum & & & & 10 & Total & & \\
\hline
\end{tabular}


Duroc Jersey Swine - Score Card

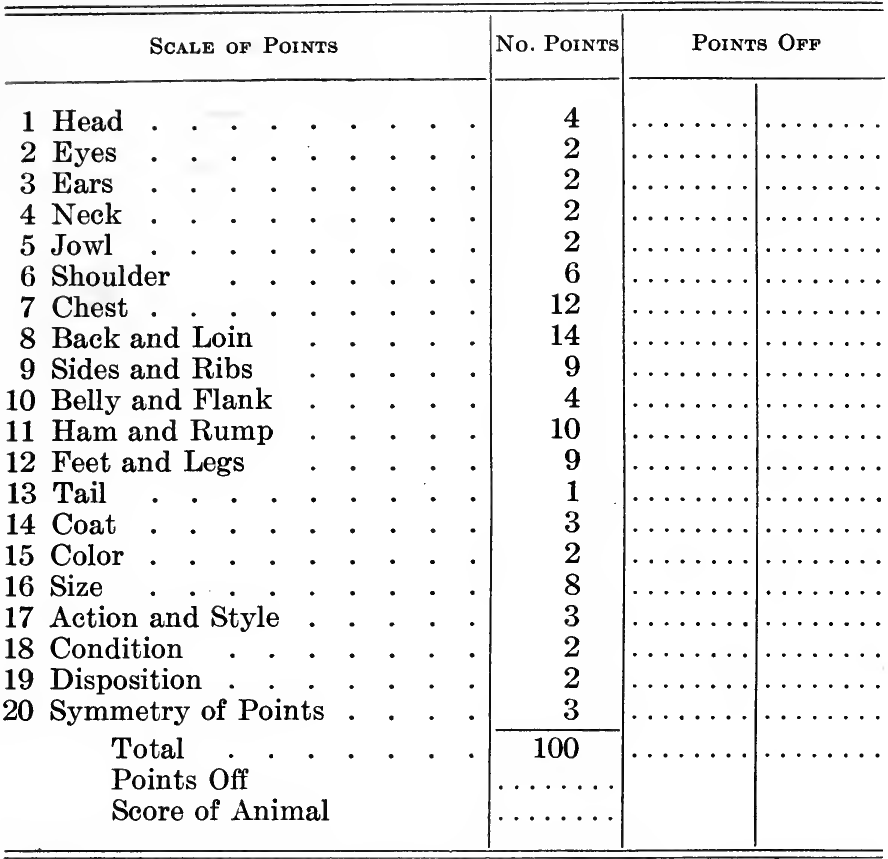

Detailed Description of Chester White Swine

Head and face. - Head short and wide; cheeks neat; jaws broad and strong; forehead medium, high and wide; face short and smooth; nose neat, tapering and slightly dished.

Objections: Head long, narrow or coarse ; cheeks too full ; forehead low and narrow; jaws contracted and weak; face long, narrow and straight; nose coarse, clumsy or dished like a Berkshire.

Eyes. - Bright, large, clear and free from wrinkles or overhanging fat.

Objections : Small, deep set, surrounded by wrinkles or fat. Ears. - Drooping at tip to give graceful appearance; thin; 
soft; pointing outward and forward; well proportioned to size of body.

Objections: Too large and coarse; thick, lopping; lying too near the face; stiff, erect, or too small. Not under control. Neck. - Wide; deep; short and nicely arched; neatly tapering from shoulder.

Objections: Narrow; thin ; long; flat on top; tucked up ; not extending down to breast bone.

Jowl. - Smooth; neat; firm; full; carrying fullness well back to shoulders and brisket when head is carried up level.

Objections: Light; rough and deeply wrinkled; too large and flabby; not carrying fullness back to shoulders and brisket.

Shoulders. - Broad; deep and full; extending in line with the side and carrying size down to line of belly.

Objections : Deficient in width or depth; extending above line of back; thick beyond line of sides and hams ; shields on boars too coarse and prominent.

Chest - Heart girth. - Large, wide, deep and full; even under line to the shoulder and sides with no creases; giving plenty of room for the heart and other organs, making a large girth indicating much vitality. Brisket smooth, even and broad; wide between the legs and extending well forward showing in front.

Objections: Pinched appearance at the top or bottom, or tucked in back of forelegs; showing too narrow between the legs, not depth enough back of the shoulder. Brisket uneven, narrow, not prominent.

Back and loin. - Broad; straight or slightly arched; uniform width; free from lumps or rolls; same height and width at shoulder as at ham.

Objections: Narrow; swayed; humped; creasing back of shoulders; sunfish shaped; uneven width; lumps or rolls. Sides. - Full; smooth; deep; carrying size down to line of belly; even with line of ham and shoulder.

Objections: Flat; thin; flabby; uneven surface; compressed at bottom; shrunken at shoulder and ham.

Ribs. - Long; well sprung at top and bottom; giving animal a square form.

Objections: Too short; flat.

Belly. - Same width as back; full; straight; drooping as low at flank as at bottom of chest; line of lower edge running parallel with sides.

Objections: Narrow; pinched; sagging or flabby. 
Flank. - Full and even with body; equaling heart girth.

Objections: Thin, tucked up or drawn in ; less than heart girth or length of body from top of head to root of tail.

Ham or rump. - Broad; full; long; wide and deep; admitting of no swells; buttock full, neat and clean; stifle well covered with flesh, nicely tapering toward the hock; rump slightly rounding from loin to root of tail, same width as back, making an even line with sides.

Objections: Narrow; short; not filled out to stifle; too much cut up in crotch or twist; not coming down to hock; buttocks flabby; rump flat, narrow, too long, too sharp or peaked at root of tail.

Legs. - Medium length; strong and straight; set well apart and well under body; bone of good size ; firm ; well muscled ; wide above knee and hock, round and tapering below knee and hock, enabling the animal to earry its weight with ease ; pasterns short and nearly upright.

Objections : Too short or too long; weak; crooked; too close together; muscles weak; bone too large and coarse, without taper; pasterns long, crooked or slim.

Feet - Short; firm; tough ; animal standing well up on toes.

Objections: Hoofs long, slim, weak; toes spreading, crooked or turned up.

Tail. - Small ; smooth; nicely tapering; root slightly covered with flesh ; carried in a curl.

Objections : Coarse; too long; clumsy; straight.

Coat. - Fine; either straight or wavy with preference for straight; evenly distributed and covering the body well.

Objections : Bristles; swirls; hair coarse, thin, standing up, not evenly distributed over all the body except the belly.

Color. - White. Red or black spots in hair disqualify, but blue spots in hide (commonly known as freckles), while objectionable and to be discouraged, do not argue impurity of blood.

Objections: Color any other than white.

Size. - Large for age and condition. Boar two years and over, if in good flesh, should weigh not less than 500 pounds; sow same age and condition, not less than 450 pounds. Boars eighteen months old, in good flesh, should weigh not less than 400 pounds; sows, 350. Boars twelve months old, not less than 350 pounds; sows, 300 . Boars and sows six months old not less than 150 pounds each, and other ages in proportion.

Objections: Overgrown, coarse, uncouth, hard to fatten. 
Action. - Easy and graceful; high carriage; active; gentle and easily handled. In males, testicles should be readily seen, and of same size and carriage.

Objections : Sluggish; awkward; low carriage; wild; vicious. In males, testicles not distinctly visible, or not of same size and carriage.

Condition. - Healthy and mellow to touch, fat evenly laid on.

Objections: Harsh to touch, flabbiness, fat in lumps on back or sides.

Disposition. - Quiet and gentle.

Objections : Cross, restless, quarrelsome.

Symmetry or adaptation of points. - The adaptation of all the points, size and style combined to make the desired type or model.

\section{O. I. C. Swine - Scale of Points}

Head and Face . . . . 4 Feet and Legs . . . . 9 Eyes . . . . . . . 2 Tail . . . . . . . 1

Ears . . . . . . . 2 Coat . . . . . . . 3

Neck . . . . . . . 2 Color . . . . . . . 2

Jowl . . . . . . . 2 Size . . . . . . . 8

Shoulders . . . . . 6 Action and Style . . . 3

Chest . . . . . . . 12 Condition . . . . . 2

Back and Loin . . . . 14 Disposition . . . . . 2

Sides and Ribs . . . . 9 Symmetry . 9 . . . 3

Belly and Flank . . . . 4 -

Ham and Rump . . . . 10 Total . . . . . . 100

\section{Detailed Description}

Head and face. - Head short and wide; cheeks neat; jaws broad and strong; forehead medium, high and wide; face short and smooth; nose neat, tapering and slightly dished.

Objections : Head long, narrow, or coarse ; cheeks too full ; forehead low and narrow; jaws contracted and weak; face long, narrow and straight; nose coarse, clumsy or dished like a Berkshire.

Eyes. - Bright, large, clear and free from wrinkles or overhanging fat.

Objections : Small, deep set, surrounded by wrinkles or fat. Ears. - Drooping at tip to give graceful appearance; thin; soft; pointing outward and forward; well proportioned to size of body. 
Objections : Too large and coarse; thick, lopping; lying too near the face; stiff, erect, or too small. Not under control.

Neck. - Wide; deep; short and nicely arched; neatly tapering from shoulder.

Objections : Narrow; thin; long ; flat on top ; tucked up ; not extending down to breast bone.

Jowl. - Smooth; neat; firm; full ; carrying fullness well back to shoulders and brisket when head is carried up level.

Objections : Light; rough and deeply wrinkled ; too large and flabby; not carrying fullness back to shoulders and brisket.

Shoulders. - Broad; deep and full; extending in line with the side and carrying size down to line of belly.

Objections: Deficient in width or depth; extending above line of back; thick beyond line of sides and hams; shields on boars too coarse and prominent.

Chest - Heart girth. - Large, wide, deep and full; even under line to the shoulder and sides with no creases; giving plenty of room for the heart and other organs, making a large girth indicating much vitality. Brisket smooth, even and broad; wide between the legs and extending well forward, showing in front.

Objections: Pinched appearance at the top or bottom, or tucked in back of forelegs; showing too narrow between the legs, not depth enough back of the shoulder. Brisket uneven, narrow, not prominent.

Back and loin. - Broad; straight or slightly arched; uniform width; free from lumps or rolls; same height and width at shoulder as at ham.

Objections : Narrow ; swayed ; humped ; creasing back of shoulders; sunfish shaped; uneven width; lumps or rolls. Sides. - Full; smooth; deep; carrying size down to line of belly; even with line of ham and shoulder.

Objections: Flat; thin; flabby; uneven surface; compressed at bottom; shrunken at shoulder and ham.

Ribs. - Long; well sprung at top and bottom; giving animal a square form.

Objections: Too short; flat.

Belly. - Same width as back; full; straight; drooping as low at flank as at bottom of chest; line of lower edge running parallel with sides.

Objections: Narrow; pinched; sagging or flabby. Flank. - Full and even with body; equaling heart girth. 
Objections: Thin, tucked up or drawn in; less than heart girth or length of body from top of head to root of tail.

Ham and rump. - Broad; full ; long; wide and deep; admitting of no swells; buttock full, neat and clean; stifle well covered with flesh, nicely tapering toward the hock; rump slightly rounding from loin to root of tail, same width as back, making an even line with sides.

Objections: Narrow; short; not filled out to stifle; too much cut up in crotch or twist; not coming down to hock; buttocks flabby; rump flat, narrow, too long, too sharp or peaked at root of tail.

Legs. - Medium length; strong and straight; set well apart and well under body; bone of good size ; firm ; well muscled ; wide above knee and hock, round and tapering below knee and hock, enabling the animal to carry its weight with ease; pasterns short and nearly upright.

Objections : Too short or too long; weak; crooked; too close together; muscles weak; bone too large and coarse, without taper; pasterns long, crooked or slim.

Feet. - Short; firm; tough; animal standing well up on toes.

Objections: Hoofs long, slim, weak; toes spreading, crooked or turned up.

Tail. - Small, smooth; nicely tapering; root slightly covered with flesh; carried in a curl.

Objections : Coarse; too long; clumsy; straight.

Coat. - Fine; either straight or wavy with preference for straight;: evenly distributed and covering the body well.

Objections: Bristles; swirls ; hair coarse, thin, standing up, not evenly distributed over all the body except the belly.

Color. - White. Red or black spots in hair disqualify, but blue spots in hide (commonly known as freckles), while objectionable and to be discouraged, do not argue impurity of blood.

Objections: Color any other than white.

Size. - Large for age and condition. Boar two years and over, if in good flesh, should weigh not less than 500 pounds; sow same age and condition not less than 450 pounds. Boars eighteen months old, in good flesh, should weigh not less than 400 pounds; sows, 350 . Boars twelve months old, not less than 350 pounds; sows, 300 . Boars and sows six months old, not less than 150 pounds each, and other ages in proportion.

Objections: Overgrown, coarse, uncouth, hard to fatten. 
Action. - Easy and graceful; high carriage; active; gentle and easily handled. In males, testicles should be readily seen, and of same size and carriage.

Objections : Sluggish; awkward; low carriage; wild ; vicious. In males, testicles not distinctly visible, or not of same size and carriage.

Condition. - Healthy and mellow touch, fat evenly laid on.

Objections: Harsh to touch, flabbiness, fat in lumps on back or sides.

Disposition. - Quiet and gentle.

Objections : Cross, restless, quarrelsome.

Symmetry or adaptation of points. - The adaptation of all of the points, size and style combined, to make the desired type of model.

\section{Hampshire Swine - Scale of Points}

\section{Disqualifications}

Color. - Spotted, more than two thirds white or solid black. Form. - Any radical deformity, ears very large or drooping over eyes, crooked or weak legs or broken-down feet.

Condition. - Seriously impaired or diseased, excessive grossness, barrenness in animals over two years of age, chuffy or squabby fat.

Size. - Not two thirds standard weight.

Pedigree. - Not eligible to record.

\section{Detailed Description}

1. Head and face. - Head medium length, rather narrow, cheeks not full; face nearly straight and medium width between the eyes, surface even and regular . .

Objections: Head large, coarse and ridgy, nose crooked or much dished.

2. Eyes. - Bright and lively, free from wrinkles or fat surroundings

Objections: Small, deep or obscure, or vision impaired by fat or other cause.

3. Ears. - Medium length, thin, slightly inclined outward and forward

Objections: Large, coarse, thick, large or long knuckle, drooping or not under good control of the animal. 
4. Neck. - Short, well set to the shoulders, tapering from shoulder to head.

Objections: Long, thick or bulky.

5. Jowl. - Light and tapering from neck to point, neat and firm

Objections : Large, broad, deep or flabby.

6. Shoulders. - Deep, medium width and fullness, well in line with back

Objections: Narrow on top or bottom, thick beyond line with sides and hams.

7. Chest. - Large, deep and roomy; full girth, extending down even with line of belly . . . . . . . .

Objections : Narrow at top or bottom; small girth, cramped or tucked up.

8. Back and loin. - Back straight or slightly arched; medium breadth, with nearly uniform thickness from shoulders to hams and full at loins; sometimes higher at hips than at shoulders

Objections: Narrow, creased or drooped behind shoulders; surface ridgy or uneven.

9. Sides and ribs. - Sides smooth, full, firm, carry size evenly from shoulders to hams; ribs strong, well sprung at top and bottom . . . . . . . . .

Objections : Sides thin, flat, flabby or creased or ribs not well sprung.

10. Belly and flank. - Straight and full, devoid of grossness; flank full and running nearly on line with sides .

Objections: Belly sagging or flabby; flank thin or tucked up.

11. Hams and rump. - Hams of medium width, long and deep ; rump slightly rounded from loin to root of tail ; buttock full, neat and firm; devoid of flabbiness or

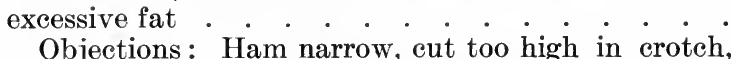
buttock flabby, rump too fat, too narrow or too steep, or peaked at root of tail.

12. Legs and feet. - Legs medium length, set well apart and squarely under body, wide above knee and hock, and rounded and well muscled below, tapering, bone medium, pasterns short and nearly upright, toes short and firm, enabling the animal to carry its weight with ease

Objections : Legs too long, slim, crooked, coarse or short; weak muscles above hock, and knee bone large and coarse, and legs without taper, pasterns too long 
to correspond with length of leg, too crooked or too slender; feet long, slim and weak; toes spreading, too long, crooked or turned up.

13. Tail. - Medium length, slightly curled .

Objections : Coarse, long, clumsy, swinging like a pendulum.

14. Coat. - Fine, straight, smooth

Objections : Bristles or swirls, coarse or curly.

15. Color. - Black, with exception of white belt encircling body, including forelegs

Objections: White running high on hind legs, or extending more than one fourth length of body or solid black.

16. Size. - Large for conditions ; boar, two years and over, 450 ; sow, same age, 400 ; eighteen months boar, 350 ; sow, 325; twelve months boar or sow, 300 ; six months, both sexes, 140

17. Action and style. - Active, vigorous, quick and graceful; style, attractive and spirited

Objections: Dull, sluggish and clumsy.

18. Conditions. - Healthy, skin free from all defects, flesh evenly laid on and smooth and firm, not patchy, and devoid of all excess of grossness .

Objections : Skin scurfy, scaly, mangy or otherwise unhealthy, hair harsh, dwarfed or cramped, not growthy.

19. Disposition. - Docile, quiet and easily handled

Objections : Cross, restless, vicious or with no ambition.

\section{Cheshire Swine - Standard of Excellence}

Head, short to medium in length, short in proportion to length of body; face somewhat dished and wide between the eyes; ears small, erect, in old animals often slightly pointed forward; neck short; shoulders broad and full; hips broad; body long, broad and deep; hams broad, nearly straight with back, and running well down towards hock; legs long and slim, set well apart and supporting the body on the toes; tail small and slim; hair fine, medium in thickness and quantity; color white. When grown and well fattened, should dress from 400 to 600 .

\section{Scale of Points}

1. Head. - Short to medium in length, short in proportion to length of body 
2. Face. - Somewhat dished and wide between the eyes .

3. Jowl. - Medium in fullness . . . . . . . . .

4. Ears. - Small, fine, erect, and in old animals slightly pointing forward

5. Neck. - Short and broad

6. Shoulders. - Broad, full and deep . . . . . . . 6

7. Girth around heart. . . . . . . . . . . . . 8

8. Back. - Long, broad and straight nearly to root of tail 10

9. Side. - Deep and full, nearly straight on bottom line .

10. Flank. - Well back and low down, making flank girth nearly equal to heart girth

11. Hams. - Broad and nearly straight with back, and running down well towards hock

12. Legs. - Small and slim, set well apart, supporting body well on toes

13. Tail. - Small, slim and tapering.

14. Hair. - Fine, medium in thickness and quantity

15. Color. - White, and colored hairs to disqualify

16. Skin. - Fine and pliable, small blue spots objectionable, but allowable

17. Symmetry. - Animal well proportioned, handsome and stylish

Total

Big Black Pig - Scale of Points

Head. - Medium length and wide between the ears

Ears. - Thin, inclined well over the face and not extending beyond point of nose.

Jowl. - Medium size

Neck. - Fairly long and muscular

Chest. - Wide and deep

Shoulders. - Well developed, in line with the ribs . . . 8

Back. - Long and level . . . . . . . . . . . . 15

Ribs. - Well sprung . . . . . . . . . . . . . 5

Loin. - Broad . . . . . . . . . . . . . . . 5

Sides. - Very deep . . . . . . . . . . . . . . . . 8

Belly and flank. - Thick and well developed . . . . . 7

Quarters. - Long, wide and not drooping . . . . . . 8

Hams. - Large and well filled to hocks . . . . . . 10

Tail. - Set high, of moderate size . . . . . . . . 3

Legs. - Short, straight, flat and strong . . . . . . 5

Skin and coat. - Fine and soft, with moderate quantity of straight, silky hair 


\section{Objections}

Head. - Narrow forehead or "dished nose."

Ears. - Thick, coarse or pricked.

Coat. - Coarse or curly, with rose; bristly mane.

Skin. - Wrinkled.

\section{Disqualification}

Color. - Any other than black.

Mule-foot Swine-Score Card

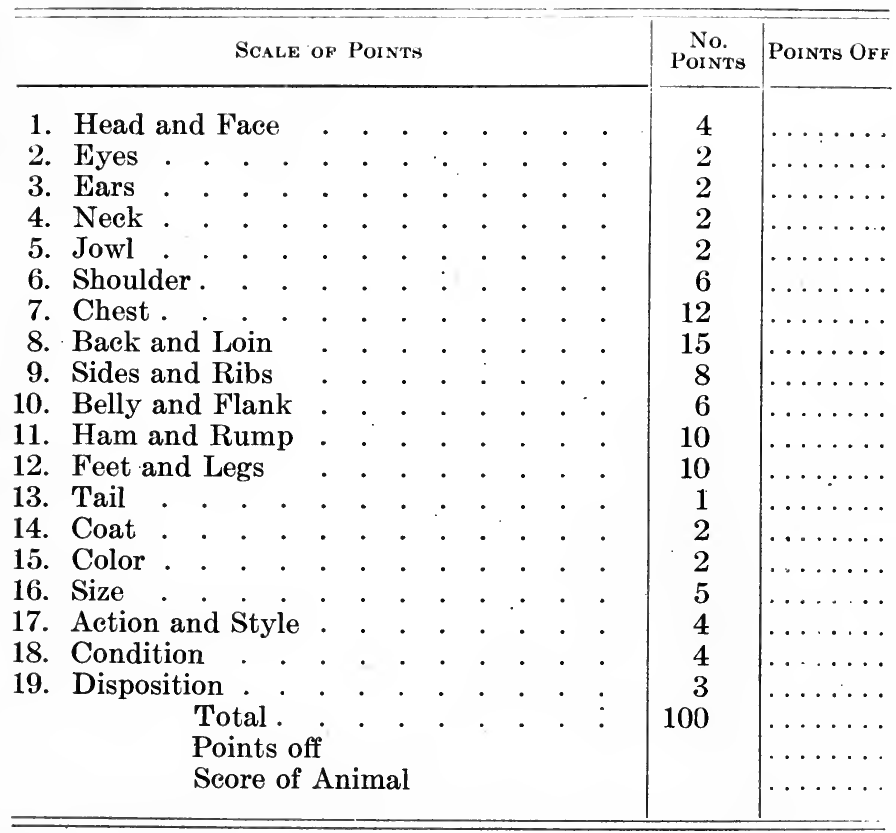

Judge

Date

Breed 


\section{Disqualifications}

Color. - More white than four white points.

Form. - Split or creased hoof ; broken down feet; any radical deformity.

Condition. - Any abnormal condition; barren or blind.

Size. - Not two thirds standard weight.

Pedigree. - Not eligible to record.

\section{Detailed Description}

1. Head and face. - Head medium length. Face broad between eyes, nearly straight, cheeks full, surface even and regular.

Objections: Head large, coarse, crooked or much dished, long nose.

2. Eyes. - Bright and lively, free from wrinkles or fat surroundings.

Objections: Small, deep, or obscure, or vision impaired by fat or other causes.

3. Ears. - Medium length, thin tipped, slightly inclined outward and forward, knuck small and well set to the head.

Objections : Large, coarse, thick, large or long knuck, drooping or not under good control of the animal, or too erect.

4. Neck. - Short, well set to the shoulders, tapering from shoulder to head.

Objections: Long, thick or bulky.

5. Jowl. - Full, neat and firm, tapering from neck to point.

Objections: Thin or flabby.

6. Shoulders. - Medium width, deep, full, not extending above line of back.

Objections: Narrow, cramped, flat, extending above line of back and sloping too much from point to top.

7. Chest. - Large, deep and roomy; full girth, extending down even with line of belly.

Objections: Narrow at top or bottom; small girth, cramped or tucked up.

8. Back and loin. - Slightly arched; good breadth, with uniform thickness from shoulders to hams ; full at loin.

Objections: Narrow, creased or drooped behind shoulders; surface ridgy or uneven.

9. Sides and ribs. - Sides full, smooth form, carrying size evenly from shoulders to hams; ribs strong, well sprung at top and bottom, 
Objections: Sides thin, flat, flabby, or creased; ribs not well sprung.

10. Belly and flank. - Straight and full, devoid of coarseness; flank full and running nearly on line with side.

Objections: Belly sagging or flabby, coarse; flank thin or tucked up.

11. Hams or rump. - Hams full, long and deep ; rump slightly rounded from loin to root of tail ; buttock full, neat and firm.

Objections : Ham narrow, cut too high in crotch; rump too steep or too narrow, peaked at root of tail; buttock flabby.

12. Legs and feet. - Legs medium length, set well apart and squarely under body, wide above knee and hock, rounded and well muscled below, tapering, medium bone, pastern short and nearly upright; foot solid, short, smooth, enabling the animal to carry its weight with ease.

Objections : Legs too long or too short, slim, crooked or coarse; muscles weak or light; joints coarse, not tapering; pastern too long, crooked or slender; foot long, slim, weak or turned up.

13. Tail. - Medium length, straight or slightly curled.

Objections : Coarse, long, clumsy, swinging.

14. Coat. - Fine, straight, smooth, soft to touch.

Objections : Bristles or swirls, coarse or curly hair.

15. Color. - Black; white points admissible.

Objections : Too much white on feet, any white spots on body or head.

16. Size. - Large for condition; boar two years and over should weigh 500 pounds, sow same age, 450; twelve months boar or sow, 300; six months boar or sow, 175 pounds.

17. Action and style. - Active, vigorous, graceful, style attractive.

Objections: Dull, sluggish and clumsy.

18. Condition. - Healthy; skin free from defect; flesh smooth, firm and evenly laid on.

Objections: Unhealthy; skin scurfy, scaly or mangy; hair harsh, not growthy.

19. Disposition. - Docile, quiet and easily handled.

Objections : Cross, restless, nervous, sluggish or without ambition. 


\section{Large Improved Yorkshire - Scale of Points}

General outline. - Long and deep in proportion to width, but not massive ; slightly arched in the back, symmetrieal and smooth, with body firmly supported by wellplaced legs of medium length . . . . . . . . .

Outline of head. - Moderate in length and size, with lower jaw well sprung, and some dish toward snout, increasing with advancing maturity.

Forehead and poll. - Wide

Eye. - Medium size, clear and bright

Jowl. - Medium, not carried too far back, toward neck, and not flabby .

Snout. - Turning upward with a slight curve, increasing with age .

Ear. - Medium in size, standing well out from head, nearly erect, but inclining slightly forward

Neck. - Of medium length, fair width and depth, rising gradually from poll to withers, muscular, but not gross, evenly connecting head with body . . . . . . Outline of body. - Long, deep, and of medium breadth, equally wide at shoulder, side and hams; top line slightly arched, under line straight .

Back. - Moderately broad, even in width from end to end ; strong in loin, short ribs of good length

Shoulder. - Large, but not massive; not open above . . 6

Arm and thigh. - Broad and of medium length and development

Brisket. - Wide and on a level with under line . . . .

Side. - Long, deep, straight and even from shoulder to hip

Ribs. - Well arched and deep

Heart girth and flank girth. - Good and about equa! . .

Hindquarters. - Long to correspond with shoulder and side,

deep, with moderate and gradual droop to tail

Ham. - Large, well let down on thigh and twist and rear outline somewhat rounded

Twist. - Well down and meaty

Tail. - Medium, not much inclined to curl

Legs. - Medium in length, strong, not coarse, but standing straight and firm .

Hair. - Abundant, long, of medium fineness without any bristles 
Skin. - Smooth and white, without scales, but dark spots in skin do not disqualify . . . . . . . . . . 2

Color. - White on every part . . . . . . . . . . . 1

Movement. - Active, but not restless $\quad \therefore \quad . \quad . \quad . \quad 5$

Total . . . . . . . . . . . . . . . . . . $\overline{100}$

\section{Tamworth - Standard of Excellence}

The following is the standard of Tamworths as adopted by the National Pig Breeders' Association of Great Britain :

Color. - Golden red hair on a flesh-colored skin, free from black. Head. - Fairly long, snout moderately long and quite straight, face slightly dished, wide between ears.

Ears. - Rather large, with fine fringe, carried rigid and incined slightly forward.

Neck. - Fairly long and muscular, especially in boar.

Chest. - Wide and deep.

Shoulders. - Fine, slanting and well set.

Legs. - Strong and shapely, with plenty of bone and set well outside body.

Pasterns. - Strong and sloping.

Feet. - Strong and of fair size.

Back. - Long and straight.

Loin. - Strong and broad.

Tail. - Set on high and well tasseled.

Sides. - Long and deep.

Ribs. - Well sprung and extending well up to flank.

Belly. - Deep, with straight under line.

Flank. - Full and well let down.

Quarters. - Long, wide, and straight from hip to tail.

Hams. - Broad and full, well let down to hocks.

Coat. - Abundant, long, straight and fine.

Action. - Firm and free.

Objections. - Black hair, very light or ginger hair, curly coat, coarse mane, black spots on skin, slouch or drooping ears, short or turned-up snout, heavy shoulders, wrinkled skin, inbent knees, hollowness at back of shoulders. 


\section{INDEX}

Aberdeen-Angus, 221.

Action, 98.

Age, 43.

determination of, 43 .

of horses, 44.

Age of cattle, 53.

determination of, 53 .

birth, 54 .

one year, 54 .

two years, 54 .

three years, 54 .

four years, 54 .

five years, 55 .

six years, 55 .

seven years, 55 .

eight years, $\mathbf{5 5}$.

horns, appearance of, 55 .

Age of horses, 44.

determination of, 44 .

one year, 44.

two years, 44 .

three years, 45 .

four years, 45 .

five years, 45 .

six years, 45 .

seven years, 45 .

eight years, 52 .

nine years, 52 .

ten years, 52 .

eleven years, 52 .

twelve years, 53.

wear of incisors, 52.

shape of incisors, 53.

Age of sheep, 55.

determination of, 55 .

Age of swine, 55 .

determination of, 55 .

Amble, 103.

American saddle horse, 162.

Anatomy, 11.

Anchylosis, 41.
Animal form, 31.

features of, 31 .

Animal machine, highest type, 6 .

definition, 6 .

economic purpose, 6 .

intermediate relation to plants and man, 7.

efficiency of, 8 .

Ayrshire, 230.

Bacon hog, 278.

production, 279.

Wiltshire side, 279.

type, 279.

conformation, 279 .

quality, 282.

condition, 282.

method of inspection, 283.

Beef carcass cuts, 183.

loin, 185.

round, 186.

ribs, 187.

chuck, 187.

score card, 188.

relative values, 188 .

Beef cattle, 182.

production, 182.

dressing percentage, 189.

type, 189.

conformation, 190.

quality, 191.

condition, 191.

method of inspection, 195.

manner of showing, 320 .

Belgian, 149.

Berkshire, 285.

Bishoping, 53.

Block type, 175, 177. early maturity, 177. rapid fattening, 177 . dressing percentage, 178. 
Blood, 18.

circulation of, 18.

Bone of horses, 115.

Bowed tendons, 43.

Breaking down, 42.

Breed, 36.

the best, 36 .

Breed character, 35 . factors determining, 36 . objectionable features, 37 .

Breeds, 147. horses, 147. cattle, 217.

sheep, 252. swine, 285.

Breeders, classes of, 3 .

Breeding, definition, 4. for improvement, 4.

Breeding, 109. influence on way of going, 109. influence of, 181.

Breeding classes, 311 . horses, 311. beef cattle, 311 . dairy cattle, 314 . sheep, 316. swine, 316.

Breeding stock, 297. selection, 297. sire, 297. dam, 297. prepotency, 298. masculinity, 302. femininity, 302 . form, 303 . constitution, 303 . substance, 305.

Brown Swiss, 231.

Canter, 105.

Carcass cuts, beef, 183. mutton, 242 . pork, 271.

Cattle, 182. breeds, 217.

Character, 34-35. breed, 35 . sex, 35.

Chester White, 289.
Cheviot, 259.

Chunk, 128.

Classes of horses, 113.

Clydesdale, 151.

Coach horse, 129.

Cob, 132.

Color, 56.

significance of, 56 .

classification of, 57 .

Combination horse, 140.

Comparison, 86.

Condition, 33. beef cattle, 191 . dairy cow, 210. mutton sheep, 245. fat hog, 277. bacon hog, 282 .

Conformation, 32. influence on way of going, 108. beef cattle, 190 . dairy cow, 204. mutton sheep, 244. wool sheep, 248. fat hog, 274 . bacon hog, 279 .

Constitution, 33. breeding stock, 303 .

Contraction of heels, 40 .

Contraction of soles, 40 .

Correlation, 58. law of, 58 . of form and function, 58 . of parts, 59.

Cotswold, 263.

Cross firing, 112.

Curb, 42.

Dairy cattle, 197. production, 197. form and function, 197. manner of showing, 321 .

Dairy cow, 198. reproduction, 198. temperament, 198-211. feeding capacity, 199. constitution, 199-210. udder, 199-205. type, 201. conformation, 204. 
Dairy cow - Continued

points, 205.

quality, 209.

substance, 210.

condition, 210.

method of inspection, 213.

Demonstrations, 85.

use of, 85 .

material for, 85 .

Disposition, 34.

Dorset-horn, 258.

Draft horse, 116-125. conformation, 117. quality, 117. temperament, 118. way of going, 118.

Dressing percentage, 178, 189.

Dry cows, 211.

Dual-purpose cattle, 214. production, 214. type, 216.

Duroc Jersey, 288.

Dutch-belted, 233.

Dwelling, 112.

Early maturity, 56, 177.

Exostoses, 40.

Expresser, 128.

Fat, 180.

color, 180 .

consistence, 180.

Fat hog, 271.

production, 271.

carcass cuts, 271.

type, 274.

conformation, 274 .

points, 275.

quality, 277 .

condition, 277.

Fat hog carcass cuts, 272.

hams, 272.

middle piece, 272 .

shoulders, 272.

lard, 274.

Feeder, 129.

Feeder cattle, 193.

production, 193.

type, 195.
Feeding hogs, 278, 282.

Femininity, 302.

Fine harness horse, 141.

Fleece, 249.

quality, 249.

condition, 249.

examination, 251.

Food, 16.

prehension of, 16.

digestion of, 16.

assimilation of, 17 .

Forging, 111.

Founder, 40.

Fox-trot, 107.

French Coach, 157.

Gaited saddle horse, 135.

Gallop, 103.

Galloway, 223.

General appearance, 31 .

German Coach, 157.

Going surface, 111.

influence on way of going, 111.

Guernsey, 227.

Hackney, 154.

Hackney pony, 167

Hampshire sheep, 257.

Hampshire swine, 290.

Handling, 61. method of, 61 .

Heaves, 40.

Heifer calves, 211.

Height, 31.

Hereford, 220.

Histology, 9. epithelial tissue, 9. connective tissue, 9 . muscle tissue, 10. nerve tissue, 10.

Holstein-Friesian, 228.

Horns, 55. appearance of, 55 .

Horse, 38. unsoundness in, 38 .

of limbs, 40 .

age, 44 .

Horses, 12.

points of, 12 . 


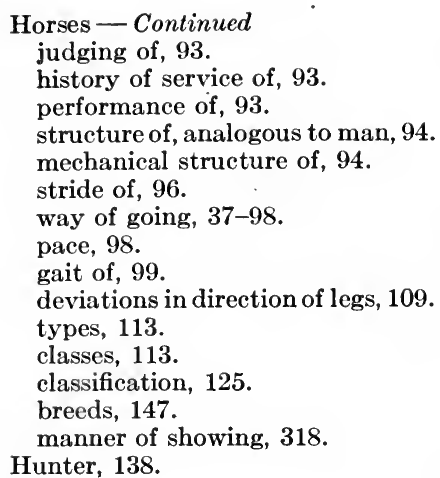

Improvement, bases of, 4 . the individual, 64. analysis of, 64 .

Inspection, 62. order of, 62. beef cattle, 195 . dairy cow, 213. sheep, 250. swine, 283.

Interfering, 111.

Jersey, 225.

Judging, proficiency in, 5 . show ring, 5 . benefits of, 5 . purpose of, 8 . definition of, 27. steps involved, 27. information, 27. observation, 27. comparison, 28. conclusion, 28. system in, 28.

first impressions, 28. practice, 64 . competitive, 87 .

Jump, 106.

Lard, 274.

Leicester, 260.

Lincoln, 263.
Live-stock husbandry, object of, 3 .

Live-stock shows, 307.

benefits, 309 .

classification, 309 .

age basis, 316 .

manner of showing, 318.

Logger, 128.

Manner of showing, 318.

horses, 318.

breeding horses, 318 .

harness and saddle horses, 319.

drafters, 319 .

beef cattle, 320 .

dairy cattle, 321 .

sheep, 322.

swine, 323.

Market classification of horses, 125.

Market division, 309.

horses, 309 .

fat classes, 309 .

Masculinity, 302 .

Meat, 175.

quality, 178.

grain, 179.

marbling, 179.

color, 180.

consistence, 180.

fat, 180.

moisture, 181.

odor, 181.

taste, 181.

lean, 181.

proportion to bone, 181 .

Meat animal, 176.

breeders' interest in, 176.

feeders' interest in, 176.

butchers' interest in, 176.

Mechanical appliances, 110.

influences on way of going, 110.

Merino, 264.

American, 265.

Delaine, 267.

Class A, 266.

Class B, 266.

Class C, 267.

Black Topped, 265.

Rambouillet, 268.

Milk, 198. 
Milking Short-horn, 236.

Milk teeth, 43.

Model horse, 141.

Mule, 168. draft, 169.

mine, 170.

plantation, 170.

score card, 75.

Muscular system, 14.

Muscles, 14. structure of, 14. arrangement of, 14 . action of, 15 .

Mutton carcass cuts, 242. saddle, 242. rack, 242.

Mutton sheep, 240. type, 243. production, 240-246. carcass cuts, 242. conformation, 244. quality, 245. condition, 245. method of inspection, 250 .

Nervous system, 19. function of, 19.

Observation, 27-60. means of making, 60 . method of, 61. system of making, 62 .

Oxford, 255.

Pace, 98-103.

Pacers, 120.

Paddling, 111.

Park horse, 129.

Pathology, 23. effect upon function, 23 .

Percheron, 147.

Physiology, 16.

Pointing, 112.

Poland China, 286.

Polled Durham, 219.

Ponies, 142. under 46 inches, 112. 11-2 to 14-2, 143. polo, 14.5 .
Pounding, 112.

Power type of horse, 113. bone, 115.

Practice judging, 64 .

Prepotency, 298.

Quality, 32. beef cattle, 191 . dairy cow, 209. mutton sheep, 245. wool sheep, 248. fat hog, 277 . bacon hog, 282 .

Race horse, 135.

Rack, 103.

Rambouillet, 268. Red Polled, 234. Reproduction, 19. impregnation, 19. gestation, 20. parturition, 20. lactation, 22. dairy cow, 198.

Ring-bone, 40.

Roadster, 132.

Roaring, 39.

Rolling, 112.

Rough joints, 42.

Runabout horse, 132.

Runners, 120.

Running walk, 107.

Saddle horse, 123.

weight carrying, 123.

conformation, 124.

quality, 124.

way of going, 124 .

intelligence, 124.

Saddle type of horse, 122.

Scale, 31 .

Scalping, 112.

Schooling, 110. influence on way of going, 110 .

Score card, 64. draft horse, 65 .

heavy harness horse, 68 . light harness horse, 70. saddle horse, 72 . 


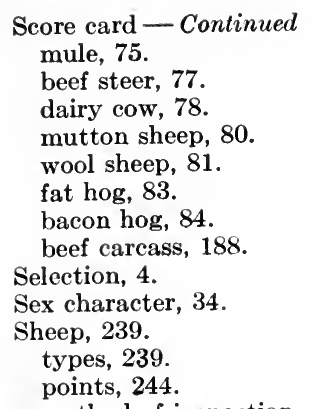

method of inspection, 250.

breeds, 252.

classification, 252.

manner of showing, 322 .

Shetland, 164.

Shire, 152.

Short-horn, 217.

Show classification of horses, 125 .

Show horse, 122.

conformation, 122.

quality, 122.

temperament, 122 .

way of going, 122 .

Showing, 29.

conditions, 29 .

posing, 29.

Show type of horse, 121.

Shropshire, 254.

Side-bone, 41.

Skeleton, the, 11.

the foreleg, 11.

the hind leg, 13.

the foot, 13 .

joints, 13.

Soundness, 37.

Southdown, 253.

Spavin, 40.

Speed horse, 135.

Speed type of horse, 118.

conformation, 120 .

quality, 120.

temperament, 120.

way of going, 120 .

trotters, 120.

pacers, 120.
Speed type of horse, runners, 120.

Speedy cutting, 112.

Splint, 40.

Standardbred, 158.

Stepping pace, 107.

Stride, 96.

deviation in, 96 .

phases of, 97.

Student judging teams, $8 \%$. coaching of, 89.

Style, 31.

Substance, 33. dairy cow, 210.

breeding stock, 305 .

Suffolk, 153.

Swine, 271.

types, 271.

points, 275 .

feeding, 278 .

breeds, 285.

classification, 285.

manner of showing, 323 .

Symmetry, 31.

Tamworth, 292.

Temperament, 34 . dairy cow, 198-211.

Thoroughbred, 160.

Thrush, 40.

Trappy, 112.

Traverse, 107.

Trot, 99.

high stepper, 99.

trotter, 99.

saddle horse, 101.

Trotters, 120.

Type, 32.

influence on way of going, 108.

beef cattle, 189 .

feeder cattle, 195.

dairy cow, 201.

dual-purpose cattle, 216.

mutton sheep, 243.

wool sheep, 247.

fat hog, 274 .

bacon hog, 279.

Types of horses, 113. 
Udder, 199-205. structure, 200. function, 200.

Unsoundness, 37. hereditary, 37 . defective conformation in, 37 . in horses, 38 . of limbs, 40 .

Veterinary examination, 320.

Walk, 99.

Walk-trot-canter saddle horse, 136. Way of going, 37, 98. pace, 98. action, 98. factors influencing, 107.

Weight, 31.

Welsh, 166.

Wiltshire side, 279.

Winding, 111.

Winging, 111.

Wool, 246.

classification, 246. clothing, 247. delaine, 247. combing, 247.

Wool sheep, 247. type, 247. conformation, 248. quality, 248. fleece, 249.

Yorkshire, 291. 

$T^{H E}$ following pages contain advertisements of a few of the Macmillan books on kindred subjects 



\section{Manual of Farm Animals}

A Practical Guide to the Choosing, Breeding, and Keep of Horses, Cattle, Sheep, and Swine

BY MERRITT W. HARPER

Assistant Professor of Animal Husbandry in the New York State College of Agriculture at Cornell University

Illustrated, decorated cloth, I2mo, 545 pp., index, \$2.oo

\section{(The Rural Manuals Edited by L. H. Bailey)}

The author discusses in this work the general care and management of farm animals rather than the breeds. However, a knowledge of the latter is not altogether excluded since it is necessary in treating of the care and management of farm animals.

The method is here adopted of freely inserting pictures of good animals of many breeds, with liberal legends, letting them run as a minor motive throughout the book. By this plan the reader will take away with him some of the main characteristics of the breeds with little effort on his part. The book is a manual, and therefore considers common practical matters in much detail.

These practical problems, which confront the stockman whether he be the owner of few animals or of many, have long needed to be systematically and authoritatively treated.

In this practical guide on the choosing, feeding, breeding, care and management of horses, cattle, sheep, and swine, is contained that information which hitherto the animal owner has had to cull from numerous sources. By calling attention to the diseases and ailments common to farm animals, the book shows the reader the importance of securing reliable aid when the subject is beyond his knowledge or skill. The work is invaluable as a practical guide in raising farm animals.

\section{THE MACMILLAN COMPANY}

Publishers

64-66 Fifth Avenue
New York 


\title{
The Training and Breaking of Horses
}

\author{
BY MERRITT W. HARPER
}

Assistant Professor of Animal Husbandry in the New York State College of Agriculture at Cornell University. Author of "Manual of Farm Animals," etc.

Illustrated, decorated cloth, I2mo, \$I.75

\section{(Rural Science Series Edited by L. H. Bailey)}

"Since the effectiveness of the horse and the safety of the master and his family depend so largely upon the understanding between men and horses," says Professor Harper, in his preface, "it seems worth while to give the methods of establishing agreeable relationships careful consideration. It is to promote this that the present volume is written. This is done with the thought that the usefulness of the horse depends on his being readily subservient to his master's will, and the author here sets forth the methods that are most likely to bring this about. Beginning with the foal, each class of horse is considered, and a separate chapter is devoted to the education of the more common classes - the work horse, the trotting horse, the coacher, the roadster, and the saddle horse.

"Special attention is also given to the training and subduing of wild horses as well as to overcoming outdoor and stable vices and whims. The book is written from a practical point of view and will be of great service to all those who have anything to do with man's principal beast of burden."

\section{Animal Husbandry for Schools}

\section{By MERRITT W. HARPER \\ Cloth, I2mo, illustrated, 409 pp., $\$ I .40$}

With the increasing study of agricultural subjects in the schools has come a demand for a book on Animal Husbandry suitable for use by students of high school age. It is to meet such a need that this book has been written, and in content, style, and arrangement it is admirably adapted to the purpose. It belongs to the Rural Textbook Series prepared under the editorial supervision of Professor L. H. Bailey of Cornell University.

In the five parts into which the book is divided the author treats horses, cattle, sheep, swine, and poultry, and each is discussed with reference to breeds, judging the animal, feeding, and care and management. There is also a chapter on the general principles of feeding. Practical questions and numerous laboratory exercises supplement the text and compel the student to think through each subject as he proceeds. The book is extensively illustrated. Designed for use as a textbook, it is also well suited for use as a reference book in schools in which time limitations make it impossible to use it as a text.

\section{THE MACMILLAN COMPANY}

\section{Publishers \\ 64-66 Fifth Avenue \\ New York}




\section{Genetics. An Introduction to the Study of Heredity}

By HERBERT EUGENE WALTER

Associate Professor of Biology, Brown University

Cloth, I2mo, $\$ I .50$

In his "Genetics" Professor Walter summarizes the more recent phases of the study of heredity and gives to the non-technical reader a clear introduction to questions that are at present agitating the biological world, and which are of particular importance to all those interested in the evolutionary or hereditary problems of breeding.

Professor Walter's conception of sexual reproduction is that it is a device for doubling the possible variations in the offspring, by the mingling of two strains of germ plasm. The weight of probability, he concludes, is decidedly against the time-honored belief in the inheritance of acquired characters. Professor Walter also predicts that the key to this whole problem will be furnished by the chemist, and that the final analysis of the matter of the "heritage carriers" will be seen to be chemical rather than morphological in nature. Professor Walter holds, if only modifications of the germ plasm can count in inheritance, and if these modifications come wholly from the combination of two germ plasms, then the only method of hereditary influence is in the selection of parents.

This book is now widely used as a class text in courses on the breeding of animals or plants given in the agricultural colleges.

"I find that it is a very useful study for an introduction to the subject. Professor Walter has certainly made one of the clearest statements of the matters involved that I have seen, and has made a book which students will find very useful because he keeps everything in such entirely simple and clear outlines, and at the same time he has brolight the book up to date." - PROFESSOR Frederic B. LoOMIS, Amherst Coll.g:

"I am much pleased with it and congratulate you upon securing so excellent a treatment. It is one of the most readable scientific books I have, and goes unerringly to the fundamentals of our most recent advances in the experimental study of heredity as well as those of the older studies." - PROFESSOR GEORGE H. SHull, Cold Spring Harbor, Long lsland, N. Y.

"There was a decided need for just such a work. The book strikes me as most excellently done." - Professor H. S. Jennings, Johns Hopkins University.

\section{THE MACMILLAN COMPANY}

\section{Publishers}

64-66 Fifth Avenue

New York 


\title{
The Feeding of Animals
}

\section{BY WHITMAN H. JORDAN}

Director of the New York Agricultural Experiment Station

Fifth edition, cloth, I2mo, $\$ 1.50$

This is not a statement of rules or details of practice, but an attempt to present the main facts and principles fundamental to the art of feeding animals. The book is a valuable contribution to agricultural literature and is worth a place in any library, but especially in one open to rural readers. The author is well known as Director of the New York Agricultural Experiment Station.

"A valuable contribution to agricultural literature. Not a statement of rules or details of practice, but an effort to present the main facts and principles fundamental to the art of feeding animals." - New England Farmer.

\section{The Scientific Feeding of Animals}

\author{
By Professor O. KELLNER
}

Authorized Translation by WILLIAM GOODWIN, B.Sc., PH.D., Lecturer on Agricultural Chemistry, and Head of the Chemical Department, SouthEastern Agricultural College (University of London), Wye, Kent.

$$
\text { Cloth, I2mo, } \$ 1.75
$$

An authorized English translation of the valuable work of Dr. O. Kellner. It explains in simple language the general laws which underlie the feeding of animals and the scientific foundations upon which the principles of animal nutrition rest.

"I wish to say that it is one of the most valuable books in the English language on Feeding Farm Animals. The author is extremely lucid in expression and concise in statement. He covers his field in a manner that is well planned and such as will give the reader a most excellent knowledge of the general principles of ·Feeding." - Professor Charles S. Plumb, Ohio State University.

"Dr. Kellner's standing as a student and investigator in this subject is too high for any words of commendation to be needed, and I feel sure that the translator and publisher have done a service in rendering this work available to English and American students."- Professor Henry P. ARMSBy, Pennsylvania State College.

\section{THE MACMILLAN COMPANY \\ Publishers \\ 64-66 Fifth Avenue \\ New York}













\section{UNIVERSITY OF CALIFORNIA LIBRARY}

BERKELEY

\section{THIS BOOK IS DUE ON THE LAST DATE STAMPED BELOW}

Books not returned on time are subject to a fine of $50 \mathrm{c}$ per volume after the third day overdue, increasing to $\$ 1.00$ per volume after the sixth day. Books not in demand may be renewed if applicatioy. Books not in expiration of loan period.

\section{3}

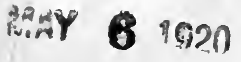

SEP 91920

NOV 3 , nom

SEF 1024 
bes in

YC 61059

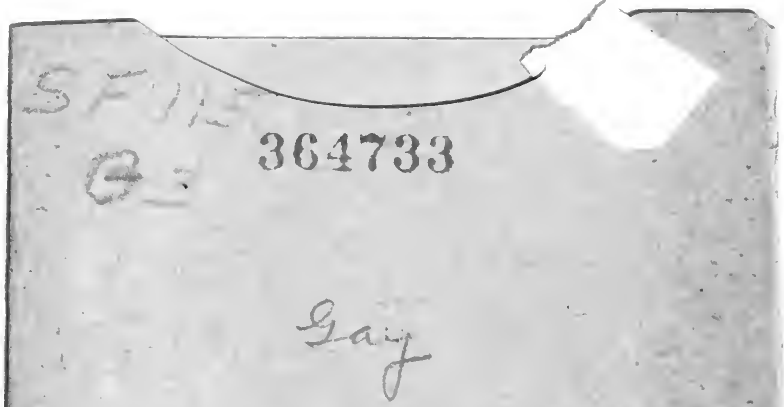

UNIVERSITY OF CALIFORNIA LIBRARY 
